ORNL/TM-2014/480

\title{
Additional EIPC Study Analysis: Final Report
}

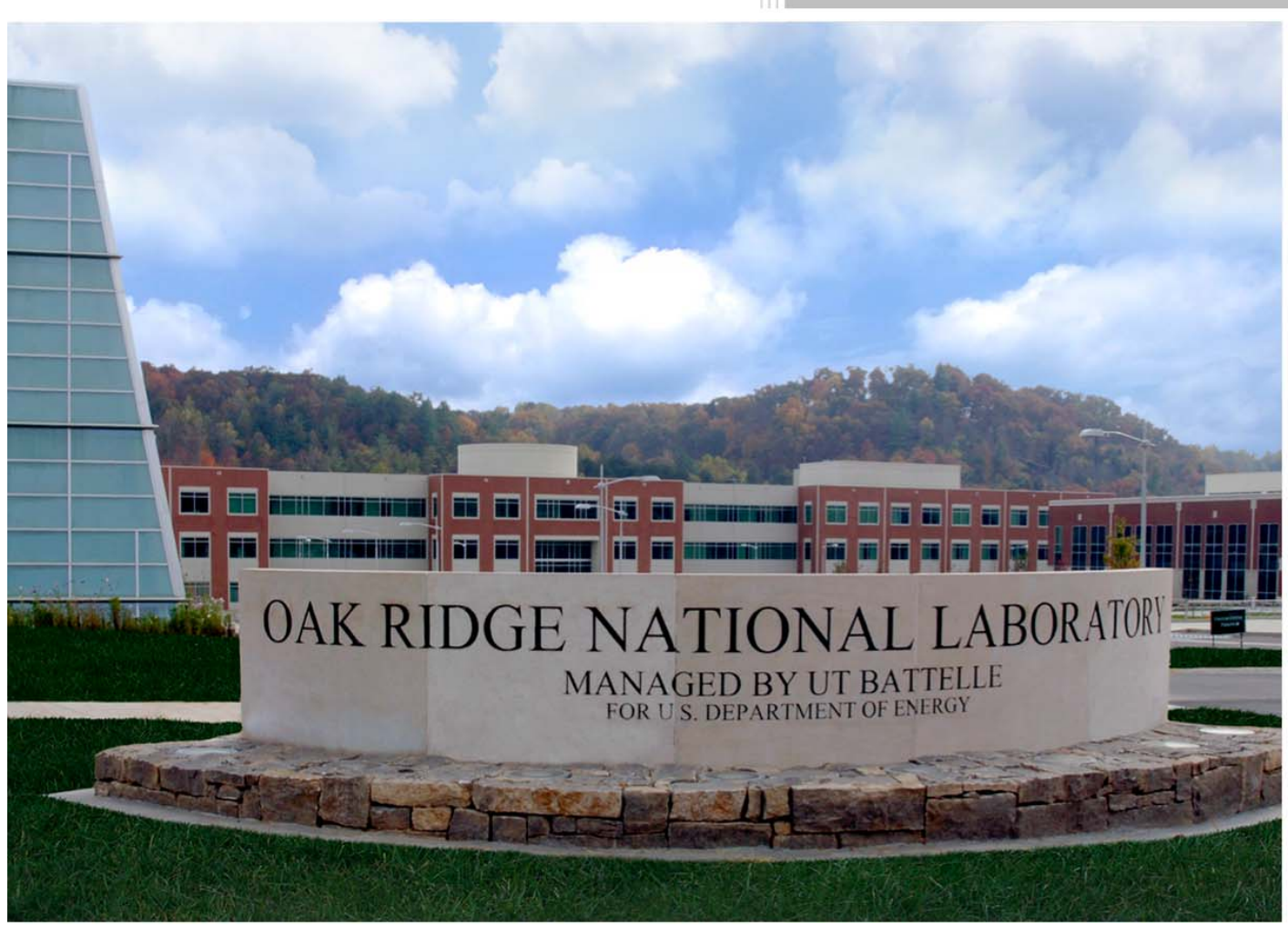

\section{Approved for public release:} distribution is unlimited.
Stanton W. Hadley Douglas J. Gotham Ralph L. Luciani

December 2014 


\section{DOCUMENT AVAILABILITY}

Reports produced after January 1, 1996, are generally available free via US Department of Energy (DOE) SciTech Connect.

Website http://www.osti.gov/scitech/

Reports produced before January 1, 1996, may be purchased by members of the public from the following source:

National Technical Information Service

5285 Port Royal Road

Springfield, VA 22161

Telephone 703-605-6000 (1-800-553-6847)

TDD 703-487-4639

Fax 703-605-6900

E-mail info@ntis.gov

Website http://www.ntis.gov/help/ordermethods.aspx

Reports are available to DOE employees, DOE contractors, Energy Technology Data Exchange representatives, and International Nuclear Information System representatives from the following source:

Office of Scientific and Technical Information

PO Box 62

Oak Ridge, TN 37831

Telephone 865-576-8401

Fax 865-576-5728

E-mail reports@osti.gov

Website http://www.osti.gov/contact.html

This report was prepared as an account of work sponsored by an agency of the United States Government. Neither the United States Government nor any agency thereof, nor any of their employees, makes any warranty, express or implied, or assumes any legal liability or responsibility for the accuracy, completeness, or usefulness of any information, apparatus, product, or process disclosed, or represents that its use would not infringe privately owned rights. Reference herein to any specific commercial product, process, or service by trade name, trademark, manufacturer, or otherwise, does not necessarily constitute or imply its endorsement, recommendation, or favoring by the United States Government or any agency thereof. The views and opinions of authors expressed herein do not necessarily state or reflect those of the United States Government or any agency thereof. 
Electrical and Electronics Systems Research Division

\title{
ADDITIONAL EIPC STUDY ANALYSIS: FINAL REPORT
}

\author{
Stanton W. Hadley (Oak Ridge National Laboratory) \\ Douglas J. Gotham (Purdue University) \\ Ralph Luciani (Navigant, Inc.)
}

December 2014

Prepared by

OAK RIDGE NATIONAL LABORATORY

Oak Ridge, Tennessee 37831-6283

managed by

UT-BATTELLE, LLC

for the

US DEPARTMENT OF ENERGY

under contract DE-AC05-00OR22725

Section 14 of this report is based upon work supported under Award Number DE-OE0000316 



\section{CONTENTS}

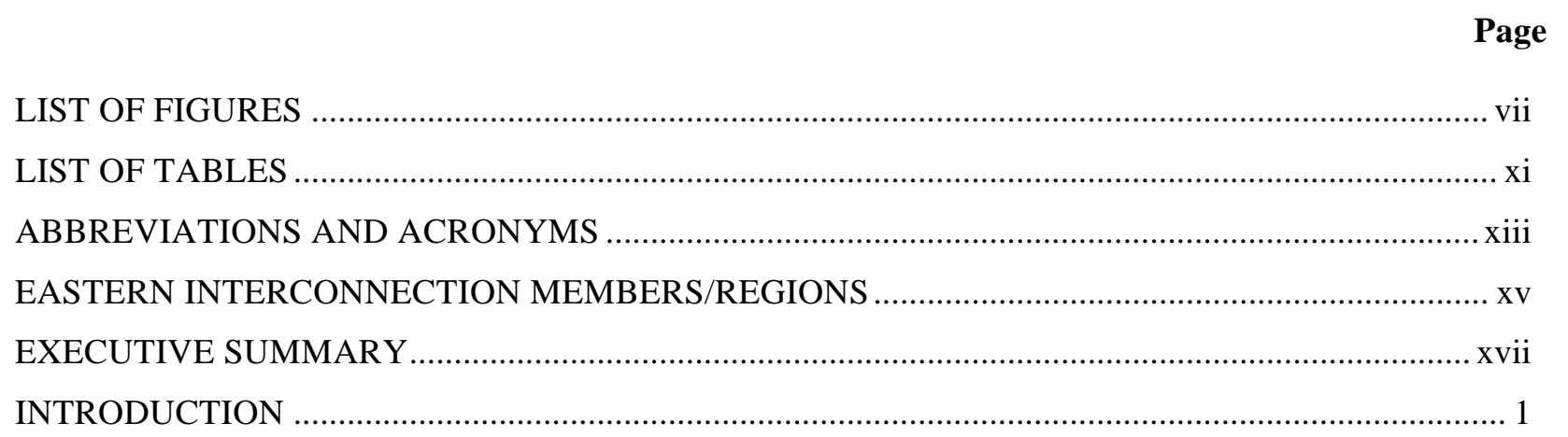

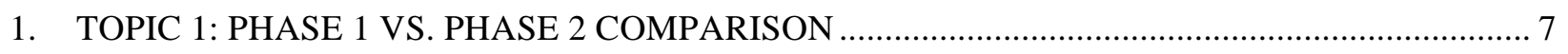

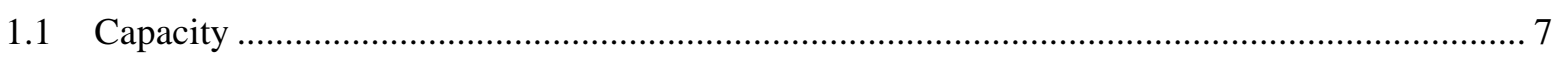

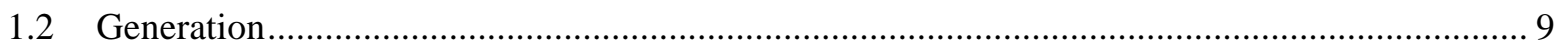

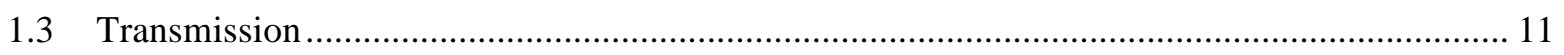

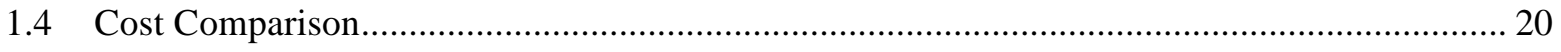

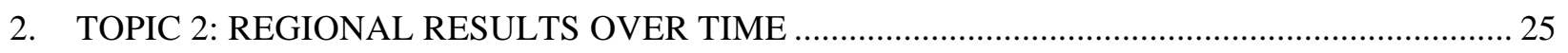

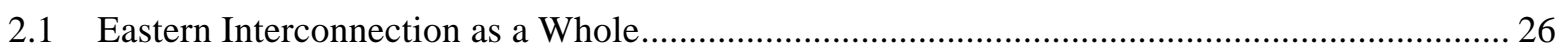

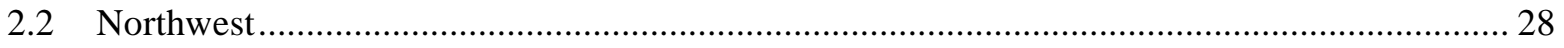

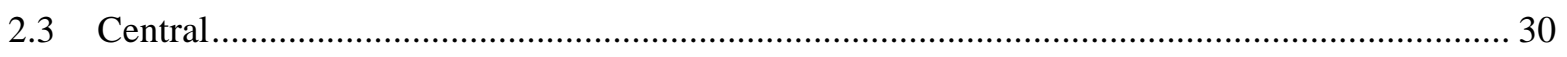

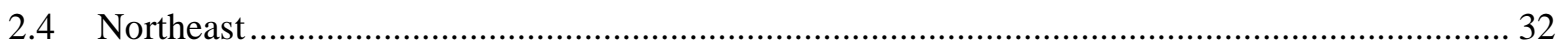

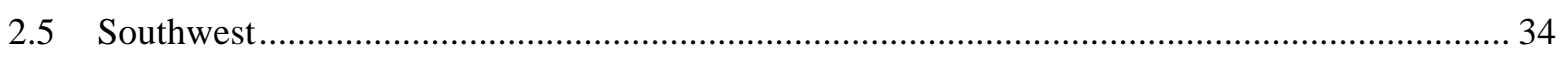

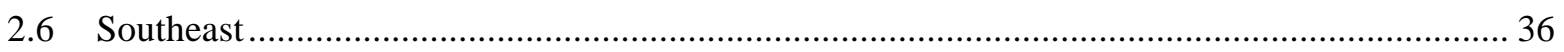

3. TOPIC 3: INTEGRATED COST COMPARISON BETWEEN SCENARIOS ................................ 39

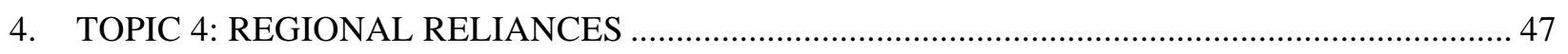

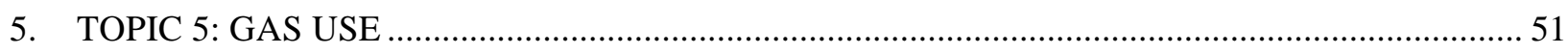

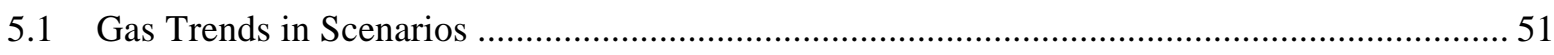

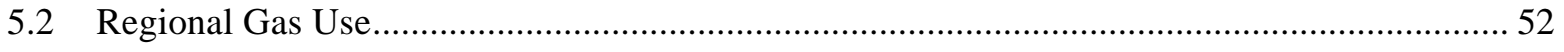

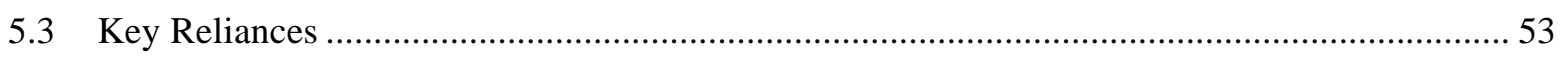

6. TOPIC 6: OPERATING AND PLANNING RESERVES ........................................................... 55

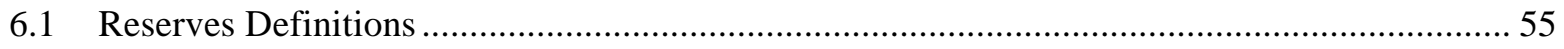

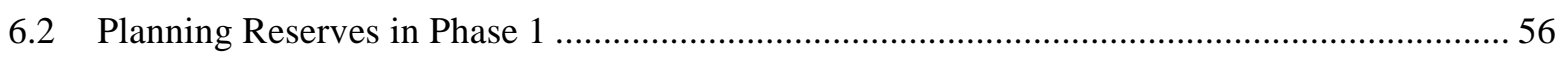

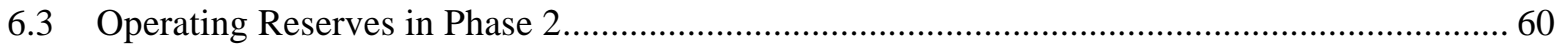

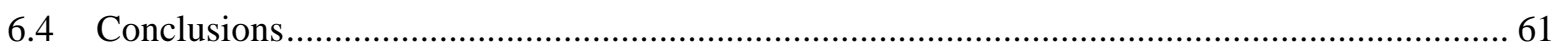

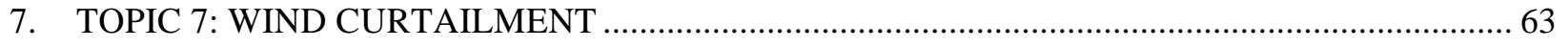

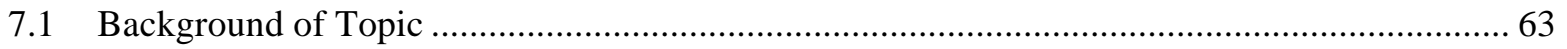

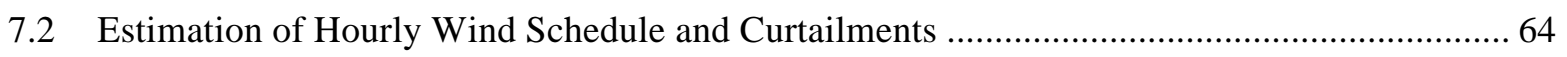

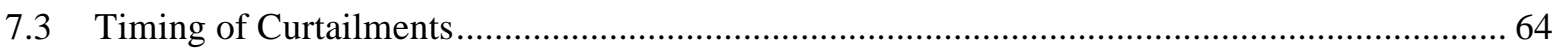

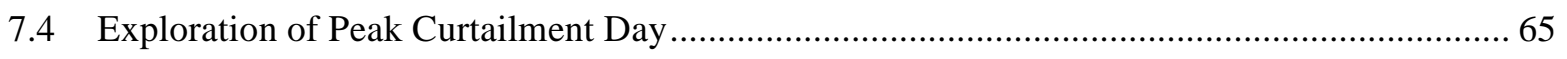

7.5 Effect of Reduced Spin Requirements and Flexible Combined Cycle .................................... 67 


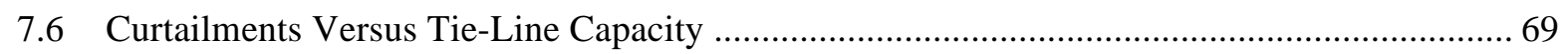

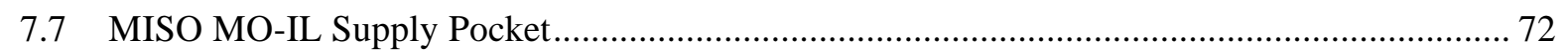

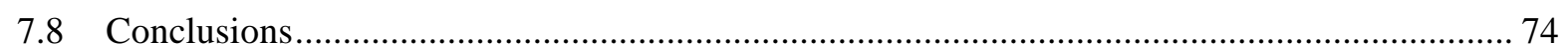

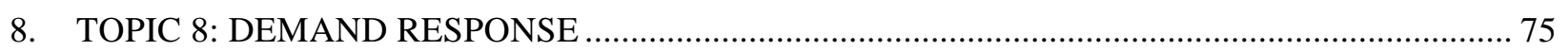

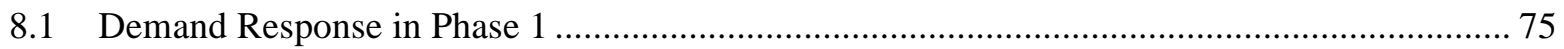

8.2 Demand Response Supply Curve for Phase 2 ….............................................................. 76

8.3 Demand Response Dispatched in Phase 2 ........................................................................ 78

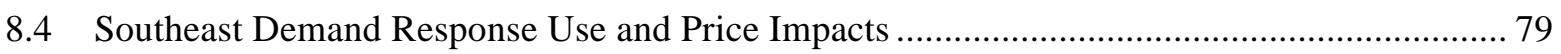

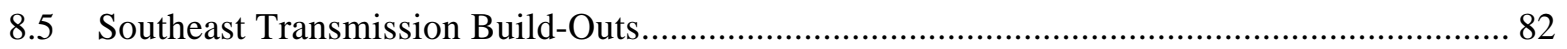

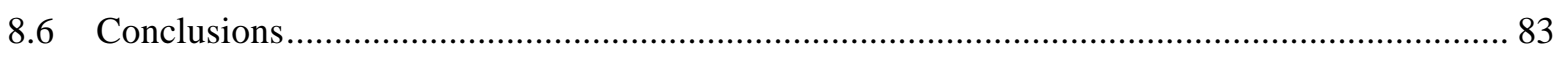

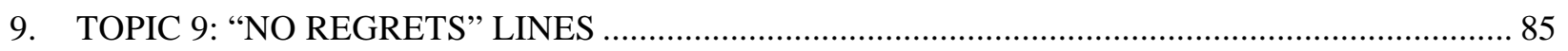

9.1 Transmission Elements Common to Multiple Scenarios..................................................... 85

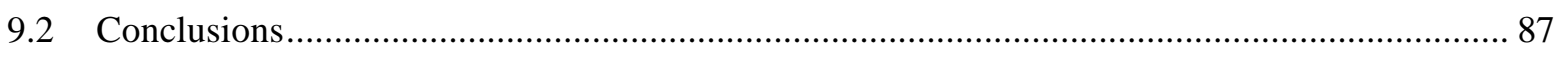

10. TOPIC 10: REGIONAL VERSUS NATIONAL IMPLEMENTATION OF POLICIES .................. 89

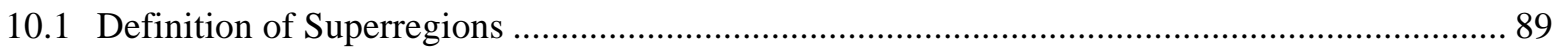

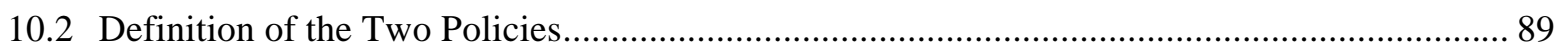

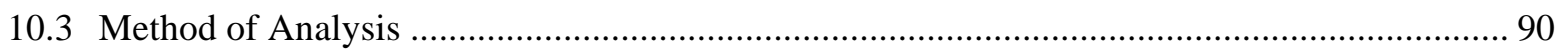

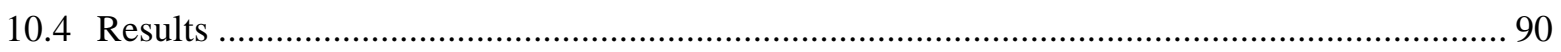

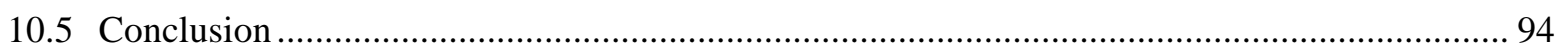

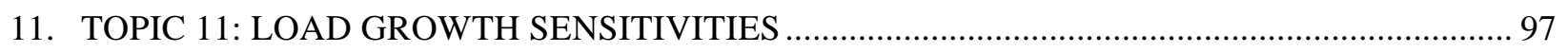

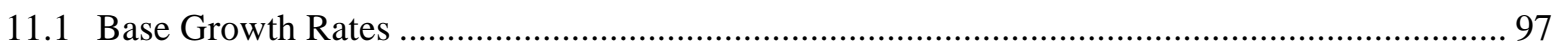

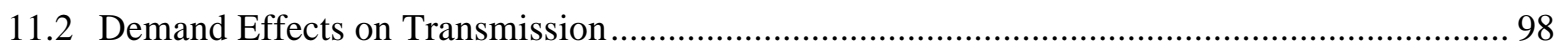

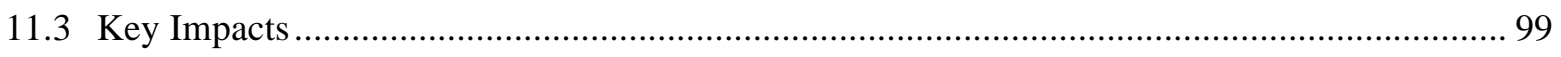

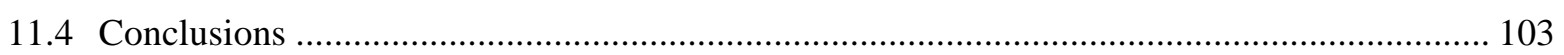

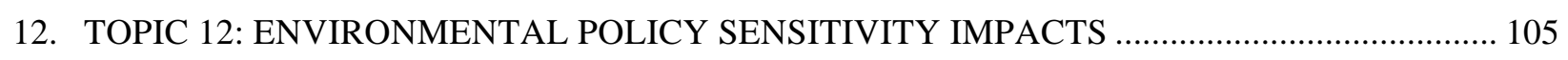

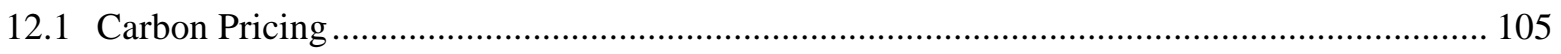

12.2 Delayed Implementation of Environmental Policies ............................................................ 107

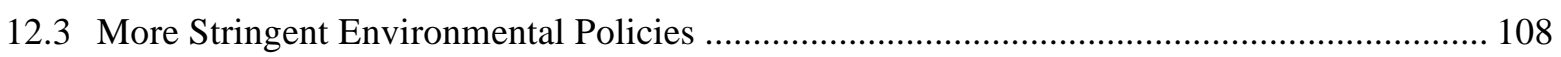

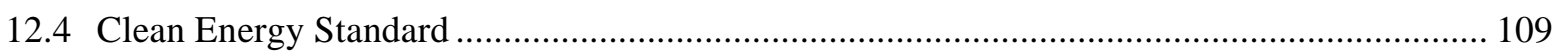

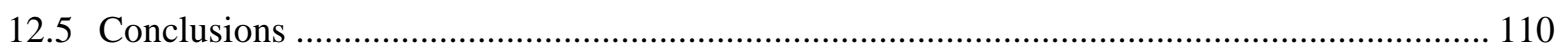

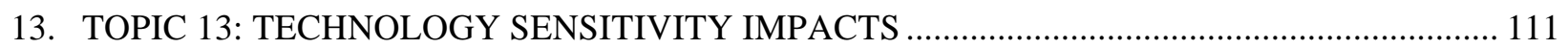

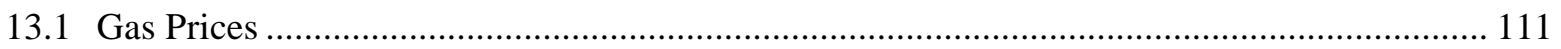

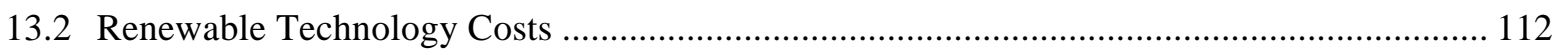

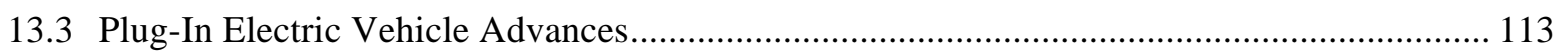

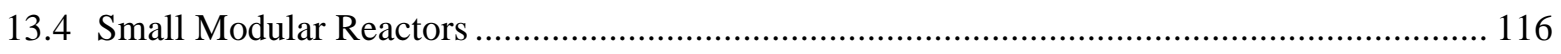

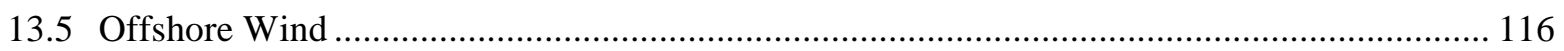

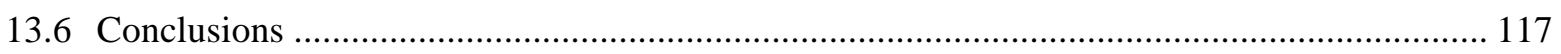

14. TOPIC 14: Change in key inputs between 2011 and 2014 ........................................................ 119

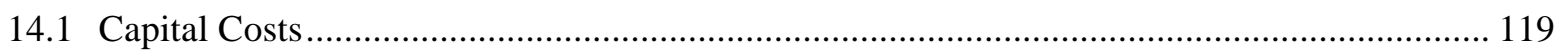

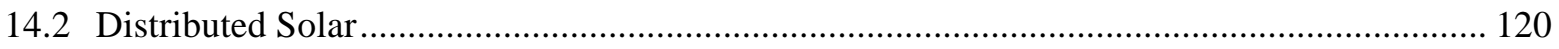




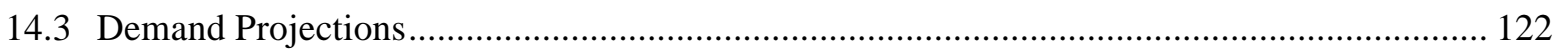

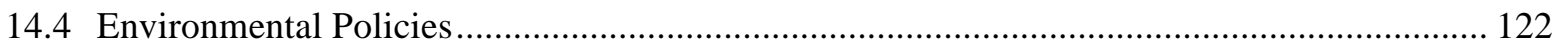

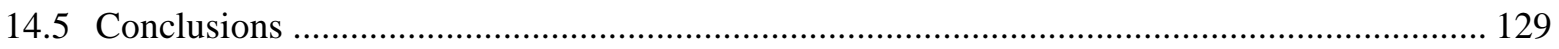

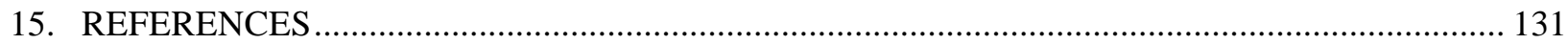





\section{LIST OF FIGURES}

Page

ES-1. Map of North American Electricity and Environment Model regions. ......................................... xvii

ES-2. Ratio of Phase 2 to Phase 1 generation costs in 2030 by region..................................................xi

ES-3. $\mathrm{CO}_{2}+$ scenario Phase 1 capacity and generation for the Eastern Interconnection (EI)................... xxi

ES-4. Phase 2 total costs for the Eastern Interconnection (EI) in 2030 ............................................ xxii

ES-5. Dominant generation source for each region and scenario. ......................................................

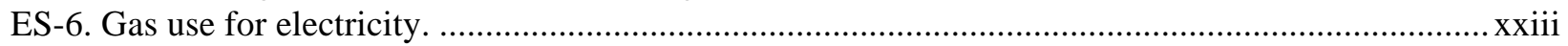

ES-7. Phase 1 ratio of capacities to peak demand in the $\mathrm{CO}_{2}+$ scenario. .............................................xxiv

ES-8. Potential wind generation, curtailments, and actual generation in the $\mathrm{CO}_{2}+$ scenario by hour

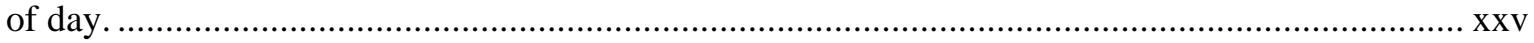

ES-9. Curtailed region April 1 morning generation levels in the $\mathrm{CO}_{2}+$ scenario and $\mathrm{Hi}$ Spin

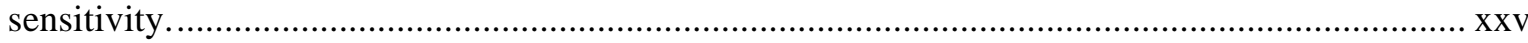

ES-10. Net transfer vs. wind curtailment in the curtailed regions in the Hi Spin sensitivity. ................. xxvi

ES-11. VACAR generation, load, and marginal price on August 1 in the $\mathrm{CO}_{2}+$ scenario.................... xxvii

ES-12. Marginal prices at six balancing areas versus the corresponding demand response (DR) demand for all of VACAR in the business as usual scenario...................................................x.

ES-13. Locations of buses with upgrades common to all three scenarios. ......................................... xxviii

ES-14. Eastern Interconnection (EI) projected generation by technology in 2030 under different

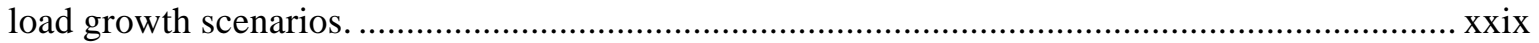

ES-15. Eastern Interconnection (EI) generation in 2030 by technology for increased

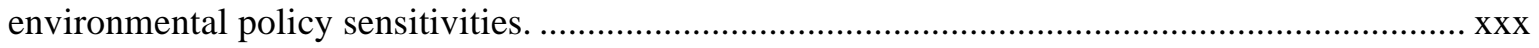

1. Map of North American Electricity and Environmental Model regions. ............................................... 1

2. Eastern Interconnection capacity estimated in Phase 2. ................................................................ 7

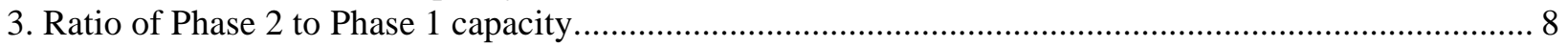

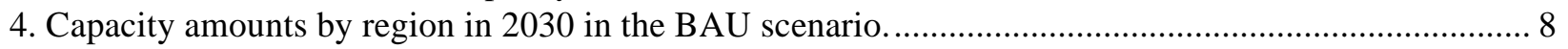

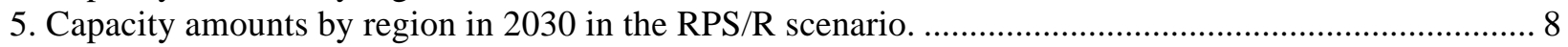

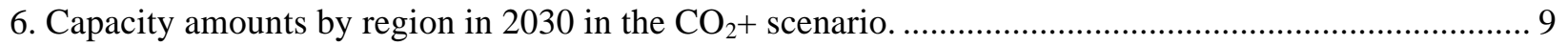

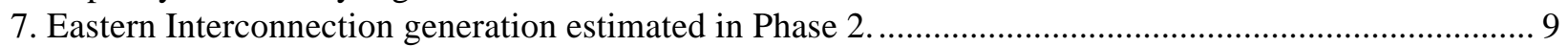

8. Ratio of Phase 2 to Phase 1 regional generation amounts. ............................................................... 10

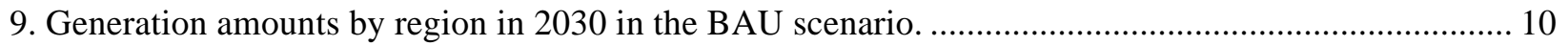

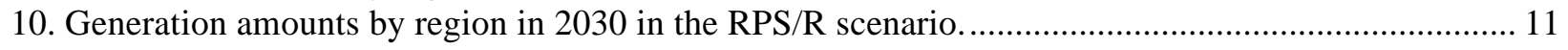

11. Generation amounts by region in 2030 in the $\mathrm{CO}_{2}+$ scenario......................................................... 11

12. Phase 1 maximum interregional transfers $(\mathrm{GW})$ in 2030 in the BAU scenario................................... 13

13. Phase 2 maximum interregional transfers $(\mathrm{GW})$ in 2030 in the BAU scenario.................................. 13

14. Phase 1 maximum interregional transfers $(\mathrm{GW})$ in 2030 in the RPS/R scenario............................. 14

15. Phase 2 maximum interregional transfers $(\mathrm{GW})$ in 2030 in the RPS/R scenario. .............................. 14

16. Phase 1 maximum interregional transfers $(\mathrm{GW})$ in 2030 in the $\mathrm{CO}_{2}+$ scenario............................... 15

17. Phase 2 maximum interregional transfers $(\mathrm{GW})$ in 2030 in the $\mathrm{CO}_{2}+$ scenario............................... 15

18. Phase 1 average interregional transfers $(\mathrm{GW})$ in 2030 in the BAU scenario. .................................... 17

19. Phase 2 average interregional transfers $(\mathrm{GW})$ in 2030 in the BAU scenario. .................................... 17

20. Phase 1 average interregional transfers (GW) in 2030 in the RPS/R scenario................................... 18

21. Phase 2 average interregional transfers $(\mathrm{GW})$ in 2030 in the RPS/R scenario.................................. 18

22. Phase 1 average interregional transfers $(\mathrm{GW})$ in 2030 in the $\mathrm{CO}_{2}+$ scenario................................... 19

23. Phase 2 average interregional transfers $(\mathrm{GW})$ in 2030 in the $\mathrm{CO}_{2}+$ scenario................................... 19

24. SPP $\mathrm{N}$ to SPP $\mathrm{S}$ transmission in the $\mathrm{CO}_{2}+$ scenario aggregated to NEEM load blocks..................... 20

25. Ratio of Phase 2 to Phase 1 generation costs in 2030 by region..................................................... 21

26. Phase 1 and Phase 2 regional total costs in 2030 in the BAU scenario............................................ 21 
27. Phase 1 and Phase 2 regional total costs in 2030 in the RPS/R scenario........................................ 22

28. Phase 1 and Phase 2 regional total costs in 2030 in the $\mathrm{CO}_{2}+$ scenario............................................. 22

29. Phase 1 and Phase 2 regional total cost per megawatt-hour generated in the BAU scenario............... 23

30. Phase 1 and Phase 2 regional total cost per megawatt-hour generated in the RPS/R scenario. ........... 23

31. Phase 1 and Phase 2 regional total cost per megawatt-hour generated in the $\mathrm{CO}_{2}+$ scenario. ............ 23

32. BAU scenario Phase 1 capacity and generation for the Eastern Interconnection as a whole.............. 26

33. RPS/R scenario Phase 1 capacity and generation for the Eastern Interconnection as a whole............. 26

34. $\mathrm{CO}_{2}+$ scenario Phase 1 capacity and generation for the Eastern Interconnection. ............................ 26

35. BAU scenario Phase 1 capacity and generation for the Northwest Eastern Interconnection. .............. 28

36. RPS/R scenario Phase 1 capacity and generation for the Northwest Eastern Interconnection............. 28

37. $\mathrm{CO}_{2}+$ scenario Phase 1 capacity and generation for the Northwest Eastern Interconnection............... 28

38. BAU scenario Phase 1 capacity and generation for the Central Eastern Interconnection.................... 30

39. RPS/R scenario Phase 1 capacity and generation for the Central Eastern Interconnection................... 30

40. $\mathrm{CO}_{2}+$ scenario Phase 1 capacity and generation for the Central Eastern Interconnection.................... 30

41. BAU scenario Phase 1 capacity and generation for the Northeast Eastern Interconnection. ............... 32

42. RPS/R scenario Phase 1 capacity and generation for the Northeast Eastern Interconnection.............. 32

43. $\mathrm{CO}_{2}+$ scenario Phase 1 capacity and generation for the Northeast Eastern Interconnection................ 32

44. BAU scenario Phase 1 capacity and generation for the Southwest Eastern Interconnection. .............. 34

45. RPS/R scenario Phase 1 capacity and generation for the Southwest Eastern Interconnection............. 34

46. $\mathrm{CO}_{2}+$ scenario Phase 1 capacity and generation for the Southwest Eastern Interconnection............... 34

47. BAU scenario Phase 1 capacity and generation for the Southeast Eastern Interconnection. ............... 36

48. RPS/R scenario Phase 1 capacity and generation for the Southeast Eastern Interconnection.............. 36

49. $\mathrm{CO}_{2}+$ scenario Phase 1 capacity and generation for the Southeast Eastern Interconnection................ 36

50. Phase 2 total costs for the Eastern Interconnection in 2030 ..................................................... 42

51. Phase 2 total costs for the Northwest Eastern Interconnection in 2030 .......................................... 42

52. Phase 2 total costs for the Central Eastern Interconnection in 2030 .............................................. 43

53. Phase 2 total costs for Northeast Eastern Interconnection in 2030 ................................................ 43

54. Phase 2 total costs for the Southwest Eastern Interconnection in 2030 .......................................... 44

55. Phase 2 total costs for the Southeast Eastern Interconnection in 2030 ............................................ 44

56. Phase 2 cost per unit of demand for the Eastern Interconnection and each territory in 2030............. 45

57. Phase 2 cost per unit using the BAU scenario demands for the Eastern Interconnection and

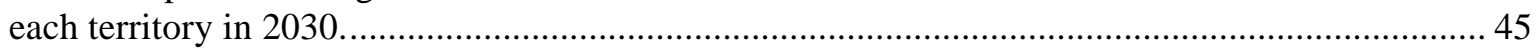

58. Dominant generation source for each region and scenario................................................................ 48

59. Henry Hub gas prices from the DOE Annual Energy Outlook (AEO) of different years.................... 51

60. Gas use for electricity in the Eastern Interconnection as a whole. ................................................... 51

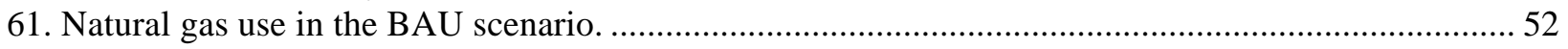

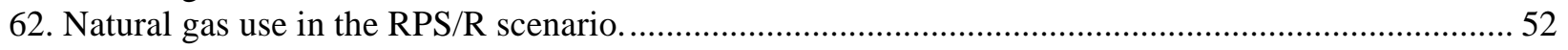

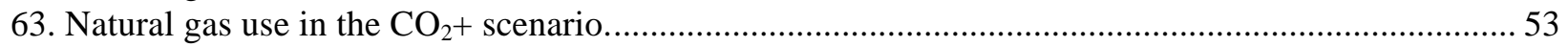

64. Phase 1 ratio of capacities to peak demand in the $\mathrm{CO}_{2}+$ scenario................................................... 58

65. Phase 1 ratio of capacities to peak demand in the RPS/R scenario............................................... 59

66. Phase 1 ratio of capacities to peak demand in the BAU scenario..................................................... 59

67. Potential wind generation, curtailments, and actual generation in the $\mathrm{CO}_{2}+$ scenario by hour

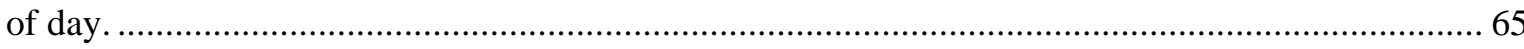

68. Supply and demand for major curtailed regions on April 1 in the $\mathrm{CO}_{2}+$ scenario...........................6 65

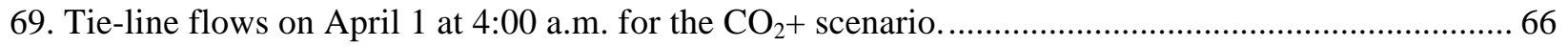

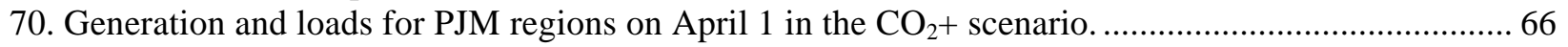

71. Locational marginal prices for balancing areas across the EI on April 1 at 4:00 a.m. for the

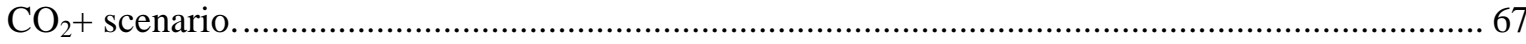

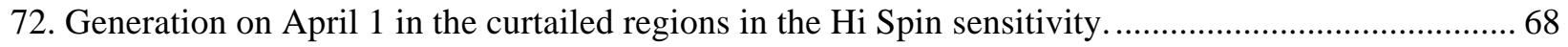

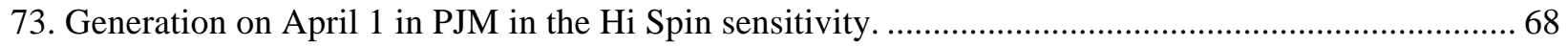

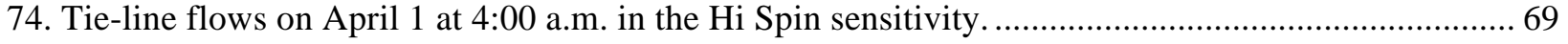


75. Net transfer vs. curtailment in the curtailed regions for the $\mathrm{CO}_{2}+$ scenario.................................... 70

76. Net transfer vs. curtailment in the curtailed regions for the Hi Spin sensitivity................................. 70

77. Percent of year that curtailments in curtailed regions were at different levels.................................. 71

78. Net transfer vs. wind curtailment in the curtailed regions in the Hi Spin sensitivity........................ 72

79. Locational marginal prices on April 1 at 10:00 a.m. in the $\mathrm{CO}_{2}+$ scenario. ....................................... 73

80. MISO MO-IL generation and load on April 1 in the $\mathrm{CO}_{2}+$ scenario................................................ 73

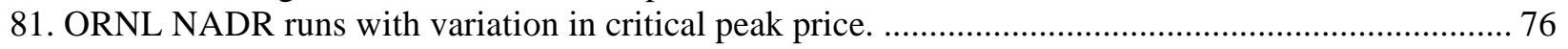

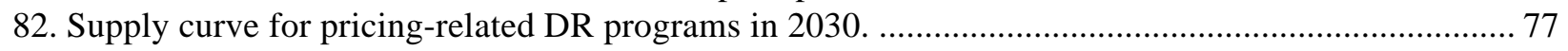

83. Six-tier supply curve and model curve with allocated nonprice demand response (DR) in 2030

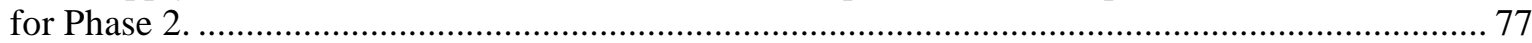

84. Capacities and peak demand for each region for the $\mathrm{CO}_{2}+$ scenario............................................ 78

85. VACAR generation, load and marginal prices on August 1 under the $\mathrm{CO}_{2}+$ scenario. ...................... 80

86. SOCO generation, load, and marginal prices on August 1 under the $\mathrm{CO}_{2}+$ scenario.......................... 80

87. Eastern Interconnection tie-line loads on August 1 at 4:00 p.m. for the $\mathrm{CO}_{2}+$ scenario.................... 81

88. Marginal prices at six balancing areas versus the corresponding DR demand for all of

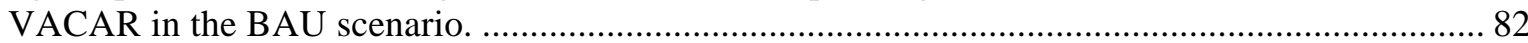

89. Phase $1 \mathrm{CO}_{2}$ + flow duration curves for the "soft" tie-line between PJM ROR and VACAR............ 83

90. Locations of buses with upgrades common to all three scenarios. .................................................... 86

91. Eastern Interconnection generation by type in 2030 under $\mathrm{CO}_{2}$ futures...................................... 91

92. Eastern Interconnection generation by superregion in 2030 under $\mathrm{CO}_{2}$ prices. ............................ 92

93. Net present value costs, 2015-2030, under $\mathrm{CO}_{2}$ prices............................................................ 92

94. Eastern Interconnection generation by type in 2030 under the renewable portfolio standard

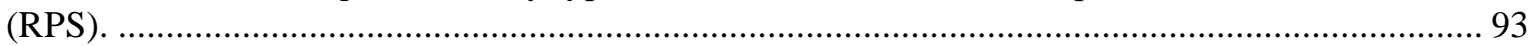

95. Eastern Interconnection generation by superregion in 2030 under the renewable portfolio

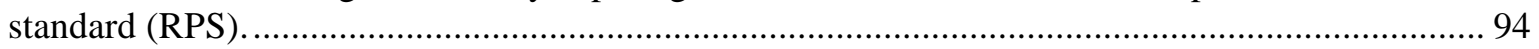

96. Net present value costs, 2015-2030, under the renewable portfolio standard (RPS)........................ 94

97. Eastern Interconnection (EI) total interregional transfers (TWh) versus peak flow (GW) in

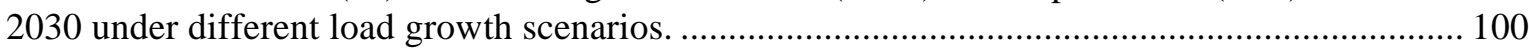

98. Eastern Interconnection (EI) generation by technology in 2030 under different load growth

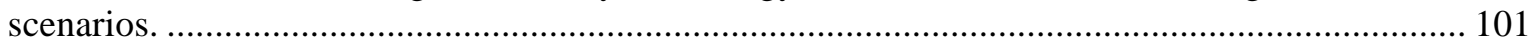

99. Eastern Interconnection generation by territory in 2030 under different load growth scenarios........ 102

100. Eastern Interconnection generation cost by territory in 2030 under different load growth

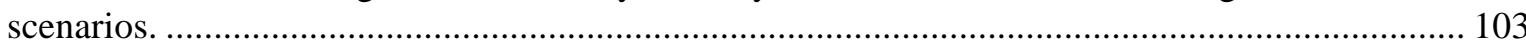

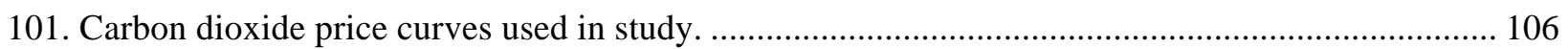

102. Eastern Interconnection (EI) Generation in 2030 by technology for $\mathrm{CO}_{2}$ price sensitivities.......... 107

103. Nuclear capacity in 2030 for the business as usual (BAU) and nuclear resurgence (NUC) futures and nuclear resurgence-carbon dioxide $\left(\mathrm{NUC} \mathrm{CO}_{2}\right)$ sensitivity.

104. Eastern Interconnection (EI) generation in 2030 by technology for increased environmental policy sensitivities.

105. Eastern Interconnection (EI) generation in 2030 by technology for Clean Energy Standard

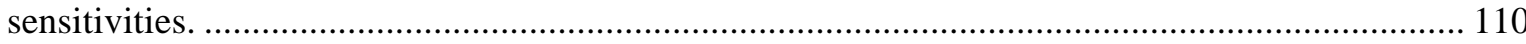

106. Henry Hub gas price inputs to the MRN-NEEM model............................................................... 111

107. Eastern Interconnection (EI) generation production share by technology for gas price sensitivities.

108. Eastern Interconnection (EI) generation share by technology for renewable cost sensitivities........ 113

109. Projected plug-in electric vehicle (PEV) quantities in the Eastern Interconnection........................ 114

110. Hourly demands from 1 million plug-in electric vehicles (PEVs) under the night and peaking

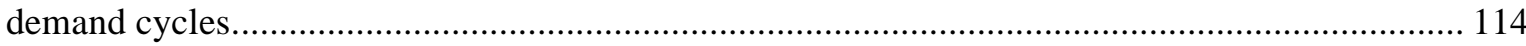

111. Peak demand increases in the Eastern Interconnection due to base and high plug-in electric vehicle (PEV) growth.

112. Changes in Eastern Interconnection (EI) generation between the base scenario (BAU) and 
plug-in electric vehicle (PEV) sensitivity for three futures.

113. Capacity changes between the base scenario (BAU) and plug-in electric vehicle (PEV) sensitivity for three futures.

114. Eastern Interconnection peak demand in the BAU and EE/DR/DG (and $\mathrm{CO}_{2}+$ ) futures before and after DG reductions

115. Energy demand in the US EI regions from the BAU and AEO reference cases.

116. Carbon dioxide price curves used in the EIPC study.

117. Carbon dioxide emissions reductions relative to 2005 levels for the BAU scenario and various sensitivities

118. Eastern Interconnection electricity generation sources under the BAU and RPS sensitivities in 2030 .

119. Eastern Interconnection electricity generation sources under the BAU and CES sensitivities in 2020 .

120. Eastern Interconnection electricity generation sources under the $\mathrm{BAU}$ and $\mathrm{CO}_{2}$ low sensitivities in 2020 . . .

121. $2030 \mathrm{CO}_{2}$ emissions levels relative to 2005 by NEEM region under RPS. ................................. 128

122. $2020 \mathrm{CO}_{2}$ emissions levels relative to 2005 by NEEM region under CES.................................... 128

123. $2020 \mathrm{CO}_{2}$ emissions levels relative to 2005 by NEEM region under low $\mathrm{CO}_{2}$ prices.................... 128 


\section{LIST OF TABLES}

$\begin{array}{rll}\text { Page } & \text { Pag }\end{array}$

ES-1. NEEM Regions, Superregions, and Territories in the Eastern Interconnection .......................... xviii

ES-2. List of Futures Studied in Phase 1 ................................................................................. xviii

ES-3. Main Sensitivities Studied in Phase 1 .................................................................................. xix

ES-4. Topics Studied as Part of Analysis of Eastern Interconnection Planning Collaborative

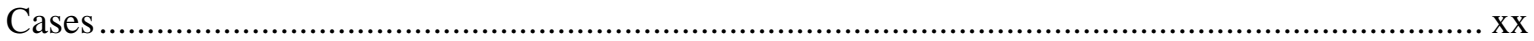

1. NEEM Regions, Superregions, and Territories in the Eastern Interconnection .................................. 2

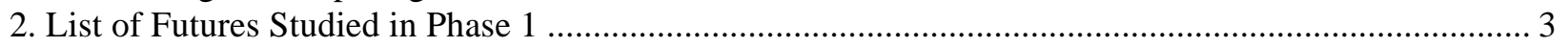

3. Main Sensitivities Studied in Phase 1 ........................................................................................ 4

4. Topics to Be Studied as Part of Analysis of Eastern Interconnection Planning Collaborative

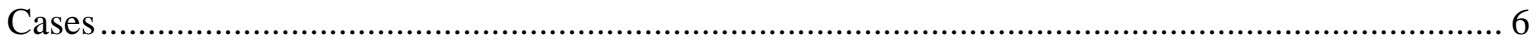

5. Duration Blocks Used for Each Year Modeled in NEEM .............................................................. 16

6. BAU Scenario Significant Changes Through 2030 in the Eastern Interconnection as a Whole ............ 27

7. RPS/R Scenario Significant Changes Through 2030 in the Eastern Interconnection as a Whole.......... 27

8. $\mathrm{CO}_{2}+$ Scenario Significant Changes Through 2030 in the Eastern Interconnection as a Whole............ 27

9. BAU Scenario Significant Changes Through 2030 in the Northwest Eastern Interconnection ............. 29

10. RPS/R Scenario Significant Changes Through 2030 in the Northwest Eastern Interconnection ......... 29

11. $\mathrm{CO}_{2}+$ Scenario Significant Changes Through 2030 in the Northwest Eastern Interconnection........... 29

12. BAU Scenario Significant Changes Through 2030 in the Central Eastern Interconnection ................ 31

13. RPS/R Scenario Significant Changes Through 2030 in the Central Eastern Interconnection.............. 31

14. $\mathrm{CO}_{2}+$ Scenario Significant Changes Through 2030 in Central the Eastern Interconnection................. 31

15. BAU Scenario Significant Changes Through 2030 in the Northeast Eastern Interconnection ............ 33

16. RPS/R Scenario Significant Changes through 2030 in Northeast Eastern Interconnection ................. 33

17. $\mathrm{CO}_{2}+$ Scenario Significant Changes through 2030 in Northeast Eastern Interconnection ................... 33

18. BAU Scenario Significant Changes Through 2030 in the Southwest Eastern Interconnection ........... 35

19. RPS/R Scenario Significant Changes Through 2030 in the Southwest Eastern Interconnection .......... 35

20. $\mathrm{CO}_{2}+$ Scenario Significant Changes through 2030 in the Southwest Eastern Interconnection ............. 35

21. BAU Scenario Significant Changes Through 2030 in the Southeast Eastern Interconnection ............ 37

22. RPS/R Scenario Significant Changes Through 2030 in the Southeast Eastern Interconnection .......... 37

23. $\mathrm{CO}_{2}+$ Scenario Significant Changes Through 2030 in the Southeast Eastern Interconnection ............ 37

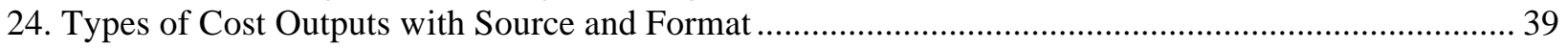

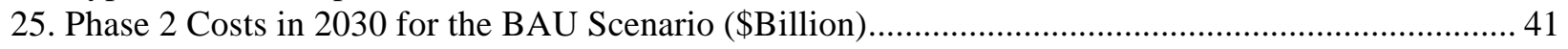

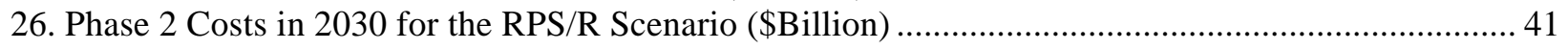

27. Phase 2 Costs in 2030 for the $\mathrm{CO}_{2}+$ Scenario (\$Billion) ................................................................ 41

28. Most Dominant Technologies in Each Region or Territory Based on Percent of Total

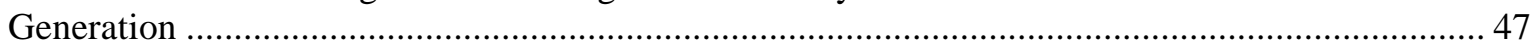

29. Number of Days that Technology Dominates Region's Generation in the BAU Scenario in

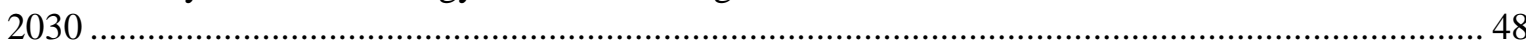

30. Number of Days that Technology Dominates Region's Generation in the RPS/R Scenario in

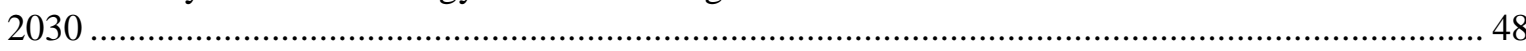

31. Number of Days that Technology Dominates Region's Generation in the $\mathrm{CO}_{2}+$ Scenario in

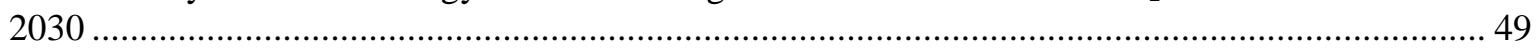

32. NERC Definitions of Reserves (NERC 2013) ......................................................................... 56

33. Reserve Margin Regions, Reserve Requirements, and NEEM Regions (CRA 2010)....................... 56

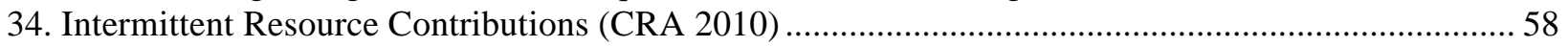

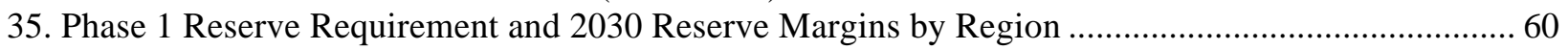

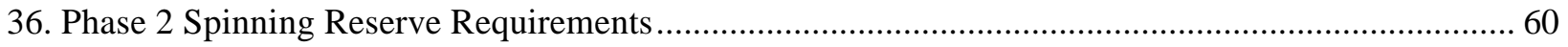


37. Regional Average Spin Requirements and Contributions from Hydro

38. Phase 2 Wind Curtailment Amounts and Percent of Potential Generation.......................................... 63

39. Curtailments and Net Transfers April 1 at 4:00 a.m. for curtailed regions........................................ 70

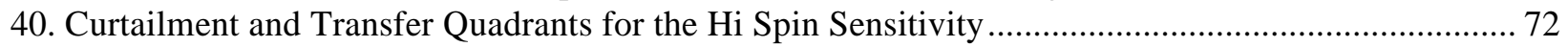

41. Demand Response Supply Curve as a Proportion of Total Demand Response Available in Regions for EIPC Study 78

42. Phase 2 Demand Response Capacity (in gigawatts and percent of demand) and Generation in NEEM Regions 79

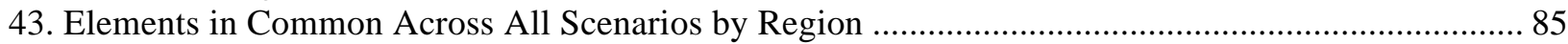

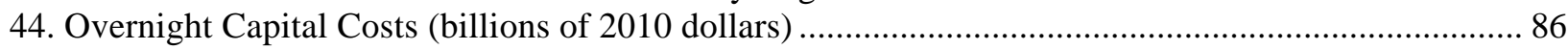

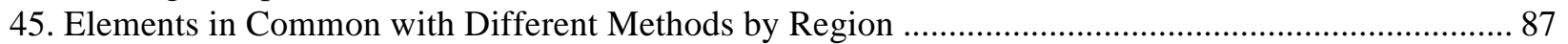

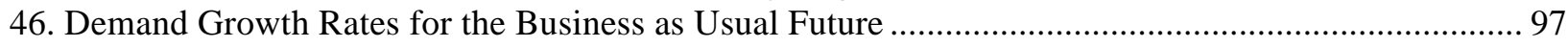

47. Growth by Region for Base, High, and Low Sensitivities (2011-2030) ......................................... 98

48. Percent Change in Generation from Base Scenario for Each Future by Technology ....................... 101

49. Percent Change in Generation from Base Scenario for Each Future by Territory ............................. 102

50. Percent Change in Cost from Base Scenario for Each Future by Territory ….................................. 103

51. Capacities in 2030 by Technology for Base and $\mathrm{CO}_{2}$ Sensitivities of Three Futures (GW) ............. 105

52. US $\mathrm{CO}_{2}$ Emissions in the Business as Usual and $\mathrm{CO}_{2} / \mathrm{N}$ Base Scenarios (billion tons) .................... 106

53. Generation by Technology in 2030 Under Different Delayed Environmental Policies (TWh) ......... 108

54. Fraction of Electricity from Clean Sources by Year Required for the Clean Energy Standard.......... 109

55. Carbon Dioxide Emissions (2015-2030 sum and 2030 alone) for Base and Clean Energy

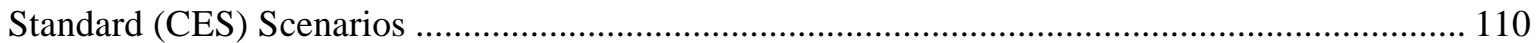

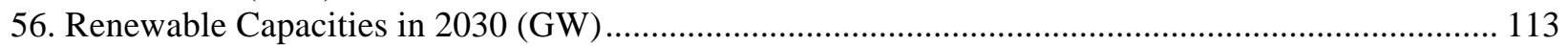

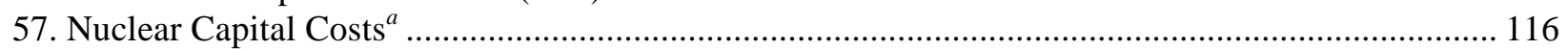

58. Offshore Wind Capacity in 2030 for Different Sensitivities (MW) .............................................. 117

59. Capital Costs for New Generation Resources by In-Service Year [\$/kW (2012\$)] ........................ 119

60. Total Installed Photovoltaic Solar Capacity in the US EI Regions in 2030 (GW) ......................... 121

61. Energy Demand in the US Eastern Interconnection Regions .................................................... 122

62. EPA Rules Modeled in Phase 1 and Their Current Status ........................................................... 123

63. Modifications to State Renewable Portfolio Standards ..................................................................... 124 


\section{ABBREVIATIONS AND ACRONYMS}

AEO

BA

BAU

$\mathrm{CC}$

CES

$\mathrm{CO}_{2} / \mathrm{N}$

$\mathrm{CO}_{2} / \mathrm{R}$

$\mathrm{CO}_{2}+$

CRA

CT

DG

DOE

DR

EE

EI

EIA

EIPC

EISPC

EPA

FERC

GE MAPS

HVDC

IGCC

LMP

MRN-NEEM

MWG

NADR

NEEM

NERC

NUC

O\&M

ORNL

PEV

PSS/E

PTC

PV

RPS
Annual Energy Outlook (EIA report)

balancing area

business as usual

combined cycle

Clean Energy Standard

high $\mathrm{CO}_{2}$ cost, implemented nationally (future)

high $\mathrm{CO}_{2}$ cost, implemented regionally (future)

high $\mathrm{CO}_{2}$ cost + aggressive EE, DR, and DG + national RPS (future)

Charles River Associates

combustion turbine

distributed generation

US Department of Energy

demand response

energy efficiency

Eastern Interconnection

Energy Information Administration

Eastern Interconnection Planning Collaborative

Eastern Interconnection States' Planning Council

US Environmental Protection Agency

Federal Energy Regulatory Commission

General Electric Multi-Area Production Simulation (software)

high voltage direct current

integrated gasification, combined cycle

locational marginal price

Multi-Region National-North American Electricity and Environment Model

Modeling Working Group (SSC)

National Assessment of Demand Response Potential (FERC report and model)

North American Electricity and Environment Model

North American Electric Reliability Corporation

nuclear resurgence (future)

operation and maintenance

Oak Ridge National Laboratory

plug-in electric vehicle

Power System Simulator for Engineering (from Siemens)

production tax credit

photovoltaic

renewable portfolio standard 
RPS/N

RPS/R

RTO

SMR

SSC

SSI

TWh
RPS, implemented nationally (future)

RPS, implemented regionally (future)

regional transmission operator

small modular reactor

stakeholder steering committee

Stakeholder-Specified Infrastructure

terawatt-hour $=1,000$ gigawatt-hours $=10^{6}$ megawatt-hours $=10^{9}$ kilowatt-hours 


\section{EASTERN INTERCONNECTION MEMBERS/REGIONS (also referred to as NEEM regions in this report)}

ENT
FRCC
IESO
MAPP CA
MAPP US
MISO IN
MISO MI
MISO MO-IL
MISO W
MISO WUMS
NE
NEISO
Non-RTO Midwest
NYISO A-F
NYISO G-I
NYISO J-K
PJM

PJM E

PJM ROM

PJM ROR

SOCO

SPP N

SPP S

TVA

VACAR
Entergy Corp. plus other utilities in central Missouri, Arkansas, Louisiana, Mississippi, east Texas

Florida Reliability Coordinating Council—Florida minus the panhandle

Independent Electricity System Operator, Ontario Canada

Mid-Continent Area Power Pool—Canada (Manitoba-Saskatchewan)

Mid-Continent Area Power Pool-US (non-MISO regions in Montana, North Dakota, South Dakota, Minnesota, Iowa)

Midcontinent Independent System Operator-Indiana

Midcontinent Independent System Operator-Michigan

Midcontinent Independent System Operator-Missouri-Illinois (eastern

Missouri, much of Illinois)

Midcontinent Independent System Operator-West (parts of Montana, North Dakota, South Dakota, Minnesota, Iowa, Wisconsin)

Mid-continent Independent System Operator-Wisconsin-Upper Michigan

Nebraska

New England Independent System Operator

Non-Regional Transmission Operator Midwest (most Kentucky, some Ohio public utilities)

New York Independent System Operator-Upstate

New York Independent System Operator-lower Hudson Valley

New York Independent System Operator-New York City-Long Island

Independent System Operator for territory from Chicago to Virginia (formerly the Pennsylvania-New Jersey-Maryland power pool)

PJM Eastern Mid-Atlantic Area Council (New Jersey, Delaware, eastern Maryland)

PJM Rest of Mid-Atlantic Area Council (eastern Pennsylvania, DC, eastern Maryland)

PJM Rest of Region (northern Illinois, Ohio, western Pennsylvania, western Maryland, West Virginia, Virginia, eastern North Carolina)

Southern Company plus other utilities in Georgia, Alabama, eastern Mississippi, western Florida

Southwest Power Pool—North (Kansas, western Missouri)

Southwest Power Pool—South (Oklahoma, north Texas, eastern New Mexico, western Arizona, western Louisiana)

Tennessee Valley Authority (Tennessee, northern Mississippi, northern Alabama, southern Kentucky)

Virginia-Carolina Subregion-South Carolina, western North Carolina 



\section{EXECUTIVE SUMMARY}

Between 2010 and 2012 the Eastern Interconnection Planning Collaborative (EIPC) conducted a major long-term resource and transmission study of the Eastern Interconnection (EI). With guidance from a stakeholder steering committee (SSC) that included representatives from the Eastern Interconnection States' Planning Council (EISPC) among others, the project was conducted in two phases. The first was a 2015-2040 analysis that looked at a broad array of possible future scenarios, while the second focused on a more detailed examination of the grid in 2030. The studies provided a wealth of information on possible future generation, demand, and transmission alternatives. However, at the conclusion there were still unresolved questions and issues. The US Department of Energy (DOE), which had sponsored the study, asked Oak Ridge National Laboratory researchers and others who worked on the project to conduct an additional study of the data to provide further insights for stakeholders and the industry.

The EI covers most of the electricity grid east of the Rockies. High voltage transmission lines interconnect the regions in the EI so power can be transferred readily between them. The EI consists of the multicolored (non-gold) regions in the map in Fig. ES-1. The regions used in the EIPC study (both EI and non-EI) are referred to as NEEM regions throughout this report because of the model (the North American Electricity and Environment Model) used for analysis in Phase 1 of the study. These NEEM regions are based on the boundaries of organizations such as utilities, regional transmission operators, coordinating authorities, independent system operators, and other natural groupings of the grid.

Table ES-1 gives a more detailed description of each region in the EI.

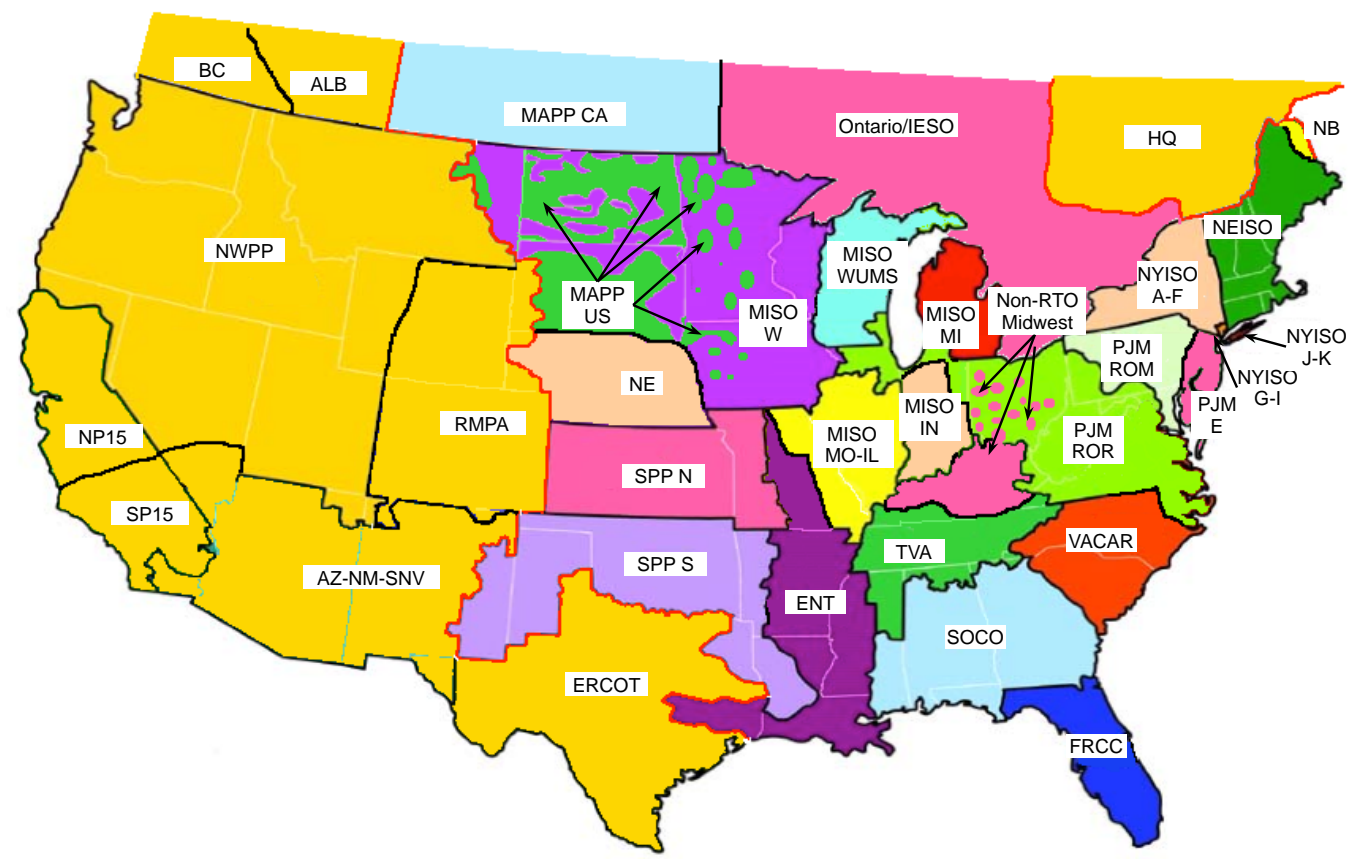

Fig. ES-1. Map of North American Electricity and Environment Model regions. (The Eastern Interconnection includes the multicolored, non-gold, regions).

For this report, results are presented at the level of the entire EI, the individual NEEM regions, or collections of NEEM regions into larger "territories" or "superregions" based on similar characteristics or transmission relationships. 
Table ES-1. NEEM Regions, Superregions, and Territories in the Eastern Interconnection

\begin{tabular}{|c|c|c|c|}
\hline Region & Description & Superregion & Territory \\
\hline MAPP CA & $\begin{array}{l}\text { Mid-Continent Area Power Pool (MAPP) Canada (Manitoba- } \\
\text { Saskatchewan) }\end{array}$ & Midwest & Northwest \\
\hline MAPP US & MAPP US (non-MISO regions in MT, ND, SD, MN, IA) & Midwest & Northwest \\
\hline MISO W & Midcontinent Independent System Operator (MISO) in Michigan & Midwest & Northwest \\
\hline MISO MO-IL & MISO Missouri-Illinois (eastern MO, much of IL) & Midwest & Northwest \\
\hline MISO WUMS & MISO Wisconsin-Upper Michigan & Midwest & Northwest \\
\hline MISO IN & MISO Indiana & Midwest & Northwest \\
\hline MISO MI & MISO West (parts of MT, ND, SD, MN, IA, MN, WI) & Midwest & Northwest \\
\hline Non-RTO Midwest & Non-RTO in Midwest (most KY, some OH) & Midwest & Central \\
\hline PJM ROR & PJM Rest of Region (parts of IL, OH, PA, MD, WV, VA, NC) & PJM ROR & Central \\
\hline PJM ROM & PJM Rest of Mid-Atlantic Area Council (parts of PA, MD, DC) & PJM MAAC & Central \\
\hline PJM E & PJM Eastern MAAC (NJ, DE, east MD) & PJM MAAC & Central \\
\hline IESO & Independent Electricity System Operator in Ontario & Ontario & Northeast \\
\hline NYISO A-F & New York Independent System Operator (ISO) in Upstate NY & Northeast & Northeast \\
\hline NYISO G-I & New York ISO in lower Hudson Valley & Northeast & Northeast \\
\hline NYISO J-K & New York ISO in New York City-Long Island & Northeast & Northeast \\
\hline NEISO & New England Independent System Operator & Northeast & Northeast \\
\hline NE & Nebraska & Southwest & Southwest \\
\hline SPP N & Southwest Power Pool (SPP) North (Kansas, western Missouri) & Southwest & Southwest \\
\hline SPP S & SPP South (Oklahoma, north TX, east NM, west AR, west LA) & Southwest & Southwest \\
\hline ENT & Entergy Corp. + other utilities in central MO, AR, LA, MS, east TX & Southwest & Southwest \\
\hline TVA & Tennessee Valley Authority (TN, north MS, north AL, south KY) & Southeast & Southeast \\
\hline $\mathrm{SOCO}$ & Southern Company + other utilities in GA, AL, east MS, west FL & Southeast & Southeast \\
\hline VACAR & South Carolina, west North Carolina & Southeast & Southeast \\
\hline FRCC & Florida minus panhandle & Southeast & Southeast \\
\hline
\end{tabular}

The Phase 1 analysis used a capacity expansion model belonging to Charles River Associates (CRA) called MRN-NEEM (Multi-Region National-North American Electricity and Environment Model). A capacity expansion model evaluates energy supply and demand over multiple decades and will build or retire capacity as needed or economic. The MRN-NEEM document on the EIPC website provides more detail on the models used (CRA 2010).

In Phase 1 of the study, the term "futures" was used to define a consistent set of input assumptions on technologies, policies, and costs. Eight futures were defined by the SSC in an attempt to cover a wide range of possible policies. The eight are listed in Table ES-2, along with a description and the short label used for each in this report.

Table ES-2. List of Futures Studied in Phase 1

\begin{tabular}{|cll|}
\hline Future & Label & Definitions \\
\hline 1 & $\mathrm{BAU}$ & Business as usual scenario \\
\hline 2 & $\mathrm{CO}_{2} / \mathrm{N}$ & High $\mathrm{CO}_{2}$ cost scenario, national implementation \\
\hline 3 & $\mathrm{CO}_{2} / \mathrm{R}$ & High $\mathrm{CO}_{2}$ cost scenario, regional implementation \\
\hline 4 & $\mathrm{EE} / \mathrm{DR}$ & Aggressive energy efficiency (EE), demand response (DR), and distributed generation (DG) \\
\hline 5 & $\mathrm{RPS} / \mathrm{N}$ & National renewable portfolio standard (RPS), national implementation \\
\hline 6 & $\mathrm{RPS} / \mathrm{R}$ & National RPS, regional implementation \\
\hline 7 & $\mathrm{NUC}$ & Nuclear resurgence \\
\hline 8 & $\mathrm{CO}_{2+}+$ & High $\mathrm{CO}_{2}$ costs scenario with aggressive EE, DR, DG, and nationally implemented RPS \\
\hline
\end{tabular}

A set of sensitivities was defined for each future, but first a base case using the general equilibrium economic model MRN had to be run to establish economy-wide, energy-related demands and prices. The 
results of these base cases could then be used to expand the transmission system between regions. Following that, other sensitivities allowed the EIPC and SSC to explore a variety of changes to technologies, costs, demands, or policies. Table ES-3 summarizes the different sensitivities analyzed.

Table ES-3. Main Sensitivities Studied in Phase 1

\begin{tabular}{|c|c|c|c|c|c|c|c|c|}
\hline Sensitivities & $\begin{array}{l}\text { Future 1: } \\
\text { BAU }\end{array}$ & $\begin{array}{l}\text { Future 2: } \\
\mathrm{CO}_{2} / \mathrm{N}\end{array}$ & $\begin{array}{l}\text { Future 3: } \\
\mathrm{CO}_{2} / \mathrm{R}\end{array}$ & $\begin{array}{c}\text { Future 4: } \\
\text { EE/DR }\end{array}$ & $\begin{array}{l}\text { Future 5: } \\
\text { RPS/N }\end{array}$ & $\begin{array}{l}\text { Future 6: } \\
\text { RPS/R }\end{array}$ & $\begin{array}{l}\text { Future 7: } \\
\text { NUC }\end{array}$ & $\begin{array}{l}\text { Future 8: } \\
\mathrm{CO}_{2+}\end{array}$ \\
\hline Expand transmission & V & $\sqrt{ }$ & $\sqrt{ }$ & & $\sqrt{ }$ & $\sqrt{ }$ & V & $\sqrt{ }$ \\
\hline \pm Load growth & $\sqrt{ }$ & $\sqrt{ }$ & $\sqrt{ }$ & & $\sqrt{ }$ & $\sqrt{ }$ & $\sqrt{ }$ & \\
\hline \pm Gas price & $\sqrt{ }$ & $\sqrt{ }$ & $\sqrt{ }$ & & $\sqrt{ }$ & $\sqrt{ }$ & & $\sqrt{ }$ \\
\hline $\begin{array}{l}\text { 士 Renewable cost or } \\
\text { deployment }\end{array}$ & $\sqrt{ }$ & $\sqrt{ }$ & $\sqrt{ }$ & & $\sqrt{ }$ & $\sqrt{ }$ & & $\sqrt{ }$ \\
\hline Delay regulations & $\sqrt{ }$ & & & & & & & \\
\hline $\mathrm{CO}_{2}$ cost adjustment & & $\sqrt{ }$ & $\sqrt{ }$ & & & & $\sqrt{ }$ & $\sqrt{ }$ \\
\hline PEV variations & & & & $\sqrt{ }$ & $\sqrt{ }$ & $\sqrt{ }$ & & \\
\hline Extra EE savings & & & & $\sqrt{ }$ & & & & \\
\hline $\begin{array}{l}\text { Clean Energy } \\
\text { Standard }\end{array}$ & & & & & $\sqrt{ }$ & $\sqrt{ }$ & & \\
\hline $\begin{array}{l}\text { Small modular } \\
\text { reactors }\end{array}$ & & & & & & & $\sqrt{ }$ & \\
\hline Higher RPS limits & & & & & & & & $\sqrt{ }$ \\
\hline
\end{tabular}

Three scenarios representing transmission needs under a broad array of hypothetical futures were selected for more extensive transmission-focused evaluation in Phase 2: a business as usual scenario (labeled BAU in this report); a scenario with a national renewable portfolio standard (RPS) that is implemented on a regional basis (labeled RPS/R here); and a combined policies scenario with a high $\mathrm{CO}_{2}$ cost, a national RPS, and aggressive energy efficiency (EE)/demand response (DR)/distributed generation (labeled $\mathrm{CO}_{2}+$ here).

In Phase 2 the EI was modeled at a very detailed level (70,000 buses, 9,900 generators) using the Power System Simulator for Engineering model for a peak hour and off-peak hour in each case (only the peak hour in the BAU case.) Transmission lines and other upgrades were added to ensure reliability criteria were met in those hours. The resulting build-outs of the transmission system in these scenarios were then used as inputs in the General Electric Multi-Area Production Simulation software (GE MAPS) model run by CRA. GE MAPS is a detailed economic dispatch and production cost model that simulates electric power system operation, taking into account transmission topology. The GE MAPS model projected energy production costs, constraints limiting dispatch and interregional transactions, anticipated emissions, renewable energy production, and other pertinent factors. Additional information regarding the EIPC modeling can be found in the EIPC Phase 1 Report (EIPC 2011), and the EIPC Phase 2 Report (EIPC 2012).

The results from Phases 1 and 2 provided a wealth of data that could be examined further to address energy-related questions. In January 2013, a small group of EIPC, EISPC, and SSC members were contacted to determine the need for additional analysis and topics of interest. Based on the responses a list of 13 study topics was developed, later supplemented with a 14th topic.

The first five topics were discussed in the report Additional EIPC Study Analysis: Interim Report on High Priority Topics (Hadley 2013). Topics 6-9 were analyzed in the report Additional EIPC Study Analysis: Interim Report on Medium Priority Topics (Hadley and Gotham 2014a). Topics 10-13 were analyzed in the report Additional EIPC Study Analysis: Report on Low Priority Topics (Hadley and Gotham 2014b). 
The findings in each of these interim reports have been incorporated into this final report, along with the analysis of Topic 14 .

Table ES-4. Topics Studied as Part of Analysis of Eastern Interconnection Planning Collaborative Cases

\begin{tabular}{|c|c|}
\hline \multicolumn{2}{|r|}{ Description } \\
\hline \multicolumn{2}{|r|}{ High Priority Topics } \\
\hline 1 & How do Phase 2 results compare to Phase $1 ?$ \\
\hline 2 & Were there significant changes in earlier years within various regions? \\
\hline 3 & When all costs are integrated, how do results compare between scenarios? \\
\hline 4 & Do some regions face overreliance on certain fuels or technologies? \\
\hline 5 & What are the gas sector interrelationships in the different regions? \\
\hline \multicolumn{2}{|r|}{ Medium Priority Topics } \\
\hline 6 & How did regional operating and planning reserves definitions affect the results? \\
\hline 7 & Why was there so much wind curtailment in the RPS/R and $\mathrm{CO}_{2}+$ scenarios? \\
\hline 8 & How much did demand response as defined in the models affect results? \\
\hline 9 & What transmission lines were of value in all scenarios? \\
\hline \multicolumn{2}{|r|}{ Low Priority Topics } \\
\hline 10 & How did regional vs. national implementation of policies differ? \\
\hline 11 & What were the impacts of load growth sensitivities on resource mix and cost? \\
\hline & What impacts were noticed from the environmental policy sensitivities? \\
\hline & What impacts were noticed from the technology sensitivities? \\
\hline \multicolumn{2}{|r|}{ EISPC Added Topic } \\
\hline & What changes in key inputs and expected results occurred since the study began? \\
\hline
\end{tabular}

\section{Topic 1: How do Phase 2 results compare to Phase 1?}

Because Phase 2 was a more detailed look at the EI, it captured more of the complexities that a real system faces and modeled the system under a broader set of circumstances (variable generation and demands). As a consequence, it required additional capacity (for reliability) and costs were higher.

Capacity amounts for the total EI differed between $4 \%$ and $6 \%$ between the two phases depending on the scenario, with some NEEM regions showing Phase 2 increases greater than $10 \%$. Some of the regional differences were due to manually improved placement of combustion turbines across the territories during Phase 2.

Generation amounts differed only slightly for the EI as a whole. There was greater regional variation because of differences in transmission modeling, hourly supply and demand variations, and reliability constraints for reserves. Several of the regions in the western EI had much lower Phase 2 generation in the $\mathrm{CO}_{2}+$ scenario. This was likely due to the excess wind that had to be curtailed in many hours in those regions in the more detailed Phase 2 modeling.

Interregional transmission was quite different between some of the regions, especially in the $\mathrm{CO}_{2}+$ scenario. The hourly modeling in Phase 2 (and the greater variation in wind generation) meant greater opportunities for transfers. In addition, there was a more explicit and accurate build-out and modeling of power flow in Phase 2 than Phase 1. The interregional maximum and average flows in Phase 2 were most different for the Western EI, again likely due to wind curtailment.

Total costs in Phase 2 for all of the EI were 16\% higher than Phase 1 in the $\mathrm{CO}_{2}+$ scenario but only $4 \%$ and $1 \%$ in the other two scenarios. Phase 2 had more precise (and generally higher) capital costs as the 
different EIPC members developed costs based on known projects; also, the phase had higher generating capacities. Generating plant capital costs heavily outweighed that of transmission. The difference in cost is most noticeable in the $\mathrm{CO}_{2}+$ scenario in the high wind regions, MISO W, SPP N, and SPP S, ${ }^{*}$ where wind capacity was highest (Fig. ES-2).

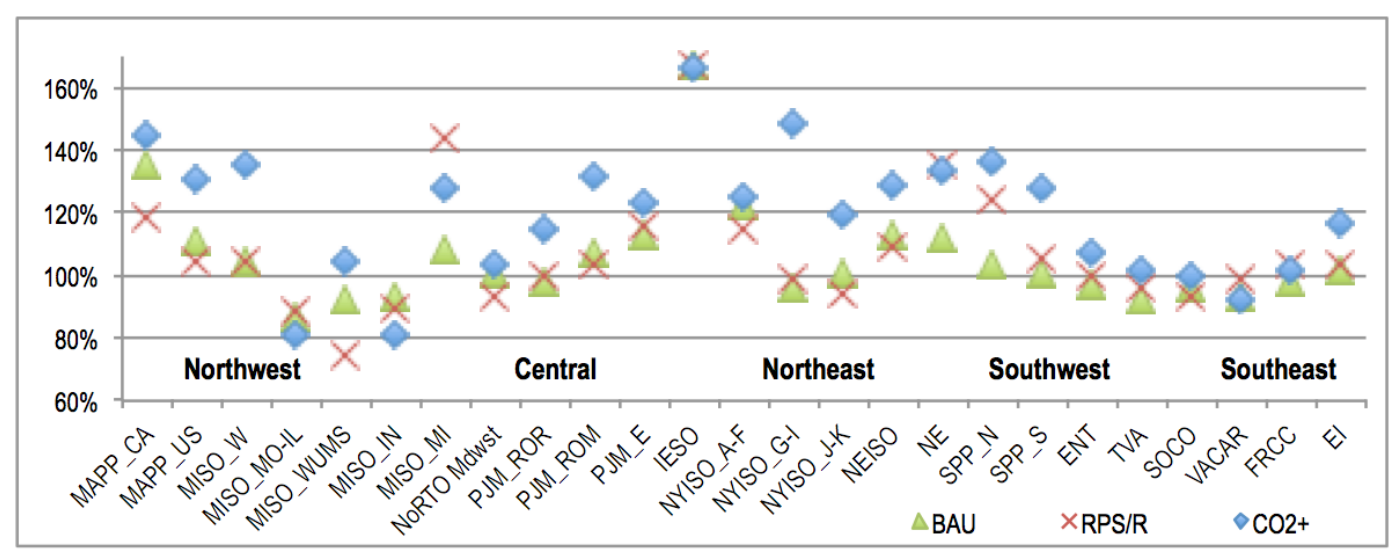

Fig. ES-2. Ratio of Phase 2 to Phase 1 generation costs in 2030 by region.

\section{Topic 2: Were there significant changes in earlier years within various regions?}

The study focused primarily on the results for the year 2030. In further examining the changes that took place from 2015 to 2025, the most consistent change across the regions was the large increase in DR expected by 2020 and 2025, especially in the $\mathrm{CO}_{2}+$ scenario. Most regions also had a large decrease in capacity between 2010 and 2015, most often that of fossil-fired steam plants.

The $\mathrm{CO}_{2}+$ scenario had the greatest change in all regions, as the carbon cost increased to high levels so carbon-based fuels declined (Fig. ES-3). Coal generation was the first to decline, often replaced with combined cycle (CC) or wind initially. In the later years, even CC plants decreased production in favor of nuclear or additional renewable generation.

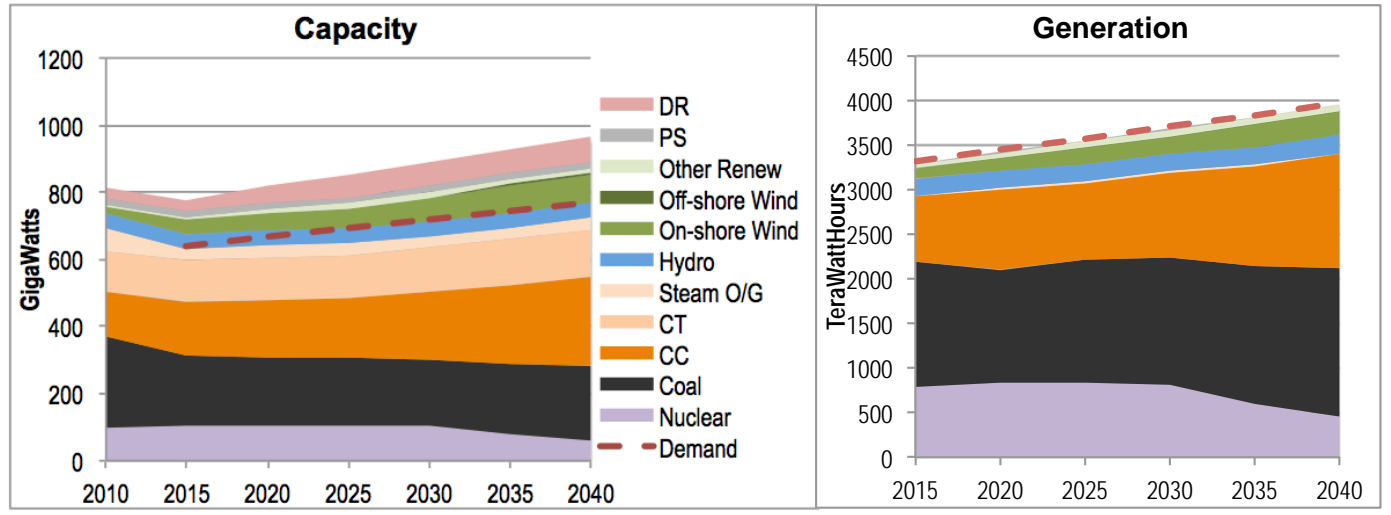

Fig. ES-3. $\mathrm{CO}_{2}+$ scenario Phase 1 capacity and generation for the Eastern Interconnection (EI).

In the RPS/R Scenario, most changes were more gradual. Wind and other renewables were added as the RPS requirement increased. As in the $\mathrm{CO}_{2}+$ scenario, large wind increases occurred somewhat sooner in the Southwest than Northwest. Offshore wind and other renewables provided almost all new capacity in

\footnotetext{
"Note: Refer to Table ES-1 or the Eastern Interconnection members/regions list at the front of this report for complete definitions of region identifiers used in the text.
} 
the Southeast. The BAU Scenario had very few large changes in capacity and generation over time in the various territories.

\section{Topic 3: When all costs are integrated, how do results compare between scenarios?}

Costs evaluated included annual fuel and operating costs, emissions costs, levelized capital costs for generation and upgrades to transmission, and several other customer costs. Phase 2 only evaluated costs in 2030 rather than values over the full 30-year period. Costs were highest for the EI in the $\mathrm{CO}_{2}+$ scenario (Fig. ES-4).

Some of this higher cost represented $\mathrm{CO}_{2}$ emissions costs that either are intangible costs (and so available for other purposes) or are costs that should be included in other scenarios for comparison. Regardless, costs were still high for the $\mathrm{CO}_{2}+$ scenario and the RPS/R scenario due to the large capital investment in new capacity. In contrast, fuel and other operating costs were much lower in the $\mathrm{CO}_{2}+$ scenario.

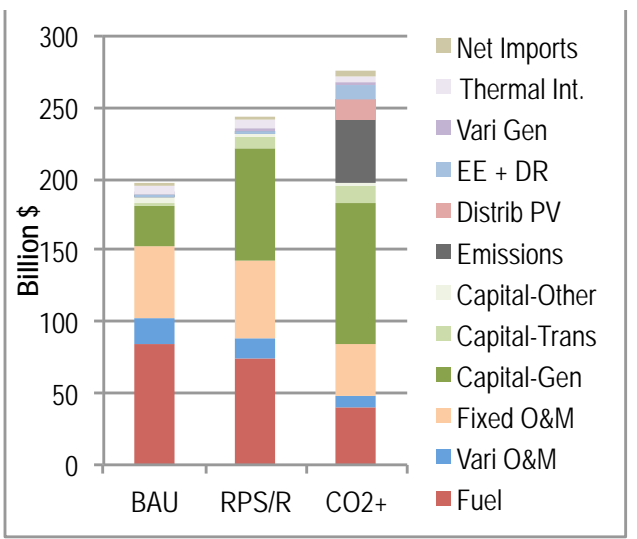

Fig. ES-4. Phase 2 total costs for the Eastern Interconnection (EI) in 2030.

Transmission cost represented only $10 \%$ of the overall capital cost, and less than $5 \%$ of total costs. It is likely that in those scenarios with high levels of curtailment and/or DR, additional transmission capacity would provide opportunities for lower cost power to displace high cost power.

\section{Topic 4: Do some regions face overreliance on certain fuels or technologies?}

Regions with a high reliance on a single fuel may be vulnerable to shortages. The $\mathrm{CO}_{2}+$ scenario had the most regions with high levels of reliance on single technologies, with 10 regions relying on a single source for more than two-thirds of their generation. These regions were generally reliant on wind, hydro, or CC, so they could be vulnerable to intermittent shortages due to calm winds, long-term drought, or low gas supply issues. Only six regions in the RPS/R and BAU scenarios had high levels of reliance, with coal, which is less likely to be vulnerable to disruptions, playing a role in most of them.

Figure ES-5 shows the shift in dominant sources for each region when going from the BAU to the RPS/R and $\mathrm{CO}_{2}+$ scenarios. Note that coal dominance in BAU and RPS/R often switches to wind in the $\mathrm{CO}_{2}+$ scenario. Nuclear is relatively dominant in a number of regions, though rarely more than $50 \%$ of the total.

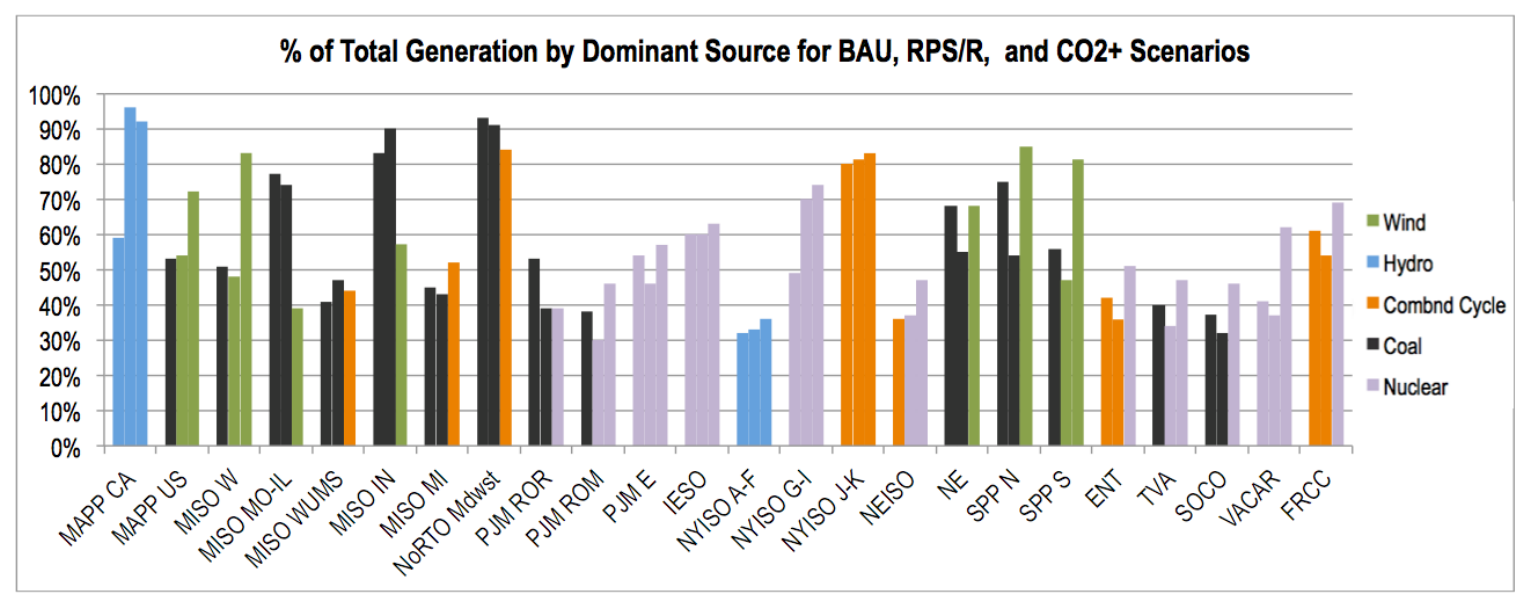

Fig. ES-5. Dominant generation source for each region and scenario. 


\section{Topic 5: What are the gas sector interrelationships in the different regions?}

The study used gas prices from the DOE Energy Information Administration's (EIA's) 2011 Annual Energy Outlook Early Release (AEO; EIA 2011a), with a price of $\$ 6.58$ by 2030. Since then, estimates of prices in 2030 have dropped $20 \%$ or more. A possible consequence is that the study did not capture the level of conversion to natural gas that is now expected by many. The exception might be that in the $\mathrm{CO}_{2}+$ scenario, even by 2015 total gas demand was $37 \%$ higher than in the BAU and RPS/R scenarios (Fig. ES-6) due to the relative cost impact of $\mathrm{CO}_{2}$ emissions on coal versus gas generation.

Some regions showed dominance by gas, most notably NYISO J-K (and Non-RTO Midwest in the $\mathrm{CO}_{2}+$ scenario).

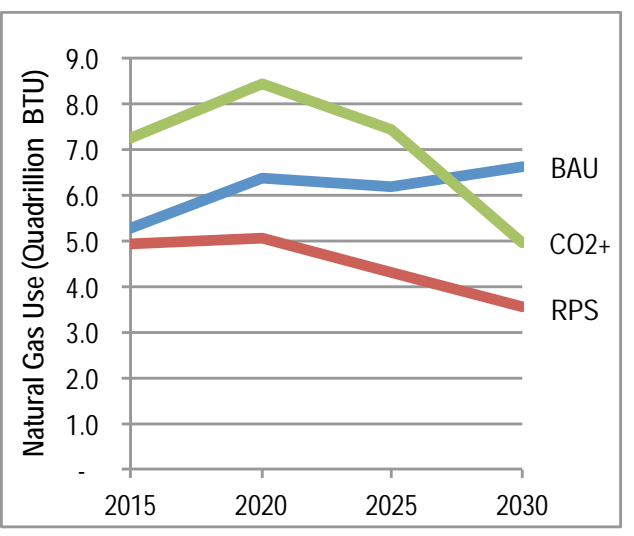

Fig. ES-6. Gas use for electricity. There did not appear to be a huge growth in gas demand between 2015 and 2030 for any region. Many regions saw declines between 2025 and 2030 in the $\mathrm{CO}_{2}+$ scenario as $\mathrm{CO}_{2}$ costs raised the cost of gas. Brief spikes in gas use appeared to hit the western regions most often. This only occurred in the $\mathrm{CO}_{2}+$ and RPS/R scenarios, and these regions were not heavy users of gas so it is unlikely they would face critical shortages.

\section{Topic 6: How did regional operating and planning reserves definitions affect the results?}

Reserves represent an amount of capacity above demand available to provide adequate electricity at the correct voltage and frequency to maintain the grid under abnormal circumstances. Two main types of reserves were used in the EIPC study: planning reserves and operating reserves. Planning reserves were used for long-term resource planning, while operating reserves were used for day-to-day operations.

Phase 1 of the study used planning reserves, and all generating capacity could be used to meet the planning reserve margin, including DR. However, the EIPC derated intermittent (solar and wind) technologies by applying a fractional "resource contribution credit." This credit ranged from $11 \%$ to $30 \%$ depending on the region and technology. Because the capacity factors for these technologies were higher than the credit, there was often a large amount of extra generation from these intermittent sources, which affected the Phase 2 curtailment quantities discussed under Topic 7.

Figure ES-7 presents the capacities in each region as a fraction of their peak demands in the $\mathrm{CO}_{2}+$ scenario. It shows both the technologies that qualify for the reserve calculation plus $100 \%$ of the intermittent capacity that is not fully credited. All regions meet their minimum reserve margins, but those with high wind capacity have significant capacity above internal reserve requirements available for export to other regions when wind production is high. Another observation is that the $\mathrm{CO}_{2}+$ scenario included significant DR to meet reserve needs. Many regions required DR to meet their peak demand (the 100\% line crosses DR in the chart) unless they could import from the regions with excess production.

Phase 2 considered operating reserves in the system modeling. In the modeling, only thermal fossil plants (coal, gas steam, and CC) and hydroelectric plants could provide reserves; these plants had to be running at least at their minimum dispatch points and could only provide limited quantities based on their ramp rates. While many regions had sufficient hydro to cover most of their reserves requirements, other regions were forced by their reserves requirements to increase output from the committed thermal units and DR while other lower-cost units (most notably wind) were curtailed. A Phase 2 sensitivity was run that cut the operating reserve requirement in half (to capture DR supply of reserves and enhanced CC flexibility). This led to a reduction in the amount of low cost power curtailed, as examined in Topics 7 and 8. 


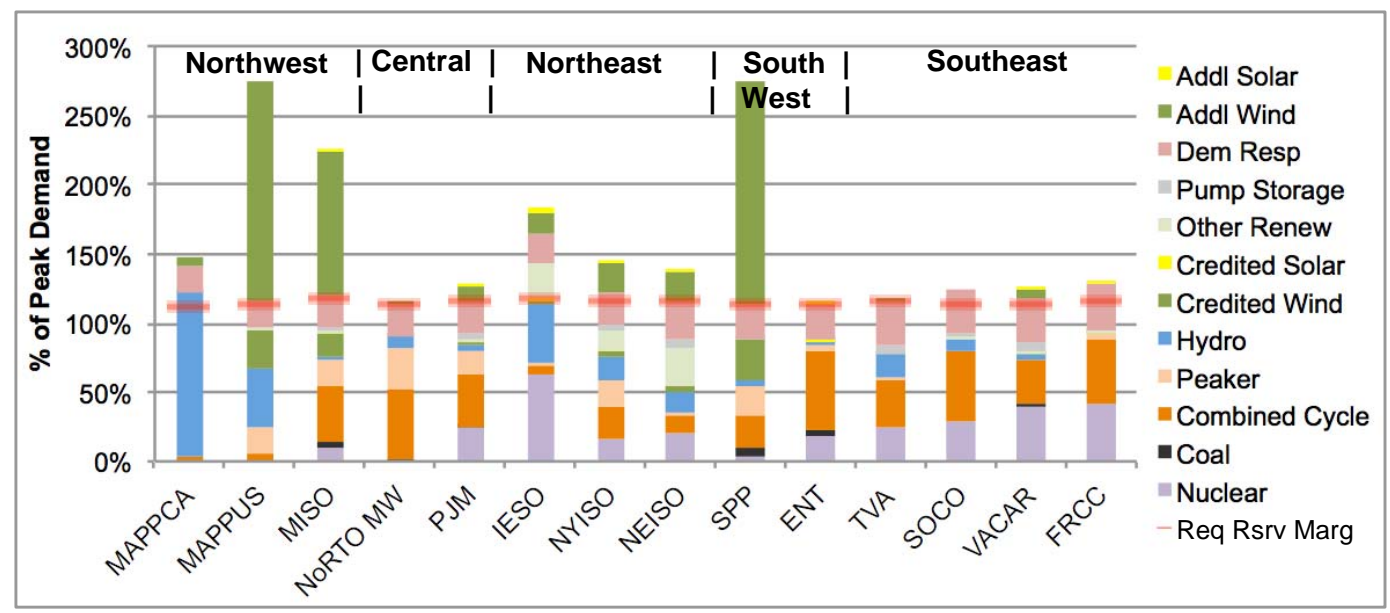

Fig. ES-7. Phase 1 ratio of capacities to peak demand in the $\mathrm{CO}_{2}+$ scenario.

\section{Topic 7: Why was there so much wind curtailment in the RPS/R and $\mathrm{CO}_{2}+$ scenarios?}

Wind power is a resource that can provide large amounts of electrical power at very low marginal cost. The variable operating cost is near zero, and when production tax credits are available the net variable cost to wind producers is actually negative. Generally, it is most economic for the sector to take all generation provided from wind. However, there are various reasons why at times the system cannot accept all the wind power available such as more production than consumers demand at the time; insufficient transmission to carry the power to other regions; or other factors such as local reserve requirements, transmission impedance, ramping limitations, and environmental regulations.

In Phase 1, there was little issue with curtailment, primarily for two reasons. First, the wind generation and loads were aggregated and averaged into just 20 periods to cover each year. Extremes of high wind generation and/or very low demand, when curtailment would be most pronounced, were not evaluated. Phase 2 provided a more detailed hourly view, resulting in large curtailments, most notably in the high wind regions of MISO and SPP in the $\mathrm{CO}_{2}+$ scenario. Second, operating reserves, which could force higher cost generators to run instead of the wind generators, were not modeled in Phase 1 of the study.

We used the results from multiple Phase 2 scenarios with differing amounts of curtailment to create a close approximation of the hourly curtailments for the five regions with the highest levels of curtailment (MISO MO-IL, MISO W, NE, SPP N, and SPP S). Our analysis showed that curtailments were highest in the morning hours for each region (Fig. ES-8), which indicates that low demand levels played an important role in curtailments. 

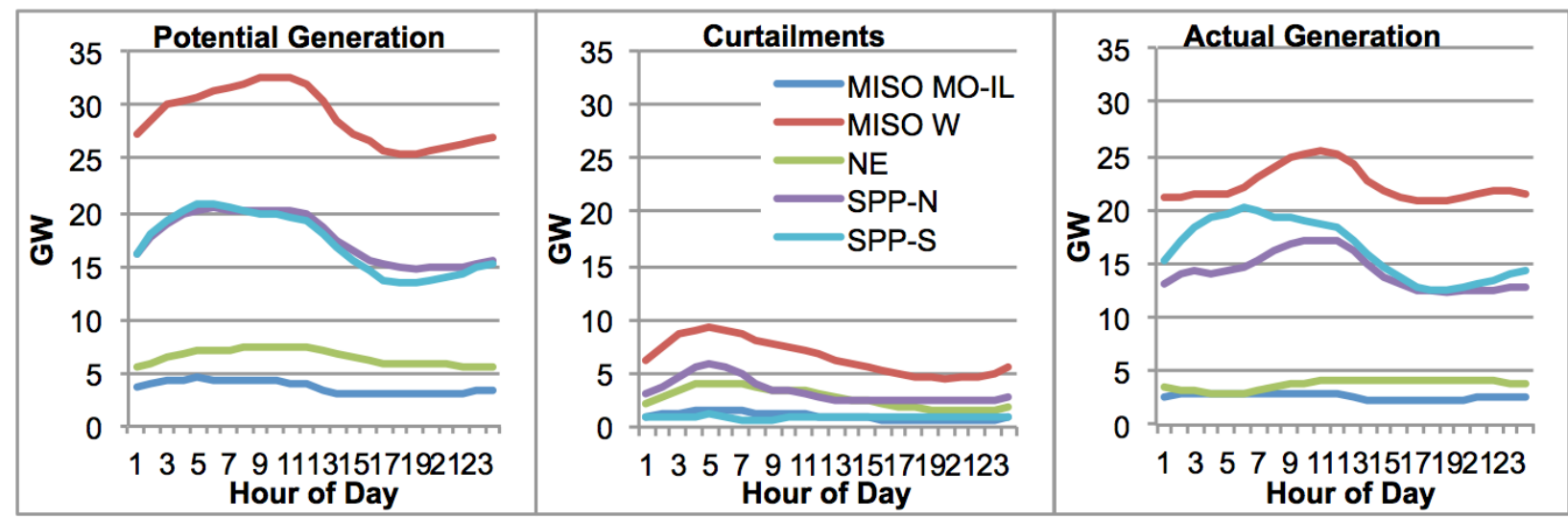

Fig. ES-8. Potential wind generation, curtailments, and actual generation in the $\mathrm{CO}_{2}+$ scenario by hour of day. (Refer to Table ES-1 or the acronym list for region explanations.)

The peak curtailment day of April 1 was analyzed in depth (Fig. ES-9). The high curtailments at 4 a.m. occurred even though interregional tie-lines were not heavily loaded, so low demand must have played a role. Another factor was that CC production occurred, especially in PJM, despite prices below the cost of production, indicating that operating reserves played a role. When the flexibility of these CCs was increased in the "Hi Spin" sensitivity, CC production was greatly reduced in the early hours, resulting in more transfers from the windy regions and less curtailment.
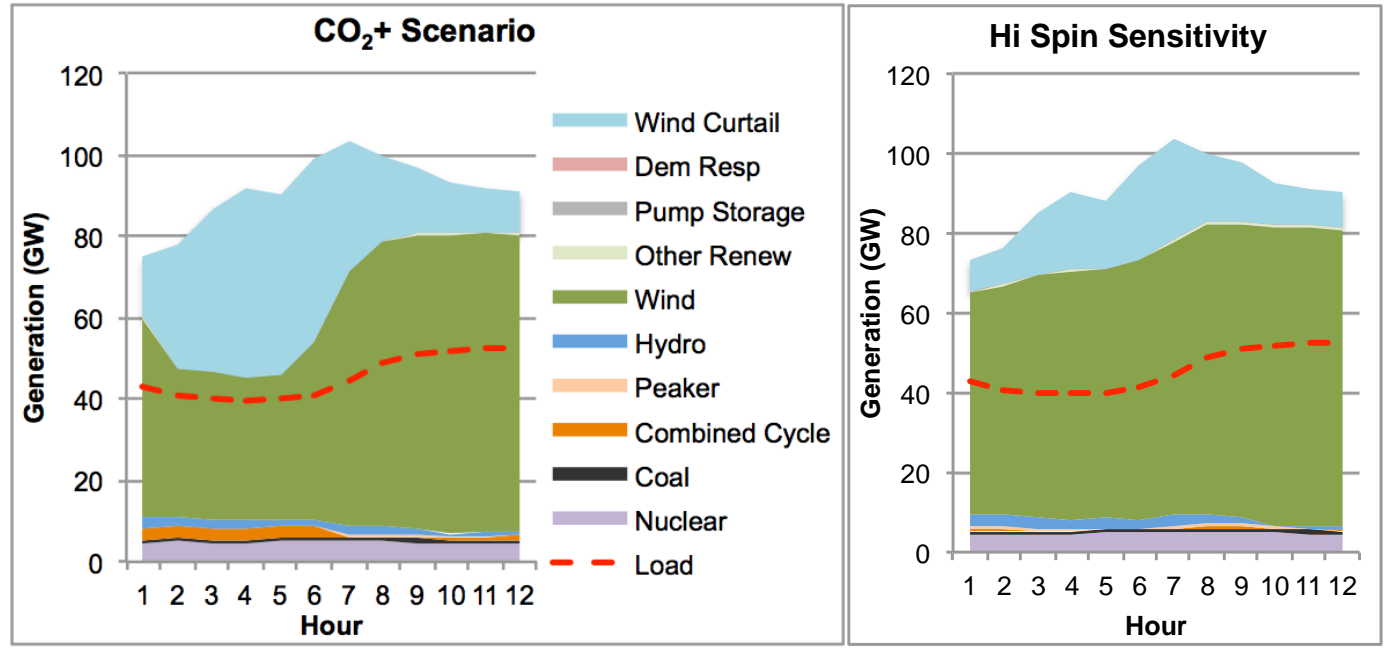

Fig. ES-9. Curtailed region April 1 morning generation levels in the $\mathrm{CO}_{2}+$ scenario and Hi Spin sensitivity.

The modifications in the Hi Spin sensitivity reduced curtailments somewhat, but there were still many hours with large curtailments. Most of the curtailments, especially the high levels of curtailment, occurred when transfers from the region were near their peak amounts (Fig. ES-10). The red lines in Fig. ES-10 show the median values for net transfers and curtailments. Each point represents a different hour in the year. The vast majority of curtailed energy ( 94 TWh in the Hi Spin sensitivity) occurs in quadrant I when both curtailments and transfers are above the median, indicating that the dominant reason for the curtailments was the transfer limitations. However, more than $60 \mathrm{GW}$ of additional transfer capacity (more than 17 high voltage direct current lines) would be required to ease the peak amount of curtailment shown in Fig. ES-10. 


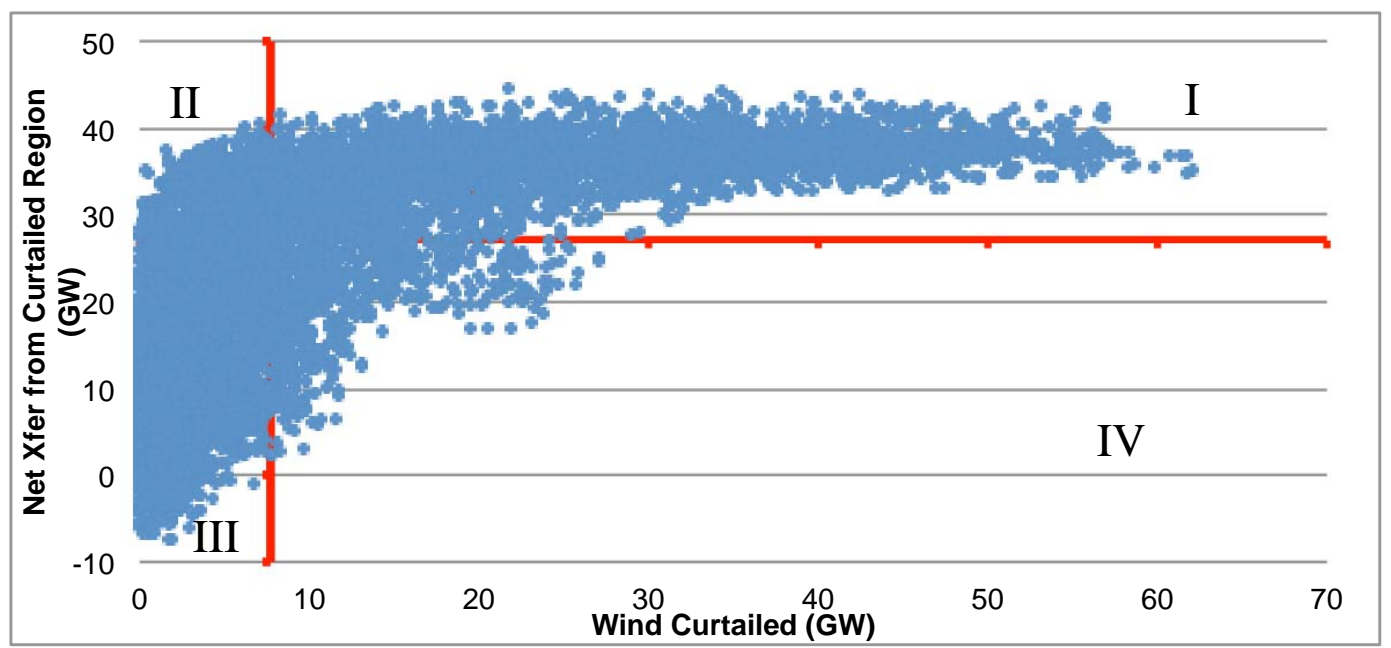

Fig. ES-10. Net transfer vs. wind curtailment in the curtailed regions in the Hi Spin sensitivity.

\section{Topic 8: How much did demand response as defined in the models affect results?}

DR is a complex collection of programs and technologies that allows demand to respond to supply, mainly through reduction of demand in the face of supply shortages. In June 2009, the Federal Energy Regulatory Commission (FERC) released a study on DR, A National Assessment of Demand Response Potential (FERC 2009), referred to in this report as the NADR. In the EIPC study, the amount of DR for each region was calculated using the state-by-state projections of DR across a combination of scenarios from the FERC NADR model.

In Phase I, the DR capacity was forced in as pseudo power plants at relatively high variable costs (price) to generate, $\$ 750 / \mathrm{MWh}$, roughly the maximum amount from the FERC study. DR energy was dispatched in just the VACAR and FRCC regions, but DR capacity reduced the quantity of ordinary capacity needed to meet reserve requirements in all regions. In Phase 2, the SSC created a DR supply curve for each region based on the amounts used in Phase 1 and the FERC model. DR was called upon more frequently in this phase because variations in demands and supplies were greater than in Phase 1,leading to periods with insufficient conventional supplies. This was compounded by the reserve requirements that limited $\mathrm{CC}$ production during high demand.

DR use was more extensive in the Southeast: SOCO, VACAR, and FRCC. Lack of surplus renewables meant little cushion during peak times, as for example in the August 1 scenario depicted in Fig. ES-11. Operating reserve requirements also contributed as CC capacity had to be reduced during periods of peak demand to provide needed spinning reserves. If DR had been allowed to provide reserves, the CC capacity might have provided more power and reduced the need to call on DR energy.

The DR capacity was scattered across a region in line with the demands. Transmission congestion issues both within a region and between regions could cause DR to be called upon in some parts of a region but not in others. This can be seen in the different marginal prices reported by the balancing areas. Within VACAR, the areas within the southern part of South Carolina (Santee Cooper, Central Electric Coop, and SC Electric \& Gas) called upon DR more often at higher levels, resulting in higher marginal prices than other areas in the region (in Fig. ES-12).

One question was why the Southeast did not build out more transmission capacity if it was going to be faced with more capacity issues than other regions. This can be partly explained because in the Phase 1 modeling the potential added transmission was only used during peak times, less than $20 \%$ of the year, and so did not meet the SSC usage criteria for these lines to be built. There could be several reasons why 
they were only used during peak times, including hurdle rates between regions or the "peakiness" in the Southeast, with higher summer demands.

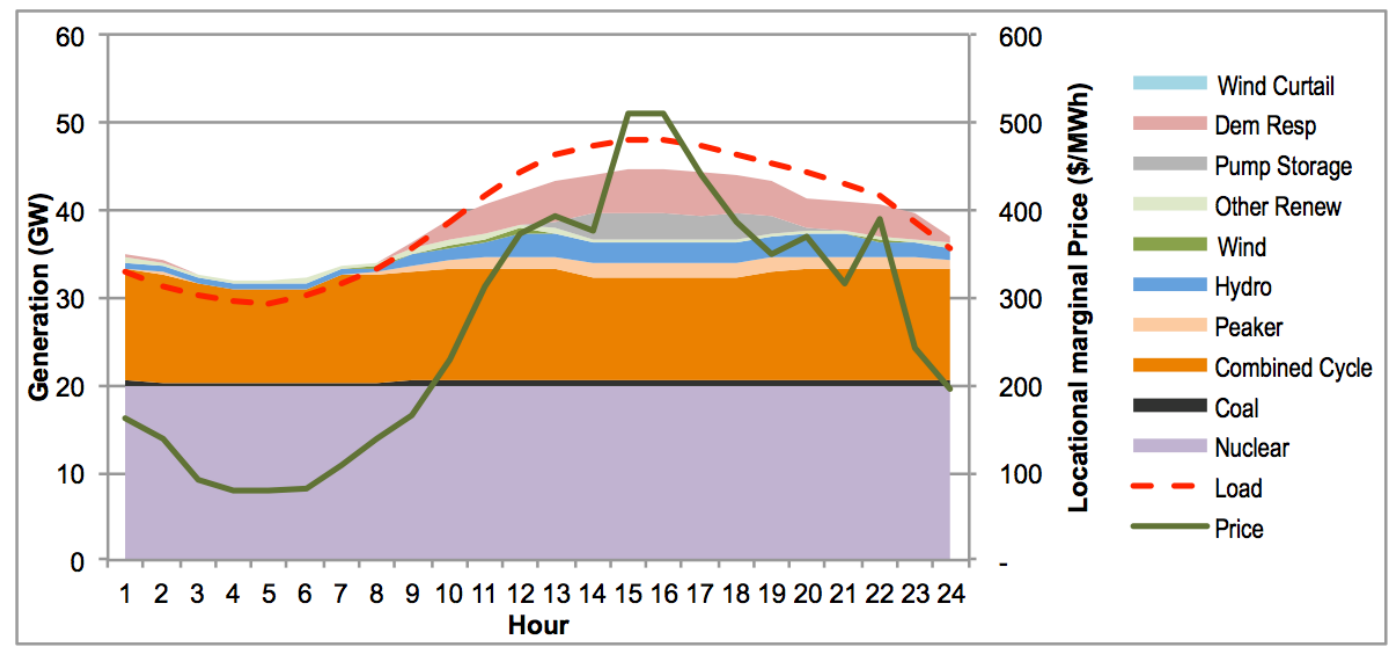

Fig. ES-11. VACAR generation, load, and marginal price on August 1 in the $\mathrm{CO}_{2}+$ scenario.

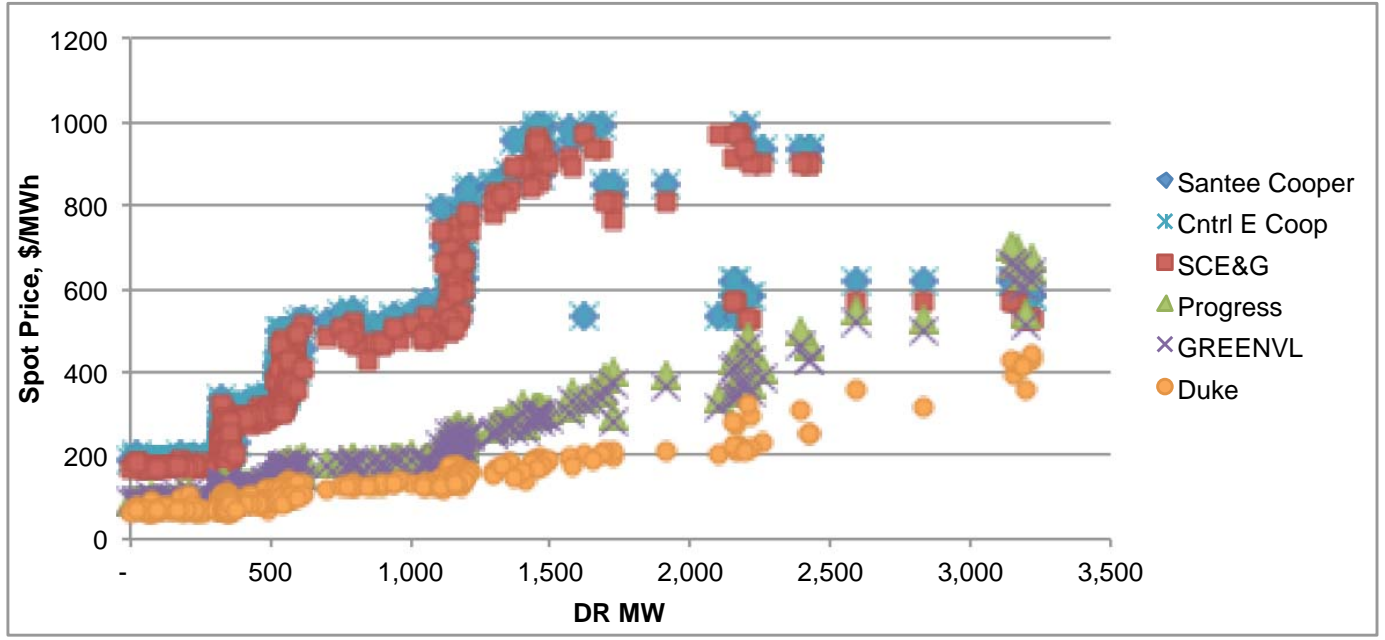

Fig. ES-12. Marginal prices at six balancing areas versus the corresponding demand response (DR) demand for all of VACAR in the business as usual scenario.

\section{Topic 9: What transmission lines were of value in all scenarios?}

Before any scenarios were run, a base transmission grid was defined, including both existing elements and new elements proposed by the EIPC and approved by the SSC. Each scenario then had elements (transmission lines, transformers, autotransformers, reactive support devices, or other upgrades) added as needed to interconnect new generation, prevent overloads, or prevent low voltage situations. Of these added elements, 89 were common to all three scenarios (Fig. ES-13). Many of these additions were in the NEISO region to support new wind farms that were added in the SSC process. In addition to these, there were 26 elements that were modified in all three scenarios, but in different ways (e.g., added circuit, reconductoring, or higher rating on new equipment). 


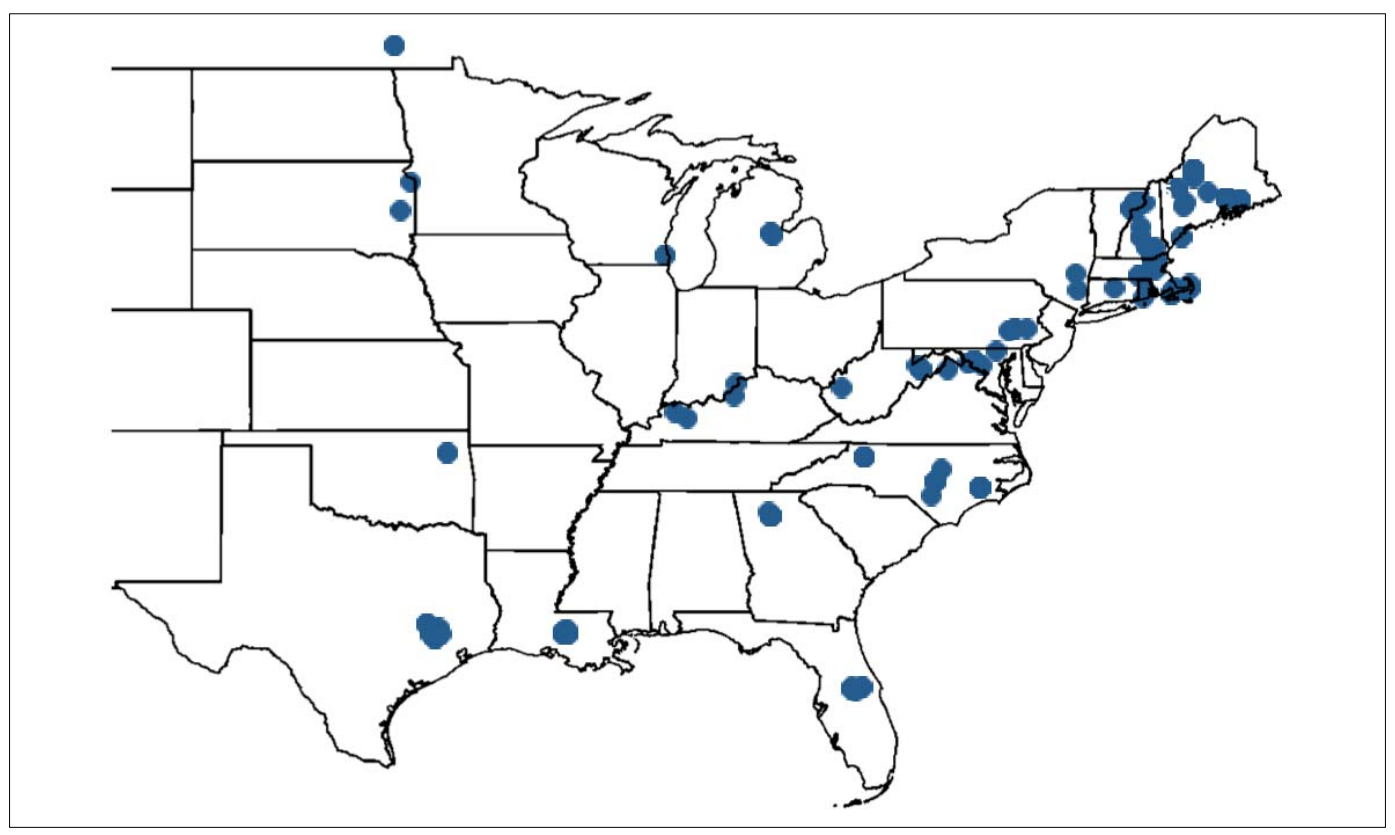

Fig. ES-13. Locations of buses with upgrades common to all three scenarios.

\section{Topic 10: How did regional vs. national implementation of policies differ?}

During Phase 1, two sets of futures were used to examine the effects of using a national approach to policy issues versus a regional approach. The first set (Futures 2 and 3) examined the impact of a $\mathrm{CO}_{2}$ cost assigned to emissions with transfer capacity increases allowed between superregions (the national implementation case, or " $\mathrm{CO}_{2} / \mathrm{N}$ ") versus a system with limited flows between superregions (the regional implementation case, or " $\mathrm{CO}_{2} / \mathrm{R}$ "). Carbon dioxide prices for the two $\mathrm{CO}_{2}$ futures were designed to lower economy-wide emissions from 2005 levels $42 \%$ by 2030 and $80 \%$ by 2050 .

The second set (Futures 5 and 6) examined the implementation of national and regional RPSs, called RPS/N and RPS/R. The RPS in the two RPS futures required that $7.5 \%$ of overall energy in 2015 be generated from a renewable source, which is defined as biomass, geothermal, hydroelectric, landfill gas, solar, or wind. The RPS requirement increased over time to $30 \%$ in 2030.

For the $\mathrm{CO}_{2}$ price futures, the regional implementation resulted in a significant drop in energy from renewables with a correspondingly large increase in energy from natural gas compared to the national implementation. Energy from coal and nuclear sources was also higher under the regional implementation. With the reduction in wind generation and increased generation from natural gas and coal, the regional implementation produced more $\mathrm{CO}_{2}$ emissions.

Unlike the $\mathrm{CO}_{2}$ price futures, the regional versus national implementation of an RPS had little impact on coal and natural gas use over the EI. The primary effect was that the regional implementation relied less heavily on wind from the Midwest and Southwest superregions and more heavily on offshore wind and biomass in the eastern portions of the EI. The regional $\mathrm{CO}_{2} \mathrm{R}$ future had greater $\mathrm{CO}_{2}$ emissions than the national $\mathrm{CO}_{2} / \mathrm{N}$ future, but at a slightly lower cost. The RPS/R future had higher overall costs than the $\mathrm{RPS} / \mathrm{N}$ future.

\section{Topic 11: What were the impacts of load growth sensitivities on resource mix and cost?}

The base scenario of each future included electricity demand growth rates that were initially calculated by the EIPC members for their respective regions. 
To examine the impact of growth, sensitivities were run on many of the futures, which either raised or lowered the growth rates. The rates were changed by adding or subtracting $1 \%$ to/from the annual rate; so for example, a growth rate of $0.85 \%$ became either $1.85 \%$ or $-0.15 \%$ depending on the sensitivity. For every future, the transmission system was only expanded during development of the base scenario. Thus, there was little actual change in the amount the transmission grid was used despite the change in demand under high or low growth.

Figure ES-14 shows projected generation by technology for the EI in 2030 for the base case and sensitivities. Natural gas generation shifted the most of all technologies between the base and sensitivities for each future with variations up to $+90 \%$ or $-49 \%$ in the high or low load sensitivities. Renewable amounts change roughly in line with the total percentage change, while coal and nuclear generation change little.

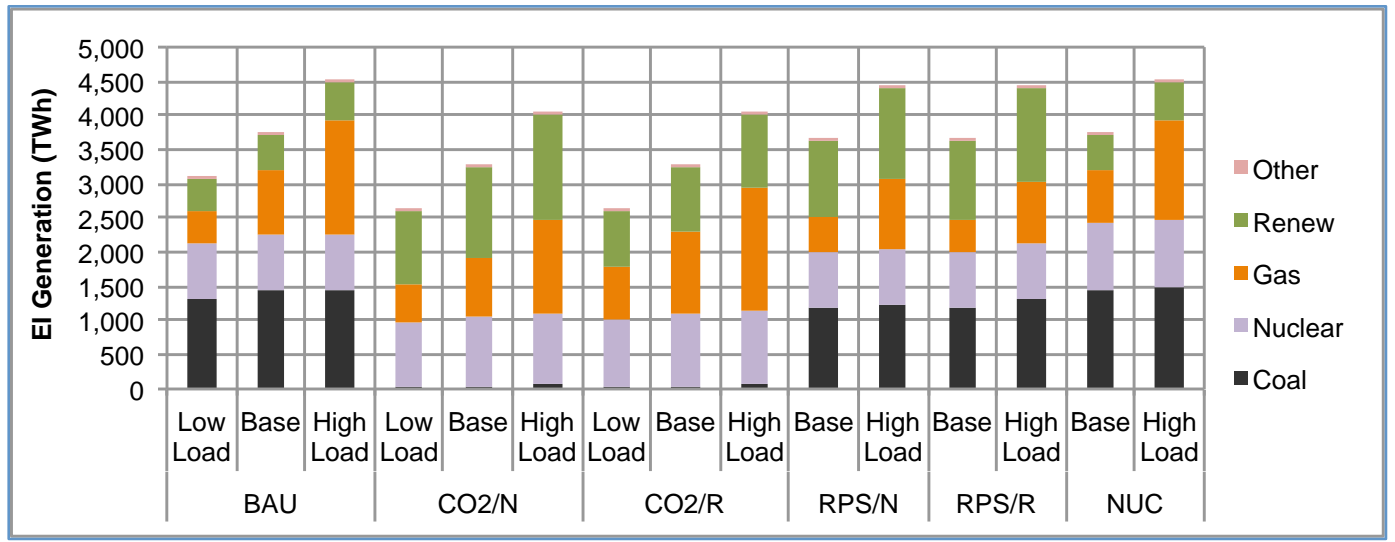

Fig. ES-14. Eastern Interconnection (EI) projected generation by technology in 2030 under different load growth scenarios.

\section{Topic 12: What impacts were noticed from the environmental policy sensitivities?}

High $\mathrm{CO}_{2}$ costs greatly "decarbonized" the electric sector, especially post-2030. Lowering $\mathrm{CO}_{2}$ prices by $20 \%$ reduced the amount of renewables and nuclear used, with gas-fired capacity increasing. Of all policies, $\mathrm{CO}_{2}$ price additions, in conjunction with other factors such as lowered capital cost, most incentivized nuclear capacity increases

Reductions or delays in implementation of environmental policies generally increased the amount of coal-fired generation at the expense of gas or renewables. Reducing current state RPS, EE, and DR goals allowed the increase of both coal- and gas-fired generation, with a smaller reduction in renewables such that overall demand increased. Simple delays in implementation of current US Environmental Protection Agency (EPA) requirements increased coal-fired generation at the expense of natural gas-fired generation, while elimination of the Production Tax Credit and state RPS requirements lowered the renewable content in favor of coal and gas, even with high load growth.

On the other hand, more stringent environmental policies generally reduced the amount of fossil fuelbased generation through increases in EE, increases in the use of renewables, and/or DR (Fig. ES-15). Lifting the original ceiling on variable generation from a maximum of $35 \%$ to $50 \%$ only increased total renewable use by $3 \%-4 \%$ because only the central and southwest regions could take advantage of this raised ceiling. Increasing EE and DR programs resulted in lower fossil fuel generation rather than renewable generation. 


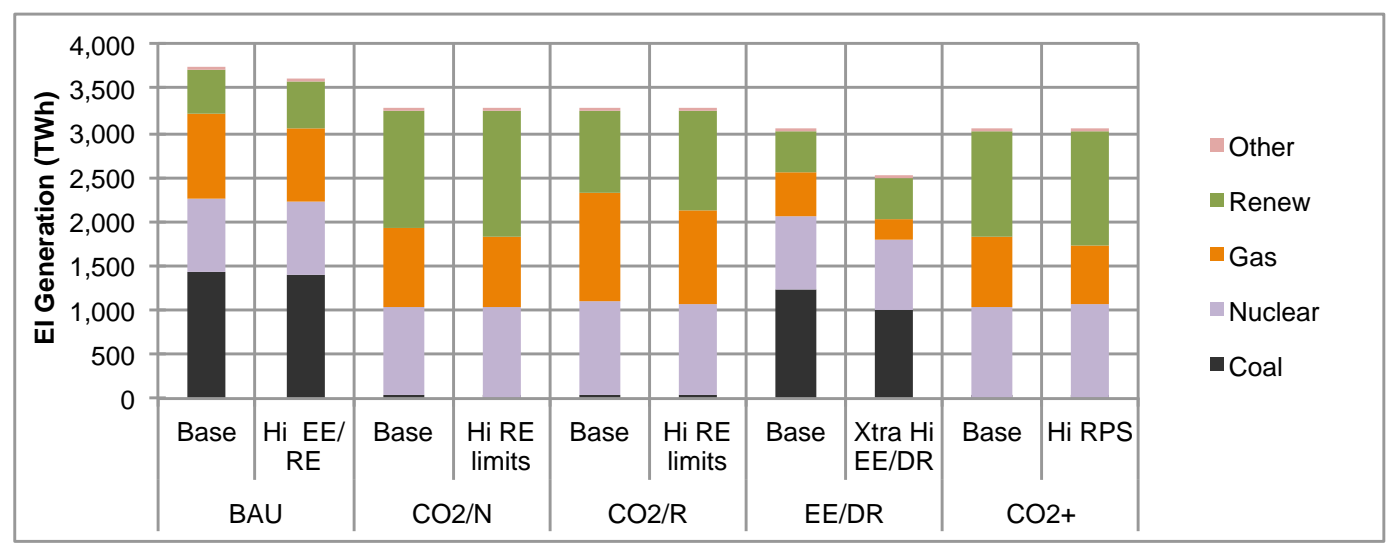

Fig. ES-15. Eastern Interconnection (EI) generation in 2030 by technology for increased environmental policy sensitivities.

The Clean Energy Standard was intermediary in its impact on carbon emissions between the base $\mathrm{CO}_{2}$ and RPS cases. By setting a standard for all carbon-reducing technologies, there was a significant reduction in coal generation and carbon emissions without the impact of added $\mathrm{CO}_{2}$ costs.

\section{Topic 13: What impacts were noticed from the technology sensitivities?}

A number of the sensitivities involved changes to the various technologies (e.g., price, cost, efficiency, or availability). Natural gas price sensitivities were included in this category because a main component of gas prices is the continued feasibility of hydrofracturing and sufficient transportation infrastructure.

The base case of each future resulted in generally different mixes of generation. Changing gas prices within each future had the expected effect: lower prices led to increased gas use while higher gas prices reduced gas-fired capacity and generation. Similarly, capital cost reductions for renewables resulted in increases in renewable capacity. Onshore wind was the main beneficiary of the lower costs, though in the $\mathrm{CO}_{2} / \mathrm{R}$ future the lower costs also increased the offshore wind, photovoltaic (PV), and hydro capacities.

Plug-in electric vehicles could raise peak demands and consequent capacity requirements, with the impact strongly depending on the timing of the charging. If charging was predominantly at peak times, then the system peak would increase by $1.2 \mathrm{~kW} /$ vehicle. If charging was delayed to nighttime (such as through smart grid implementation), then the peak would only increase by $0.1 \mathrm{~kW} / \mathrm{vehicle}$. Marginal generation to meet the added demand came from natural gas, with some coal and renewables under the RPS futures.

Despite the lower capital cost, there was no change in the nuclear capacity built between the nuclear resurgence base and the small modular reactor sensitivity through 2030 . Offshore wind capacity could be selected in all cases but was only selected in sensitivities with lower renewable capital costs or in the RPS future with regional response (RPS/R). In this study, the preferred location for offshore wind was in VACAR, followed by PJM E and then PJM ROM

\section{Topic 14: What changes in key inputs and expected results occurred since the study began?}

The input assumptions used in the EIPC study were formulated by stakeholders largely in the late 2010 to early 2011 time frame. These input assumptions are now roughly 4 years old, and this topic examines changes to four key input assumptions since the time of the EIPC study: (1) capital costs for new generation resources, (2) distributed solar projections, (3) electricity demand, and (4) environmental policies. 
Capital Costs for New Generation Resources: Using updated EIA sources similar to those used in the EIPC study, the projected capital costs of most fossil-fired resources are largely unchanged since the time of the EIPC study. The projected capital cost of onshore wind turbines is $7 \%$ to $11 \%$ lower today than in the EIPC study. If everything else is equal, this would result in the construction of more wind power facilities than projected in the EIPC study. Any increase would be tempered by other EIPC study input assumptions such as RPS requirements and penetration limits on intermittent resources. The projected capital cost of PV solar capacity has declined by $15 \%$ to $25 \%$ today from the time of the EIPC study. PV solar capacity was constructed in the three EIPC Phase 2 scenarios largely to meet solar RPS requirements. With these reduced capital costs, it is plausible that PV solar would substitute to a certain extent for biomass in the RPS/R scenario and possibly, depending on location, for onshore wind in all three Phase 2 scenarios.

Distributed Solar Projections: A comparison was made of current projections of PV solar capacity (EIA 2014) with those projected in the EIPC study for 2030, considering both utility and distributed solar installations. The EIA 2014 reference case has $12 \mathrm{GW}$ of total PV solar in service in 2030, of which $10 \mathrm{GW}$ is distributed solar. In comparison, the BAU future in the EIPC study had $9 \mathrm{GW}$ of total PV solar in service in 2030, of which about $6 \mathrm{GW}$ was distributed solar. In the EIA 2014 sensitivity cases, the total PV solar capacity in the US EI reached as high as 25 to $30 \mathrm{GW}$ by 2030, with the share of distributed solar ranging from $50 \%$ to $90 \%$. In comparison, the $\mathrm{CO}_{2}+$ scenario in the EIPC study had total PV solar capacity of $33 \mathrm{GW}$ in the US EI in 2030, of which about $90 \%$ was distributed solar. Overall then, while the total amount of solar capacity in service in the EIPC study in 2030 was somewhat lower than today's EIA 2014 projections, certain EIPC study futures did capture the high range of solar capacity projected by EIA today.

Electricity Demand: The projected energy demand used in the EIPC study for the first 10 years was largely from the individual planning authorities for each region, while later years used the growth rates from the AEO 2011. Projected energy demands for 2011 were relatively the same in the BAU scenario and AEO 2011, differing just $0.7 \%$. But the utility estimates for growth between 2011 and 2015 in the BAU scenario were an annualized $1.2 \%$, while the AEO 2011 grew at only a $0.2 \%$ rate. From 2015 on, the growth rates were similar in both projections, around $0.8 \%$ per year. This led to differences in the totals of around $4 \%$ for the study period. The projected demands from the AEO 2014 are even slightly lower than the AEO 2011 so that the BAU scenario was $4 \%$ to 5\% higher than the current projection from EIA. Lowering demands by $5 \%$ could have a major impact on results.

Environmental Policies: With the exception of EPA's proposed Clean Power Plan, the changes to proposed/finalized environmental regulations that have occurred after the Phase 1 modeling would be unlikely to have a significant impact on the modeling results. These changes include the reinstatement of the Cross-State Air Pollution Rule and the finalization of the Mercury and Air Toxics Standard, the New Source Performance Standard for $\mathrm{CO}_{2}$, and the Cooling Water Intake Structures rule. Similarly, changes in state RPS requirements would not have a major impact. No new state RPS has been added, and the modifications to existing ones have primarily been a redefinition of the resources that qualify or the creation of a carve-out for a specific technology. The most significant modification is in Ohio, which has established a 2-year hiatus for its RPS. The restrictions on $\mathrm{CO}_{2}$ emissions associated with the proposed Clean Power Plan would have a much larger effect. A number of Phase 1 sensitivities result in significant reductions in $\mathrm{CO}_{2}$ emissions, but none of them are close matches to the proposed rule. The $\mathrm{CO}_{2}$ futures result in much greater reductions, while the RPS futures do not differentiate between higher and lower emission nonrenewable sources. Even though these sensitivities do not model the proposed rule specifically, they do indicate that a reduction in coal use and an increase in renewables and natural gas is a likely outcome. 
xxxii 


\section{INTRODUCTION}

Between 2010 and 2012 the Eastern Interconnection Planning Collaborative (EIPC) conducted a major long-term resource and transmission study of the Eastern Interconnection (EI). With guidance from a stakeholder steering committee (SSC) that included representatives from the Eastern Interconnection States' Planning Council (EISPC) among others, the project was conducted in two phases. The first was a 2015-2040 analysis that looked at a broad array of possible future scenarios, while the second focused on a more detailed examination of the grid in 2030. The studies provided a wealth of information on possible future generation, demand, and transmission alternatives; however, at the conclusion there were still unresolved questions and issues. The US Department of Energy (DOE), which had sponsored the study, asked Oak Ridge National Laboratory (ORNL) researchers and others who had worked on the project to conduct an additional study of the data to provide further insights for stakeholders and the industry. This report documents the results of that study, including the results of earlier studies that provided interim results (Hadley 2013; Hadley and Gotham 2014a; Hadley and Gotham 2014b).

The EI covers most of the electricity grid east of the Rockies. High voltage transmission lines interconnect the regions in the EI so power can be transferred readily between them. The EI consists of the multicolored (non-gold) regions in the map in Fig. 1. The regions used in the EIPC study (both EI and non-EI) are referred to as NEEM regions throughout this report because of the model (the North American Electricity and Environment Model) used for analysis in Phase 1 of the study. These NEEM regions are based on the boundaries of organizations such as utilities, regional transmission operators (RTOs), coordinating authorities, independent system operators, and other natural groupings based on the structure of the grid. Table 1 gives a more detailed description of each region in the EI.

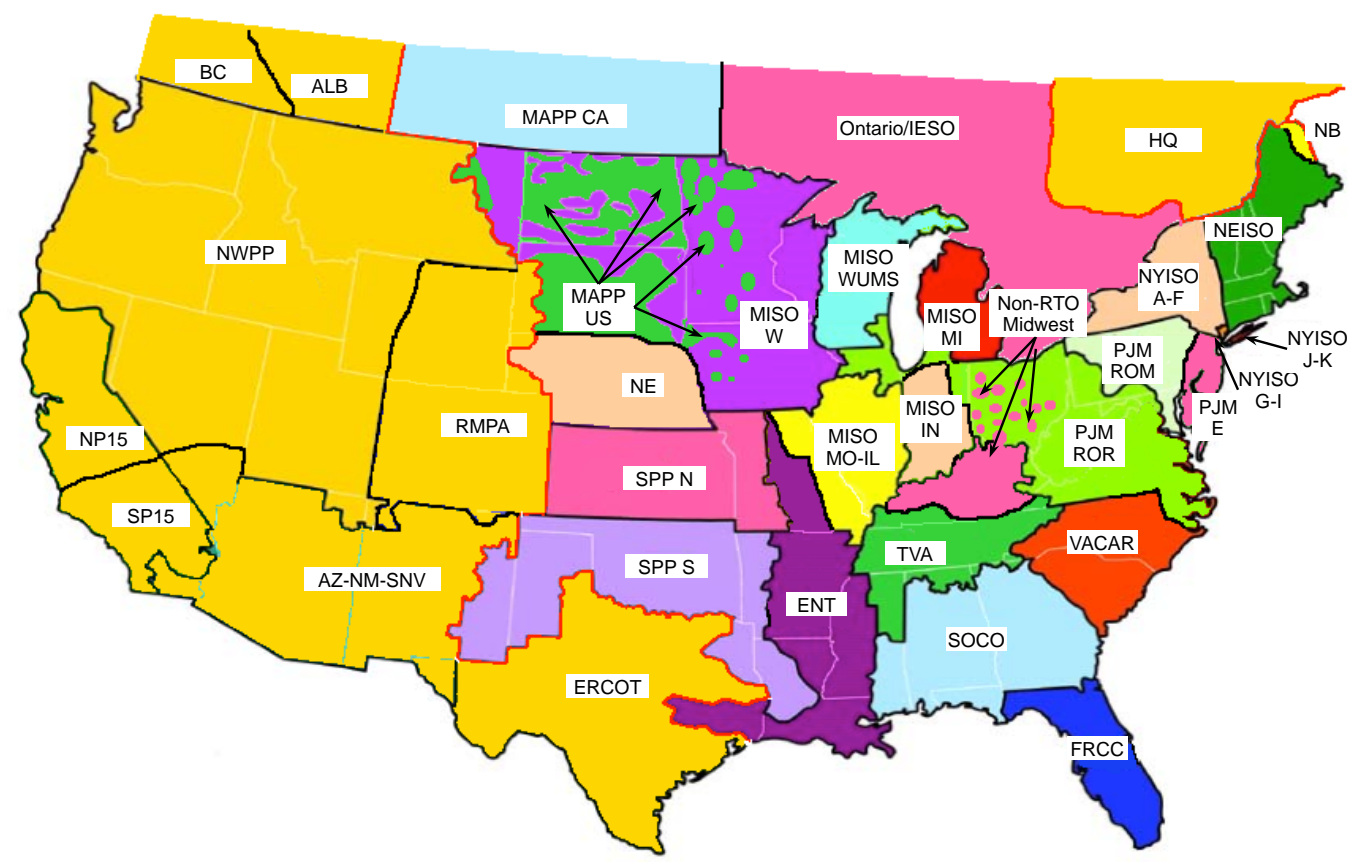

Fig. 1. Map of North American Electricity and Environmental Model regions. (The Eastern Interconnection includes the multicolored, non-gold, regions.)

For this report, results are presented at the level of the entire EI, the individual NEEM regions, or collections of NEEM regions into larger territories or superregions based on transmission relationships. The two larger groupings, territory and superregion, are slightly different. The five territories are larger 
groupings for reporting purposes only. The seven superregions split $\mathrm{PJM}^{*}$ into two different superregions and include a separate superregion for IESO (Ontario). Also, the Non-RTO Midwest is in the Central territory with PJM but in the MISO superregion.

Table 1. NEEM Regions, Superregions, and Territories in the Eastern Interconnection

\begin{tabular}{|c|c|c|c|}
\hline Region & Description & Superregion & Territory \\
\hline MAPP CA & $\begin{array}{l}\text { Mid-Continent Area Power Pool (MAPP) Canada (Manitoba- } \\
\text { Saskatchewan) }\end{array}$ & Midwest & Northwest \\
\hline MAPP US & MAPP US (non-MISO regions in MT, ND, SD, MN, IA) & Midwest & Northwest \\
\hline MISO W & Midcontinent Independent System Operator (MISO) in Michigan & Midwest & Northwest \\
\hline MISO MO-IL & MISO Missouri-Illinois (eastern MO, much of IL) & Midwest & Northwest \\
\hline MISO WUMS & MISO Wisconsin-Upper Michigan & Midwest & Northwest \\
\hline MISO IN & MISO Indiana & Midwest & Northwest \\
\hline MISO MI & MISO West (parts of MT, ND, SD, MN, IA, MN, WI) & Midwest & Northwest \\
\hline Non-RTO Midwest & Non-RTO in Midwest (most KY, some OH) & Midwest & Central \\
\hline PJM ROR & PJM Rest of Region (parts of IL, OH, PA, MD, WV, VA, NC) & PJM ROR & Central \\
\hline PJM ROM & PJM Rest of Mid-Atlantic Area Council (parts of PA, MD, DC) & PJM MAAC & Central \\
\hline PJM E & PJM Eastern MAAC (NJ, DE, east MD) & PJM MAAC & Central \\
\hline IESO & Independent Electricity System Operator in Ontario & Ontario & Northeast \\
\hline NYISO A-F & New York Independent System Operator (ISO) in Upstate NY & Northeast & Northeast \\
\hline NYISO G-I & New York ISO in lower Hudson Valley & Northeast & Northeast \\
\hline NYISO J-K & New York ISO in New York City-Long Island & Northeast & Northeast \\
\hline NEISO & New England Independent System Operator & Northeast & Northeast \\
\hline NE & Nebraska & Southwest & Southwest \\
\hline SPP N & Southwest Power Pool (SPP) North (Kansas, western Missouri) & Southwest & Southwest \\
\hline SPP S & SPP South (Oklahoma, north TX, east NM, west AR, west LA) & Southwest & Southwest \\
\hline ENT & Entergy Corp. + other utilities in central MO, AR, LA, MS, east TX & Southwest & Southwest \\
\hline TVA & Tennessee Valley Authority (TN, north MS, north AL, south KY) & Southeast & Southeast \\
\hline SOCO & Southern Company + other utilities in GA, AL, east MS, west FL & Southeast & Southeast \\
\hline VACAR & South Carolina, west North Carolina & Southeast & Southeast \\
\hline FRCC & Florida minus panhandle & Southeast & Southeast \\
\hline
\end{tabular}

The Phase 1 analysis used a capacity expansion model belonging to Charles River Associates (CRA) called MRN-NEEM (Multi-Region National-North American Electricity and Environment Model). A capacity expansion model evaluates energy supply and demand over multiple decades and builds or retires capacity as needed or economic. The MRN-NEEM document on the EIPC website provides more detail on the models used (CRA 2010). The following are some of the key characteristics of the Phase 1 modeling.

- Each region was treated as a single point or "bubble," with no transmission modeled internally.

- Each region was connected to other regions by single "pipes" for transferring electricity rather than physical transmission lines operating at different voltages.

- Transfer capacities between regions were initially calculated by the EIPC; however, a method was created to use model results to determine how much to expand the capacity in the different scenarios.

- The model calculated the supply, demand, and consequent generation capacity needed for each 5-year point between 2010 and 2050; however, only results for 2015-2040 were reported.

\footnotetext{
*Note: Refer to Table 1 or the Eastern Interconnection members/regions list at the front of this report for complete definitions of region identifiers used in the text.
} 
- The model attempted to minimize costs over the period, taking into account various reliability and policy constraints such as minimum reserve margins and environmental regulations.

- The hours of each year were aggregated into 20 blocks of different duration: 10 blocks covered the summer hours, while 5 blocks each covered the winter and "shoulder" seasons.

CRA and the EIPC members formulated some of the initial inputs for the model, with final values determined by the SSC. This group pulled in information from utilities, DOE sources, and others to establish such factors as growth rates, cost projections, technology changes, etc. The inputs to and outputs from the model are available on the EIPC website (http://www.eipconline.com/). In addition, the EIPC prepared preliminary estimates of the cost of transmission expansion under each of the scenarios. Results of the Phase 1 analysis are in the EIPC Phase 1 Report (EIPC 2011).

In Phase 1 of the study the term "futures" was used to define a consistent set of input assumptions for technologies, policies, and costs. Eight futures were defined by the SSC in an attempt to cover a wide range of possible policies. The futures explored ranged from business as usual (BAU) to various $\mathrm{CO}_{2}$ limits, renewable portfolio standards (RPSs), end-user activities, and nuclear resurgence (NUC). The eight are listed in Table 2, along with a description and the short label used for each in this report.

Table 2. List of Futures Studied in Phase 1

\begin{tabular}{|c|c|c|}
\hline Future & Label & Definitions \\
\hline 1 & BAU & Business as usual scenario \\
\hline 2 & $\mathrm{CO}_{2} / \mathrm{N}$ & High $\mathrm{CO}_{2}$ cost scenario, national implementation \\
\hline 3 & $\mathrm{CO}_{2} / \mathrm{R}$ & High $\mathrm{CO}_{2}$ cost scenario, regional implementation \\
\hline 4 & EE/DR & $\begin{array}{l}\text { Aggressive energy efficiency (EE), demand response (DR), and distributed generation } \\
\text { (DG) }\end{array}$ \\
\hline 5 & RPS/N & National renewable portfolio standard (RPS), national implementation \\
\hline 6 & RPS/R & National RPS, regional implementation \\
\hline 7 & NUC & Nuclear resurgence \\
\hline 8 & $\mathrm{CO}_{2+}+$ & High $\mathrm{CO}_{2}$ costs scenario with aggressive $\mathrm{EE}, \mathrm{DR}, \mathrm{DG}$, and nationally implemented RPS \\
\hline
\end{tabular}

A set of sensitivities was defined for each future, but first a base case using the general equilibrium economic model MRN had to be run to establish economy-wide, energy-related demands and prices for each of the futures. The results of these base cases could then be used to expand the transmission system between regions. Following that, other sensitivities allowed the EIPC and the SSC to explore a variety of changes to technologies, costs, demands, or policies. Table 3 summarizes the different sensitivities analyzed.

Future 1 was the BAU scenario. It had 17 sensitivities that were used to establish the transmission buildout and explore the effects of gas prices, renewable costs, delayed implementation of environmental policies, and other factors. The final scenario in that group, Future 1 Scenario 17 or F1S17, was used as the basis for the BAU scenario in Phase 2. Futures 2 and 3 examined the impact of raising the cost of $\mathrm{CO}_{2}$ to lower the level of $\mathrm{CO}_{2}$ emissions from all sectors of the economy to $80 \%$ of 2005 levels by 2050, with an intermediate value of $42 \%$ by 2030 . The distinction between them was the amount of interregional cooperation and transfer capacity within EI. Future 4 examined the effect of more aggressive energy efficiency (EE), demand response (DR), and distributed generation (DG). Because it reduced demand, there was no need to expand the transmission grid.

Futures 5 and 6 examined a national RPS with different levels of interregional cooperation. The second, Future 6, had only regional implementation, meaning each larger group of regions (each superregion) was responsible for meeting its RPS requirements, and transmission capacity was not expanded between these superregions to assist. There were 10 sensitivities in this future, and the final one, F6S10, was used for 
Phase 2. Future 7 examined the potential for nuclear expansion based on lower costs for nuclear and other factors; a base and four sensitivities were examined. Future 8 was the final future of Phase 1 and combined both the $\mathrm{CO}_{2}$ costs from Future 2 with the aggressive EE-DR-DG expansion from Future 4 and the RPS from Future 5. Seven sensitivities were included in Future 8 with F8S7 used in Phase 2.

Table 3. Main Sensitivities Studied in Phase 1

\begin{tabular}{|c|c|c|c|c|c|c|c|c|}
\hline Sensitivities & $\begin{array}{c}\text { Future } 1 \\
\text { BAU }\end{array}$ & $\begin{array}{c}\text { Future } 2 \\
\mathrm{CO}_{2} / \mathrm{N}\end{array}$ & $\begin{array}{c}\text { Future } 3 \\
\mathrm{CO}_{2} / \mathrm{R}\end{array}$ & $\begin{array}{c}\text { Future } 4 \\
\text { EE/DR }\end{array}$ & $\begin{array}{c}\text { Future } 5 \\
\text { RPS/N }\end{array}$ & $\begin{array}{c}\text { Future } 6 \\
\text { RPS/R }\end{array}$ & $\begin{array}{c}\text { Future } 7 \\
\text { NUC }\end{array}$ & $\begin{array}{c}\text { Future : } \\
\mathrm{CO}_{2+}\end{array}$ \\
\hline $\begin{array}{l}\text { Expand } \\
\text { transmission }\end{array}$ & $\sqrt{ }$ & $\sqrt{ }$ & $\sqrt{ }$ & & $\sqrt{ }$ & $\sqrt{ }$ & $\sqrt{ }$ & $\sqrt{ }$ \\
\hline \pm Load growth & $\sqrt{ }$ & $\sqrt{ }$ & $\sqrt{ }$ & & $\sqrt{ }$ & $\sqrt{ }$ & $\sqrt{ }$ & \\
\hline $\begin{array}{l} \pm \text { Natural gas } \\
\text { prices }\end{array}$ & $\sqrt{ }$ & $\sqrt{ }$ & $\sqrt{ }$ & & $\sqrt{ }$ & $\sqrt{ }$ & & $\sqrt{ }$ \\
\hline $\begin{array}{l} \pm \text { Renewable } \\
\text { cost or } \\
\text { deployment }\end{array}$ & $\sqrt{ }$ & $\sqrt{ }$ & $\sqrt{ }$ & & $\sqrt{ }$ & $\sqrt{ }$ & & $\sqrt{ }$ \\
\hline $\begin{array}{l}\text { Delay } \\
\text { regulations }\end{array}$ & $\sqrt{ }$ & & & & & & & \\
\hline $\begin{array}{l}\mathrm{CO}_{2} \text { cost } \\
\text { adjustment }\end{array}$ & & $\sqrt{ }$ & $\sqrt{ }$ & & & & $\sqrt{ }$ & $\sqrt{ }$ \\
\hline PEV variations & & & & $\sqrt{ }$ & $\sqrt{ }$ & $\sqrt{ }$ & & \\
\hline $\begin{array}{l}\text { Extra EE } \\
\text { savings }\end{array}$ & & & & $\sqrt{ }$ & & & & \\
\hline $\begin{array}{l}\text { Clean Energy } \\
\text { Standard }\end{array}$ & & & & & $\sqrt{ }$ & $\sqrt{ }$ & & \\
\hline $\begin{array}{l}\text { Small modular } \\
\text { reactors }\end{array}$ & & & & & & & $\sqrt{ }$ & \\
\hline $\begin{array}{l}\text { Higher RPS } \\
\text { limits }\end{array}$ & & & & & & & & $\sqrt{ }$ \\
\hline
\end{tabular}

Three scenarios, representing transmission needs under a broad array of hypothetical futures (or "bookends"), were selected for more extensive transmission-focused evaluation in Phase 2. The EI was modeled at a very detailed level (70,000 buses, 9,900 generators) using the Power System Simulator for Engineering (PSS/E) model for a peak hour and off-peak hour in each case (only the peak hour in the BAU case). Transmission lines and other upgrades were added to ensure reliability criteria were met in those hours. The resulting build-outs of the transmission system in these scenarios were then used to model the EI in the General Electric Multi-Area Production Simulation software (GE MAPS) model run by CRA. GE MAPS is a detailed economic dispatch and production cost model that simulates electric power system operation, taking into account transmission topology, to predict energy production costs, constraints limiting dispatch and interregional transactions, anticipated emissions, renewable energy production, and other pertinent factors. Results from the GE MAPS cases (hourly and annual results for the year 2030) were released to stakeholders. In addition, the EIPC and the SSC calculated costs for transmission and generation capital costs and other costs not calculated in GE MAPS. Following are some of the key characteristics of the Phase 2 modeling phase.

- The transmission build-out with PSS/E used an hour from Block 1 (peak summer) and an hour from Block 13 (mid-shoulder), using the average expected wind generation for each block.

- Transmission lines and substations were added during the build-out, primarily to meet reliability concerns; cost optimization was not a factor except indirectly through engineering judgment on line placement. 
- GE MAPS modeled the system chronologically for the 8,760 hours of 2030, incorporating CRA estimates of wind patterns for the different regions.

- Operating reserves rather than planning reserves were modeled; technologies to meet reserve requirements were more restrictive than in Phase 1 and limited to coal, combined cycle (CC), and hydro units.

In Phase 2 the nomenclature for cases changed. The EIPC focused first on building out the transmission for the $\mathrm{CO}_{2}+$ future. Consequently, it was called Scenario 1. Four sensitivities were run on the scenario to examine questions surrounding the amount of wind curtailment that occurred in the base case. The RPS/R (RPS implemented regionally) future was chosen as the second one to examine in Phase 2 and so was called Scenario 2, with no sensitivities run for it. The BAU future was the last to be examined and so was called Scenario 3. Two sensitivities were run for it: higher gas prices and higher demands.

The mixture of futures, sensitivities, and scenarios, with different nomenclature, has caused some confusion during the process. While many cases and scenarios were analyzed, the final results discussed in this report were derived based on three main scenarios. Brief descriptions of the three follow, including the names of the cases from the two different phases and the labels used in the follow-on reports.

\section{- Business as Usual}

- Labeled BAU

- Future 1 Sensitivity 17 (F1S17) in Phase 1

- Scenario 3 (S3) in Phase 2

- A continuation of current trends, policies, laws, and regulations

- National Renewable Portfolio Standard Implemented Regionally

- Labeled RPS/R

- Future 6 Sensitivity 10 (F6S10) in Phase 1

- Scenario 2 (S2) in Phase 2

- A national RPS of $30 \%$ by 2030 , with regional implementation

- Combined $\mathrm{CO}_{2}+\mathrm{RPS}+$ EE-DR-DG

- Labeled $\mathrm{CO}_{2}+$

- Future 8 Sensitivity 7 (F8S7) in Phase 1

- Scenario 1 (S1) in Phase 2

- Also called "Combined Policies" in some reporting

- A combination of a high $\mathrm{CO}_{2}$ cost, $\sim \$ 140 /$ metric ton $\mathrm{CO}_{2}$; national RPS of $30 \%$; and aggressive energy efficiency, demand response, and distributed generation expansion

The results from Phase 1 and Phase 2 provided a wealth of data that could be examined further to address energy-related questions. In January 2013, a small group of EIPC, EISPC, and SSC members were contacted about possible additional analyses and what topics would be of most interest. Based on feedback from this group, a list of 13 potential study topics was developed, which the group categorized as high, medium, or low priority and then ranked within these categories (Table 4). Order in the ranking was determined in such a way that earlier, lower numbered, items contribute to later items within the same category. 
Table 4. Topics to Be Studied as Part of Analysis of Eastern Interconnection Planning Collaborative Cases

\begin{tabular}{|rl|}
\multicolumn{1}{c|}{ High Priority Topics } \\
\hline 1 & How do Phase 2 results compare to Phase 1? \\
\hline 2 & Were there significant changes in earlier years within various regions? \\
\hline 3 & When all costs are integrated, how do results compare between scenarios? \\
\hline 4 & Do some regions face overreliance on certain fuels or technologies? \\
\hline 5 & What are the gas sector interrelationships in the different regions? \\
\hline & \\
\hline 6 & Mow did regional operating and planning reserves definitions affect the results? \\
\hline 7 & Why was there so much wind curtailment in the RPS/R and CO ${ }_{2}+$ scenarios? \\
\hline 8 & How much did demand response as defined in the models affect results? \\
\hline 9 & What transmission lines were of value in all scenarios? \\
\hline & \\
\hline 10 & Low Priority Topics \\
\hline 11 & What were the impacts of load growth sensitivities on resource mix and cost? \\
\hline 12 & What impacts were noticed from the environmental policy sensitivities? \\
\hline 13 & What impacts were noticed from the technology sensitivities? \\
\hline & \\
\hline 14 & What changes in key inputs and expected results occurred since the study began? \\
\hline
\end{tabular}

This report collects the results from previous interim reports plus a discussion of the last topic. Each chapter covers a separate topic. The first five topics were previously discussed in the report Additional EIPC Study Analysis: Interim Report on High Priority Topics (Hadley 2013). The second set of topics was analyzed in the report Additional EIPC Study Analysis: Interim Report on Medium Priority Topics (Hadley and Gotham 2014a). The third set of topics was covered in the report Additional EIPC Study Analysis: Report on Low Priority Topics (Hadley and Gotham 2014b). 


\section{TOPIC 1: PHASE 1 VS. PHASE 2 COMPARISON}

The Phase 1 and Phase 2 analysis processes were described in the introduction. The first questions that arose following the study were related to whether the results from the two phases were so different as to cause people to question the results. Were data faithfully transferred between the two? Were differences in results explainable? How did differences in geography, time, and electrical system modeling influence the results? The sections below compare the results of Phase 1 and Phase 2 for power plant capacity, generation, interregional transmission, and costs.

\subsection{Capacity}

Figure 2 shows the total capacity in 2030 estimated in Phase

2. The RPS/R scenario has the largest overall capacity, largely because wind technologies were only credited at a fraction of their full capacity for purposes of determining reserve margins so more was needed to meet the minimum. While the $\mathrm{CO}_{2}+$ scenario has more wind than the RPS/R scenario, its overall demands were less so the total required was lower. In the $\mathrm{CO}_{2}+$ scenario, DR and wind are more significant fractions of capacity, while peaking plants are reduced and coal is practically eliminated. The corresponding graphs for each region are included in Appendix A.

While the totals for generating capacity in most regions in Phase 1 and Phase 2 are close, more often the amounts are

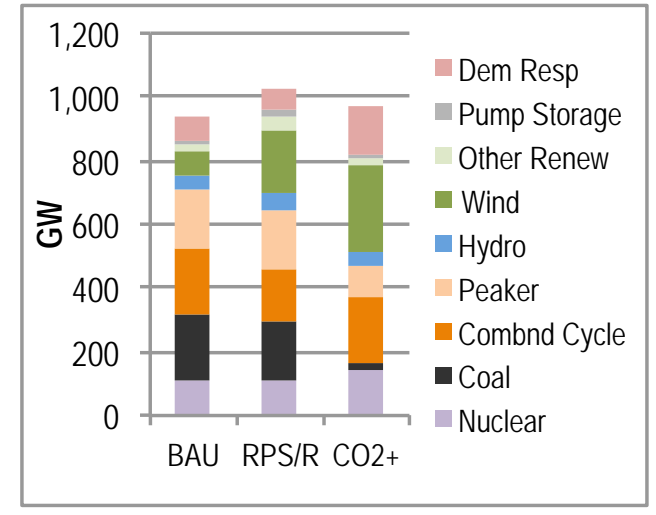

Fig. 2. Eastern Interconnection capacity estimated in Phase 2. somewhat higher in Phase 2 than Phase 1. This is possibly due to a combination of higher capacities needed to meet ancillary services (reserves) requirements and incomplete deactivation of existing plants when transferring data from Phase 1 to Phase 2. Figure 3 shows the ratio of total capacity between the two phases. The ratio is greater than $100 \%$ for many regions, most notably for Entergy, MISO W, PJM E, and IESO. On the other hand, MISO WUMS has a ratio of only $62 \%$, but just in the RPS/R scenario. This occurs because in Phase 1, a large number of combustion turbines (CTs) was added for MISO as a whole, but all were added in MISO WUMS by NEEM because capital costs were slightly lower there. The NEEM model did not use them for production, so there was no impact on generation-related costs. In the final steps of Phase 1, these CTs were scattered across the territory more realistically in the $\mathrm{CO}_{2}+$ and BAU scenarios, but not RPS/R (because a final sensitivity run was not needed for that case.) So most of the MISO variations in RPS/R are simply the result of movement of CTs from MISO WUMS to the rest of MISO in Phase 2.

The next set of graphs, Figures 4-6, shows the actual amounts of capacity in 2030 for each region by technology. Some regions show slight differences in capacity between the two phases, mainly in coal, wind, and peaking plant technologies. Also, each bar in the figures shows the level of peak demand for the region in 2030. Regions generally should have sufficient capacity to cover peak demands plus a planning reserve of $\sim 15 \%$. Those with high wind capacity show a much greater capacity than demand, but this is because wind (and solar) contributions to reserves were only credited at $12 \%$ to $30 \%$ of their capacity. All regions have sufficient capacity to cover demands except the downstate New York regions because they rely on firm imports for a portion of capacity. 


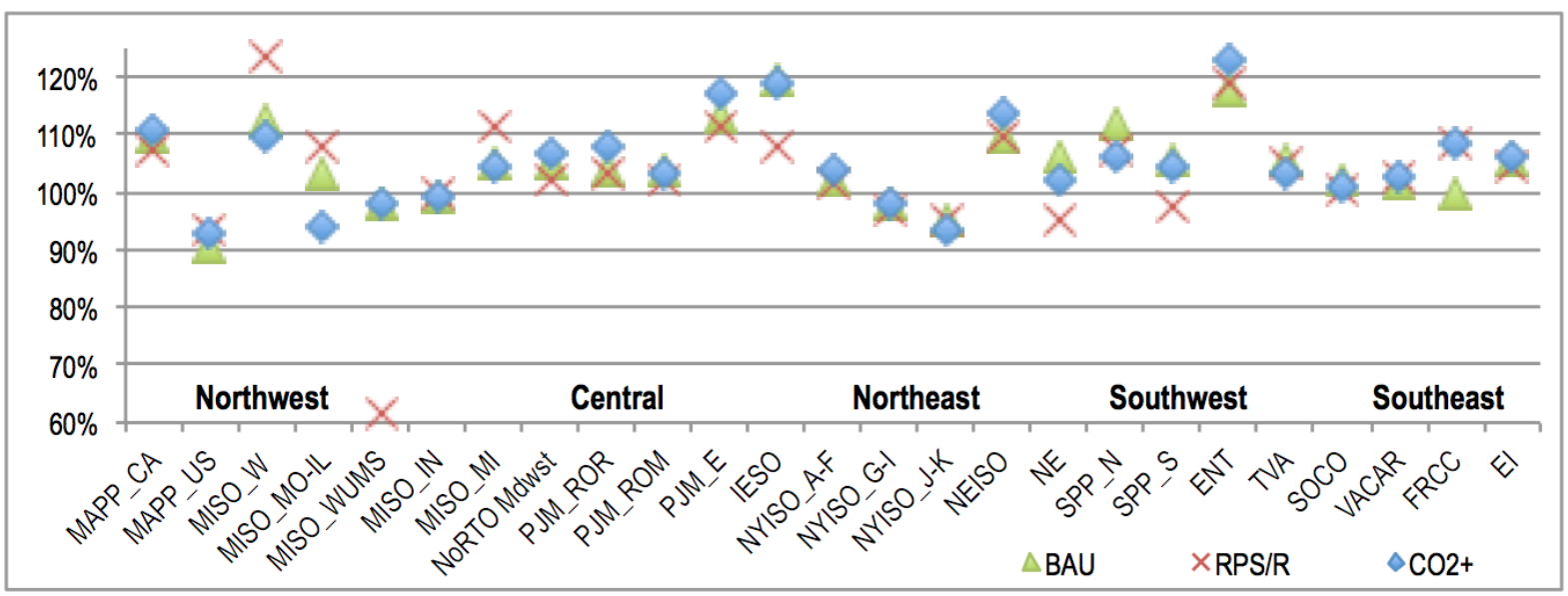

Fig. 3. Ratio of Phase 2 to Phase 1 capacity.

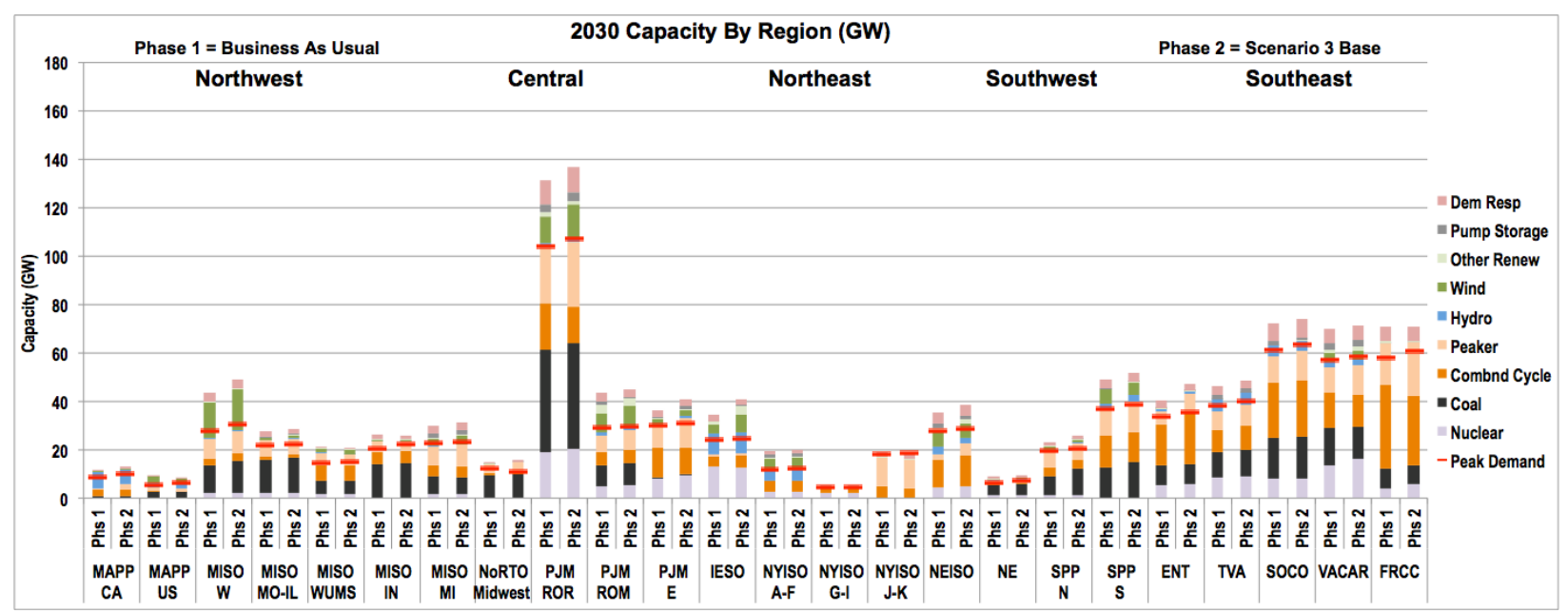

Fig. 4. Capacity amounts by region in 2030 in the BAU scenario. (Red rules/marks on the bars indicate the levels of peak demand in 2030.)

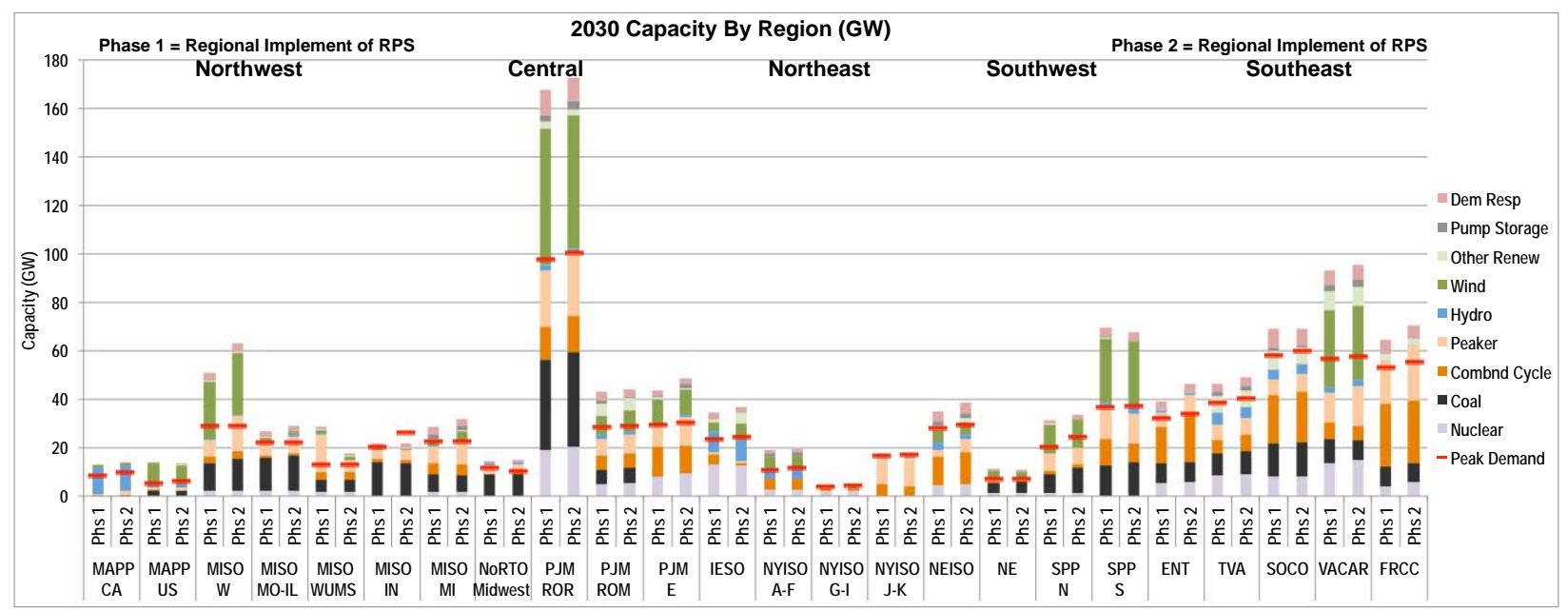

Fig. 5. Capacity amounts by region in 2030 in the RPS/R scenario. (Red rules/marks on the bars indicate the levels of peak demand in 2030.) 


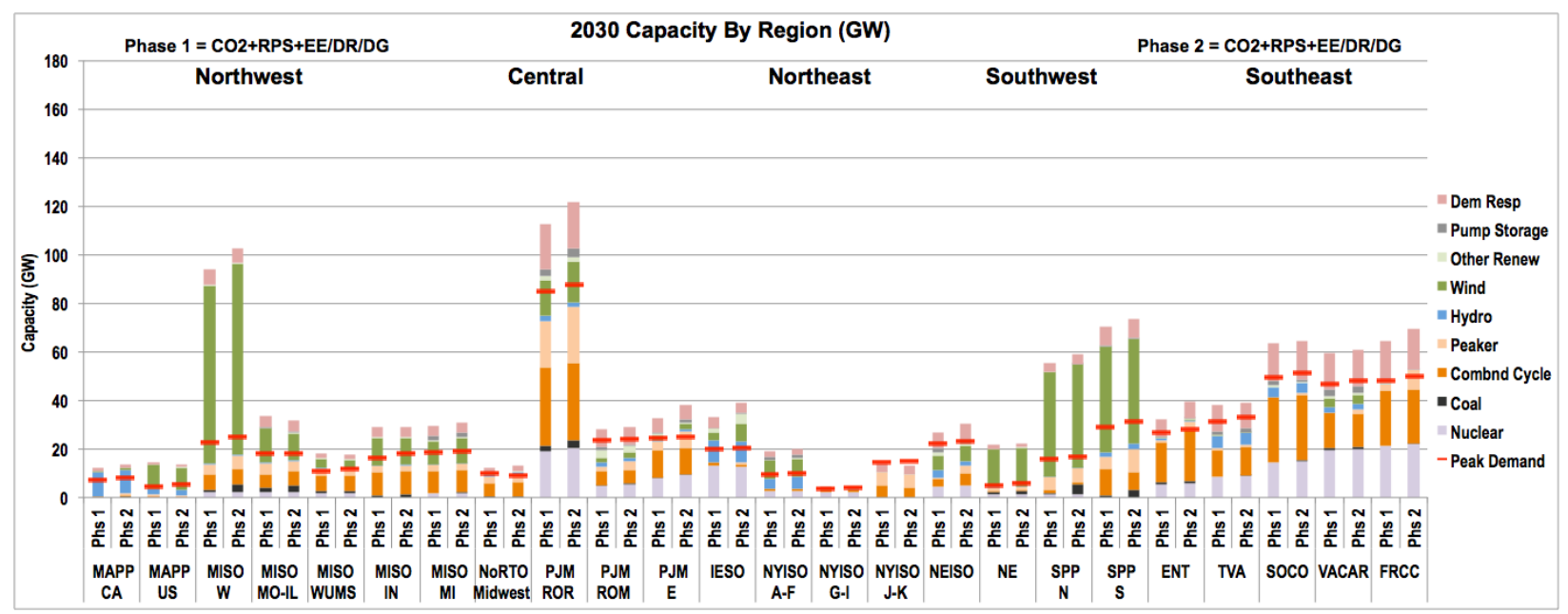

Fig. 6. Capacity amounts by region in 2030 in the $\mathbf{C O}_{2}+$ scenario. (Red rules/marks on the bars indicate the levels of peak demand in 2030.)

\subsection{Generation}

Figure 7 shows the total 2030 generation estimated in Phase 2. As expected, the BAU scenario has the highest generation. The RPS/R scenario did not explicitly have lower load growth but had lower demand due to higher electricity prices in the MRN-NEEM model. In the $\mathrm{CO}_{2}+$ scenario, demand was explicitly reduced to represent EE and DG effects. Wind generation was highest in the $\mathrm{CO}_{2}+$ scenario, and coal generation was almost eliminated. Combined cycle plants were used to provide flexible generation and reserves, while nuclear grew, largely in Florida. The corresponding graphs for each region and territory are included in Appendix A.

As with capacity, the generation amounts in Phase 1 and Phase 2 for most regions are very similar. This is shown in Fig. 8 as the ratio of generation in Phase 2 to Phase 1 for each

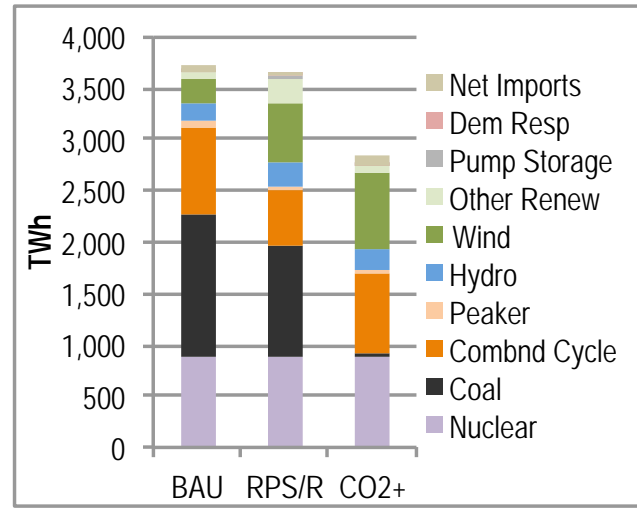

Fig. 7. Eastern Interconnection generation estimated in Phase 2. region, where $100 \%$ means they match exactly. If the values are similar this indicates that the models in the two phases dispatched the generation similarly, and so the modeling in the two phases and the transfer of results between phases was generally accurate.

A number of regions (MAPP US, MISO MO-IL, MISO IN, PJM ROR) show lower generation in Phase 2, indicated by ratios below $100 \%$, with countervailing increases in other regions (PJM E, NYISO J-K, NEISO). This is likely due to the improved modeling of the grid in Phase 2, with more detailed representation of power flow and hourly variation versus the 20 power blocks used in Phase 1 . Three factors are involved in the improved modeling. Power flows on transmission follow the paths of least resistance so may take routes that could lead to overloads unless amounts are reduced. Wind generation on an hourly basis will fluctuate more so may not be available when it could be transmitted. And limits on technologies providing operating reserves force some plants to operate within a region despite cheaper power available over transmission. Note that the ratios are highest or lowest in the $\mathrm{CO}_{2}+$ scenario, which involved the most interregional transmission. 


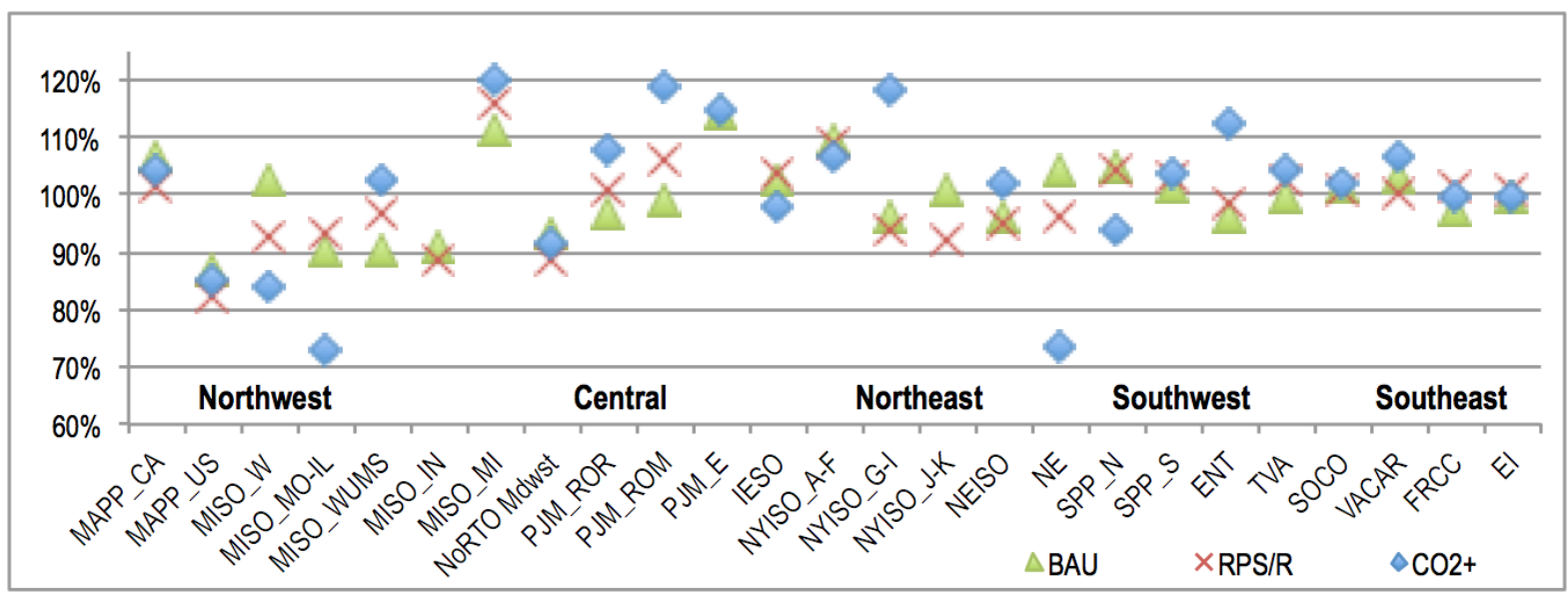

Fig. 8. Ratio of Phase 2 to Phase 1 regional generation amounts.

Figures 9-11 show the levels of generation for each region by technology in terawatt-hours in 2030. Also, each bar shows the level of total demand for the region in 2030, including energy used for pumped storage. A few regions show some differences in generation between the two phases, most notably in coal, wind, and $\mathrm{CC}$ technologies.

In the $\mathrm{CO}_{2}+$ scenario, a few regions are large exporters of electricity (notably MISO W, Nebraska, SPP N, SPP S, and the Canadian regions), while most others import at least some of their energy needs. Several, such as Entergy, PJM, New York, and New England, rely extensively on imports. (Imports from non-EI Canadian provinces are shown as a separate item in the columns.) The BAU and RPS/R scenarios have most of the regions relatively self-sufficient in power.

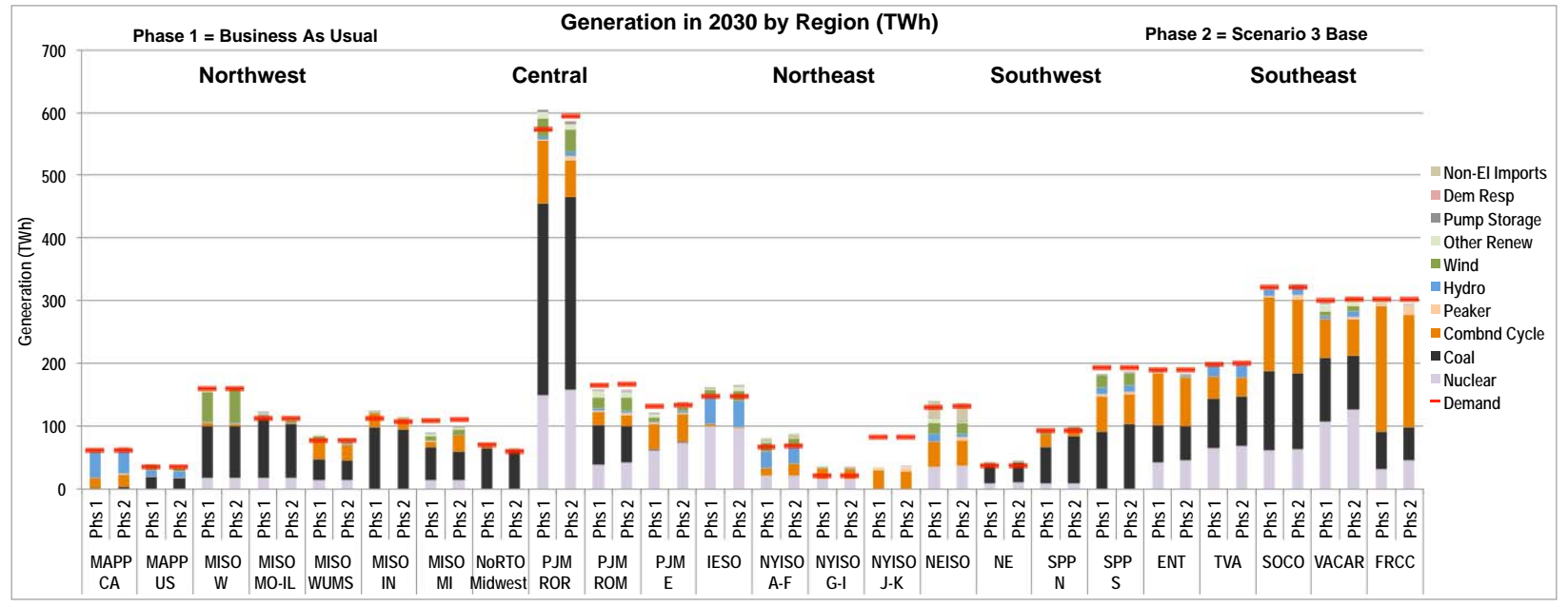

Fig. 9. Generation amounts by region in 2030 in the BAU scenario. (Red rules/marks on the bars indicate the levels of total demand in 2030.) 


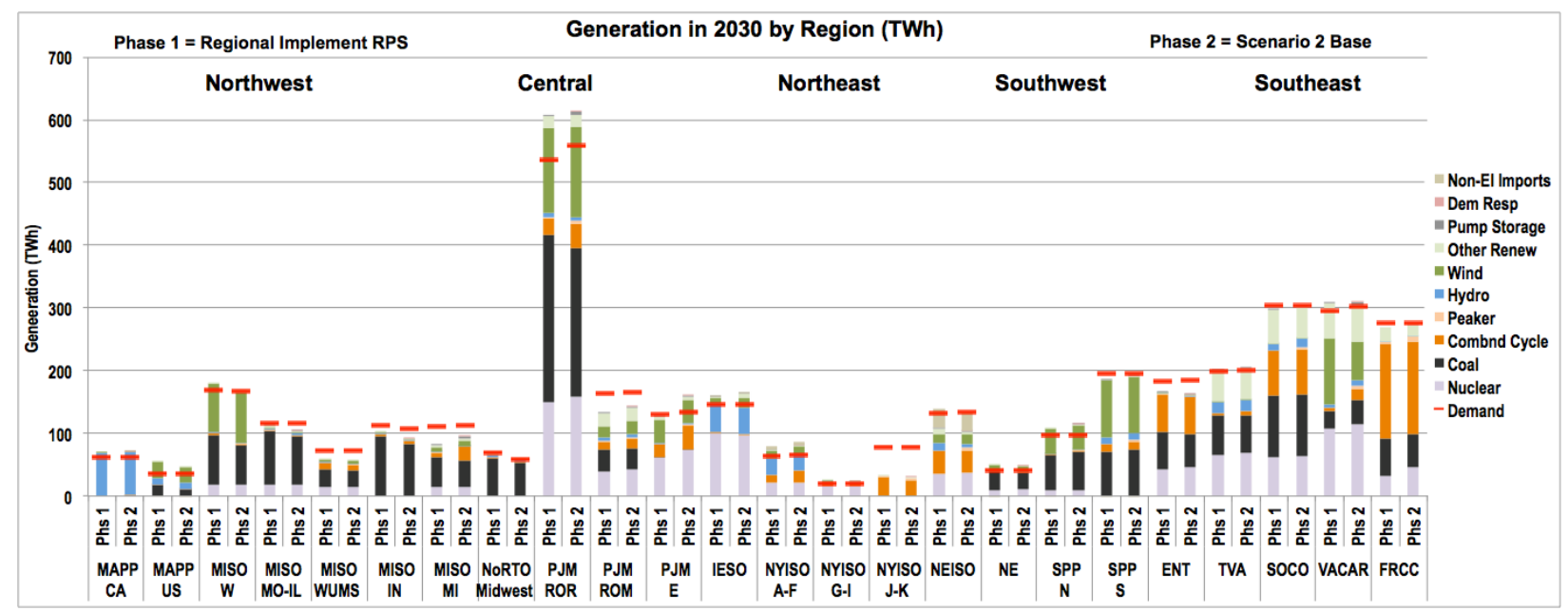

Fig. 10. Generation amounts by region in 2030 in the RPS/R scenario. (Red rules/marks on the bars indicate the levels of total demand in 2030.)

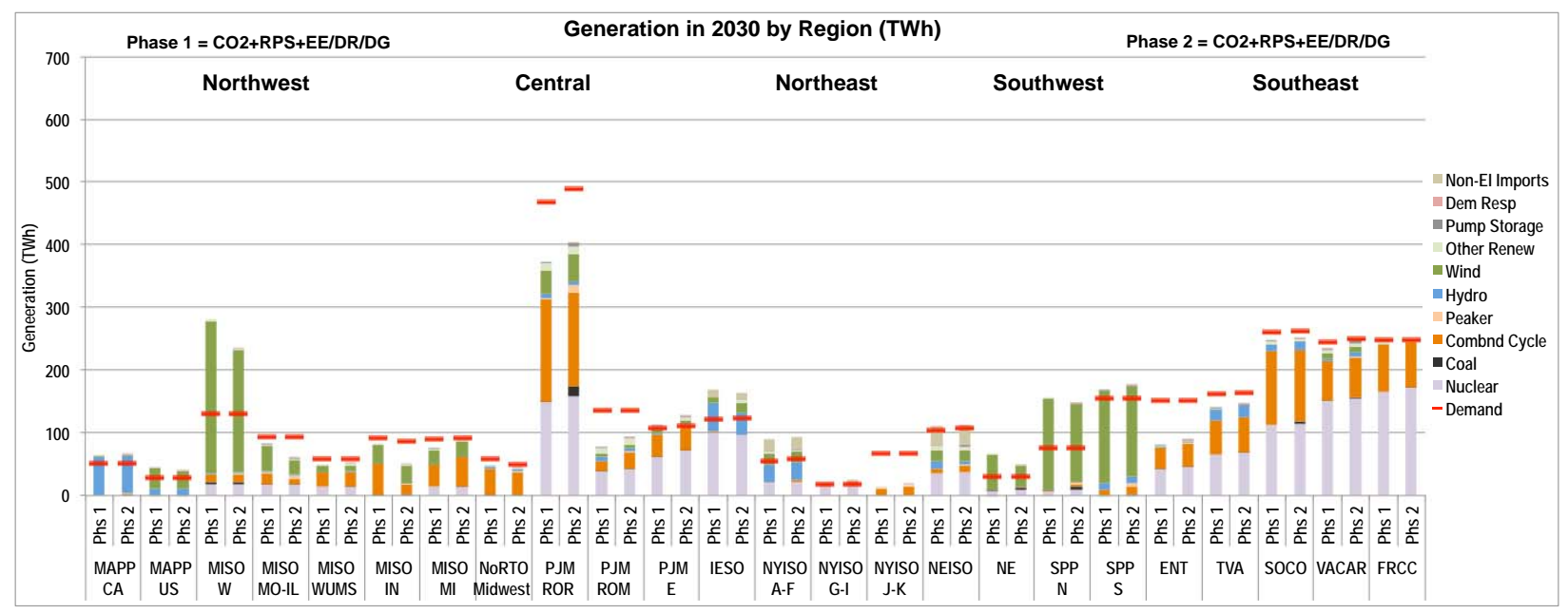

Fig. 11. Generation amounts by region in 2030 in the $\mathbf{C O}_{2}+$ scenario. (Red rules/marks on the bars indicate the levels of total demand in 2030.)

\subsection{Transmission}

Phase 1 and Phase 2 show significant differences in transmission between some of the key regions, largely because of refinements in the transmission system design in Phase 2. In Phase 1, transmission (or rather "transfer capacity") was modeled in a complicated process to let the NEEM model expand the capacity in connection with the relative cost difference between regions. First, the reference case was run with no expansion of transmission. Next, a "soft" future was run where the capacity was allowed to fluctuate based on the relative marginal generating costs between regions determined in the reference case. Lastly, the SSC examined the results over the 2025-2040 period and created a set of algorithms that "hardened" that capacity into available transfer capacity that applied in all years. In Phase 2, the EIPC began with the hardened transfer capacity calculated in Phase 1 as a target and set the generation and demand for each region based on the NEEM results from two points during 2030. Transmission lines were then added in the PSS/E build-outs so that generation would supply the demand along with meeting key North American Electric Reliability Corporation (NERC) reliability requirements. 
Figures 12-17 are stylized maps of the NEEM regions showing the peak amount of transmission between each region in Phase 1 and Phase 2. The peak amount is shown because tie-line capacity (which is part of what transmission planning attempts to assess) is more directly related to the peak amount of transfer rather than the average amount. Use of a transmission line will vary from hour to hour (or second to second in reality). Power transfer can reverse direction depending on the relative supply and demand for power in the different regions. Furthermore, the tie-lines shown here are rough approximations of actual transmission line flows. Electricity actually follows the "path of least resistance," and transfers between regions will travel over a number of lines and through multiple neighboring regions. Voltage levels, substation design, and other factors greatly complicate actual electricity flows over the wires.

The BAU scenario had the least level of transfer (Figs. 12 and 13) because without an RPS or $\mathrm{CO}_{2}$ cost, most regions used more of their internally generated fossil fuel power. There were no high voltage direct current (HVDC) lines added in either phase for this scenario. There was still some transfer due to variations in generation and cost between regions that facilitated exchange. Phase 2 showed relatively the same amounts of transfer as Phase 1; some regions had higher levels and others lower.

The RPS/R scenario had increased peak amounts of transfer, and the peaks are higher for Phase 2 than for Phase 1 (Figs. 14 and 15). In this scenario, much of the transfer was from PJM ROR to surrounding regions, rather than into the region as in the $\mathrm{CO}_{2}+$ scenario. There were no HVDC lines added for this scenario. This was due to the regional implementation of RPS (resulting in little transmission to other regions) plus the lack of a $\mathrm{CO}_{2}$ cost, so that much of the coal capacity in the region remained active. The Phase 2 results have higher transfers because the hourly modeling with variations in wind and other generation gives opportunities for transfers that the Phase 1 NEEM model does not see.

For the $\mathrm{CO}_{2}+$ scenario (Figs. 16 and 17), in Phase 1 the largest transfer is $19.8 \mathrm{GW}$ from MISO W to PJM ROR over the high voltage alternating current lines (blue in the figures) as there were no HVDC lines (red in Fig. 17) included in the model. In Phase 2, PJM ROR also received significant power from the two SPP regions (over HVDC lines) as well as from MISO WUMS and MISO MI. Significant flows go out from PJM ROR in both phases, but in Phase 2 the flow returns back into MISO IN instead of just to the east and south.

More detailed information on transmission amounts on each of the interregional tie-lines, including both peak and average flow amounts in the two phases for different scenarios, is available in Sect. 4.2.5 of the EIPC Phase 2 Report, Part 2 (EIPC 2012). The key result from that analysis was that in the $\mathrm{CO}_{2}+$ scenario there was a total of $223 \mathrm{GW}$ in peak power transfer in Phase 2 while the Phase 1 case only had $137 \mathrm{GW}$. The PSS/E analysis performed in Phase 2 increased the requirement for transmission capacity in the $\mathrm{CO}_{2}+$ scenario beyond what Phase 1 specified to meet reliability constraints, and the GE MAPS model took advantage of the added capacity to the maximum extent possible. 


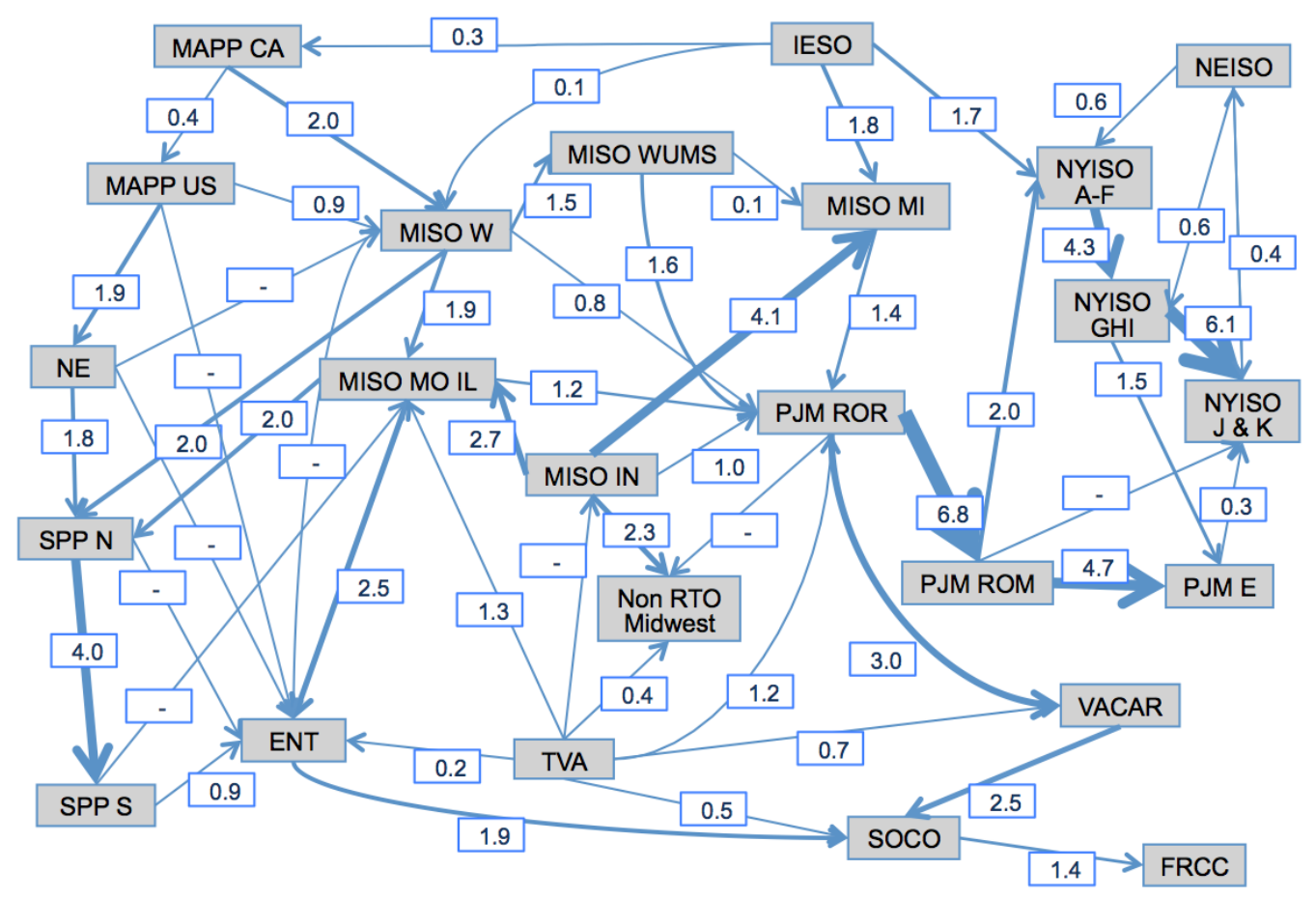

Fig. 12. Phase 1 maximum interregional transfers $(G W)$ in 2030 in the BAU scenario.

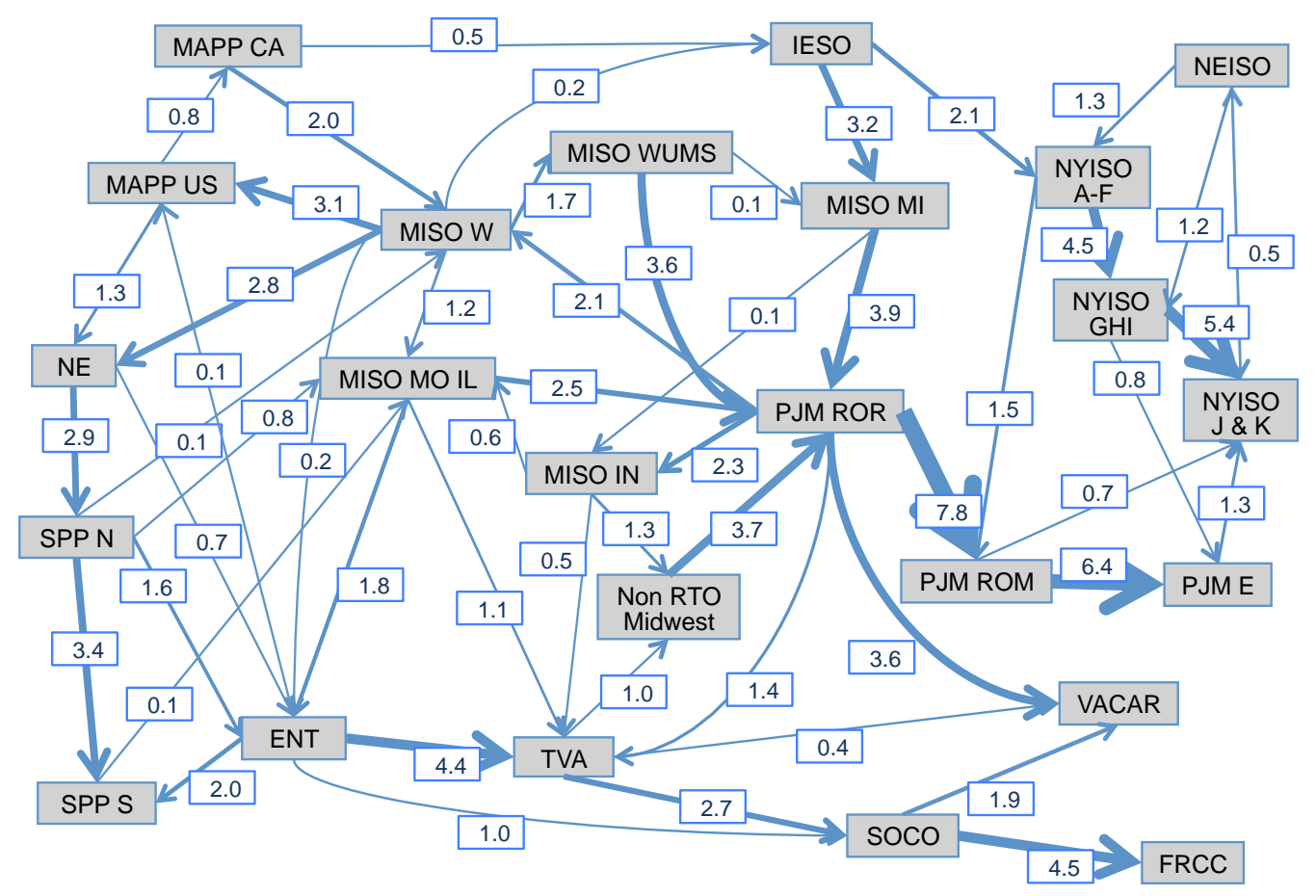

Fig. 13. Phase 2 maximum interregional transfers $(G W)$ in 2030 in the BAU scenario. 


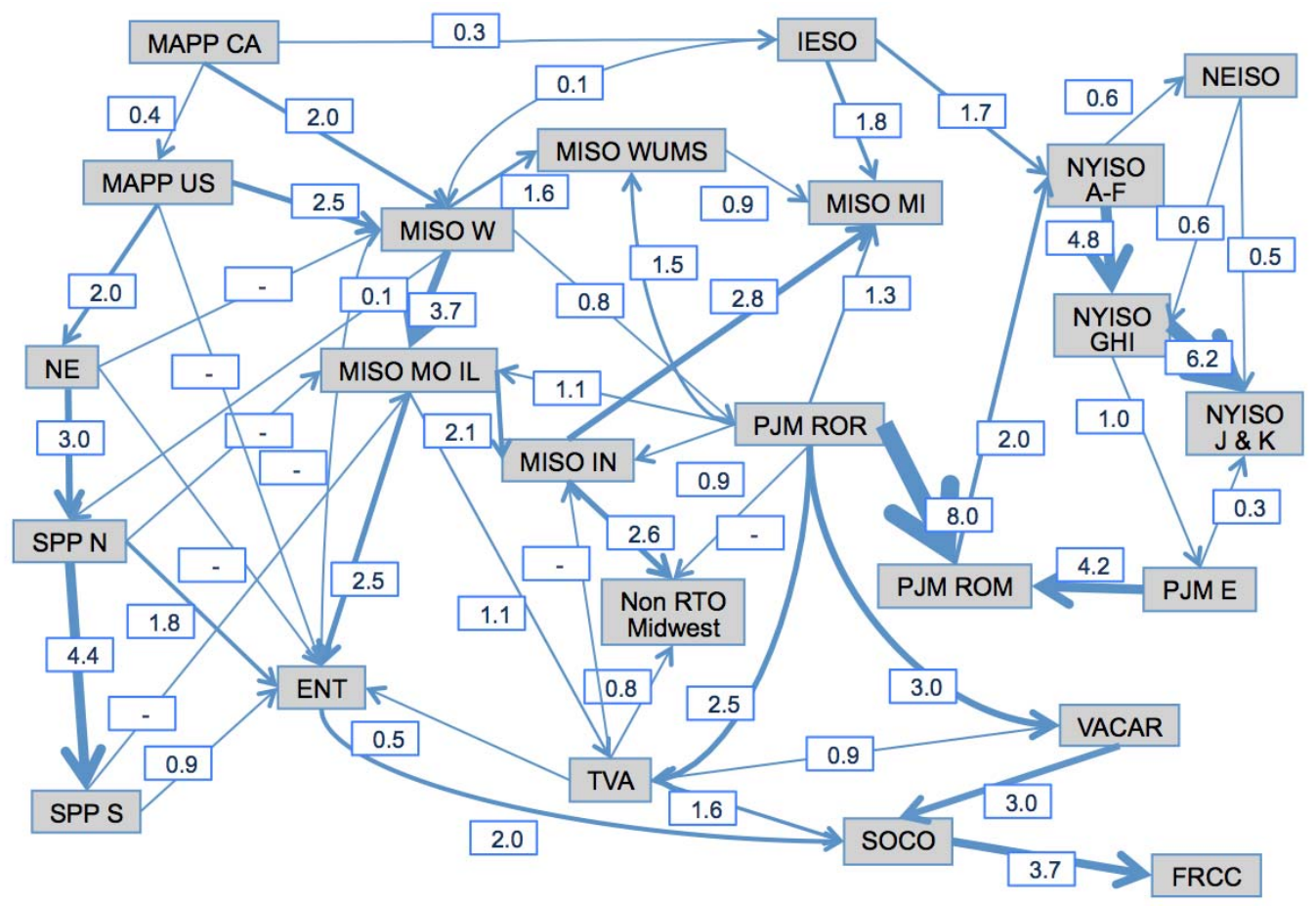

Fig. 14. Phase 1 maximum interregional transfers $(G W)$ in 2030 in the RPS/R scenario.

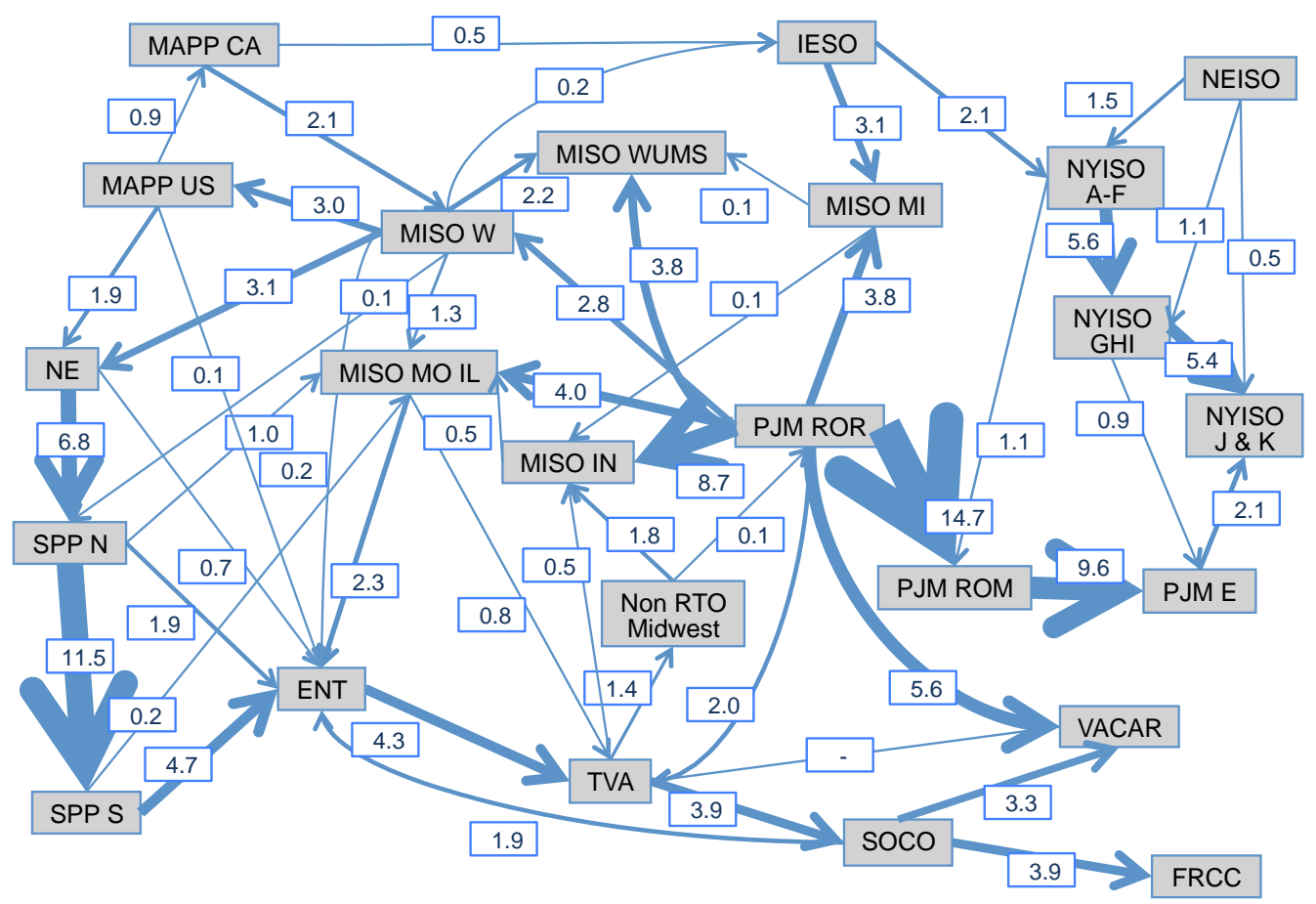

Fig. 15. Phase 2 maximum interregional transfers $(G W)$ in 2030 in the RPS/R scenario. 


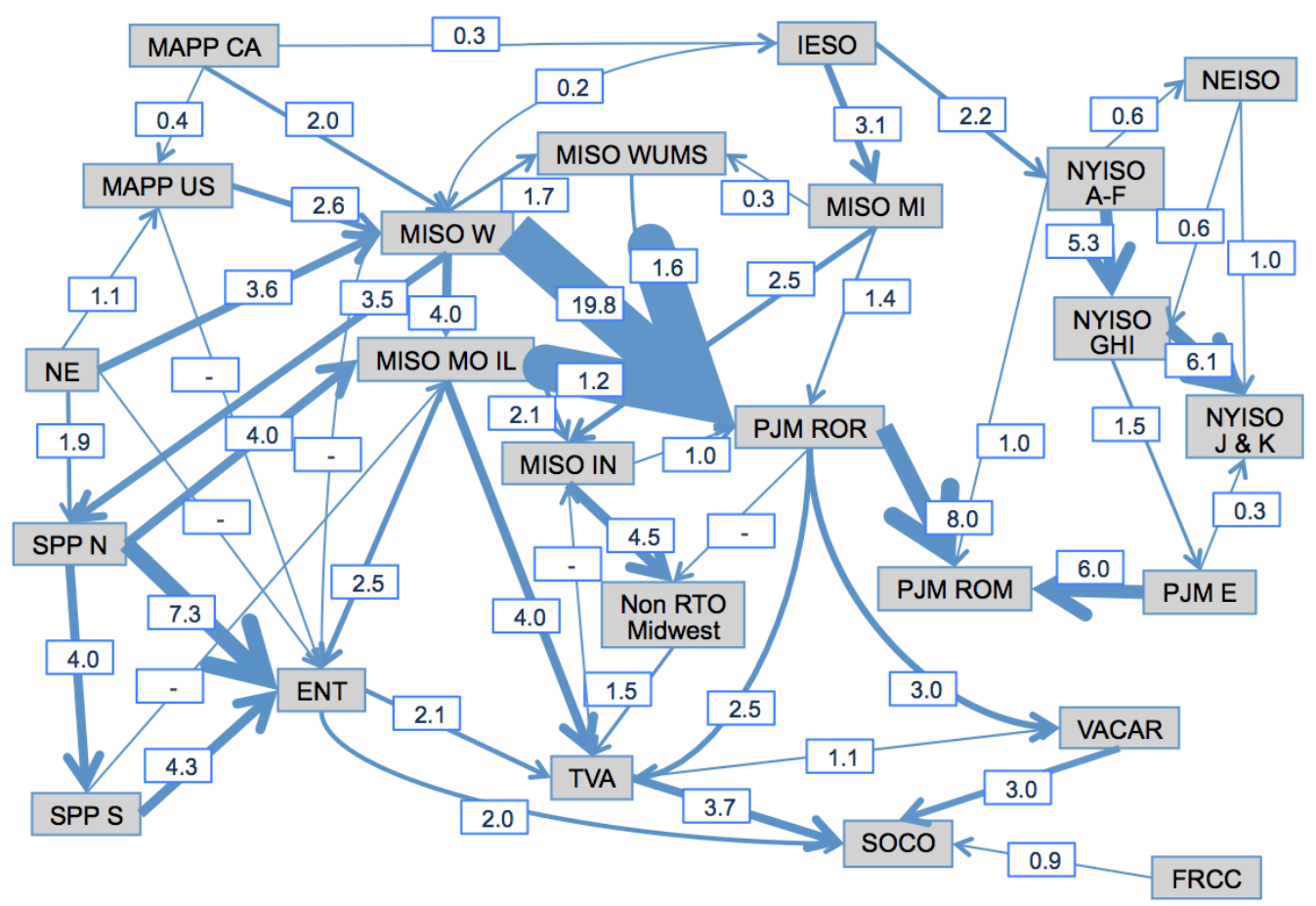

Fig. 16. Phase 1 maximum interregional transfers $(\mathrm{GW})$ in 2030 in the $\mathrm{CO}_{2}+$ scenario.

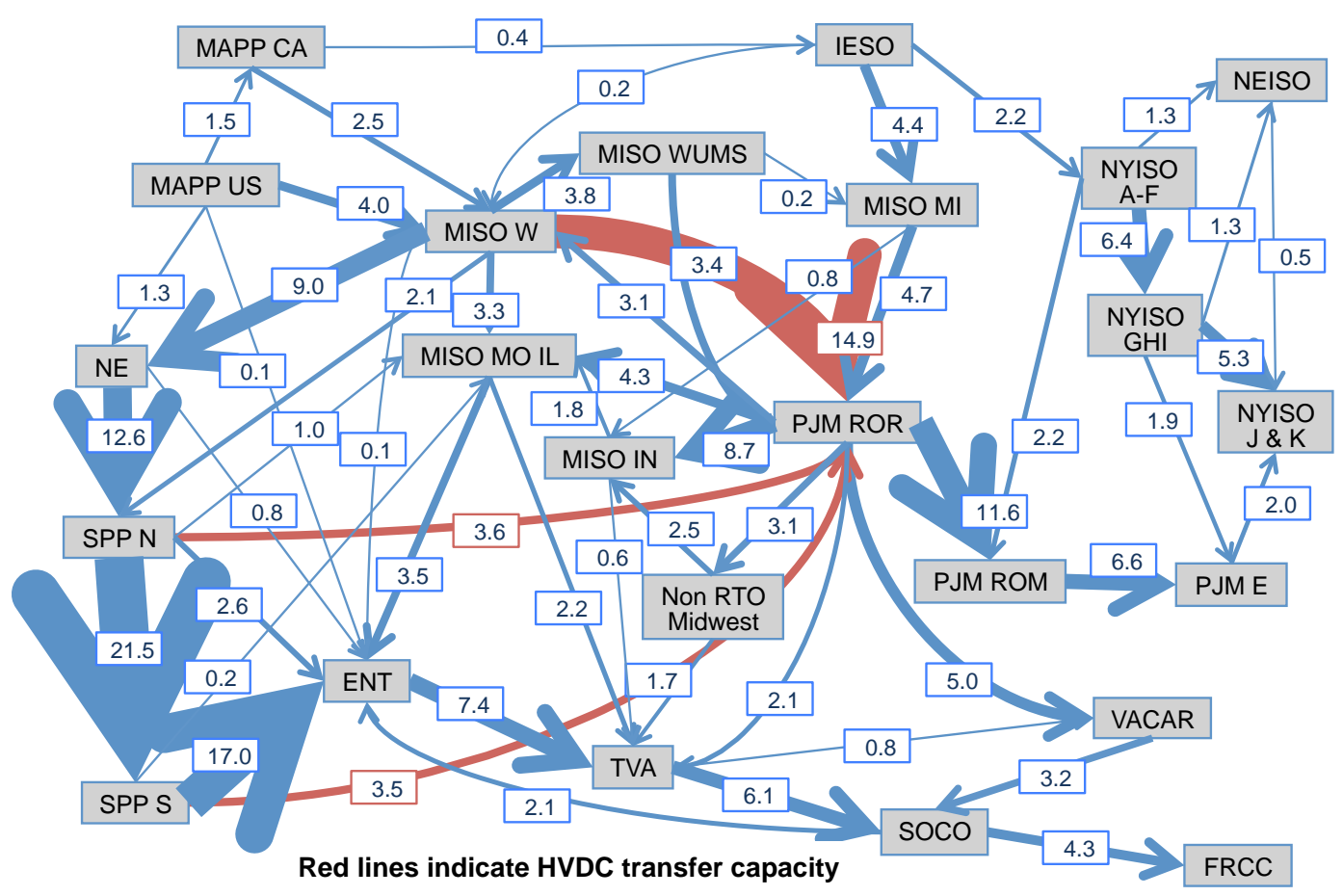

Fig. 17. Phase 2 maximum interregional transfers $(\mathrm{GW})$ in 2030 in the $\mathrm{CO}_{2}+$ scenario. 
Figures 12-17 focus on the peak amount of transfer between regions; however, another important factor is the total amount transferred over a year. Figures 18-23 show the average amount or, more precisely, the total amount transferred in gigawatt-years $(1 \mathrm{GWy}=8,760 \mathrm{GWh})$. Besides the amount transferred, the regions are colored based on the net amount of generation either imported in (red) or exported out (blue) of the region. The scale for the colors varies depending on the highest exports and imports.

The BAU scenario shows relatively little transfer over the full year in the two phases (Figs. 18 and 19). The major transfers are from upstate New York down to NYISO J-K and from PJM ROR to PJM ROM and further east. There is little difference between the two phases.

The RPS/R scenario has similar levels of annual flow to those of the BAU, although transfers are up slightly (Figs. 20 and 21). This is likely due to the increased renewable production in certain regions and transfers needed to move that to other regions. In this scenario, sharing of renewable resources occurred within territories for purposes of meeting the RPS.

For the $\mathrm{CO}_{2}+$ scenario, in Phase 1 there was a consistent high amount of transfer from MISO W to PJM ROR (Fig. 22). This was a major driving force for adding four HVDC lines between the regions during the transmission build-out in Phase 2 (Fig. 23). In addition, it worked well to have some of the exports from the Southwest go directly to PJM ROR over two HVDC lines rather than transfer through MISO W. An interesting side impact of the HVDC lines in Phase 2 was that a significant amount of power flowed back in to MISO IN from PJM ROR. This may be due to placement of several of the HVDC termini on PJM lines that are within Indiana.

A key difference between Phase 1 and Phase 2 was the number of periods analyzed over the course of a year, twenty blocks in Phase 1 versus 8,760 hours in Phase 2. Table 5 shows the number of hours used in each block in Phase 1.

Table 5. Duration Blocks Used for Each Year Modeled in NEEM

\begin{tabular}{|c|c|c|c|c|c|c|c|c|c|c|c|c|c|c|c|c|c|c|c|c|}
\hline & \multicolumn{10}{|c|}{ Summer } & \multicolumn{5}{|c|}{ Shoulder } & \multicolumn{5}{|c|}{ Winter } \\
\hline Block & B1 & B2 & B3 & B4 & B5 & B6 & B7 & B8 & B9 & B10 & B11 & B12 & B13 & B14 & B15 & B16 & B17 & B18 & B19 & B20 \\
\hline Hours & 10 & 25 & 75 & 100 & 200 & 300 & 400 & 500 & 800 & 1262 & 25 & 200 & 600 & 900 & 1203 & 25 & 100 & 400 & 700 & 935 \\
\hline
\end{tabular}

Modeling each hour separately in Phase 2 provided much more opportunity for transmission to increase, decrease, or even change direction depending on the generation and demands in different regions. We can aggregate the hourly results from Phase 2 into the corresponding blocks from Phase 1 to see how the transmission varied over the year. There are 56 tie-lines between the regions. To pick one as an example, Fig. 24 shows the power transferred between SPP N and SPP S during the $\mathrm{CO}_{2}+$ scenario. This line saw much heavier use in Phase 2 than Phase 1. In Phase 1, each block could have a different transfer amount, so there were a maximum of 20 different transfer amounts over the course of a year in NEEM. These blocks contain between 10 and 1,262 hours and total to the 8,760 hours of the year. We aggregated the corresponding hours from the MAPS results and derived the average, maximum, and minimum for each block. The last set of points in the figure shows the annual aggregated values. 


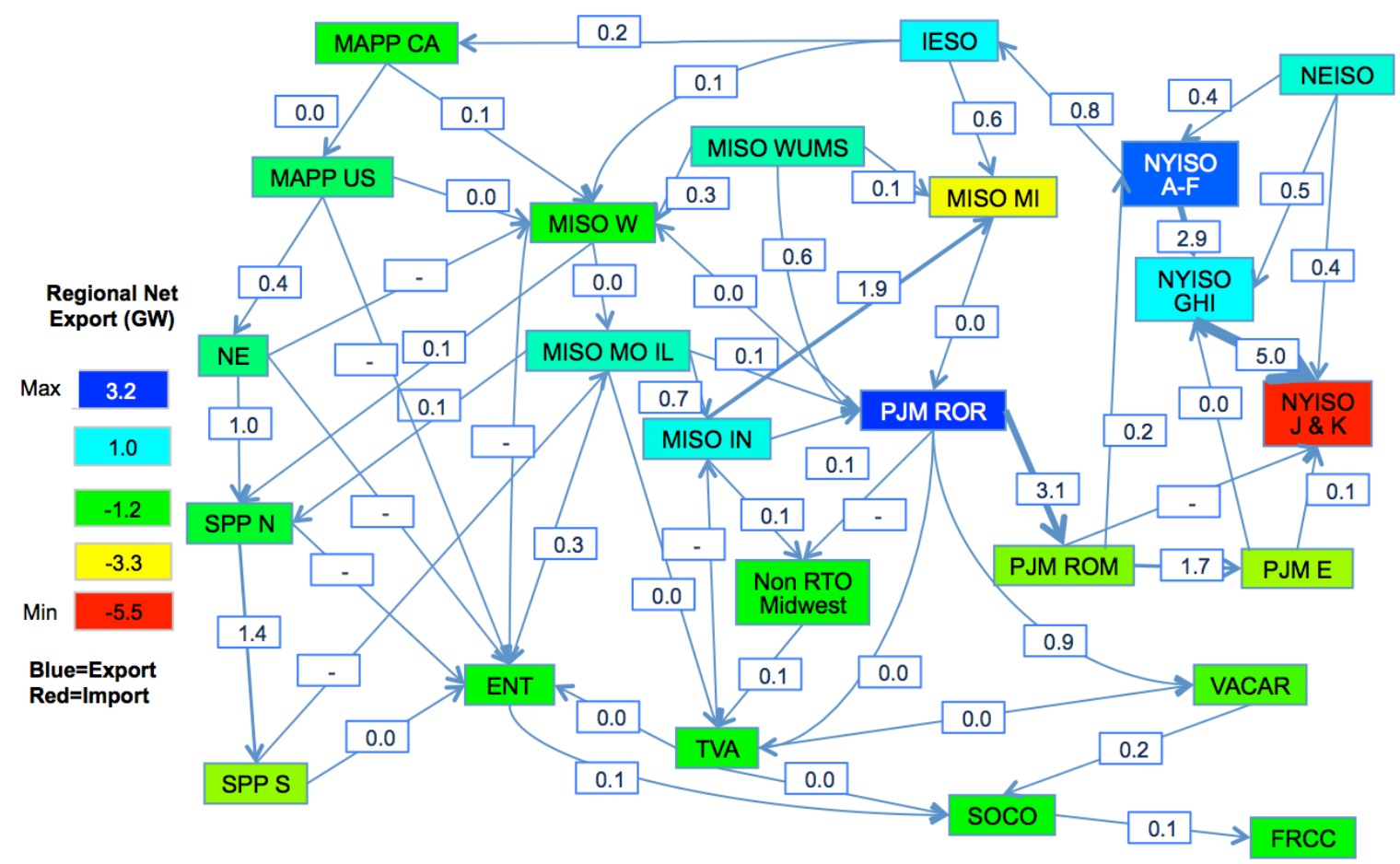

Fig. 18. Phase 1 average interregional transfers $(G W)$ in 2030 in the BAU scenario.

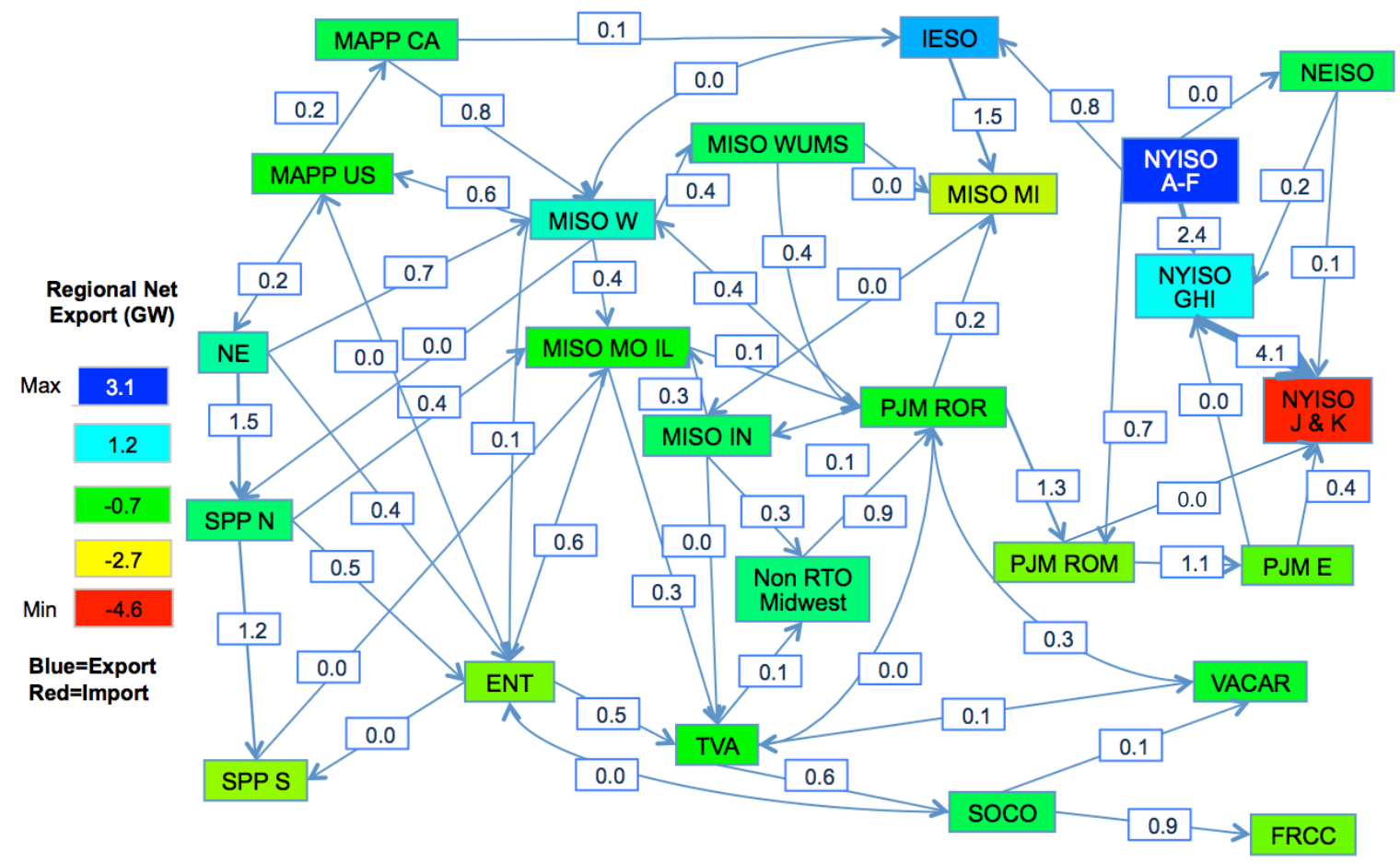

Fig. 19. Phase 2 average interregional transfers (GW) in 2030 in the BAU scenario. 


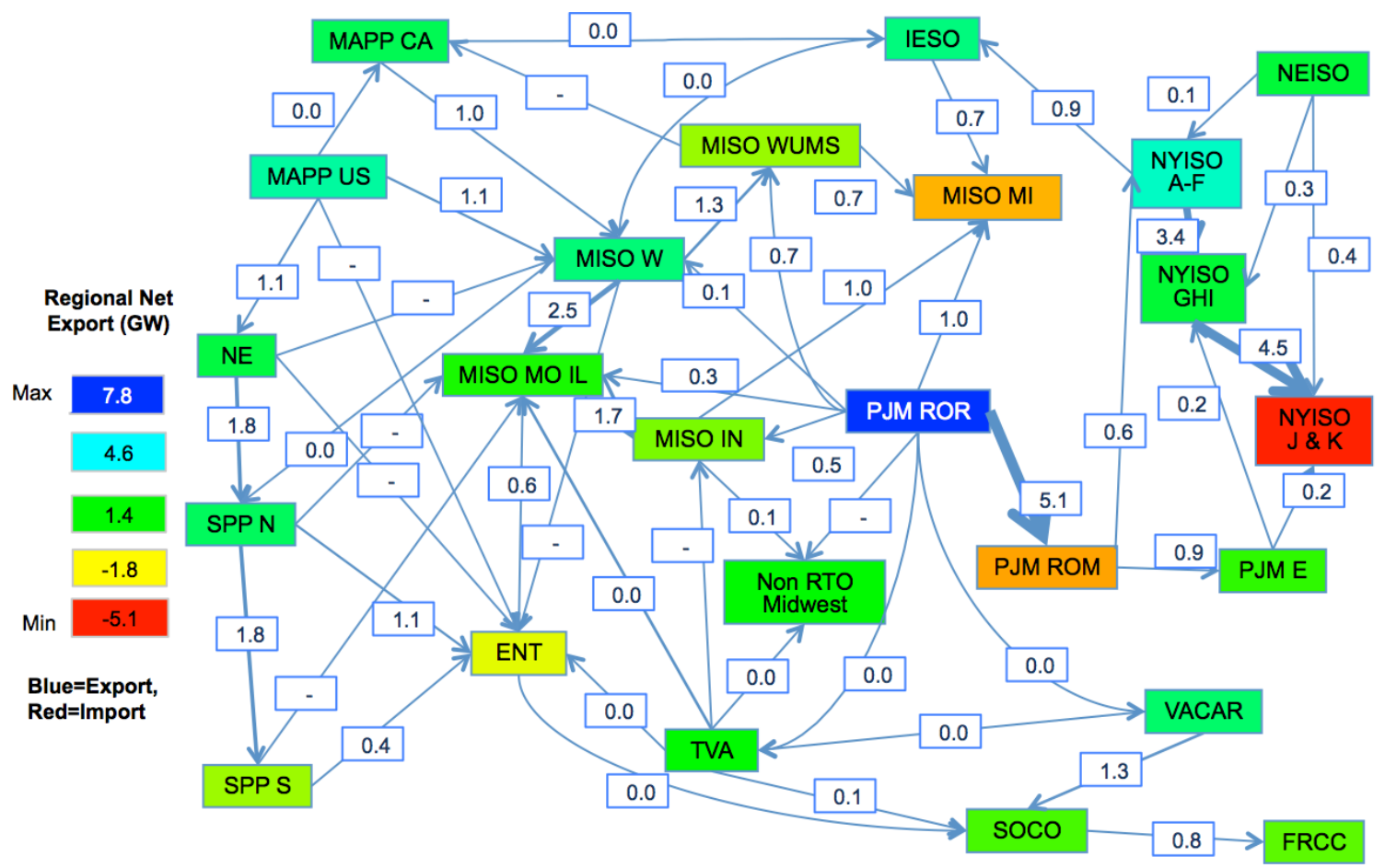

Fig. 20. Phase 1 average interregional transfers $(G W)$ in 2030 in the RPS/R scenario.

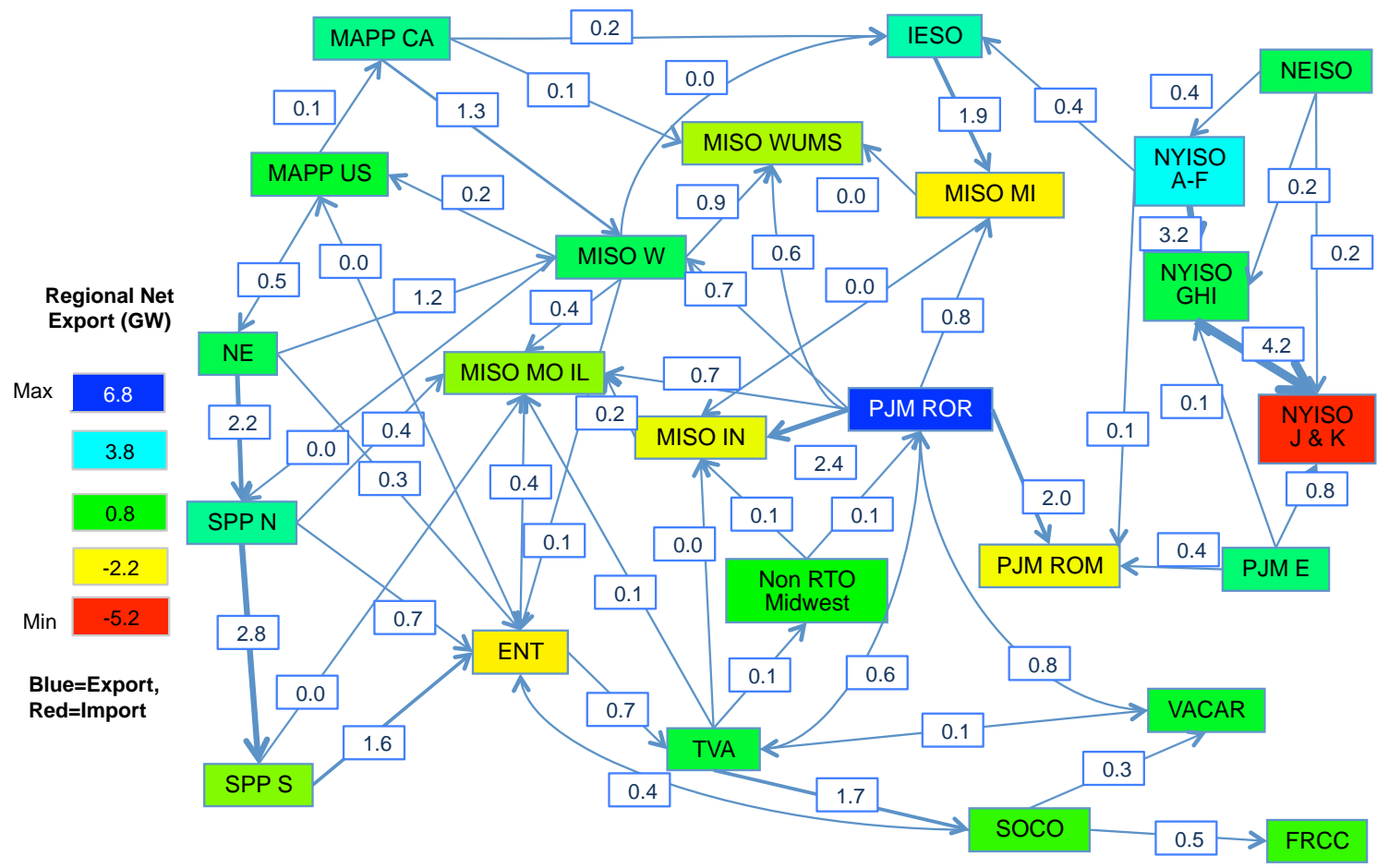

Fig. 21. Phase 2 average interregional transfers $(G W)$ in 2030 in the RPS/R scenario. 


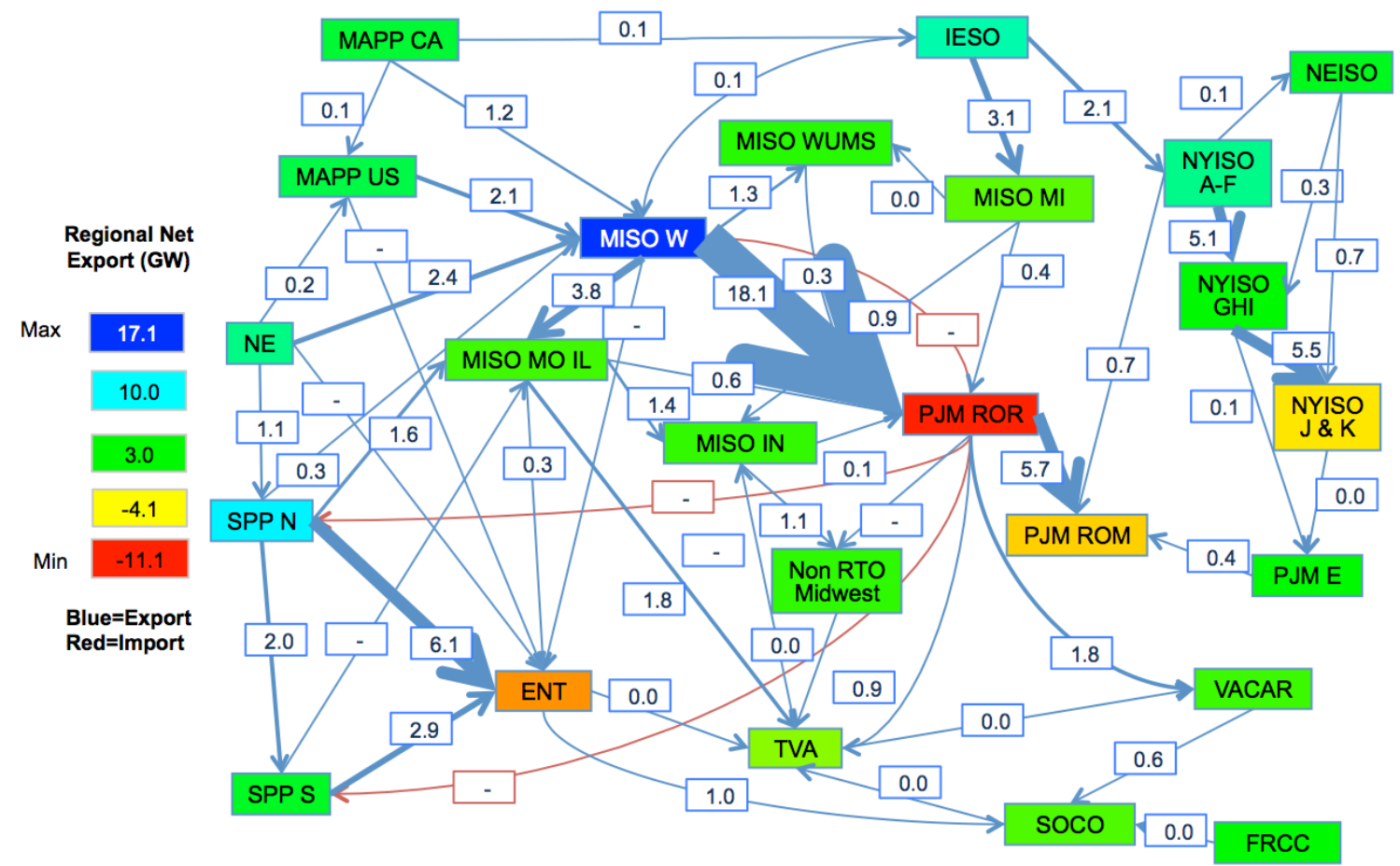

Fig. 22. Phase 1 average interregional transfers $(G W)$ in 2030 in the $\mathrm{CO}_{2}+$ scenario.

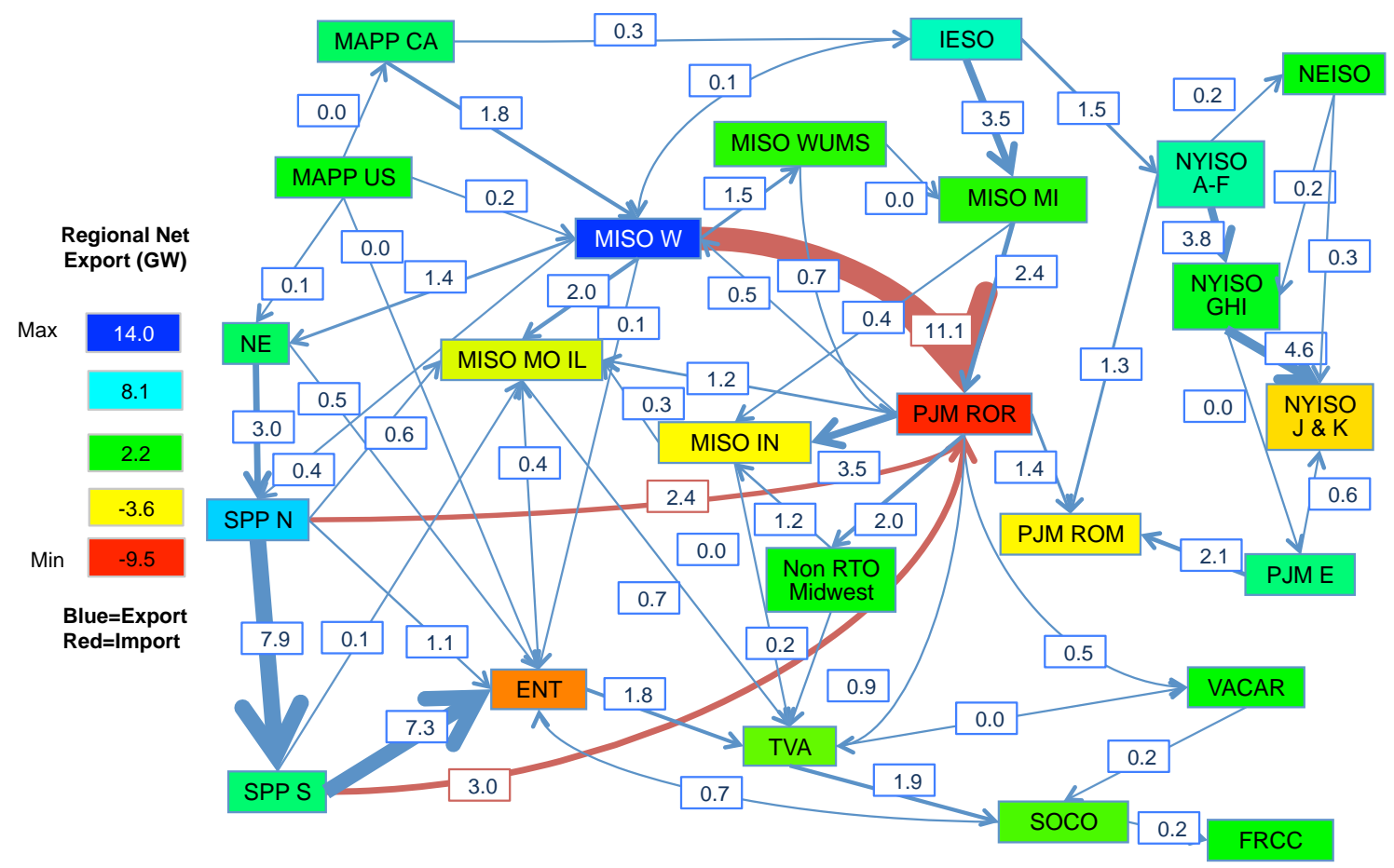

Fig. 23. Phase 2 average interregional transfers $(G W)$ in 2030 in the $\mathrm{CO}_{2}+$ scenario.

In Fig. 24, Block 1, the 10 summer peak hours, Phase 1 results had $640 \mathrm{MW}$ of power transferring from SPP S to SPP N; Phase 2 results had between 5 and 14 GW transferred from SPP N to SPP S, with an average of $10 \mathrm{GW}$. Recall that Phase 2 included the SPP high voltage overlay that provided extensive 
transfer capacity between the two regions. Other blocks showed even broader diversity in the amount transferred between the regions. (Blocks 11 and 16 are the peak hours for the other seasons and so have less diversity.) During Block 18 (400 hours in the winter), in Phase 2 the transfers ranged from $3 \mathrm{GW}$ traveling south to north to $21 \mathrm{GW}$ traveling north to south. This variation could be due to wind pattern differences, plant outages, different internal or export demands, or the modeling of minor cost differences during times of surplus generation. This will be explored in more detail in the next set of topics.

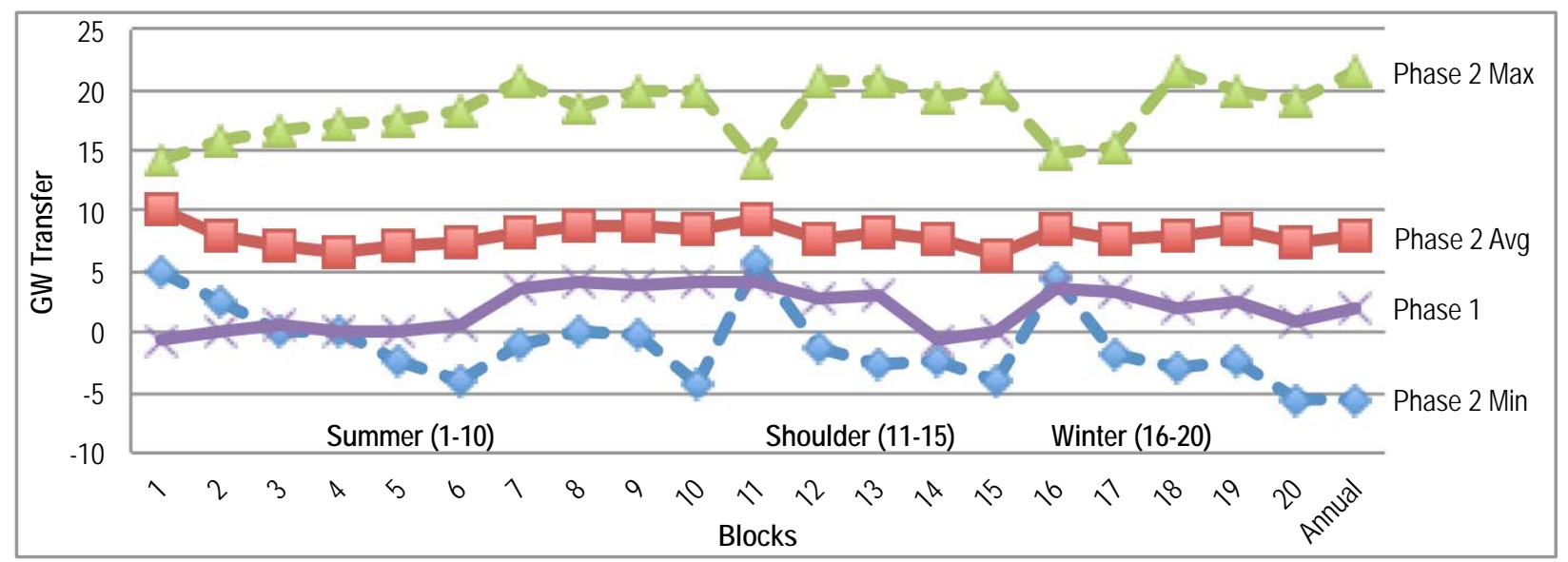

Fig. 24. SPP $\mathrm{N}$ to SPP S transmission in the $\mathrm{CO}_{2}+$ scenario aggregated to NEEM load blocks.

\subsection{Cost Comparison}

Total costs include generation costs as calculated within the models plus other costs calculated separately. These costs include the transmission capital costs, nuclear uprates, DR, EE, DG, and others. These are discussed in more detail in Topic 3. Some cost categories were calculated differently in Phase 1 than in Phase 2. For example, in Phase 1 the capital costs for generation were levelized into costs applied each year, using capital recovery factors between $11 \%$ and $12 \%$ depending on the technology. Transmission capital costs were only calculated as a single total construction cost for the whole period and only applied to transmission over and above the Stakeholder-Specified Infrastructure (SSI). In Phase 2, both generation and transmission capital costs were calculated as the total period's construction cost. To levelize the generation and transmission construction costs, we applied an average capital recovery factor of $11.5 \%$ to all capital.

\subsubsection{Ratio of Total Cost in 2030 Between Scenarios}

As the focus of this chapter is a comparison of Phase 2 results to Phase 1 results, the ratio of total 2030 cost indicates how they compared (Fig. 25). Costs for most of the regions were higher in Phase 2 (ratio $>100 \%$ ), especially in the $\mathrm{CO}_{2}+$ scenario with total costs $16 \%$ higher. Capital costs appear to be a main driver in this; Phase 2 capital costs were 24\% higher for the entire EI. Only five regions had capital costs lower in Phase 2 than Phase 1. 


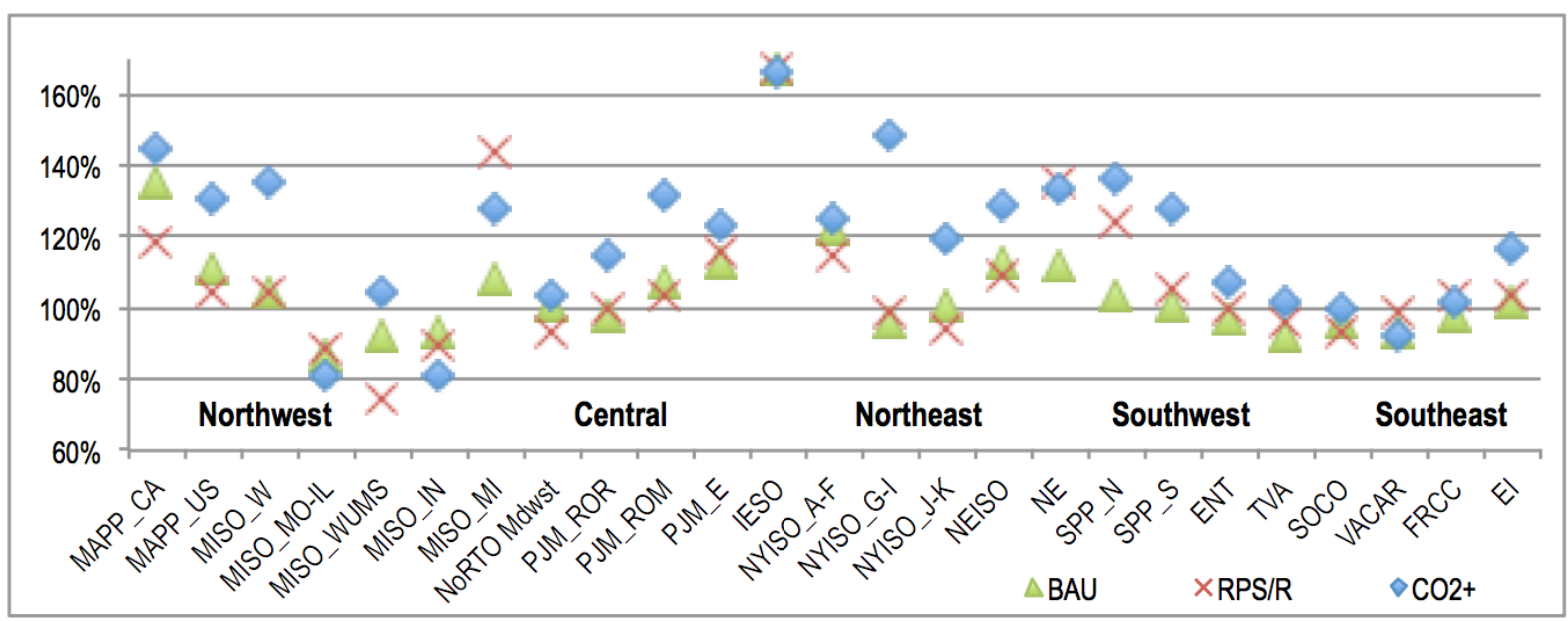

Fig. 25. Ratio of Phase 2 to Phase 1 generation costs in 2030 by region.

\subsubsection{Total by Type and Region}

Total costs for most regions are relatively similar between Phase 1 and 2 (Figs. 26-28). The largest differences are in those regions that have high wind generation (MISO W, SPP N, SPP S) in the $\mathrm{CO}_{2}+$ scenario. Capital costs make up the biggest difference in MISO W, but in SPP the cost difference also includes more fuel and emissions cost due to the added coal, CC, and CT generation during wind shortfalls or for reserves. Scenarios 2 and 3 do not have as great a difference between phases.

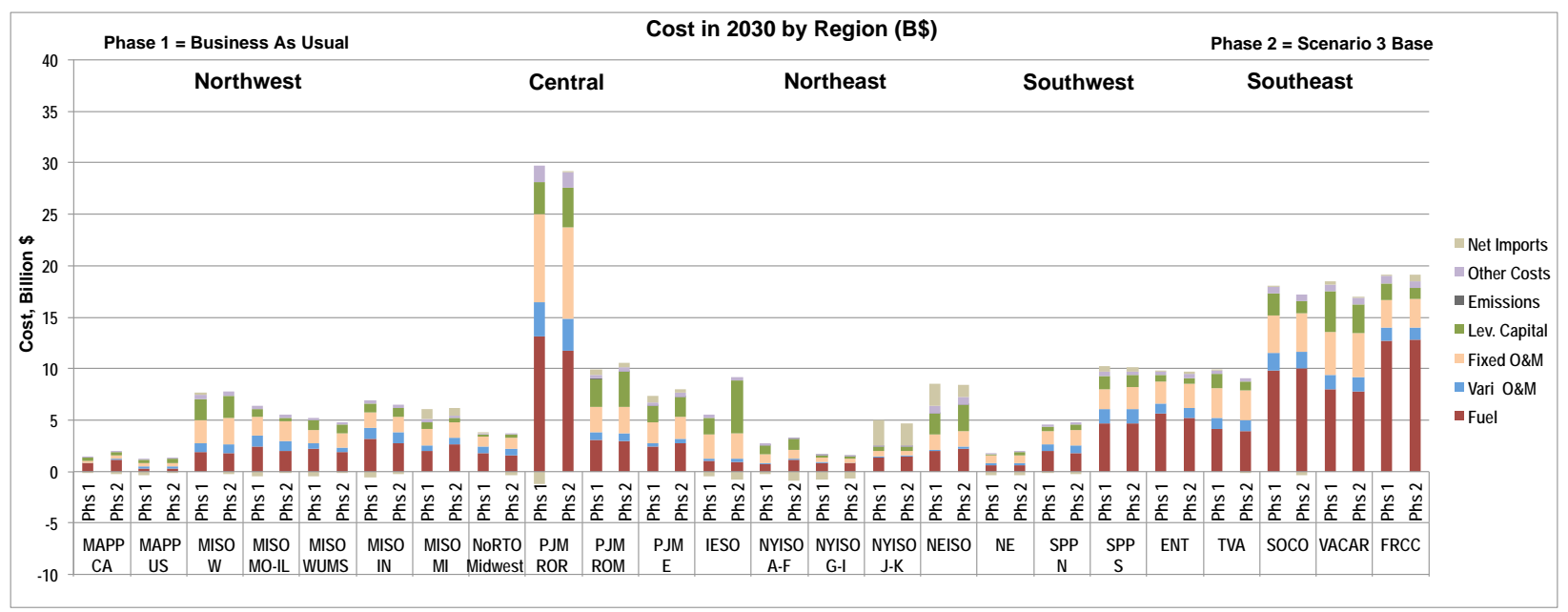

Fig. 26. Phase 1 and Phase 2 regional total costs in 2030 in the BAU scenario. 


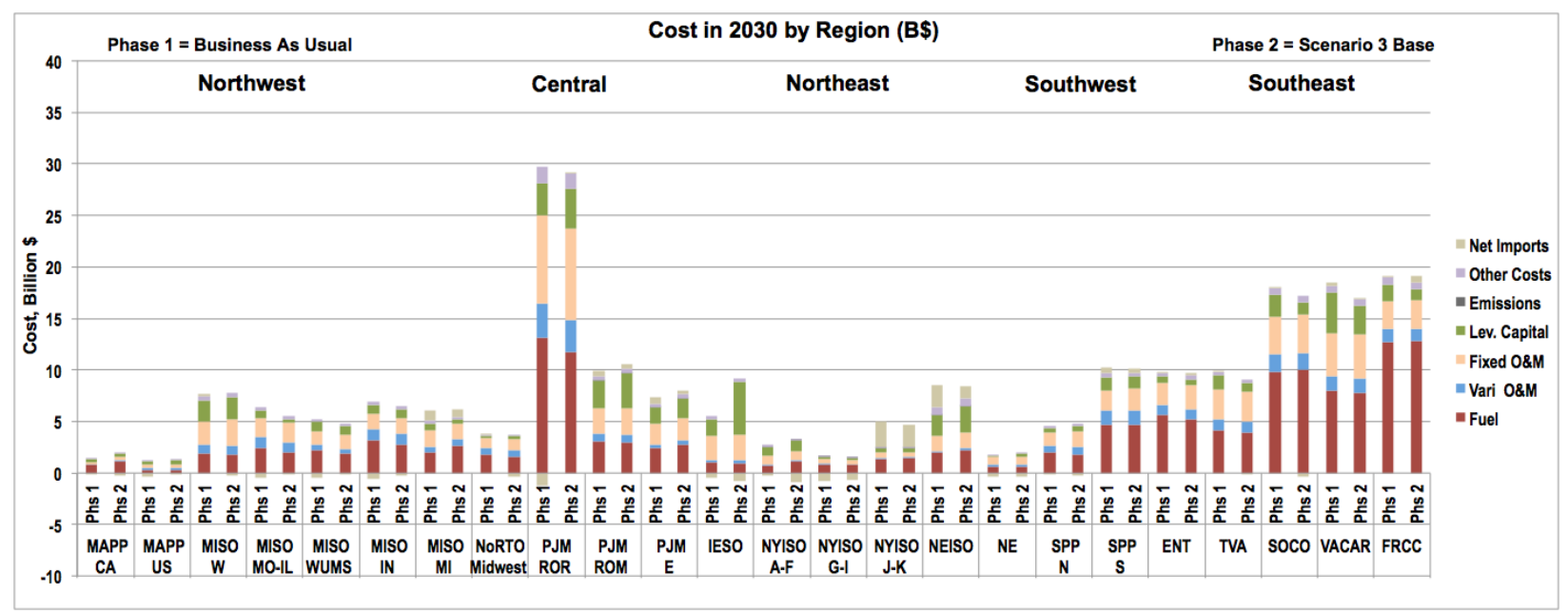

Fig. 27. Phase 1 and Phase 2 regional total costs in 2030 in the RPS/R scenario.

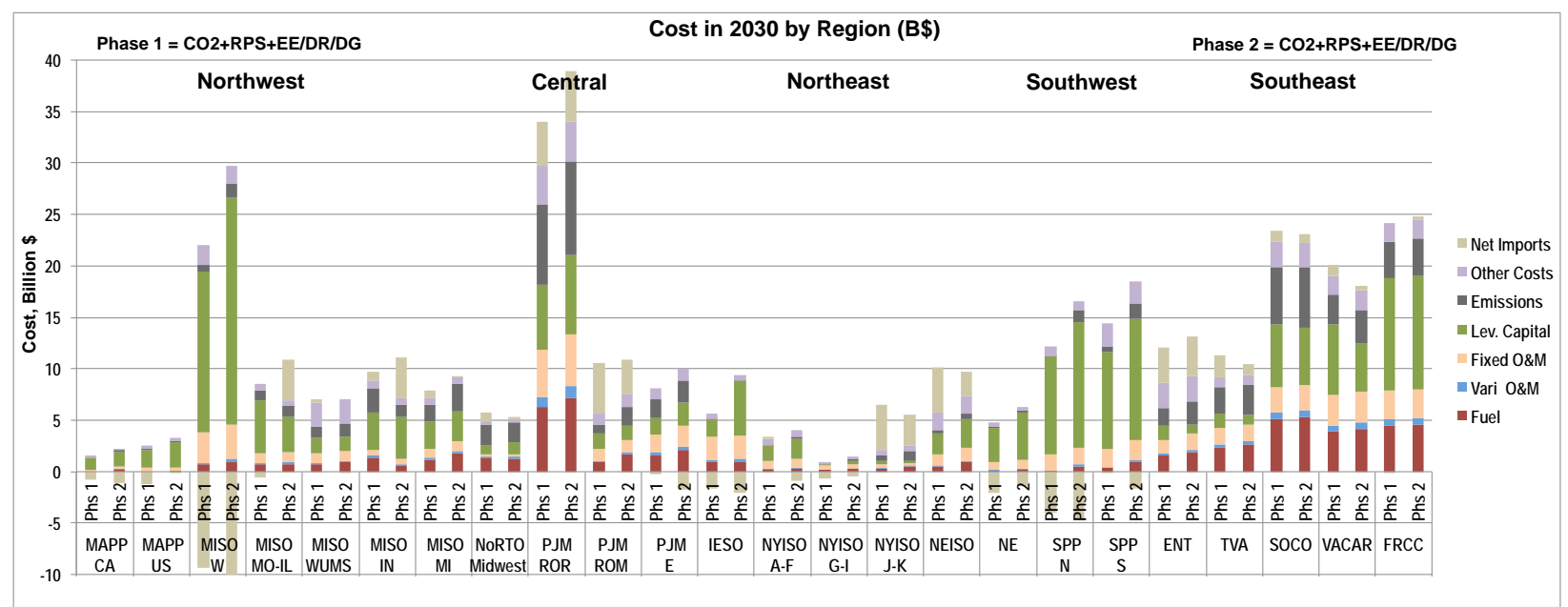

Fig. 28. Phase 1 and Phase 2 regional total costs in 2030 in the $\mathrm{CO}_{2}+$ scenario.

\subsubsection{Cost per Unit of Generation}

Cost per unit of generation puts cost on a more comparable basis between regions (Figs. 29-31). Cost per unit of generation results amplify the differences in the $\mathrm{CO}_{2}+$ scenario for those regions with high wind production, MAPP US, MISO W, NE, SPP N, and SPP S. These costs do not include the net import costs and the divisor does not include imports or exports, so this is a measure of the average cost per unit of generation, not cost per unit of demand in the region. 


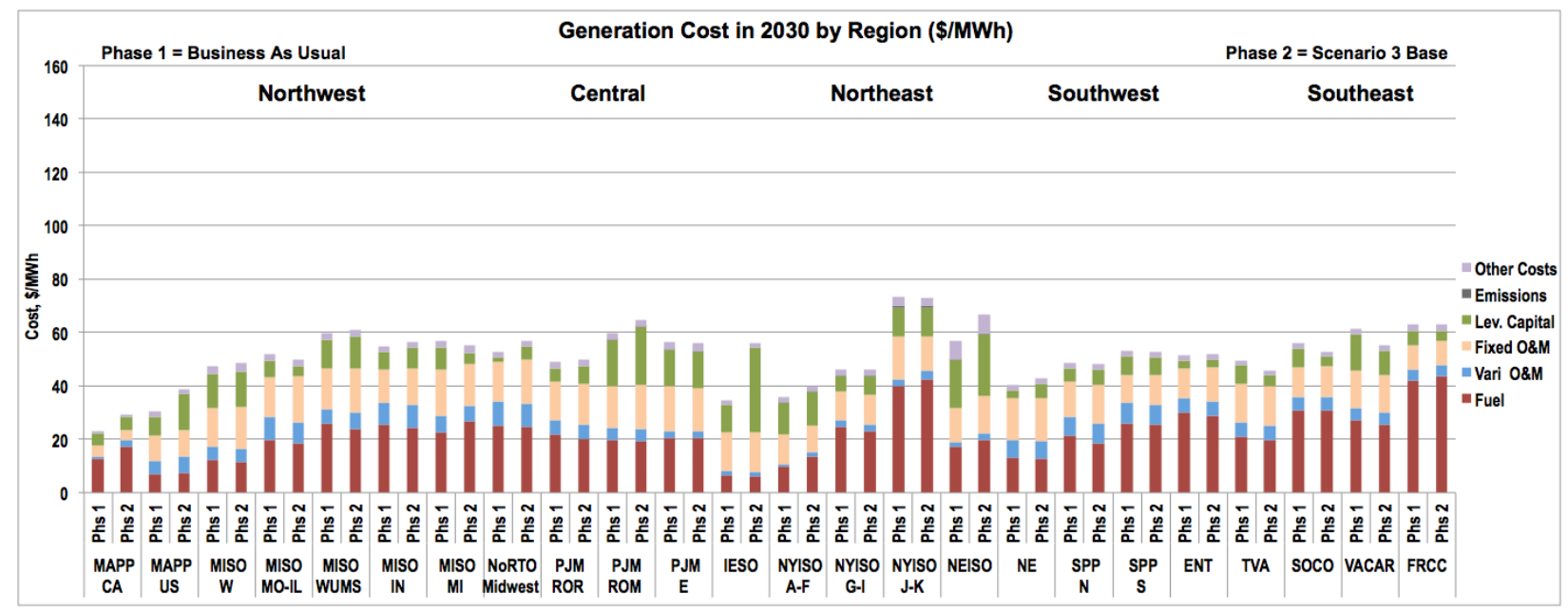

Fig. 29. Phase 1 and Phase 2 regional total cost per megawatt-hour generated in the BAU scenario.

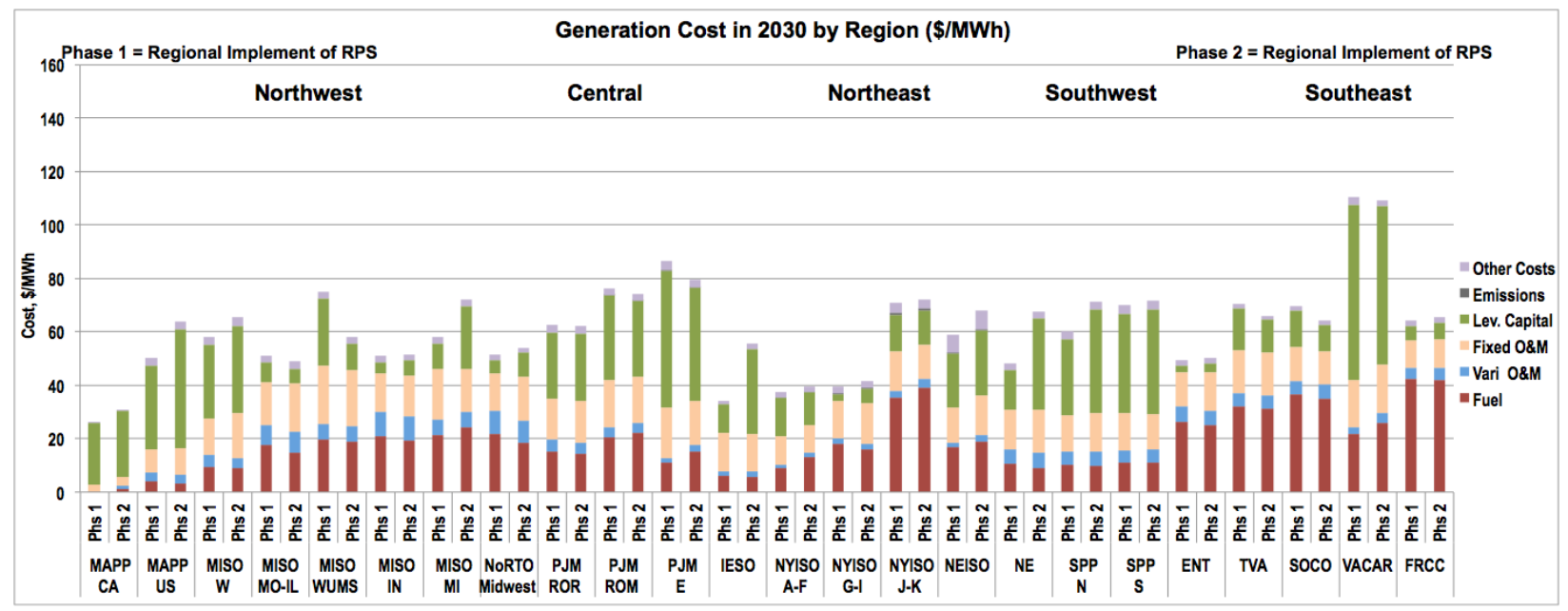

Fig. 30. Phase 1 and Phase 2 regional total cost per megawatt-hour generated in the RPS/R scenario.

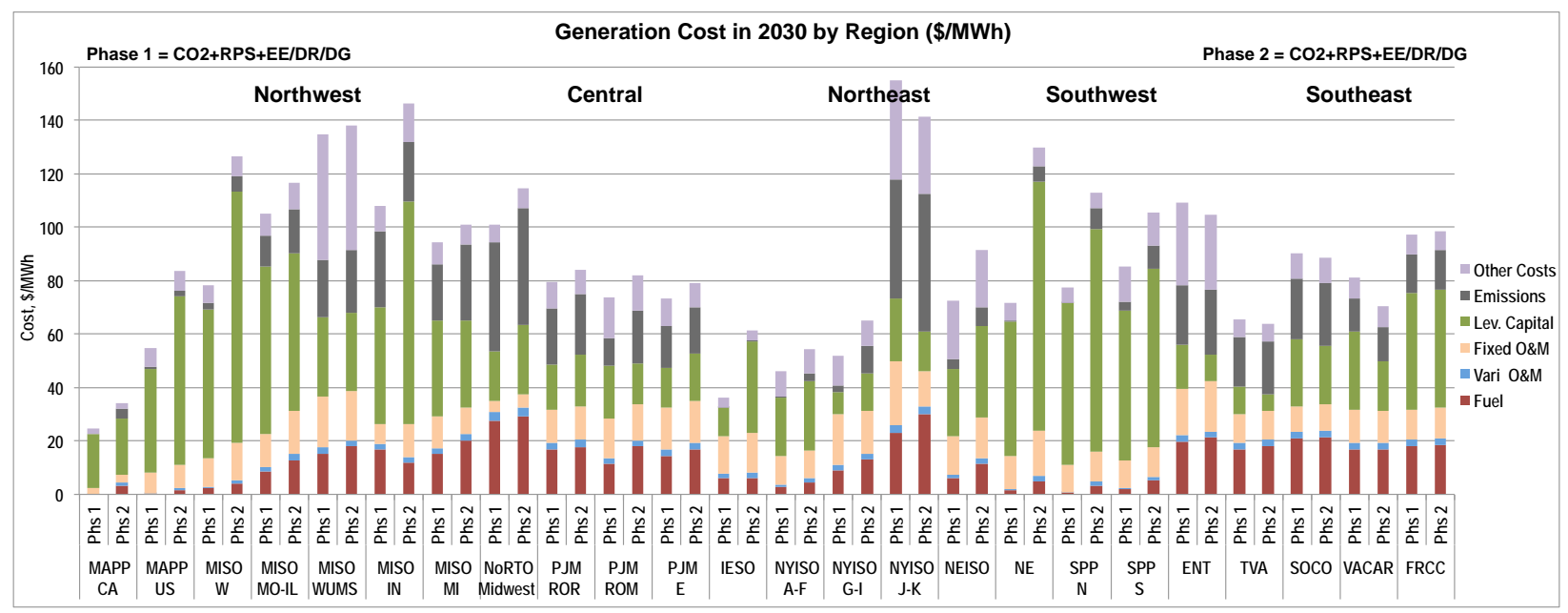

Fig. 31. Phase 1 and Phase 2 regional total cost per megawatt-hour generated in the $\mathrm{CO}_{2}+$ scenario. 



\section{TOPIC 2: REGIONAL RESULTS OVER TIME}

This chapter evaluates the change in capacity, generation, and interregional transfers over time. The reason for this topic is many regulators or other stakeholders were concerned that there could be issues that they might face in the nearer term than 2030. The most pressing issues might be changes in generation or transmission capacity, since these require the most upfront response.

Earlier years than 2030 were only analyzed in Phase 1 of the study. Most results were only reported in 5year increments beginning in 2015. The timing of transmission changes is difficult to evaluate because the amount of transfer capacity between regions was modeled as a constant over the full time period.

The figures below show the changes in capacity and generation over time, based on the Phase 1 results. Rather than show all 24 regions, the section below shows the changes for each of the major territories as defined in Table 1. In addition, tables showing the points of major change in capacity, generation, and net exports are highlighted. Only those technologies that have more than a 5\% share of the generation and have a change greater than $25 \%$ are shown. Export changes greater than $+/-10 \%$ between years are highlighted. Changes past 2030 are not included in the tables as those years are more speculative and of less interest than results up to 2030.

In all regions and scenarios, excess generation is deactivated between 2010 and 2015 by MRN-NEEM. Most often this capacity is coal and steam oil/gas. DR grows in capacity significantly through 2025.

The following sections show the graphs of capacity from 2010-2040 next to the graphs of generation from 2015-2040 for each scenario for a given territory, with that of the EI as a whole first. Following the figures in each section are tables telling when significant changes occurred to capacity, generation, and net transfers for the territory between 2010 and 2015 (capacity changes only), 2015 and 2020, 2030 and 2025 , and 2005 and 2030. Following the tables is a brief description of key changes. 


\subsection{Eastern Interconnection as a Whole}
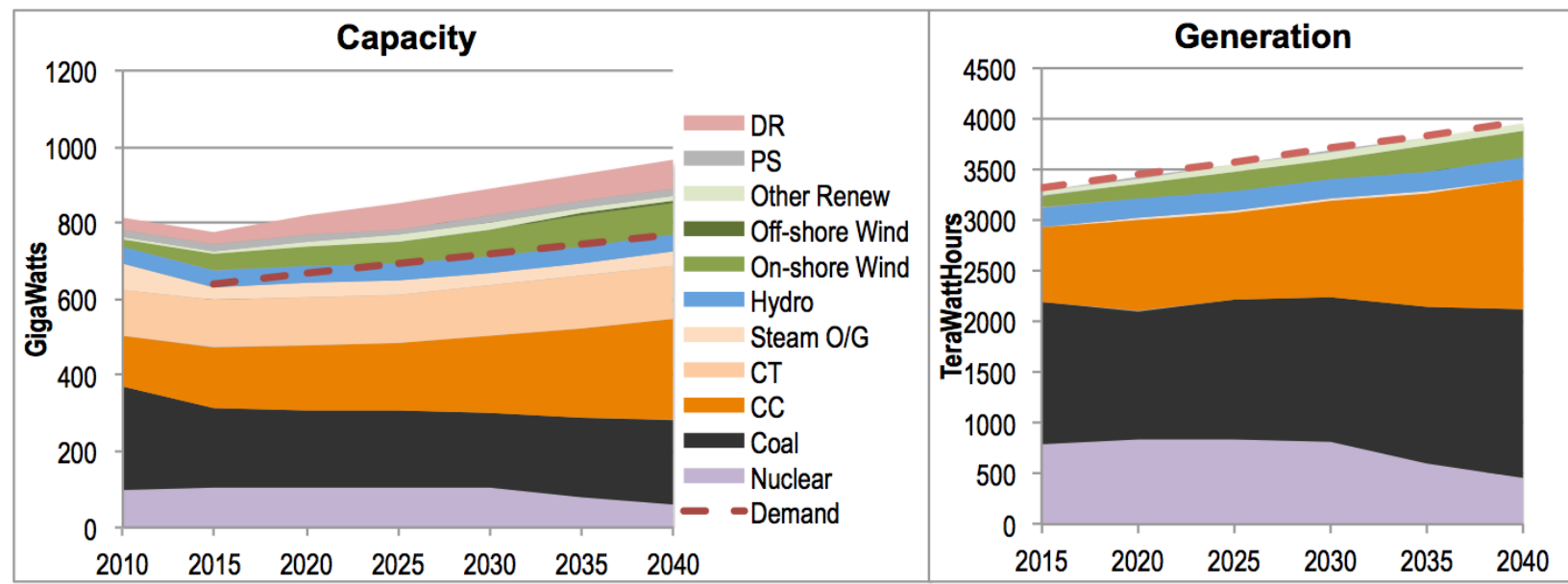

Fig. 32. BAU scenario Phase 1 capacity and generation for the Eastern Interconnection as a whole.

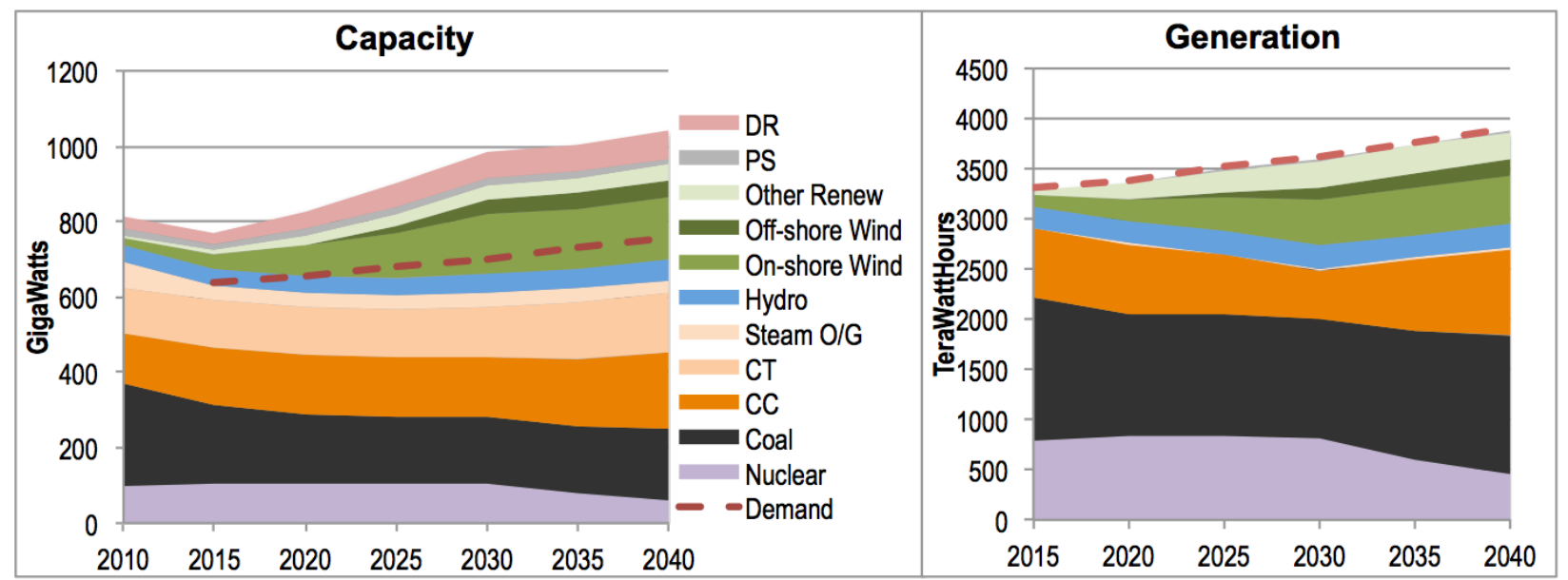

Fig. 33. RPS/R scenario Phase 1 capacity and generation for the Eastern Interconnection as a whole.

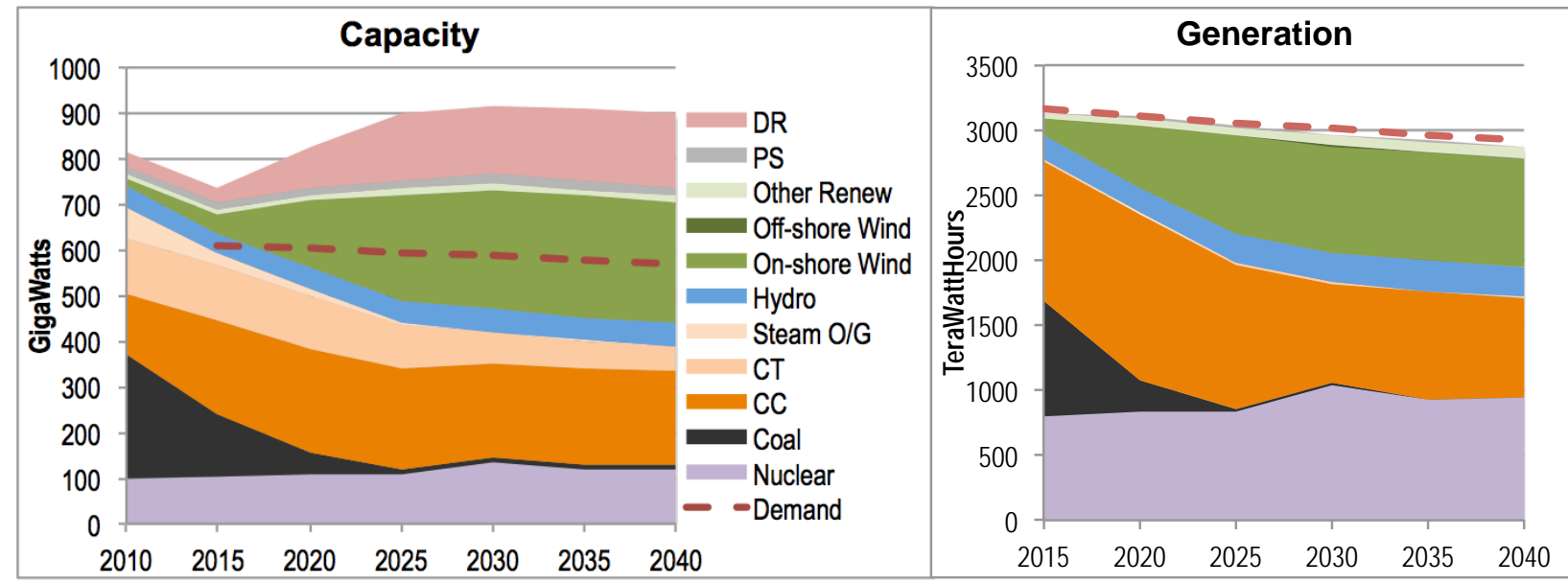

Fig. 34. $\mathrm{CO}_{2}+$ scenario Phase 1 capacity and generation for the Eastern Interconnection. 
Table 6. BAU Scenario Significant Changes Through 2030 in the Eastern Interconnection as a Whole

\begin{tabular}{|c|c|c|c|}
\hline $\begin{array}{l}\text { NEEM Region: } \\
2015\end{array}$ & 2020 & Scenario & F1S17 \\
\hline \multicolumn{4}{|c|}{ Significant Capacity Changes } \\
\hline $\begin{array}{l}\text { - Steam O/G down } 52 \% \text { to } \\
34.6 \mathrm{GW} \\
\text { - Onshore wind up } 119 \% \\
\text { to } 40.9 \mathrm{GW}\end{array}$ & $\begin{array}{l}\text { - Onshore wind up } 30 \% \\
\text { to } 53.1 \mathrm{GW} \\
\text { - DR up } 53 \% \text { to } 48.6 \mathrm{GW}\end{array}$ & $\begin{array}{l}\text { - Demand response (DR) up } \\
40 \% \text { to } 68.2 \mathrm{GW}\end{array}$ & \\
\hline \multicolumn{4}{|c|}{ Significant Generation Changes } \\
\hline Significant Net Export Chi & iges (negative = Imports & & \\
\hline
\end{tabular}

Table 7. RPS/R Scenario Significant Changes Through 2030 in the Eastern Interconnection as a Whole

\begin{tabular}{|c|c|c|c|}
\hline $\begin{array}{l}\text { NEEM Region: } \\
2015\end{array}$ & 2020 & 2025 Scenario: & F6S10 \\
\hline \multicolumn{4}{|c|}{ Significant Capacity Changes } \\
\hline $\begin{array}{l}\text { - Steam O/G down } 50 \% \\
\text { to } 35.9 \mathrm{GW} \\
\text { - Onshore wind up } 119 \% \\
\text { to } 40.9 \mathrm{GW}\end{array}$ & $\begin{array}{l}\text { - Onshore wind up } 99 \% \text { to } \\
81.3 \mathrm{GW} \\
\text { - Demand response (DR) up } \\
53 \% \text { to } 48.6 \mathrm{GW}\end{array}$ & $\begin{array}{l}\text { - Onshore wind up } 45 \% \text { to } \\
118.2 \mathrm{GW} \\
\text { - DR up } 40 \% \text { to } 68.2 \mathrm{GW}\end{array}$ & $\begin{array}{l}\text { - Onshore wind up } 35 \% \\
\text { to } 159.3 \mathrm{GW}\end{array}$ \\
\hline \multicolumn{4}{|c|}{ Significant Generation Changes } \\
\hline & $\begin{array}{l}\text { - Onshore wind up 95\% to } \\
227.5 \text { TWh }\end{array}$ & $\begin{array}{l}\text { - Onshore wind up } 46 \% \text { to } \\
332.6 \text { TWh } \\
\text { - Other renewables up } 32 \% \\
\text { to } 210.5 \text { TWh }\end{array}$ & $\begin{array}{l}\text { - Onshore wind up } 38 \% \\
\text { to } 457.6 \text { TWh }\end{array}$ \\
\hline \multicolumn{4}{|c|}{ Significant Net Export Changes (negative = Imports) } \\
\hline
\end{tabular}

Table 8. $\mathrm{CO}_{2}+$ Scenario Significant Changes Through 2030 in the Eastern Interconnection as a Whole

\begin{tabular}{|c|c|c|c|}
\hline $\begin{array}{l}\text { NEEM Region: } \\
2015\end{array}$ & 2020 & $\begin{array}{l}\text { Scenario: } \\
2025\end{array}$ & F8S7 \\
\hline \multicolumn{4}{|c|}{ Significant Capacity Changes } \\
\hline $\begin{array}{l}\text { - Coal down } 49 \% \text { to } \\
138.8 \text { GW } \\
\text { - Combined cycle (CC) up } \\
56 \% \text { to } 207.2 \mathrm{GW} \\
\text { - Steam O/G down } 67 \% \text { to } \\
23.9 \mathrm{GW} \\
\text { - On-shore Wind up } 119 \% \\
\text { to } 40.9 \mathrm{GW}\end{array}$ & $\begin{array}{l}\text { - Coal down } 66 \% \text { to } 47.2 \mathrm{GW} \\
\text { - Onshore wind up } 259 \% \text { to } \\
146.7 \mathrm{GW} \\
\text { - Demand response (DR) up } \\
172 \% \text { to } 86.5 \mathrm{GW}\end{array}$ & $\begin{array}{l}\text { - Coal down } 78 \% \text { to } \\
10.2 \mathrm{GW} \\
\text { - Onshore wind up } 58 \% \\
\text { to } 231.5 \mathrm{GW} \\
\text { - DR up } 70 \% \text { to } \\
146.9 \mathrm{GW}\end{array}$ & $\begin{array}{l}\text { - Combustion turbine down } \\
31 \% \text { to } 66.0 \mathrm{GW}\end{array}$ \\
\hline \multicolumn{4}{|c|}{ Significant Generation Changes } \\
\hline & $\begin{array}{l}\text { - Coal down } 72 \% \text { to } \\
\text { 250.6 TWh } \\
\text { - Onshore wind up } 309 \% \text { to } \\
\text { 474.9 TWh }\end{array}$ & $\begin{array}{l}\text { - Coal down } 93 \% \text { to } \\
18.1 \text { TWh } \\
\text { - Onshore wind up } 57 \% \\
\text { to } 746.6 \text { TWh }\end{array}$ & $\begin{array}{l}\text { - CC down } 31 \% \text { to } 769.5 \\
\text { TWh }\end{array}$ \\
\hline
\end{tabular}

Changes to the EI as a whole have been described in the full EIPC report. The BAU scenario has most growth occurring steadily, with coal and CC the major contributors (Fig. 32). In the RPS/R scenario, onshore wind grows more gradually over time; offshore wind and other renewables become more significant contributors in place of $\mathrm{CC}$ (Fig. 33). The $\mathrm{CO}_{2}+$ scenario shows a rapid decline in coal 
capacity and generation and a large increase in both wind and DR capacity. Nuclear capacity grows somewhat and provides a growing fraction of generation (Fig. 34).

\subsection{Northwest}
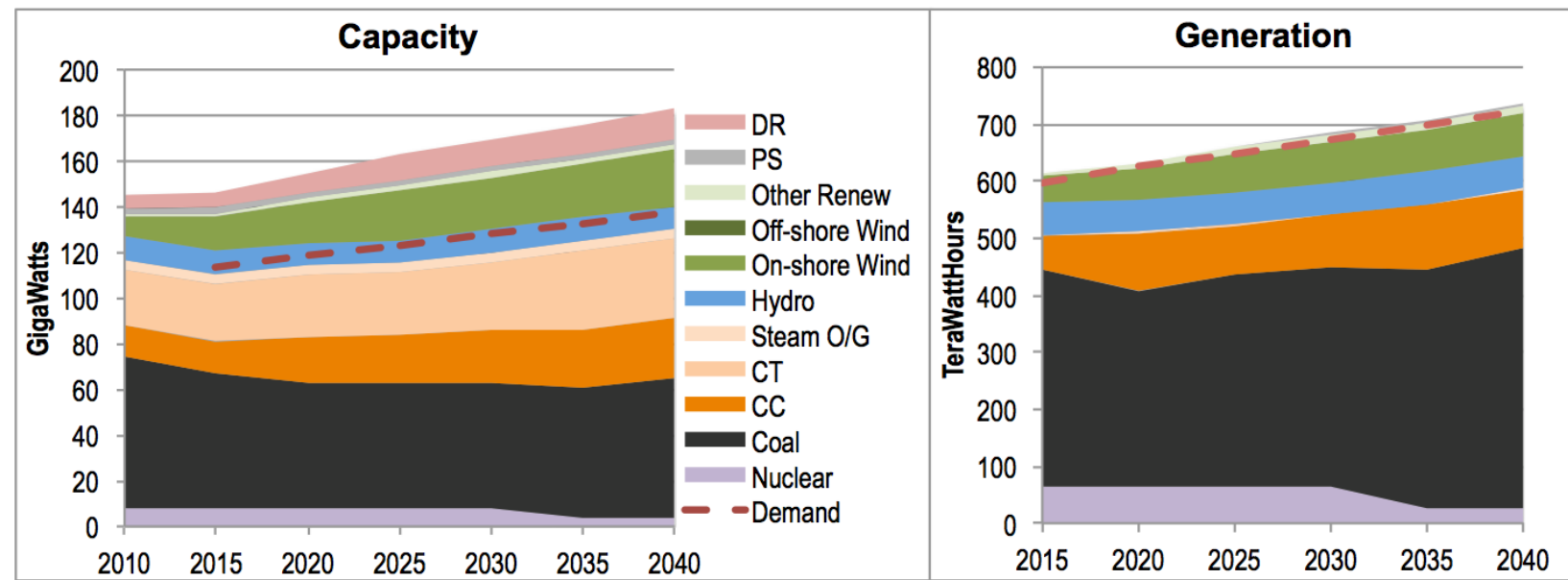

Fig. 35. BAU scenario Phase 1 capacity and generation for the Northwest Eastern Interconnection.
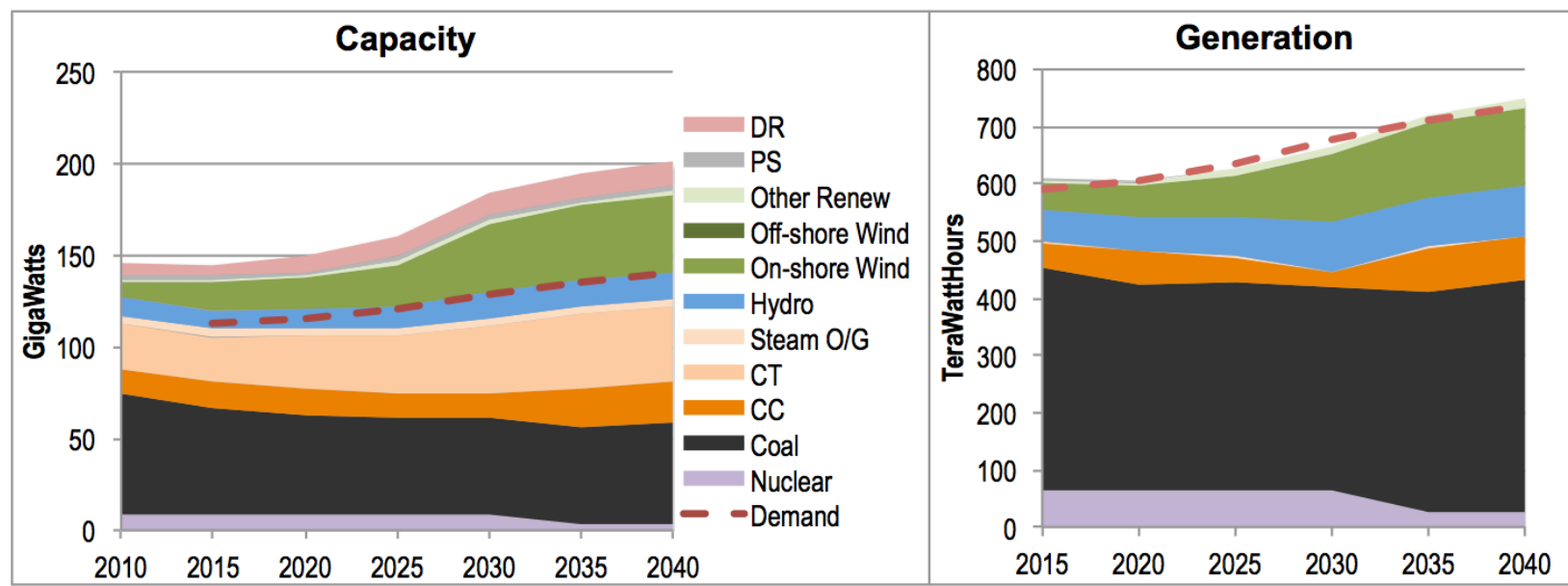

Fig. 36. RPS/R scenario Phase 1 capacity and generation for the Northwest Eastern Interconnection.
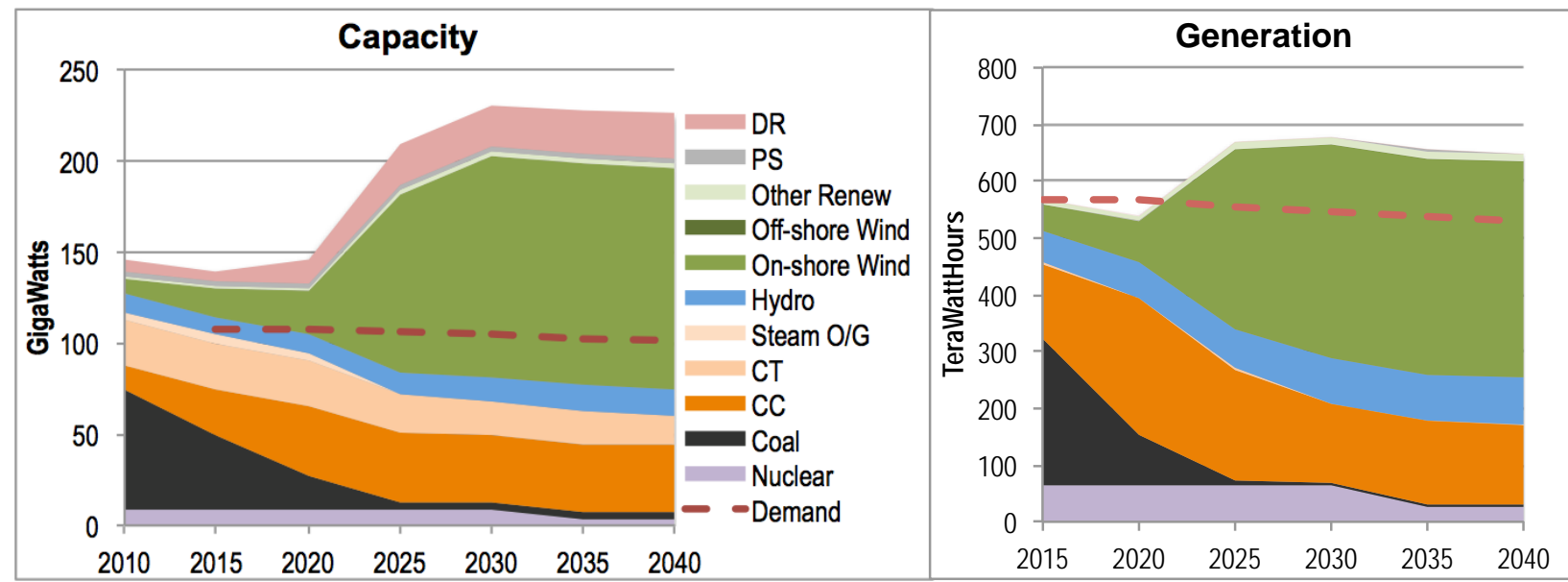

Fig. 37. $\mathrm{CO}_{2}+$ scenario Phase 1 capacity and generation for the Northwest Eastern Interconnection. 
Table 9. BAU Scenario Significant Changes Through 2030 in the Northwest Eastern Interconnection

\begin{tabular}{|c|c|c|c|}
\hline Territory: & Northwest & Scenario: & $\begin{array}{l}\text { F1S1 } \\
7 \\
2030\end{array}$ \\
\hline \multicolumn{4}{|l|}{ Significant Capacity Changes } \\
\hline $\begin{array}{l}\text { - Onshore wind up } 78 \% \text { to } \\
15.5 \mathrm{GW}\end{array}$ & $\begin{array}{l}\text { - Combined cycle (CC) up } 36 \% \text { to } \\
19.6 \mathrm{GW} \\
\text { - DR up } 40 \% \text { to } 8.6 \mathrm{GW}\end{array}$ & $\begin{array}{l}\text { - Demand response (DR) up 34\% to } \\
11.6 \mathrm{GW}\end{array}$ & \\
\hline \multicolumn{4}{|c|}{ Significant Generation Changes } \\
\hline & - CC up $68 \%$ to $101.1 \mathrm{TWh}$ & & \\
\hline
\end{tabular}

Table 10. RPS/R Scenario Significant Changes Through 2030 in the Northwest Eastern Interconnection

\begin{tabular}{|c|c|c|c|}
\hline \multicolumn{2}{|c|}{ Territory: Northwest } & \multicolumn{2}{|c|}{ Scenario: F6S10 } \\
\hline 2015 & 2020 & 2025 & 2030 \\
\hline \multicolumn{4}{|c|}{ Significant Capacity Changes } \\
\hline $\begin{array}{l}\text { - Onshore wind up } 78 \% \\
\text { to } 15.5 \mathrm{GW}\end{array}$ & $\begin{array}{l}\text { - Demand response (DR) up } \\
40 \% \text { to } 8.6 \mathrm{GW}\end{array}$ & $\begin{array}{l}\text { - Onshore wind up } 30 \% \\
\text { to } 22.2 \mathrm{GW} \\
\text { - DR up } 34 \% \text { to } 11.6 \mathrm{GW}\end{array}$ & $\begin{array}{l}\text { - Onshore wind up } 67 \% \text { to } \\
36.9 \mathrm{GW}\end{array}$ \\
\hline \multicolumn{4}{|c|}{ Significant Generation Changes } \\
\hline & $\begin{array}{l}\text { - Combined cycle (CC) up } 34 \% \\
\text { to } 58.7 \text { TWh }\end{array}$ & $\begin{array}{l}\cdot \text { CC down } 27 \% \text { to } \\
43.0 \text { TWh } \\
\text { - Onshore wind up } 32 \% \\
\text { to } 69.8 \mathrm{TWh}\end{array}$ & $\begin{array}{l}\text { - CC down } 41 \% \text { to } 25.4 \\
\text { TWh } \\
\text { - Onshore wind up } 71 \% \text { to } \\
\text { 119.4 TWh }\end{array}$ \\
\hline
\end{tabular}

Table 11. $\mathrm{CO}_{2}+$ Scenario Significant Changes Through 2030 in the Northwest Eastern Interconnection

\begin{tabular}{|c|c|c|c|}
\hline \multicolumn{2}{|c|}{ Territory: Northwest } & \multicolumn{2}{|c|}{ Scenario: $\quad$ F8S7 } \\
\hline 2015 & 2020 & 2025 & 2030 \\
\hline \multicolumn{4}{|c|}{ Significant Capacity Changes } \\
\hline $\begin{array}{l}\cdot \text { Coal down } 37 \% \text { to } \\
41.9 \mathrm{GW} \\
\text { - Combined cycle (CC) up } \\
84 \% \text { to } 25.0 \mathrm{GW} \\
\cdot \text { Onshore Wind up } 78 \% \text { to } \\
15.5 \mathrm{GW}\end{array}$ & $\begin{array}{l}\text { - Coal down } 56 \% \text { to } \\
18.3 \mathrm{GW} \\
\text { - CC up } 56 \% \text { to } 39.0 \mathrm{GW} \\
\text { - Onshore wind up } 50 \% \text { to } \\
23.4 \mathrm{GW} \\
\text { - DR up } 123 \% \text { to } 13.7 \mathrm{GW}\end{array}$ & $\begin{array}{l}\cdot \text { Coal down } 79 \% \text { to } \\
3.8 \mathrm{GW} \\
\cdot \text { Onshore wind up } 319 \% \\
\text { to } 97.8 \mathrm{GW} \\
\text { - Demand response (DR) } \\
\text { up } 61 \% \text { to } 22.2 \mathrm{GW}\end{array}$ & \\
\hline \multicolumn{4}{|c|}{ Significant Generation Changes } \\
\hline & $\begin{array}{l}\text { - Coal down } 65 \% \text { to } \\
89.7 \text { TWh } \\
\text { - CC up } 83 \% \text { to } 239.4 \text { TWh } \\
\text { - Onshore wind up } 56 \% \text { to } \\
\text { 74.9 TWh }\end{array}$ & $\begin{array}{l}\text { - Coal down } 93 \% \text { to } \\
6.4 \text { TWh } \\
\text { - Onshore wind up } 323 \% \\
\text { to } 316.7 \text { TWh }\end{array}$ & $\begin{array}{l}\text { - CC down } 29 \% \text { to } \\
139.8 \mathrm{TWh}\end{array}$ \\
\hline \multicolumn{4}{|c|}{ Significant Net Export Changes (negative = Imports) } \\
\hline & & $\begin{array}{l}\text { - Net exports up } 25 \% \text { to } \\
20 \% \text { of demand }\end{array}$ & \\
\hline
\end{tabular}

The Northwest Territory (MISO and MAPP) has a major expansion in wind capacity between 2020 and 2025 in the $\mathrm{CO}_{2}+$ scenario (Fig. 37), while the RPS/R scenario's biggest increase is delayed to between 2025 and 2030 (Fig. 36). Coal continues as the dominant resource in the BAU (Fig. 35) and RPS/R scenarios, while wind dominates and $\mathrm{CC}$ generation expands in the $\mathrm{CO}_{2}+$ scenario. 


\subsection{Central}
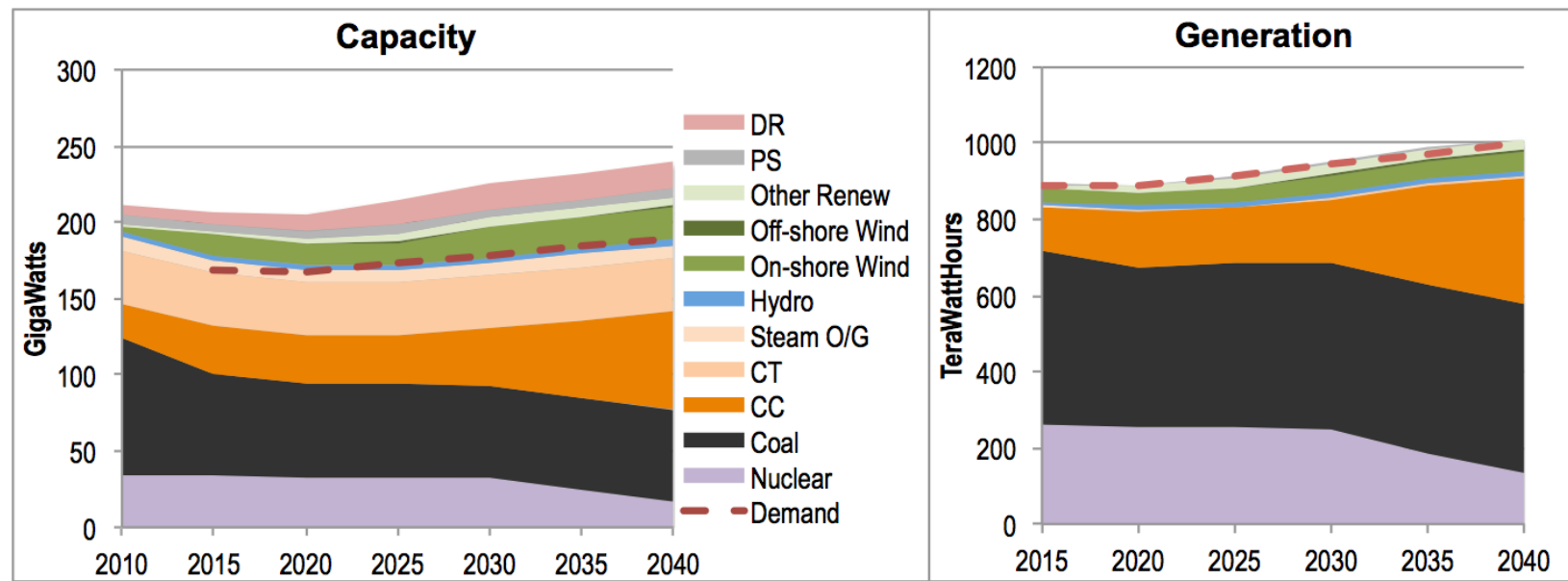

Fig. 38. BAU scenario Phase 1 capacity and generation for the Central Eastern Interconnection.
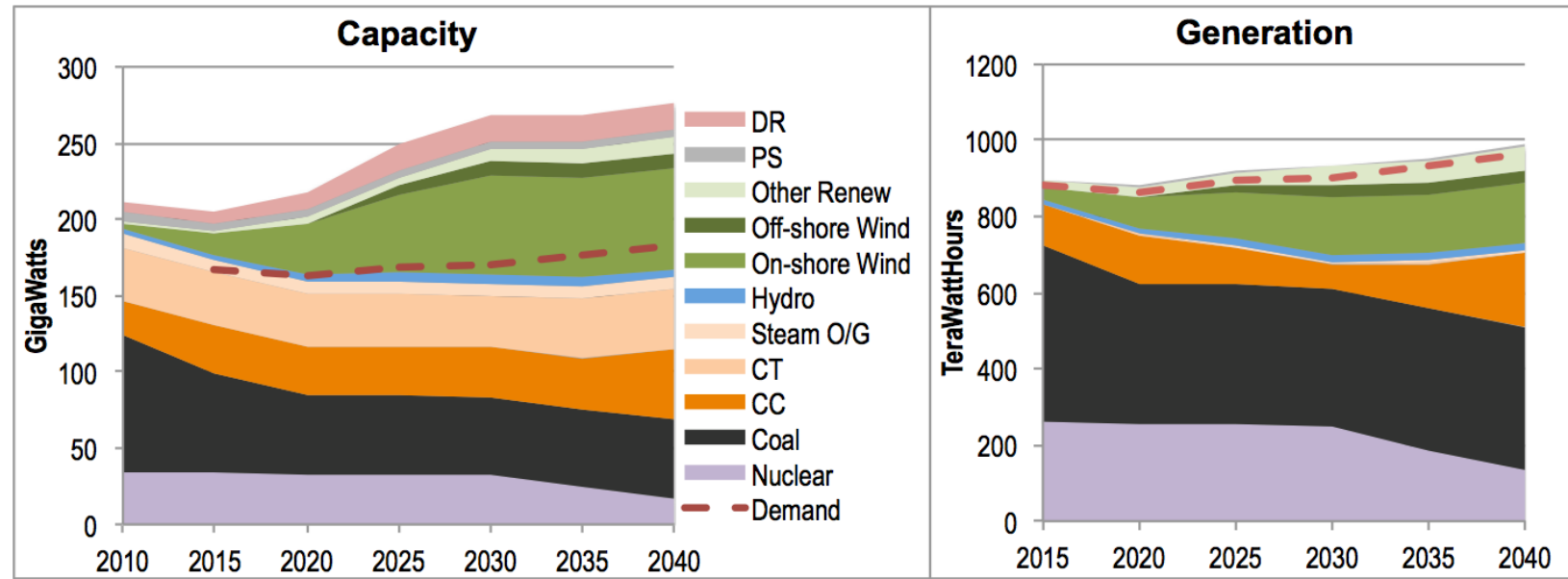

Fig. 39. RPS/R scenario Phase 1 capacity and generation for the Central Eastern Interconnection.
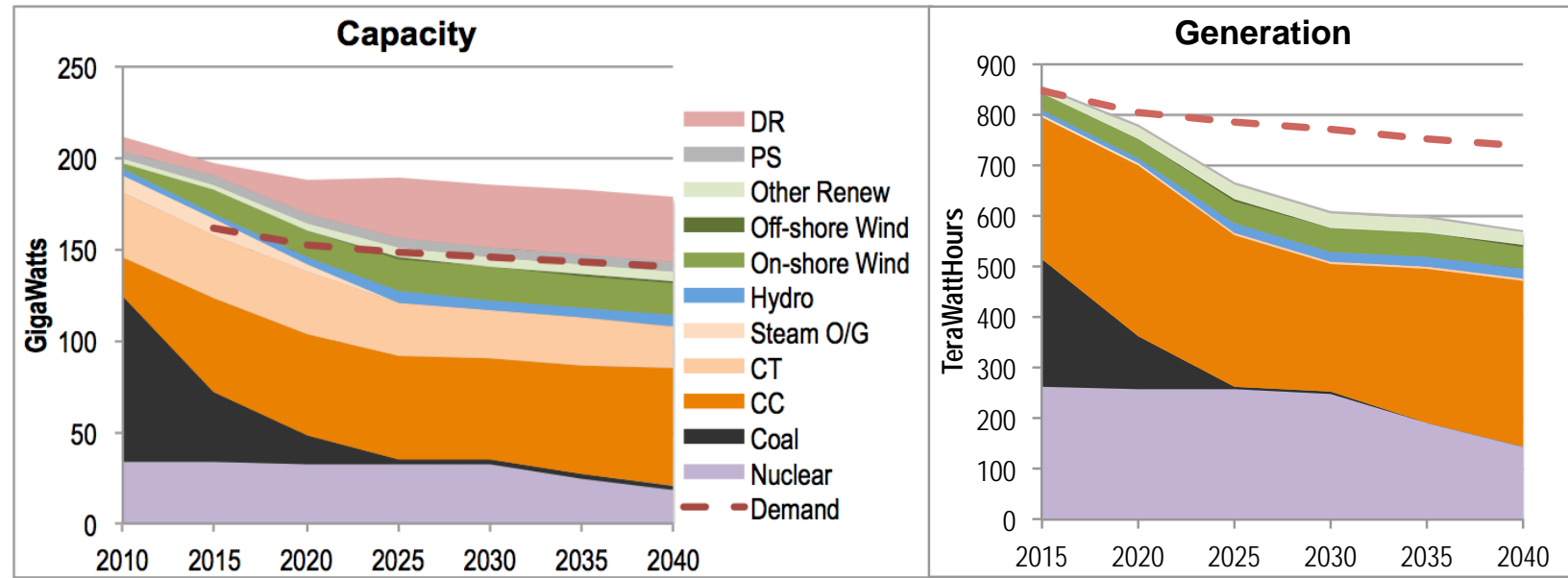

Fig. 40. $\mathrm{CO}_{2}+$ scenario Phase 1 capacity and generation for the Central Eastern Interconnection. 
Table 12. BAU Scenario Significant Changes Through 2030 in the Central Eastern Interconnection

\begin{tabular}{|c|c|c|c|}
\hline \multicolumn{2}{|c|}{ Territory: Central } & \multicolumn{2}{|c|}{ Scenario: F1S17 } \\
\hline 2015 & 2020 & 2025 & 2030 \\
\hline \multicolumn{4}{|l|}{ Significant Capacity Changes } \\
\hline $\begin{array}{l}\text { - Coal down } 26 \% \text { to } 67.2 \mathrm{GW} \\
\text { - Combined Cycle (CC) up } 42 \% \\
\text { to } 31.6 \mathrm{GW} \\
\text { - Onshore wind up } 292 \% \text { to } \\
13.4 \mathrm{GW}\end{array}$ & $\begin{array}{l}\text { - Demand response (DR) } \\
\text { up } 59 \% \text { to } 11.2 \mathrm{GW}\end{array}$ & - DR up $45 \%$ to $16.3 \mathrm{GW}$ & $\begin{array}{l}\text { - Onshore wind up } 41 \% \text { to } \\
20.1 \mathrm{GW}\end{array}$ \\
\hline \multicolumn{4}{|c|}{ Significant Generation Changes } \\
\hline & $\begin{array}{l}\text { - CC up } 29 \% \text { to } 145.9 \\
\text { TWh }\end{array}$ & & $\begin{array}{l}\text { - Onshore wind up } 34 \% \text { to } \\
\text { 48.2 TWh }\end{array}$ \\
\hline Significant Net Export Change & (negative = Imports) & & \\
\hline
\end{tabular}

Table 13. RPS/R Scenario Significant Changes Through 2030 in the Central Eastern Interconnection

\begin{tabular}{|c|c|c|c|}
\hline \multirow{2}{*}{2015 Territory: } & Central & \multicolumn{2}{|c|}{ Scenario: F6S10 } \\
\hline & 2020 & 2025 & 2030 \\
\hline \multicolumn{4}{|c|}{ Significant Capacity Changes } \\
\hline $\begin{array}{l}\text { - Coal down } 28 \% \text { to } 65.6 \\
\text { GW } \\
\text { - Combined cycle (CC) up } \\
42 \% \text { to } 31.6 \mathrm{GW} \\
\text { - Onshore wind up } 292 \% \text { to } \\
13.4 \mathrm{GW}\end{array}$ & $\begin{array}{l}\text { - Onshore wind up } 149 \% \text { to } \\
33.2 \mathrm{GW} \\
\text { - Demand response (DR) up } \\
59 \% \text { to } 11.2 \mathrm{GW}\end{array}$ & $\begin{array}{l}\text { - Onshore wind up } 55 \% \\
\text { to } 51.4 \mathrm{GW} \\
\text { - DR up } 45 \% \text { to } 16.3 \\
\text { GW }\end{array}$ & $\begin{array}{l}\text { - Onshore wind up } 27 \% \text { to } \\
65.2 \mathrm{GW}\end{array}$ \\
\hline \multicolumn{4}{|c|}{ Significant Generation Changes } \\
\hline & $\begin{array}{l}\text { - Onshore wind up } 136 \% \text { to } \\
79.1 \mathrm{TWh}\end{array}$ & $\begin{array}{l}\cdot \text { CC down } 26 \% \text { to } \\
92.9 \text { TWh } \\
\text { - Onshore wind up } 54 \% \\
\text { to } 121.9 \text { TWh }\end{array}$ & $\begin{array}{l}\cdot \text { CC down } 32 \% \text { to } \\
62.9 \text { TWh } \\
\text { - Onshore wind up } 27 \% \text { to } \\
154.5 \mathrm{TWh} \\
\text { - Other renewables up } \\
63 \% \text { to } 47.0 \mathrm{TWh}\end{array}$ \\
\hline \multicolumn{4}{|c|}{ Significant Net Export Changes (negative = Imports) } \\
\hline
\end{tabular}

Table 14. $\mathrm{CO}_{2}+$ Scenario Significant Changes Through 2030 in Central the Eastern Interconnection

\begin{tabular}{|c|c|c|c|}
\hline Territory: & $\begin{array}{r}\text { Central } \\
2020\end{array}$ & Scenario: & $\begin{array}{r}\text { F8S7 } \\
2030\end{array}$ \\
\hline \multicolumn{4}{|l|}{ Significant Capacity Changes } \\
\hline $\begin{array}{l}\text { - Coal down } 57 \% \text { to } 38.7 \mathrm{GW} \\
\text { - Combined cycle (CC) up } 132 \% \text { to } \\
51.5 \mathrm{GW} \\
\text { - Onshore wind up } 292 \% \text { to } 13.4 \mathrm{GW}\end{array}$ & $\begin{array}{l}\text { - Coal down } 60 \% \text { to } 15.3 \mathrm{GW} \\
\text { - Demand response (DR) up } \\
174 \% \text { to } 19.4 \mathrm{GW}\end{array}$ & $\begin{array}{l}\text { - Coal down } 84 \% \text { to } 2.5 \mathrm{GW} \\
\text { - DR up } 71 \% \text { to } 33.2 \mathrm{GW}\end{array}$ & \\
\hline \multicolumn{4}{|l|}{ Significant Generation Changes } \\
\hline & $\begin{array}{l}\text { - Coal down } 58 \% \text { to } \\
\text { 106.6 TWh }\end{array}$ & - Coal down $94 \%$ to $6.2 \mathrm{TWh}$ & \\
\hline \multicolumn{4}{|c|}{ Significant Net Export Changes (negative = Imports) } \\
\hline & & $\begin{array}{l}\text { - Net exports down } 13 \% \text { to }-15 \% \\
\text { of demand }\end{array}$ & \\
\hline
\end{tabular}

In the BAU scenario, coal maintains its dominant market share of production (Fig. 38). In the RPS/R scenario, wind capacity including offshore wind is expanded, and other renewables are developed as well to meet the RPS requirements (Fig. 39). Capacity declines in the $\mathrm{CO}_{2}+$ scenario, and the Central territory 
(PJM and Non-RTO Midwest) becomes a significant importer (Fig. 40). Nuclear continues to play a significant role through 2030, and CC generation is expanded as coal is reduced.

\subsection{Northeast}

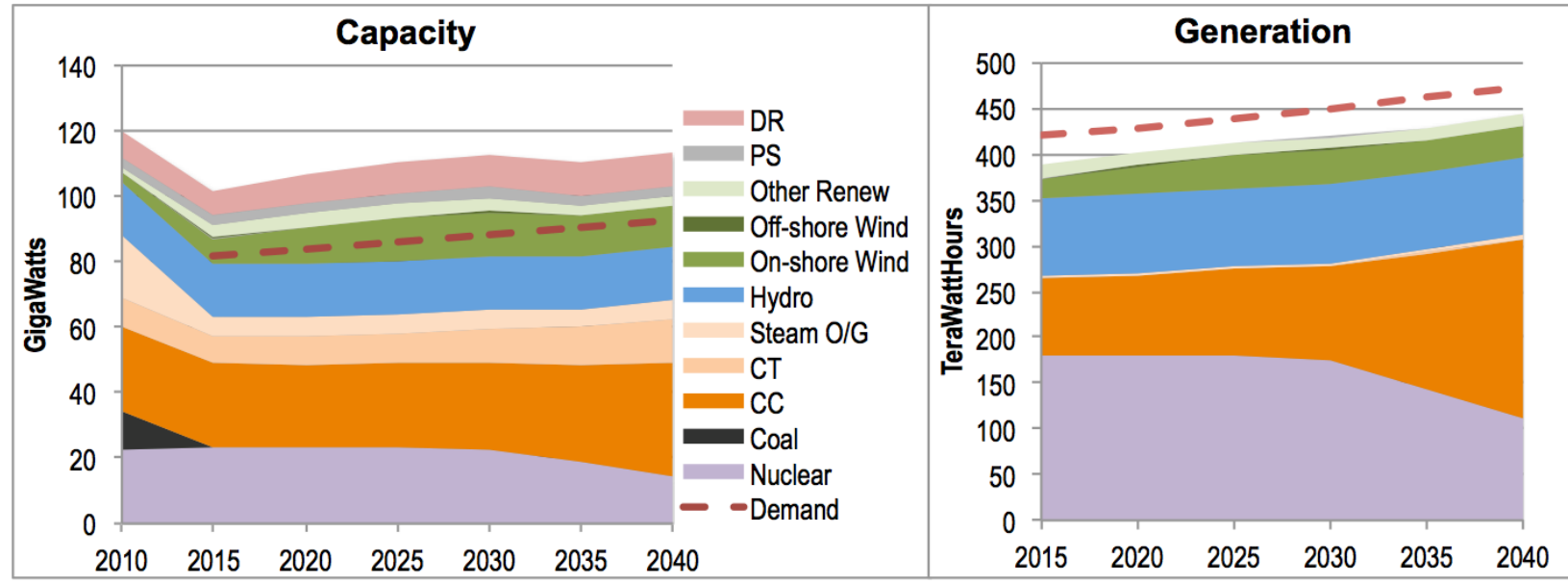

Fig. 41. BAU scenario Phase 1 capacity and generation for the Northeast Eastern Interconnection.

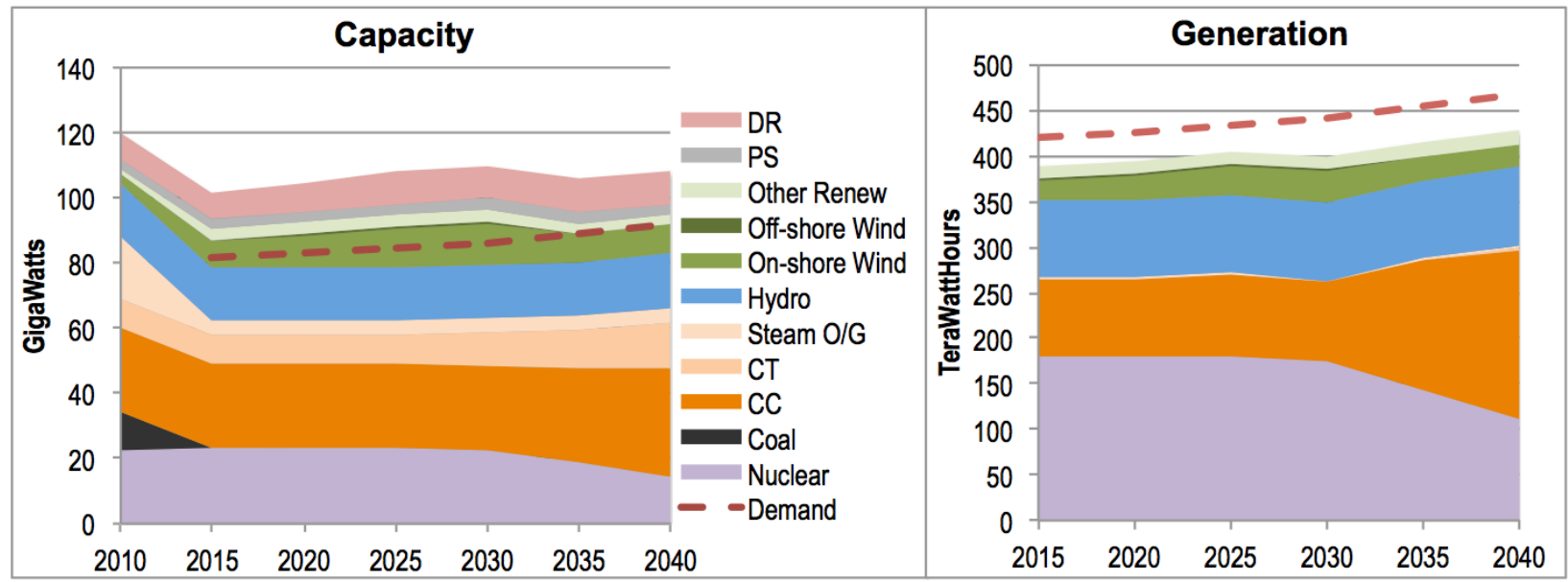

Fig. 42. RPS/R scenario Phase 1 capacity and generation for the Northeast Eastern Interconnection.

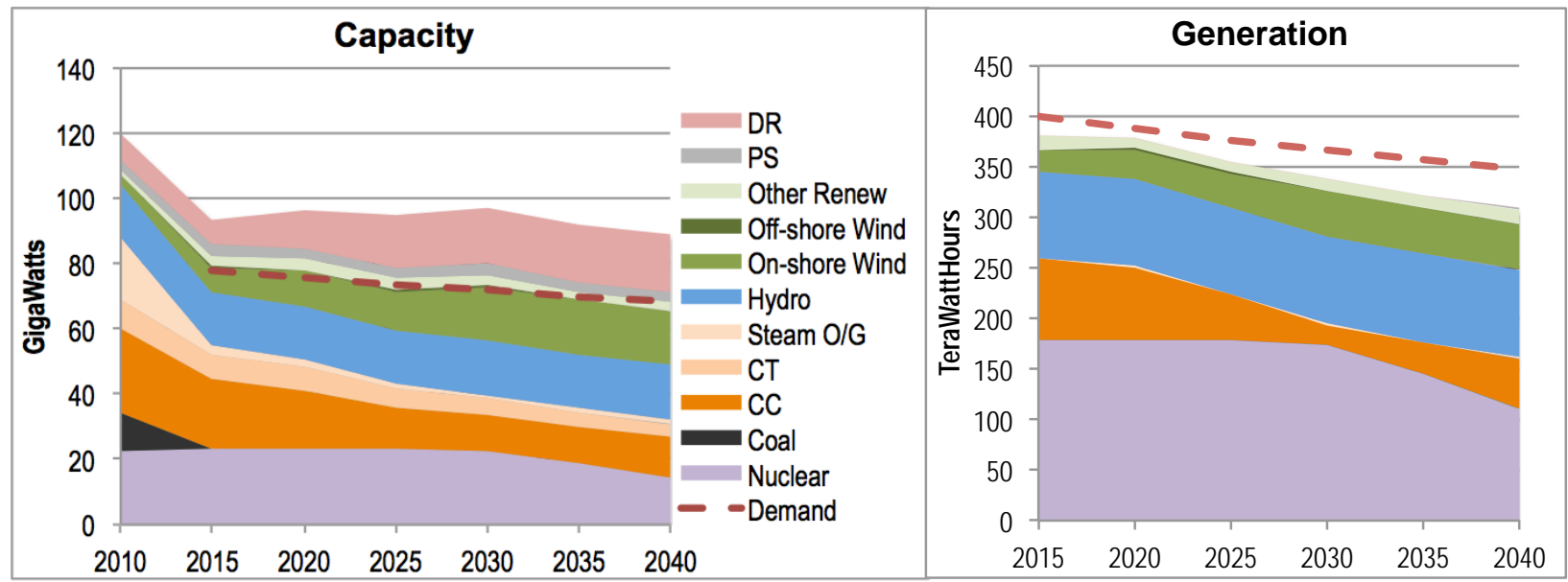

Fig. 43. $\mathrm{CO}_{2}+$ scenario Phase 1 capacity and generation for the Northeast Eastern Interconnection. 
Table 15. BAU Scenario Significant Changes Through 2030 in the Northeast Eastern Interconnection

\begin{tabular}{|c|c|c|c|}
\hline Territory: & Northeast & $\begin{array}{l}\text { Scenario: } \\
2025\end{array}$ & $\begin{array}{r}\text { F1S17 } \\
2030\end{array}$ \\
\hline \multicolumn{4}{|l|}{ Significant Capacity Changes } \\
\hline $\begin{array}{l}\text { - Coal down } 97 \% \text { to } 0.3 \mathrm{GW} \\
\text { - Steam O/G down } 71 \% \text { to } 5.7 \mathrm{GW} \\
\text { - Onshore wind up } 174 \% \text { to } 7.6 \mathrm{GW}\end{array}$ & - Onshore wind up $46 \%$ to $11.1 \mathrm{GW}$ & & \\
\hline \multicolumn{4}{|l|}{ Significant Generation Changes } \\
\hline & - Onshore wind up 51\% to $30.0 \mathrm{TWh}$ & & \\
\hline
\end{tabular}

Table 16. RPS/R Scenario Significant Changes through 2030 in Northeast Eastern Interconnection

\begin{tabular}{|c|c|c|c|}
\hline $\begin{array}{ll}2015 & \text { Territory: } \\
\end{array}$ & Northeast & $\begin{array}{l}\text { Scenario: } \\
2025 \\
\end{array}$ & $\begin{array}{r}\text { F6S10 } \\
2030 \\
\end{array}$ \\
\hline \multicolumn{4}{|l|}{ Significant Capacity Changes } \\
\hline $\begin{array}{l}\text { - Coal down } 97 \% \text { to } 0.3 \mathrm{GW} \\
\text { - Steam O/G down } 77 \% \text { to } 4.4 \mathrm{GW} \\
\text { - Onshore wind up } 174 \% \text { to } 7.6 \mathrm{GW}\end{array}$ & - Onshore wind up $27 \%$ to $9.6 \mathrm{GW}$ & & \\
\hline \multicolumn{4}{|l|}{ Significant Generation Changes } \\
\hline & - Onshore wind up 29\% to 25.7 TWh & & \\
\hline
\end{tabular}

Table 17. $\mathrm{CO}_{2}+$ Scenario Significant Changes through 2030 in Northeast Eastern Interconnection

\begin{tabular}{|c|c|c|c|}
\hline \multicolumn{2}{|c|}{ Territory: Northeast } & Scenario: & F8S7 \\
\hline \multicolumn{4}{|c|}{ Significant Capacity Changes } \\
\hline $\begin{array}{l}\text { - Coal down } 97 \% \text { to } 0.3 \\
\text { GW } \\
\text { - Steam O/G down } 85 \% \\
\text { to } 2.9 \mathrm{GW} \\
\text { - Onshore Wind up } \\
174 \% \text { to } 7.6 \mathrm{GW}\end{array}$ & $\begin{array}{l}\text { - Onshore wind up } 43 \% \text { to } \\
10.9 \mathrm{GW} \\
\cdot \text { Demand response (DR) up } \\
55 \% \text { to } 11.8 \mathrm{GW}\end{array}$ & $\begin{array}{l}\text { - Combined cycle (CC) } \\
\text { down } 31 \% \text { to } 12.6 \mathrm{GW} \\
\text { - DR up } 40 \% \text { to } 16.5 \mathrm{GW}\end{array}$ & $\begin{array}{l}\text { - Onshore wind up } 40 \% \text { to } \\
16.6 \mathrm{GW}\end{array}$ \\
\hline \multicolumn{4}{|c|}{ Significant Generation Changes } \\
\hline & $\begin{array}{l}\text { - Onshore wind up } 48 \% \text { to } \\
28.9 \mathrm{TWh}\end{array}$ & $\begin{array}{l}- \text { CC down } 38 \% \text { to } \\
43.8 \mathrm{TWh}\end{array}$ & $\begin{array}{l}\text { - CC down } 57 \% \text { to } \\
18.8 \text { TWh } \\
\text { - Onshore Wind up } 40 \% \text { to } \\
\text { 44.6 TWh }\end{array}$ \\
\hline Significant Net Export & hanges (negative = Imports) & & \\
\hline
\end{tabular}

The Northeast territory (New York, New England, and Ontario) imports power from Hydro Quebec and the Maritimes in all three scenarios, with the $\mathrm{CO}_{2}+$ scenario having the highest imports (Figs. 41-43). A large proportion of power produced is from nuclear and hydro including much from Ontario that supplies both internal demand and the other regions. 


\subsection{Southwest}
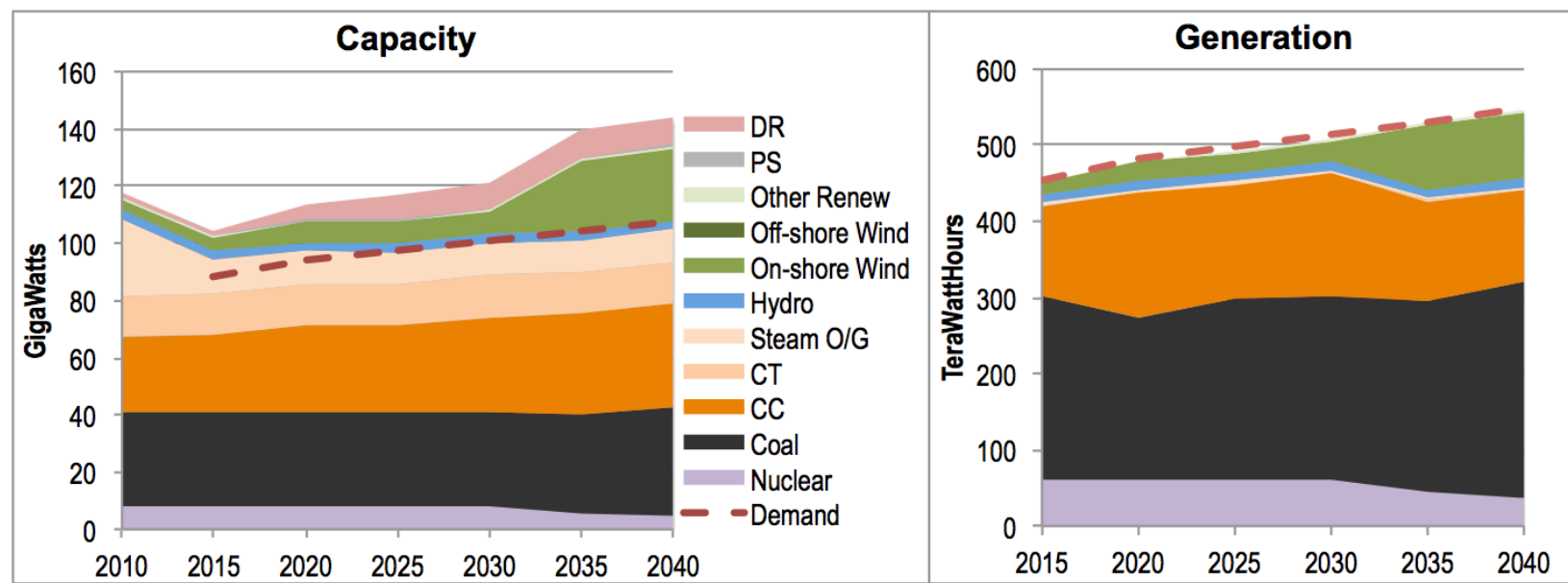

Fig. 44. BAU scenario Phase 1 capacity and generation for the Southwest Eastern Interconnection.
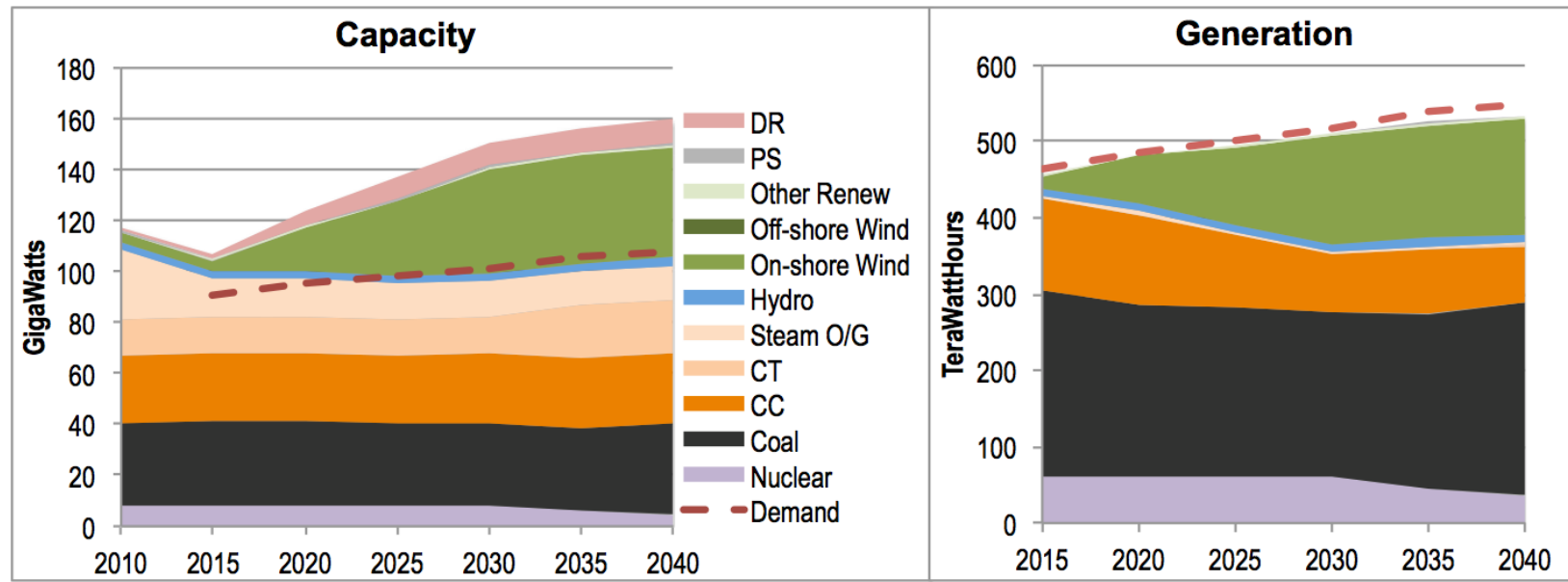

Fig. 45. RPS/R scenario Phase 1 capacity and generation for the Southwest Eastern Interconnection.
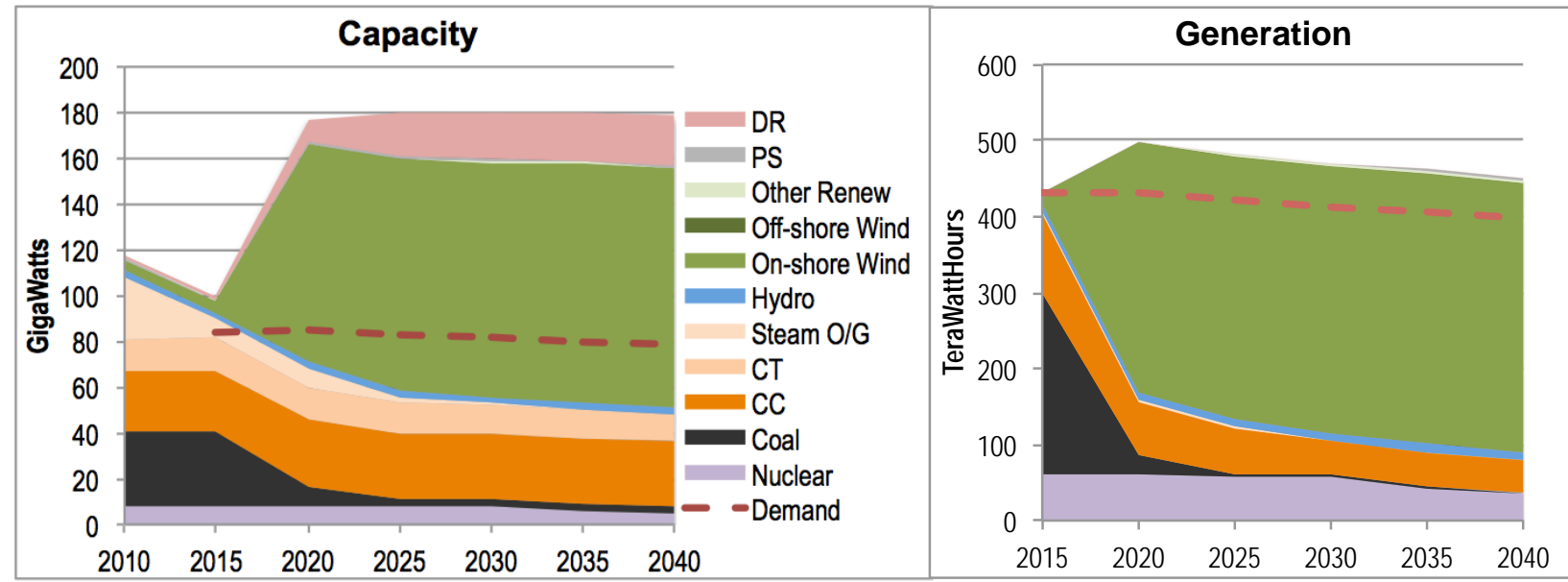

Fig. 46. $\mathrm{CO}_{2}+$ scenario Phase 1 capacity and generation for the Southwest Eastern Interconnection. 
Table 18. BAU Scenario Significant Changes Through 2030 in the Southwest Eastern Interconnection

\begin{tabular}{|c|c|c|c|}
\hline Territory: & Southwest & Scenario: & $\begin{array}{l}\text { F1S1 } \\
7 \\
2030\end{array}$ \\
\hline \multicolumn{4}{|l|}{ Significant Capacity Changes } \\
\hline $\begin{array}{l}\text { - Steam O/G down } 57 \% \text { to } 11.9 \\
\text { GW }\end{array}$ & - Onshore wind up $60 \%$ to $7.0 \mathrm{GW}$ & $\begin{array}{l}\text { - Demand response up } 76 \% \text { to } 8.8 \\
\text { GW }\end{array}$ & \\
\hline \multicolumn{4}{|l|}{ Significant Generation Changes } \\
\hline & $\begin{array}{l}\text { - Combined cycle up } 37 \% \text { to } 164.2 \\
\text { TWh } \\
\text { - Onshore wind up } 60 \% \text { to } \\
24.3 \text { TWh }\end{array}$ & & \\
\hline Significant Net Export Change & (negative = Imports) & & \\
\hline
\end{tabular}

Table 19. RPS/R Scenario Significant Changes Through 2030 in the Southwest Eastern Interconnection

\begin{tabular}{|c|c|c|c|}
\hline \multicolumn{2}{|c|}{ Territory: Southwest } & \multicolumn{2}{|c|}{ Scenario: $\quad$ F6S10 } \\
\hline 2015 & 2020 & 2025 & 2030 \\
\hline \multicolumn{4}{|c|}{ Significant Capacity Changes } \\
\hline $\begin{array}{l}\text { - Steam O/G down } 46 \% \\
\text { to } 14.8 \mathrm{GW}\end{array}$ & $\begin{array}{l}\text { - Onshore wind up } 303 \% \text { to } \\
17.8 \mathrm{GW}\end{array}$ & $\begin{array}{l}\text { - Onshore wind up } 65 \% \text { to } \\
29.3 \mathrm{GW} \\
\text { - Demand response up } 76 \% \\
\text { to } 8.8 \mathrm{GW}\end{array}$ & $\begin{array}{l}\text { - Onshore wind up } 40 \% \text { to } \\
40.9 \mathrm{GW}\end{array}$ \\
\hline \multicolumn{4}{|c|}{ Significant Generation Changes } \\
\hline & $\begin{array}{l}\text { - Onshore wind up } 305 \% \text { to } \\
\text { 61.4 TWh }\end{array}$ & $\begin{array}{l}\text { • Onshore wind up } 64 \% \text { to } \\
\text { 101.0 TWh }\end{array}$ & $\begin{array}{l}\text { - Onshore wind up } 40 \% \text { to } \\
\text { 141.1 TWh }\end{array}$ \\
\hline
\end{tabular}

Table 20. $\mathrm{CO}_{2}+$ Scenario Significant Changes through 2030 in the Southwest Eastern Interconnection

\begin{tabular}{|c|c|c|c|}
\hline Territory: & Southwest & $\begin{array}{l}\text { Scenario: } \\
2025\end{array}$ & $\begin{array}{r}\text { F8S7 } \\
2030\end{array}$ \\
\hline \multicolumn{4}{|l|}{ Significant Capacity Changes } \\
\hline $\begin{array}{l}\text { - Steam O/G down } 69 \% \text { to } \\
\text { 8.4 GW }\end{array}$ & $\begin{array}{l}\text { - Coal down } 74 \% \text { to } 8.6 \mathrm{GW} \\
\text { - Onshore wind up } 2,048 \% \text { to } 94.6 \mathrm{GW} \\
\text { - DR up } 615 \% \text { to } 10.2 \mathrm{GW}\end{array}$ & $\begin{array}{l}\text { - Demand response (DR) } \\
\text { up } 92 \% \text { to } 19.7 \mathrm{GW}\end{array}$ & \\
\hline \multicolumn{4}{|l|}{ Significant Generation Changes } \\
\hline & $\begin{array}{l}\text { - Coal down } 89 \% \text { to } 26.7 \text { TWh } \\
\text { - Combined cycle down } 33 \% \text { to } \\
\text { 68.9 TWh } \\
\text { - Onshore wind up 2,060\% to } 327.3 \mathrm{TWh}\end{array}$ & $\begin{array}{l}\text { - Coal down } 88 \% \text { to } \\
\text { 3.3 TWh }\end{array}$ & \\
\hline \multicolumn{4}{|c|}{ Significant Net Export Changes (negative = Imports) } \\
\hline & - Net exports up $15 \%$ to $15 \%$ of demand & & \\
\hline
\end{tabular}

The Southwest territory (Nebraska, SPP, and Entergy) has a large increase in wind capacity in the $\mathrm{CO}_{2}+$ scenario in 2020, sooner than the Northwest territory but with little further growth after that point (Fig. 46). In the RPS/R scenario the growth is more gradual over the study period (Fig. 45), while in the BAU scenario, wind capacity is relatively small until 2035 (Fig. 44). Coal and CC provide the bulk of generation in the BAU and RPS/R scenarios. 


\subsection{Southeast}
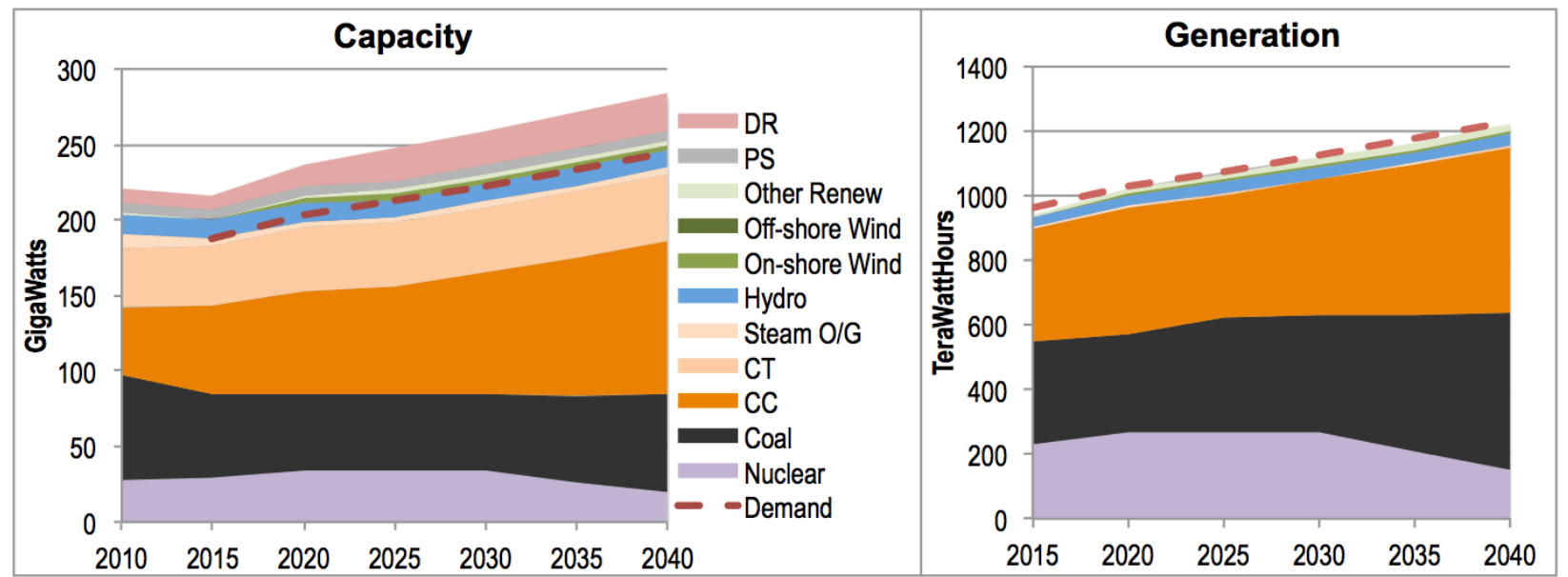

Fig. 47. BAU scenario Phase 1 capacity and generation for the Southeast Eastern Interconnection.
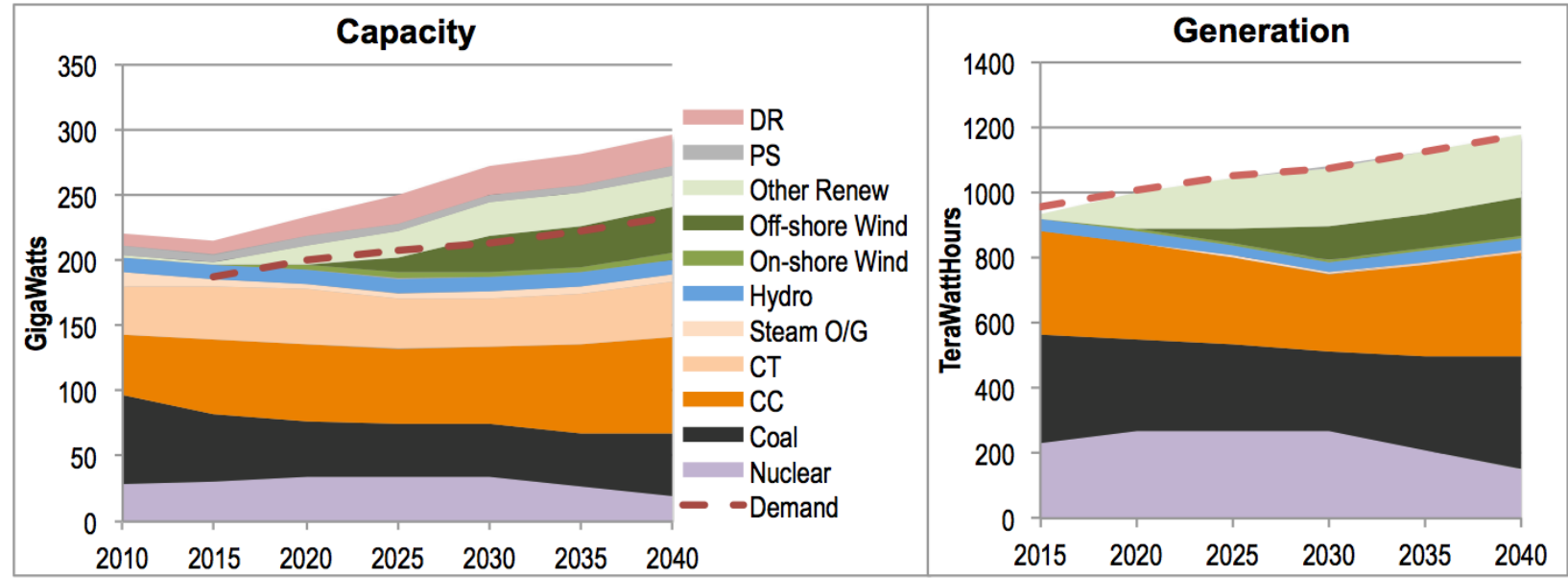

Fig. 48. RPS/R scenario Phase 1 capacity and generation for the Southeast Eastern Interconnection.
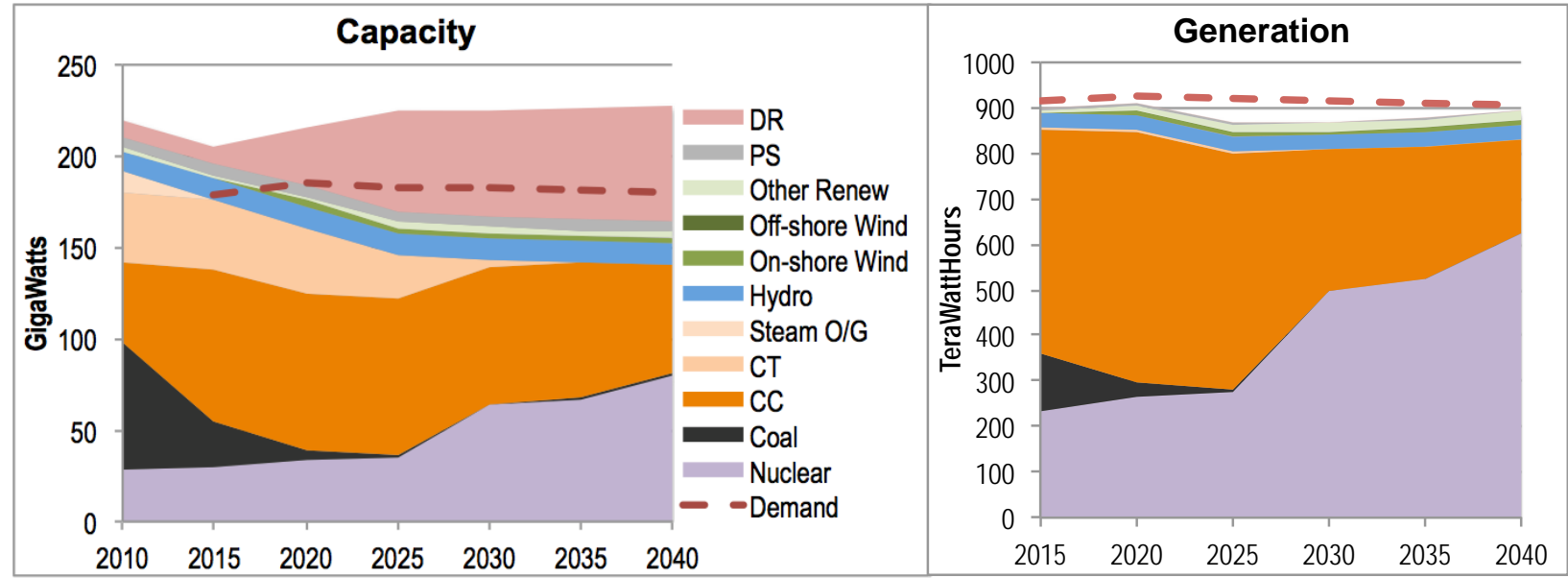

Fig. 49. $\mathrm{CO}_{2}+$ scenario Phase 1 capacity and generation for the Southeast Eastern Interconnection. 
Table 21. BAU Scenario Significant Changes Through 2030 in the Southeast Eastern Interconnection

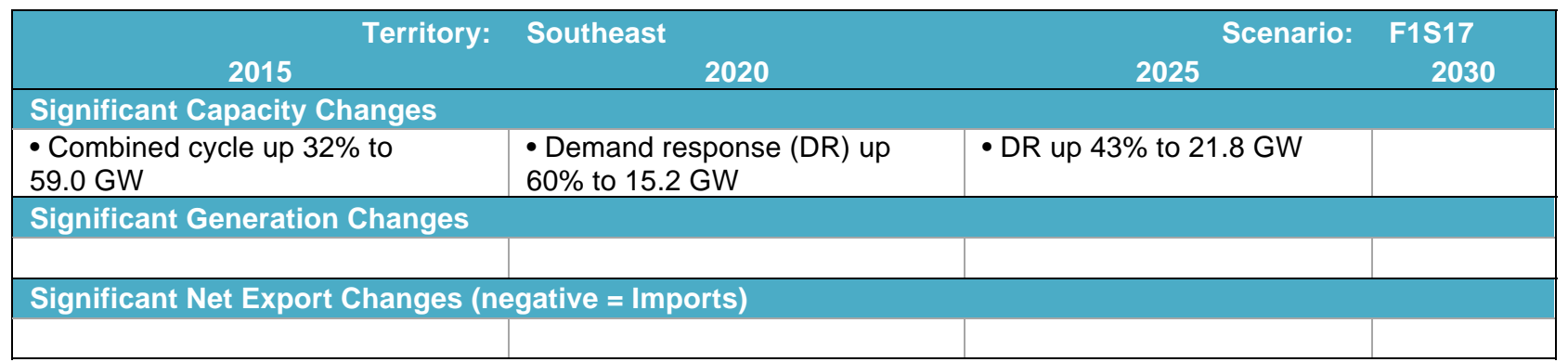

Table 22. RPS/R Scenario Significant Changes Through 2030 in the Southeast Eastern Interconnection

\begin{tabular}{|c|c|c|c|}
\hline $\begin{array}{l}\text { Territory: } \\
2015\end{array}$ & Southeast & Scenario: & F6S10 \\
\hline \multicolumn{4}{|c|}{ Significant Capacity Changes } \\
\hline & $\begin{array}{l}\text { - Other renewables up } 698 \% \text { to } \\
14.9 \mathrm{GW} \\
\text { - Demand response (DR) up } \\
60 \% \text { to } 15.2 \mathrm{GW} \\
\end{array}$ & $\begin{array}{l}\text { - Other renewables up } 40 \% \text { to } \\
21.0 \mathrm{GW} \\
\text { - DR up } 43 \% \text { to } 21.8 \mathrm{GW}\end{array}$ & $\begin{array}{l}\text { - Offshore wind up } 150 \% \text { to } 28.5 \\
\text { GW }\end{array}$ \\
\hline \multicolumn{4}{|c|}{ Significant Generation Changes } \\
\hline & $\begin{array}{l}\text { - Other renewables up } 725 \% \text { to } \\
\text { 110.3 TWh }\end{array}$ & $\begin{array}{l}\text { - Other renewables up } 41 \% \text { to } \\
155.4 \mathrm{TWh}\end{array}$ & $\begin{array}{l}\text { - Offshore wind up } 150 \% \text { to } 98.7 \\
\text { TWh }\end{array}$ \\
\hline
\end{tabular}

Table 23. $\mathrm{CO}_{2}+$ Scenario Significant Changes Through 2030 in the Southeast Eastern Interconnection

\begin{tabular}{|c|c|c|c|}
\hline \multicolumn{2}{|c|}{ Territory: Southeast } & \multicolumn{2}{|c|}{ Scenario: $\quad$ F8S7 } \\
\hline 2015 & 2020 & 2025 & 2030 \\
\hline \multicolumn{4}{|c|}{ Significant Capacity Changes } \\
\hline $\begin{array}{l}\text { - Coal down } 64 \% \text { to } 25.3 \\
\text { GW } \\
\text { - Combined Cycle (CC) up } \\
85 \% \text { to } 82.6 \mathrm{GW}\end{array}$ & $\begin{array}{l}\text { - Coal down } 80 \% \text { to } 5.0 \mathrm{GW} \\
\text { - Demand Response (DR) up } \\
230 \% \text { to } 31.2 \mathrm{GW}\end{array}$ & $\begin{array}{l}\text { - Combustion Turbine (CT) } \\
\text { down } 32 \% \text { to } 24.5 \mathrm{GW} \\
\text { - DR up } 77 \% \text { to } 55.3 \mathrm{GW}\end{array}$ & $\begin{array}{l}\text { - Nuclear up } 79 \% \\
\text { to } 63.6 \mathrm{GW} \\
\text { - CT down } 86 \% \text { to } \\
3.5 \mathrm{GW}\end{array}$ \\
\hline \multicolumn{4}{|c|}{ Significant Generation Changes } \\
\hline & $\begin{array}{l}\text { - Coal down } 78 \% \text { to } \\
27.6 \mathrm{TWh}\end{array}$ & & $\begin{array}{l}\text { - Nuclear up } 79 \% \\
\text { to } 495.1 \mathrm{TWh} \\
\text { - CC down } 40 \% \text { to } \\
311.6 \mathrm{TWh}\end{array}$ \\
\hline Significant Net Export Chi & nges (negative = Imports) & & \\
\hline
\end{tabular}

In the $\mathrm{CO}_{2}+$ scenario, the Southeast territory (TVA, SOCO, VACAR, and Florida) has few renewable resources but instead relies on nuclear and $\mathrm{CC}$ for the bulk of its capacity (Fig. 49). Nuclear expands greatly between 2025 and 2030, most notably in Florida. An interesting note is that regional capacity is insufficient for the region except for significant employment of DR. This gets reflected in the marginal prices during peak times in both Phase 1 and Phase 2. Offshore wind and other renewables are aggressively developed in the RPS/R scenario (Fig. 48), while the BAU scenario continues its reliance on nuclear, coal, and CC (Fig. 47). 



\section{TOPIC 3: INTEGRATED COST COMPARISON BETWEEN SCENARIOS}

Costs were determined in the study through a variety of means. In Phase 1, most of the major costs were calculated within the MRN-NEEM model. In addition, other costs were calculated by either the EIPC or by working groups of the SSC. In Phase 2, the MAPS model calculated fewer categories of costs. In some instances the missing values were recalculated based on Phase 2 analysis, while in others, the Phase 1 results were simply transferred over.

Over the course of the study, costs were calculated in three formats: annual costs (either for every 5 years in Phase 1 or just 2030 in Phase 2); one-time costs over the course of the study period, such as construction costs; or levelized capital costs that provided the annual cost to recover the construction cost plus interest and other associated costs. Besides these, sub-annual or hourly costs were calculated in some circumstances, but these can be summed to annual costs. The list of costs, their sources, and formats are in Table 24.

Table 24. Types of Cost Outputs with Source and Format

\begin{tabular}{|c|c|c|c|c|}
\hline \multirow[t]{2}{*}{ Cost } & \multicolumn{2}{|c|}{ Phase 1} & \multicolumn{2}{|c|}{ Phase 2} \\
\hline & Source & Format & Source & Format \\
\hline Fuel & MRN-NEEM & Annual every 5 years & MAPS & 2030 cost \\
\hline Variable Oper. \& Maint. & MRN-NEEM & Annual every 5 years & MAPS & 2030 cost \\
\hline Fixed Oper. \& Maint. & MRN-NEEM & Annual every 5 years & $\begin{array}{l}\text { Phase } 1 \\
\text { adjusted }\end{array}$ & 2030 cost \\
\hline Capital-Generation & MRN-NEEM & $\begin{array}{l}\text { Levelized every } \\
5 \text { years }\end{array}$ & EIPC & $\begin{array}{c}\text { One-time } \\
\text { construction cost }\end{array}$ \\
\hline Capital-Transmission & EIPC & $\begin{array}{c}\text { One-time construction } \\
\text { cost }\end{array}$ & EIPC & $\begin{array}{c}\text { One-time } \\
\text { construction cost }\end{array}$ \\
\hline Capital_Nuclear Uprates & EIPC & $\begin{array}{c}\text { One-time construction } \\
\text { cost }\end{array}$ & EIPC & $\begin{array}{c}\text { One-time } \\
\text { construction cost }\end{array}$ \\
\hline Capital-Pollution controls & MRN-NEEM & $\begin{array}{c}\text { Levelized every } \\
5 \text { years } \\
\end{array}$ & EIPC & $\begin{array}{c}\text { One-time } \\
\text { construction cost }\end{array}$ \\
\hline Distributed Photovoltaic & SSC & Annual and levelized & Phase 1 & 2030 cost \\
\hline Energy Efficiency & SSC & Annual and levelized & Phase 1 & 2030 cost \\
\hline Demand Response & SSC & Annual and levelized & Phase 1 & 2030 cost \\
\hline Variable Generation Cost & SSC/MRN-NEEM & Annual and levelized & SSC / MAPS & 2030 cost \\
\hline Thermal Integration Cost & SSC/MRN-NEEM & Annual and levelized & SSC / MAPS & 2030 cost \\
\hline Net Imports & MRN-NEEM & Annual every 5 years & MAPS/Phase 1 & 2030 cost \\
\hline
\end{tabular}

Phase 1 costs can be put on the same basis and summed by using the annual costs, treating the levelized costs as the cost to be paid each year, and levelizing the remaining construction costs to provide an annualized amount. Costs between the 5-year increments can be interpolated as well to create an annual stream of costs. These were then discounted to create the net present value of the costs for each scenario. This method was used in reporting the Phase 1 results (EIPC 2011).

Phase 2 costs are largely either costs only for 2030 or one-time construction costs without interest, otherwise known as overnight construction costs. It is possible to scale the annual costs in other years from Phase 1 based on the relationship between the 2030 costs from the two phases for each scenario. The study conducted by Synapse, Inc. (Fagan et al. 2013) uses this method to compare the relative costs of the three scenarios for the entire EI, taking into account that emissions costs assumptions and kilowatt-hour outputs are different in each.

It would be difficult, however, to apply a consistent scaling method if looking at regional costs because regional capacity, generation, technologies, and transfers were different between the two phases. For that 
reason, the analysis below focuses simply on integrating the costs in the year 2030 for each region using Phase 2 results. Comparisons to Phase 1 costs in 2030 are in Figs. 26-28.

Fixed operation and maintenance (O\&M) costs from Phase 1 were adjusted based on the capacity changes in Phase 2 for each technology. To convert the overnight construction costs to costs in 2030, we applied an average capital recovery factor (or fixed cost recovery factor) of $11.5 \%$ to the construction costs. Actual capital recovery factors as used in Phase 1 [Table 12 of the Input Assumptions (CRA 2010)] varied from $11.2 \%$ for nuclear plants, $11.3 \%$ for CC, and $11.8 \%$ for most other technologies. (Coal was set at $10.5 \%$ but represents little or no portion of new construction.) Because total generating construction costs were not disaggregated by type and no factor was set for transmission costs, a single representative number seemed most fitting. This value may understate the capital cost for renewables while overstating that for traditional technologies and transmission.

Net import costs represent the cost of imports into a region minus the revenues from sales out of the region. The costs are based on the sales amount and marginal cost at the time of generation. (MRNNEEM also applies transfer and wheeling charges in the Phase 1 calculations.) In Phase 2, the hourly locational marginal prices (LMPs) were reported for 154 balancing areas (BAs) spread across the NEEM regions. These were averaged on a weighted basis across each NEEM region to determine regional marginal prices. Any transfers between regions were costed at the price in the importing region. For example, if region A during a specific hour had a marginal price of $\$ 50 / \mathrm{MWh}$ and the neighboring region $\mathrm{B}$ had a price of $\$ 60 / \mathrm{MWh}$, the sales into region B would be priced at $\$ 60 / \mathrm{MWh}$. This calculation is somewhat simplistic as it does not take into account bilateral trades that may be priced at a fixed cost, but rather treats all sales as a wholesale market activity.

For a given NEEM region that exports electricity, the cost of that export would be included in the fuel, variable O\&M, etc. costs, but the revenue from those exports would offset those costs. Similarly, if a region imported power, it would be costed at its LMP. The final sum of costs including the net import cost will give a better representation of the total cost of power for that region.

Hydro Quebec power was modeled differently than other regions in Phase 1 and 2. In Phase 1, the import capability to different regions was modeled as pseudo-units. The resulting imports were priced based on LMPs. For Phase 2, the interchange flows were taken from Phase 1 and applied as generation sources in the various regions. To cost this power, we applied the average cost of the Hydro Quebec power from Phase 1 to the generation (which essentially matched Phase 1) so both phases had the same costs. Exports and imports to WECC and ERCOT were calculated within MRN-NEEM and MAPS. Unit costs associated with them were determined from NEEM results in Phase 1 and applied to Phase 2.

Tables 25-27 show the costs for each major territory and category in the three scenarios. Note that these do not include major costs that are common to all cases such as capital on existing assets, SSI, and base levels of DG. DR and EE expenses are those specified for 2030 and so do not include earlier years' values. Only the average values for categories that had high/low ranges are shown. 
Table 25. Phase 2 Costs in 2030 for the BAU Scenario (\$Billion)

\begin{tabular}{|lrrrrrr|} 
& \multicolumn{1}{l}{ EI } & Northwest & Central & Northeast & Southwest & Southeast \\
\hline Fuel & 85.1 & 12.6 & 19.1 & 6.5 & 12.3 & 34.5 \\
\hline $\begin{array}{l}\text { Variable Operation and Maintenance } \\
\text { (O\&M) }\end{array}$ & 18.4 & 4.1 & 4.7 & 0.9 & 3.4 & 5.4 \\
\hline Fixed O\&M & & & & & & \\
\hline Levelized Capital-Generation & 50.3 & 9.5 & 14.8 & 5.7 & 6.6 & 13.7 \\
\hline Levelized Capital-Transmission & 27.9 & 4.5 & 8.0 & 8.8 & 1.7 & 4.9 \\
\hline Levelized Capital-Other & 1.8 & 0.4 & 0.4 & 0.5 & 0.4 & 0.1 \\
\hline Emissions & 3.1 & 0.7 & 1.0 & 0.1 & 0.5 & 0.8 \\
\hline Distributed Photovoltaic & 0.2 & - & 0.1 & 0.1 & - & - \\
\hline $\begin{array}{l}\text { Energy Efficiency + Demand } \\
\text { Response }\end{array}$ & - & - & - & - & - & - \\
\hline Variable Generation Penalty & 1.5 & 0.2 & 0.4 & 0.6 & 0.0 & 0.2 \\
\hline Large Thermal Penalty & 1.1 & 0.4 & 0.3 & 0.2 & 0.1 & 0.0 \\
\hline Net Imports & 6.2 & 1.0 & 1.7 & 0.6 & 0.9 & 2.1 \\
\hline Total & 1.6 & $(0.2)$ & 0.5 & 0.9 & 0.1 & 0.2 \\
\hline
\end{tabular}

Table 26. Phase 2 Costs in 2030 for the RPS/R Scenario (\$Billion)

\begin{tabular}{|lrrrrrr|} 
& El & Northwest & Central & Northeast & Southwest & Southeast \\
\hline Fuel & 73.8 & 8.5 & 15.4 & 5.6 & 7.7 & 36.6 \\
\hline $\begin{array}{l}\text { Variable Operation and Maintenance } \\
\text { (O\&M) }\end{array}$ & 15.5 & 3.4 & 3.9 & 0.8 & 2.7 & 4.7 \\
\hline Fixed O\&M & & & & & & \\
\hline Levelized Capital-Generation & 54.0 & 9.6 & 15.7 & 5.5 & 7.3 & 15.9 \\
\hline Levelized Capital-Transmission & 78.1 & 11.3 & 24.0 & 8.6 & 10.4 & 23.9 \\
\hline Levelized Capital-Other & 7.8 & 1.2 & 1.9 & 0.5 & 3.3 & 0.8 \\
\hline Emissions & 2.9 & 0.7 & 0.8 & 0.1 & 0.5 & 0.7 \\
\hline Distributed Photovoltaic & 0.1 & - & 0.1 & 0.1 & - & - \\
\hline $\begin{array}{l}\text { Energy Efficiency + Demand } \\
\text { Response }\end{array}$ & - & - & - & - & - & - \\
\hline Variable Generation Penalty & 1.5 & 0.2 & 0.4 & 0.6 & 0.0 & 0.2 \\
\hline Large Thermal Penalty & 2.6 & 0.6 & 0.9 & 0.2 & 0.6 & 0.3 \\
\hline Net Imports & 5.0 & 0.8 & 1.4 & 0.5 & 0.7 & 1.6 \\
\hline Total & 1.4 & 1.3 & $(1.6)$ & 1.3 & 0.3 & 0.1 \\
\hline
\end{tabular}

Table 27. Phase 2 Costs in 2030 for the $\mathrm{CO}_{2}+$ Scenario (\$Billion)

\begin{tabular}{|lrrrrrr|} 
& \multicolumn{1}{c}{ El } & Northwest & Central & Northeast & Southwest & Southeast \\
\hline Fuel & 40.8 & 5.2 & 12.2 & 3.0 & 3.5 & 16.8 \\
\hline $\begin{array}{l}\text { Variable Operation and Maintenance } \\
\text { (O\&M) }\end{array}$ & 6.4 & 1.0 & 1.8 & 0.7 & 0.7 & 2.2 \\
\hline Fixed O\&M & 36.6 & 7.3 & 8.5 & 4.9 & 6.1 & 9.9 \\
\hline Levelized Capital-Generation & 99.8 & 33.6 & 9.9 & 9.5 & 26.0 & 20.9 \\
\hline Levelized Capital-Transmission & 11.3 & 4.0 & 2.3 & 1.0 & 3.2 & 0.9 \\
\hline Levelized Capital-Other & 1.3 & 0.3 & 0.4 & 0.1 & 0.2 & 0.2 \\
\hline Emissions & 45.3 & 7.6 & 15.0 & 2.0 & 5.1 & 15.7 \\
\hline Distributed Photovoltaic & 13.9 & 3.2 & 2.9 & 1.8 & 3.2 & 2.8 \\
\hline $\begin{array}{l}\text { Energy Efficiency + Demand } \\
\text { Response }\end{array}$ & 8.9 & 1.7 & 2.3 & 1.3 & 1.1 & 2.5 \\
\hline Variable Generation Penalty & 2.9 & 1.2 & 0.2 & 0.2 & 1.2 & 0.0 \\
\hline Large Thermal Penalty & 3.8 & 0.4 & 1.1 & 0.4 & 0.3 & 1.6 \\
\hline Net Imports & 3.8 & $(3.6)$ & 6.8 & 1.8 & $(3.8)$ & 2.6 \\
\hline Total & 275.0 & 61.9 & 63.4 & 26.7 & 46.8 & 76.2 \\
\hline
\end{tabular}


In all scenarios, transmission capital costs represent at most $10 \%$ of the overall capital cost and less than $5 \%$ of total costs. It is likely that in those scenarios with high levels of curtailment and/or DR, additional transmission capacity would provide opportunities for lower cost power to displace high cost power. This is examined more thoroughly in Topic 7.

Total cost may be a better comparison between scenarios than cost per kilowatt-hour because demands and generation differ but the energy services are essentially the same. EE, DG, price elasticity, etc. all influence the amount of energy generated, thereby influencing the denominator. On the other hand, cost per kilowatt-hour with regional imports and exports accounted for may provide an additional perspective on the possible cost for electricity to consumers under the different scenarios. Generation costs per megawatt-hour are shown in Figs. 29-31 for each region. Figures 50-55 show the components based on demand, in billion dollars for each territory (using the data from Tables 25-27), and Figures 56 and 57 show the costs per unit of demand.

Figure 50 presents the cost summation for the entire EI in 2030. Fuel costs are highest in the BAU scenario, while levelized capital costs increase drastically in the other scenarios. Generator capital cost far outweighs the impact of transmission and other capital costs. On a straight comparison, the $\mathrm{CO}_{2}+$ scenario has the highest cost. However, from a societal perspective, the picture is complex. Much of the top categories of costs are generally not born by the electricity sector in that EE and distributed photovoltaic (PV) costs are largely borne by end users. Large $\mathrm{CO}_{2}$ emissions costs are only accounted for in the $\mathrm{CO}_{2}+$ scenario, and customers do not purchase a physical resource unique to this scenario but rather the legal right to emit $\mathrm{CO}_{2}$. Either the funds can be considered unencumbered and other societal costs (e.g., taxes) could be

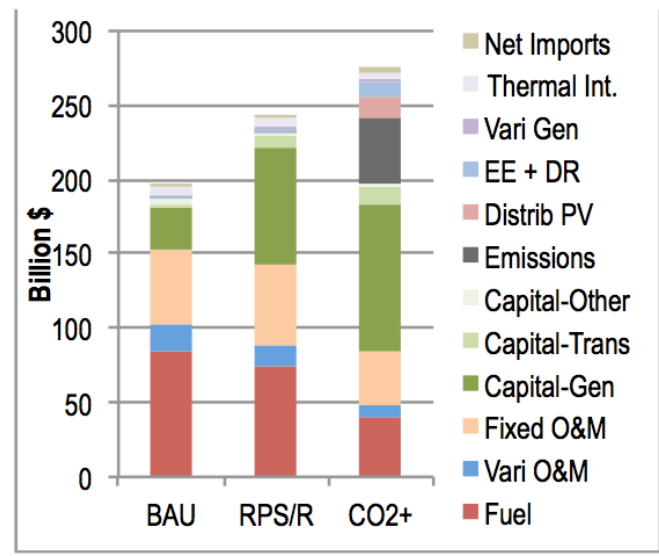

Fig. 50. Phase 2 total costs for the Eastern Interconnection in 2030.

reduced, or they represent a damage cost that should be borne by $\mathrm{CO}_{2}$ emissions in the other scenarios but is not. Nevertheless, the various cost impacts do serve to raise the price of electricity in this scenario thereby driving demand lower.

The following figures present the cost information for each of the major territories of the EI as defined in Table 1. More detailed regional information is presented in Appendix A.

The Northwest territory (MISO + MAPP) develops a large amount of wind capacity in the $\mathrm{CO}_{2}+$ scenario, almost 100 GW more than in the BAU scenario. The utilities, RTOs, etc. in the territory also build $15 \mathrm{GW}$ more CC plants. Together, these lead to the large levelized capital cost for generating plants shown in Fig. 51. Some export revenue is returned to the region to offset some of the costs, but in Phase 2 (shown) more of the generation remained in the region than during Phase 1. Emissions costs are $11 \%$ of total costs in the $\mathrm{CO}_{2}+$ scenario. The RPS/R scenario has some increase in capital costs due to wind and $\mathrm{CC}$ build-out but much less than the $\mathrm{CO}_{2}+$ scenario. With the local preference for renewable resources and no $\mathrm{CO}_{2}$ cost, new capacity is spread to other regions and $50 \mathrm{GW}$ of coal capacity is left online. Rather than exports, the territory as a

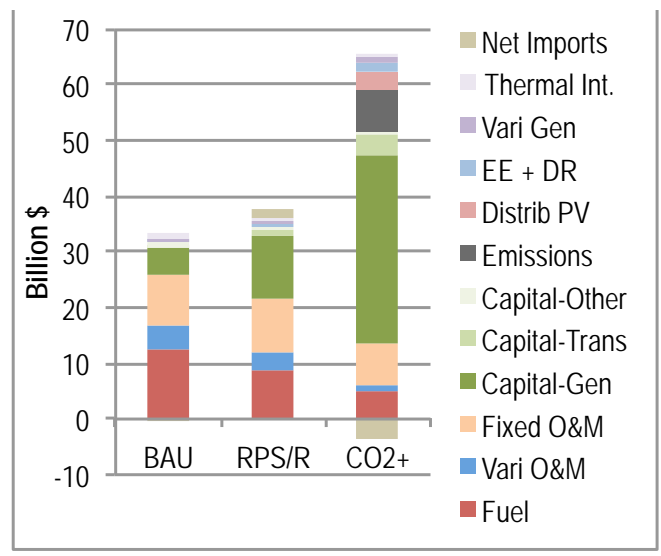

Fig. 51. Phase 2 total costs for the Northwest Eastern Interconnection in 2030. 
whole imports a small amount of power. The BAU scenario has much lower capital costs, but the highest fuel cost. Coal and $\mathrm{CC}$ production are highest in this scenario. The corresponding graphs for each region and territory are included in Appendix A.

The Central territory (PJM and Non-RTO Midwest) has slightly lower costs in the $\mathrm{CO}_{2}+$ scenario than the RPS/R scenario (Fig. 52). It imports power from several regions in the $\mathrm{CO}_{2}+$ scenario, most notably the Northwest and Southwest through new HVDC lines. This territory's emissions costs are highest of all at $24 \%$ of total costs. With lower production (due to both lower demand and imports) operating and fuel costs are reduced. In the RPS/R scenario capital costs are much higher as new renewable capacity is constructed within the region to achieve the renewable portfolio standard. A small amount of generation is exported. The BAU scenario has the highest fuel and other operating costs but much lower capital costs and no $\mathrm{CO}_{2}$ emissions cost.

The Northeast territory (New York, New England, and Ontario) has relatively similar costs in all three scenarios (Fig. 53). The $\mathrm{CO}_{2}+$ scenario has lower fuel costs but higher capital and emissions costs. The territory also imports more power from Hydro Quebec in the $\mathrm{CO}_{2}+$ scenario. The RPS/R scenario has the lowest overall cost with reductions in most categories. However, imports are $\$ 400$ million higher. Within the territory, there is a great deal of difference in generation and cost between regions. NYISO A-F, NYISO G-I, and IESO are all net exporters, while NYISO J-K and NEISO are net importers. Hydro Quebec power flows to IESO, NYISO A-F, and NEISO, but much of it then passes on to the other two NYISO regions. NYISO J-K gets $58 \%$ to $74 \%$ of its demand from imports, comprising $45 \%$ to $55 \%$ of the total cost. These results can be seen in Appendix A.

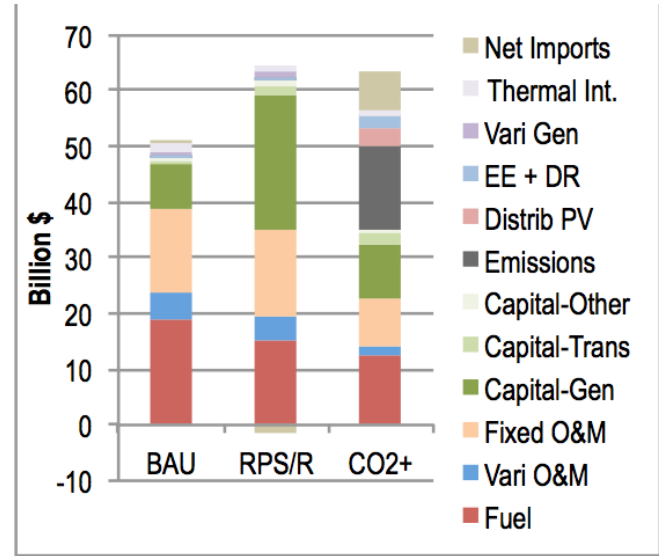

Fig. 52. Phase 2 total costs for the Central Eastern Interconnection in 2030.

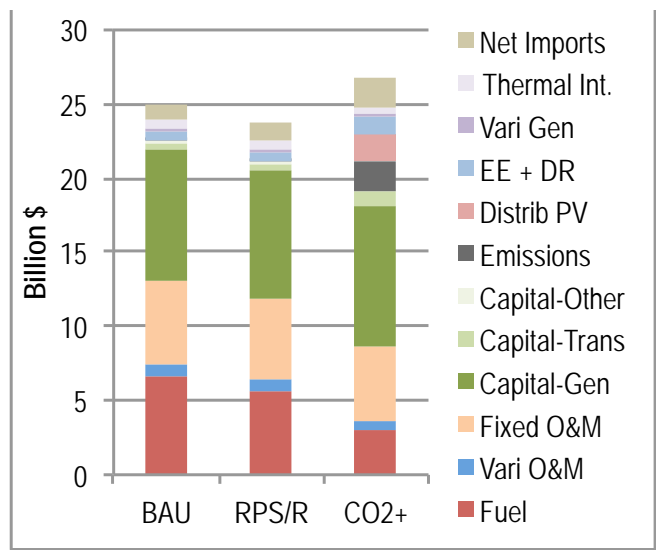

Fig. 53. Phase 2 total costs for Northeast Eastern Interconnection in 2030. 
As with the Northwest territory, the Southwest territory has a large build-out of wind ( $94 \mathrm{GW}$ more than the BAU scenario) to offset deactivations of coal, $\mathrm{CC}$, and less efficient peaking plants. Although the region does export a good share of its power, much of it is used internally because the Entergy region becomes a large importer. The territory is relatively self-sufficient in scenarios 2 and 3.

Wind capacity is $34 \mathrm{GW}$ higher in the RPS/R scenario than the BAU scenario, and capital costs are higher accordingly. Also, both the $\mathrm{CO}_{2}+$ scenario and the RPS/R scenario have an extensive build-out of transmission to collect the wind generation. The BAU scenario has the lowest costs, with little addition in capacity over and above the baseline for all three cases (Fig. 54). Fuel costs are higher as coal and gas are major sources.

The Southeast territory of the EI (TVA, Georgia, Alabama, Florida, and the Carolinas) has high capital costs in the $\mathrm{CO}_{2}+$ scenario, largely from a build-out of $26 \mathrm{GW}$ of nuclear power, mainly in Florida (Fig. 55). With fewer renewable resources available, the region uses nuclear power for a noncarbon resource. The region also relies more heavily on CC capacity (at $35 \%$ of total) than any other region. In the RPS/R scenario, offshore wind is developed to provide local renewable resources, despite its relatively high cost. Fuel cost is higher both because of the need for local generation and increases in biomass and other renewables.

Figure 56 shows the relative cost per megawatt-hour for each territory, dividing the total cost (including net imports) by the demand in the region. As explained above, this is

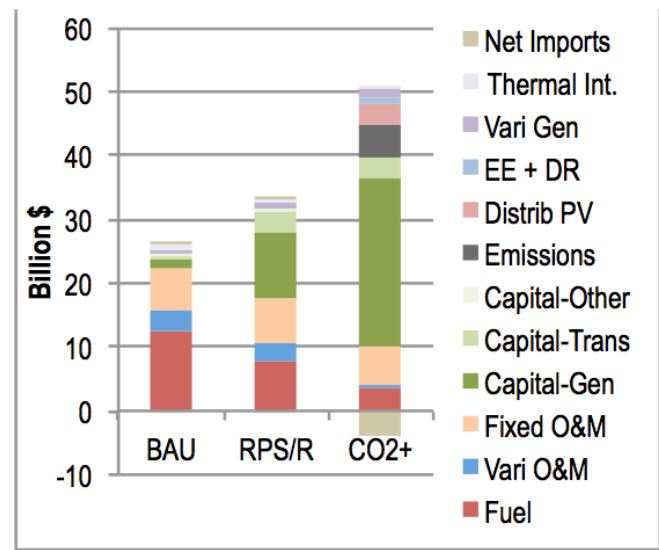

Fig. 54. Phase 2 total costs for the Southwest Eastern Interconnection in 2030.

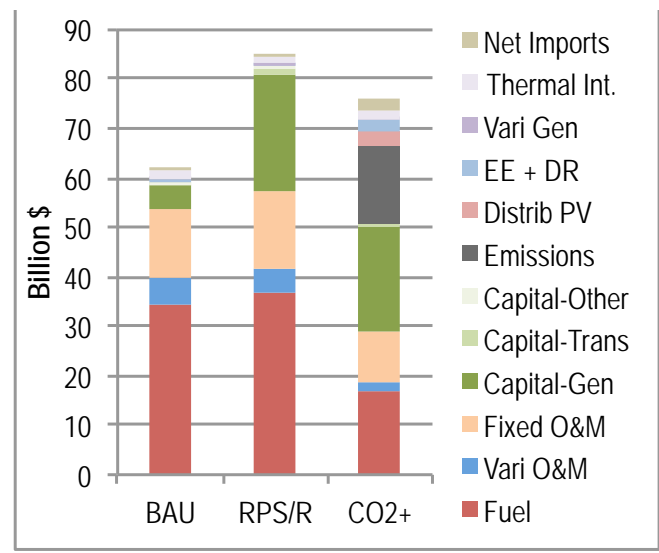

Fig. 55. Phase 2 total costs for the Southeast Eastern Interconnection in 2030. closer to a comparison of what each region would pay for electricity rather than the relative cost to provide the energy services. Figure 57 uses the BAU scenario demands for each territory to lessen that distortion. However, even with a constant denominator in all three scenarios, the $\mathrm{CO}_{2}+$ scenario is still relatively expensive. Most interesting is the cost in the Southwest and Northwest territories. There is a high capital cost for new generation, but exports only recover a portion of that. Much of the new generation is used internally within the territory. For example, the Southwest includes the exporting regions of SPPN, SPP S, and NE, while ENT is a major importer. Part of this higher cost per unit is a result of the large amount of curtailed wind power in the $\mathrm{CO}_{2}+$ scenario for these two regions. 


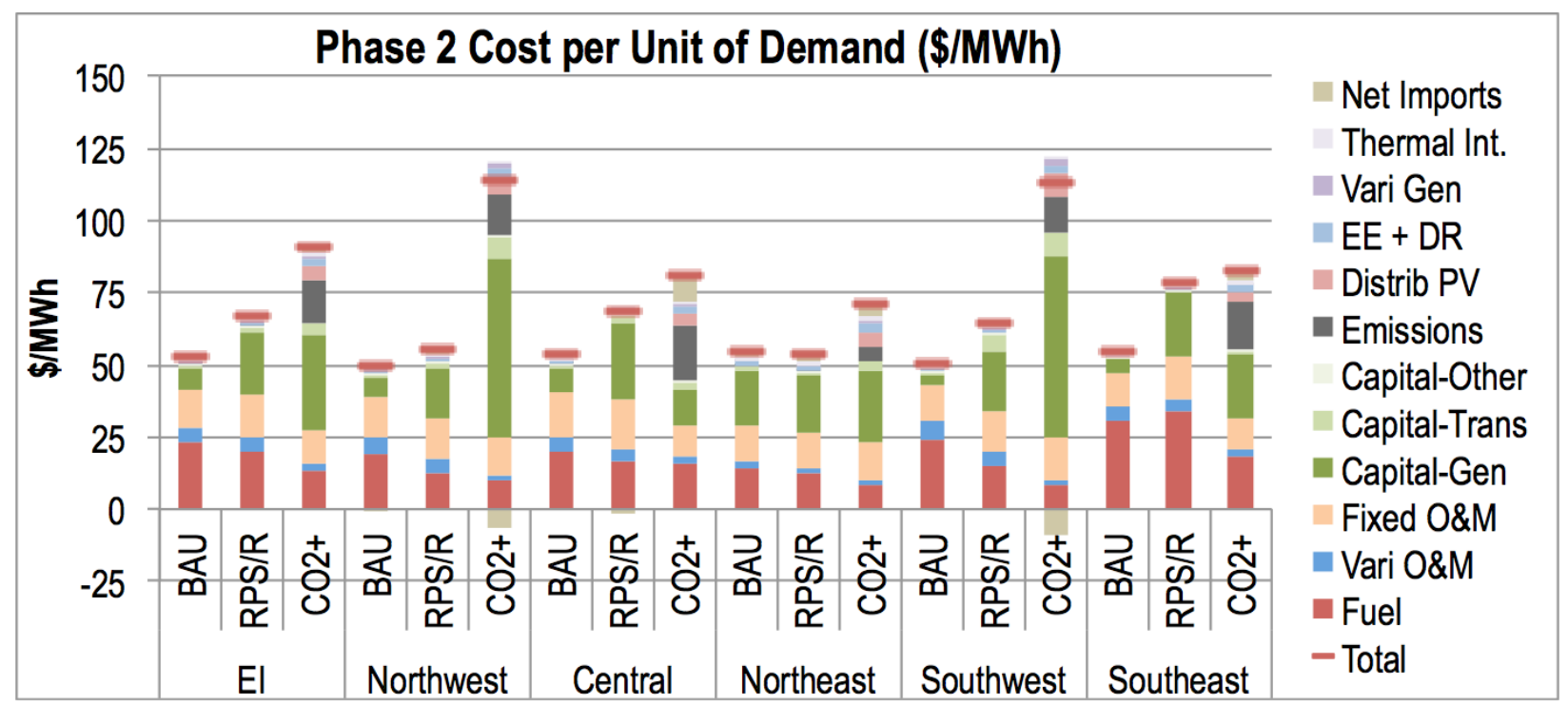

Fig. 56. Phase 2 cost per unit of demand for the Eastern Interconnection and each territory in 2030.

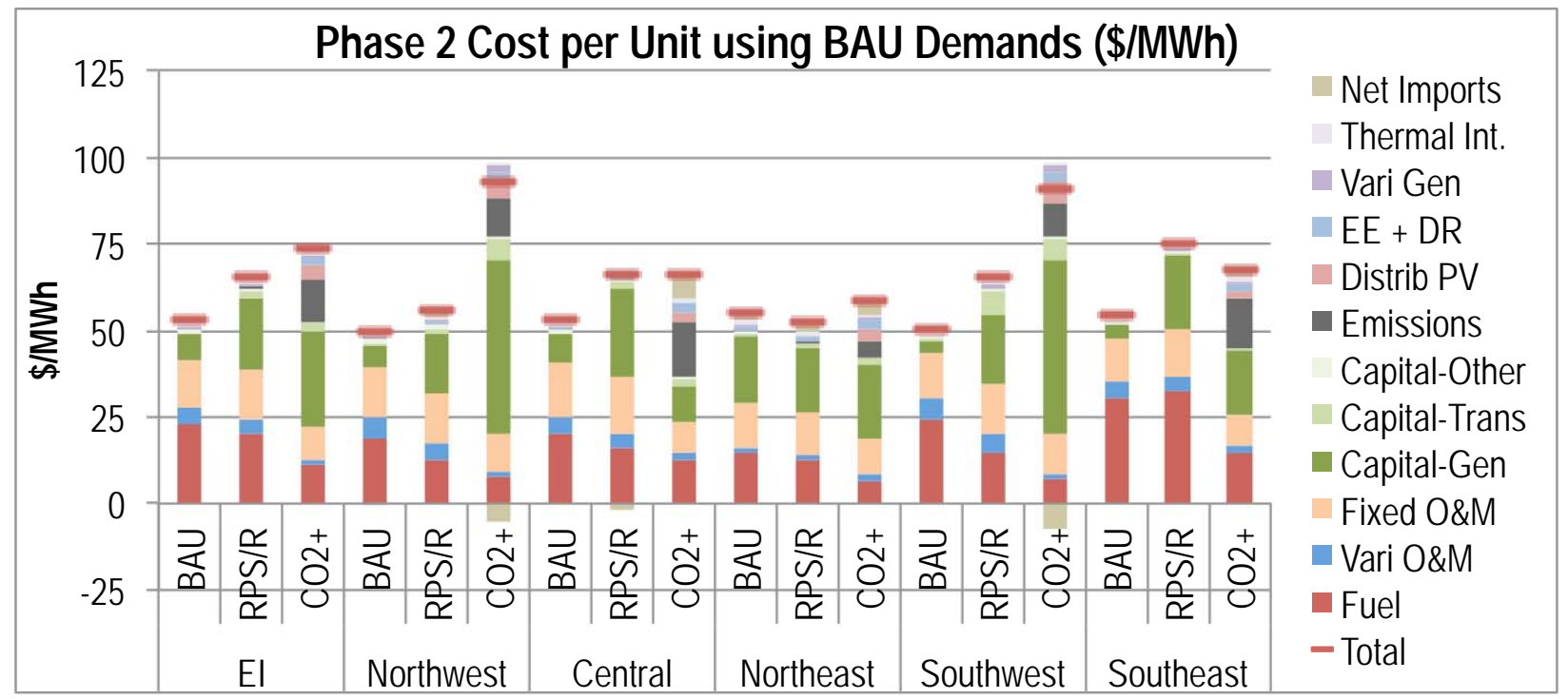

Fig. 57. Phase 2 cost per unit using the BAU scenario demands for the Eastern Interconnection and each territory in 2030. 



\section{TOPIC 4: REGIONAL RELIANCES}

According to the Phase 2 hourly generation reports, some regions can have one technology dominate their generation over extended periods such as a week or the course of a year. Table 28 shows the most dominant generating technologies over the full year of 2030 in Phase 2 for each of the regions and territories. In the $\mathrm{CO}_{2}+$ scenario, 11 regions have one technology provide more than two-thirds of their generation (highlighted in red). In both the RPS/R and BAU scenarios only six do. Wind is often dominant in the $\mathrm{CO}_{2}+$ scenario, with some regions relying on nuclear or CC. The "wind regions" export a fair amount of that production but still face some issues of wind curtailment and/or high DR use. These are examined more thoroughly in Topics 7 and 8. Coal continues its dominance in the BAU but declines some in the RPS/R scenario. The $\mathrm{CO}_{2}+$ scenario clearly shows the shift to new technologies, where $\mathrm{CO}_{2}$ producing technologies are heavily penalized and thus production minimized.

Table 28. Most Dominant Technologies in Each Region or Territory Based on Percent of Total Generation

\begin{tabular}{|c|c|c|c|c|c|c|}
\hline \multirow[b]{2}{*}{ Region or Territory } & \multicolumn{2}{|c|}{ BAU } & \multicolumn{2}{|c|}{ RPS/R } & \multicolumn{2}{|c|}{$\mathrm{CO}_{2+}$} \\
\hline & Technology & $\begin{array}{c}\% \text { Gen in } \\
2030\end{array}$ & Technology & $\begin{array}{l}\% \text { Gen } \\
\text { in } 2030\end{array}$ & Technology & $\begin{array}{l}\% \text { Gen } \\
\text { in } 2030\end{array}$ \\
\hline MAPP CA & Hydro & $59 \%$ & Hydro & $96 \%$ & Hydro & $92 \%$ \\
\hline MAPP US & Coal & $53 \%$ & Wind & $54 \%$ & Wind & $72 \%$ \\
\hline MISO W & Coal & $51 \%$ & Wind & $48 \%$ & Wind & $83 \%$ \\
\hline MISO MO-IL & Coal & $77 \%$ & Coal & $74 \%$ & Wind & $39 \%$ \\
\hline MISO WUMS & Coal & $41 \%$ & Coal & $47 \%$ & Comb. Cycle & $44 \%$ \\
\hline MISO IN & Coal & $83 \%$ & Coal & $90 \%$ & Wind & $57 \%$ \\
\hline MISO MI & Coal & $45 \%$ & Coal & $43 \%$ & Comb. Cycle & $52 \%$ \\
\hline Non-RTO Midwest & Coal & $93 \%$ & Coal & $91 \%$ & Comb. Cycle & $84 \%$ \\
\hline PJM ROR & Coal & $53 \%$ & Coal & $39 \%$ & Nuclear & $39 \%$ \\
\hline PJM ROM & Coal & $38 \%$ & Nuclear & $30 \%$ & Nuclear & $46 \%$ \\
\hline PJM E & Nuclear & $54 \%$ & Nuclear & $46 \%$ & Nuclear & $57 \%$ \\
\hline IESO & Nuclear & $60 \%$ & Nuclear & $60 \%$ & Nuclear & $63 \%$ \\
\hline NYISO A-F & Hydro & $32 \%$ & Hydro & $33 \%$ & Hydro & $36 \%$ \\
\hline NYISO G-I & Nuclear & $49 \%$ & Nuclear & $70 \%$ & Nuclear & $74 \%$ \\
\hline NYISO J-K & Comb. Cycle & $80 \%$ & Comb. Cycle & $81 \%$ & Comb. Cycle & $83 \%$ \\
\hline NEISO & Comb. Cycle & $36 \%$ & Nuclear & $37 \%$ & Nuclear & $47 \%$ \\
\hline NE & Coal & $68 \%$ & Coal & $55 \%$ & Wind & $68 \%$ \\
\hline SPP N & Coal & $75 \%$ & Coal & $54 \%$ & Wind & $85 \%$ \\
\hline SPP S & Coal & $56 \%$ & Wind & $47 \%$ & Wind & $81 \%$ \\
\hline ENT & Comb. Cycle & $42 \%$ & Comb. Cycle & $36 \%$ & Nuclear & $51 \%$ \\
\hline TVA & Coal & $40 \%$ & Nuclear & $34 \%$ & Nuclear & $47 \%$ \\
\hline SOCO & Coal & $37 \%$ & Coal & $32 \%$ & Nuclear & $46 \%$ \\
\hline VACAR & Nuclear & $41 \%$ & Nuclear & $37 \%$ & Nuclear & $62 \%$ \\
\hline FRCC & Comb. Cycle & $61 \%$ & Comb. Cycle & $54 \%$ & Nuclear & $69 \%$ \\
\hline Northwest & Coal & $55 \%$ & Coal & $48 \%$ & Wind & $53 \%$ \\
\hline Central & Coal & $46 \%$ & Coal & $33 \%$ & Nuclear & $41 \%$ \\
\hline Northeast & Nuclear & $41 \%$ & Nuclear & $43 \%$ & Nuclear & $50 \%$ \\
\hline Southwest & Coal & $52 \%$ & Coal & $42 \%$ & Wind & $66 \%$ \\
\hline Southeast & Comb. Cycle & $34 \%$ & Nuclear & $27 \%$ & Nuclear & $57 \%$ \\
\hline EI & Coal & $38 \%$ & Coal & $30 \%$ & Nuclear & $37 \%$ \\
\hline
\end{tabular}

Figure 58 provides these data in a chart showing the dominant resource for each region for each of the scenarios. The first column in each grouping is the BAU, the second is the RPS/R, and the third is the 
$\mathrm{CO}_{2}+$. Note that coal dominance in BAU and RPS/R often switches to wind in the $\mathrm{CO}_{2}+$ scenario. Nuclear is relatively dominant in a number of regions though rarely more than $50 \%$ of the total.

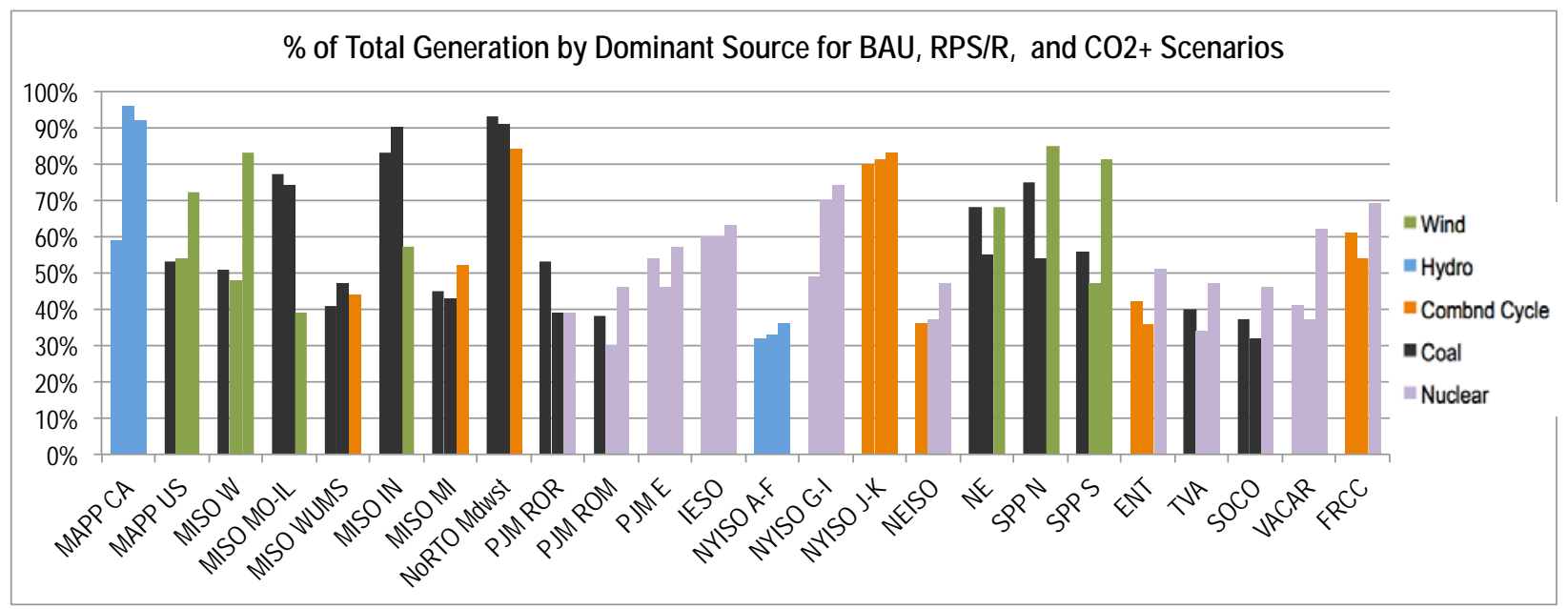

Fig. 58. Dominant generation source for each region and scenario.

Another indicator of domination by a single technology is how many days in a year certain technologies provide the overwhelming share of generation. Even in regions that do not have a dominant technology over the entire year, there may be periods of time when the region is highly reliant on a single one. Tables 29-31 show the number of days in 2030 that one technology provides more than $80 \%$ of the generation in at least 20 of the 24 hours of the day.

Table 29. Number of Days that Technology Dominates Region's Generation in the BAU Scenario in 2030

\begin{tabular}{|lcc|}
\hline MISO IN & Coal & Combined Cycle \\
\hline MISO MO-IL & 162 & - \\
\hline NE & 45 & - \\
\hline Non-RTO Midwest & 3 & - \\
\hline NYISO G-I & 360 & - \\
\hline NYISO J-K & - & 3 \\
\hline SPP N & - & 269 \\
\hline
\end{tabular}

Table 30. Number of Days that Technology Dominates Region's Generation in the RPS/R Scenario in 2030

\begin{tabular}{|lccccc|}
\hline & Nuclear & Coal & Combined Cycle & Hydro & Wind \\
\hline MAPP US & - & - & - & - & 18 \\
\hline MISO IN & - & 339 & - & - & - \\
\hline MISO MO-IL & - & 24 & - & - & - \\
\hline MISO W & - & - & - & - & 3 \\
\hline Non-RTO Midwest & - & 360 & - & - & - \\
\hline NYISO G-I & 15 & - & - & - & - \\
\hline NYISO J-K & - & - & 281 & - & - \\
\hline SPP N & - & 2 & - & - & 4 \\
\hline MAPP CA & - & - & - & 348 & - \\
\hline
\end{tabular}


Table 31. Number of Days that Technology Dominates Region's

Generation in the $\mathrm{CO}_{2}+$ Scenario in 2030

\begin{tabular}{|lcccc|}
\hline & Nuclear & Combined Cycle & Hydro & Wind \\
\hline ENT & 47 & - & - & - \\
\hline MRCC & 13 & - & - & - \\
\hline MISO IN & - & - & - & 101 \\
\hline MISO W & - & - & - & 40 \\
\hline NE & - & - & - & 181 \\
\hline Non-RTO Midwest & - & - & - & 15 \\
\hline NYISO G-I & 31 & 243 & - & - \\
\hline NYISO J-K & - & - & - & - \\
\hline SPP N & - & 178 & - & 157 \\
\hline SPP S & - & - & - & 111 \\
\hline VACAR & 4 & - & - & - \\
\hline MAPP CA & - & - & 310 & - \\
\hline
\end{tabular}

Note that in the $\mathrm{CO}_{2}+$ scenario, wind is a dominant provider for more than 15 days in six different regions. All of the regions located along the western part of the EI have numerous days where wind is the main contributor. Nebraska (NE) is reduced because they have two nuclear plants that continue to provide baseload noncarbon electricity. Four regions have nuclear providing a dominant share on multiple days. These are regions that do not have significant renewable resources. Lastly, two smaller regions use CC plants for much of their generation. They either have converted their coal to gas production or have few other resources available.

In the RPS/R scenario coal continues to be viable and dominates in several regions, especially two regions in the Midwest (MISO IN and Non-RTO Midwest) that currently have high coal market share. Hydro is a major component of MAPP Canada as it builds additional capacity for the RPS market. In the BAU scenario, coal dominates more regions because there is less renewable development, although current projected US Environmental Protection Agency (EPA) regulations continued to be modeled in this scenario as in the others. CC generation dominates in NYISO J-K (NYC and Long Island) in all three scenarios. 



\section{TOPIC 5: GAS USE}

Many people expect that the amount of natural gas used for generation will increase significantly in the coming years. The rapid increase in availability of shale gas has lowered the prices for natural gas, making it a viable broadscale source of baseload power. One topic of interest to EISPC members was how much growth was projected by the EIPC cases. Regionally, might the growth be significantly more than current amounts such that the current infrastructure might need rapid expansion to handle the growth?

While natural gas prices in the EIPC cases were projected to moderate from previous years' estimates, they did not take fully into account the current drop in prices. Figure 59 is a graph of the prices as used in the cases, based on the DOE Energy Information Administration's (EIA's) 2011 Annual Energy Outlook (AEO) early release reference case (EIA 2011a). Also on the graph are EIA projections from other years, including the AEOs from 2010, 2012, and 2013. Note how the 2013 estimate has natural gas prices by 2030 roughly $20 \%$

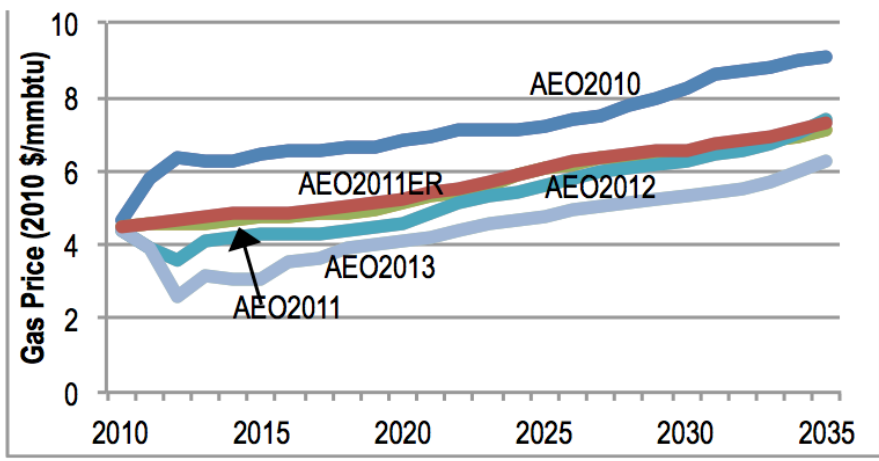

Fig. 59. Henry Hub gas prices from the DOE Annual Energy Outlook (AEO) of different years. (\$1.27) lower than the price used for the EIPC study. The "low gas price" sensitivities in Phase 1 used a constant price of $\$ 4.50$ for the entire period, while the "high gas price" sensitivities had a gradual shift from the AEO 2011 early release price to the AEO 2010 price by 2025 and the AEO 2010 price for all subsequent years. This equaled $\$ 8.20$ in 2030. So the current expected gas prices were bounded by the high and low sensitivities in 2030, although the AEO 2013 prices are below the low gas sensitivity through 2022.

\subsection{Gas Trends in Scenarios}

Natural gas use for electricity in the EI started at about the same level in the BAU and RPS/R scenarios, 5.3 quadrillion Btu (Quads) in the BAU scenario and only 4.9 Quads in the RPS/R scenario (Fig. 60). Demands were slightly lower in the latter, and less $\mathrm{CC}$ generation was used. Gas use stayed flat and then declined further in the RPS/R scenario because coal generation remained economic while renewable generation increased its percentage, squeezing gas use. In the $\mathrm{CO}_{2}+$ scenario, gas use in 2015 is 7.2 Quads, 38\% more than in the BAU. Even at the beginning of the study period, $\mathrm{CO}_{2}$ costs cause the conversion of coal to natural gas generation, and gas generation continues to grow to 8.4 Quads by 2020 . However, by 2028 or so, the reduction in demand in the $\mathrm{CO}_{2}+$ scenario lowered gas use to below that of the BAU scenario.

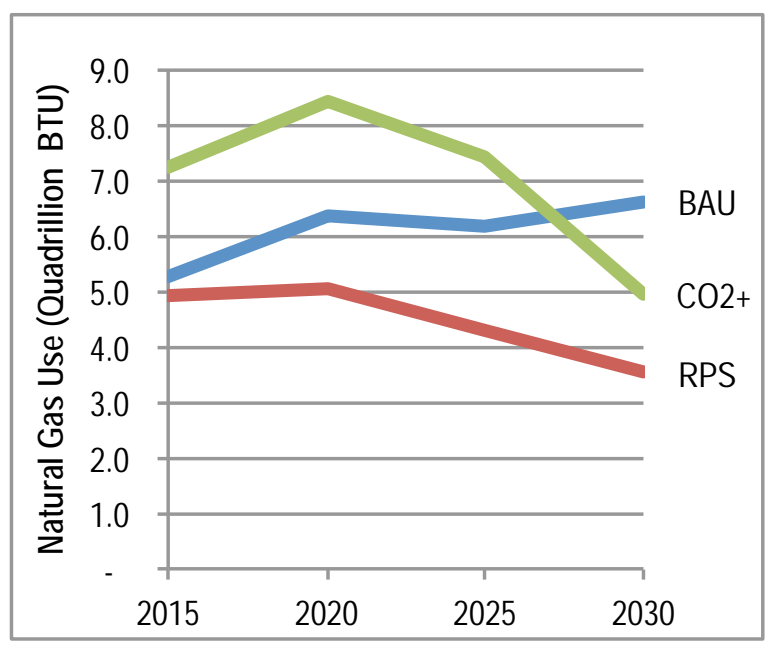

Fig. 60. Gas use for electricity in the Eastern Interconnection as a whole. 


\subsection{Regional Gas Use}

As expected, natural gas use changes over time and is highly dependent on the scenario studied. Figures 61-63 show the gas use from Phase 1 for 2015-2030 for each scenario. In addition, they show the estimated gas use for 2030 from Phase 2 (right side of the graphs). Some of the key region results are named in the graphs, with the rest of the regions shown as fainter lines.

In the BAU scenario (Fig. 61), most regions have a relatively flat amount of natural gas use over the period. FRCC had continued growth as CC plants were used to provide additional power. PJM ROR had less CC generation in Phase 2 than Phase 1 (Fig. 9), resulting in lower gas use.

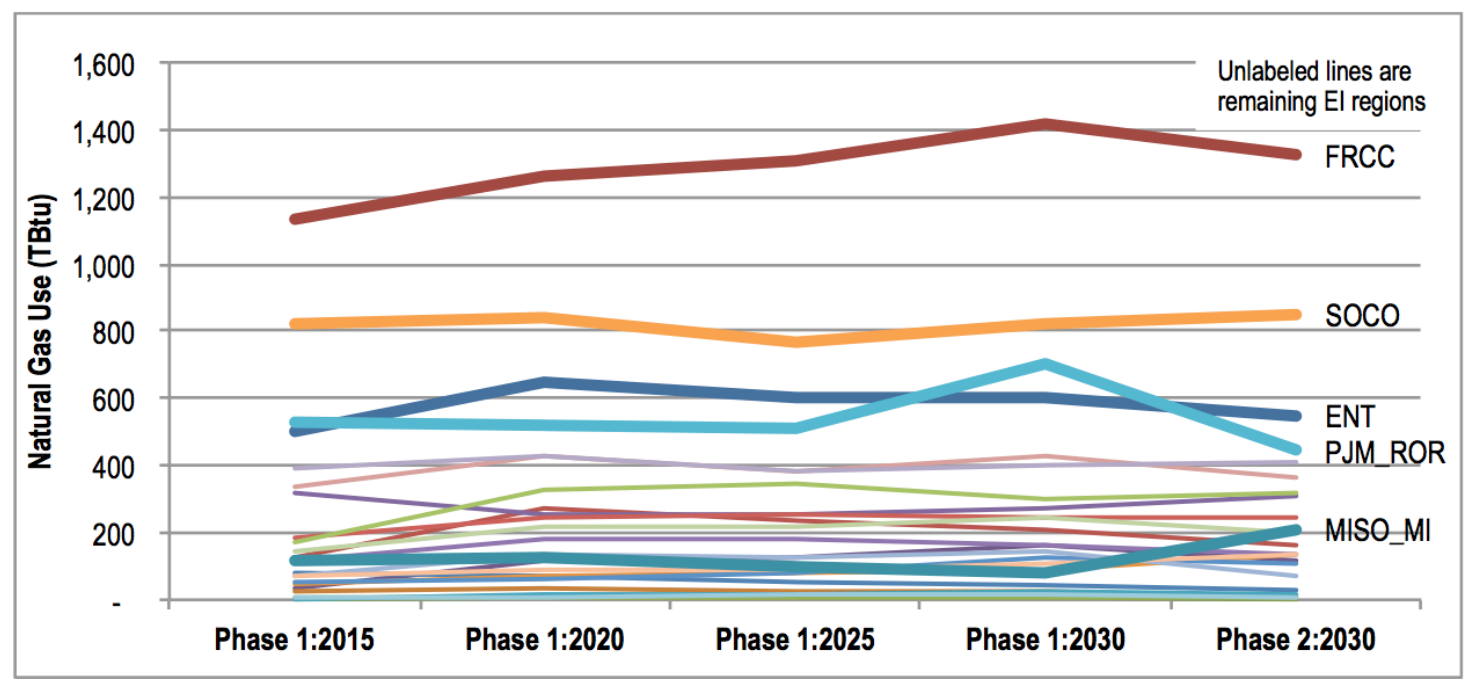

Fig. 61. Natural gas use in the BAU scenario.

In the RPS/R scenario (Fig. 62), most regions had relatively flat or declining growth in gas use as renewables gradually assumed a larger share of the market. Some regions, such as PJM ROR and MISO MI, had higher gas levels in Phase 2 than Phase 1. Their CC generation was higher in Phase 2, although a small portion of their overall generation (Fig. 10.)

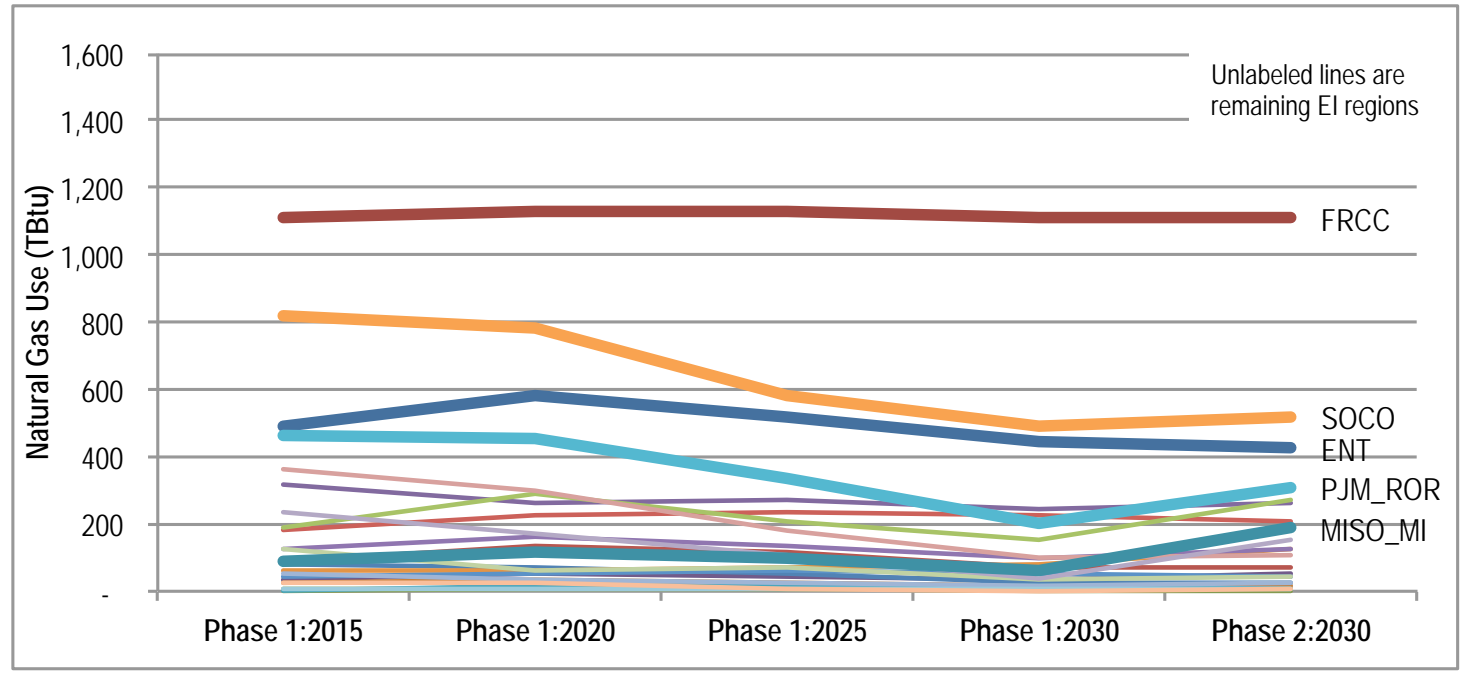

Fig. 62. Natural gas use in the RPS/R scenario. 
In the $\mathrm{CO}_{2}+$ scenario (Fig. 63), all of the regions showed declines in gas use between 2025 and 2030 as gas production decreased while other resources increased, due largely to the increase in $\mathrm{CO}_{2}$ costs. Most notable was the drop in FRCC; the region had a large increase in nuclear capacity between those years that supplanted much of the gas generation. PJM ROR and SOCO were other large users in gas. While most regions saw roughly the same amount of gas use in 2030 from both Phase 1 and 2, a few saw significant changes. MISO IN had the biggest difference, as can be seen by the slope of the line between the last two points. In Phase 2, that region received a good amount of its power from MISO W through PJM ROR from the HVDC lines, resulting in lower internal generation (Fig. 11.)

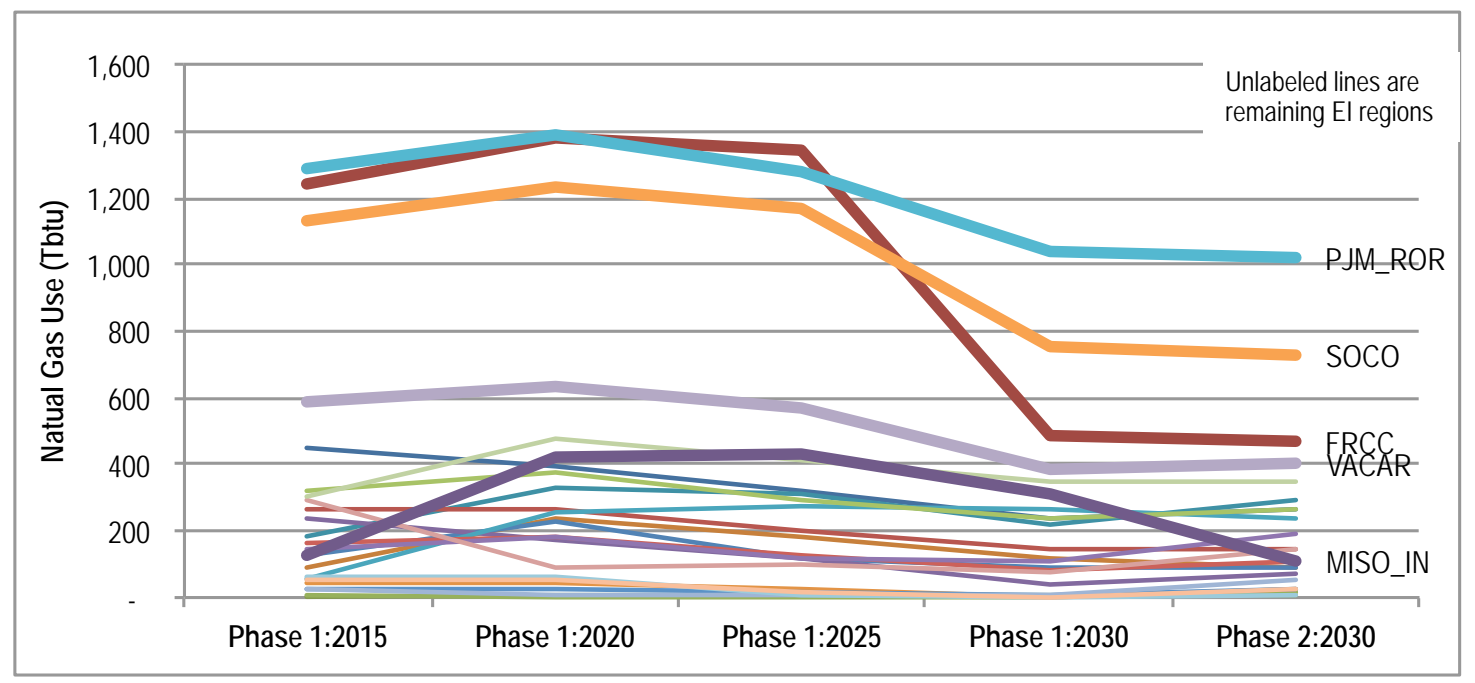

Fig. 63. Natural gas use in the $\mathrm{CO}_{2}+$ scenario.

Many people may be surprised by the great amount of natural gas used in FRCC in the three scenarios. $\mathrm{CC}$ plants are the dominant supply for most years except by 2030 in the $\mathrm{CO}_{2}+$ scenario, where nuclear became a major source. The region has historically been a high gas user since it is relatively far from coal sources while having more available access to natural gas from the Gulf.

\subsection{Key Reliances}

While there does not appear to be a large growth in gas use between 2015 and $2030\left(-32 \%\right.$ in the $\mathrm{CO}_{2}+$ scenario, $-29 \%$ in the RPS/R scenario, $+26 \%$ in the BAU scenario), the other question raised was whether there were key times in a year when natural gas was a critical source of power. Did natural gas use spike at certain times so that while the annual amount was low, the relative amount was high for certain days?

This is somewhat the converse of the analysis in Chapter 4 (Topic 4). In that chapter we showed that CC technology dominated in only NYISO J-K for all three scenarios. This region, New York City and Long Island, has limited alternative technologies available. The other major sources there are peaking plants, and they are largely fueled by natural gas as well. Imports provided almost all of the rest of the power needed. In the $\mathrm{CO}_{2}+$ scenario, CCs also provided a large portion of supply for the Non-RTO Midwest, since the region's coal plants were largely converted to gas. In FRCC in the BAU scenario, natural gas played an important role as the main source of new production. Nevertheless, in that scenario gas use only rose by $25 \%$ over a 15 -year period.

Those regions that have low relative levels of natural gas use generally have their peak amounts occur in the peak months of July and August. During this time CT and other peaking capacity is needed. In the $\mathrm{CO}_{2}+$ scenario, no region required more than $10 \%$ of its total gas in a single week and no region used more than $21 \%$ of its annual demand in a 3-week period. In the RPS/R scenario, the western regions had 
the largest spike in gas use (during mid-July). MAPP US used $56 \%$ of its annual amount in the middle 3 weeks of July, with MISO W and NE at $48 \%$ and SPP N at 38\%. The BAU scenario had similar spikes in gas demand, with MAPP US needing $54 \%$ of its annual gas, Nebraska $45 \%$, and both MISO W and MISO MO-IL 39\%. None of these regions was among the highest gas users, so it is unclear whether they would feel some constraints during this time. 


\section{TOPIC 6: OPERATING AND PLANNING RESERVES}

\subsection{Reserves Definitions}

Reserves represent an amount of capacity above demand available to provide adequate electricity at the correct voltage and frequency to maintain the grid under unusual or abnormal circumstances. Two main types of reserves were used in the EIPC study: planning reserves and operating reserves. They each have different purposes and definitions, but the distinctions are often lost in discussions.

Planning reserves are used for long-term resource planning and defining regional planning reserve margins. These were discussed at length in the EISPC-sponsored white paper The Economic Ramifications of Resource Adequacy White Paper (Astrape 2013). NERC publishes the standards for all regions on its website (NERC 2013). Most regions begin with a reliability criterion such as 1 day of outages in 10 years, but there are a number of variations on how this is calculated. The regions then determine the reserve margin required to meet that criterion. For example, the ReliabilityFirst Corporation region includes the following requirements (among others), as listed in Standard BAL-502-RFC-02 of the NERC reliability standards.

R1 The Planning Coordinator shall perform and document a Resource Adequacy analysis annually. The Resource Adequacy analysis shall [Violation Risk Factor: Medium]:

R1.1 Calculate a planning reserve margin that will result in the sum of the probabilities for loss of Load for the integrated peak hour for all days of each planning year analyzed (per R1.2) being equal to 0.1. (This is comparable to a "one day in 10 years" criterion).

R1.1.1 The utilization of Direct Control Load Management or curtailment of Interruptible Demand shall not contribute to the loss of Load probability.

R1.1.2 The planning reserve margin developed from R1.1 shall be expressed as a percentage of the median forecast peak Net Internal Demand (planning reserve margin). (NERC 2013)

In this example, the planning reserve margin is to meet the 1-day-in-10-year loss of load probability; load lost through utility-controlled DR (direct load control and interruptible rates) will not be counted as loss of load for the probability, and the reserve margin is applied to the median forecast peak load to determine the number of megawatts needed for the region. Planning reserve margins were included in NEEM in Phase 1.

In Phase 2, the GE MAPS model used operating reserves or its subset spinning reserves as a key variable. These reserves are needed on an ongoing basis and vary as demand and other factors come into play. The NERC "Glossary of Terms" in the NERC reliability standards (NERC 2013) defines the different reserves, shown in Table 32. Note that the terms include two definitions for spinning reserves. In one, only unloaded generation is included, but in the second, load fully removable from the system is included as well. This distinction plays a role in the results from Phase 2.

As a complement to operating reserves, the NERC standards also define "contingency reserves" (Standard BAL-002-1). These reserves "may be supplied from generation, controllable load resources, or coordinated adjustments to interchange schedules." (R1). The contingency reserves are a mix of the operating reserves - spinning and the operating reserves — supplemental, as defined in Table 32. Both of these must be capable of being synchronized to the grid within the "disturbance recovery period." 
Elsewhere in the standards the default value for the period is set at $15 \mathrm{~min}$, although individual interconnections are allowed to set alternatives with approval of the NERC Operating Committee.

Table 32. NERC Definitions of Reserves (NERC 2013)

\begin{tabular}{|c|c|}
\hline NERC Term & Definition \\
\hline Operating Reserve & $\begin{array}{l}\text { That capability above firm system demand required to provide for regulation, load } \\
\text { forecasting error, equipment forced and scheduled outages, and local area protection. It } \\
\text { consists of spinning and nonspinning reserve. }\end{array}$ \\
\hline Non-Spinning Reserve & $\begin{array}{l}\text { 1. That generating reserve not connected to the system but capable of serving demand } \\
\text { within a specified time. } \\
\text { 2. Interruptible load that can be removed from the system in a specified time. }\end{array}$ \\
\hline Spinning Reserve & Unloaded generation that is synchronized and ready to serve additional demand. \\
\hline Contingency Reserve & $\begin{array}{l}\text { The provision of capacity deployed by the Balancing Authority to meet the Disturbance } \\
\text { Control Standard (DCS) and other NERC and Regional Reliability Organization } \\
\text { contingency requirements. }\end{array}$ \\
\hline $\begin{array}{l}\text { Operating Reserve-- } \\
\text { Spinning }\end{array}$ & $\begin{array}{l}\text { The portion of Operating Reserve consisting of } \\
\text { - Generation synchronized to the system and fully available to serve load within the } \\
\text { Disturbance Recovery Period following the contingency event or } \\
\text { - Load fully removable from the system within the Disturbance Recovery Period } \\
\text { following the contingency event. }\end{array}$ \\
\hline $\begin{array}{l}\text { Operating Reserve-- } \\
\text { Supplemental }\end{array}$ & $\begin{array}{l}\text { The portion of Operating Reserve consisting of } \\
\text { - Generation (synchronized or capable of being synchronized to the system) that is } \\
\text { fully available to serve load within the Disturbance Recovery Period following the } \\
\text { contingency event or } \\
\text { - Load fully removable from the system within the Disturbance Recovery Period } \\
\text { following the contingency event. }\end{array}$ \\
\hline
\end{tabular}

\subsection{Planning Reserves in Phase 1}

Phase 1 of the EIPC study used planning reserve margins, with each region supplying its requirement (Table 33). MRN-NEEM took into account reserve margins for individual regions and for collections of regions into larger regions, such as MISO* and NYISO. MRN-NEEM covers all of the United States and Canada, so reserve margins were defined for regions inside and outside of the EI.

Table 33. Reserve Margin Regions, Reserve Requirements, and NEEM Regions (CRA 2010)

\begin{tabular}{|lcl|}
\hline Reserve Margin Area & Reserve Requirement & NEEM Regions \\
\hline ALB & $18.0 \%$ & ALB \\
\hline AZ-NM-SNV & $15.7 \%$ & AZ-NM-SNV \\
\hline BC & $18.0 \%$ & BC \\
\hline CA & $16.6 \%$ & NP15 \\
\hline & & SP15 \\
\hline ENT & $14.0 \%$ & ENT \\
\hline ERCOT & NA & ERCOT \\
\hline FRCC & $16.0 \%$ & FRCC \\
\hline MAPP US & $14.0 \%$ & MAPP US \\
\hline MAPP CA & $12.0 \%$ & MAPP CA \\
\hline MISO & $17.4 \%{ }^{*}$ & MISO IN \\
\hline
\end{tabular}

\footnotetext{
*Note: Refer to Table 1 or the Eastern Interconnection regions list at the front for complete definitions of region identifiers used in the figures, tables, and text.
} 
Table 33 (continued)

\begin{tabular}{|c|c|c|}
\hline Reserve Margin Area & Reserve Requirement & NEEM Regions \\
\hline & & MISO MI \\
\hline & & MISO MO-IL \\
\hline & & MISO W \\
\hline & & MISO WUMS \\
\hline NEISO & $16.0 \%$ & NEISO \\
\hline Non-RTO Midwest & $14.0 \%$ & Non-RTO Midwest \\
\hline NWPP & $18.0 \%$ & NWPP \\
\hline \multirow[t]{3}{*}{ NYISO } & $16.5 \%{ }^{*}$ & NYISO A-F \\
\hline & & NYISO GHI \\
\hline & & NYISO JK \\
\hline \multirow[t]{2}{*}{ NYISO GHI JK } & $-5.0 \%$ & NYISO GHI \\
\hline & & NYISO JK \\
\hline NYISO JK & $-8.0 \%$ & NYISO JK \\
\hline OH (IESO) & $17.0 \%$ & $\mathrm{OH}$ \\
\hline \multirow[t]{3}{*}{ PJM } & $15.3 \%{ }^{*}$ & PJM E \\
\hline & & PJM ROM \\
\hline & & PJM ROR \\
\hline PJM E & $-2.2 \%$ & PJM E** \\
\hline RMPA & $14.0 \%$ & RMPA \\
\hline soco & $14.0 \%$ & SOCO \\
\hline \multirow[t]{3}{*}{ SPP } & $13.6 \%$ & NE \\
\hline & & SPP N \\
\hline & & SPP S \\
\hline TVA & $15.0 \%$ & TVA \\
\hline VACAR & $14.0 \%$ & VACAR \\
\hline $\begin{array}{l}\text { * Based on coincid } \\
\text { applied a diversity }\end{array}$ & $\begin{array}{l}k \text { in reserve margir } \\
\text { o the noncoinciden }\end{array}$ & $\begin{array}{l}\text { For PJM, CRA } \\
\text { ks. }\end{array}$ \\
\hline
\end{tabular}

For planning reserve margin calculations, all generating capacity qualified to meet the reserve margin, including DR. However, the EIPC applied a fractional resource contribution credit to intermittent generation (wind and solar). The installed capacity of the technology is multiplied by this fraction to represent the amount of capacity that will be available during the peak period. The amount can vary depending on the type of technology and quality of resources in the region. Solar generation is set at $30 \%$ to reflect that the peak time is likely on a hot, sunny day, but often later in the day when the sun is not at full strength. Offshore wind is set similarly based on expectations for future installations. Onshore wind generation is set lower to reflect that its generation during the peak can be lower than its average generation because winds are often calmer on the hottest, highest demand days. Table 34 lists the credit factors for each region as used in Phase 1 of the study.

An important consequence of the capacity credit is that wind generation on average is higher than its credit, yet a region will build its combined total capacity to meet the reserve margin using the lower value. This means that there will be significant generation capacity above what is needed, and even with the low capacity factors of intermittent renewables $(25 \%-40 \%)$ there should be a number of hours in which there is substantial low or zero variable cost renewable power being generated. If this power cannot be absorbed within its own region, it will be exported if tie-line capacity is available. In Fig. 64 the $\mathrm{CO}_{2}+$ scenario generating capacities for each major region are shown as a fraction of the region's peak demand. In it, the intermittent generation (solar, wind) have been split into two categories; the amount credited toward the reserve margin is shown immediately above the hydro capacity, while the remaining wind and solar capacity are shown on the top of each column. MAPP US, MISO, and SPP have significant amounts of capacity above the required amounts. This power is available for internal use or export if it is being 
produced and transmission capacity is available. If the production cannot be used then the plants must be curtailed, with loss of revenues to plant owners and loss of low-cost power to users. This was a significant issue in the $\mathrm{CO}_{2}+$ scenario, as described in Chapter 3.

Table 34. Intermittent Resource Contributions (CRA 2010)

\begin{tabular}{|lcc|}
\multicolumn{1}{c}{ NEEM Region } & Technology & $\begin{array}{c}\text { Reserve } \\
\text { Contribution }\end{array}$ \\
\hline All Regions & Photovoltaic & $30 \%$ \\
\hline All Regions & Solar Thermal & $30 \%$ \\
\hline All Regions & Offshore Wind & $30 \%$ \\
\hline California & Wind & $25 \%$ \\
\hline Canada & Wind & $20 \%$ \\
\hline ERCOT & Wind & $9 \%$ \\
\hline New York & Wind & $15 \%$ \\
\hline PJM (-E, -ROM, -ROR) & Wind & $13 \%$ \\
\hline SPP & Wind & $15 \%$ \\
\hline TVA & Wind & $12 \%$ \\
\hline IESO & Wind & $11 \%$ \\
\hline MAPP CA & Wind & $11 \%$ \\
\hline All Other Regions & Wind & $15 \%$ \\
\hline
\end{tabular}

Another note of interest is that, at least for the $\mathrm{CO}_{2}+$ scenario (Fig. 64), the line representing $100 \%$ of peak demand passes through the capacity from DR. While many regions will import from the wind-rich areas to avoid use of DR, those regions far from wind sources (e.g., VACAR, FRCC) need to use DR for some of their peak hours. This does not occur in the BAU or RPS/R scenarios as DR is not as significant a fraction of the capacity contribution to the reserve margin for these two scenarios.

The RPS/R and BAU scenarios also do not have the large surpluses of wind that were in the $\mathrm{CO}_{2}+$ scenario (Figs. 65 and 66). In the RPS/R scenario, MAPP US continues a high proportion of wind to demand to supply the rest of the Northwest. MISO and SPP have much lower surplus wind capacity because they do not have the transmission capability to export to the east. PJM and VACAR increase their surplus wind capacity to help meet RPS requirements for their regions. The BAU scenario has relatively little excess capacity because RPS requirements are not expanded beyond current state regulations.

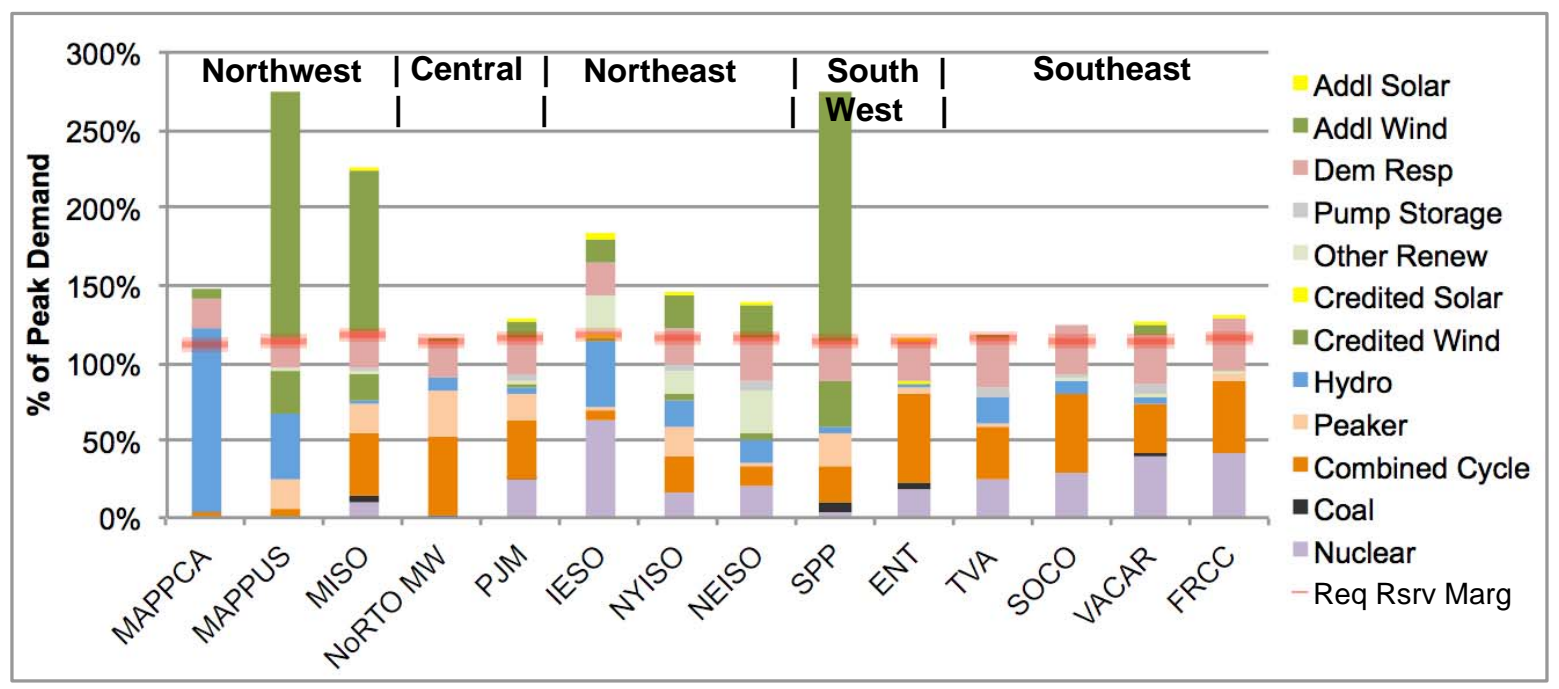

Fig. 64. Phase 1 ratio of capacities to peak demand in the $\mathrm{CO}_{2}+$ scenario. 


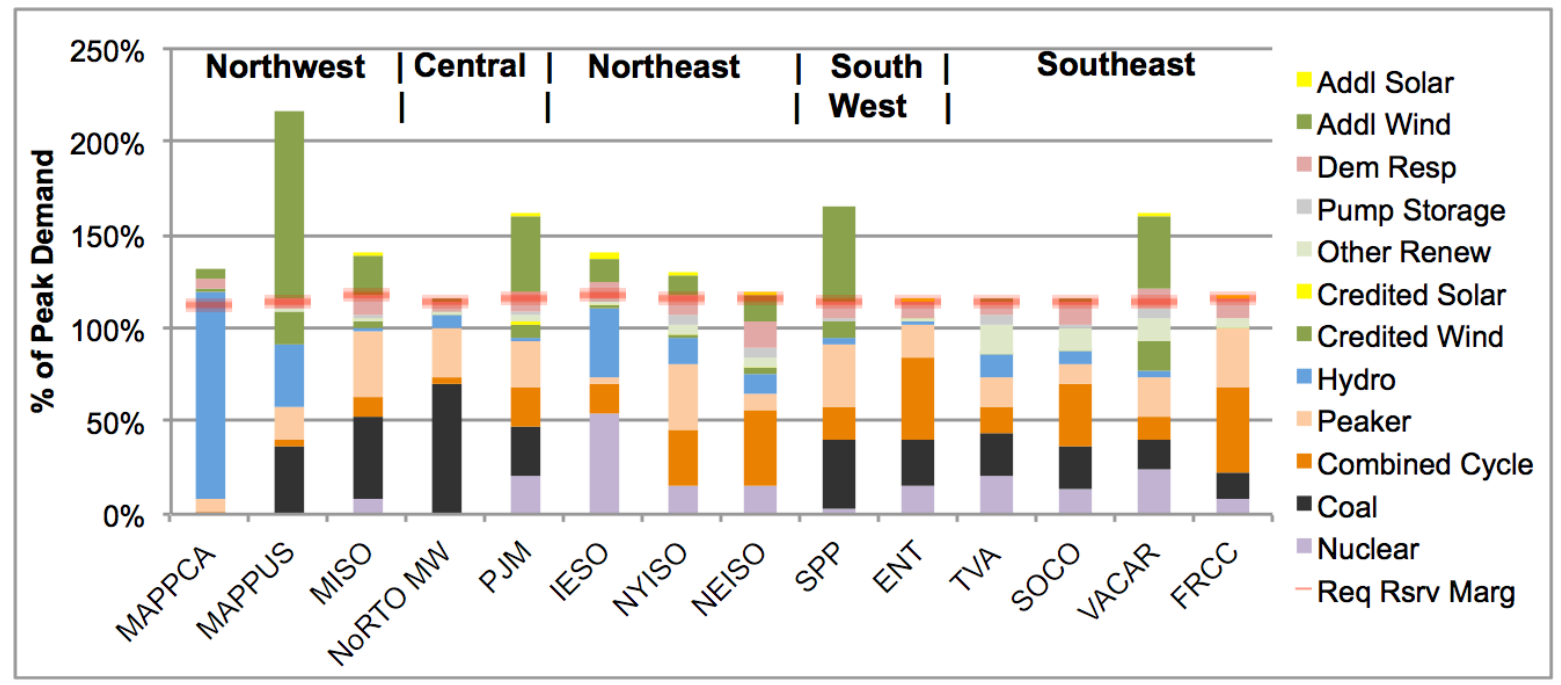

Fig. 65. Phase 1 ratio of capacities to peak demand in the RPS/R scenario.

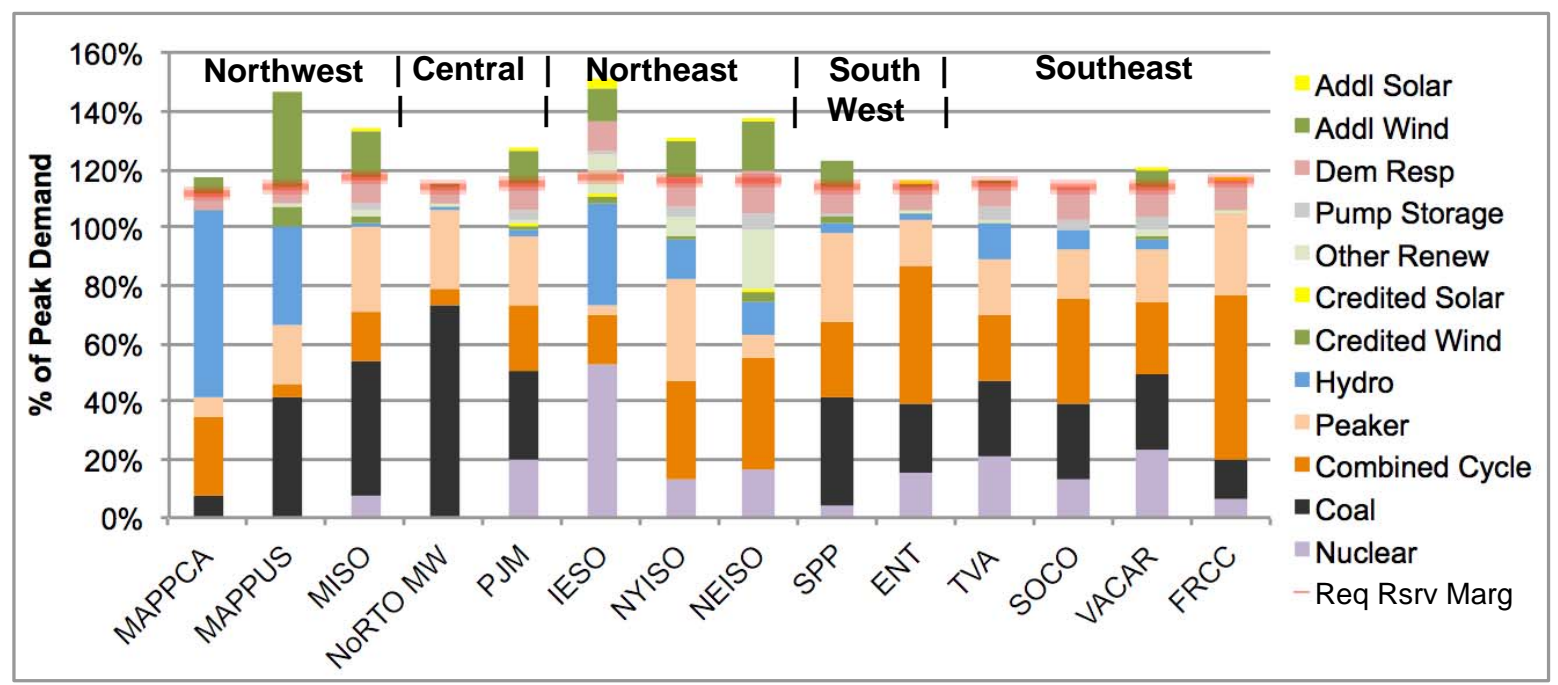

Fig. 66. Phase 1 ratio of capacities to peak demand in the BAU scenario.

Figures 65 and 66 include lines on each column showing the planning reserve margin for each region. One question raised early in the EIPC study was whether NEEM would force capacity down to the reserve margin in each year or would leave capacity higher than the minimum if it was cost-effective overall. This could happen if one region had a lower cost resource that it could use for export to other regions. At the same time, the importing regions still must have sufficient capacity to meet their internal reserve margins unless they have formal reserve sharing agreements. The $\mathrm{CO}_{2}+$ scenario allowed reserve sharing between the southwest and southeast territories and between the northwest and central territories. In the RPS/R scenario a more regional condition was set, with each territory required to meet its requirements internally. (Hydro Quebec power could be counted for NYISO and NEISO in all cases.)

Examining the results, it is clear that NEEM did allow capacity to be higher. Table 35 shows the reserve requirement in 2030 for each consolidated region and the actual reserve margin for each of the three final cases studied. In the BAU scenario, almost all regions were at their minimum requirement, but in the subsequent scenarios some regions had higher margins as needed for minimizing costs. 
Table 35. Phase 1 Reserve Requirement and 2030 Reserve Margins by Region

\begin{tabular}{|lcccc|}
\hline Reserve Margin Area & $\begin{array}{c}\text { Reserve } \\
\text { Requirement }\end{array}$ & BAU & $\begin{array}{c}\text { 2030 Reserve Margin } \\
\text { RPS/R }\end{array}$ & $\mathbf{C O}_{2+}$ \\
\hline MAPP CA & $12.0 \%$ & $12.0 \%$ & $26.2 \%$ & $40.8 \%$ \\
\hline MAPP US & $14.0 \%$ & $14.0 \%$ & $15.9 \%$ & $15.5 \%$ \\
\hline MISO & $17.4 \%$ & $17.4 \%$ & $17.4 \%$ & $20.1 \%$ \\
\hline Non-RTO Midwest & $14.0 \%$ & $14.0 \%$ & $14.0 \%$ & $14.0 \%$ \\
\hline PJM & $15.3 \%$ & $15.3 \%$ & $19.9 \%$ & $15.3 \%$ \\
\hline IESO & $17.0 \%$ & $23.7 \%$ & $25.5 \%$ & $43.3 \%$ \\
\hline NYISO & $16.5 \%$ & $16.5 \%$ & $16.5 \%$ & $18.9 \%$ \\
\hline NEISO & $16.0 \%$ & $19.3 \%$ & $20.4 \%$ & $16.0 \%$ \\
\hline SPP & $13.6 \%$ & $13.6 \%$ & $13.6 \%$ & $13.6 \%$ \\
\hline ENT & $14.0 \%$ & $14.0 \%$ & $14.0 \%$ & $14.0 \%$ \\
\hline TVA & $15.0 \%$ & $15.0 \%$ & $15.0 \%$ & $15.0 \%$ \\
\hline SOCO & $14.0 \%$ & $14.0 \%$ & $14.9 \%$ & $23.5 \%$ \\
\hline VACAR & $14.0 \%$ & $14.0 \%$ & $21.0 \%$ & $17.3 \%$ \\
\hline FRCC & $16.0 \%$ & $16.0 \%$ & $16.0 \%$ & $28.1 \%$ \\
\hline
\end{tabular}

\subsection{Operating Reserves in Phase 2}

In Phase 2, the focus in the GE MAPS modeling was on spinning reserves rather than planning reserves. The amounts for each region were based on the EIPC members' stated requirements for each, taking into account loss of the single largest generator, largest generator plus half of the second largest, or percentage of demand. Table 36 is from the Phase 2 final report (EIPC 2012). NYISO includes requirements both for the region as a whole (600 MW) and for subregions (300 MW for zone J-K, 0 MW for zone K). PJM similarly has requirements both for the mid-Atlantic region and the full region. Note that the PJM region has the largest reserve requirement. With a peak demand of $137 \mathrm{GW}$, its spinning reserve at peak is $11.8 \mathrm{GW}, 7.6$ times that of SOCO, the next largest, at its peak.

Table 36. Phase 2 Spinning Reserve Requirements

\begin{tabular}{|c|c|c|c|}
\hline $\begin{array}{c}\text { GE MAPS } \\
\text { Commitment Pool }\end{array}$ & $\begin{array}{l}\text { GE MAPS Operating } \\
\text { Reserve Group }\end{array}$ & Spinning Reserve Requirement & $\begin{array}{c}\text { Spinning Reserve Amount at } \\
\text { Peak }\end{array}$ \\
\hline NEISO & NEISO & $530 \mathrm{MW}$ & $530 \mathrm{MW}$ \\
\hline NYISO & Long Island & $0 \mathrm{MW}$ for NYISO-K (Long Island) & $0 \mathrm{MW}$ \\
\hline NYISO & East NY & $300 \mathrm{MW}$ for NYISO-G NYISO-K & $300 \mathrm{MW}$ \\
\hline NYISO & NYISO & $600 \mathrm{MW}$ for NYISO-A NYISO-K & $600 \mathrm{MW}$ \\
\hline PJM & PJM Mid Atlantic & $1150 \mathrm{MW}+7.5 \%$ of load & $4,844 \mathrm{MW}$ \\
\hline PJM & PJM RTO & $1509 \mathrm{MW}+7.5 \%$ of load & $11,785 \mathrm{MW}$ \\
\hline Midwest & MISO & $800 \mathrm{MW}$ & $800 \mathrm{MW}$ \\
\hline TVA & TVA & $625 \mathrm{MW}$ & $625 \mathrm{MW}$ \\
\hline SPP & SPP & $983 \mathrm{MW}$ & $983 \mathrm{MW}$ \\
\hline VACAR & VACAR & $2 \%$ of hourly load & $958 \mathrm{MW}$ \\
\hline SOCo & SOCO & $3 \%$ of hourly load & $1,542 \mathrm{MW}$ \\
\hline FRCC & FRCC & $350 \mathrm{MW}$ & $350 \mathrm{MW}$ \\
\hline IESO & IESO & $225 \mathrm{MW}$ & $225 \mathrm{MW}$ \\
\hline
\end{tabular}

Another factor was the technologies that qualified as spinning reserve and the quantity available from them. According to the Phase 2 documentation (EIPC 2012), only coal, gas/oil steam, CC, and hydro units were available to provide spin. The amount of spin available was calculated on a unit-by-unit basis. The maximum spin from thermal plants was limited to the lesser of the amount of capacity above their minimum amount and 10 times their per minute ramp rate (to reflect a $10 \mathrm{~min}$ response.) Because the ramp rates used were $3 \mathrm{MW} / \mathrm{min}$ for coal, $6 \mathrm{MW} / \mathrm{min}$ for oil/gas steam, and $10 \mathrm{MW} / \mathrm{min}$ for CC, the 
maximum spin was $30 \mathrm{MW}$ from coal units, $60 \mathrm{MW}$ from oil/gas steam, and $100 \mathrm{MW}$ from CC. Also, the reserves were limited to $50 \%$ of the unit's capacity.

As an example, a $600 \mathrm{MW}$ CC plant has a minimum capacity of $300 \mathrm{MW}$. So to provide the maximum $100 \mathrm{MW}$ of spin it must operate at a minimum of $300 \mathrm{MW}$. To provide 10,000 MW of spin for PJM, assuming $600 \mathrm{MW} \mathrm{CC}$ plants, there would need to be $30 \mathrm{GW}$ of CC plants operating. Using this formula, smaller units of $200 \mathrm{MW}$ could run at their minimum of just $100 \mathrm{MW}$ and still provide $100 \mathrm{MW}$ of spinning reserve. (Note: The capacity and operations of specific plants are not available from the results reported, so it is not possible to determine which plants provided spinning reserves.)

Besides thermal plants, hydro plants could provide spinning reserves equal to $50 \%$ of the difference between the plant's capacity and the month's average generation. So for example, a $300 \mathrm{MW}$ hydro plant operating at $100 \mathrm{MW}$ on average for a given month could provide $100 \mathrm{MW}$ of spin. For many of the regions, hydro capacity could provide a large portion of the spin requirement. Table 37 shows the amount of spin required and available by month for the $\mathrm{CO}_{2}+$ scenario. Six of the regions have sufficient hydro to provide all of their spinning reserve; two others have more than half provided by hydro. Only PJM and FRCC require significant spinning reserve from thermal resources.

Table 37. Regional Average Spin Requirements and Contributions from Hydro

\begin{tabular}{|lcccccccccc|}
\hline $\begin{array}{l}\text { Average Spin } \\
\text { Required }\end{array}$ & 530 & 600 & 7,665 & 800 & 625 & 983 & 520 & 889 & 350 & 225 \\
\hline $\begin{array}{l}\text { Average Spin } \\
\text { from Hydro }\end{array}$ & 1,303 & 652 & 1,621 & 632 & 1,507 & 527 & 596 & 1,324 & 24 & 2,320 \\
\hline Ratio & $246 \%$ & $109 \%$ & $21 \%$ & $79 \%$ & $241 \%$ & $54 \%$ & $115 \%$ & $151 \%$ & $7 \%$ & $1031 \%$ \\
\hline
\end{tabular}

One sensitivity was run on the $\mathrm{CO}_{2}+$ scenario that relaxed several variables relative to reserve requirements. The "Hi-Spin" sensitivity implementation included the following.

- $\quad$ Reduce spinning reserve requirements in MISO, SPP, PJM and Ontario by 50\%.

- All CC units were modeled with a $100 \mathrm{MW} / \mathrm{min}$ ramp rate, turndown $14 \%$ of base load, minimum runtime, and downtime of $2 \mathrm{~h}$.

Ontario already met all spin requirements from hydro, so the changes had no effect on it. MISO, SPP, and PJM received some of their spin requirements from thermal plants, so a change in their generation was expected because of these modifications. The second step in the sensitivity greatly increased the flexibility and amount of spin from CC plants. Plants could provide up to 1,000 MW of spin based on the new ramp rate, which effectively eliminated that restriction. The earlier example of a $600 \mathrm{MW}$ CC plant could operate as low as $84 \mathrm{MW}$ while providing $300 \mathrm{MW}$ of spin (half of its capacity), so 10,000 MW of spin would only need $2,800 \mathrm{MW}$ of CC operating at minimum power. This is less than $1 / 10$ of the amount needed under the original specification. Furthermore, the minimum runtime and downtime of $2 \mathrm{~h}$ are much less than the base case values of $6 \mathrm{~h}$ and $8 \mathrm{~h}$ for minimum runtime and downtime. These combined changes reduced the need for CC plants and also allowed for their shut down when not needed much more frequently. This resulted in less forced curtailment of wind generation, as discussed in the next section.

\subsection{Conclusions}

In Phase 1, the regional planning reserve requirement, given a demand forecast and schedule of plant retirements, determines the need for new resource builds. Planning reserves include all generation technologies in the calculation but reduce the capacities of wind and solar to reflect their limited availability during peak demands. Some scenarios (the $\mathrm{CO}_{2}+$ scenario especially) included large amounts 
of wind, which contributed only a small fraction toward meeting the planning reserve requirement. Because generation from these sources was often much larger than the reduced amount included in the reserves requirement, there was extra generation for export to other regions if transmission was available but curtailments were necessary (as noted in Phase 2) if not. This is discussed further in Chapter 3.

The Phase 2 calculations used operating reserves in their calculations. The required reserve quantities varied greatly by region, with PJM having the greatest requirements, both in megawatts and as a percentage of demand. In the modeling, only thermal fossil plants (coal, gas steam, and CC) and hydroelectric plants could provide reserves; these plants had to be running at least at their minimum dispatch points and could only provide limited quantities based on their ramp rates. While many regions had sufficient hydro to cover most of their reserves requirement, other regions were forced by their reserves requirements to increase output from the committed thermal units while other lower cost units (most notably wind) were curtailed. A sensitivity was run that reduced the reserves requirement by 50\% (to represent DR supply of reserves in some of the regions) and enhanced CC flexibility (minimum power levels, minimum up/down times, and ramp rates). This led to a reduction in the amount of low cost power curtailed, more fully discussed in Chapter 3. During peak times, some regions had to back down their more efficient CC plants to provide reserves and call on more expensive CT units and DR to provide energy, as discussed in Chapter 4. 


\section{TOPIC 7: WIND CURTAILMENT}

\subsection{Background of Topic}

Wind power is a resource that can provide large amounts of electrical power at very low marginal cost. The variable operating cost is near zero, and with production tax credits (PTCs) the final cost to producers is actually negative. Generally, it is most economic for the sector to take all generation provided from wind. However, there are various reasons why at times the system cannot accept all the wind power available and some wind farms have to reduce power levels. There can be multiple contributing factors to curtailment: there is simply more production than consumers demand at the time; there is insufficient transmission to carry the power to other regions where there is demand; and/or there are other factors such as local reserve requirements, transmission impedance, ramping limitations, environmental regulations, or other low cost resources available. These factors become more of an issue as the fraction of power from wind increases.

In Phase 1 of the EIPC study, there was a brief question about whether any curtailment would occur. An analysis showed that even in the $\mathrm{CO}_{2}+$ scenario, the level of curtailment was less than $2 \%$ in all of the regions. However, in Phase 2 there was a significant amount of wind curtailment in the $\mathrm{CO}_{2}+$ scenario from the GE MAPS runs, along with some in the RP/R scenario as well. CRA released data that showed the amount curtailed over the course of the year for each region (Table 38).

Table 38. Phase 2 Wind Curtailment Amounts and Percent of Potential Generation

\begin{tabular}{|c|c|c|c|c|c|c|}
\hline & \multicolumn{2}{|c|}{ BAU } & \multicolumn{2}{|c|}{ RPS/R } & \multicolumn{2}{|c|}{$\mathrm{CO}_{2+}$} \\
\hline & GWh & $\%$ Potential & GWh & $\%$ Potential & GWh & $\%$ Potential \\
\hline ENT & 0 & $0 \%$ & 0 & $0 \%$ & 237 & $30 \%$ \\
\hline MAPP US & 1 & $0 \%$ & 393 & $2 \%$ & 3,894 & $12 \%$ \\
\hline MISO IN & 0 & $0 \%$ & 0 & $0 \%$ & 521 & $2 \%$ \\
\hline MISO MI & 1 & $0 \%$ & 1 & $0 \%$ & 35 & $0 \%$ \\
\hline MISO MO-IL & 1 & $0 \%$ & 1 & $0 \%$ & 8,426 & $26 \%$ \\
\hline MISO W & 123 & $0 \%$ & 4,553 & $5 \%$ & 65,463 & $25 \%$ \\
\hline MISO WUMS & 0 & $0 \%$ & 0 & $0 \%$ & 52 & $1 \%$ \\
\hline NE & 0 & $0 \%$ & 119 & $1 \%$ & 22,417 & $40 \%$ \\
\hline NEISO & 49 & $0 \%$ & 2 & $0 \%$ & 439 & $2 \%$ \\
\hline NYISO A-F & 11 & $0 \%$ & 3 & $0 \%$ & 985 & $5 \%$ \\
\hline PJM E & 0 & $0 \%$ & 14 & $0 \%$ & 47 & $1 \%$ \\
\hline PJM ROM & 3 & $0 \%$ & 3 & $0 \%$ & 2 & $0 \%$ \\
\hline PJM ROR & 5 & $0 \%$ & 444 & $0 \%$ & 504 & $1 \%$ \\
\hline SPP N & 1 & $0 \%$ & 1,053 & $3 \%$ & 21,271 & $15 \%$ \\
\hline SPP S & 1 & $0 \%$ & 3,713 & $4 \%$ & 4,910 & $3 \%$ \\
\hline TVA & 0 & $0 \%$ & 1 & $0 \%$ & - & $0 \%$ \\
\hline VACAR & 4 & $0 \%$ & 19,162 & $24 \%$ & 11 & $0 \%$ \\
\hline IESO & 865 & $5 \%$ & 528 & $3 \%$ & 2,192 & $13 \%$ \\
\hline MAPP CA & 0 & $0 \%$ & 25 & $2 \%$ & 5 & $0 \%$ \\
\hline EI & 1,066 & $0 \%$ & 30,015 & $5 \%$ & 131,412 & $15 \%$ \\
\hline
\end{tabular}

The $\mathrm{CO}_{2}+$ scenario had the most widespread curtailments and so was the subject of the most scrutiny. The western plains regions had the largest amount of curtailment, although there were pockets of curtailments in other regions as well. In the RPS/R scenario, the largest curtailments occurred in VACAR. These were likely offshore wind curtailments and possibly due to inadequate transmission build-out. 


\subsection{Estimation of Hourly Wind Schedule and Curtailments}

To explore the various reasons for the curtailments it was necessary to determine when the curtailments happened and what the demands and production requirements were across the EI. The Phase 2 reports included hourly output for all types of generation, including wind, for each NEEM region. The reports also included the amount of wind energy curtailed for the year by NEEM region (Table 38). Neither wind curtailments nor wind energy available (also referred to here as potential wind generation) were provided on an hourly basis. Thus, we had to estimate the amount of wind energy available in each hour based on the data available. We created a heuristic and applied it to five specific regions that had high levels of curtailment (MISO MO-IL, MISO W, NE, SPP N, and SPP S). These regions are highlighted in Table 38. MISO MO-IL, MISO W, NE, and SPP N all experienced high levels of wind curtailments in the $\mathrm{CO}_{2}+$ scenario. SPP S experienced high levels of wind curtailments in the RPS/R scenario. While VACAR also experienced high levels of wind curtailments in RPS/R, an estimated hourly wind availability schedule could not be produced for that region due to inconsistencies in the reported data for wind output and capacity. A comparison of the estimated wind availability to the wind output from the model provided an estimate of hourly curtailments.

Hourly wind availability was estimated using the hourly wind generation information from the $\mathrm{CO}_{2}+$ and RPS/R scenarios and their sensitivities. Because the $\mathrm{CO}_{2}+$ and RPS/R scenarios and the $\mathrm{CO}_{2}+$ sensitivity that had reduced wind capacity have different amounts of wind capacity installed, the hourly wind generation was normalized based on the amount of capacity for each scenario or sensitivity. Thus, the hourly wind generation data were converted from a megawatt basis to a fraction of wind capacity basis. This placed the various scenarios and sensitivities on an equal footing for a direct comparison. The estimated wind availability for a particular hour was determined by taking the maximum of the normalized wind generation levels across the scenarios/sensitivities for that hour. This operation was performed for all hours of the year to find the estimated wind availability schedule.

The estimated hourly wind availability schedule was then converted back to a megawatt basis for the various scenarios and sensitivities. The hourly curtailments were then estimated by subtracting the hourly wind generation from the hourly wind availability.

The estimation method does not capture all of the curtailments but does significantly reduce the amount of unaccounted for energy for all of the regions except MISO MO-IL. (MISO MO-IL experienced significant local congestion in the production costing model that likely caused curtailments across all the sensitivities.) While the estimation method does not exactly recreate the hourly wind availability, it is sufficient to identify specific hours of the year with large curtailment levels. The transmission interchange levels and generation levels of other generation sources can then be examined for these hours to provide insight into the causes of the wind curtailments.

\subsection{Timing of Curtailments}

A first analysis compares the potential wind generation, wind curtailments, and wind generation by hour of day (Fig. 67). These curves show the average values for all 365 days of the year. Curtailments were highest in the early morning hours, peaking around 5:00 a.m. Because demands are lowest at these times, there is clearly a connection between level of curtailments and demand. While it is also true that potential wind generation is also highest before noon, a clear suppression of demand in the early hours can be seen for most regions examined. SPP-S has a relatively flat and low level of curtailment, so its actual generation stays about the same shape as the potential generation. 


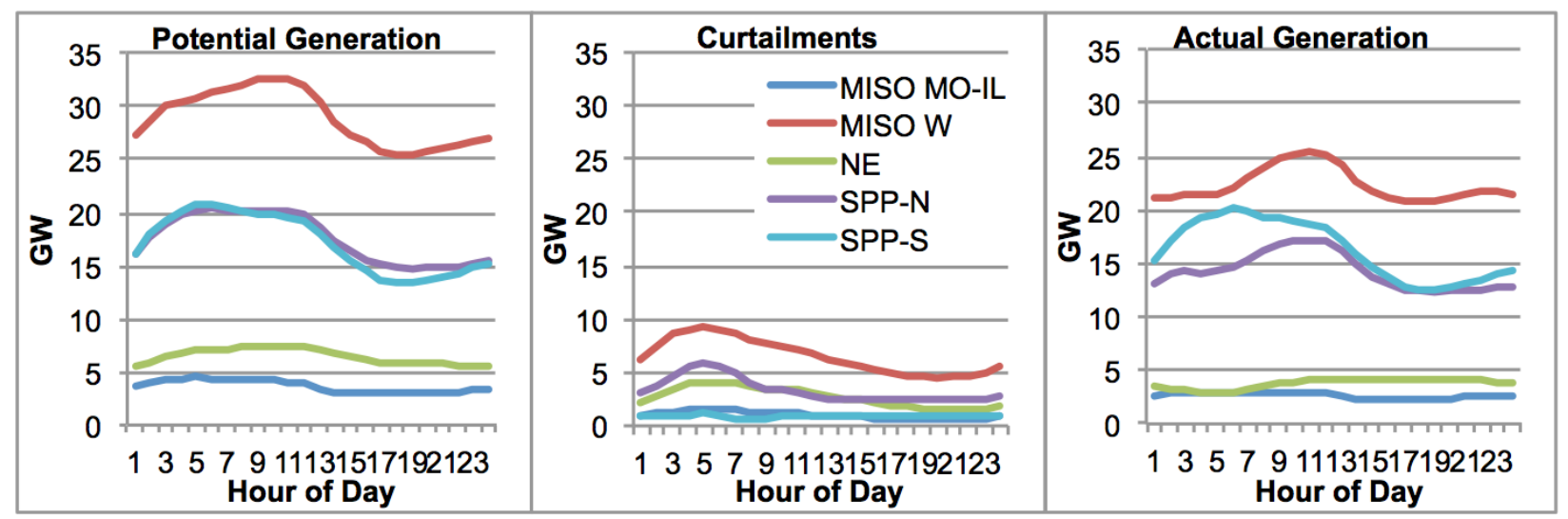

Fig. 67. Potential wind generation, curtailments, and actual generation in the $\mathrm{CO}_{2}+$ scenario by hour of day.

\subsection{Exploration of Peak Curtailment Day}

Another avenue of exploration is to examine the transmission flows during an hour of high curtailment to see whether regional transfer capacities are being strained. As an example, April 1 had the highest level of curtailment for the year for those regions in which we calculated hourly curtailments (Fig. 68). There was major curtailment in the early hours and supply was only slightly above the region's demands, so little was exported.

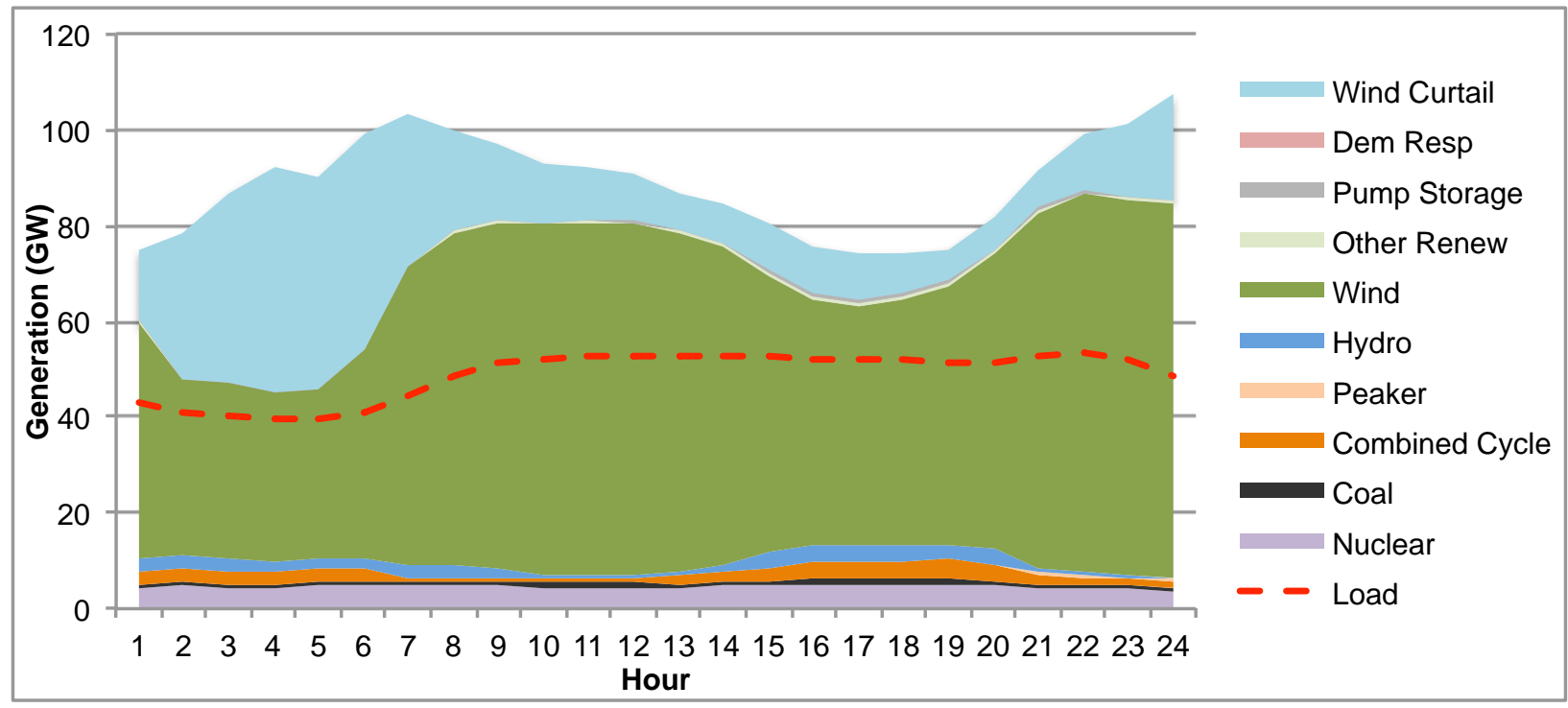

Fig. 68. Supply and demand for major curtailed regions on April 1 in the $\mathrm{CO}_{2}+$ scenario.

The lack of export is verified by looking at the tie-line flows at 4:00 a.m. for the scenario (Fig. 69). Even the HVDC lines from SPP N and MISO W to PJM were only lightly loaded. (In the detailed reports, one of the four HVDC lines between MISO W and PJM ROR was actually flowing back into MISO W.) PJM and other regions were not able to absorb the extra wind power in this hour. 


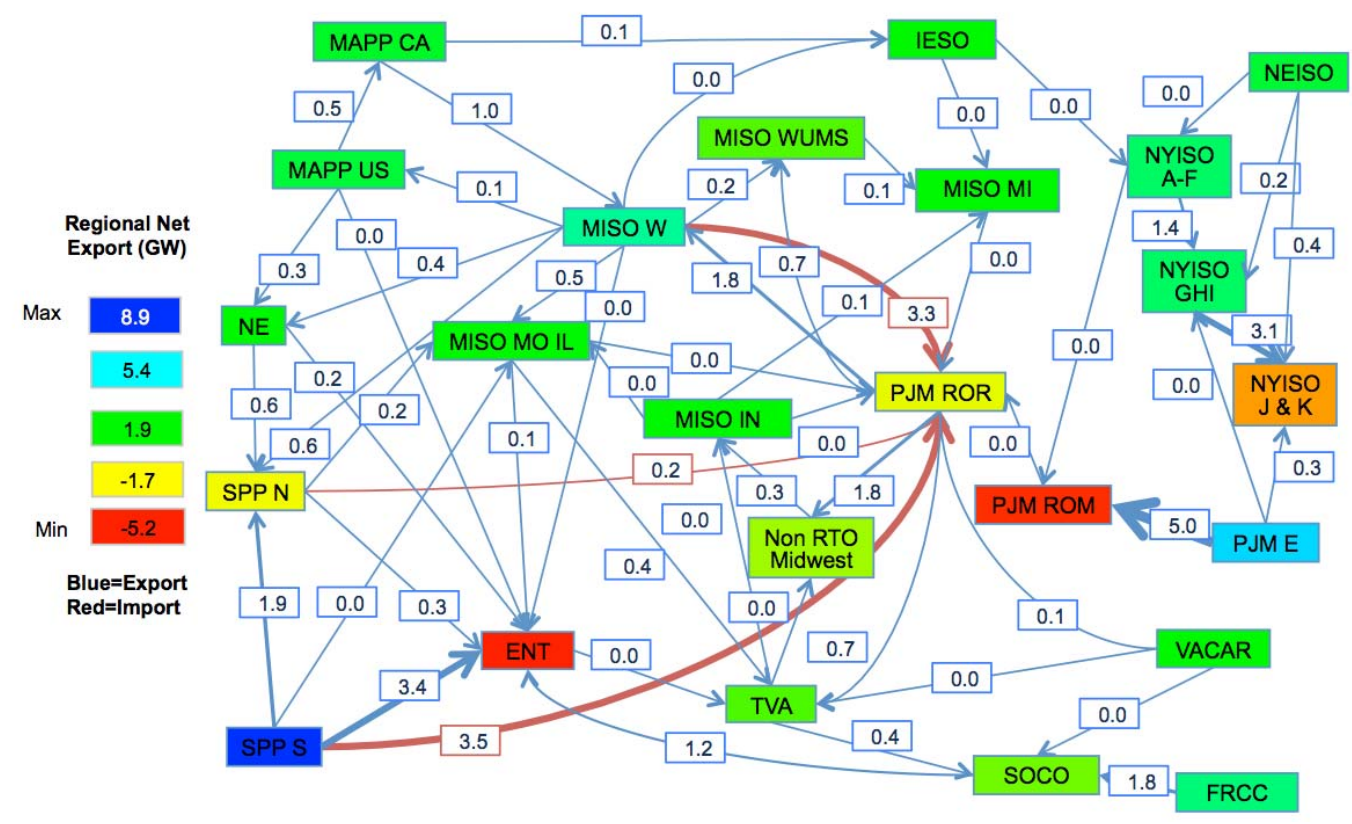

Fig. 69. Tie-line flows on April 1 at 4:00 a.m. for the $\mathrm{CO}_{2}+$ scenario.

The PJM region could not take additional power because its plants were running at the minimum levels or had to be running to be available in later hours. In Fig. 70, the generation levels by technology are shown for the three PJM regions combined. Note that the CC plants are running at 17,300 MW constantly through the morning. If these were all $750 \mathrm{MW}$ plants running at their minimum of $50 \%$ of capacity, then there would be 50 plants running, and they would provide 5,000 $\mathrm{MW}$ of reserves. Based on the equation for required reserves, PJM needs 6,200 MW of reserves in that hour. Subtracting 1,400 MW supplied by hydro leaves 4,800 MW of reserves needed, about the same amount as provided by the CCs. So for this hour, it appears that the main cause of the curtailed wind was the reserves requirements and other operating constraints, not lack of transmission.

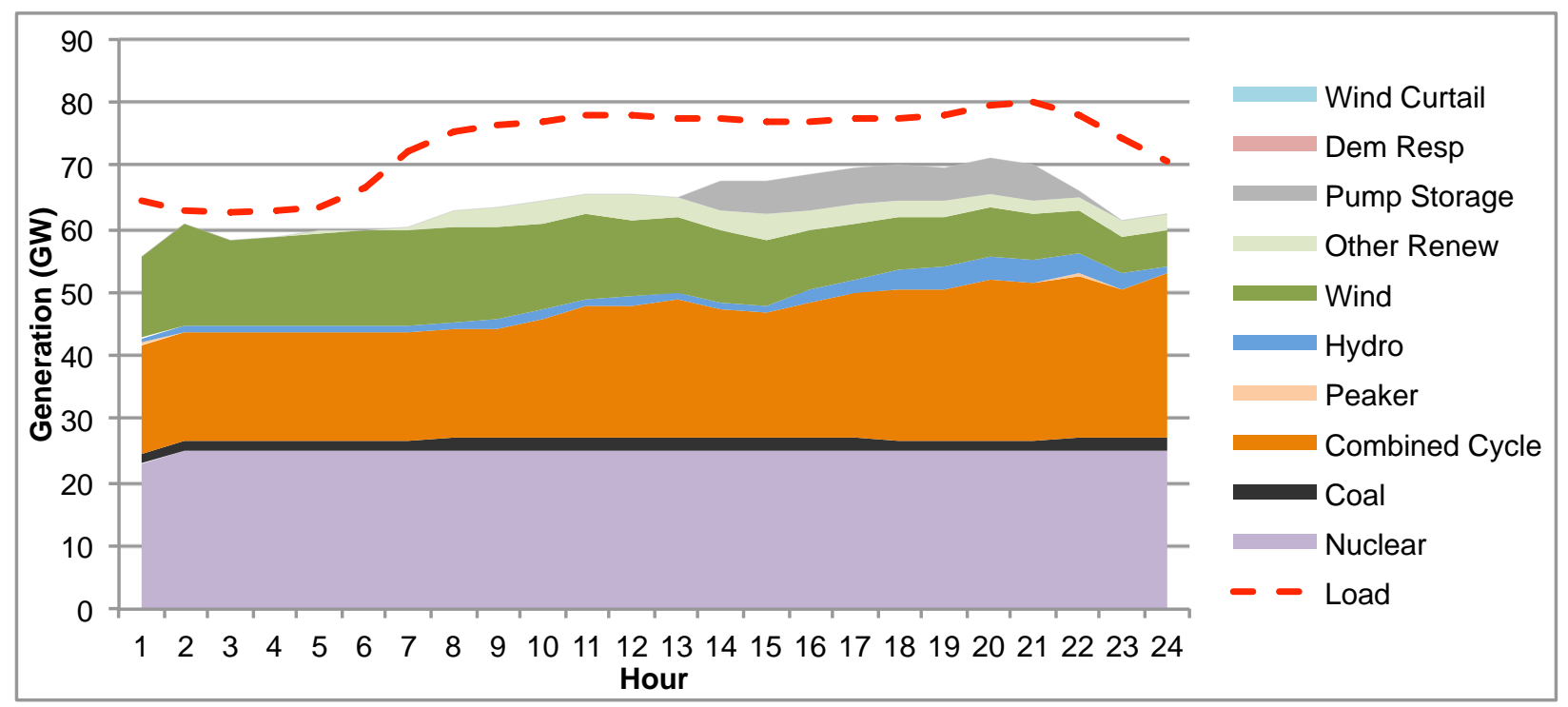

Fig. 70. Generation and loads for PJM regions on April 1 in the $\mathrm{CO}_{2}+$ scenario. 
A further bit of information about the state of the grid at any point in time is the LMPs for the different BAs. CRA reports the hourly prices for 154 different BAs across the EI. These have been mapped to the general location of the areas, although some BAs cover overlapping regions and have their headquarters near each other. Plotting the points and color-coding based on the price shows the span of prices across the EI for the April 1 case (Fig. 71). Most areas have prices at or below \$10/MWh, with some areas even below zero. As all coal and CC plants have variable costs higher than this price, they must be operating at a loss on energy sales and operating because either they are needed for operating reserves or because they will be needed later in the day. (The location in North Dakota with a high spot price appears to be the result of a localized transmission issue resulting in a load pocket.) Sure enough, by 10 a.m. prices have risen across most of the EI to around $\$ 60 / \mathrm{MWh}$.

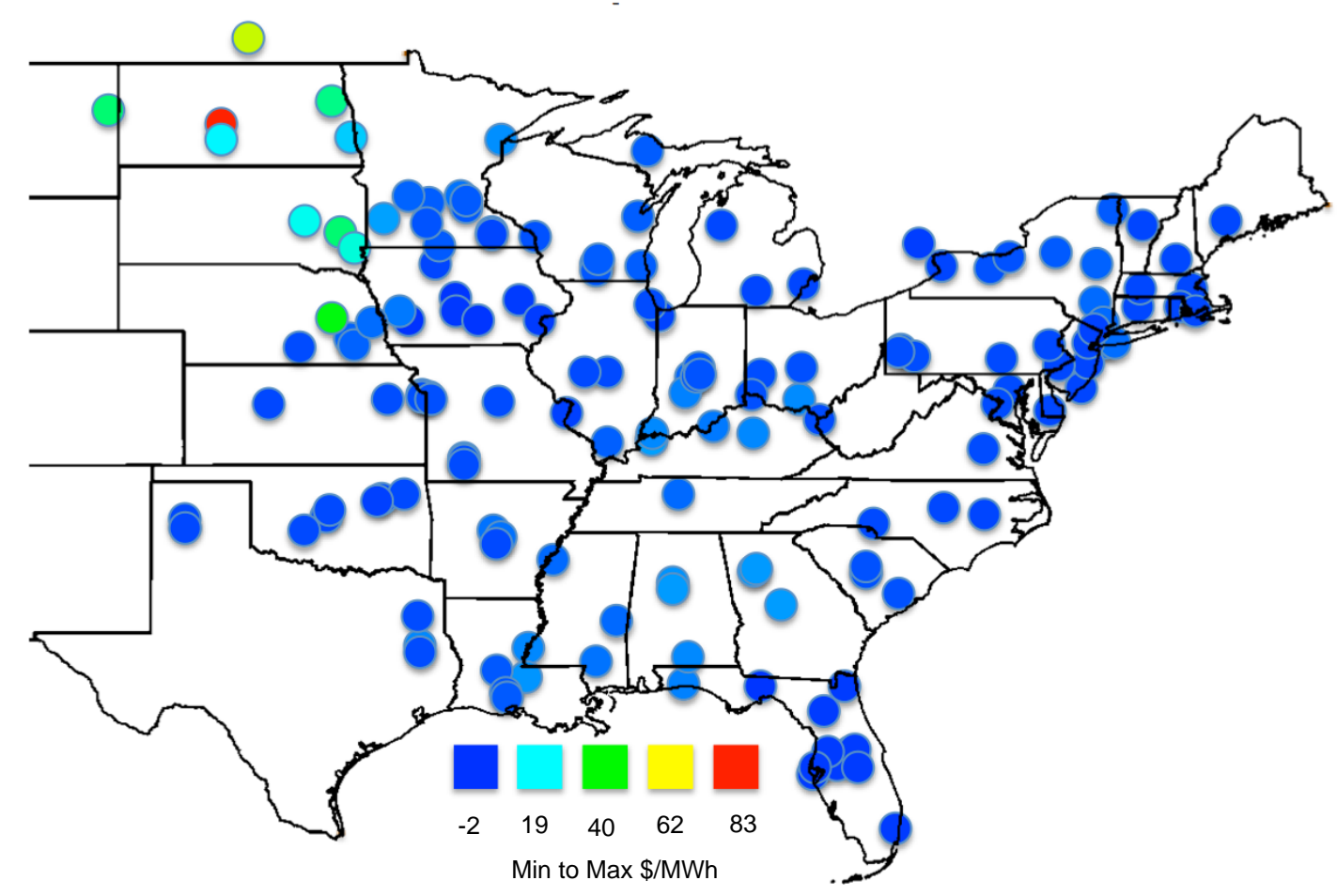

Fig. 71. Locational marginal prices for balancing areas across the EI on April 1 at 4:00 a.m. for the $\mathrm{CO}_{2}+$ scenario.

\subsection{Effect of Reduced Spin Requirements and Flexible Combined Cycle}

Another means to examine the question is to evaluate the results from the Hi Spin sensitivity. As mentioned previously, spin requirements were lowered for several regions, while ramp rates (and consequent reserves supply) were increased for several technologies, and the minimum up and down times for these technologies were also reduced. These changes all combined to significantly reduce the curtailments in many of the hours of study. Production levels on April 1 are significantly different for both the curtailed regions and PJM, as shown in Fig. 72 and Fig. 73. Comparing these to Fig. 68 and Fig. 70 reveals a much lower level of curtailment in the curtailed regions and a greatly reduced level of CC production in PJM in the early hours of the day. Clearly the spin requirements and/or minimum up/down times in the base case played a role in the level of curtailments. This is further revealed in the tie-line flows for 4 a.m. across the EI (Fig. 74). The HVDC lines become almost fully loaded and large amounts of power are transferred from MISO W, NE, and SPP N through SPP S to ENT, TVA, and SOCO (as compared to the $\mathrm{CO}_{2}+$ case in Fig. 69.) 


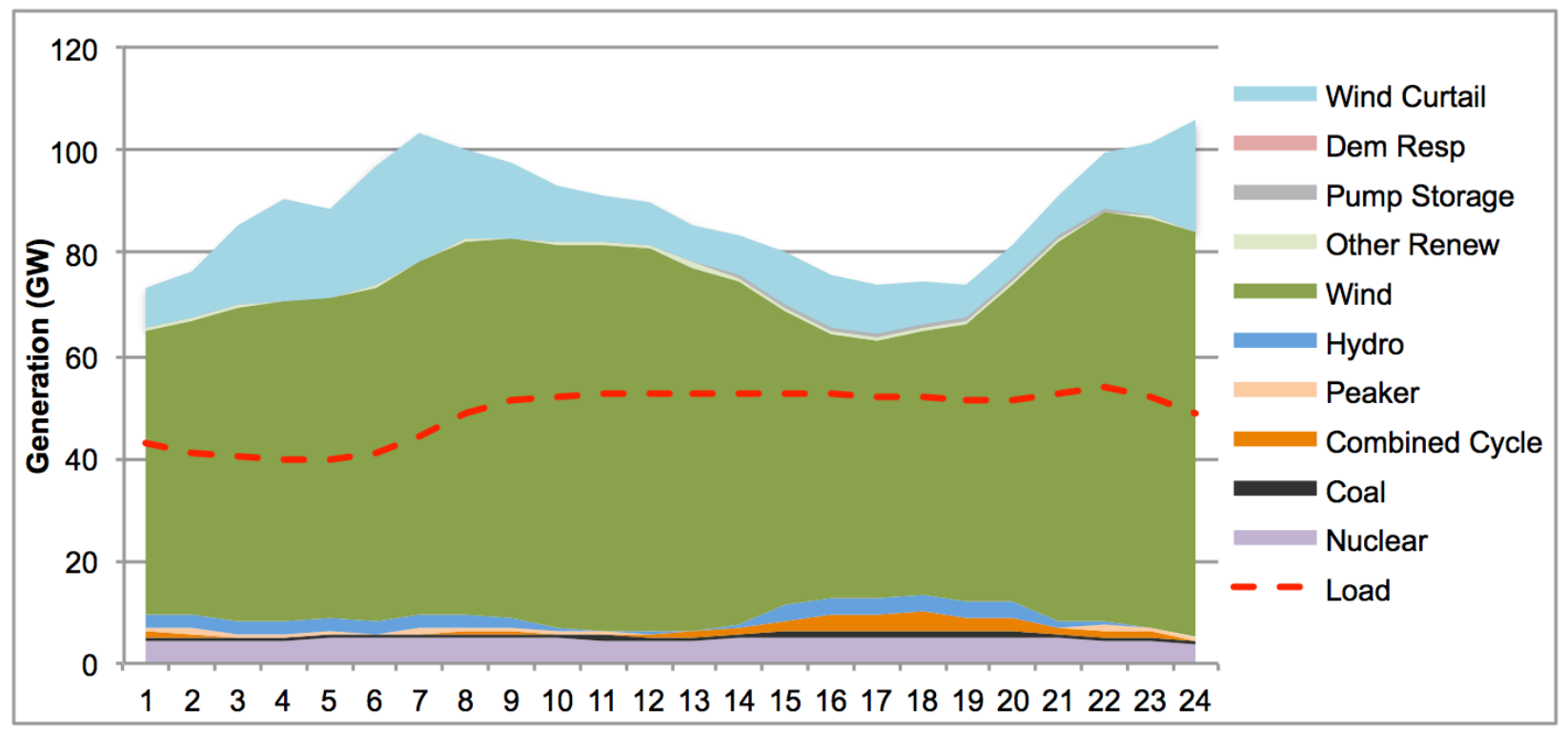

Fig. 72. Generation on April 1 in the curtailed regions in the Hi Spin sensitivity.

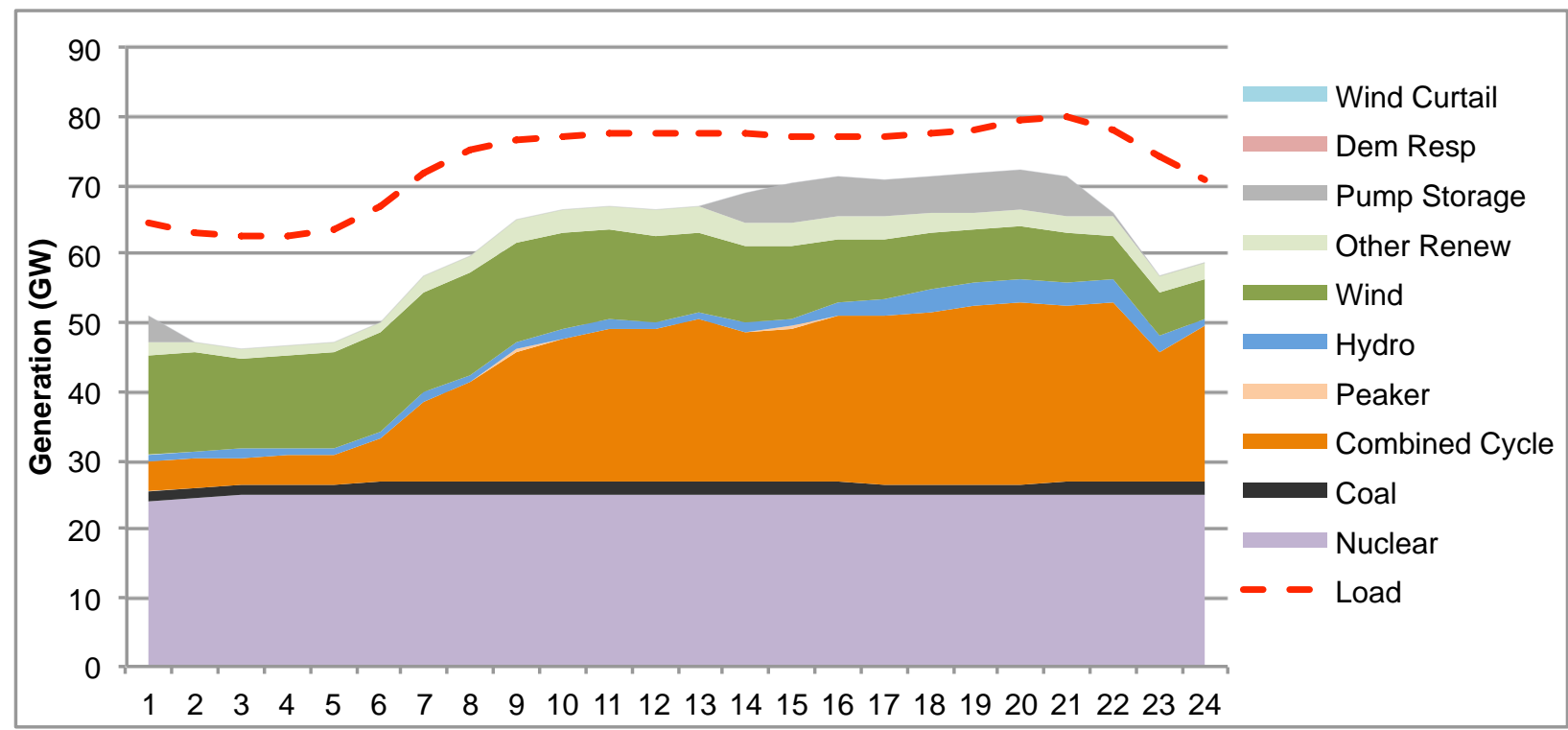

Fig. 73. Generation on April 1 in PJM in the Hi Spin sensitivity. 


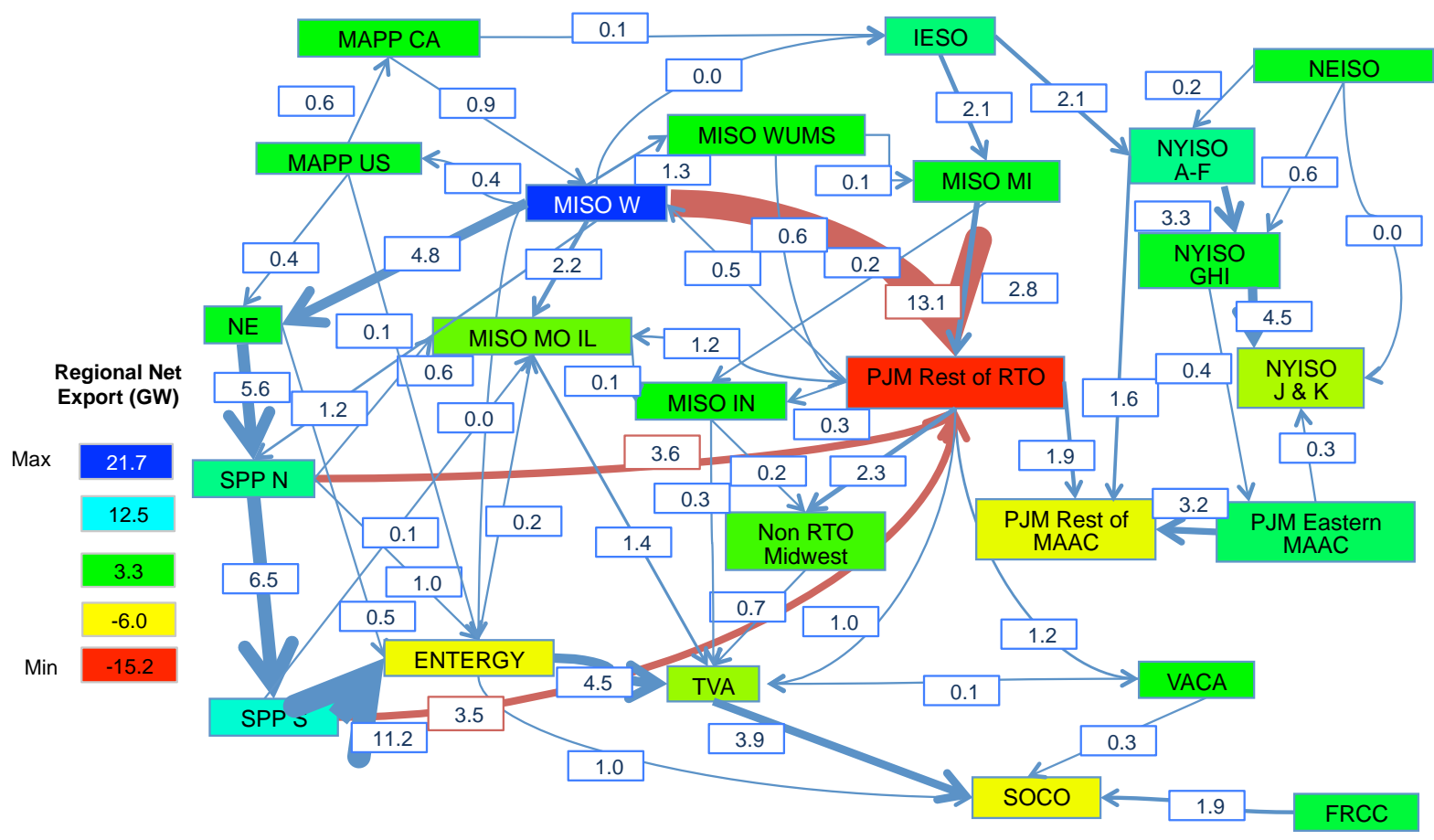

Fig. 74. Tie-line flows on April 1 at 4:00 a.m. in the Hi Spin sensitivity.

While spinning reserve requirements and generating plant parameters had some effect on the amount of curtailment, relaxing those requirements still left most of the curtailments. The total curtailments dropped just 9\% from $131 \mathrm{TWh}$ in $\mathrm{CO}_{2}+$ to $120 \mathrm{TWh}$ in the Hi Spin sensitivity. MISO W curtailments for the whole year dropped just 5\%, from $65 \mathrm{TWh}$ to $62 \mathrm{TWh}$. Spinning reserve requirements do not seem to account for all wind curtailments. We next examined tie-line loading to determine whether those constraints may have resulted in additional curtailment.

\subsection{Curtailments Versus Tie-Line Capacity}

It is possible that wind is curtailed because there is not enough transmission capacity to transport it to where it is needed. If the curtailments occurred due to tie-lines being fully loaded, then most curtailment should occur during high tie-line activity. We summed the hourly net tie-line flows out of the five curtailed regions for which we calculated the curtailments by hour. We then compared that to the amount of curtailment in these five regions combined. In the $\mathrm{CO}_{2}+$ scenario there is a general peak tie-line flow out of the curtailed regions of around $40 \mathrm{GW}$ (Fig. 75). The highest curtailments typically occurred when the tie-lines were at this power level, which indicates that curtailments could probably have been reduced with increasing tie-line capacity. 


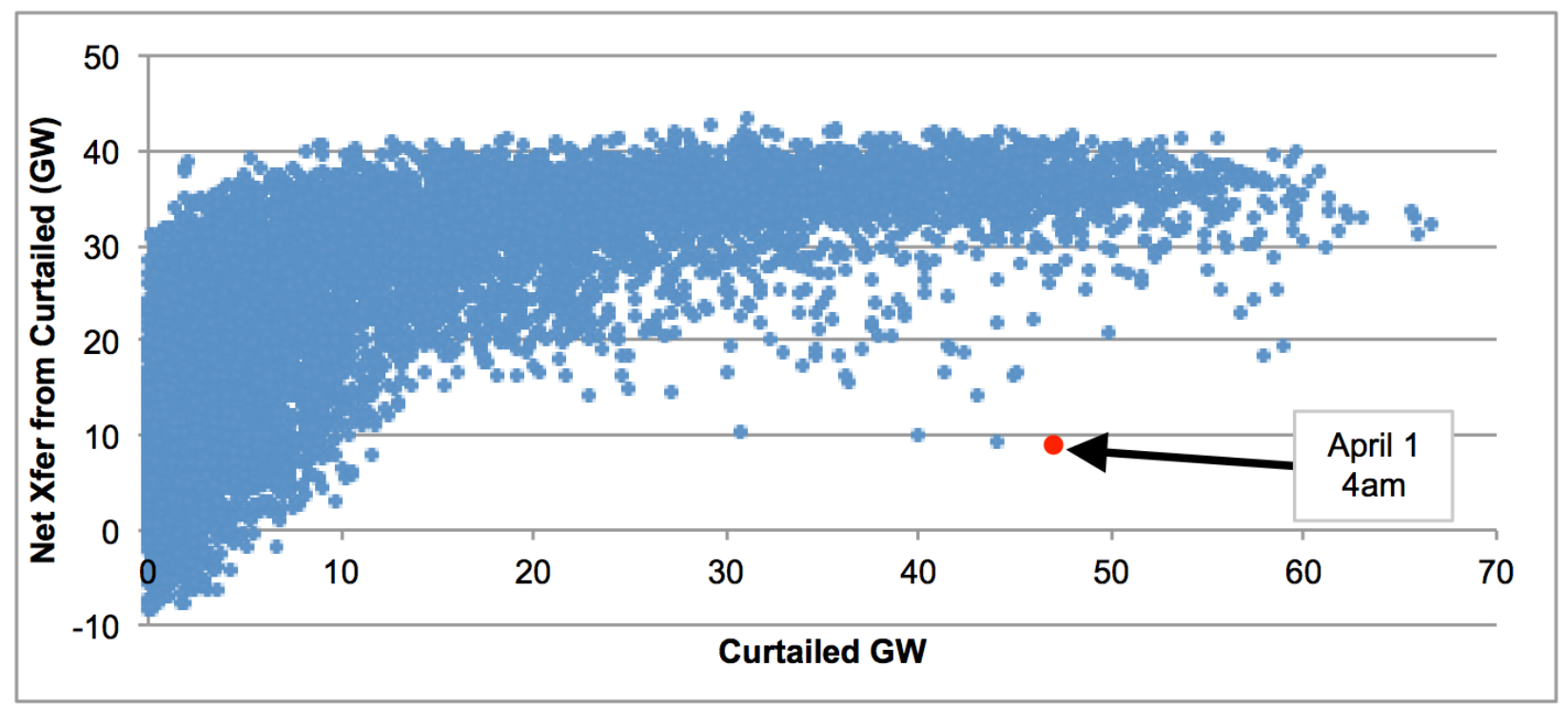

Fig. 75. Net transfer vs. curtailment in the curtailed regions for the $\mathrm{CO}_{2}+$ scenario.

This is even more apparent when comparing the Hi-Spin sensitivity (Fig. 76). Many of the points with high curtailments but low tie-line flows either increase their flow, reduce their curtailment, or both. Examples include the April 1 4:00 a.m. example, with curtailments and transfers for the two cases shown in Table 39. In those hours affected by the changes in reserve requirements and plant capabilities, the tielines were more heavily used and the curtailment amounts went down because the power was used in the other regions.

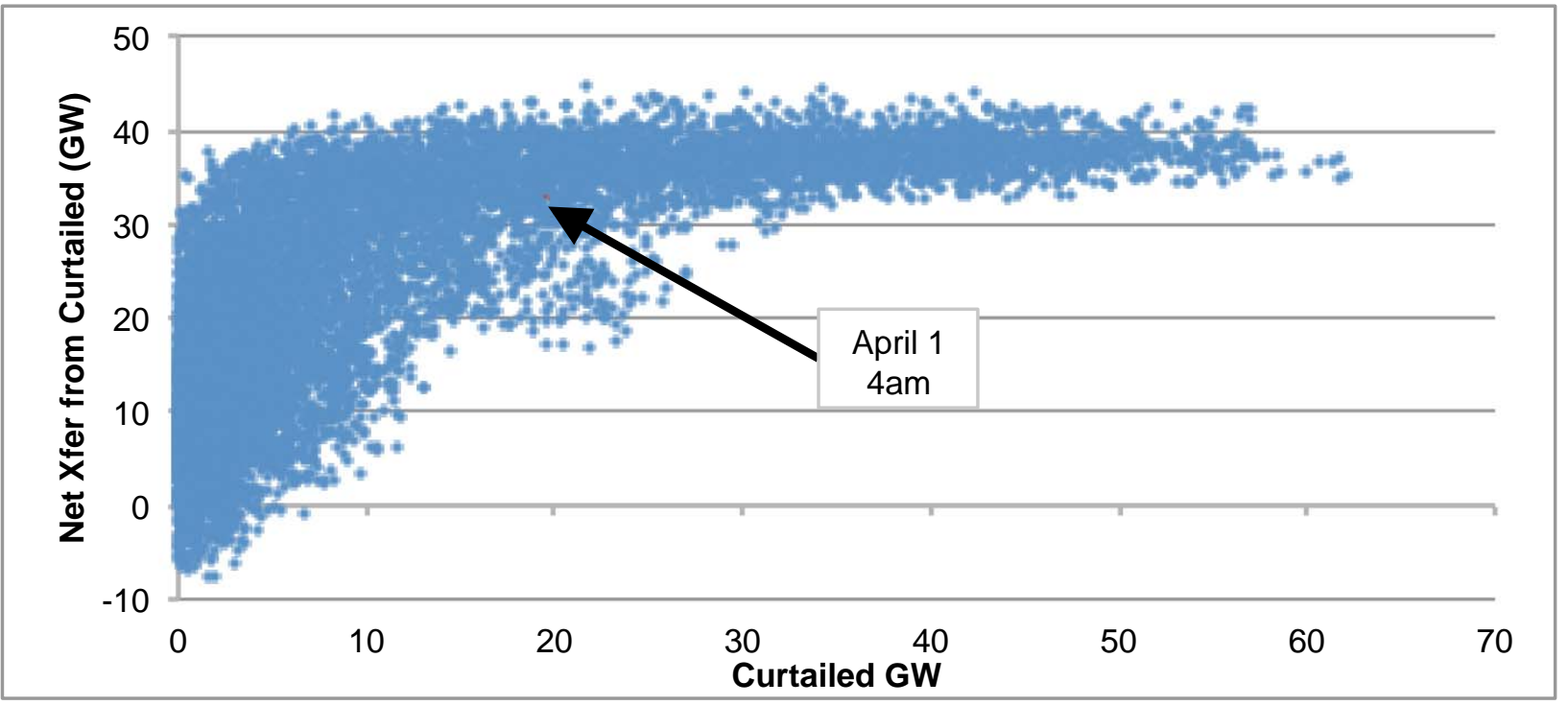

Fig. 76. Net transfer vs. curtailment in the curtailed regions for the Hi Spin sensitivity.

Table 39. Curtailments and Net Transfers April 1 at 4:00 a.m. for curtailed regions

\begin{tabular}{|lcc|}
\hline $\mathbf{C O}_{2}+$ Scenario & Curtailments & Transfers \\
\hline Hi Spin Scenario & $19.0 \mathrm{GW}$ & $8.9 \mathrm{GW}$ \\
\hline
\end{tabular}


More than half the hours have curtailments below $10 \mathrm{GW}$ in the five regions studied and over $70 \%$ of the time curtailments are below $20 \mathrm{GW}$. Figure 77 is a histogram showing the fraction of the year for different ranges of curtailment levels. There is a slight difference between the $\mathrm{CO}_{2}+$ scenario and the $\mathrm{HI}$ Spin sensitivity, reflecting the shift to lower curtailment amounts with the Hi Spin changes in reserves requirements and plant capabilities.

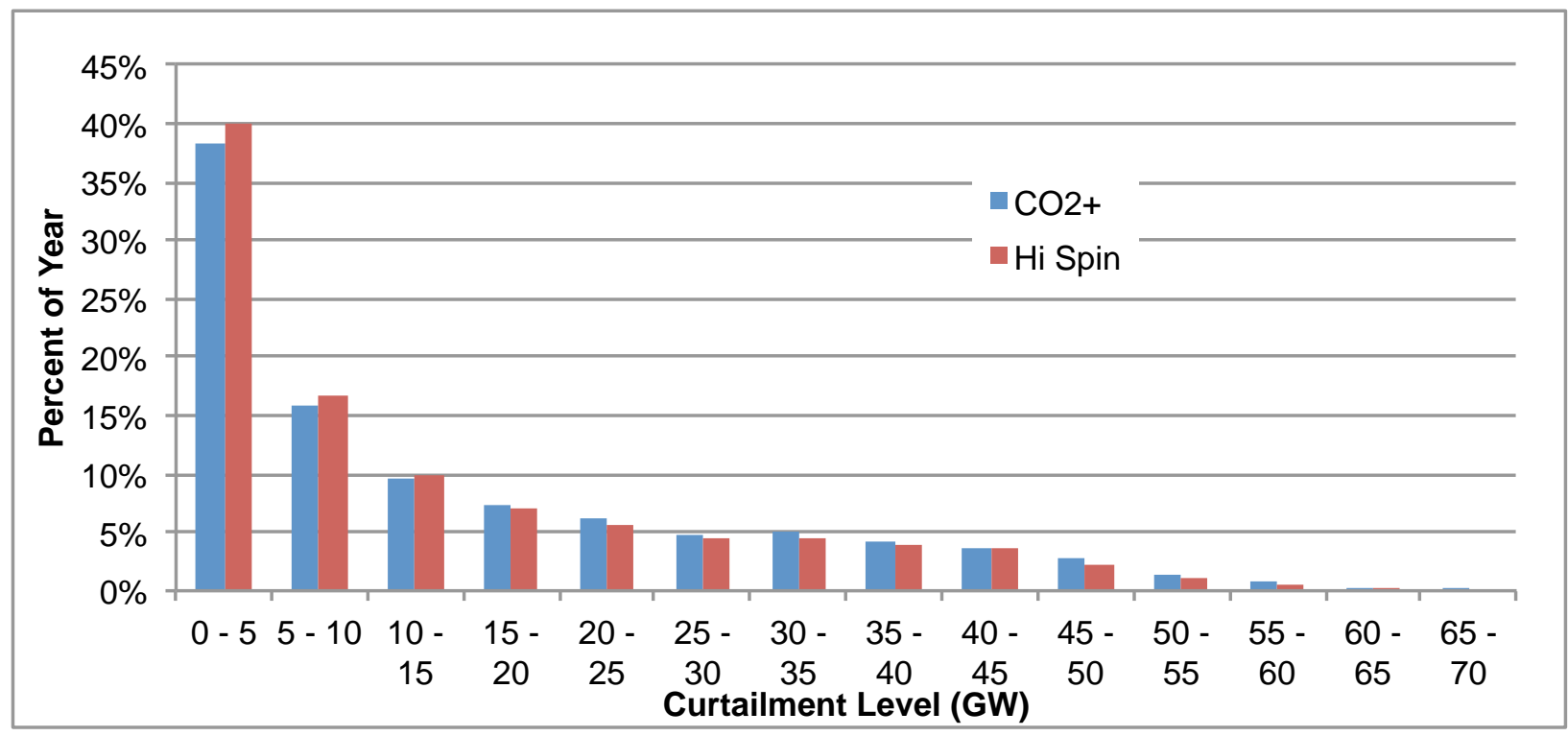

Fig. 77. Percent of year that curtailments in curtailed regions were at different levels.

The amount of curtailments that could be resolved through tie-line improvements is unknown. The $\mathrm{CO}_{2}+$ scenario included $21 \mathrm{GW}$ of additional HVDC lines (plus a large amount of conventional transmission). As there were still some hours with more than $60 \mathrm{GW}$ of curtailment, adding 4 times as much HVDC capacity as in that scenario might eliminate most but still not all curtailments. Also, their construction would be quite difficult and placement would likely require significant upgrades in supporting infrastructure. The economic rationale for expansion of the grid, which must balance a large number of factors, is thus more complicated than just meeting reliability criteria during peak times (the method used in the EIPC study) or eliminating all wind curtailments.

An examination of the hourly curtailments in the Hi Spin sensitivity reveals that the periods with high levels of curtailments also have high levels of tie-line transfers out of the curtailed regions. Figure 78 shows the curtailments in the curtailed region (MISO W, MISO MO-IL, SPP N, SPP S, and NE) and the net transfer from the curtailed regions to other areas for each hour, the same as Fig. 76. The vertical red line represents the median hourly wind curtailment $(7,712 \mathrm{MW})$. Thus, half of the hourly curtailments lie to the left of the line (lower than the median) and the other half lie to the right of the line (greater than the median). The horizontal red line represents the median hourly net transfer $(27,174 \mathrm{MW}$ ) from the curtailed region. These lines divide the graph into four quadrants, described in Table 40.

If the two sets of data are independent, roughly the same number of points will lie in each quadrant. If quadrants I and III are overrepresented, the sets of data tend to be correlated. In this case, there are $3,690 \mathrm{~h}$ in each of quadrants I and III and $690 \mathrm{~h}$ in each of II and IV. This means that $42 \%$ of the time both transfers and curtailments are higher than the median, $42 \%$ of the time they are both lower than the median, and $8 \%$ for each of the other two possibilities. In general, this indicates that high levels of wind curtailments occur when net transfers are high and low levels of curtailments happen when net transfers are low. 


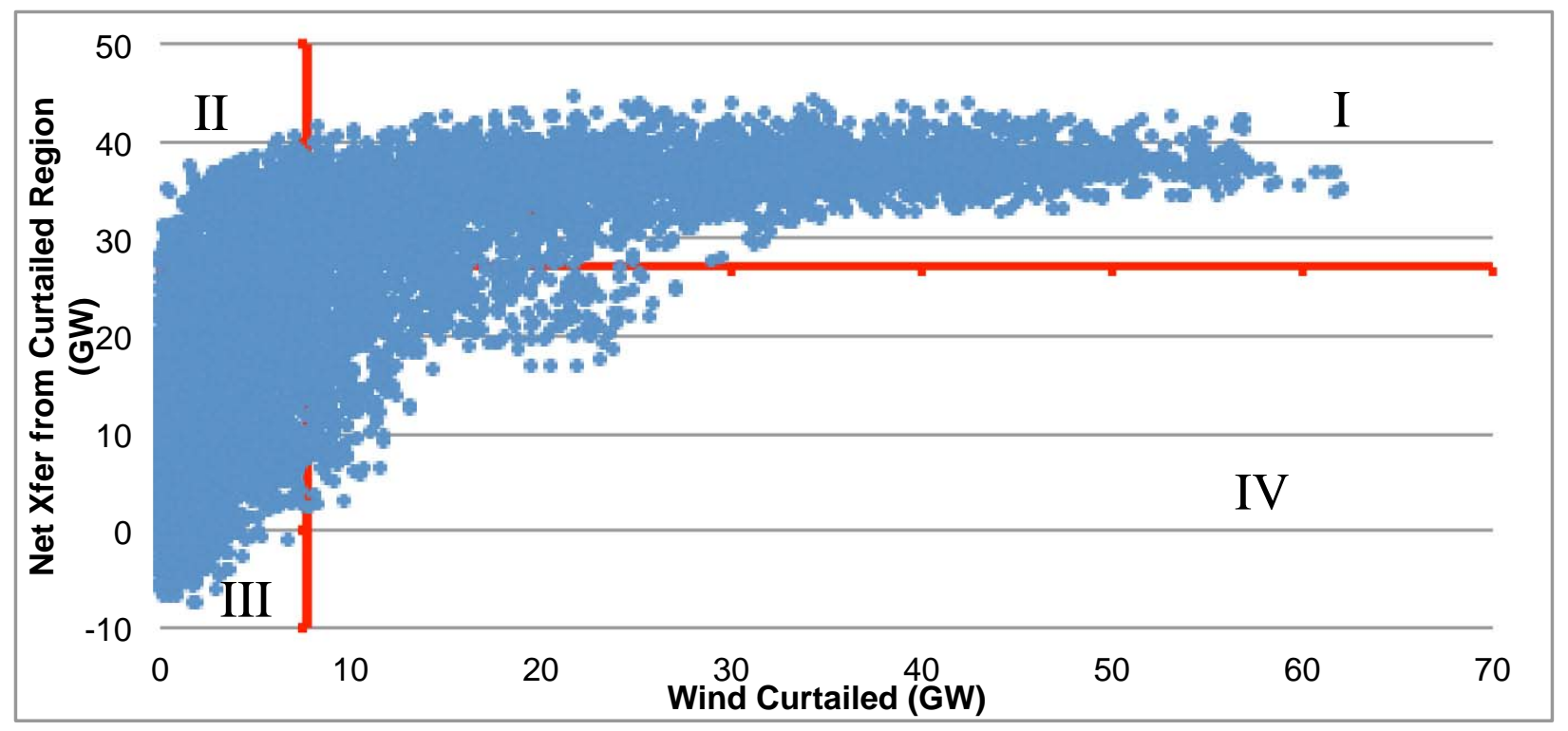

Fig. 78. Net transfer vs. wind curtailment in the curtailed regions in the Hi Spin sensitivity.

Table 40. Curtailment and Transfer Quadrants for the Hi Spin Sensitivity

\begin{tabular}{|ccccc|}
\hline Region & Transfers & Curtailments & Hours & Curtail TWh \\
\hline I & $>$ Median & $>$ Median & 3,690 & 96.5 \\
\hline II & $>$ Median & $<$ Median & 690 & 3.1 \\
\hline III & $<$ Median & $<$ Median & 3,690 & 9.4 \\
\hline IV & $<$ Median & $>$ Median & 690 & 8.5 \\
\hline
\end{tabular}

Looking further out toward the extremes, there are 1,390 hours where curtailments exceed $30 \mathrm{GW}$. Of those, only two occur in hours with less than $30 \mathrm{GW}$ of transfers, and neither of those occurs when transfers are lower than the median. Thus, once we account for the hours where large amounts of curtailments result from spinning reserve requirements by adjusting the spinning reserve requirements and generator characteristics in the Hi Spin sensitivity, the high curtailments occur during hours with high transfers. This indicates that transfer limitations are a major factor.

A final point is that the vast majority of curtailed energy occurs in Quadrant I (last column in Table 40), when both curtailments and transfers are above the median. More than $96 \mathrm{TWh}$ of curtailment from these five regions occurred in Quadrant I in the Hi Spin sensitivity. In the $\mathrm{CO}_{2}+$ scenario, Quadrant I contained more than $101 \mathrm{TWh}$. The Hi Spin sensitivity only reduced curtailment by $9 \mathrm{TWh}$ overall, so compared to spinning reserve requirements, the dominant reason for the curtailments was the transfer limitations.

\subsection{MISO MO-IL Supply Pocket}

There still remain a number of hours in the Hi Spin sensitivity when net transfers are well below the peak amount but curtailments arise. These can occur when there are local pockets of congestion within a region. Wind power is available but blocked behind a bus with inadequate capacity, even though there is capacity available on one of the outbound tie-lines. This occurred in the MISO MO-IL region (as well as the VACAR and MAPP US regions) a significant percent of the time.

Figure 79 is a map of the locational marginal prices at the different BAs on April 1 at 10:00 a.m. in the $\mathrm{CO}_{2}+$ scenario. The price in the Ameren Corporation control area, located in southwestern Illinois, is 
\$125/MWh (the highest in the EI), while in the neighboring Columbia Water and Light area (Columbia, Missouri), the price is only $\$ 1 / \mathrm{MWh}$ (the lowest in the EI) in that hour.

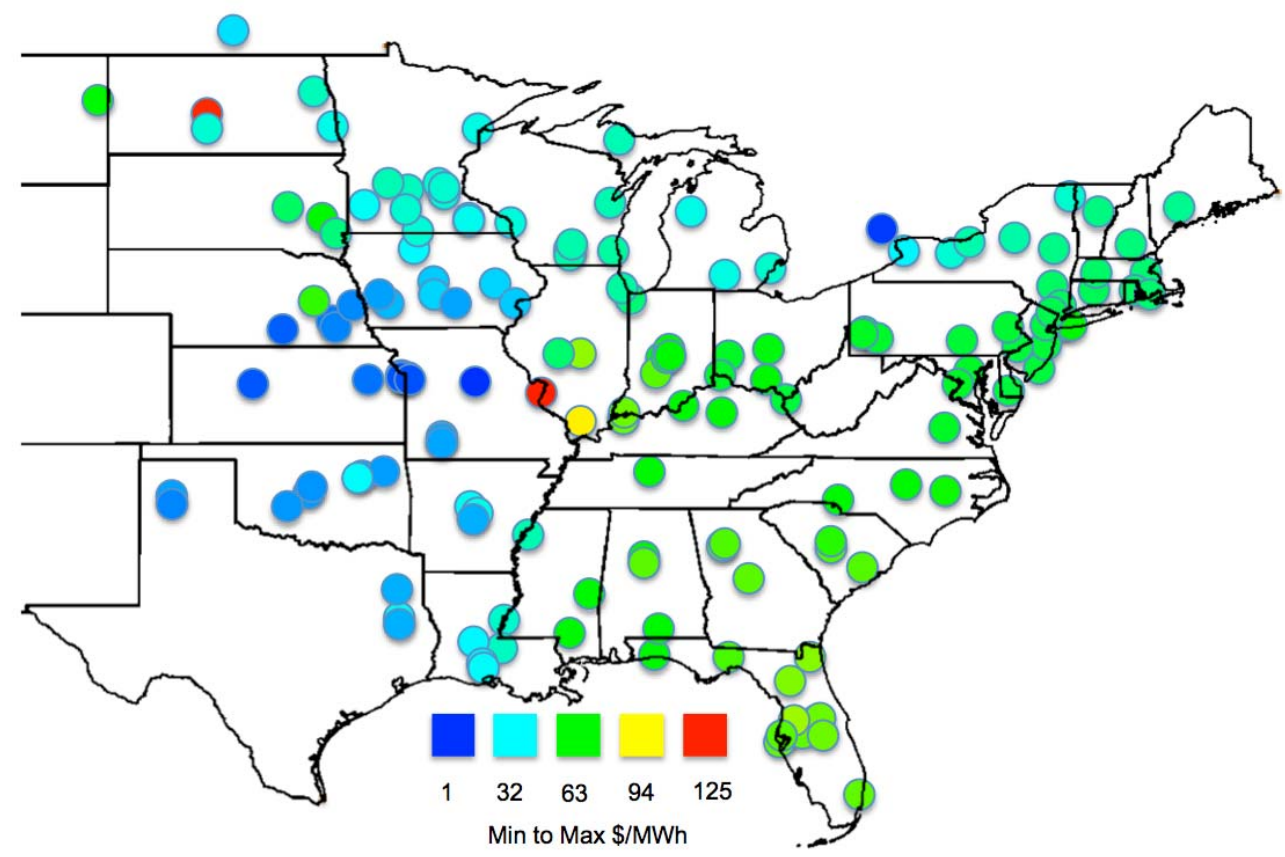

Fig. 79. Locational marginal prices on April 1 at 10:00 a.m. in the $\mathrm{CO}_{2}+$ scenario.

Wind was curtailed in MISO MO-IL throughout the morning in this scenario, even though MISO MO-IL had to import significant amounts of power after 7:00 a.m. (Fig. 80). Meanwhile, some "peaker" capacity had to be run, especially in the late evening. This indicates that some regions within MISO MO-IL could not access the available power in other parts of the region.

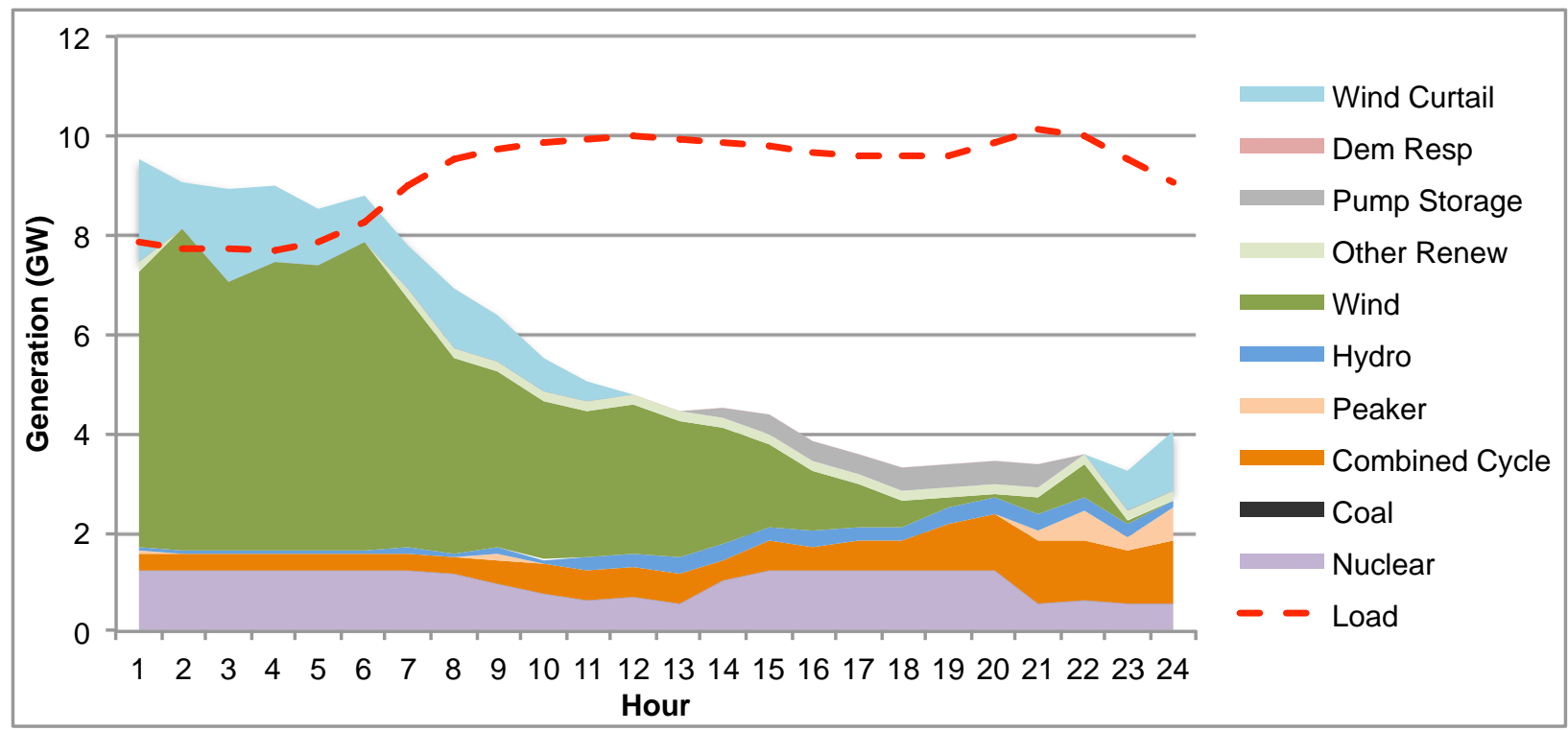

Fig. 80. MISO MO-IL generation and load on April 1 in the $\mathrm{CO}_{2}+$ scenario.

Discussions with EIPC and examination of the transmission build-out revealed that a significant wind farm $(4,000 \mathrm{MW})$ had been added to the grid in northeast Missouri. Shadow prices between flowgates 
from GE MAPS show a frequent difference in price between certain buses west of St. Louis. Likely, this bus or tie-line should have been upgraded to open up the curtailed wind to the Ameren control area but was not caught during the first part of Phase 2. It would require further analysis in the PSS/E model to determine appropriate changes and possible consequent changes to other infrastructure.

\subsection{Conclusions}

The high levels of wind curtailments in Phase 2 occurred because the GE MAPS model was unable to use all of the available wind during a number of hours of the year. The factors driving this inability differed depending on the hour and region being examined. During certain hours, such as the morning of April 1, operating reserve requirements outside of the curtailed region limited the ability to export power even though tie-line capacity was not being fully used. During other periods, tie-line capacity was not sufficient to move the available power to other regions. Finally, local transmission congestion such as within the MISO MO-IL region created a generation pocket from which wind generation could not get out to the rest of the system. 


\section{TOPIC 8: DEMAND RESPONSE}

\subsection{Demand Response in Phase 1}

DR is a complex collection of programs and technologies that let demand respond to supply, mainly through reduction of demand in the face of supply shortages. The Federal Energy Regulatory Commission (FERC) defines DR as "the changes in electric usage by demand-side resources from their normal consumption patterns in response to changes in the price of electricity over time, or to incentive payments designed to induce lower electricity use at times of high wholesale market prices or when system reliability is jeopardized" (FERC 2009). Different DR programs can be automated or not, controlled by the utility or customer, involve direct price incentives or appeals, and apply to different demand sectors. Several studies on DR in the EI were commissioned during the EIPC process. ${ }^{*}$ The following are two notable ones.

- Baek, Young Sun, et al. Eastern Interconnection Demand Response Potential. ORNL/TM2012/303. Oak Ridge, TN: Oak Ridge National Laboratory, November 2012.

- Navigant, Assessment of Demand-Side Resources within the Eastern Interconnection, prepared for the Eastern Interconnection States' Planning Council, March 2013.

In June 2009, FERC released a study on DR, A National Assessment of Demand Response Potential, or NADR (FERC 2009). For the EIPC study, the amount of DR for each region was calculated using the state-by-state projections of DR from the FERC NADR model. The model projects both future DR and future peak demand through 2019 for four different scenarios: BAU, expanded BAU, achievable amounts, and full participation. The state-weighted average ratio of DR to peak demand was found for each NEEM region in the study.

For most of the futures in Phase 1, the SSC decided that the percentage of demand that DR could supply would transition from the percentages of demand in the FERC BAU scenario in 2015 to that of the FERC Expanded BAU by 2025 and then continue with those percentages to the end of the period. For the aggressive DR Future 4, the SSC transitioned from the BAU percentages in 2015 to the full participation percentages by 2025 and then continued those percentages to the end. Some utilities treat DR as an alternative supply (where $1 \mathrm{MW}$ of DR equals $1 \mathrm{MW}$ of supply) and some as a reduction in demand (where $1 \mathrm{MW}$ of DR reduces demand by $1 \mathrm{MW}$, and so for calculation of the reserve requirement the DR is equal to its capacity times 1 plus the reserve margin). To approximate the variations between regions, the SSC multiplied the DR capacity by one plus half of the required reserve margin for each region.

The calculations fixed the amount of DR capacity that would be added within each region rather than allowing NEEM to select how much DR capacity to build. However, the model could choose to call upon, or dispatch, this power. Within NEEM, CRA modeled DR as a forced-in pseudo-generator with no fixed cost but a high energy cost (and consequent price for dispatch decisions) so that it would only be used when most or all other supplies were deployed. In Phase I of the modeling, the original amount of potential DR from NADR was calculated based on NADR's default ratio of critical peak price (CPP) to average price of 8 . With the default ratio of CPP to average price and a rough estimate of average retail electricity price, the average price of dispatching DR was set at $\$ 750 / \mathrm{MWh}$. This estimated DR price was applied to all DR supplies in the dispatch process of NEEM. However, in Phase 1 very little DR was dispatched, just $39 \mathrm{GWh}$ in the VACAR and $24 \mathrm{GWh}$ in the FRCC in the $\mathrm{CO}_{2}+$ scenario and none in the

\footnotetext{
* A similar study (Satchwell et al., 2013) was conducted for the Western Interconnection.
} 
other regions or scenarios. Even so, DR served to reduce the capacity requirements from other resources for all regions because it could be applied in the reserve margin calculations.

\subsection{Demand Response Supply Curve for Phase 2}

The modeling in Phase 2 allowed a more detailed approach but still treated DR as pseudo-generators within each region. Instead of a single price, there could be up to six supply amounts, each at a different price point. Still, as with NEEM, the GE MAPS model did not limit DR to a maximum number of hours per year or total amount of generation over the year, so the modeling had to use price as a lever to get DR to be dispatched semi-realistically. A more realistic DR supply curve was needed than the single tier at $\$ 750 / \mathrm{MWh}$. Therefore, a tiered pricing arrangement or supply curve for DR was calculated, with six different DR price tiers, but still with an average price for DR of \$750/MWh to match the Phase 1 assumption.

ORNL researchers who conducted the DR study created a national stepwise DR supply curve for 2030 based on the ORNL version of the FERC NADR model (ORNL NADR). Under the full deployment scenario of the ORNL NADR, 30 different cases with a variation of CPP ranging from $\$ 50 / \mathrm{MWh}$ to $\$ 1,500 / \mathrm{MWh}$ were run to see how system peak load would respond to changes in CPP (Fig. 81).

Figure 82 shows three supply curves for comparison: a supply curve for pricing-related full DR deployment, the five-tier step function of the same supply curve, and the supply curve used in NEEM for Phase 1. The NEEM curve from Phase 1 was driven based on the FERC 2009 NADR results and shows the maximum DR available in 2030 would be $209 \mathrm{GW}$.

Actual DR would have a mixture of programs that dispatchers could call upon. Some programs have no specific price but have time or frequency limits. Some allow customers to vary their response at different price points. In addition, the variation in CPP addresses only the impact from pricing programs (Fig. 81 and Fig. 82). To reflect such DR supply from nonpricing programs, ORNL researchers chose to allocate the nonpricing DR amount into each tier proportionally (Fig. 83). Seventy percent of the peak load reductions (PLR) that came from nonpricing DR was distributed into the first five price tiers, and the remaining $30 \%$ of PLR was allocated to a new sixth price tier. The price for this last tier was set so that the weighted average of DR price stayed at \$750/MWh to maintain consistency with Phase 1.

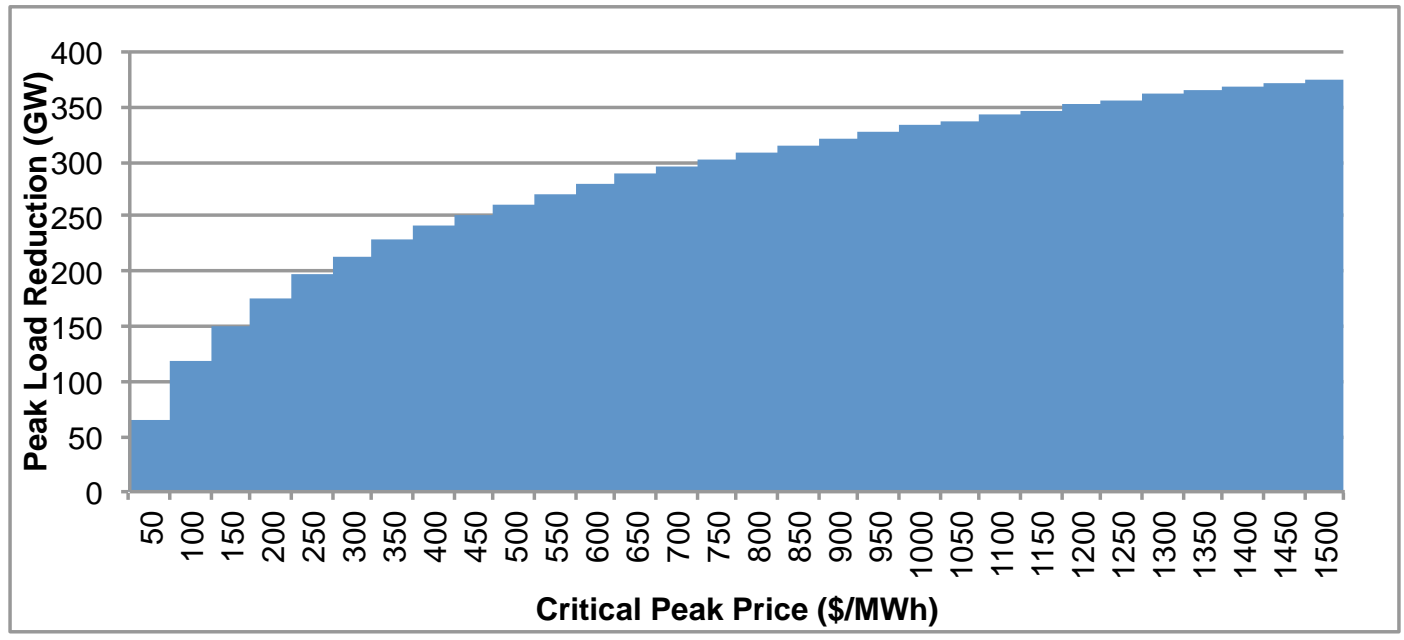

Fig. 81. ORNL NADR runs with variation in critical peak price. 


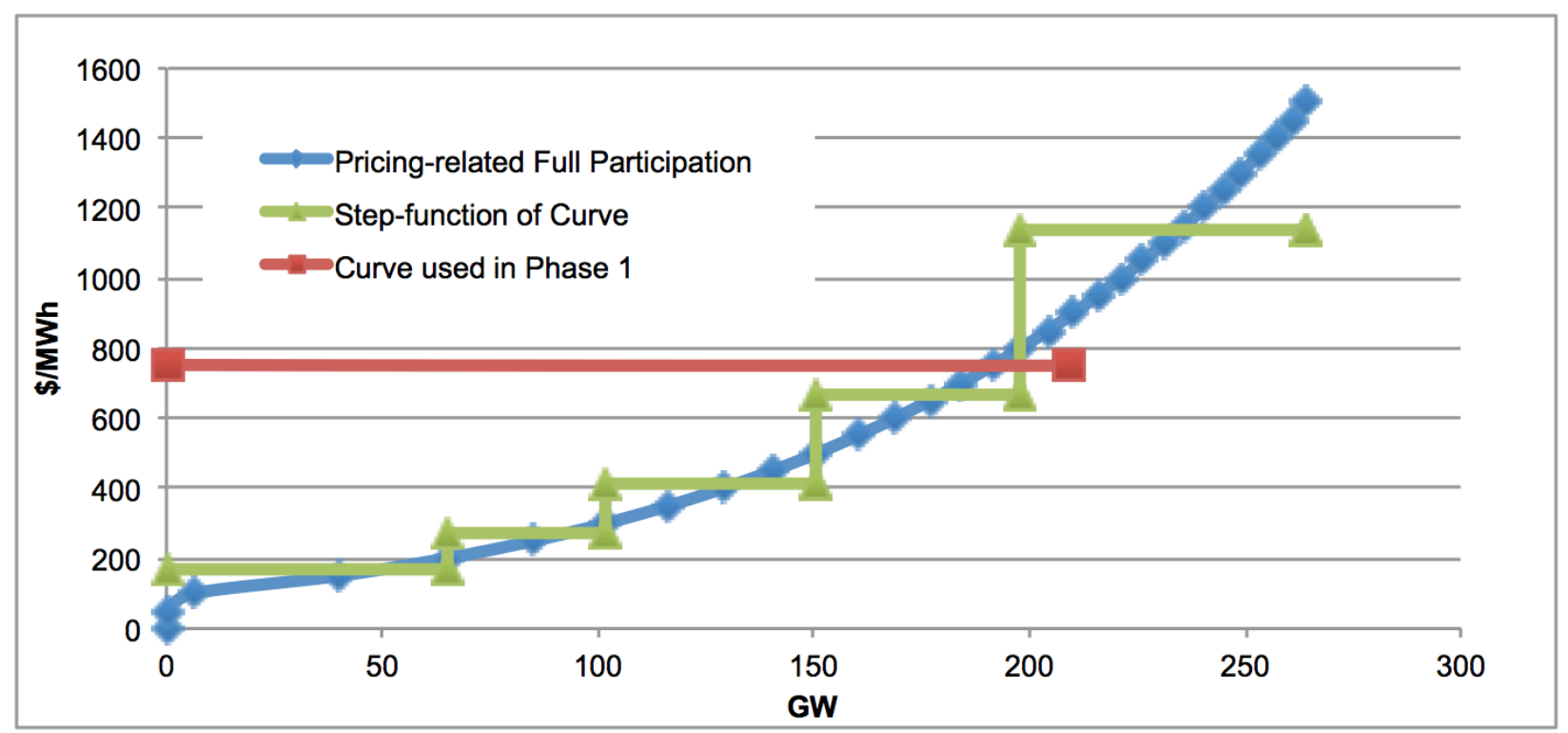

Fig. 82. Supply curve for pricing-related DR programs in 2030. Five-tier approximation and Phase 1 single tier curve also shown.

The lowest tier size was picked so that its average price would be in the neighborhood of the cost of a CT. The lowest cost tier of $22 \%$ of maximum DR available in any region could be supplied at the first price tier of $\$ 165 / \mathrm{MWh}$, roughly between the efficient and inefficient CT costs, as shown in Fig. 83. This amount of DR could possibly replace CTs in the dispatch process. The last price tier represents exceptionally expensive DR options such as rotational blackouts that involve high societal costs but are not included in the typical DR program categories.

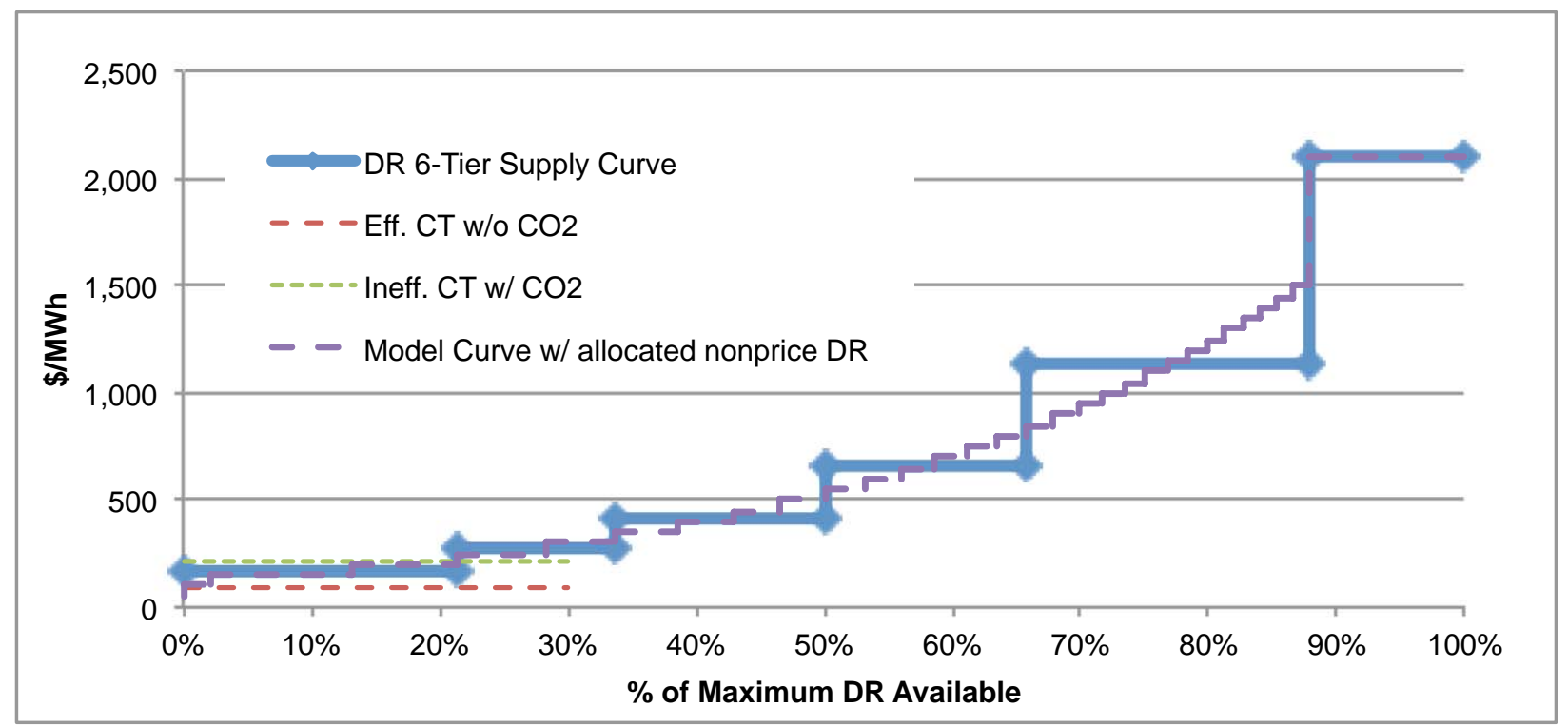

Fig. 83. Six-tier supply curve and model curve with allocated nonprice demand response (DR) in 2030 for Phase 2.

The resulting six tiers with both their price and the fraction of total DR within each region, as used in the EIPC Phase 2 study, are shown in Table 41. Each region's total DR potential for the scenario in question was multiplied by the fractions from the table and priced at the amount shown. This simplified the supply curve for modeling each region's DR amounts for the purpose of the analysis. 
Table 41. Demand Response Supply Curve as a Proportion of Total Demand Response Available in Regions for EIPC Study

\begin{tabular}{|cccc|}
\hline Tier & $\begin{array}{c}\text { Price } \\
\text { \$/MWh }\end{array}$ & \multicolumn{2}{c|}{$\begin{array}{c}\text { Percent of Total Capacity } \\
\text { Incremental }\end{array}$} \\
\hline $\mathbf{1}$ & 165 & 22 & 22 \\
\hline $\mathbf{2}$ & 273 & 12 & 34 \\
\hline $\mathbf{3}$ & 418 & 16 & 50 \\
\hline $\mathbf{4}$ & 665 & 16 & 66 \\
\hline $\mathbf{5}$ & 1,142 & 22 & 88 \\
\hline $\mathbf{6}$ & 2,100 & 12 & 100 \\
\hline
\end{tabular}

\subsection{Demand Response Dispatched in Phase 2}

As shown in Fig. 64, many of the regions rely on DR to supply some amount of capacity to meet $100 \%$ of their peak demand. This is also shown for the $\mathrm{CO}_{2}+$ scenario in Fig. 84 for all of the NEEM regions individually. The wind and solar capacities are split between the fraction that counts toward the reserve margin and the uncredited capacities that do not contribute to the reserve margin. The red lines show the peak demand for the year in specific regions for the $\mathrm{CO}_{2}+$ scenario. DR equals a significant fraction of the supply as shown in Table 42 (between $20 \%$ and 30\% in most regions).

In the BAU and RPS/R scenarios, DR generation is concentrated in the three most southeastern regions (Table 42). Overall DR capacity and generation was highest in the $\mathrm{CO}_{2}+$ scenario. All regions had at least some small amount of DR use. The most significant use is in two regions with wind power (MISO MOIL, and MAPP US) where, based on BA prices, there appeared to be some internal load pockets or generation constraints as described in the previous section. The other major area was the Southeast, with FRCC, SOCO, and especially VACAR showing high levels of DR use. These regions do not have easy access to significant amounts of wind power and so must rely on DR to provide power during peaking periods.

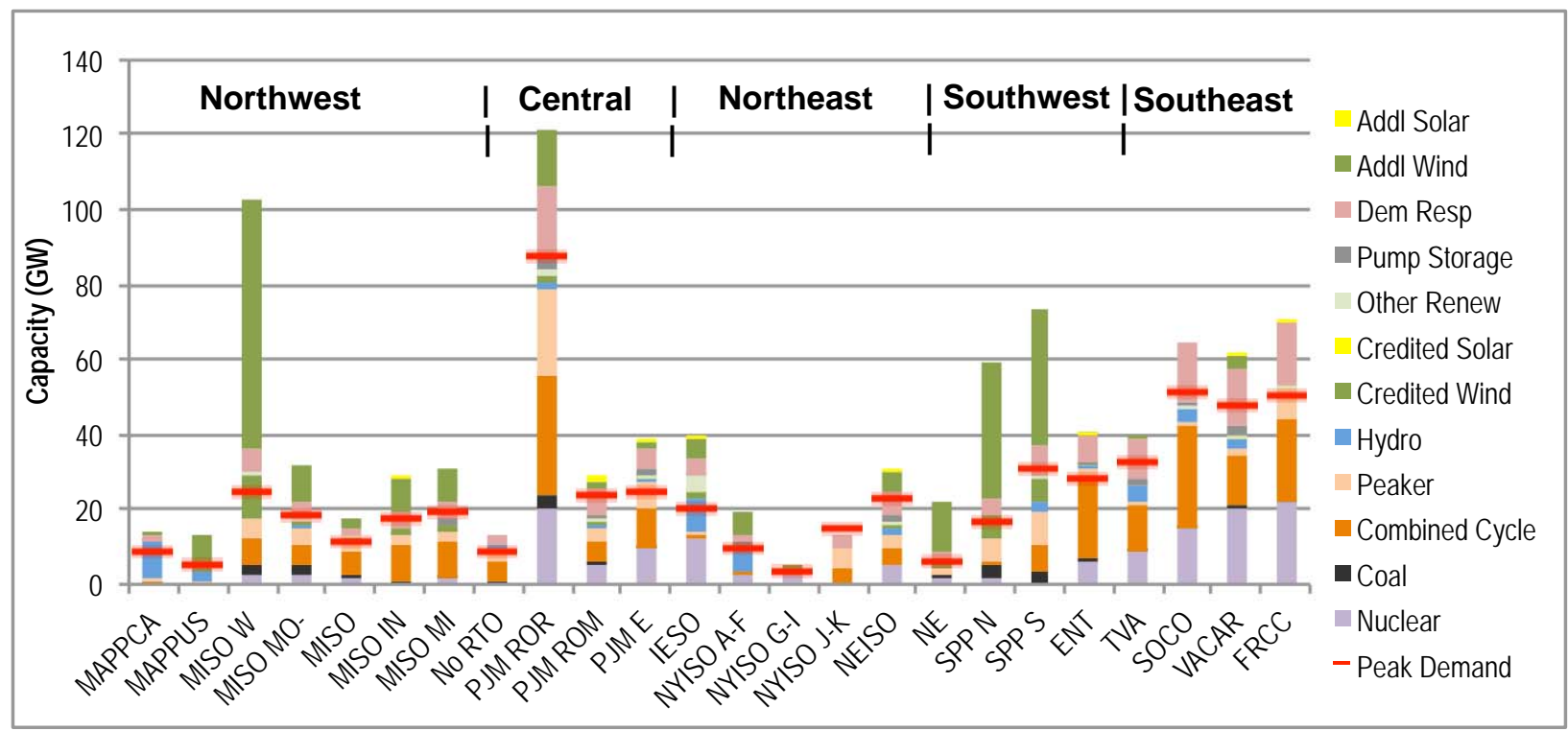

Fig. 84. Capacities and peak demand for each region for the $\mathrm{CO}_{2}+$ scenario. 
Table 42. Phase 2 Demand Response Capacity (in gigawatts and percent of demand) and Generation in NEEM Regions

\begin{tabular}{|c|c|c|c|c|c|c|c|c|c|}
\hline Region & $\begin{array}{c}\text { BAU } \\
\text { Capacity } \\
\text { (GW) }\end{array}$ & $\begin{array}{c}\text { BAU } \\
\text { Capacity } \\
(\% \text { Peak })\end{array}$ & $\begin{array}{l}\text { BAU } \\
\text { Gener- } \\
\text { ation } \\
\text { (GWh) }\end{array}$ & $\begin{array}{c}\text { RPS/R } \\
\text { Capacity } \\
\text { (GW) }\end{array}$ & $\begin{array}{c}\text { RPS/R } \\
\text { Capacity } \\
\text { (\% Peak) }\end{array}$ & $\begin{array}{c}\text { RPS/R } \\
\text { Gener- } \\
\text { ation } \\
\text { (GWh) }\end{array}$ & $\begin{array}{c}\mathrm{CO}_{2+} \\
\text { Capacity } \\
\text { (GW) }\end{array}$ & $\begin{array}{c}\mathrm{CO}_{2+} \\
\text { Capacity } \\
\text { (\% Peak) }\end{array}$ & $\begin{array}{c}\mathrm{CO}_{2+} \\
\text { Gener- } \\
\text { ation } \\
\text { (GWh) }\end{array}$ \\
\hline MAPP CA & 0.6 & $6 \%$ & 1 & 0.56 & $6 \%$ & 0 & 1.49 & $18 \%$ & 26 \\
\hline MAPP US & 0.4 & $6 \%$ & - & 0.39 & $6 \%$ & - & 0.99 & $19 \%$ & 119 \\
\hline MISO W & 3.4 & $11 \%$ & - & 3.26 & $11 \%$ & - & 5.99 & $24 \%$ & 3 \\
\hline MISO MO-IL & 2.2 & $10 \%$ & - & 2.17 & $10 \%$ & 0 & 4.60 & $25 \%$ & 139 \\
\hline MISO WUMS & 0.8 & $5 \%$ & - & 0.67 & $5 \%$ & - & 1.80 & $16 \%$ & 1 \\
\hline MISO IN & 1.5 & $7 \%$ & 0 & 1.83 & $7 \%$ & 0 & 3.93 & $22 \%$ & 14 \\
\hline MISO MI & 3.1 & $13 \%$ & 1 & 3.06 & $13 \%$ & 0 & 4.04 & $21 \%$ & 16 \\
\hline $\begin{array}{l}\text { Non-RTO } \\
\text { Midwest }\end{array}$ & 0.7 & $7 \%$ & - & 0.72 & $7 \%$ & - & 2.46 & $27 \%$ & 7 \\
\hline PJM ROR & 10.2 & $9 \%$ & 5 & 9.54 & $9 \%$ & 7 & 18.79 & $21 \%$ & 147 \\
\hline PJM ROM & 3.5 & $12 \%$ & 5 & 3.41 & $12 \%$ & 4 & 7.32 & $30 \%$ & 69 \\
\hline PJM E & 2.5 & $8 \%$ & 2 & 2.44 & $8 \%$ & 3 & 5.85 & $23 \%$ & 25 \\
\hline IESO & 2.4 & $10 \%$ & - & 2.39 & $10 \%$ & - & 4.41 & $22 \%$ & 0 \\
\hline NYISO A-F & 1.2 & $10 \%$ & 1 & 1.11 & $10 \%$ & 1 & 2.14 & $22 \%$ & 19 \\
\hline NYISO G-I & 0.5 & $10 \%$ & 1 & 0.42 & $10 \%$ & 1 & 0.83 & $22 \%$ & 6 \\
\hline NYISO J-K & 1.8 & $10 \%$ & 2 & 1.68 & $10 \%$ & 2 & 3.27 & $22 \%$ & 26 \\
\hline NEISO & 4.3 & $15 \%$ & 5 & 4.35 & $15 \%$ & 4 & 6.28 & $27 \%$ & 42 \\
\hline NE & 1.0 & $14 \%$ & - & 0.97 & $13 \%$ & 1 & 1.75 & $30 \%$ & 66 \\
\hline SPP N & 1.5 & $7 \%$ & - & 1.78 & $7 \%$ & 2 & 3.81 & $23 \%$ & 2 \\
\hline SPP S & 3.7 & $10 \%$ & 81 & 3.53 & $10 \%$ & 5 & 7.68 & $25 \%$ & 2 \\
\hline ENT & 2.9 & $8 \%$ & 0 & 2.83 & $8 \%$ & 1 & 7.09 & $25 \%$ & 5 \\
\hline TVA & 3.4 & $9 \%$ & - & 3.45 & $9 \%$ & - & 10.49 & $32 \%$ & 2 \\
\hline SOCO & 7.5 & $12 \%$ & 573 & 7.09 & $12 \%$ & 135 & 15.60 & $30 \%$ & 677 \\
\hline VACAR & 5.9 & $10 \%$ & 212 & 5.84 & $10 \%$ & 64 & 15.12 & $32 \%$ & 1,929 \\
\hline FRCC & 5.9 & $10 \%$ & 48 & 5.36 & $10 \%$ & 24 & 16.72 & $33 \%$ & 151 \\
\hline
\end{tabular}

\subsection{Southeast Demand Response Use and Price Impacts}

The lack of local surplus wind and solar in the Southeast is further compounded in that DR cannot be used as reserves, so the regions must run their CC plants at partial load to supply required operating reserves while using DR to supply energy. This is shown for the $\mathrm{CO}_{2}+$ scenario in Fig. 85 and Fig. 86 for the VACAR and SOCO regions on August 1. Demands increase throughout the day, and various technologies are added (at increasing cost) to respond. However, as demand continues to rise, CC generation declines slightly to provide a compensating supply of reserves. Peakers are added and pumped storage is used, and DR is called upon for a number of hours over the day. The gap between generation and load is supplied by imports. If DR or peakers could be used for reserves, then additional CC capacity could be used for generation. The figures also include the LMP for each region (a weighted average based on the prices and loads in the different BAs within the region.) The rise in prices as DR was called upon is readily apparent. If DR had been allowed to qualify for reserves, then less would have been dispatched and prices would have been lower. 


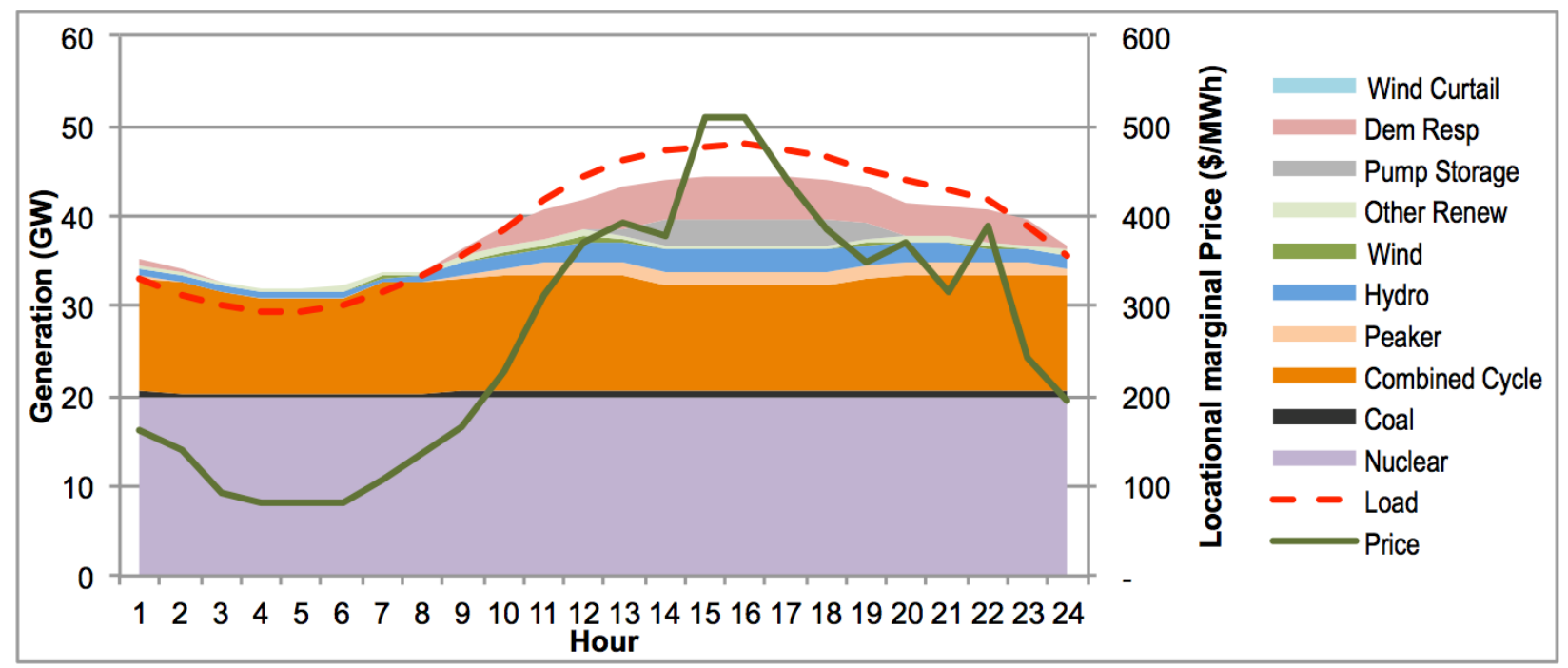

Fig. 85. VACAR generation, load and marginal prices on August 1 under the $\mathrm{CO}_{2}+$ scenario.

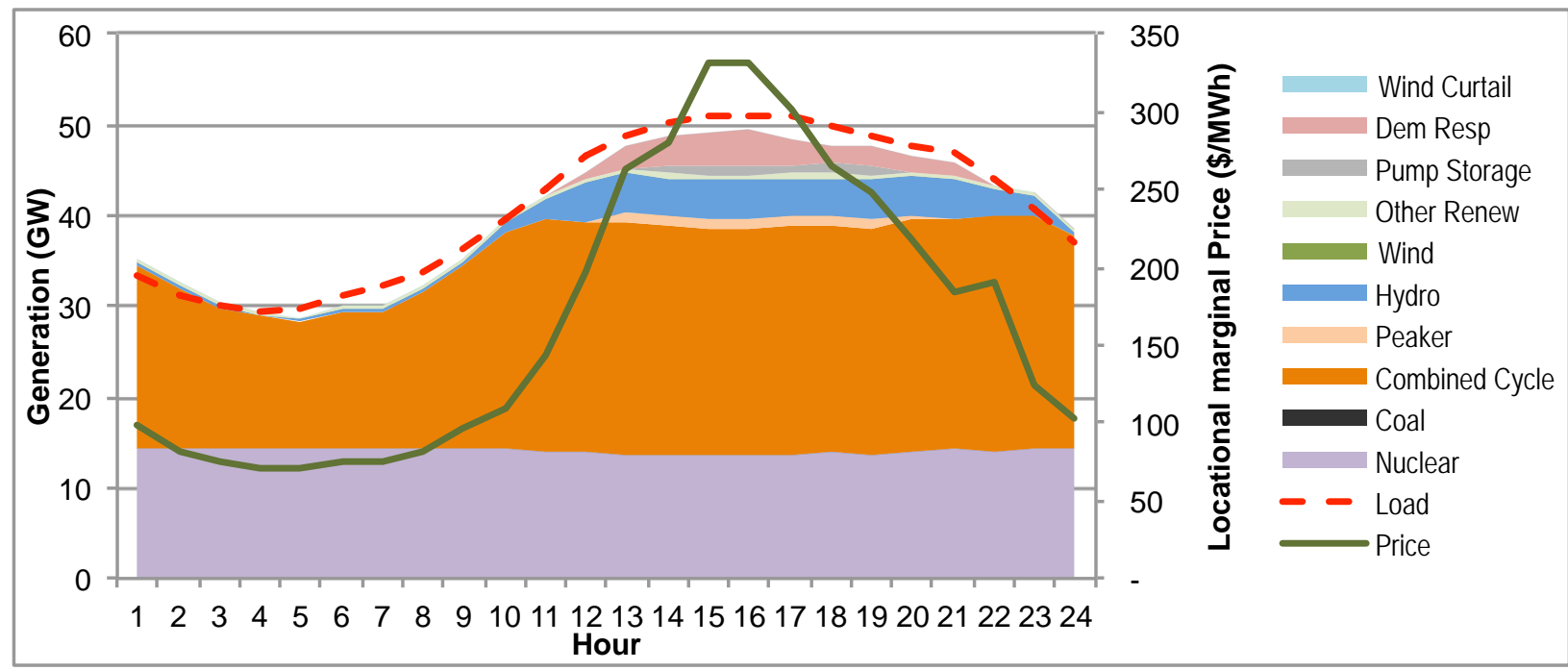

Fig. 86. SOCO generation, load, and marginal prices on August 1 under the $\mathrm{CO}_{2}+$ scenario.

A key question that arose during the EIPC study was the lack of new lines in the Southeast despite high prices for the region, especially VACAR. The August 1 data are a case in point. VACAR can send and receive power from PJM ROR, SOCO, and TVA. In the scenario represented in Fig. 87, at 4:00 p.m. VACAR is receiving $4.5 \mathrm{GW}$ of power from PJM ROR, which is near the maximum. It also receives a small amount from TVA and actually ships power to SOCO to supply its shortfall. SOCO is also using DR to meet demands while getting power from ENT, TVA, and VACAR and sending power to FRCC. 


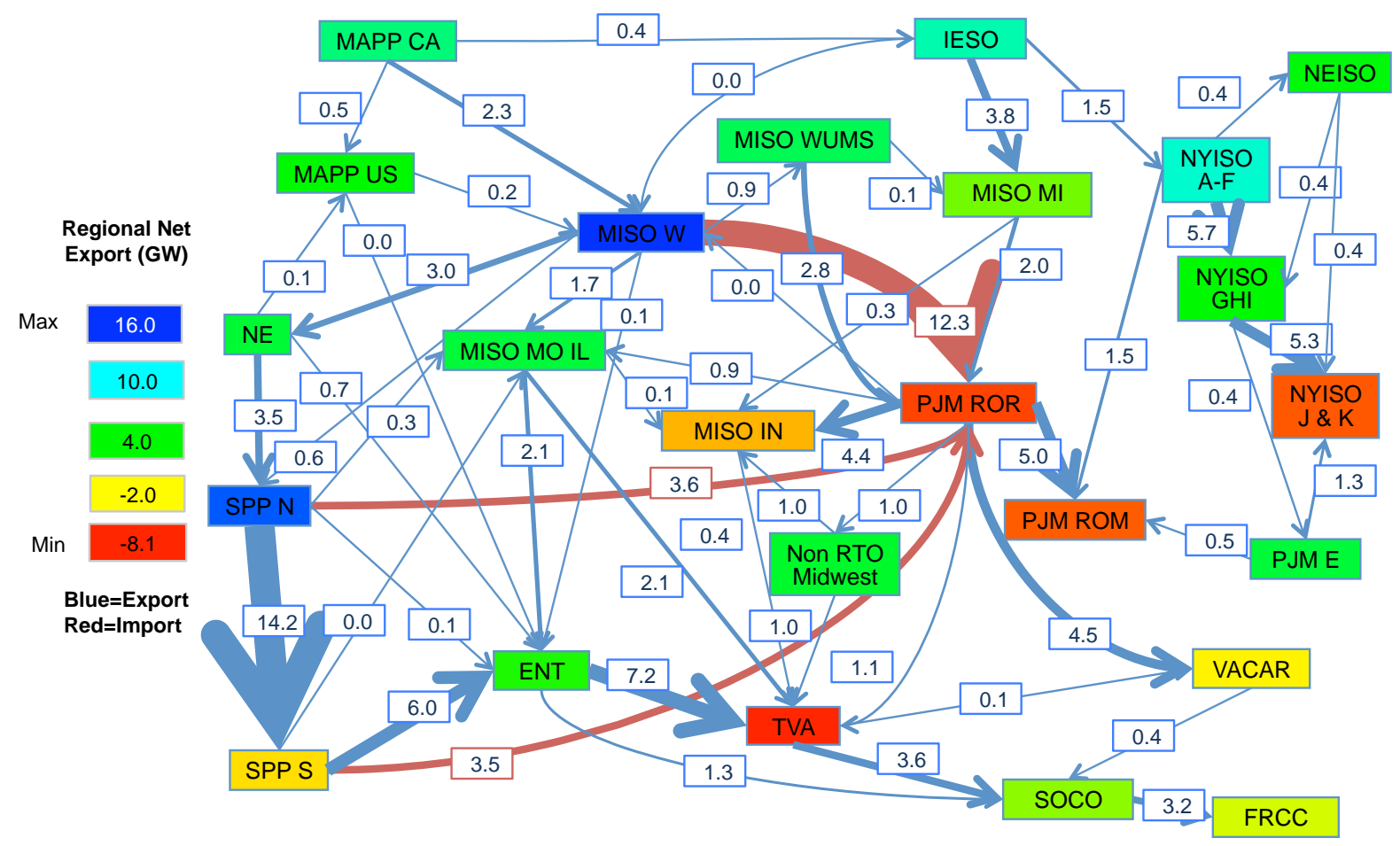

Fig. 87. Eastern Interconnection tie-line loads on August 1 at 4:00 p.m. for the $\mathrm{CO}_{2}+$ scenario.

An examination of the flows and shadow prices on the individual flowgates to, from, and within VACAR show where some of the congestion occurs. There are three main flowgates from PJM ROR to VACAR; in this hour much of the power is flowing from central Virginia down toward central South Carolina, with a shadow price of $\$ 100 / \mathrm{MWh}$. This represents the cost difference for power at either end of the line and indicates a congested line. (Other flowgates from PJM ROR do not appear to have shadow prices and so are not immediate congestion points.) Larger congestion occurs on the lines between SOCO and VACAR. There are three main flowgates between the two. Around $2.7 \mathrm{GW}$ is flowing from VACAR to SOCO on the western link, but power is flowing in the other direction on the eastern two. Shadow prices are high on the line from Plant Vogtle into South Carolina, reflecting this line being highly constrained. A review of the PSS/E results indicates that this line is heavily loaded. There are also a few lines within the state that are congested in this hour, as shown by flowgate shadow prices.

Similar analyses show a mixture of congested lines within SOCO. While there were no shadow prices between it and ENT, within SOCO there were several lines indicating congestion, with marginal prices between $\$ 100 / \mathrm{MWh}$ and $\$ 500 / \mathrm{MWh}$. These would indicate load pockets within the state that caused the dispatch of DR shown in Fig. 86.

As shown in Fig. 83, the DR capacity has a rising price as more is required. The DR was modeled by CRA as being spread across a region in proportion to its peak load, so DR can be called upon in load pockets even if the region as a whole has lower cost capacity available. Because DR generation was only reported at the NEEM region level and marginal prices at the BA level, while potential load pockets were at the bus level, it is difficult to show the relationship between prices and supply. However, by plotting the marginal prices within VACAR vs. the DR amounts a distinct supply curve appears.

Figure 88 plots the marginal prices for each of the six BAs in VACAR versus the total VACAR DR generation in the BAU scenario in the 412 hours where DR was dispatched. Three of the regions [Santee Cooper, Central Electric Power Cooperative, and South Carolina Electric and Gas (SCE\&G)] have prices 
that stair step at DR levels of $300 \mathrm{MW}, 600 \mathrm{MW}$, and 1,200 MW. The last one, SCE\&G, is located in the southern part of the state next to Georgia, while the other two are cooperatives that purchase much of their power from the other utilities. As mentioned previously, there appears to be a transmission constraint between SOCO and VACAR, and so these areas are the first to reach constraints and need to dispatch DR.

The last three entries in the legend for Fig. 88 (Progress Energy, Duke, and Greenville Utilities) are located in North Carolina or the northern part of South Carolina. Their prices are lower and smoother than the first three utilities and are likely less constrained by having transmission access to PJM and TVA. The Progress and Greenville prices don't rise above \$200/MWh until the total DR generation increases above 1,200 MW. DR for these two utilities starts being dispatched at this time, starting with the lowest cost supply for each. Duke prices are lowest, likely because it has the easiest access to the supplies of other regions. It likely does not start dispatching DR until the others have already begun using theirs. As DR continues to be dispatched, all utilities start to see increasing marginal prices, with some fluctuations at the highest levels where all utility prices become more highly correlated.

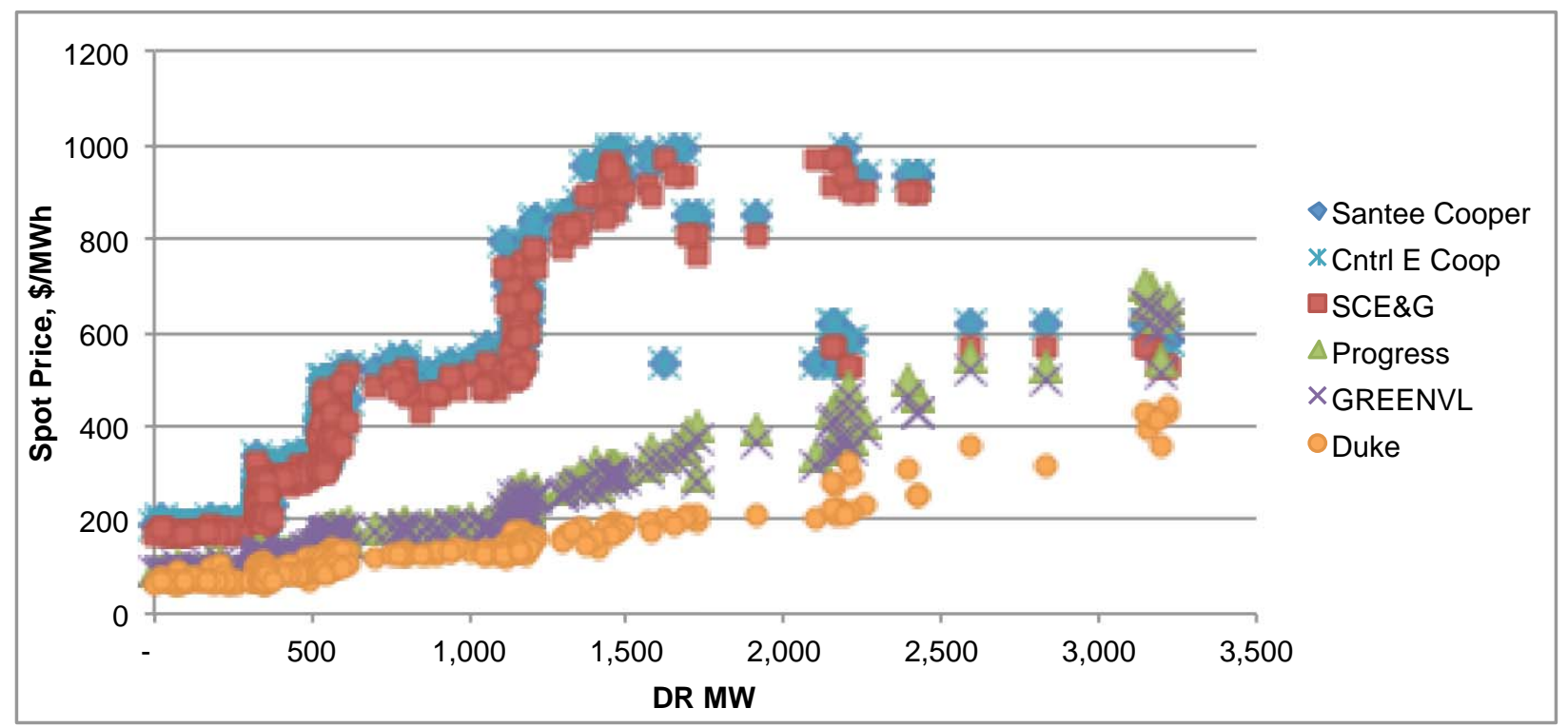

Fig. 88. Marginal prices at six balancing areas versus the corresponding DR demand for all of VACAR in the BAU scenario.

\subsection{Southeast Transmission Build-Outs}

If DR was needed for a number of hours in these scenarios, why were lines not built during Phase 1 ? In Phase 1, the initial NEEM run for each future established the marginal prices between regions and the second run calculated "soft" lines between each region based on those prices and the relative power needs. NEEM added soft lines that varied in capacity for each block of each year studied. Because a "real" line had to be set at a constant size for all blocks and years, the SSC had to calculate a representative size to "harden" the lines between regions.

In the case of the southeastern regions, the soft lines added by NEEM were used for roughly $20 \%$ of the year, during the peak periods. As an example, Fig. 89 shows the flow duration curves for the PJM ROR to VACAR tie-line in Phase 1 for several different study years. In Phase 1, members of the SSC Modeling Working Group (MWG) developed several complex methods that considered the capacity factors over multiple years to harden the lines. The results of the different methods are the data points on the baseline that represent existing capacity. The soft expansions in the Southeast were not used for a large enough 
fraction of the year to justify their construction as hardened lines in the Phase 1 modeling. Instead, it was more cost-effective to use DR or peaking plants for the time they would be needed. There could be additional factors such as hurdle rates between the regions or it could simply be due to the "peakiness" of loads in the south with higher summer demand.

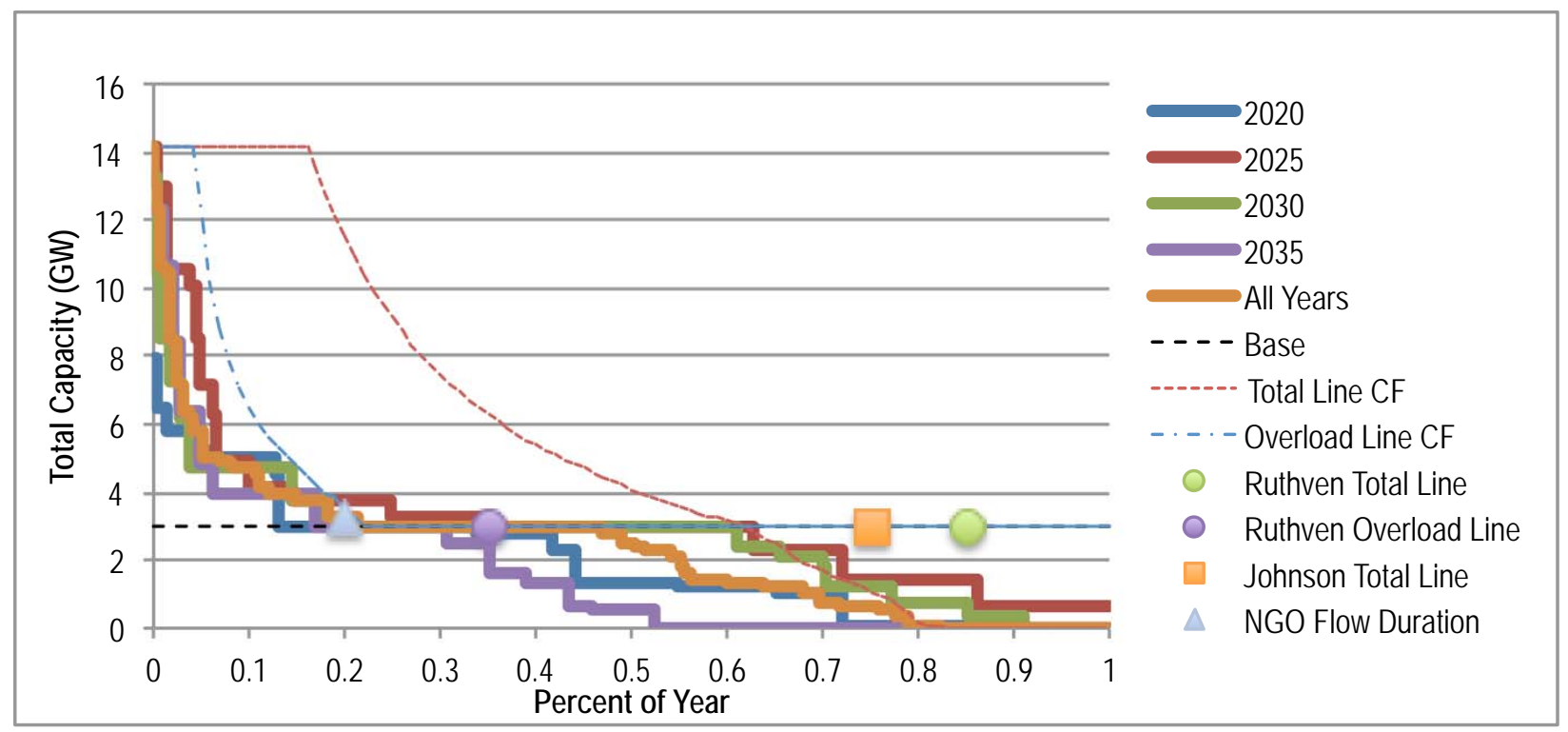

Fig. 89. Phase $1 \mathrm{CO}_{2}+$ flow duration curves for the "soft" tie-line between PJM ROR and VACAR.

In Phase 2, the build-out of lines was based on the results from Phase 1 plus the addition of lines solely for reliability purposes during the hour studied. Also, in Phase 2 the interregional flows were based on actual transmission lines and flowgates, so tie-line capacities could be different from Phase 1. Loop flows could also have limited the amount of net power transfer. As an example, Fig. 89 shows the Phase 1 flows with the existing capacity set at 3,000 MW, but in Phase 2 the maximum flow between PJM ROR and VACAR was 5,000 MW. Economics did not play a role in the build-out portion of the study. It was only in the last part when using GE MAPS that the full cost impact over the period was identified. In addition, there were one or two lines between SOCO and VACAR that should have been strengthened during the first part of Phase 2 but were missed by the planners.

\subsection{Conclusions}

The modeling efforts in this study provide only a rough approximation of the vital role DR can play in balancing supply and demand. The resource had to be modeled as a pseudo-generator with a price set high to model its limited availability. In Phase 1, because only a single price for all DR could be applied, it was set at roughly what the available models represented for the total potential supply. In Phase 2 a more complex supply curve with six price steps provided a more nuanced approach. Because DR was used in meeting the minimum planning reserve margin, some regions relied on it to meet their peak demand. In the $\mathrm{CO}_{2}+$ scenario DR capacity was highest cost and those regions without access to surplus wind (most notably VACAR) used high levels of DR at consequent high prices. Some of this was due to the differences in the geographic, transmission, and time step detail in Phase 1 and Phase 2 modeling. At times, DR was called on because of transmission constraints that limited the ability to import power from other regions or elsewhere within a region. 



\section{TOPIC 9: "NO REGRETS” LINES}

\subsection{Transmission Elements Common to Multiple Scenarios}

In Phase 2 a number of transmission components were included in the build-outs of each of the three scenarios to address reliability concerns. Because the scenarios capture significantly different outlooks for the future, there may be value in examining the components that show up in all three scenarios as they potentially represent elements that will be needed under a wide variety of future circumstances. If they were to be constructed, it would not be at the expense of other opportunities or more advantageous outcomes as it appears they will be needed regardless of what happens in the future.

An important consideration when examining the transmission elements that are common to all three scenarios is the development of the SSI in Phase 1. Before the MRN-NEEM runs, stakeholders identified new transmission and generation facilities that were to be included in the models. The SSI would eventually impact the transmission build-outs for all three scenarios as some of the elements common to all scenarios were added to fully integrate the SSI additions rather than strictly for reliability reasons.

Table 43 lists the number of transmission build-out elements that are common to all three scenarios by region and stated reason for inclusion. A large number of the NEISO elements resulted from the inclusion of a number of wind farms in the SSI. A number of lines and transformers were included to interconnect those facilities to the network.

Table 43. Elements in Common Across All Scenarios by Region

\begin{tabular}{|c|c|c|c|c|}
\hline Region & $\begin{array}{c}\text { Interconnect } \\
\text { New Generation }\end{array}$ & $\begin{array}{l}\text { Prevent } \\
\text { Overloads }\end{array}$ & $\begin{array}{c}\text { Prevent } \\
\text { Low Voltage }\end{array}$ & Total \\
\hline ENT & & 11 & & 11 \\
\hline FRCC & & 3 & & 3 \\
\hline MAPP CA & & 3 & & 3 \\
\hline MISO IN & & 1 & & 1 \\
\hline MISO MI & & 2 & & 2 \\
\hline MISO W & 1 & & & 1 \\
\hline MISO WUMS & & 1 & & 1 \\
\hline NEISO & 41 & 4 & 1 & 46 \\
\hline Non-RTO Midwest & & 1 & & 1 \\
\hline NYISO & & 1 & & 1 \\
\hline PJM ROM & 2 & 2 & & 4 \\
\hline PJM ROR & & 5 & & 5 \\
\hline SOCO & & 3 & & 3 \\
\hline VACAR & 5 & 2 & & 7 \\
\hline TOTAL & 49 & 39 & 1 & 89 \\
\hline
\end{tabular}

Of the 89 elements, 49 are new transmission lines, 14 are new transformers or autotransformers, 8 are new reactive support devices (reactors or static var controllers), and 18 are upgrades to existing facilities. A number of the new devices also require modifications to existing facilities (like adding bays to a substation), but they are classified as new here. In some instances, there were two separate circuits added between a pair of buses. Those are treated as separate lines for this purpose. (The appendix to this report is a list of the elements, including a description of the project and reason for its need.)

Most of the costs associated with the common elements are for connecting new generation, much of which is associated with the SSI. Table 44 shows the midrange estimate of the overnight capital costs of the common elements by reason of inclusion and the total costs from the three scenarios [from Table ES-3 of the EIPC Phase 2 Report (EIPC 2012)]. 
Table 44. Overnight Capital Costs (billions of 2010 dollars)

\begin{tabular}{|lccccc|}
\multicolumn{1}{c}{ Costs } & Common & $\mathrm{CO}_{2+}$ & RPS/R & BAU \\
\hline Interconnect New Generation & 5.7 & 49.6 & 54.3 & 7.3 & \\
\hline Prevent Overloads & 2.8 & 48.4 & 13.0 & 7.9 \\
\hline Prevent Low Voltage & 0.04 & 0.5 & 0.1 & 0.2 \\
\hline
\end{tabular}

Fig. 90 shows the locations of buses where the common transmission lines have a termination point or where common transformers or reactive support devices are located.

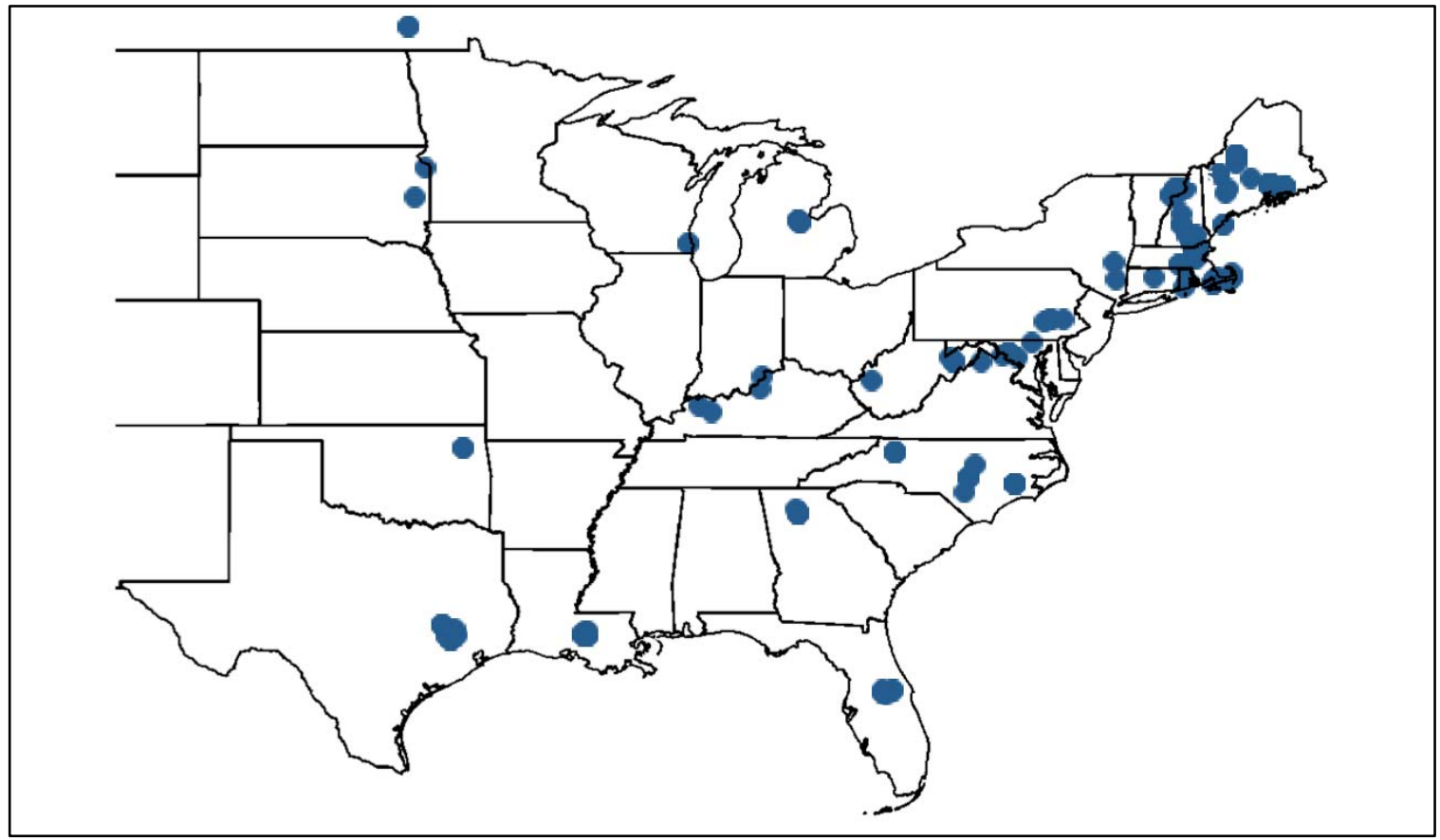

Fig. 90. Locations of buses with upgrades common to all three scenarios.

In some cases, elements were added or upgraded in each of the three scenarios, but the same thing is not done in each one. For instance, while one scenario may add an additional circuit to a transmission line, the others re-conductor the existing circuit. Alternatively, one scenario may include an element with a higher rating. While the stated reason is generally the same across all scenarios, this is not always the case. The scenario that used the least cost method is used for the reason in Table 45. 
Table 45. Elements in Common with Different Methods by Region

\begin{tabular}{|c|c|c|c|c|}
\hline Region & $\begin{array}{c}\text { Interconnect } \\
\text { New Generation }\end{array}$ & $\begin{array}{l}\text { Prevent } \\
\text { Overloads }\end{array}$ & $\begin{array}{c}\text { Prevent } \\
\text { Low Voltage }\end{array}$ & Total \\
\hline ENT & & 1 & & 1 \\
\hline FRCC & & 2 & & 2 \\
\hline MAPP CA & & 5 & & 5 \\
\hline MISO MI & & 2 & & 2 \\
\hline MISO MO-IL & & & 1 & 1 \\
\hline NEISO & 1 & & & 1 \\
\hline PJM E & 1 & & & 1 \\
\hline PJM ROM & 3 & & & 3 \\
\hline PJM ROR & 1 & & & 1 \\
\hline SPP S & & 7 & & 7 \\
\hline VACAR & 1 & 1 & & 2 \\
\hline TOTAL & 7 & 18 & 1 & 26 \\
\hline
\end{tabular}

There are also a number of instances where an element shows up in two of the three scenarios. Of the total, 176 elements are common to the $\mathrm{CO}_{2}+$ and RPS/R scenarios but not the BAU scenario. Many of these are in SPP and MISO as part of the wind collector systems. There are 50 pairs of buses that have entries in common with the $\mathrm{CO}_{2}+$ and BAU scenarios but not the RPS/R scenario. There are 46 pairs of buses that have entries in common to RPS/R and BAU but not $\mathrm{CO}_{2}+$.

\subsection{Conclusions}

There are 89 transmission elements that are common to all three scenarios. In another 26 instances something was done at a bus (or between a pair of buses) under each scenario, but the same thing was not done in all three. In many cases, the elements were included to support new generation that was included by the SSC in the early stages of the Phase 1 process. Those elements would only be "no regrets" if the associated new generation is actually constructed. 



\section{TOPIC 10: REGIONAL VERSUS NATIONAL IMPLEMENTATION OF POLICIES}

During Phase 1 two sets of futures examined the effects of using a regional approach to policy issues versus a national approach. The first set (Futures 2 and 3) examined the impact of a $\mathrm{CO}_{2}$ cost assigned to emissions; the second set (Futures 5 and 6) examined the implementation of a national RPS, either nationally (RPS/N) or regionally (RPS/R). This chapter examines the impact of a regional implementation in comparison to a national implementation for the $\mathrm{CO}_{2}$ cost and RPS futures.

\subsection{Definition of Superregions}

For the two regional implementation futures in Phase 1 (Futures 3 and 6), NEEM regions were grouped into seven superregions. Transfer limits were allowed to increase within a superregion but not between superregions. Furthermore, the superregions formed the basis for the upper limit on the penetration of variable resources like wind and solar. Thus, compliance with national policy goals was forced to occur primarily within each superregion, with little contribution from imports from other superregions. The seven superregions are listed in Table 1. As mentioned previously, the seven superregions are slightly different than the five territories used elsewhere in this and the other reports. The superregions had important distinctions for modeling. Stakeholders wanted to capture the limits in transfer capacities between eastern and western PJM and between Ontario and the Northeast. Also, in Phase 1 the Non-RTO Midwest region was not connected electrically with PJM, so it needed to be included in the Midwest superregion. Territories are more consolidated and just used for reporting purposes.

As opposed to the regional analysis, in the two national implementation futures implementation could be carried out across the EI as a whole (without Canada). Transfer limits were allowed to increase between any adjoining regions regardless of the superregion in which they were located. Also, the $\mathrm{CO}_{2} / \mathrm{N}$ (i.e., high $\mathrm{CO}_{2}$ cost, implemented nationally) future aggregated the EI into four defined regions where each had a maximum intermittency share of 35\% (Southeast plus Southwest regions, Midwest plus PJM regions, Ontario, and the Northeast) while the $\mathrm{CO}_{2} / \mathrm{R}$ (i.e., high $\mathrm{CO}_{2}$ cost, implemented regionally) future applied the intermittency limits to the seven smaller superregions.

\subsection{Definition of the Two Policies}

\subsubsection{Carbon Dioxide Prices}

Carbon dioxide price penalties for Futures 2 and 3 were developed using the MRN-NEEM model in an iterative fashion to find the $\mathrm{CO}_{2}$ prices that would lower economy-wide emissions from 2005 levels $42 \%$ by 2030 and $80 \%$ by 2050 . This was done originally for the national implementation (Future 2), and the resulting prices were also used for the regional implementation (Future 3). The resulting $\mathrm{CO}_{2}$ prices (in 2010 dollars) were $\$ 27 /$ ton in 2015 , $\$ 140 /$ ton in 2030 and $\$ 369 /$ ton in 2040, with additional increases afterwards. Further discussion on the $\mathrm{CO}_{2}$ prices is in Sect. 12.1, where variations on the $\mathrm{CO}_{2}$ price are examined.

The differences between the national and regional implementation of the carbon constraint futures stem from two factors: limitations on transfer limits between the superregions and the level of aggregation for the intermittent resource penetration limit. While the national implementation allowed all transfer limits to be expanded, the regional implementation did not allow expansion of the transfer limits between superregions. While both imposed a 35\% limit on the penetration of intermittent resources, the national implementation applied that limit to each of four larger areas while the regional implementation applied it to the seven superregions. This allowed for a larger penetration of intermittent resources under the national implementation within individual NEEM regions as the overall pool that the region was in was larger. 


\subsubsection{Renewable Portfolio Standard}

The RPS in Futures 5 and 6 requires that $7.5 \%$ of overall energy in 2015 be generated from a renewable source, which is defined as biomass, geothermal, hydroelectric, landfill gas, solar, and wind. The RPS requirement increases over time to $30 \%$ in 2030.

There are three differences between the national and regional implementations of the RPS. These are the two identified for the $\mathrm{CO}_{2}$ prices, limitations on transfer limits and level of aggregation for intermittent penetration limits, and the level of aggregation for the renewable standard itself. In the national implementation, the RPS must be met on an EI-wide basis. In the regional implementation, each superregion must supply its own resources to meet the standard within the superregion. In effect, the national implementation allows one superregion to be under the standard as long as other superregions make up the difference (subject to the intermittent penetration limit for each of the four large areas).

\subsection{Method of Analysis}

This chapter uses the MRN-NEEM results from Phase 1 to examine the effects of regional versus national implementation for the $\mathrm{CO}_{2}$ cost and RPS futures. A number of sensitivities were developed in addition to the base case for each of the futures in Phase 1. In a number of cases, parallel sensitivities were run for both the national and regional implementation futures using variations in load growth, natural gas prices, carbon prices, and capital costs of specific technologies. However, as the impacts of these variations are covered in other chapters of this report, this chapter focuses on a comparison of the base cases with hardened transmission limits.

\subsection{Results}

\subsubsection{Carbon Dioxide Prices}

The national implementation of $\mathrm{CO}_{2}$ prices resulted in a dramatic shift away from coal toward natural gas and wind, with the retirement of $250 \mathrm{GW}$ of coal-fired capacity in the EI by 2030 and the addition of $299 \mathrm{GW}$ of onshore wind and $118 \mathrm{GW}$ of natural gas CC capacity. More than $70 \%$ of the wind generation was located in either the MISO or SPP regions.

While the regional implementation of $\mathrm{CO}_{2}$ prices also resulted in a shift away from coal toward natural gas and wind, the effect was somewhat altered: $241 \mathrm{GW}$ of coal was retired in the EI by 2030 and only $179 \mathrm{GW}$ of onshore wind was added. Roughly half of the wind capacity was located in MISO and SPP. The amount of natural gas CC capacity increased to $143 \mathrm{GW}$. The changes were driven largely by a shift from a heavy reliance on wind from the western regions under the national implementation to more local sources in the eastern regions due to the lower transmission limits under the regional implementation.

This resulted in a significant drop in energy from renewables with a correspondingly large increase in energy from natural gas, as is shown in Fig. 91. Use of both coal and nuclear sources also increased under the regional implementation. 


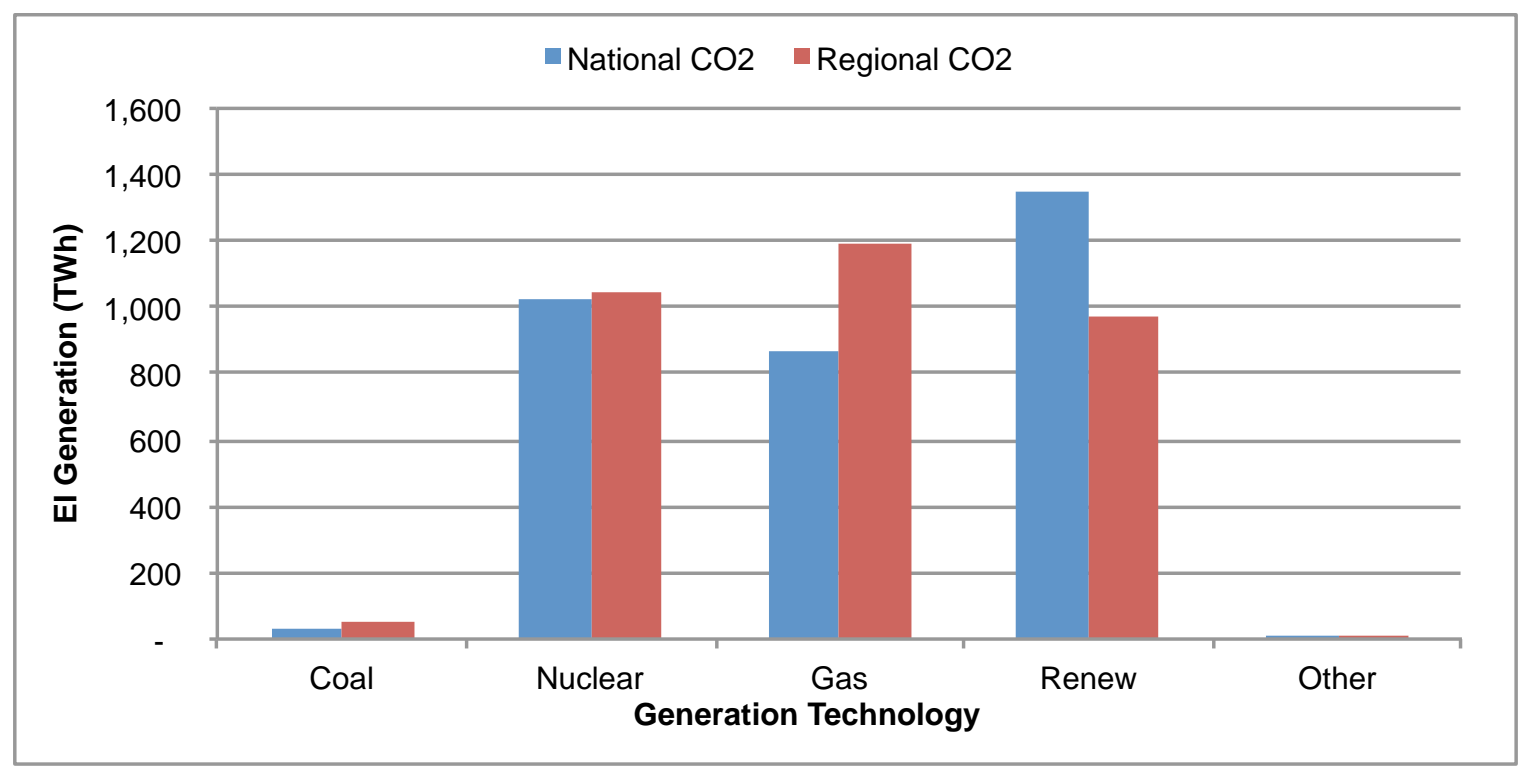

Fig. 91. Eastern Interconnection generation by type in 2030 under $\mathrm{CO}_{2}$ futures.

As shown in Fig. 92, generation levels in the Southwest and Midwest dropped under the regional implementation (as compared to the national implementation). Generation increased in the Southeast and PJM ROR superregions. The Midwest superregion had less wind, more natural gas, and reduced exports under the regional implementation. The Northeast saw little change between the two, while PJM MAAC saw little change until after 2030. PJM ROR had more wind under the regional implementation and became a net exporter. The Southeast superregion imported less and generated more from natural gas under the regional implementation. The Southwest had much less wind, more natural gas, and no exports under the regional implementation. A visual comparison of the generation sources for each of the superregions over the study period is provided in the appendix of this report.

With the reduction in wind generation and increased generation from natural gas and coal, the regional implementation produced more $\mathrm{CO}_{2}$ emissions. Because the $\mathrm{CO}_{2}$ prices were determined based on achieving the desired emissions reduction for the national implementation, this indicates that the regional implementation would not achieve that level of emissions reductions. A higher $\mathrm{CO}_{2}$ price, at least for some superregions, would need to be implemented to achieve an equivalent level of emissions reduction.

The national implementation resulted in lower fuel costs and emissions costs, as shown in Fig. 93. The regional implementation resulted in lower capital costs and O\&M costs. The national implementation showed an annualized net present value of costs that is about $\$ 17$ billion higher than the regional, when high-level transmission capital costs are included, due to the $40 \mathrm{GW}$ of new transmission capability at $\$ 30$ billion in that case versus the regional implementation addition of $5 \mathrm{GW}$ at just $\$ 2$ billion, Thus, the national implementation achieved a greater level of $\mathrm{CO}_{2}$ emissions reductions, but at a higher cost. 


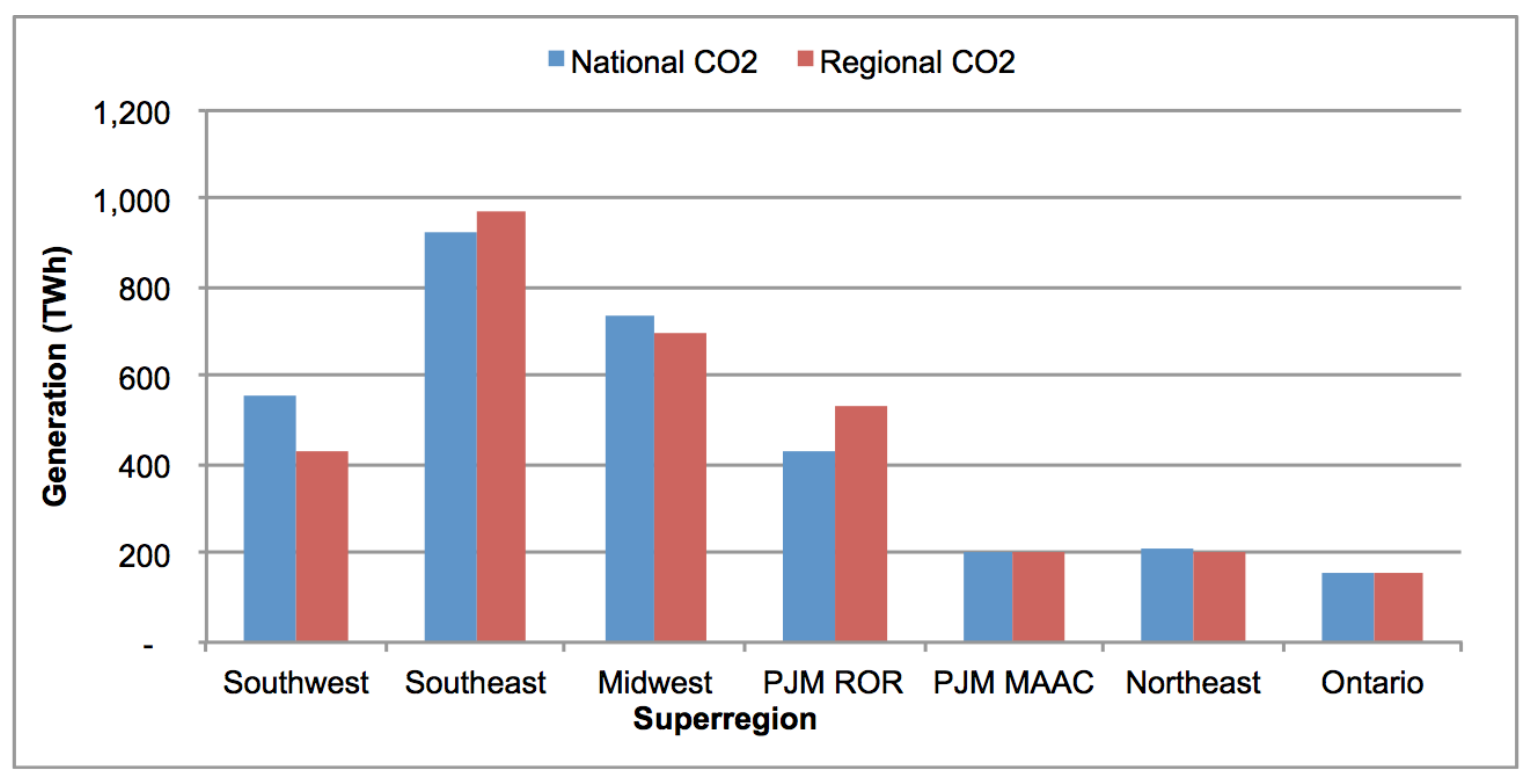

Fig. 92. Eastern Interconnection generation by superregion in 2030 under $\mathrm{CO}_{2}$ prices.

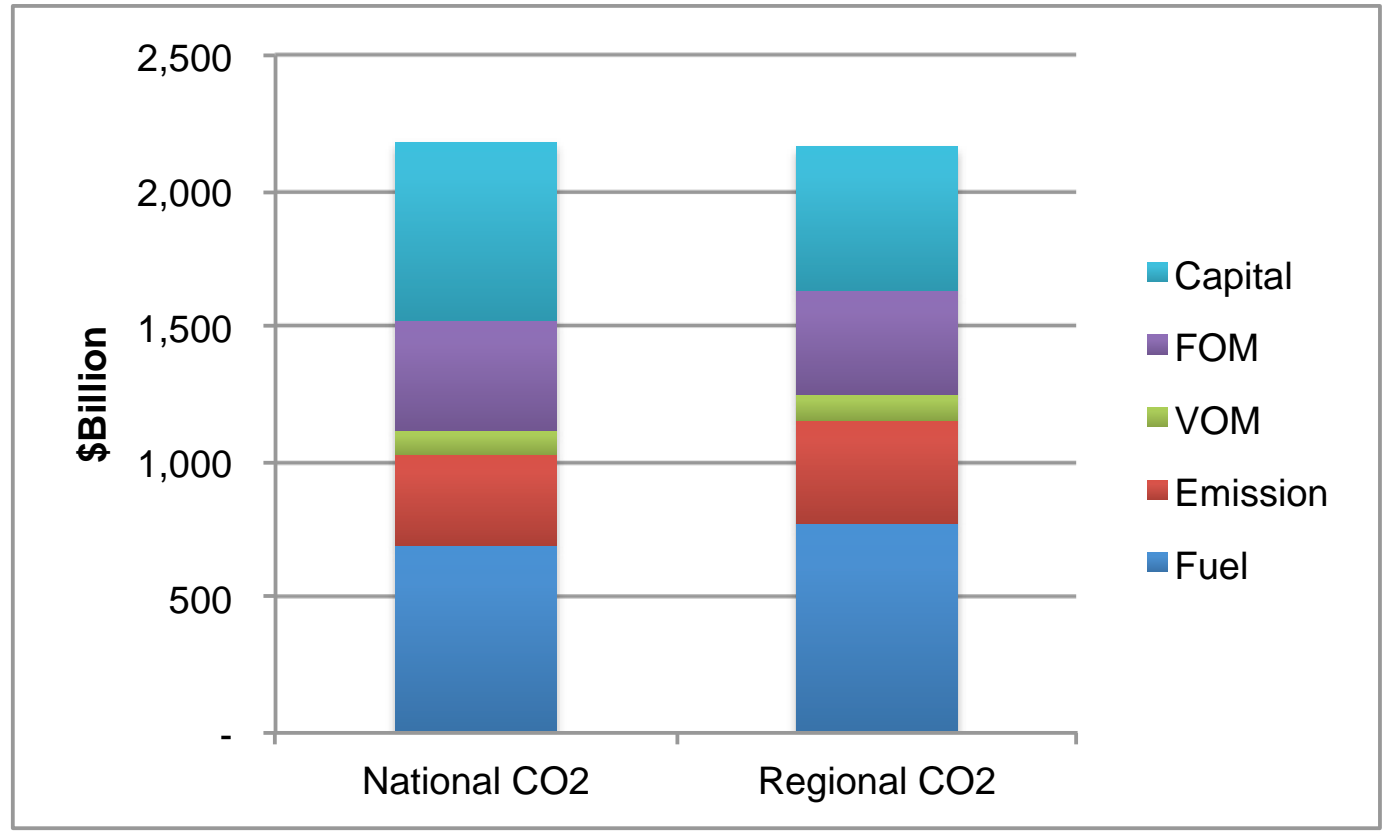

Fig. 93. Net present value costs, 2015-2030, under $\mathrm{CO}_{2}$ prices.

\subsubsection{Renewable Portfolio Standard}

Unlike the $\mathrm{CO}_{2}$ price futures, the impact of regional versus national implementation of an RPS had little impact on coal and natural gas use over the EI. The primary effect was that the regional implementation relied less heavily on wind from the Midwest and Southwest superregions and more heavily on offshore wind and biomass in the eastern portions of the EI. 
Coal retirements under both RPS implementations were $102 \mathrm{GW}$. The regional implementation had less new natural gas CC capacity ( $30 \mathrm{GW}$ vs. $40 \mathrm{GW}$ ) and onshore wind (141 GW vs. $198 \mathrm{GW})$, while it had more offshore wind ( $38 \mathrm{GW}$ vs. $1 \mathrm{GW}$ ) and other renewables (33 GW vs. $10 \mathrm{GW})$.

This resulted in very little change in energy from coal and nuclear, as shown in Fig. 94. Natural gas generation was down slightly in the regional implementation. Onshore wind generation was down by $36 \%$ in the regional implementation, while both offshore wind and biomass made significant contributions.

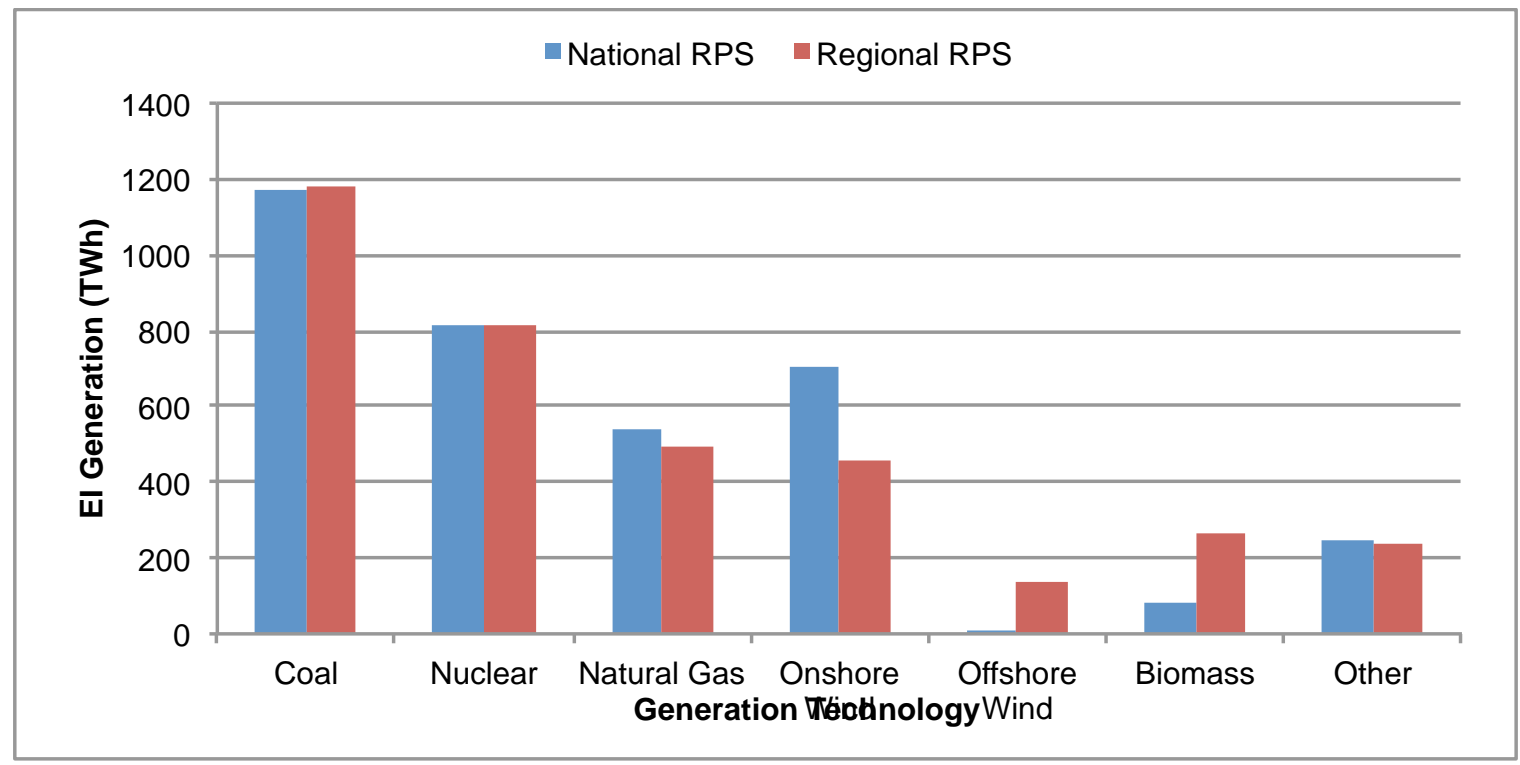

Fig. 94. Eastern Interconnection generation by type in 2030 under the renewable portfolio standard (RPS).

From a regional perspective, the Midwest superregion had less wind, with more natural gas and coal, in the regional implementation than in the national. The Northeast had more natural gas and lower imports in the regional implementation. PJM MAAC had more offshore wind and less generation from coal and natural gas in the regional implementation, while PJM ROR had more onshore wind, less natural gas, and became a net exporter. The Southeast had more offshore wind and other renewables, with less coal and natural gas in the regional implementation. The Southwest had much less wind and more coal and natural gas and did not export in the regional implementation. Figure 95 shows the comparison of total generation under the two implementation strategies, and a breakdown by source is provided in the appendix.

Because it is better able to take advantage of the abundant wind resources in the Great Plains, the national implementation results in lower fuel, capital, and O\&M costs as shown in Fig. 96. On a net present value basis, the national implementation is roughly $\$ 86$ billion lower than the regional implementation. This is despite the fact that the national implementation includes $64 \mathrm{GW}$ of additional transmission capacity at a cost of $\$ 36$ billion compared to only $3 \mathrm{GW}$ and $\$ 2$ billion for the regional implementation. 


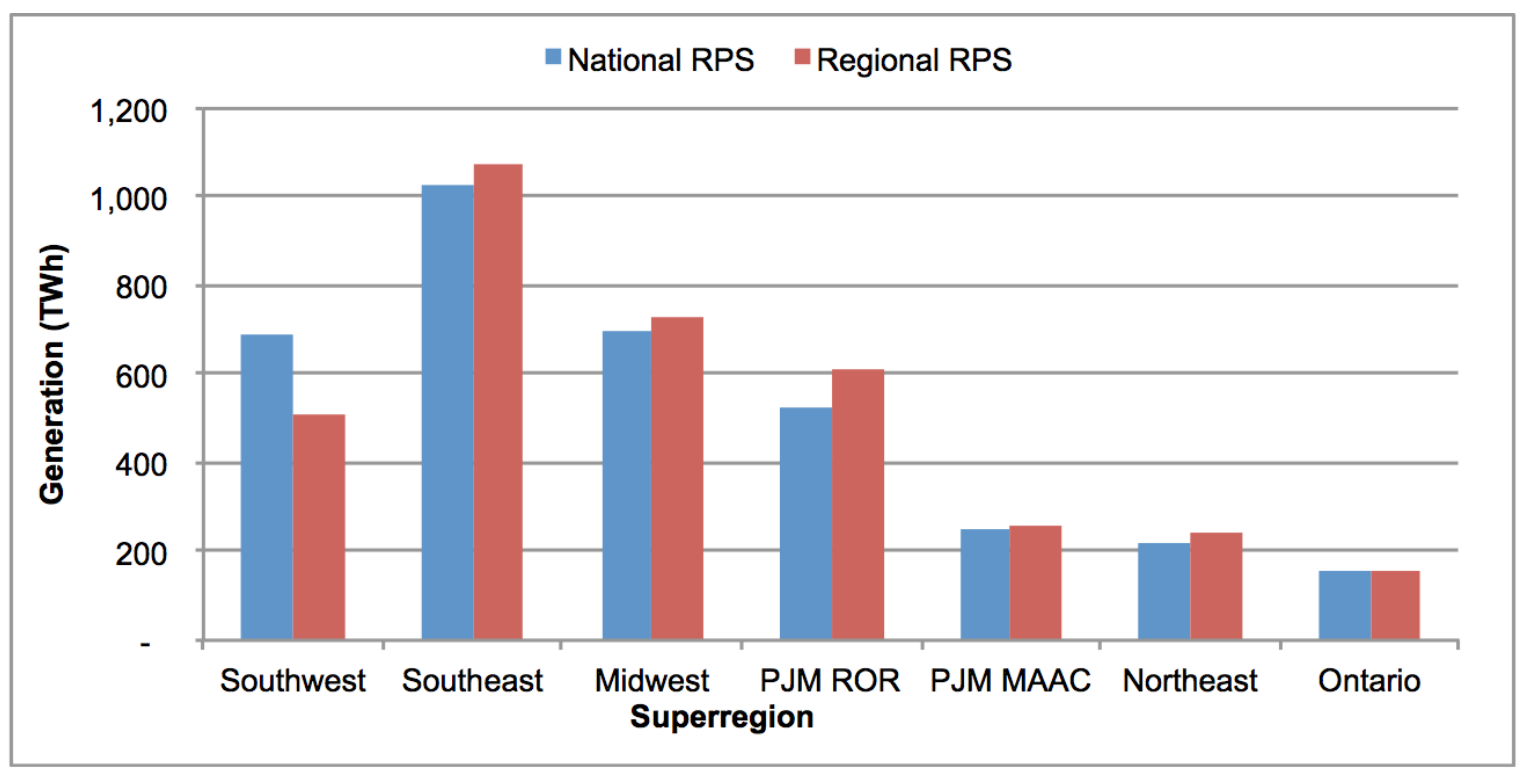

Fig. 95. Eastern Interconnection generation by superregion in 2030 under the renewable portfolio standard (RPS).

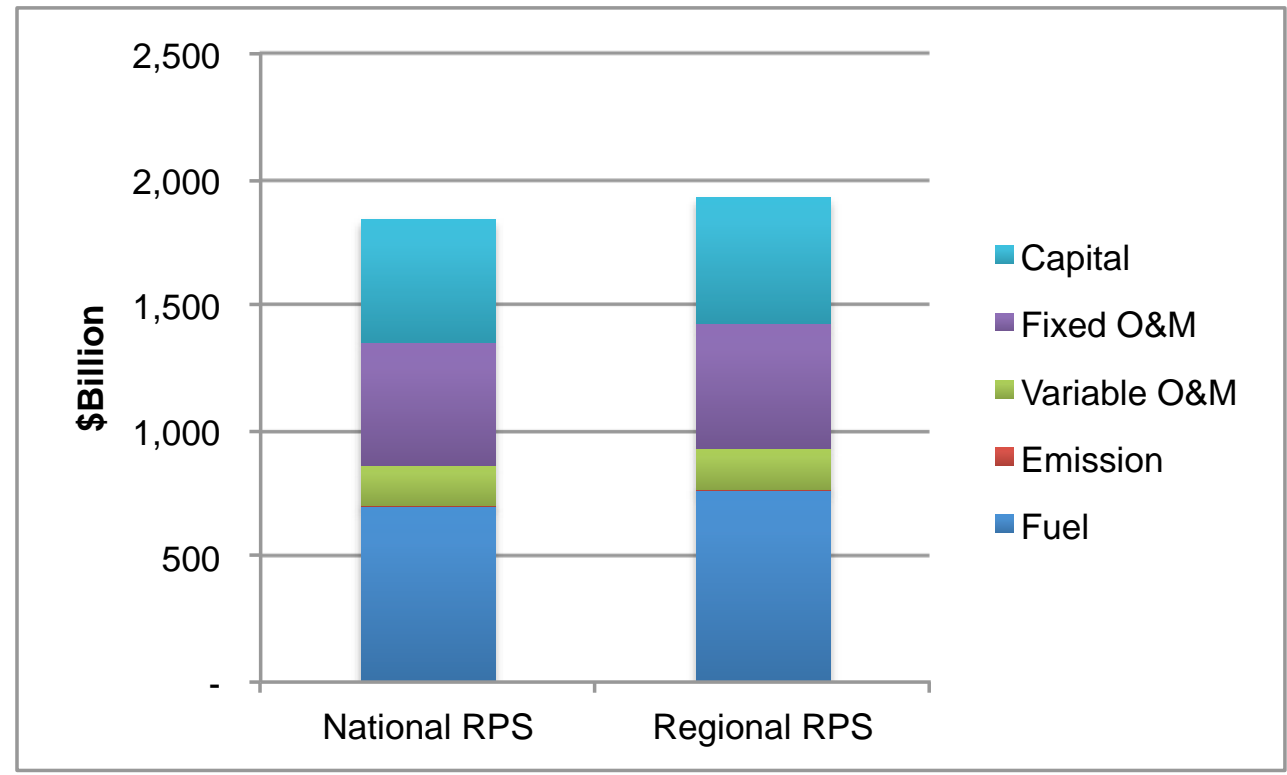

Fig. 96. Net present value costs, 2015-2030, under the renewable portfolio standard (RPS).

\subsection{Conclusion}

As was intended when the futures were developed, the switch from a national implementation to a regional implementation caused reduced reliance on interregional transfers of energy and increased reliance on local generation. Under both the $\mathrm{CO}_{2}$ price and RPS futures, wind generation in the Southwest and Midwest superregions were lower for the regional implementation. The replacement for the displaced wind energy was different in the $\mathrm{CO}_{2}$ price future than in the RPS. The regional $\mathrm{CO}_{2}$ price resulted in 
increased use of fossil fuels, especially natural gas, while the regional RPS saw increased use of offshore wind and other renewables such as biomass.

The regional $\mathrm{CO}_{2}$ price led to greater $\mathrm{CO}_{2}$ emissions than the national $\mathrm{CO}_{2}$ price, but at a slightly lower cost. The RPS/R future had higher overall costs than the RPS/N future. 



\section{TOPIC 11: LOAD GROWTH SENSITIVITIES}

\subsection{Base Growth Rates}

The initial futures had demands based on expected growth rates as determined by the planning authorities and the SSC as shown in Table 46. Those shown are for the BAU future; the other futures began with these values but could vary because the MRN economic model incorporated price elasticity to reduce demands as prices rose. In addition, the EE/DR and $\mathrm{CO}_{2}+$ futures included a $1 \%$ reduction in growth rates to represent the impact of EE programs. Each region can have a different growth rate depending on its expected use patterns and economic growth. Some regions have flat to negative growth (e.g., PJM E and NEISO) based on their existing EE plans.

Table 46. Demand Growth Rates for the Business as Usual Future

\begin{tabular}{|lccc|} 
NEEM Region & $\begin{array}{c}2011 \text { Energy } \\
\text { (GWh) }\end{array}$ & $\begin{array}{c}2011-2020 \\
\text { Growth Rate } \\
(\%)\end{array}$ & $\begin{array}{c}\text { 2020-2050 } \\
\text { Growth Rate } \\
(\%)\end{array}$ \\
\hline MAPP CA & 48.1 & 2.00 & 0.78 \\
\hline MAPP US & 29.8 & 0.87 & 0.78 \\
\hline MISO W & 137.7 & 0.85 & 0.78 \\
\hline MISO MO-IL & 96.2 & 0.87 & 0.82 \\
\hline MISO WUMS & 66.4 & 1.10 & 0.66 \\
\hline MISO IN & 97.1 & 1.05 & 0.61 \\
\hline MISO MI & 94.7 & 0.80 & 0.79 \\
\hline Non-RTO Midwest & 58.1 & 1.66 & 0.49 \\
\hline PJM ROR & 520.0 & 0.40 & 0.61 \\
\hline PJM ROM & 144.0 & 0.86 & 0.67 \\
\hline PJM E & 135.8 & -0.98 & 0.67 \\
\hline IESO & 142.3 & -0.29 & 0.67 \\
\hline NYISO A-F & 63.3 & 0.20 & 0.51 \\
\hline NYISO G-I & 19.5 & 0.14 & 0.85 \\
\hline NYISO J-K & 73.3 & 0.39 & 0.88 \\
\hline NEISO & 129.8 & 0.02 & 0.00 \\
\hline NE & 29.5 & 1.81 & 0.78 \\
\hline SPP N & 76.0 & 1.22 & 0.91 \\
\hline SPP S & 163.9 & 1.15 & 0.64 \\
\hline ENT & 159.5 & 1.37 & 0.53 \\
\hline TVA & 173.6 & 0.97 & 0.49 \\
\hline SOCO & 249.5 & 1.94 & 0.81 \\
\hline VACAR & 236.1 & 1.62 & 0.96 \\
\hline FRCC & 229.0 & 1.73 & 1.24 \\
\hline Total EI & $3,173.2$ & 0.92 & 0.72 \\
\hline & & & \\
\hline & & & \\
\hline
\end{tabular}

To examine the impact of growth, sensitivities that either raised or lowered the growth rates were run for many of the regions. The rates were changed by adding or subtracting $1 \%$ to the annual rate, so for example, a growth rate of $0.85 \%$ became either $1.85 \%$ or $-0.15 \%$ depending on the sensitivity. Load growth sensitivities were run in six different futures: the $\mathrm{BAU}, \mathrm{CO}_{2} / \mathrm{N}, \mathrm{CO}_{2} / \mathrm{R}, \mathrm{RPS} / \mathrm{N}, \mathrm{RPS} / \mathrm{R}$, and NUC. The first three included both high and low load growths, but only high load growth impacts were evaluated for the last three.

The consequent growth rates led to widely different growth levels between 2011 and 2030 for each of the regions (Table 47). Growth was highest in the Southeast territory, followed by the Southwest, Northwest, 
Central, and Northeast. Under high demand, growth overall exceeded $40 \%$ by 2030 , while with low growth, the demand in the EI actually shrank.

Table 47. Growth by Region for Base, High, and Low Sensitivities (2011-2030)

\begin{tabular}{|lccc|} 
NEEM Region & $\begin{array}{c}\text { Low } \\
\text { Demand } \\
(\%)\end{array}$ & $\begin{array}{c}\text { Base } \\
(\%)\end{array}$ & $\begin{array}{c}\text { High Demand } \\
(\%)\end{array}$ \\
\hline MAPP CA & 7 & 29 & 56 \\
\hline MAPP US & -3 & 17 & 41 \\
\hline MISO W & -4 & 17 & 41 \\
\hline MISO MO-IL & -3 & 17 & 42 \\
\hline MISO WUMS & -3 & 18 & 42 \\
\hline MISO IN & -4 & 17 & 41 \\
\hline MISO MI & -4 & 16 & 40 \\
\hline Non-RTO Midwest & 1 & 22 & 47 \\
\hline PJM ROR & -9 & 10 & 33 \\
\hline PJM ROM & -5 & 15 & 39 \\
\hline PJM E & -19 & -2 & 18 \\
\hline IESO & -14 & 4 & 26 \\
\hline NYISO A-F & -12 & 7 & 29 \\
\hline NYISO G-I & -9 & 10 & 33 \\
\hline NYISO J-K & -7 & 13 & 37 \\
\hline NEISO & -17 & 0 & 21 \\
\hline NE & 5 & 27 & 53 \\
\hline SPP N & 1 & 22 & 48 \\
\hline SPP S & -2 & 18 & 43 \\
\hline ENT & -2 & 19 & 44 \\
\hline TVA & -5 & 15 & 38 \\
\hline SOCO & 6 & 29 & 56 \\
\hline VACAR & 5 & 27 & 54 \\
\hline FRCC & 9 & 32 & 60 \\
\hline Total EI & -4 & 17 & 41 \\
\hline & & & \\
\hline & -2 & & 41 \\
\hline
\end{tabular}

Growth in demand can influence marked changes in the amount of transmission that is needed for reliability or to improve economics. In many cases higher demand will lead to the need for increased transmission capacity, but not in all cases. There can be occasions where reduced demand near a low-cost resource will lead to calls for increased transmission capacity to facilitate export to distant load centers. Once transmission capacity is constructed, the relative cost differences between regions, including hurdle rates and/or wheeling charges, will determine actual transfers at any point in time.

\subsection{Demand Effects on Transmission}

In his 2004 paper for DOE and the Edison Electric Institute, Eric Hirst identified four broad reasons for construction of new transmission (Hirst 2004).

- Interconnection of new load or generation: Facilities required to connect to the transmission grid, but not necessarily to transport power across the grid.

- Reliability: Facilities required to meet NERC (North American Electric Reliability Corporation), regional reliability council, and other standards, primarily the NERC (1997) Planning Standards. 
- Economics: Facilities that lower the cost of electricity production by reducing losses and congestion to permit greater use of low-cost generators to serve distant load centers.

- Replacement: Facilities that replace old, worn-out, and/or obsolete equipment.

In addition, a fifth reason has become more prevalent.

- Environmental: Facilities required to interconnect clean resources such as renewables to load for society to meet portfolio standards or other policy goals.

Demand changes can affect transmission capacity needs in all of these categories.

Interconnection. If demand is lowered or DG increased at the end-user location, then fewer or less expensive interconnections of new load or generation are needed, while increases in demand can increase the interconnections needed.

Reliability. Generation planning reserves are a function of the expected peak demand, so demand changes will raise or lower the need for planning reserves and thereby interconnections. On an operational basis and to meet contingencies, the system must maintain operating reserves based on demands at any point in time. Demand changes will have a direct effect on the transmission and distribution resources needed to support the operational reserves and meet contingencies.

Economics. Demand resources can compete with supply both indirectly as customers invest in EE and directly as DR bids into the wholesale markets in several regions of the country. Their deployment near loads reduces the capital cost of transmission and the transmission losses from bringing power from more distant plants. Increased demands raise the amount of generation required. If the new generation comes from distant sources then transmission will be needed. However, if the generation uses fuel sources that can be more easily or cheaply transported (e.g., natural gas through pipelines), then new transmission will less likely be needed.

Replacement. EE and DR reduce demand, so they may reduce the need for or size of replacement capacity when equipment becomes worn-out. However, this effect may be limited on the distribution side depending on how local power companies size their replacements. DG may similarly reduce the need, but because it can feed power back into the grid, upgrades to the local distribution system may be required. DR and DG also require enhanced communication capabilities (i.e., smart grid) for them to be used to full effect. This may lead to making some equipment obsolete and requiring earlier replacement.

Environmental. Reduced demand will help to avoid emissions from generation and avoid land and water impacts from generation and transmission capacity. Many portfolio standards and other policies recognize the benefits of increased EE in the establishment and calculation of standards. However, there can be an increase in transmission demand if the lowered demand is near environmentally attractive or economic generation resources that are limited geographically. These freed up generation resources may need added transmission resources to carry their production to more distant loads.

\subsection{Key Impacts}

For every future the transmission system was only expanded during development of the base scenario. A three step process consisting of the following was used (1) run the MRN-NEEM with the input assumptions for the future and no change to the transmission system, (2) use the consequent regional cost differences to allow the model to build variable capacities of transmission between regions, and (3) harden the sizes of the resulting transmission to be the same over the study period. This method was 
not applied to each sensitivity, since sensitivities by definition are modest changes to one or a few inputs without major changes to the future as a whole.

\subsubsection{Transmission Changes}

Because transmission capacity between regions was not changed with the increase or decrease in growth rates, there was little actual change in the amount the transmission grid was used despite the change in demand; either the maximum interregional flow or total energy transferred over the system. Figure 97 shows both of these factors as $\mathrm{x}$-axis and $\mathrm{y}$-axis values for the base and sensitivities with load changes. The clumping together of similar future results (shown by the colors of the data points) indicates that neither the total energy transferred nor the peak amount during the year varied greatly within the future.

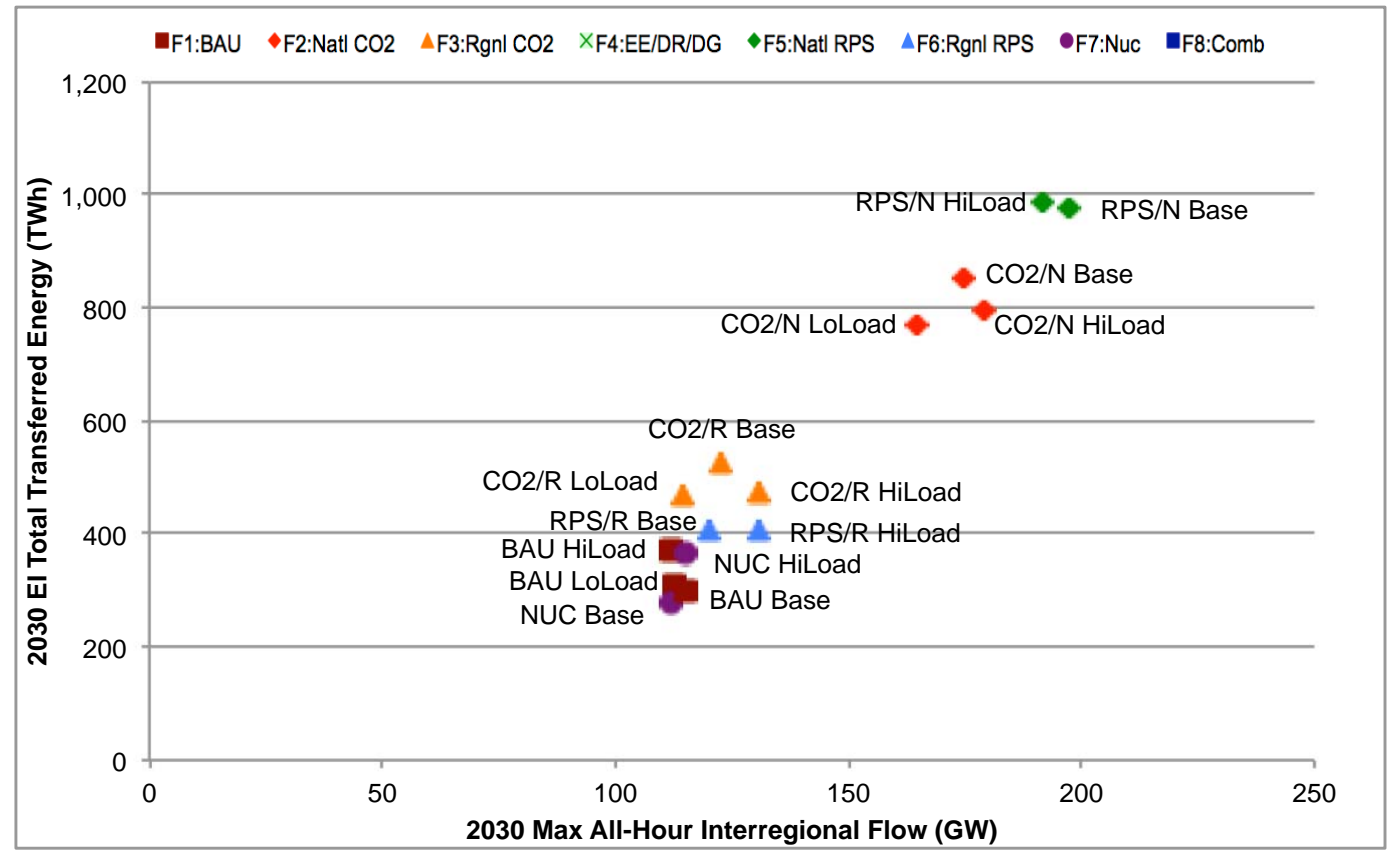

Fig. 97. Eastern Interconnection (EI) total interregional transfers (TWh) versus peak flow $(\mathbf{G W})$ in 2030 under different load growth scenarios.

The nationally implemented RPS cases had the highest amount of flow, both peak and summed over the year (green diamonds in Fig. 97). This future had the largest amount of transmission capacity added in the base scenario, $64 \mathrm{GW}$, of the futures. The high load sensitivity had higher overall flows but lower peak flows than the base case for that future. Both of the $\mathrm{CO}_{2}$ futures had their peak flows consistent with load levels, but in terms of overall energy flow, the base cases were the highest. Other futures showed a mix of increases or decreases that were not necessarily correlated with the load levels.

\subsubsection{Supply Mix Changes}

Fig. 98 shows the EI generation amounts in 2030 by technology for the base case and sensitivities. As shown in Table 48, the total generation amounts changed by less than $25 \%$ up or down. Natural gas generation shifts the most between the base and sensitivities for each future with variations ranging from $+90 \%$ to $-49 \%$ in the high and low load sensitivities. Coal as a percentage change was quite high in the two $\mathrm{CO}_{2}$ futures, but that is not significant because the amount of coal generation is near zero in those cases. Renewable amounts change roughly in line with the total percentage change, while nuclear 
generation changes little. Changes to renewables in the RPS futures would of necessity change at about the same rate as the total as their share of the market is defined by the RPS.

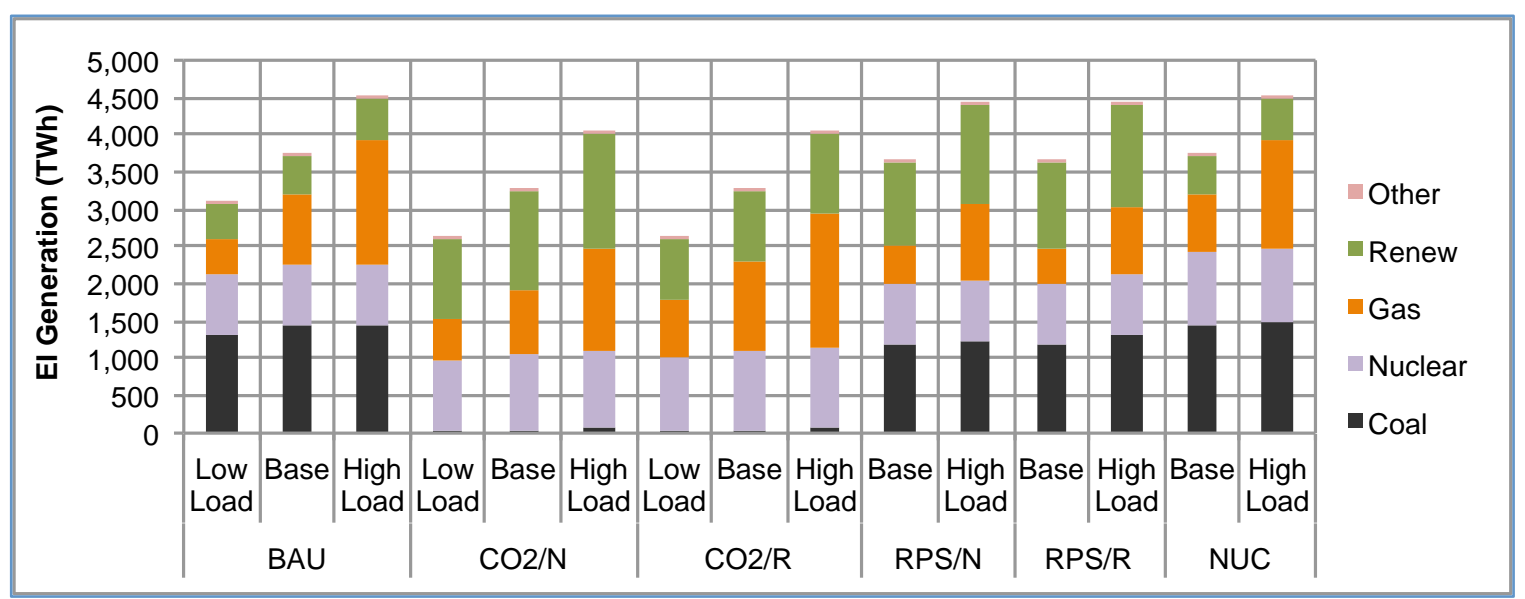

Fig. 98. Eastern Interconnection (EI) generation by technology in 2030 under different load growth scenarios.

Table 48. Percent Change in Generation from Base Scenario for Each Future by Technology

\begin{tabular}{|cccccccc|}
\hline \multirow{2}{*}{ Future } & Sensitivity & Coal & Nuclear & Gas & Renew & Other & Total \\
\hline \multirow{2}{*}{$\mathrm{BAU}$} & Low Load & -9 & 0 & -49 & -8 & -33 & -17 \\
\cline { 2 - 8 } & High Load & 2 & 0 & 73 & 8 & 3 & 21 \\
\hline \multirow{2}{*}{$\mathrm{CO}_{2} / \mathrm{N}$} & Low Load & -44 & -5 & -36 & -20 & -20 & -20 \\
\cline { 2 - 8 } & High Load & 123 & 4 & 57 & 15 & 27 & 24 \\
\hline \multirow{2}{*}{$\mathrm{CO}_{2} / \mathrm{R}$} & Low Load & -55 & -3 & -35 & -16 & -13 & -20 \\
\cline { 2 - 8 } & High Load & 38 & 2 & 51 & 13 & 49 & 24 \\
\hline $\mathrm{RPS} / \mathrm{N}$ & High Load & 5 & 0 & 90 & 20 & 20 & 21 \\
\hline $\mathrm{RPS} / \mathrm{R}$ & High Load & 12 & 0 & 84 & 19 & 37 & 21 \\
\hline $\mathrm{NUC}$ & High Load & 3 & 0 & 93 & 7 & -15 & 21 \\
\hline
\end{tabular}

\subsubsection{Regional Changes}

Most regions had similar changes in generation levels as demand increased or decreased (Fig. 99). With no change in transmission capacity and little change in actual transfers between regions, it follows that each region increased or decreased its generation to meet the change in demand. However, in a few futures, certain regional changes stand out. These are highlighted in Table 49, which shows the percentage change for each territory from the base scenario of each future. In the $\mathrm{CO}_{2} / \mathrm{N}$ future, the Central region (mainly PJM) had bigger swings in its generation levels than the other regions. In that future, the region imported large amounts from the Midwest, and as shown in the previous study (Hadley and Gotham 2014), the transfers between the regions hit the capacity limits much of the time. With the demand increased, the region had to generate proportionately more to meet demand. Conversely, with lower demands the lines between the regions were constrained less frequently and more power could transfer from the Midwest, further reducing the need for generation in the Central region. 


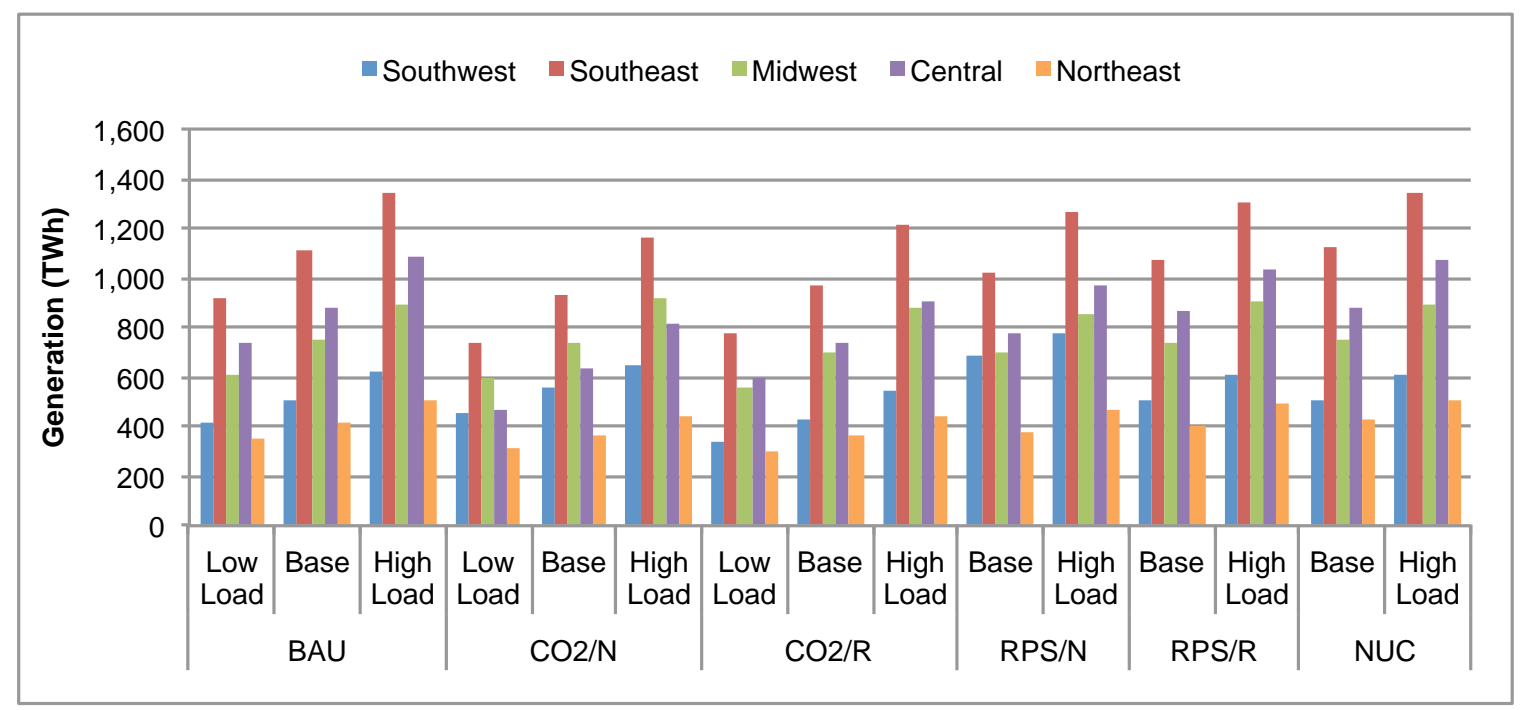

Fig. 99. Eastern Interconnection generation by territory in 2030 under different load growth scenarios.

Table 49. Percent Change in Generation from Base Scenario for Each Future by Territory

\begin{tabular}{|cccccccc|}
\hline \multirow{2}{*}{ Future } & Sensitivity & Southwest & Southeast & Midwest & Central & Northeast & Total \\
\cline { 2 - 8 } BAU & Low Load & -19 & -18 & -19 & -16 & -16 & -18 \\
\cline { 2 - 8 } & High Load & 22 & 20 & 18 & 23 & 22 & 21 \\
\hline \multirow{2}{*}{$\mathrm{CO}_{2} / \mathrm{N}$} & Low Load & -17 & -20 & -19 & -25 & -16 & -20 \\
\cline { 2 - 8 } & High Load & 17 & 26 & 24 & 29 & 20 & 24 \\
\hline \multirow{2}{*}{$\mathrm{CO}_{2} / \mathrm{R}$} & Low Load & -20 & -20 & -21 & -20 & -16 & -20 \\
\cline { 2 - 8 } & High Load & 26 & 25 & 25 & 23 & 21 & 24 \\
\hline $\mathrm{RPS} / \mathrm{N}$ & High Load & 13 & 24 & 22 & 25 & 23 & 22 \\
\hline $\mathrm{RPS} / \mathrm{R}$ & High Load & 21 & 22 & 23 & 19 & 24 & 21 \\
\hline $\mathrm{NUC}$ & High Load & 21 & 20 & 20 & 23 & 20 & 21 \\
\hline
\end{tabular}

In the RPS/N future, the effect on the Southwest was opposite that on the Central region. It exported significant amounts of power to the Southeast and Central regions. The lines were fully loaded much of the time; under higher demands they could not ship proportionately as much power to the east. As a consequence, its percentage increase in generation was lower than that of the other regions.

\subsubsection{Regional Cost Changes}

Costs of course increase with higher demands and decline with lower demands. Figure 100 shows the cost by territory for the base and load growth sensitivities. The Southeast, Midwest, and Central territories dominate the costs, although the Southwest has relatively high costs, especially in the RPS/N future where it provides its most significant contribution through wind generation. (These costs are those calculated within the MRN-NEEM model and do not include transmission and distribution, EE/DR, and a few smaller cost components calculated externally to the model.) The percentage changes from the base future are shown in Table 50. The Southwest territory generally sees smaller differences in cost as demand increases or decreases. Transmission limits constrain higher generation and costs for supplying exports to other regions, while declines in demand free up transmission space for increased exports. On the other hand, the Central and Northeast regions have larger increases in costs than the average with higher demands because they must generate more of their own power. Because much of that power will be either gas generation or higher cost renewables, their costs will go up proportionately. In addition, the 
transmission constraints mean that imports will be a smaller proportion of their total generation so that internal generation costs rise proportionately.

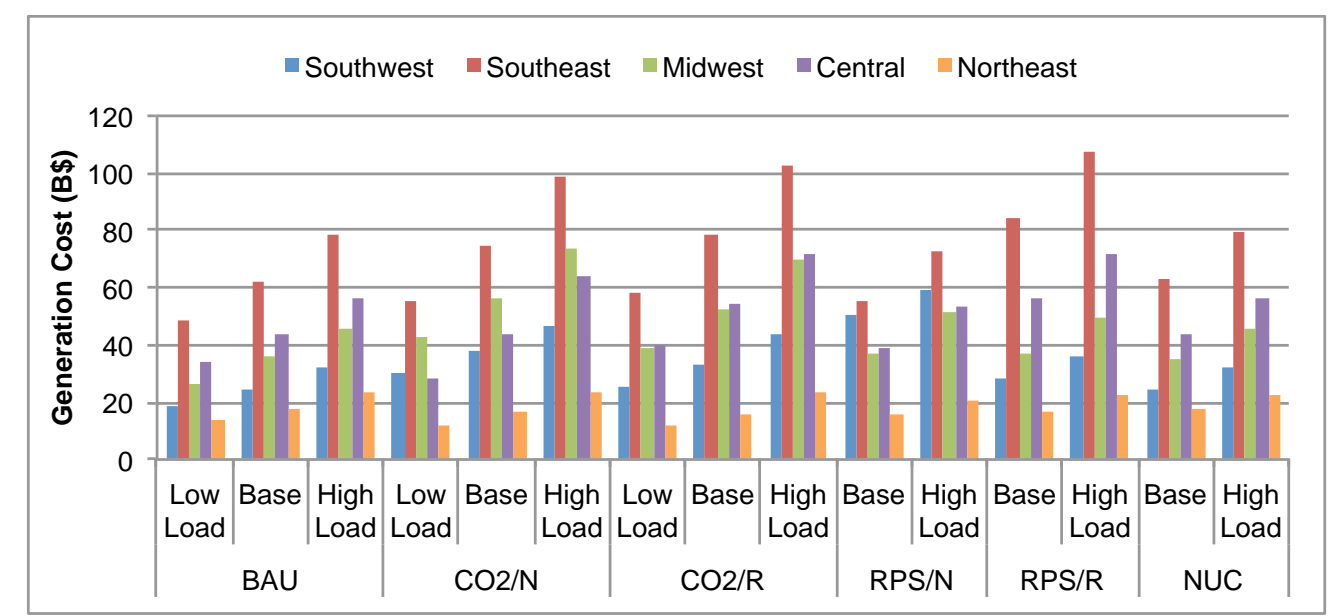

Fig. 100. Eastern Interconnection generation cost by territory in 2030 under different load growth scenarios.

Table 50. Percent Change in Cost from Base Scenario for Each Future by Territory

\begin{tabular}{|cccccccc|}
\hline \multirow{2}{*}{ Future } & Sensitivity & Southwest & Southeast & Midwest & Central & Northeast & Total \\
\cline { 2 - 8 } $\mathrm{BAU}$ & Low Load & -25 & -22 & -27 & -22 & -22 & -24 \\
\cline { 2 - 8 } & High Load & 32 & 26 & 28 & 30 & 33 & 29 \\
\hline \multirow{2}{*}{$\mathrm{CO}_{2} / \mathrm{N}$} & Low Load & -20 & -25 & -25 & -36 & -26 & -26 \\
\cline { 2 - 8 } & High Load & 23 & 33 & 31 & 45 & 44 & 34 \\
\hline \multirow{2}{*}{$\mathrm{CO}_{2} / \mathrm{R}$} & Low Load & -24 & -25 & -25 & -27 & -24 & -25 \\
\cline { 2 - 8 } & High Load & 31 & 31 & 32 & 32 & 46 & 33 \\
\hline $\mathrm{RPS} / \mathrm{N}$ & High Load & 17 & 31 & 39 & 38 & 34 & 30 \\
\hline $\mathrm{RPS} / \mathrm{R}$ & High Load & 27 & 28 & 34 & 28 & 34 & 29 \\
\hline $\mathrm{NUC}$ & High Load & 29 & 26 & 30 & 31 & 31 & 29 \\
\hline
\end{tabular}

\subsection{Conclusions}

Because load growth changes were made to the different futures after the transmission capacity between regions was set, there was little change in the amounts transferred between regions. Rather, natural gas generation, which was modeled as available in any region, was most often added or subtracted in each region as needed. Those constraints meant that regions that exported significant amounts could not increase their exports in line with the growth in demand and so did not have as strong a growth in generation, while importing regions had to expand their internal generation proportionately more. Cost changes tended to mirror generation changes but with some amplification because higher cost generation was the marginal amount added. 



\section{TOPIC 12: ENVIRONMENTAL POLICY SENSITIVITY IMPACTS}

A large number of the futures and sensitivities were defined to explore the effect of different environmental policies. The futures themselves looked at the major policies of $\mathrm{CO}_{2}$ price inclusion, aggressive EE/DR/DG, RPS, NUC, or a combination of these factors. Within each, as well as the BAU, environmental policies were strengthened, reduced, or combined. This chapter looks at the effects of these modifications to the environmental policies in place in the different futures.

\subsection{Carbon Pricing}

Carbon pricing was a major component for three of the futures $\left(\mathrm{CO}_{2} / \mathrm{N}, \mathrm{CO}_{2} / \mathrm{R}, \mathrm{CO}_{2}+\right)$ and a sensitivity in the NUC future. This section focuses on the effect of the different $\mathrm{CO}_{2}$ price penalties within each policy and not the effects between futures. Five sensitivities allow a check on changing $\mathrm{CO}_{2}$ prices compared to their bases. Table 51 shows the mix of capacities for the EI in 2030 in those different scenarios. "Other" includes both pumped storage and DR, which were put into the model and did not vary in the cases shown in the table.

Table 51. Capacities in 2030 by Technology for Base and $\mathrm{CO}_{2}$ Sensitivities of Three Futures (GW)

\begin{tabular}{|c|c|c|c|c|c|}
\hline Case & Coal & Nuclear & Gas & Renewables & Other \\
\hline $\mathrm{CO}_{2} / \mathrm{N}$ Base & 31 & 131 & 364 & 398 & 88 \\
\hline $\mathrm{CO}_{2} / \mathrm{N}$ Flat $\mathrm{CO}_{2}$ & 12 & 127 & 388 & 392 & 88 \\
\hline $\mathrm{CO}_{2} / \mathrm{N}$ Low $\mathrm{CO}_{2}$ & 34 & 114 & 383 & 358 & 88 \\
\hline $\mathrm{CO}_{2} / \mathrm{R}$ Base & 39 & 134 & 372 & 280 & 88 \\
\hline $\mathrm{CO}_{2} / \mathrm{R}$ Flat $\mathrm{CO}_{2}$ & 12 & 133 & 402 & 267 & 88 \\
\hline $\mathrm{CO}_{2} / \mathrm{R}$ Low $\mathrm{CO}_{2}$ & 33 & 112 & 402 & 251 & 88 \\
\hline NUC Base & 199 & 129 & 340 & 142 & 88 \\
\hline $\mathrm{NUC} \mathrm{CO}_{2}$ added & 63 & 191 & 409 & 195 & 88 \\
\hline
\end{tabular}

The goal of the futures involving $\mathrm{CO}_{2}$ prices was to lower economy-wide emissions from 2005 levels $42 \%$ by 2030 and $80 \%$ by 2050 . Rather than attempt a long series of automated iterations to establish a price for each year studied, the SSC set initial prices at $\$ 30 /$ ton in 2015 , increasing by $\$ 7 /$ year, and then let CRA adjust them to meet the goals. CRA had to run the MRN-NEEM several times to establish a price curve that met the requirements. One outcome was that in the years up to 2030 most carbon reduction came from the electricity sector so that while the economy as a whole had a reduction of $41 \%$ in emissions, the electricity sector had a reduction of $78 \%$. By 2040, the electric sector was essentially "decarbonized." Table 52 shows the $\mathrm{CO}_{2}$ emissions for the United States as a whole and for the US electric sector from the BAU base case and the initial $\mathrm{CO}_{2} / \mathrm{N}$ case. (Electricity transfer capacities were subsequently hardened to create the $\mathrm{CO}_{2} / \mathrm{N}$ base case.)

The resulting $\mathrm{CO}_{2}$ price curves are shown in Fig. 101. The preponderance of reductions in the electricity sector makes sense as the substitutes for $\mathrm{CO}_{2}$-emitting generation are relatively well known and inexpensive. Other sectors, notably transportation, may have a difficult time making reductions as significant as these, at least as modeled in MRN-NEEM. 
Table 52. US $\mathrm{CO}_{2}$ Emissions in the Business as Usual and $\mathrm{CO}_{2} / \mathrm{N}$ Base Scenarios (billion tons)

\begin{tabular}{|c|c|c|c|c|c|c|c|c|}
\hline \multicolumn{9}{|c|}{ United States Economy as a Whole } \\
\hline & 2015 & 2020 & 2025 & 2030 & 2035 & 2040 & 2045 & 2050 \\
\hline BAU Base & 5.7 & 5.6 & 5.8 & 5.9 & 6.2 & 6.5 & 6.9 & 7.3 \\
\hline $\mathrm{CO}_{2} / \mathrm{N}$ Base & 4.9 & 4.4 & 4.0 & 3.5 & 2.9 & 2.3 & 1.8 & 1.2 \\
\hline Percent reduction from BAU & 13 & 21 & 31 & 41 & 54 & 64 & 75 & 84 \\
\hline Target emissions & & & & 3.5 & & & & 1.2 \\
\hline \multicolumn{9}{|c|}{ US Electric Sector } \\
\hline & 2015 & 2020 & 2025 & 2030 & 2035 & 2040 & 2045 & 2050 \\
\hline BAU Base & 2.1 & 2.0 & 2.2 & 2.2 & 2.4 & 2.6 & 2.9 & 3.2 \\
\hline $\mathrm{CO}_{2} / \mathrm{N}$ Base & 1.60 & 1.1 & 0.7 & 0.5 & 0.3 & 0.1 & 0.1 & 0.04 \\
\hline Percent reduction from BAU & 25 & 47 & 67 & 78 & 89 & 96 & 98 & 99 \\
\hline
\end{tabular}

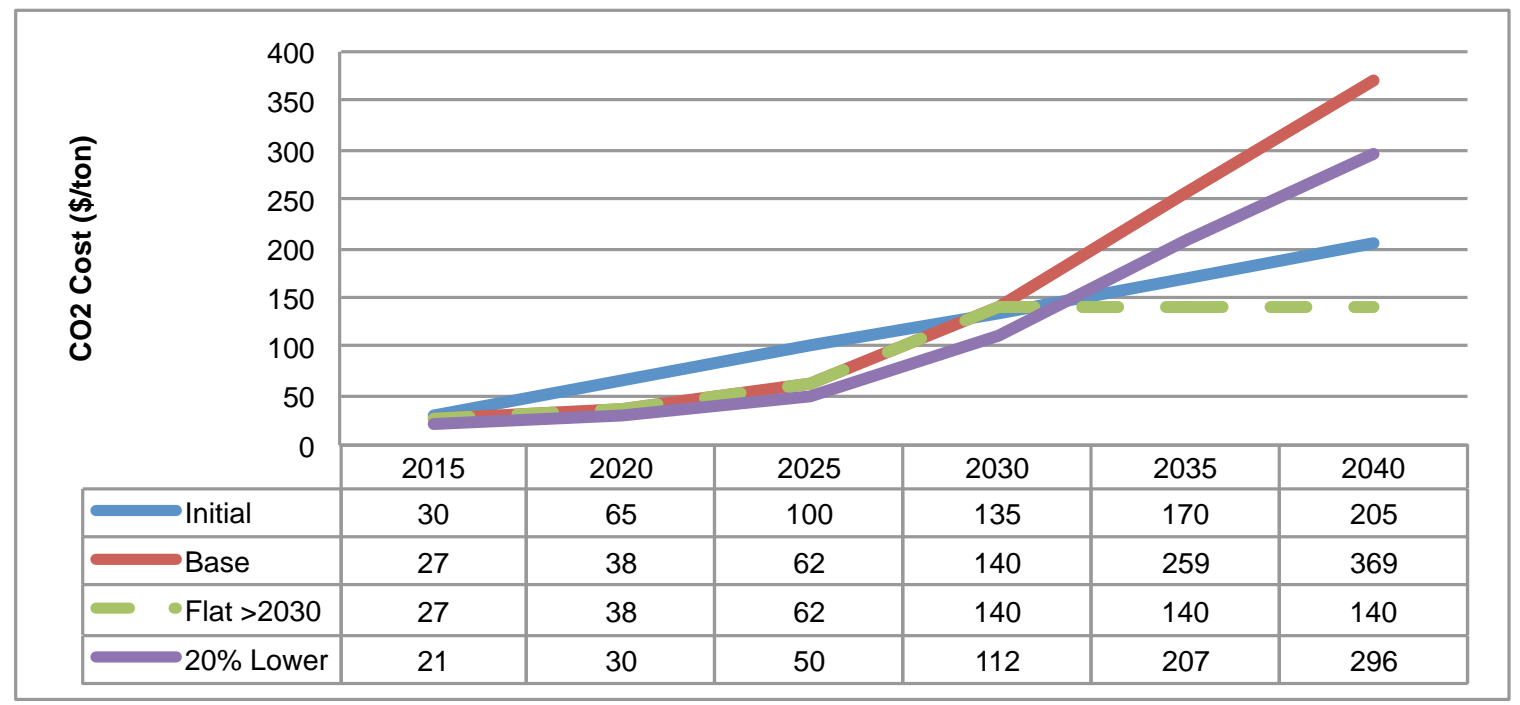

Fig. 101. Carbon dioxide price curves used in study.

The later years saw rapidly increasing $\mathrm{CO}_{2}$ prices, with the cost by 2045 at $\$ 553 /$ ton and by 2050 at $\$ 942 /$ ton (beyond the scale in Fig. 101). This was a result of the extreme amount of $\mathrm{CO}_{2}$ emissions reductions required and possibly because the model had few levers to drastically change $\mathrm{CO}_{2}$ emissions in the transportation or other sectors. High prices and resulting economic impacts were the major tools available. To see the impacts of the $\mathrm{CO}_{2}$ price levels, two sensitivities were developed. In one (Low $\left.\mathrm{CO}_{2}\right)$, $\mathrm{CO}_{2}$ prices in all years were reduced by $20 \%$. This demonstrated the effect of $\mathrm{CO}_{2}$ costs over all years. In the other (Flat $\mathrm{CO}_{2}$ ), the 2030 price was held constant from 2030 on. This just demonstrated the effect on the electric sector if those prices were not high in the later years. The MRN was not rerun for sensitivities, so economy-wide changes due to flat $\mathrm{CO}_{2}$ prices were not examined.

For the two $\mathrm{CO}_{2}$ futures, the Flat $\mathrm{CO}_{2}$ sensitivity had only a small impact on generation in 2030 (Fig. 102) because $\mathrm{CO}_{2}$ prices were the same up to that point. Capacity changes were similarly small by this point in time. By 2050 capacity and generation types and quantities differed greatly from the base scenario with its higher $\mathrm{CO}_{2}$ prices, but results post-2030 were not a focus of this analysis. The Low $\mathrm{CO}_{2}$ sensitivity resulted in more natural gas-fired generation and less generation by renewable sources, which would be expected with a decrease in $\mathrm{CO}_{2}$ price. The base NUC future did not include a $\mathrm{CO}_{2}$ price so coal generation was extensive in it. Adding the base $\mathrm{CO}_{2}$ price curve to the NUC future created a large change in generation and capacity, with the practical elimination of coal and large increases in nuclear power and gas-fired and renewable generation. This sensitivity had by far the largest use of nuclear power of all of 
the cases in Phase 1, with 191 GW in place in 2030. Figure 103 shows the amount of nuclear capacity in those regions that had changes from the BAU future. Note that the Southeast had most of the growth in nuclear, both when going from the BAU to the NUC base and from the $\mathrm{NUC}$ base to the $\mathrm{NUC} \mathrm{CO}_{2}$ sensitivity. Florida (FRCC) had the most significant changes.

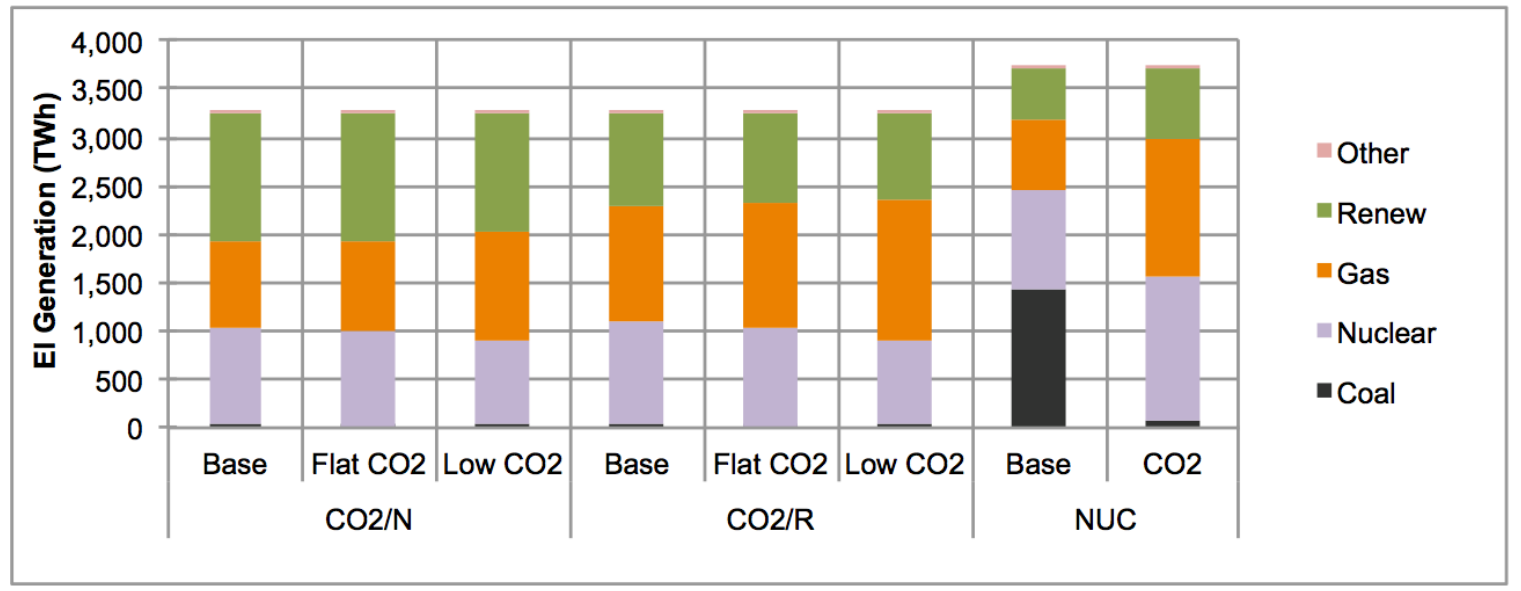

Fig. 102. Eastern Interconnection (EI) Generation in 2030 by technology for $\mathrm{CO}_{2}$ price sensitivities.

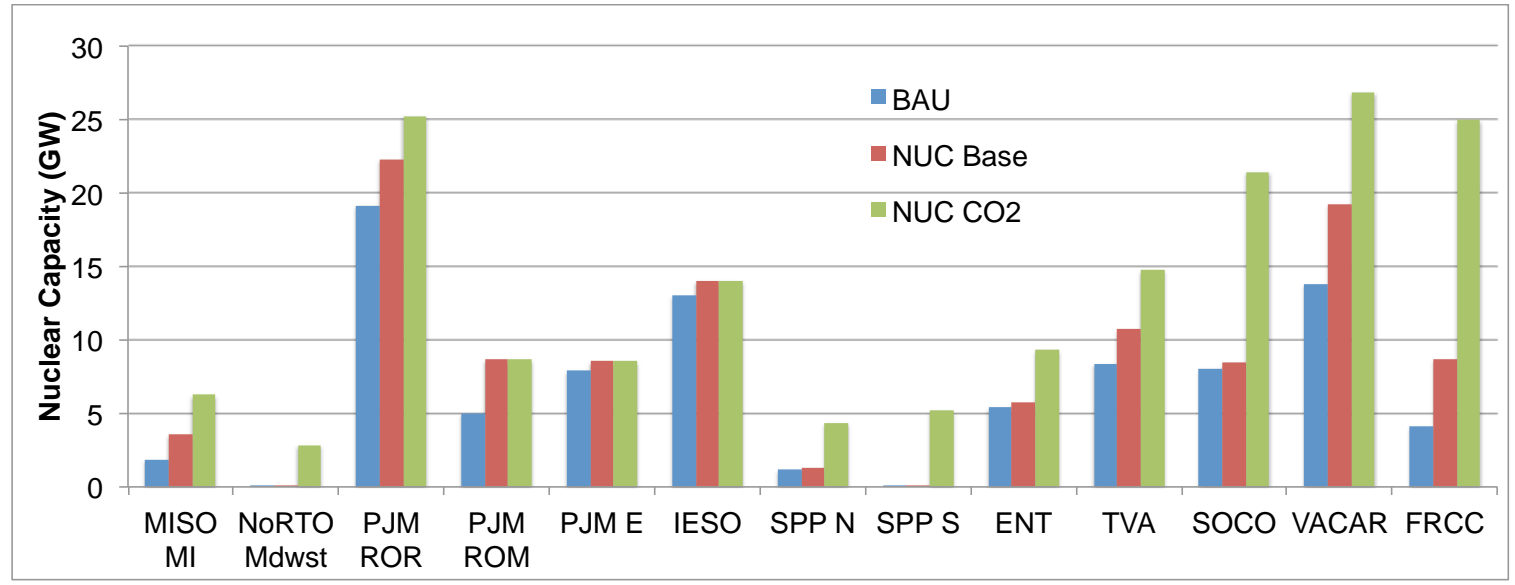

Fig. 103. Nuclear capacity in 2030 for the business as usual (BAU) and nuclear resurgence (NUC) futures and nuclear resurgence-carbon dioxide $\left(\mathrm{NUC} \mathrm{CO}_{2}\right)$ sensitivity.

\subsection{Delayed Implementation of Environmental Policies}

The base cases of the different futures included the expected EPA air and water regulations affecting power plants, including the Transport Rule, Utility Mercury and Air Toxics Standards Rule, Utility New Source Performance Standards Rule, Coal Combustion Residuals Rule, and Cooling Water Intake Structures Rule. Also examined were the PTC and existing state RPS rules. While many of the sensitivities increased the attractiveness of renewables, five sensitivities were run in the BAU future that examined downgrading environmental policies through delays in implementation or removal entirely (Table 53). 
Table 53. Generation by Technology in 2030 Under Different Delayed Environmental Policies (TWh) (Base row shows generation amount while other rows show difference from base.)

\begin{tabular}{|c|c|c|c|c|c|c|}
\hline Case & Description & Coal & Nuclear & Gas & Renew & Other \\
\hline Base & Business as Usual & 1,428 & 818 & 956 & 505 & 10 \\
\hline $\begin{array}{l}\text { Reduce } \\
\text { RPS/EE/DR } \\
\text { requirements }\end{array}$ & $\begin{array}{l}\text { Reduce existing state RPS by } 5 \% \text { in absolute } \\
\text { terms within the time frame specified by each } \\
\text { state's RPS requirement. Reduce EE/DR } \\
\text { requirements (in states that have them) by } 5 \\
\text { percentage points each by end of study period. }\end{array}$ & 44 & 0 & 138 & -53 & -2 \\
\hline $\begin{array}{l}\text { Delay EPA } \\
5 \text { years }\end{array}$ & $\begin{array}{l}\text { Less-aggressive implementation of upcoming } \\
\text { EPA regulations by delaying implementation } \\
5 \text {-years }\end{array}$ & 26 & 0 & -26 & 0 & 0 \\
\hline Delay EPA & $\begin{array}{l}\text { Delay implementation of new noncarbon EPA } \\
\text { regulations beyond period of study }\end{array}$ & 121 & 0 & -117 & -4 & 0 \\
\hline No PTC no RPS & $\begin{array}{l}\text { No policies/regulations continued past current } \\
\text { expiration (PTC/ITC, etc.); RPS requirements } \\
\text { removed. }\end{array}$ & 18 & 0 & 85 & -104 & 0 \\
\hline $\begin{array}{l}\text { No PTC No } \\
\text { RPS High Load }\end{array}$ & No PTC/RPS plus high load growth. & 30 & 0 & 842 & -103 & 0 \\
\hline
\end{tabular}

The first sensitivity listed reduced the RPS and EE/DR requirements that states currently have in place. Coal and gas generation increased while renewable generation decreased in response to these changes. Total generation increased by $3.4 \%$ due to the removal of EE requirements. Delaying implementation of the EPA rules by 5 years increased coal production relative to the base at the expense of gas-fired generation. Delaying implementation of the rules beyond 2030 increased coal generation even more, again at the expense of gas. Removing the PTCs once they expire and any RPS requirements shifts generation from renewable ( $-104 \mathrm{TWh})$ to gas $(85 \mathrm{TWh})$ and coal $(18 \mathrm{TWh})$. Most of the higher demand in the last sensitivity was met by gas-fired generation; coal use increased slightly.

\subsection{More Stringent Environmental Policies}

Most of the futures had some form of environmental policies in place, but sensitivities were added that increased the level of these policies. In the BAU future, the state-level EE and renewable energy requirements were raised by 5\% each. The resulting generation in 2030 was reduced and also had an increase in renewable generation (Fig. 104). These both served to reduce the amount of gas-fired generation.

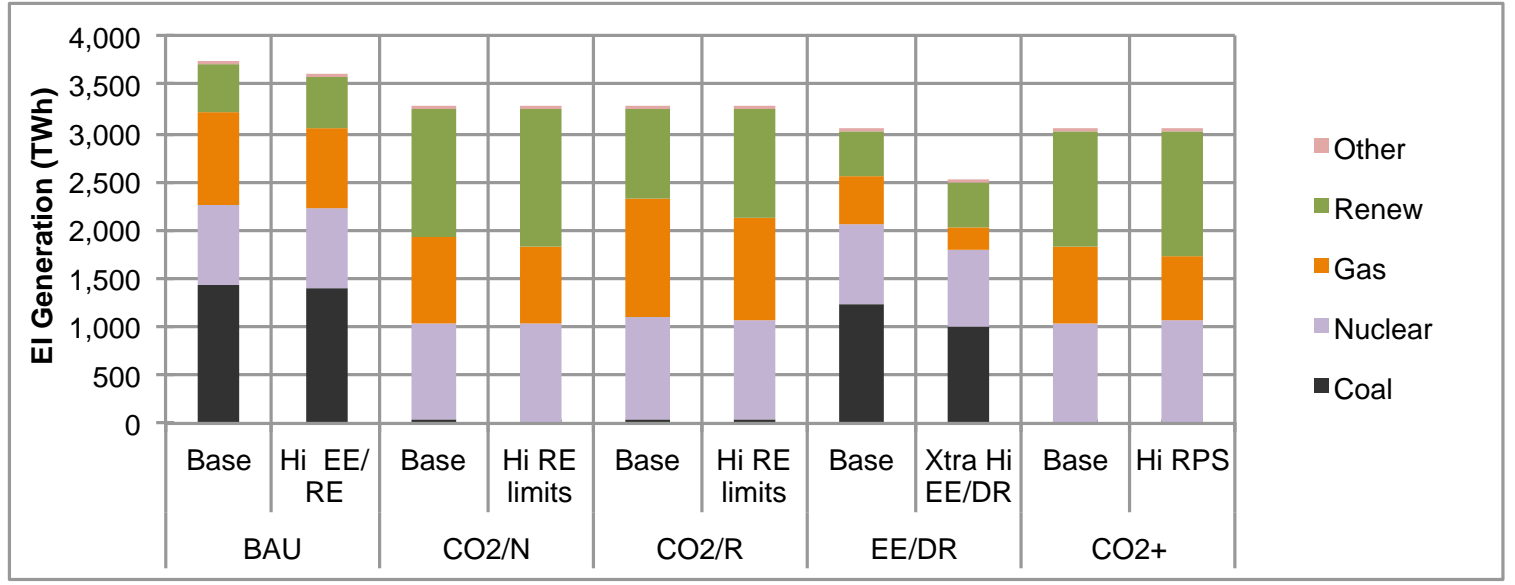

Fig. 104. Eastern Interconnection (EI) generation in 2030 by technology for increased environmental policy sensitivities. 
In all futures, the base scenarios had a ceiling on the amount of variable generation (wind + solar) of $35 \%$ of the total generation. A sensitivity was run in the $\mathrm{CO}_{2} / \mathrm{N}$ and $\mathrm{CO}_{2} / \mathrm{R}$ futures that increased this limit to $50 \%$ of generation. This increased the EI's variable generation in the $\mathrm{CO}_{2} / \mathrm{N}$ future from $30 \%$ to $33 \%$. (The total is below the ceiling because the constraints were applied to groupings of regions such as the northeast, south, or central states. The ceiling could be binding in one region without reaching it in another.) Further, the ceilings were not reached until 2035 for $\mathrm{CO}_{2} / \mathrm{N}$ (with its larger territories) but were reached by 2025 in the $\mathrm{CO}_{2} / \mathrm{R}$ future.

The sensitivity in the $\mathrm{CO}_{2}+$ future was similar. It raised the RPS from $30 \%$ to $40 \%$ and the variable generation limit to $40 \%$ as well. This increased the renewable generation from $39 \%$ to $43 \%$ of the total. Variable generation went from $28 \%$ to $31 \%$ of total demand in 2030 .

The aggressive EE/DR future base case did not modify the RPS or $\mathrm{CO}_{2}$ price, so renewables had a small proportion of total generation while coal remained significant. Rather, it increased the effect of EE by a $1 \%$ reduction in the annual demand growth rate along with an increase in the available DR for each region and a further reduction in demand through DG. The sensitivity within this future further increased the EE impact with an additional $1 \%$ reduction in growth rates and DR expansion beyond the full participation amounts reported in the FERC national assessment of DR (FERC 2009). The result of this sensitivity was a further decrease in coal- and gas-fired generation (Fig. 104).

\subsection{Clean Energy Standard}

An interesting variation on the RPS was the modeling of the federal administration's Clean Energy Standard (CES). The standard was a requirement on the ratio of qualified generation to total generation. It broadened the category of fuels that qualify for the standard from just renewables to all that lower or eliminate $\mathrm{CO}_{2}$ emissions, including nuclear and gas-fired $\mathrm{CC}$. The gas-fired generation was credited at only half of its generation since it still releases $\mathrm{CO}_{2}$ but at about half the rate of coal-fired generation. The standard increased over time using the percentages in Table 54.

Table 54. Fraction of Electricity from Clean Sources by Year Required for the Clean Energy Standard

\begin{tabular}{|lllll|} 
& & & 2030 & 2035 \\
Clean Energy Fraction & 2020 & 2025 & $70 \%$ & $80 \%$ \\
\hline
\end{tabular}

In the national implementation future (RPS/N), the standard was applied to all parts of the EI as a whole, while in the regional implementation (RPS/R), each region was expected to meet the standard. Some trading of credits between regions could alleviate that segregation however.

As can be seen in Fig. 105, the CES sensitivities dramatically reduce coal-fired generation as compared to the base scenario in each future. Gas-fired generation expands greatly, but generation from renewable sources does not grow as much as in the base. Figure 105, which includes the BAU future, also shows that even though the CES sensitivities do not have as much renewable generation as the base (with a $35 \%$ RPS), there is still much more than in the BAU. Furthermore, $\mathrm{CO}_{2}$ emissions are dramatically less in the CES sensitivity than in the RPS base scenarios, as shown in Table 55. The base scenarios in the RPS futures only reduce $\mathrm{CO}_{2}$ emissions by $24 \%$ from the BAU in 2030 while the CES sensitivities reduce it by $50 \%$. The 2015-2030 $\mathrm{CO}_{2}$ impacts are less because the early years have little change, but the difference grows over time. 


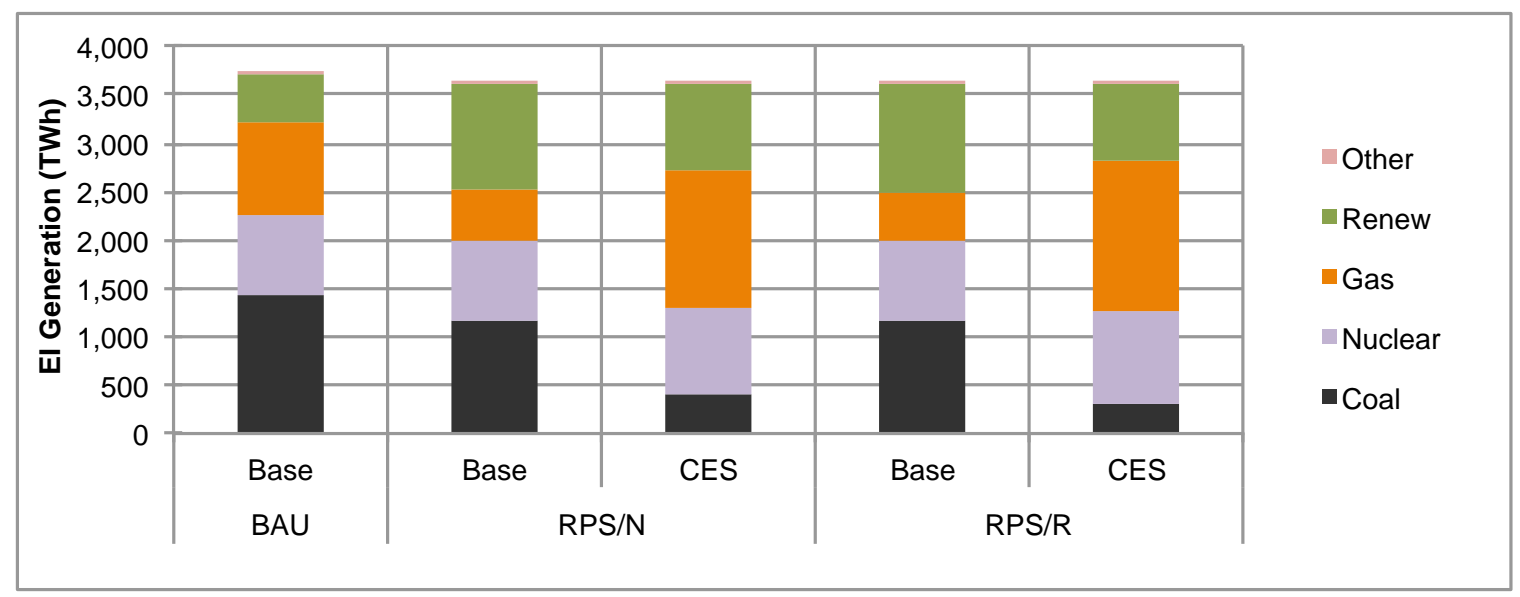

Fig. 105. Eastern Interconnection (EI) generation in 2030 by technology for Clean Energy Standard sensitivities.

Table 55. Carbon Dioxide Emissions (2015-2030 sum and 2030 alone) for Base and Clean Energy Standard (CES) Scenarios

\begin{tabular}{|lrrrrr|} 
& \multicolumn{2}{c}{ BAU } & \multicolumn{2}{c}{ RPS/N } & \multicolumn{2}{c|}{ RPS/R } \\
& Base & \multicolumn{1}{c}{ Base } & CES & \multicolumn{1}{c|}{ Base } & \multicolumn{1}{c|}{ CES } \\
\hline El 2015-2030 CO 2 Emissions (MMT) & 26,031 & 23,272 & 20,697 & 23,012 & 19,791 \\
\hline El 2030 $\mathrm{CO}_{2}$ Emissions (MMT) & 1,716 & 1,310 & 864 & 1,316 & 826 \\
\hline
\end{tabular}

\subsection{Conclusions}

The high $\mathrm{CO}_{2}$ prices in the three $\mathrm{CO}_{2}$ futures greatly decarbonized the electric sector, especially post2030. Lowering the $\mathrm{CO}_{2}$ prices by $20 \%$ lowered the amount of renewable and nuclear capacity, with gasfired capacity increasing. Of all policies, $\mathrm{CO}_{2}$ price additions, in conjunction with other factors such as lowered capital cost, most incentivized nuclear capacity increases. Lowered nuclear costs by themselves had little effect on increasing nuclear share.

Reductions in stringency of or delays in implementing environmental policies generally increased the amount of coal-fired generation at the expense of gas-fired or renewable-source generation. Reducing current state RPS, EE, and DR goals allowed the increase of both coal- and gas-fired generation, with a smaller reduction in renewables such that overall demand increased. Simple delays in the current EPA requirements increased coal-fired generation at the expense of natural gas-fired generation, while elimination of the PTC and state RPS requirements lowered generation from renewable sources in favor of coal and gas, even with high load growth.

On the other hand, more stringent environmental policies generally reduced the amount of fossil fuelfired generation through increases in EE, use of renewables, and/or DR. Lifting the original ceiling on variable generation from a maximum of $35 \%$ to $50 \%$ only increased total renewable amounts by $3 \%-4 \%$ because only the central and southwest regions could take advantage of this raised ceiling. Increasing the EE and DR programs resulted in lower fossil fuel-fired generation.

The CES program was intermediary between the base $\mathrm{CO}_{2}$ and RPS cases. By setting a standard for all carbon-reducing technologies there was a significant reduction in coal-fired generation and carbon emissions without the impact of added $\mathrm{CO}_{2}$ costs. 


\section{TOPIC 13: TECHNOLOGY SENSITIVITY IMPACTS}

A number of the sensitivities involved changes to the various technologies (e.g., price, cost, efficiency, or availability). These were to explore the robustness of results under uncertainty as to how these technologies would perform in the future. Gas price sensitivities are included in this category because a main driver for projections of future gas prices is the continued feasibility of hydrofracturing technology and sufficient transportation infrastructure.

\subsection{Gas Prices}

The base gas prices followed a trajectory based on the reference case from the EIA's 2011 AEO (early release) (EIA 2011a). To explore the sensitivities of high and low gas prices, the SSC developed three other trajectories. The high gas price used the high gas case from the AEO 2010 (EIA 2010), with a composite between the two scenarios in the years before 2025. An extra high gas price trajectory that accelerated the rise in prices but was the same price as the high gas price trajectory by 2030 was also used. A low gas price trajectory was set at a flat $\$ 4.50 / \mathrm{mmBtu}$. While these prices were the foundation for the modeling, they were adjusted in the inputs to reflect price differences between regions and between seasons. Figure 106 shows the price curves used for the base and sensitivities. It also shows the latest gas price forecast from the AEO 2014 (EIA 2014). The reference case in the AEO 2014 projects a price roughly $\$ 1 / \mathrm{mmBtu}$ lower than the EIPC study base but still higher than the study's low gas price sensitivity for most years.

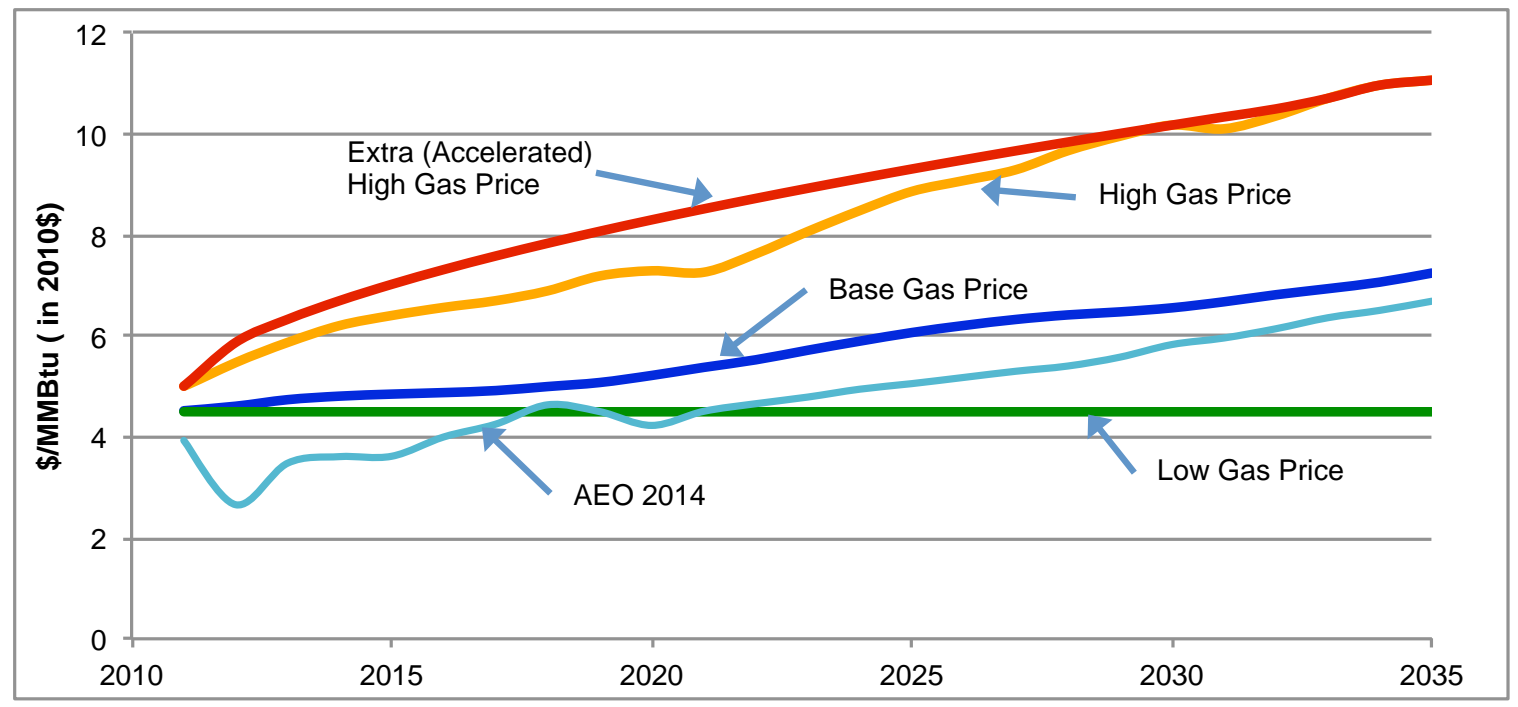

Fig. 106. Henry Hub gas price inputs to the MRN-NEEM model.

Five futures included gas price sensitivities. The BAU scenario included the high gas price and extra high gas price curves from Fig. 106 as sensitivities. The two $\mathrm{CO}_{2}$ scenarios included the low gas price and extra high gas price curves as sensitivities, while the two RPS scenarios just used the high gas price sensitivity.

The generation shares in 2030 for each major technology group for the entire EI are shown in Fig. 107. In the BAU future with high gas prices coal retirements decrease and new coal and wind capacity is constructed. Fewer CC plants and CTs are constructed, and more steam oil/gas plants retire. With extra high gas prices, 2030 results are very similar to the high gas price sensitivity, as gas prices are the same by 2030 . 


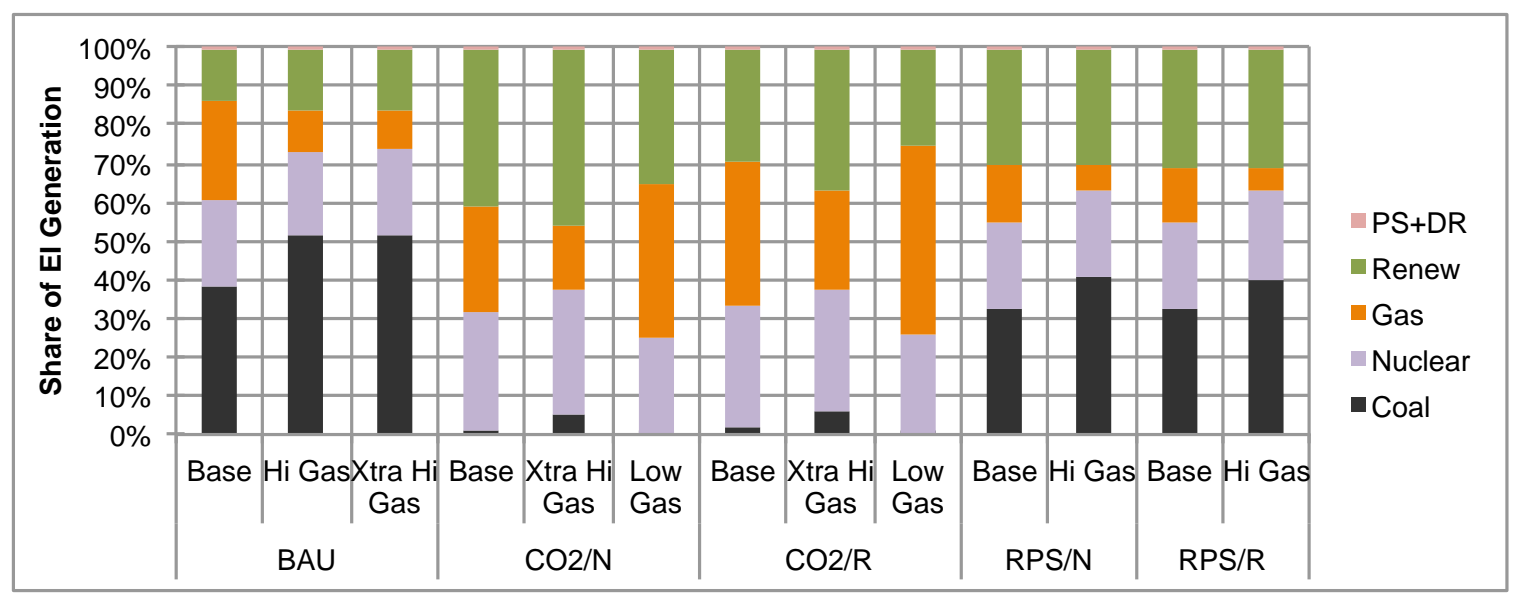

Fig. 107. Eastern Interconnection (EI) generation production share by technology for gas price sensitivities.

In the $\mathrm{CO}_{2} / \mathrm{N}$ future, extra high gas prices lead to a $10 \%$ reduction in the gas-fired generation share (from $27 \%$ to $17 \%$ ), with wind and coal making up most of the difference. The low gas price sensitivity had a $14 \%$ increase in the gas-fired generation share (from $27 \%$ to $40 \%$ ), with reductions in renewable (6\%), nuclear $(6 \%)$, and coal-fired $(1 \%)$ generation. Coal was reduced to almost no production.

In the $\mathrm{CO}_{2} / \mathrm{R}$ future, extra high gas prices had about the same effect as in the $\mathrm{CO}_{2} / \mathrm{N}$ future but started from a higher share, going from $37 \%$ to $26 \%$ of generation. Coal-fired generation increased $4 \%$ while renewables increased $7 \%$ to be $37 \%$ of generation. The low gas price sensitivity had gas-fired generation increase to $49 \%$ of generation, with nuclear going from $32 \%$ to $25 \%$, renewables from $30 \%$ to $25 \%$, and coal from $2 \%$ to $0 \%$. The lack of transmission expansion meant that natural gas-fired generation was higher in the base case versus the $\mathrm{CO}_{2} / \mathrm{N}$ future (see Chapter 2), and in the low gas price sensitivity, gas-fired generation had its highest market share of all cases.

In the RPS/N and RPS/R futures, the high gas price lowered the gas-fired generation share by $8 \%$, with coal-fired generation replacing it. Because renewables were to meet the portfolio standard of $30 \%$, they were only slightly affected by the gas price changes.

\subsection{Renewable Technology Costs}

The BAU future had a sensitivity that lowered the capital cost of renewables by $20 \%$ and one that lowered costs by $32.5 \%$. The two $\mathrm{CO}_{2}$ futures each had a sensitivity with the extra low costs for renewables, while the $\mathrm{CO}_{2}+$ future ran the sensitivity with only a $20 \%$ reduction. These sensitivities were not included in the other futures because the SSC felt that lowered cost would not be a major driver for increased renewables or it was not the focus of the future.

As seen in Fig. 108, there is a small but noticeable increase in renewable generation with the lower costs. Table 56 provides more detail on the capacity levels for renewables in the different cases. Onshore wind makes up the bulk of renewables. A small amount of growth in offshore wind and hydro also occurs with the reduction in renewable costs. The biggest change is in the $\mathrm{CO}_{2} / \mathrm{R}$ future, where the lower costs lead to large increases in offshore wind and other renewables. Since transmission is not available to transport onshore wind to coastal areas and the Southeast, offshore and other renewables become a cost-effective solution with high $\mathrm{CO}_{2}$ costs. 


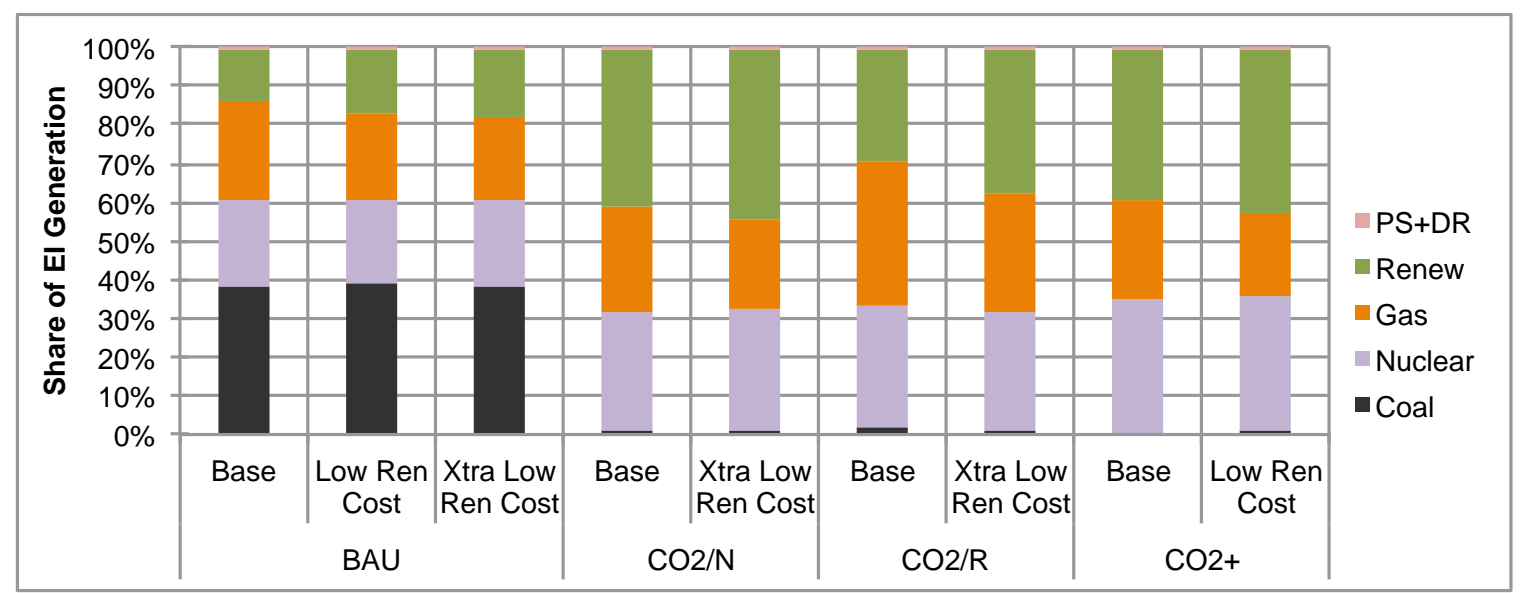

Fig. 108. Eastern Interconnection (EI) generation share by technology for renewable cost sensitivities.

Table 56. Renewable Capacities in 2030 (GW)

\begin{tabular}{|c|c|c|c|c|c|}
\hline & Hydro & $\begin{array}{l}\text { Onshore } \\
\text { Wind }\end{array}$ & $\begin{array}{l}\text { Offshore } \\
\text { Wind }\end{array}$ & Other Renew & $\begin{array}{c}\mathrm{HQ} / \\
\text { Maritimes }\end{array}$ \\
\hline BAU Base & 45 & 68 & 2 & 16 & 9 \\
\hline BAU Low Renew Cost & 45 & 108 & 4 & 15 & 9 \\
\hline BAU Extra Low Renew Cost & 45 & 120 & 4 & 15 & 9 \\
\hline $\mathrm{CO}_{2} / \mathrm{N}$ Base & 51 & 317 & 2 & 16 & 12 \\
\hline $\mathrm{CO}_{2} / \mathrm{N}$ Extra Low Renew Cost & 52 & 357 & 3 & 15 & 12 \\
\hline $\mathrm{CO}_{2} / \mathrm{R}$ Base & 52 & 197 & 2 & 16 & 13 \\
\hline $\mathrm{CO}_{2} / \mathrm{R}$ Extra Low Renew Cost & 53 & 215 & 59 & 30 & 13 \\
\hline $\mathrm{CO}_{2}+$ Base & 50 & 261 & 2 & 15 & 14 \\
\hline $\mathrm{CO}_{2}+$ Low Renew Cost & 51 & 294 & 3 & 15 & 14 \\
\hline
\end{tabular}

\subsection{Plug-In Electric Vehicle Advances}

The electricity demand from a small number of plug-in electric vehicles (PEVs) was built into the base demand assumptions because demand was largely from the EIA AEO 2011 that includes them. To explore the impact of a possible expansion of PEVs, the SSC increased the quantity of PEVs in 2030 by 10 times over that in the base, resulting in 25 million PEVs on the road in 2030. The expansion factor over the base grew over time, with 3 times in 2015, 6 times in 2020, and 9 times in 2025. Figure 109 is a chart of the PEV fleet size used in the analyses. The base case amount is from the AEO 2011 results, and the power demands are assumed to already be included in the base demands. Vehicle numbers are adjusted to reflect the quantity in the EI, including Canada. The base has 2.5 million vehicles by 2030, while under high growth the total is 24.6 . So the high growth sensitivity includes an additional 22.1 million PEVs. 


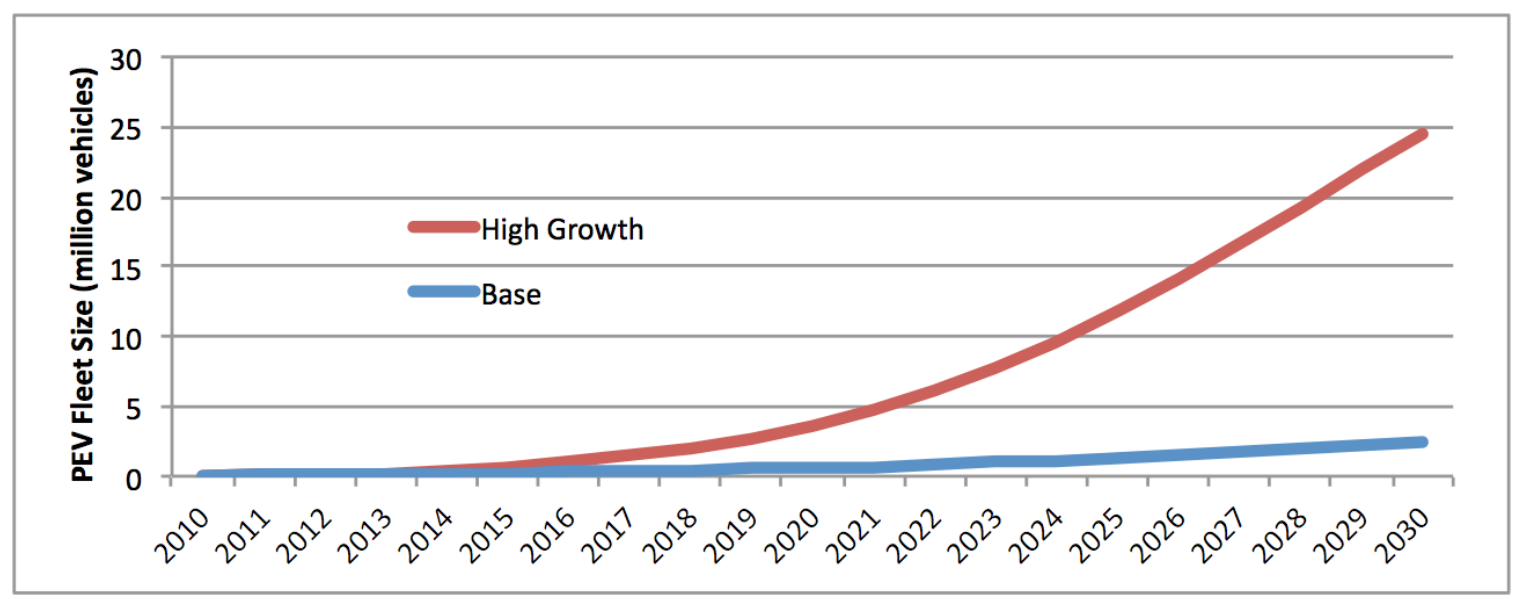

Fig. 109. Projected plug-in electric vehicle (PEV) quantities in the Eastern Interconnection.

The timing of PEV battery charging can have a major impact on the amount and type of capacity needed on the grid. If drivers charge their cars during the early evening when they return home, they will be using capacity at peak times. If they wait until later at night, the demand can be met during off-peak times when there is spare capacity. Two demand profiles were developed for vehicles, using a mixture of daily charging schedules and power levels based on an ORNL study (Sikes, et al. 2010). Figure 110 shows the load curves over 2 days when 10\% begin charging between 5:00 p.m. and 7:00 p.m. (night) and when $50 \%$ begin charging during those times (peaking).

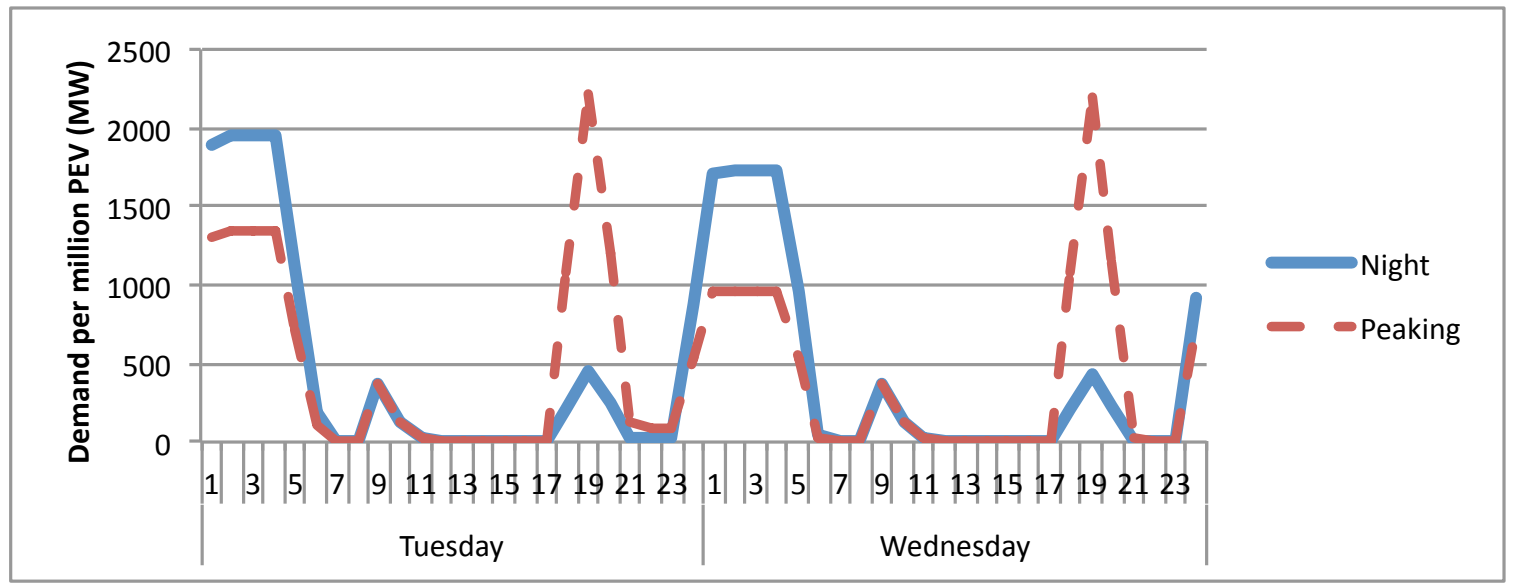

Fig. 110. Hourly demands from 1 million plug-in electric vehicles (PEVs) under the night and peaking demand cycles.

These were applied to the vehicles in each region to create demand profiles for each year. Because the base amounts were already included in system demands, just the demands from the additional vehicles were added to the system demands. The consequence of the two demand schedules can be seen in Fig. 111. If charging at nighttime using a smart grid, the impact on peak demands is only $5 \mathrm{GW}$. In the peaking scenario, $50 \%$ of vehicles begin charging upon return home between 5:00 p.m. and 7:00 p.m., and demand during the system peak is $27 \mathrm{GW}$ by 2030 . Translating into average capacity per vehicle, the night-dominant charging raises peak demand by just $0.1 \mathrm{~kW} /$ vehicle, while the peaking-dominant charging raises system peaks by $1.2 \mathrm{~kW} /$ vehicle. 


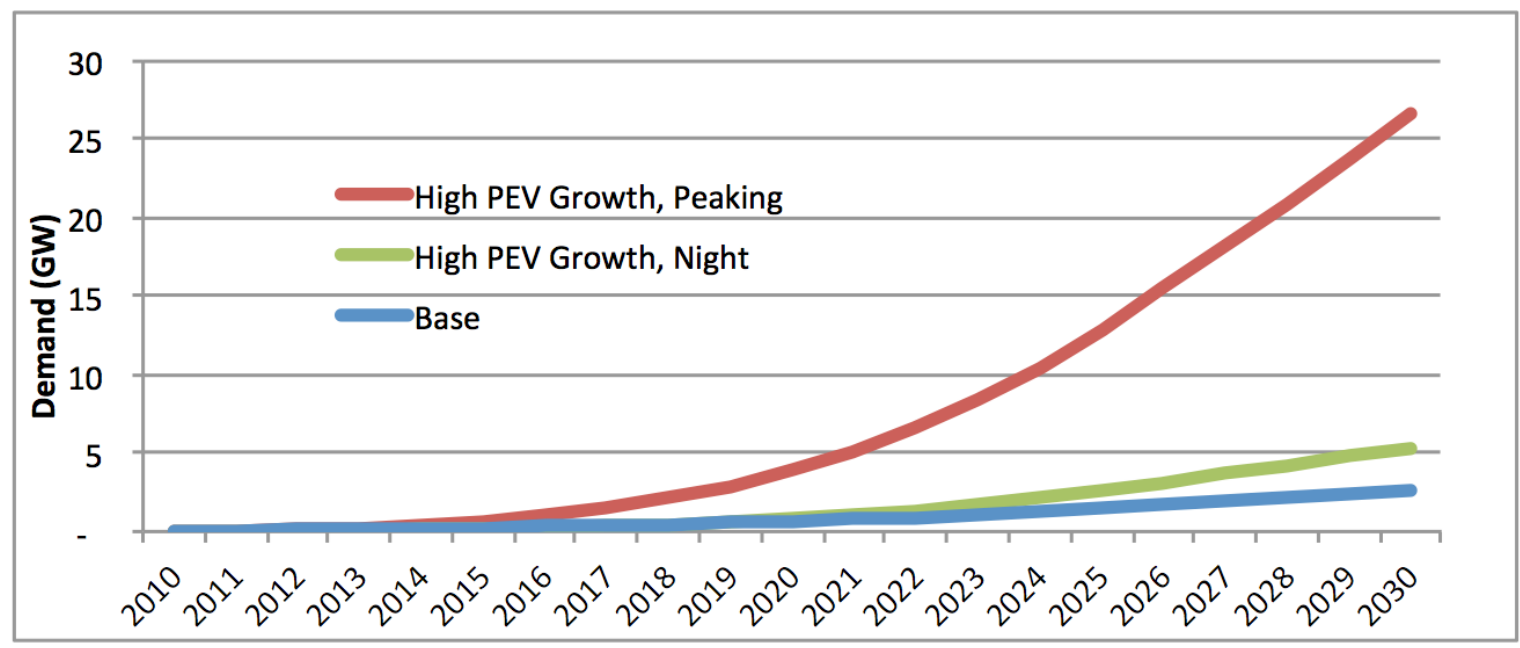

Fig. 111. Peak demand increases in the Eastern Interconnection due to base and high plug-in electric vehicle (PEV) growth.

Increased PEV market sensitivities were included in the BAU, EE/DR, RPS/N, and RPS/R futures. In all of the futures, adding PEVs increased the total generation for the EI by about 77 TWh (Fig. 112), or 3.5 MWh/vehicle. The BAU, RPS/N, and RPS/R futures all modeled just the peaking PEV charging behavior, while the EE/DR future had sensitivities for both the peaking and the night (smart grid) PEV charging. Figure 112 identifies the marginal generation used to meet the PEV demands. For the BAU future, added demand for PEV charging was almost totally provided by natural gas-fired generation, either CC or CT. The EE/DR future included coal as a marginal provider because demands were low enough that some charging was during periods when coal capacity was available. Note that in Fig. 113 the capacity added for the PEV night charging sensitivity is significantly less than that for the peak charging sensitivity. Gas-fired capacity was actually less than the base case despite the increase in demand. The RPS futures had coal, gas, and renewables as marginal providers because, as shown in Fig. 113, renewable capacity was added in the PEV charging sensitivity over and above what was added in the base RPS futures.

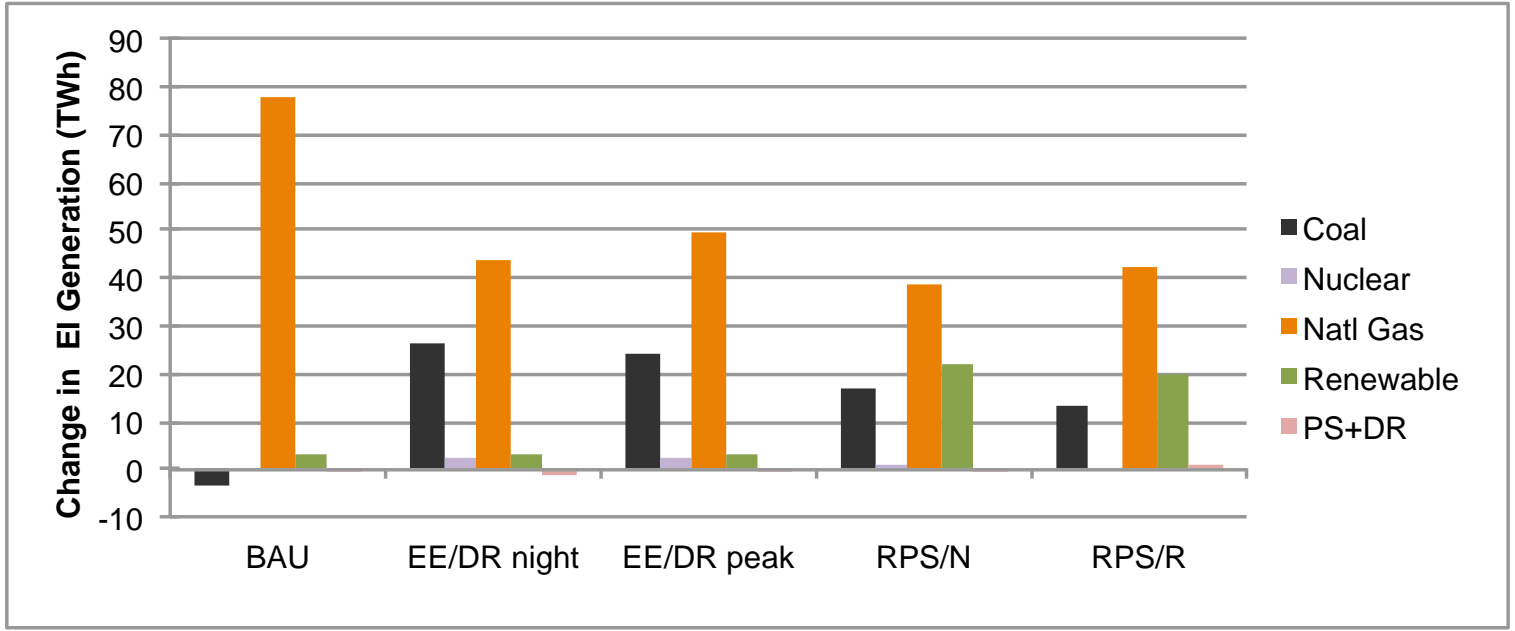

Fig. 112. Changes in Eastern Interconnection (EI) generation between the base scenario (BAU) and plug-in electric vehicle (PEV) sensitivity for three futures. The energy efficiency/demand response (EE/DR) future had two sensitivities: one with more PEV charging at peak times and one with charging at night (off-peak). 


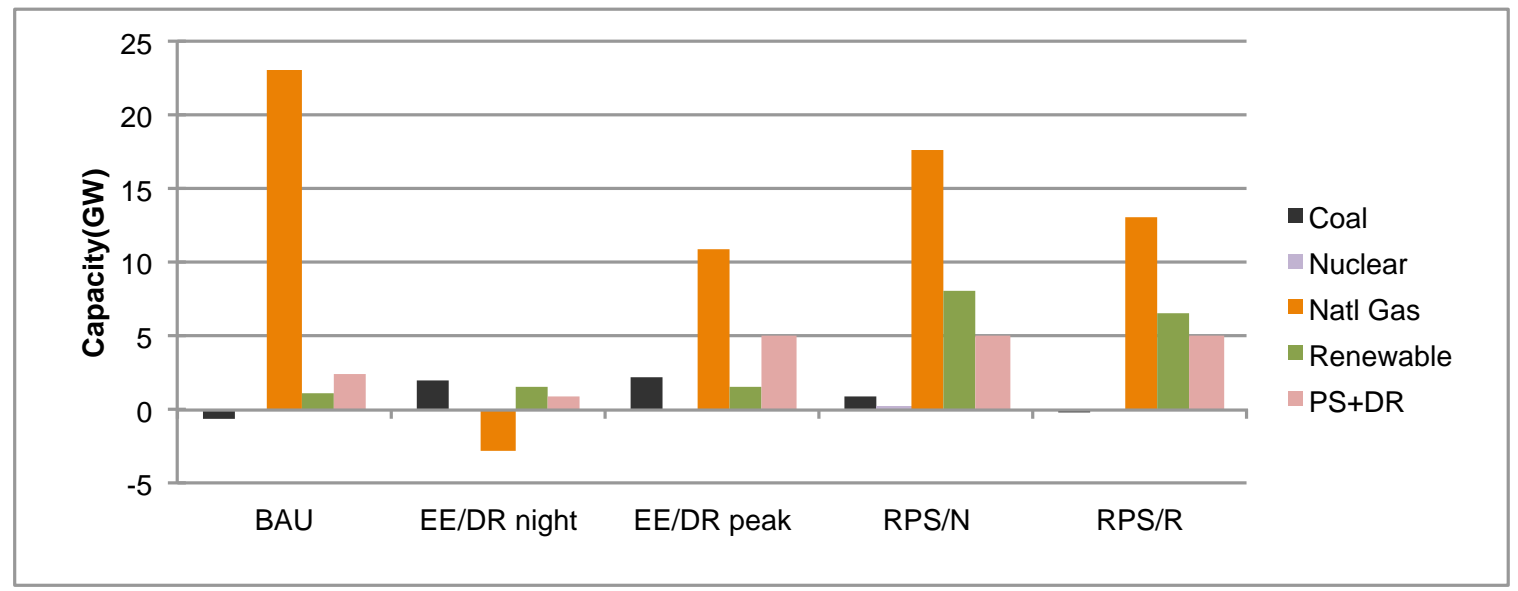

Fig. 113. Capacity changes between the base scenario (BAU) and plug-in electric vehicle (PEV) sensitivity for three futures. The energy efficiency/demand response (EE/DR) future had two sensitivities: one with more PEV charging at peak times and one with charging at night (off-peak).

\subsection{Small Modular Reactors}

The NUC future was used to examine the possible effect of policies and technologies that might increase the use of nuclear power in the EI. One sensitivity examined the effect of increasing the availability of small modular reactors (SMRs) as a viable alternative to large nuclear plants. The mechanism to model the difference was to decrease the capital cost between 2011 and 2025 by $15 \%$ instead of 10\% in addition to using the $20 \%$ reduction in nuclear capital cost as in the base NUC future. The overnight capital costs used in the other futures, the NUC base, and the SMR cases are shown in Table 57.

Table 57. Nuclear Capital Costs ${ }^{a}$

\begin{tabular}{|lccccc|} 
& $\begin{array}{c}\text { AEO: Base } \\
\text { Overnight } \\
\text { Costs in 2011 }\end{array}$ & $\begin{array}{c}\text { Learning by } \\
2025\end{array}$ & $\begin{array}{c}\text { Base Overnight } \\
\text { Capital Costs } \\
\text { in 2025 }\end{array}$ & $\begin{array}{c}\text { Other } \\
\text { Overnight } \\
\text { Capital Costs }\end{array}$ & $\begin{array}{c}\text { All-in Capital } \\
\text { Cost in 2025 } \\
\text { w/o IDC }\end{array}$ \\
\hline Base & 5,339 & $10 \%$ & 4,805 & 276 & 5,081 \\
\hline $\begin{array}{l}\text { Nuclear resurgence } \\
\text { (20\% reduction) }\end{array}$ & 4,271 & $10 \%$ & 3,844 & 276 & 4,120 \\
\hline $\begin{array}{l}\text { Small modular } \\
\text { reactors }\end{array}$ & 4,271 & $15 \%$ & 3,631 & 276 & 3,906 \\
\hline
\end{tabular}

${ }^{a}$ All costs are in 2010 dollars per kilowatt.

Despite the lower capital cost, there is no change in the nuclear capacity built between the nuclear resurgence base and the SMR sensitivity through 2030. There is a $\$ 2$ billion levelized cost saving from 2015 to 2030 for the SMR sensitivity but this is less than $0.1 \%$ of total costs. The savings reflect both the lowered capital cost of new nuclear plants built in the cases and minor variations from modeling.

\subsection{Offshore Wind}

The base case for all scenarios except RPS/R included 1,569 MW of offshore wind forced into the model: 1,100 MW in PJM E, $468 \mathrm{MW}$ in NEISO, and $1 \mathrm{MW}$ in VACAR. In these futures the offshore wind capacity increased in the sensitivities with lower renewable costs. In the $\mathrm{CO}_{2} / \mathrm{R}$ with extra high gas prices, the combination of the two cost changes also led to some increase. The RPS/R future showed increased capacities in all cases except the CES sensitivity because it allowed a broader range of technologies to qualify for the standard. Table 58 lists the different scenarios with the amount of offshore wind capacity in 2030 by region. The main regions that expanded resources were VACAR (the Carolinas), and PJM E 
(New Jersey). The model added some capacity in PJM ROM (Maryland and Delaware) in a couple of sensitivities once VACAR and PJM E had reached their capacities. All other additions were input into the model by the SSC to reflect expected additions under different scenarios.

Table 58. Offshore Wind Capacity in 2030 for Different Sensitivities (MW)

\begin{tabular}{|lcccccccc|} 
& $\begin{array}{c}\text { MISO } \\
\text { MI }\end{array}$ & $\begin{array}{c}\text { PJM } \\
\text { ROR }\end{array}$ & $\begin{array}{c}\text { PJM } \\
\text { ROM }\end{array}$ & $\begin{array}{c}\text { PJM } \\
\text { E }\end{array}$ & $\begin{array}{c}\text { NYISO } \\
\text { J-K }\end{array}$ & NEISO & VACAR & Total \\
\hline $\begin{array}{l}\mathrm{B} A U, \mathrm{CO}_{2} \text {, EE/DR, RPS/N, } \mathrm{CO}_{2}+\mathrm{Base} \\
\text { (plus all other sensitivities not listed) }\end{array}$ & - & - & & 1,100 & - & 468 & 1 & 1,569 \\
\hline BAU Extra Low Renewable Cost & - & - & - & 1,100 & - & 468 & 2,672 & 4,240 \\
\hline BAU Low Renewable Resources Cost & - & - & - & 1,100 & - & 468 & 2,654 & 4,222 \\
\hline $\mathrm{CO}_{2} / \mathrm{N}$ Extra Low Renewable Costs & - & - & - & 1,100 & - & 468 & 1,155 & 2,723 \\
\hline $\mathrm{CO}_{2} /$ R Extra high natural gas price & - & - & - & 1,100 & - & 468 & 8,073 & 9,641 \\
\hline $\mathrm{CO}_{2} /$ R Extra Low Renewable Costs & - & - & 10,010 & 9,600 & - & 468 & 39,250 & 59,328 \\
\hline RPS/N High Offshore Wind & 250 & 2,125 & - & 5,624 & 4,500 & 5,968 & 2,000 & 20,467 \\
\hline RPS/R Base & - & - & - & 9,453 & - & 468 & 28,546 & 38,467 \\
\hline RPS/R High Load Growth & - & - & 1,976 & 9,600 & - & 468 & 39,250 & 51,294 \\
\hline RPS/R High Natural Gas Price & - & - & - & 9,600 & - & 468 & 28,890 & 38,958 \\
\hline RPS/R Higher Canada Hydro & - & - & - & 9,453 & - & 468 & 28,886 & 38,807 \\
\hline RPS/R Higher PEV Levels & - & - & - & 9,600 & - & 468 & 29,026 & 39,094 \\
\hline RPS/R High Offshore Wind & 250 & 2,125 & - & 9,453 & 4,500 & 5,968 & 28,764 & 51,060 \\
\hline CO 2 Low Renewable Cost & - & - & - & 1,100 & - & 468 & 1,081 & 2,649 \\
\hline
\end{tabular}

\subsection{Conclusions}

The base case of each future resulted in generally different mixes of generation. Changing gas prices within each future had the expected effect: lower prices led to increased gas use while higher gas prices reduced the gas-fired capacity and generation. Similarly, renewable capital cost reductions result in increases in renewable capacity. Onshore wind is the main beneficiary of the lower costs, though in the $\mathrm{CO}_{2} / \mathrm{R}$ future, the lower costs also increase the offshore wind, $\mathrm{PV}$, and hydro capacities.

PEVs could raise peak demands and consequent capacity requirements, with the impact strongly depending on the timing of the charging. If charging is prominently at peak times, then the system peak increases by $1.2 \mathrm{~kW} / \mathrm{vehicle}$. If charging is delayed to nighttime (such as through smart grid implementation), then the peak only increases by $0.1 \mathrm{~kW} / \mathrm{vehicle.} \mathrm{Marginal} \mathrm{generation} \mathrm{to} \mathrm{meet} \mathrm{the} \mathrm{added}$ demand comes from natural gas, with some coal and renewables under the RPS futures.

Offshore wind capacity could be selected in all cases but was only selected in sensitivities with lower renewable capital costs or in the RPS future with regional response (RPS/R). In this study, the preferred location for offshore wind was in VACAR, followed by PJM E, and then PJM ROM. Other regions had offshore wind forced in, but capacity did not grow beyond the input amounts. 



\section{TOPIC 14: CHANGE IN KEY INPUTS BETWEEN 2011 AND 2014}

The input assumptions used in the EIPC study were formulated by stakeholders largely in the late 2010 to early 2011 time frame. These inputs included such key assumptions as projected gas prices, electricity demand, capital costs for new generation resources, and DG installations. There were multiple sensitivities conducted in the EIPC study to help capture the impact of uncertainty around these key assumptions.

These input assumptions are now roughly 4 years old and updated estimates are available. This topic examines the sensitivity of the results to the assumptions whose estimates have changed substantially since the EIPC study. Four key assumptions were identified for examination: (1) capital costs for new generation resources, (2) distributed solar projections, (3) electricity demand, and (4) environmental policies. Each key assumption is examined in turn below. [Note that changes in gas prices since the time of the EIPC study are discussed under Topic 13 (Chapter 13).]

\subsection{Capital Costs}

The capital costs of new generation resources such as CTs, CC facilities, and wind power facilities are a key determinant in the type of new generation that will be constructed in the model. Using the same methods and sources applied by EIPC study stakeholders in 2010-2011, we updated the costs of these resources to 2014. For capital cost assumptions, the main source used in the EIPC study was EIA's AEO 2011 (EIA 2011b). Because of this, updated EIA capital costs were obtained from AEO 2014 (EIA 2014), and the comparison to the EIPC study assumptions is provided in Table 59. Also shown are the cumulative additions by 2030 for each capacity type in each of the three EIPC Phase 2 futures.

Table 59. Capital Costs for New Generation Resources by In-Service Year [\$/kW (2012\$)]

\begin{tabular}{|c|c|c|c|c|c|c|c|c|c|}
\hline \multirow[b]{2}{*}{ Technology } & \multicolumn{2}{|c|}{ EIPC Study } & \multicolumn{2}{|c|}{2014 Update } & \multicolumn{2}{|c|}{ Increase } & \multicolumn{3}{|c|}{ EIPC 2030 Additions (GW) } \\
\hline & 2015 & 2030 & 2015 & 2030 & 2015 & 2030 & BAU & RPS/R & $\mathrm{CO}_{2+}$ \\
\hline Nuclear & 5,679 & 5,282 & 5,762 & 5,369 & $1 \%$ & $2 \%$ & 7 & 7 & 36 \\
\hline Advanced Coal & 2,957 & 2,851 & 2,961 & 2,856 & $0 \%$ & $0 \%$ & 8 & 8 & 8 \\
\hline CC, H-Frame & 1,061 & 1,024 & 1,052 & 1,015 & $-1 \%$ & $-1 \%$ & 75 & 30 & 108 \\
\hline CT & 730 & 705 & 720 & 696 & $-1 \%$ & $-1 \%$ & 14 & 21 & 5 \\
\hline IGCC & 3,343 & 3,224 & 3,805 & 3,670 & $14 \%$ & $14 \%$ & 1 & 1 & 1 \\
\hline $\begin{array}{l}\text { IGCC } \\
\text { (w/sequestration) }\end{array}$ & 5,428 & 4,993 & 6,575 & 6,061 & $21 \%$ & $21 \%$ & 0 & 0 & 0 \\
\hline Wind & 2,485 & 2,304 & 2,223 & 2,144 & $-11 \%$ & $-7 \%$ & 49 & 141 & 243 \\
\hline Wind Offshore & 5,880 & 4,992 & 6,185 & 5,743 & $5 \%$ & $15 \%$ & 2 & 38 & 2 \\
\hline Photovoltaic & 4,684 & 3,978 & 3,570 & 3,315 & $-24 \%$ & $-17 \%$ & 5 & 5 & 4 \\
\hline Solar Thermal & 4,622 & 3,925 & 5,044 & 4,683 & $9 \%$ & $19 \%$ & 0 & 0 & 0 \\
\hline Biomass & 3,826 & 3,253 & 3,943 & 3,663 & $3 \%$ & $13 \%$ & 2 & 26 & 2 \\
\hline Geothermal & 4,205 & 3,897 & 4,364 & 4,052 & $4 \%$ & $4 \%$ & 0 & 0 & 0 \\
\hline
\end{tabular}

As shown, the updated capital costs for nuclear, advanced coal, CCs and CTs are largely unchanged from those used in the EIPC study. While the cost of integrated gasification, combined cycle (IGCC), with or without sequestration, is projected to be more expensive today, little or no new IGCC was constructed in the EIPC study.

The projected capital cost of onshore wind turbines is $7 \%$ to $11 \%$ lower today than in the EIPC study. If everything else were equal, this would result in the construction of more wind power facilities than 
projected in the EIPC study. Any increase would be tempered by other EIPC study input assumptions limiting the penetration of intermittent resources and the extent to which in a given future wind facilities were constructed primarily to meet RPS requirements.

The projected cost of offshore wind facilities is roughly $15 \%$ higher today than projected in the EIPC study. In most EIPC study scenarios, few or no offshore wind facilities were constructed. However, in the RPS/R future, this increase in the cost of offshore wind facilities would have acted to decrease the number constructed (38 GW through 2030), all else equal.

Little or no solar thermal or geothermal capacity was constructed in the EI through 2030 in the EIPC study, thus the increase in projected capital costs shown in Table 59 would not have had much impact.

One key change is in the projected capital cost of PV solar capacity, which has declined by $15 \%$ to $25 \%$ today from the time of the EIPC study. PV solar capacity was constructed in the EIPC Phase 2 futures, largely to meet solar RPS requirements. Given the corresponding increase in the capital cost of biomass capacity, it is plausible that PV solar would substitute to a certain extent for biomass in the RPS/R scenario and possibly, depending on location, for onshore wind in all three scenarios.

\subsection{Distributed Solar}

\subsubsection{Distributed Solar Modeling}

Generator modeling in the MRN-NEEM model focused on central station facilities rather than end-userowned DG. To model the accelerated acceptance of DG for the EE/DR/DG and $\mathrm{CO}_{2}+$ futures, the SSC MWG had to decide (1) how much to accelerate the growth, (2) what technology to model, and (3) how to incorporate it into the model.

Many of the inputs used in the analysis were based on the EIA AEO 2011 early reference case (EIA 2011a). Included in its output are DG estimates. Customer demands for the EIPC study were based on utility demands that already had the DG production demands removed. If further DG is built, then demands must be further reduced to reflect the additional generation. The MWG decided that a plausible acceleration of DG would be to have a doubling of DG over the coming years. By 2030, DG reduces demand across the EI by $4 \%(24 \mathrm{GW})$. Figure 114 shows the amount of DG capacity for the EI in comparison to the demands in the BAU and EE/DR/DG futures (that also include a flattening due to EE).. The $\mathrm{CO}_{2}+$ future had the same demands as the EE/DR/DG future.

The additional DG next had to be allocated to the different NEEM regions. The AEO 2011 reports the amounts for each of the 22 regions used in its model, called Electricity Market Module regions. These amounts had to be converted to the 32 NEEM regions used in the EIPC study. Most regions have similar borders but the NEEM regions included some further disaggreation and Canadian provinces. A matrix was created to weight the amounts based on total electricity sales. Once determined, the additional capacity growth was allocated to each region for each year of the study.

The MWG recommended that this new DG be modeled as solar capacity. Because solar is generated intermittently, this required knowledge of the hourly patterns. Researchers at NREL selected key cities near the center of each NEEM region and calculated the hourly generation from a $1 \mathrm{~kW}$, fixed tilt panel for each hour of 2006 using their System Advisor Model. The average value represents the capacity factor for each region, which ranged from 16.5\% in SPP S to 11.3\% in NYISO. The year 2006 was selected because it matches the demand and wind profiles that were used elsewhere in the study. 


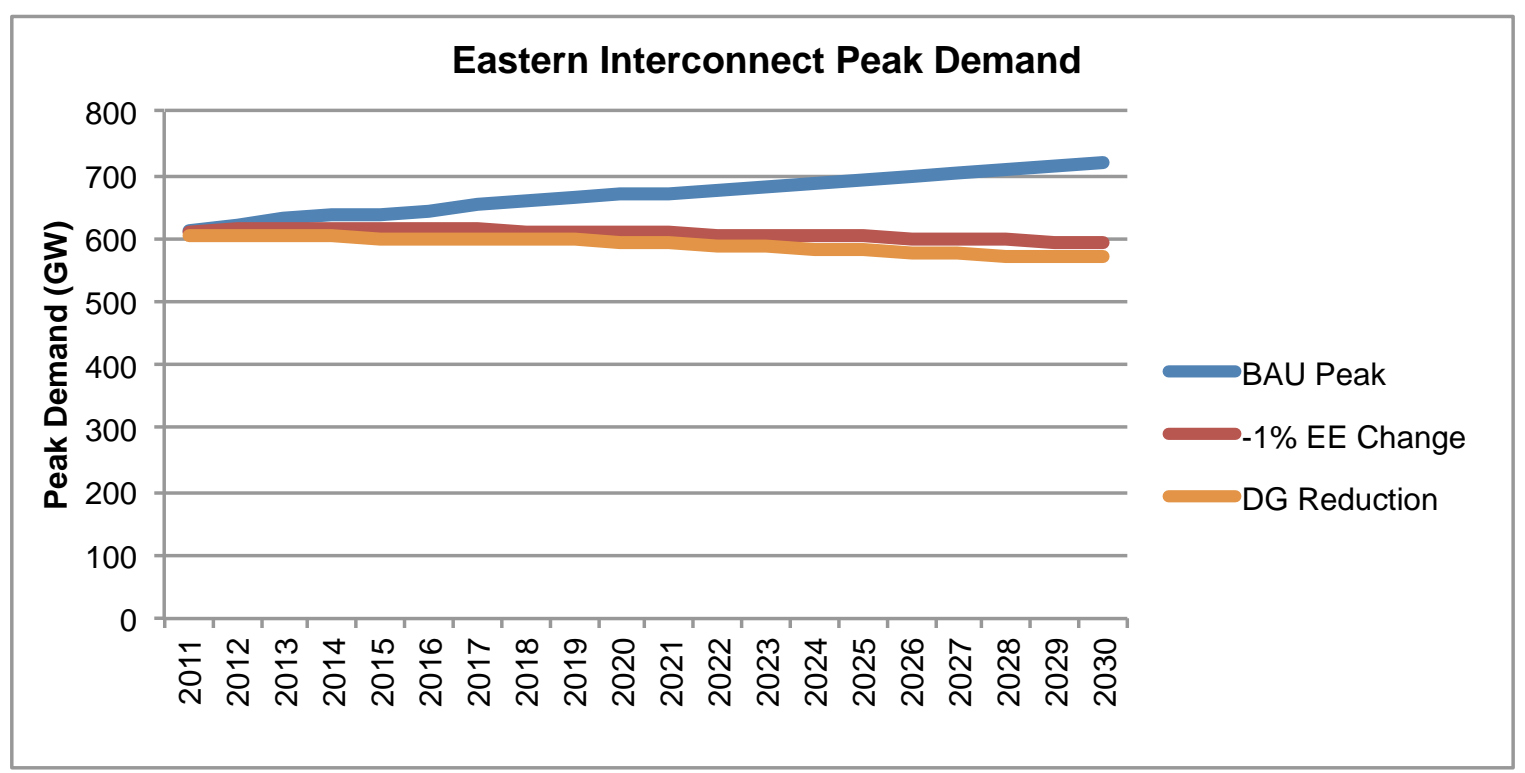

Fig. 114. Eastern Interconnection peak demand in the $\mathrm{BAU}$ and EE/DR/DG (and $\mathrm{CO}_{2}+$ ) futures before and after DG reductions.

CRA provided a schedule of the demands by hour for the EI. The NEEM model uses 20 blocks of varying size to represent the 8,760 hours of the year. The DG production for each region in each hour was calculated by multiplying the DG capacity with the NREL irradiance data. These were aggregated into the 20 blocks to determine the energy production and consequent demand reduction for each block over the study period. The new demand and peak demand amounts were then supplied to CRA for calculations in NEEM.

\subsubsection{Distributed Solar EIPC Study Inputs}

A comparison was made to current (EIA 2014) projections of PV solar capacity in 2030 with those projected in the EIPC study, considering both utility and distributed solar. Certain simplifying assumptions were used to derive the results for the US portion of the EI from the total EIA 2014 PV results.

Total PV solar, both in service in the electric power sector (i.e., central stations) and in service in the enduse sector (distributed solar), is shown in Table 60. The EIA 2014 reference case has $12 \mathrm{GW}$ of total PV solar in service in 2030, of which $10 \mathrm{GW}$ was distributed solar. In comparison, the BAU future in the EIPC study had $9 \mathrm{GW}$ of total PV solar in service in 2030, of which $6 \mathrm{GW}$ was distributed solar. In the EIA 2014 sensitivity cases, the total PV solar capacity in the US EI reached as high as 25 to $30 \mathrm{GW}$ by 2030 , with the share of distributed solar ranging from $50 \%$ to $90 \%$. In comparison, the $\mathrm{CO}_{2}+$ case in the EIPC study had total PV solar capacity of $33 \mathrm{GW}$ in the US EI in 2030, of which about $90 \%$ was distributed solar.

Table 60. Total Installed Photovoltaic Solar Capacity in the US EI Regions in 2030 (GW)

\begin{tabular}{|c|c|c|c|c|c|c|c|c|c|c|}
\hline & \multicolumn{7}{|c|}{ EIA 2014 Cases } & \multicolumn{3}{|c|}{ EIPC Study Futures } \\
\hline Sector & Reference & $\begin{array}{c}\text { No } \\
\text { Sunset }\end{array}$ & $\begin{array}{l}\text { Low Cost } \\
\text { Renewable }\end{array}$ & $\begin{array}{c}\text { GHG } \\
25\end{array}$ & $\begin{array}{l}\text { High } \\
\text { Growth }\end{array}$ & $\begin{array}{l}\text { Low } \\
\text { Growth }\end{array}$ & $\begin{array}{l}\text { High } \\
\text { Price }\end{array}$ & BAU & RPS/R & $\mathrm{CO}_{2+}$ \\
\hline Electric Power & 2 & 4 & 5 & 12 & 3 & 2 & 2 & 4 & 4 & 3 \\
\hline End-Use & 10 & 26 & 13 & 13 & 11 & 9 & 10 & 6 & 6 & 30 \\
\hline Total & 12 & 30 & 18 & 25 & 14 & 11 & 12 & 9 & 9 & 33 \\
\hline
\end{tabular}


While the total amount of solar capacity in service in the EIPC study in 2030 was somewhat lower than today's EIA 2014 projections in the BAU and RPS/R scenarios, the $\mathrm{CO}_{2}+$ scenario did capture the high range of solar capacity projected by EIA today.

\subsection{Demand Projections}

The projected energy demand in the EIPC study was largely taken from the AEO 2011 assumptions. However, planning authorities provided alternative estimates of growth through 2020 to reflect the estimates they provided to NERC for its long-term reliability assessment. Additionally, some regional groups on the SSC (e.g., the New England States Committee on Electricity) gave alternative growth amounts to reflect additional savings from established EE plans. Figure 115 and Table 61 show the projected energy demand for the US portion of the EI for the BAU scenario, as projected in the 2011 AEO, and as currently projected by EIA in the 2014 AEO (EIA 2014).

Projected energy demands for 2011 were relatively the same in the BAU and AEO 2011, differing just

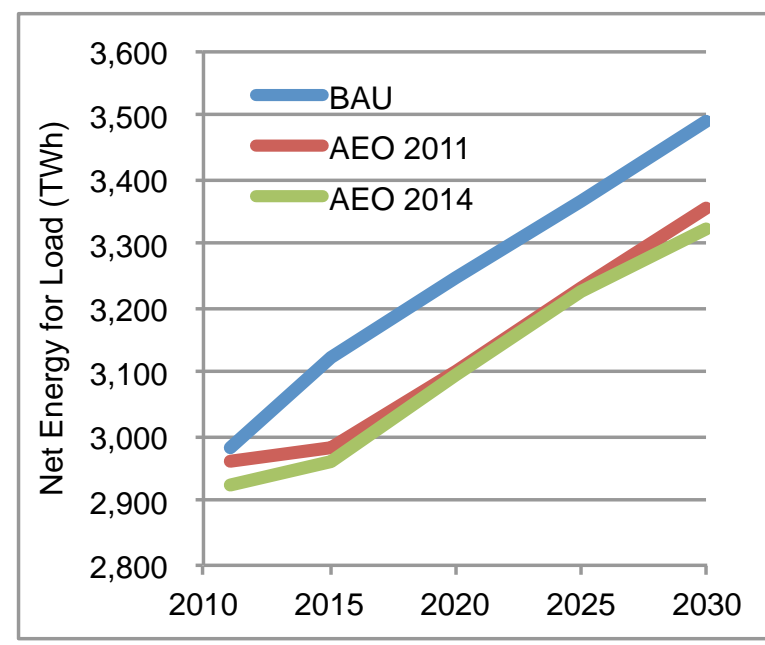

Fig. 115. Energy demand in the US EI regions from the BAU and AEO reference cases.

$0.7 \%$. But the utility estimates for growth between 2011 and 2015 were an annualized $1.2 \%$ growth rate while the AEO 2011 grew at only a $0.2 \%$ rate. From 2015 on, the growth rates were similar in both projections, around $0.8 \%$ per year. This led to differences in the amounts of around $4 \%$ for the study period (Table 61.) The projected demands from the AEO 2014 are even slightly lower than the AEO 2011 so that the BAU was $4 \%$ to $5 \%$ higher than the current projection from EIA. Lowering demands by $5 \%$ could have a major impact on results.

Table 61. Energy Demand in the US Eastern Interconnection Regions

\begin{tabular}{|cccccc|}
\hline BAU & 2011 & 2015 & 2020 & 2025 & 2030 \\
\hline Net Energy for Load (Twh) & 2,983 & 3,123 & 3,250 & 3,369 & 3,492 \\
\hline Annual Growth Rate & & $1.2 \%$ & $0.8 \%$ & $0.7 \%$ & $0.7 \%$ \\
\hline AEO 2011 & & & & \\
\hline Net Energy for Load (Twh) & 2,962 & 2,984 & 3,103 & 3,230 & 3,357 \\
\hline Annual Growth Rate & & $0.2 \%$ & $0.8 \%$ & $0.8 \%$ & $0.8 \%$ \\
\hline $\begin{array}{c}\text { \% Reduction from BAU } \\
\text { AEO 2014 }\end{array}$ & $-0.7 \%$ & $-4.4 \%$ & $-4.5 \%$ & $-4.1 \%$ & $-3.9 \%$ \\
\hline Net Energy for Load (Twh) & 2,925 & 2,964 & 3,099 & 3,228 & 3,325 \\
\hline Annual Growth Rate & & $0.3 \%$ & $0.9 \%$ & $0.8 \%$ & $0.6 \%$ \\
\hline \% Reduction from BAU & $-1.9 \%$ & $-5.1 \%$ & $-4.7 \%$ & $-4.2 \%$ & $-4.8 \%$ \\
\hline
\end{tabular}

\subsection{Environmental Policies}

\subsubsection{Environmental Rules}

With the exception of the EPA proposed Clean Power Plan, the changes to proposed/finalized environmental regulations that have occurred after the Phase 1 modeling would be unlikely to have a significant impact on the modeling results. Table 62 lists the EPA rules that were included in the EIPC analysis and summarizes their current status. 
Table 62. EPA Rules Modeled in Phase 1 and Their Current Status

\begin{tabular}{|c|c|c|}
\hline Phase 1 & Now & Result \\
\hline Transport Rule & $\begin{array}{l}\text { The Cross-State Air Pollution Rule was } \\
\text { reinstated by the Supreme Court, } \\
\text { replacing the Transport Rule }\end{array}$ & $\begin{array}{l}\text { While this may have some impact in the short } \\
\text { term, long-term effects should be minor }\end{array}$ \\
\hline $\begin{array}{l}\text { Mercury and Air } \\
\text { Toxics Standard }\end{array}$ & Finalized with minor changes & The changes should have little effect \\
\hline $\begin{array}{l}\text { New Source } \\
\text { Performance } \\
\text { Standard for } \mathrm{CO}_{2}\end{array}$ & Finalized with minor changes & $\begin{array}{l}\text { The options for new sources modeled in Phase } 1 \\
\text { meet the final rule, so there would be no effect }\end{array}$ \\
\hline $\begin{array}{l}\text { Coal Combustion } \\
\text { Residuals }\end{array}$ & Has not been finalized & $\begin{array}{l}\text { Any change would be speculation prior to } \\
\text { finalization }\end{array}$ \\
\hline $\begin{array}{l}\text { Cooling Water Intake } \\
\text { Structures [316(b)] }\end{array}$ & $\begin{array}{l}\text { Finalized with significant flexibility in } \\
\text { terms of compliance options }\end{array}$ & $\begin{array}{l}\text { It would be difficult to model the potential for each } \\
\text { site to use various options. The flexibility in the } \\
\text { final rule may result in lower compliance costs, but } \\
\text { there would likely be little effect on retirement } \\
\text { decisions. }\end{array}$ \\
\hline
\end{tabular}

The retrofit costs for $\mathrm{SO}_{2}, \mathrm{NO}_{x}$, and mercury were based on information dated from 2006 to 2010. While updated costs would likely differ, there have not been any recent developments that would result in significant changes.

Phase 1 included a number of forced retrofits. It is not known which of those retrofits actually occurred or are under way. If some units have not been retrofit, they may be candidates for retirement rather than retrofit.

\subsubsection{Renewable Portfolio Standards}

While no state has either added or removed an RPS since the EIPC Phase 1 modeling was completed, a number of them have made modifications to existing standards. Most of the modifications either redefined which resources qualified for the RPS or created or modified a carve-out for a specific technology within the RPS. In 2014, Ohio established a 2-year hiatus for its RPS, which pushes back the subsequent targets by 2 years. Table 63 lists the RPS modifications that have occurred since the EIPC analysis.

These modifications would likely have a small impact on the Phase 1 modeling results. The carve-outs would increase the amount of solar and offshore wind in the affected regions, but the levels of the carveouts are small (a few percent) and only affect a few states. 
Table 63. Modifications to State Renewable Portfolio Standards

\begin{tabular}{|lll|}
\hline State/District & Year & Modification \\
\hline CT & 2013 & Redefined qualifying resources \\
\hline DC & 2011 & Increased solar carve-out from $0.4 \%$ to $2.5 \%$ by 2023 \\
\hline DE & 2011 & Redefined qualifying resources \\
\hline MD & 2011,2012 & Redefined qualifying resources \\
\cline { 2 - 3 } & 2012 & Accelerated solar carve-out compliance requirements \\
\cline { 2 - 3 } & 2013 & $\begin{array}{l}\text { Created offshore wind carve-out for 2017 and beyond (level to be determined by } \\
\text { the Public Service Commission at a maximum of 2.5\%) }\end{array}$ \\
\hline MN & 2013 & Created solar carve-out of 1.5\% by end of 2020 \\
\hline MT & 2013 & Redefined qualifying resources \\
\hline NC & 2011 & Allowed electricity demand reduction to count toward the standard \\
\hline NH & 2012 & Redefined qualifying resources \\
\hline NJ & 2012 & Increased the solar carve-out to require 4.1\% by 2028 \\
\hline OH & 2012 & Redefined qualifying resources \\
\cline { 2 - 3 } & 2014 & Established a 2-year hiatus \\
\hline
\end{tabular}

\subsubsection{EPA Carbon Rules}

EPA's release of its proposed $\mathrm{CO}_{2}$ rule for existing power plants under Section 111(d) of the Clean Air Act brings up the question of how the various Phase 1 futures and sensitivities compare to the proposed rule. Under the EPA proposed rule, $\mathrm{CO}_{2}$ emissions in the United States are targeted to decrease by $30 \%$. A number of Phase 1 sensitivities similarly result in significant $\mathrm{CO}_{2}$ emissions reductions, either through the implementation of a direct carbon cost or by establishing requirements for zero or low carbon generation sources.

Futures 2 and 3 were specifically designed to achieve $\mathrm{CO}_{2}$ emissions reductions using a cost adder associated with each ton released. These futures were designed to achieve economy-wide reductions of $42 \%$ in 2030 and $80 \%$ in 2050 . To obtain these reductions in the models, a $\mathrm{CO}_{2}$ price trajectory was first determined by solving the MRN model iteratively. An initial price estimate was implemented, the model was run, and the price was adjusted to increase or decrease emissions as appropriate. This process was repeated until the desired reductions were achieved. Figure 116 shows the initial price estimate, the final price (Base) and two different trajectories used in sensitivities. The prices labeled "Flat>2030" are identical to the Base price until 2030 and are held constant afterwards. The prices labeled " $20 \%$ Lower" are $20 \%$ below the Base price for all years.

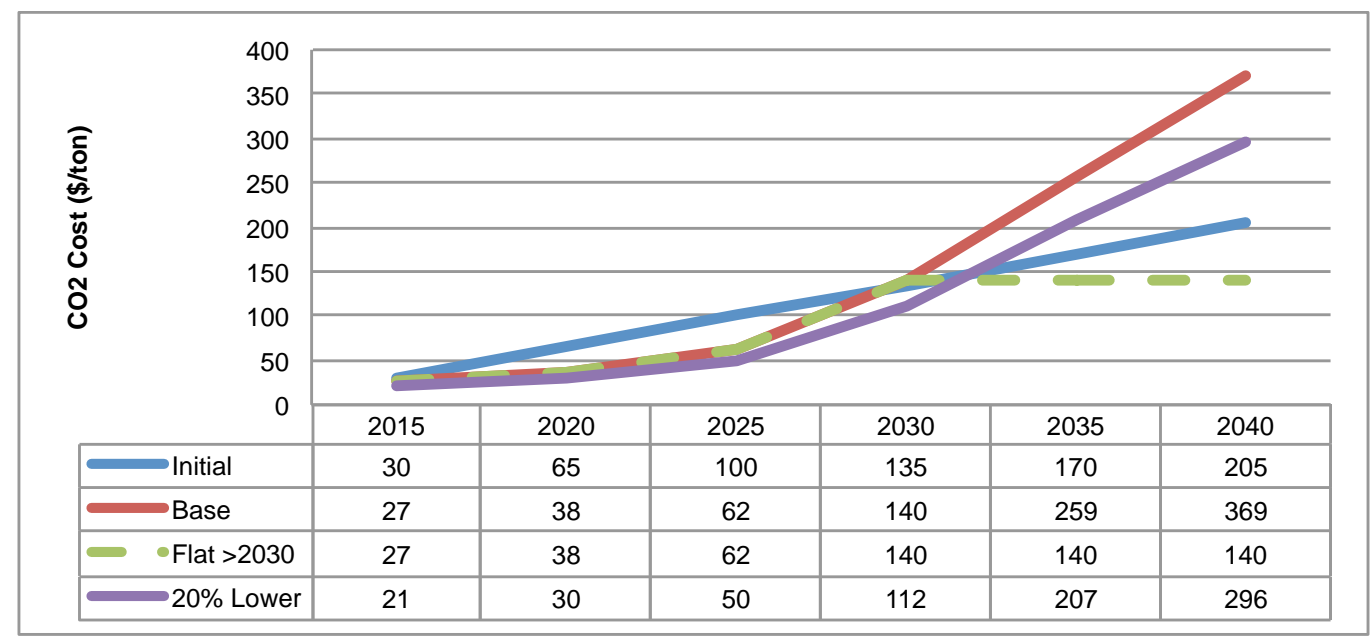

Fig. 116. Carbon dioxide price curves used in the EIPC study. 
Because the MRN model indicated that $\mathrm{CO}_{2}$ emission reductions in the electricity sector were more cost-effective to achieve than in other sectors of the economy, the resultant electricity sector reductions were significantly higher than the economy-wide targets of $42 \%$ in 2030 and $80 \%$ in 2050 . Thus, the various Phase 1 sensitivities that incorporate $\mathrm{CO}_{2}$ prices result in much higher levels of electricity sector emission reductions than the EPA target of 30\%. The electricity sector emission reductions in 2030 under the Base price were $83 \%$ under a national implementation (F2S11) and 78\% under a regional implementation ( $\mathrm{F} 3 \mathrm{~S} 12)$. The lower $\mathrm{CO}_{2}$ price resulted in reductions that were $5 \%$ lower under both implementations (F2S9 and F3S8).

In contrast to the $\mathrm{CO}_{2}$ emission reductions explicitly targeted in Futures 2 and 3, Futures 5 and 6 included a national RPS requiring that $30 \%$ of electricity generation come from renewable sources by 2030 . While these futures achieve levels of $\mathrm{CO}_{2}$ emission reduction similar to those proposed by EPA (29\% in F5S10 and F6S10), they do not differentiate between higher and lower emission nonrenewable sources.

Furthermore, the Phase 2 analysis resulted in significant wind curtailments when modeling the regional approach contained in the RPS/R scenario (F6S10). Thus the emission reductions indicated in Phase 1 did not all materialize in the more detailed analysis in Phase 2.

Futures 5 and 6 each contained a sensitivity that modeled a national CES. These sensitivities required that $70 \%$ of electricity generation come from clean sources, defined as renewables, gas-fired CC units, and nuclear, by 2030. These sensitivities resulted in $\mathrm{CO}_{2}$ emissions reductions that exceeded the EPA target for 2030, 52\% under national implementation (F5S5) and 54\% under regional implementation (F6S4). The reductions were $27 \%$ and $23 \%$ respectively in 2020, much closer to the EPA target. The NUC future included a CES sensitivity (F7S3) that resulted in a 72\% reduction in 2030.

Future 8 modeled a combination of federal policies. The combination of an RPS, charges for $\mathrm{CO}_{2}$ emissions, and aggressive EE/DR/DG (F8S7) resulted in the greatest levels of emissions reductions at $85 \%$ in 2030 . Figure 117 shows the $\mathrm{CO}_{2}$ emissions reductions at the EI level for the BAU and various sensitivities that produce significant $\mathrm{CO}_{2}$ emissions reductions.

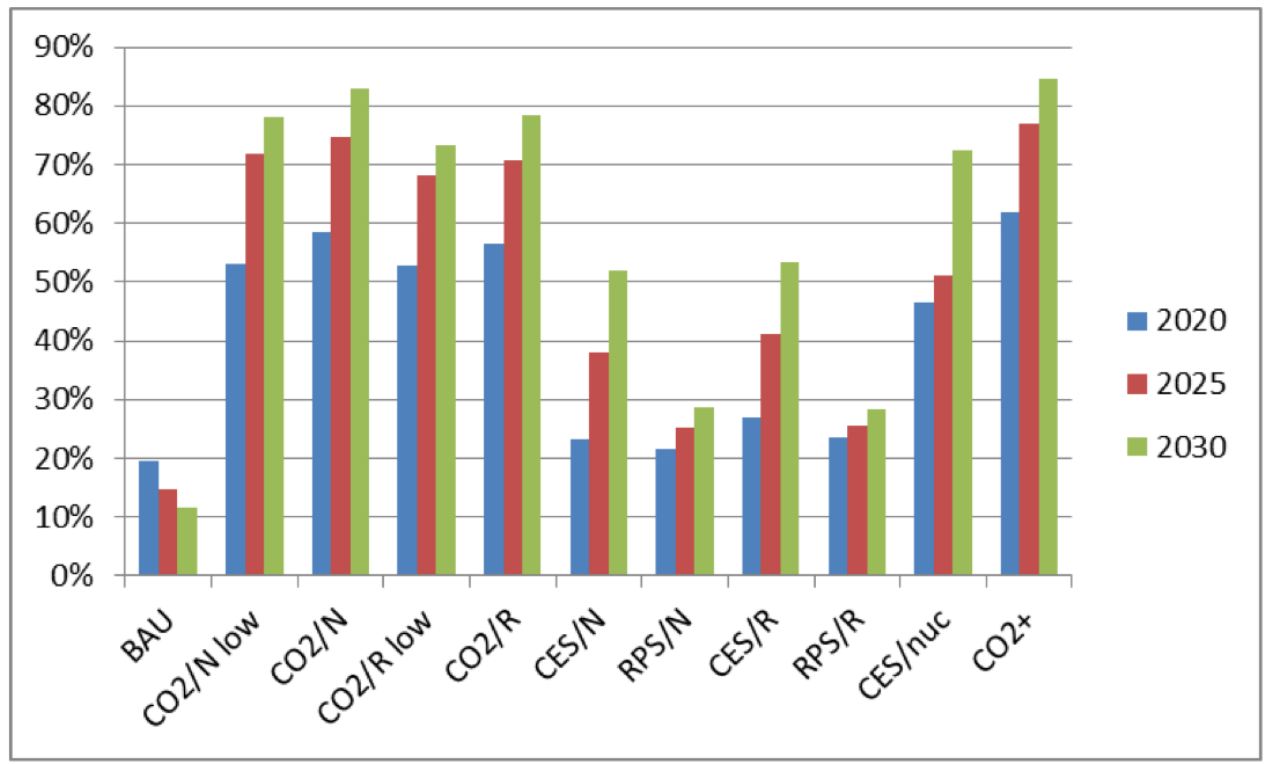

Fig. 117. Carbon dioxide emissions reductions relative to 2005 levels for the BAU scenario and various sensitivities. 


\section{Generation Mix Impacts in Selected $\mathrm{CO}_{2}$ Reduction Sensitivities}

Because the target of the proposed EPA rule is to achieve a $30 \%$ reduction in $\mathrm{CO}_{2}$ emissions, those sensitivities that achieve similar levels of reductions in a particular year are of interest for further analysis. These include both RPS sensitivities in 2030 (29\% reduction) and the Future 5 CES/N (27\%) and Future $6 \mathrm{CES} / \mathrm{R}(23 \%)$ sensitivities in 2020 . The $2020 \mathrm{CO}_{2} / \mathrm{N}$ and $\mathrm{CO}_{2} / \mathrm{R}$ low sensitivities are also included as they have the lowest $\mathrm{CO}_{2}$ reductions of the cases that specifically target $\mathrm{CO}_{2}$ emissions (53\%).

The federal and regional implementations of the RPS in Futures 5 and 6 achieved the $\mathrm{CO}_{2}$ reductions that most closely approximated the target of the proposed EPA rule, with both reducing emissions by $29 \%$ in 2030. As Fig. 118 illustrates for the EI, the RPS sensitivities increase the amount of wind and other renewables relative to the BAU, while natural gas and coal generation are reduced. It is important to note that the Futures 5 and 6 RPS sensitivities treat natural gas and coal equally as nonrenewable sources, even though they have different levels of carbon emissions. This causes natural gas generation to drop more than it likely would if the goal were to reduce emissions rather than increase renewables.

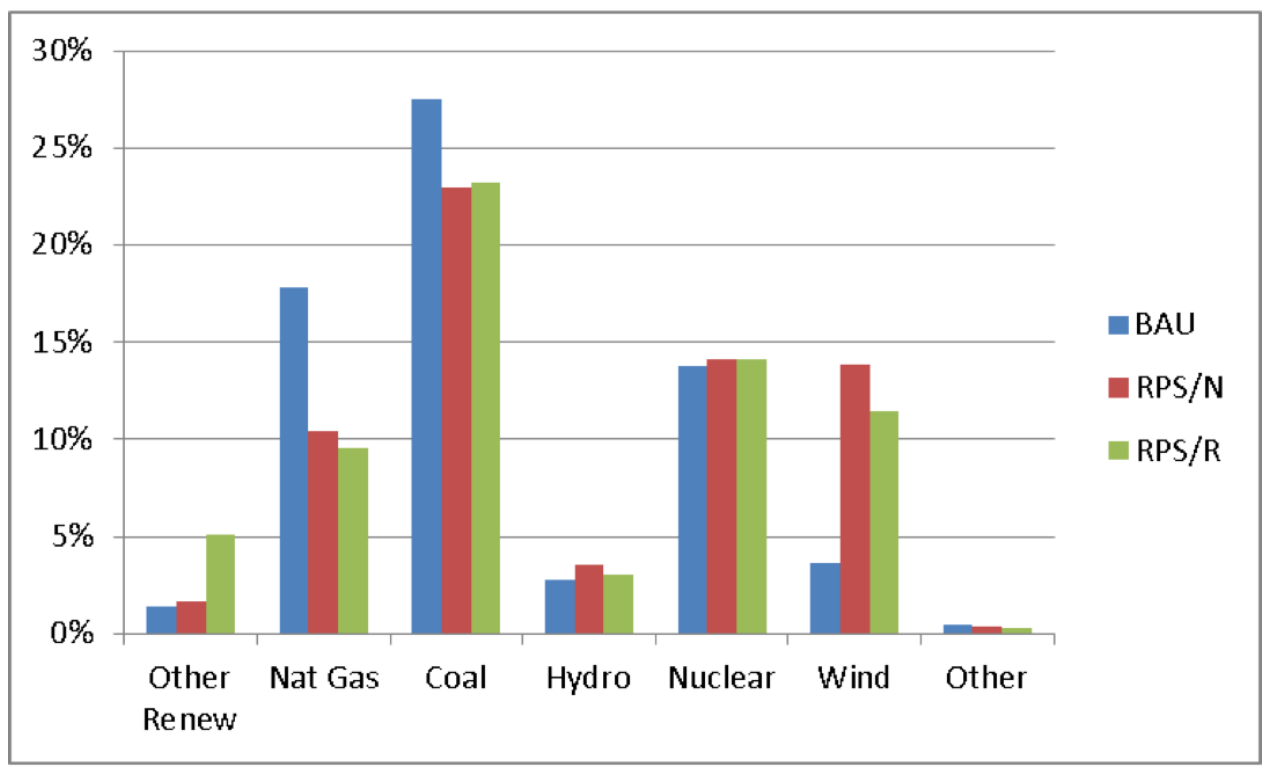

Fig. 118. Eastern Interconnection electricity generation sources under the BAU and RPS sensitivities in 2030.

The Futures 5 and 6 CES sensitivities achieved $27 \%$ and $23 \% \mathrm{CO}_{2}$ emissions reductions under the regional and national approaches, respectively, in 2020. As can be seen in Fig. 119, these sensitivities resulted in increased natural gas use and less coal.

The Futures 2 and 3 low $\mathrm{CO}_{2}$ price sensitivities still produced significantly more $\mathrm{CO}_{2}$ emissions reductions by 2020 than the EPA target. As early as 2020, both the national and regional implementations achieved a 53\% reduction. While these reductions exceed the EPA target, they have the lowest levels of reductions in any of the sensitivities that are specifically designed to reduce carbon emissions. They do provide some indication of the generation mix impact that would be incurred, even though the magnitude is too large. Figure 120 shows the generation mix for the $\mathrm{EI}$ in 2020 for the low $\mathrm{CO}_{2}$ price sensitivities. Natural gas and wind increase relative to the BAU, while coal decreases. The gain in share by other technologies such as nuclear and hydro comes from a decrease in demand due to higher prices rather than from an increase in generation from those sources. It should be noted that natural gas use begins to decline in later years as $\mathrm{CO}_{2}$ prices increase. 


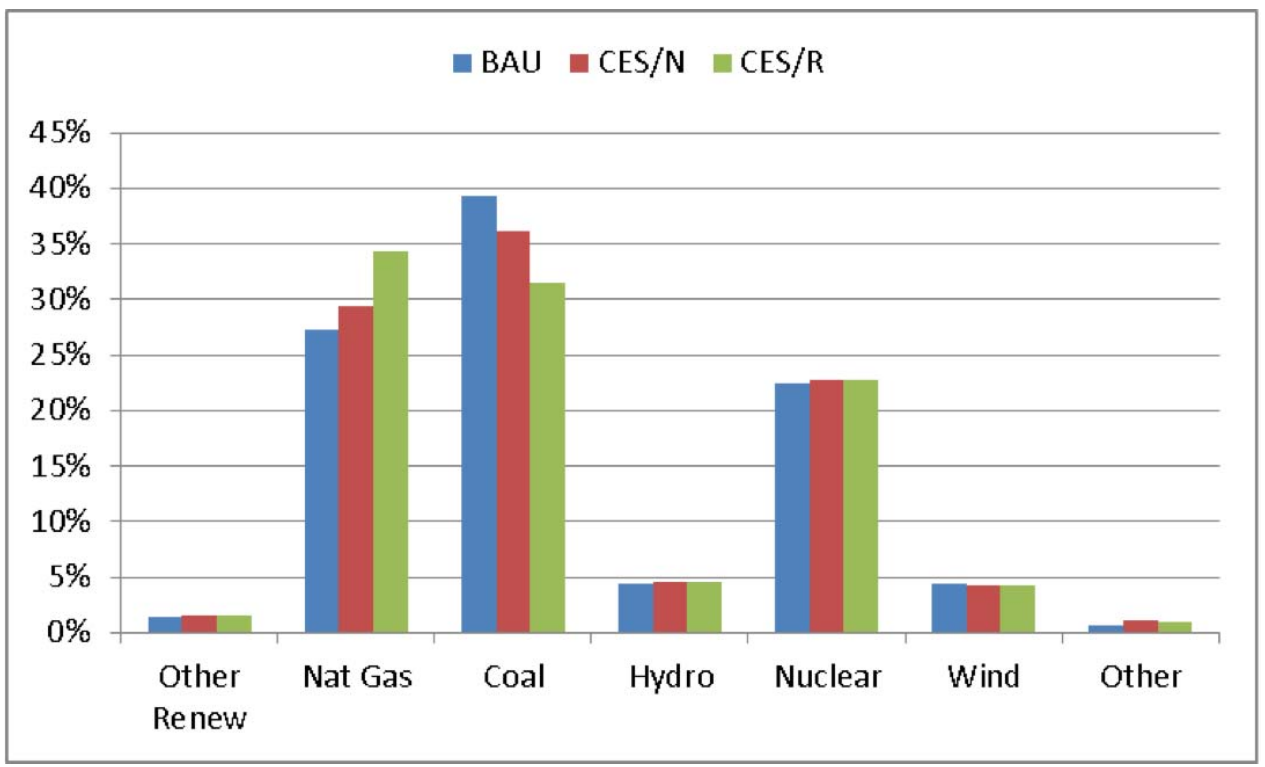

Fig. 119. Eastern Interconnection electricity generation sources under the BAU and CES sensitivities in 2020.

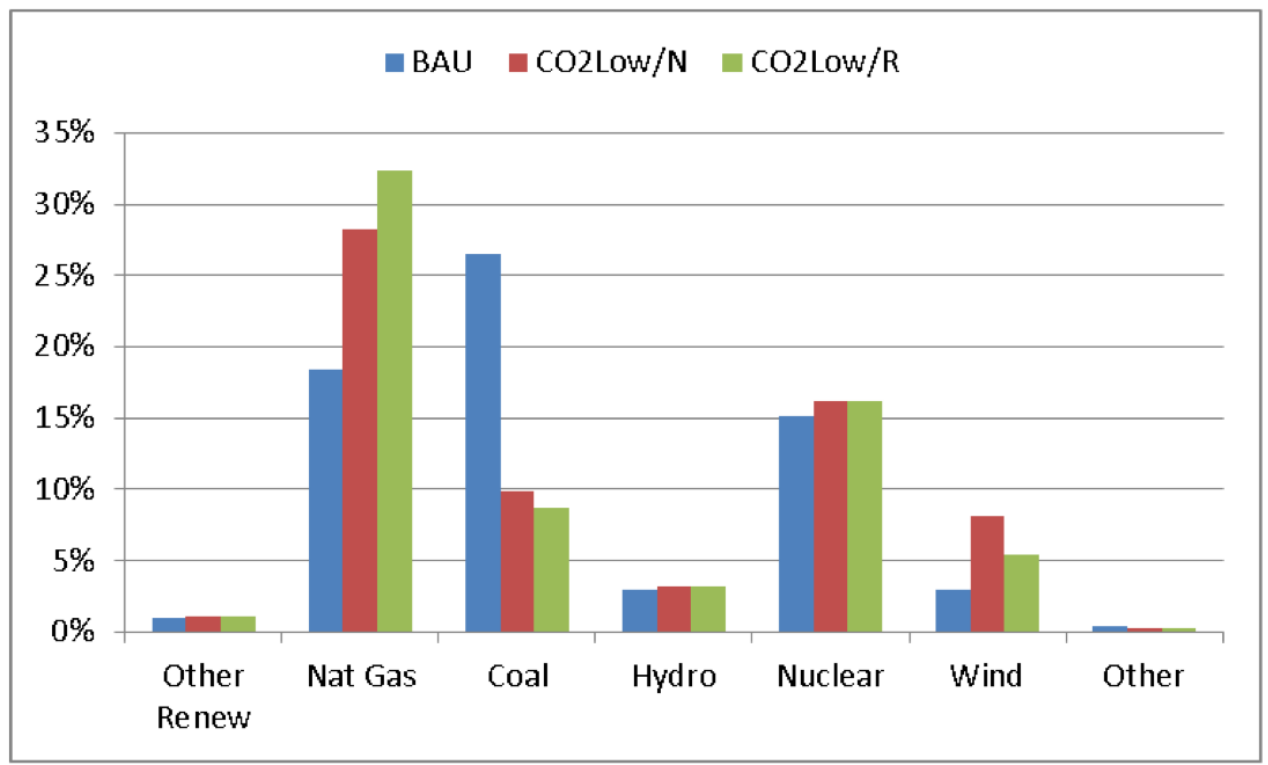

Fig. 120. Eastern Interconnection electricity generation sources under the BAU and $\mathrm{CO}_{2}$ low sensitivities in 2020.

As was seen in the discussion of Topic 11 (Chapter 11), the Future 3 and Future 5 regional implementations generally result in more natural gas and less wind than the Future 2 and Future 4 national implementations. The implementation strategy can also have a significant effect on $\mathrm{CO}_{2}$ reductions by NEEM region. Figures 121-123 show the ratio of $\mathrm{CO}_{2}$ emissions levels in 2030 to the 2005 amounts for the two implementation strategies by NEEM region. 


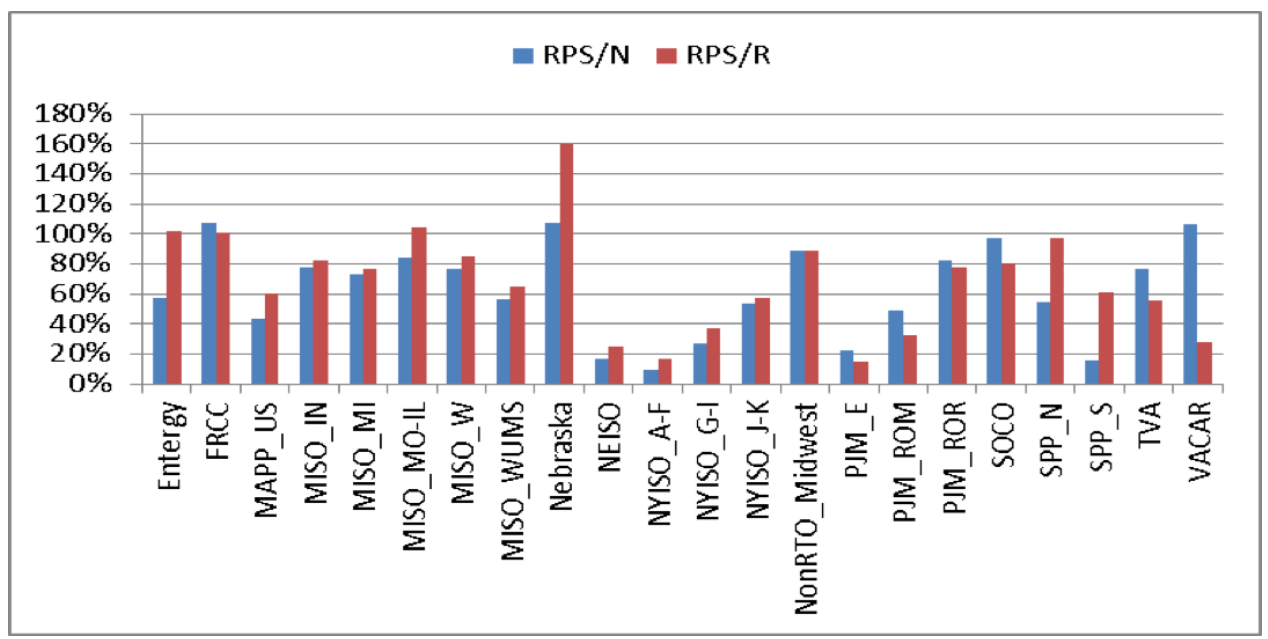

Fig. 121. $2030 \mathrm{CO}_{2}$ emissions levels relative to 2005 by NEEM region under RPS.

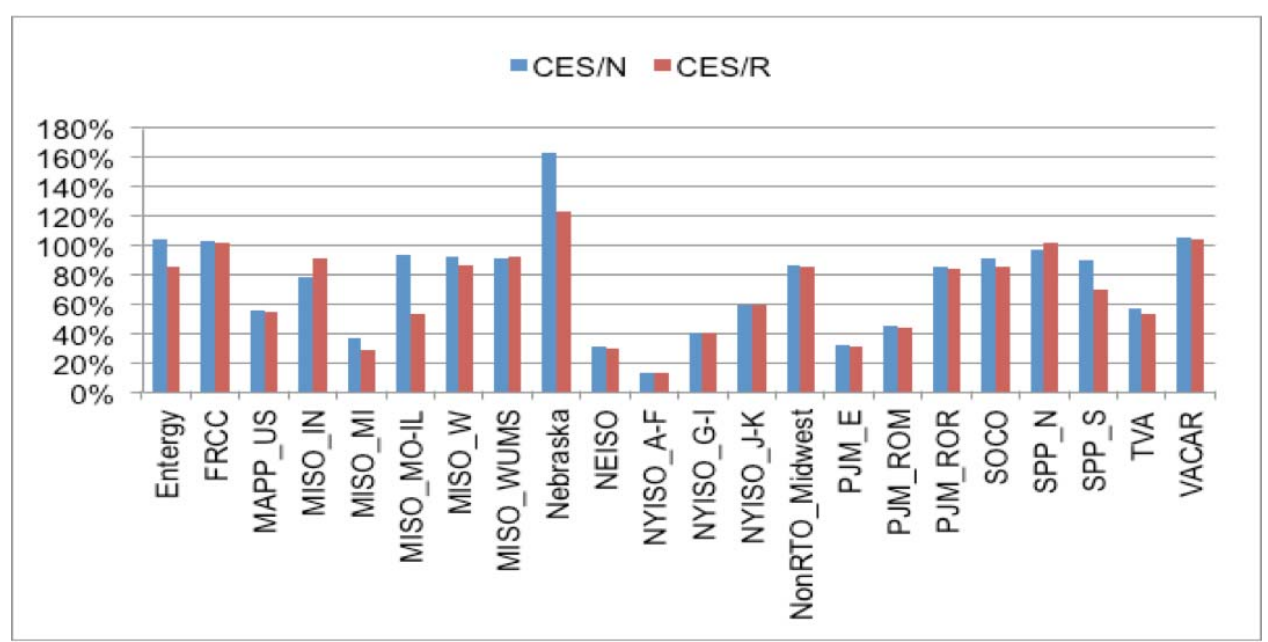

Fig. 122. $2020 \mathrm{CO}_{2}$ emissions levels relative to 2005 by NEEM region under CES.

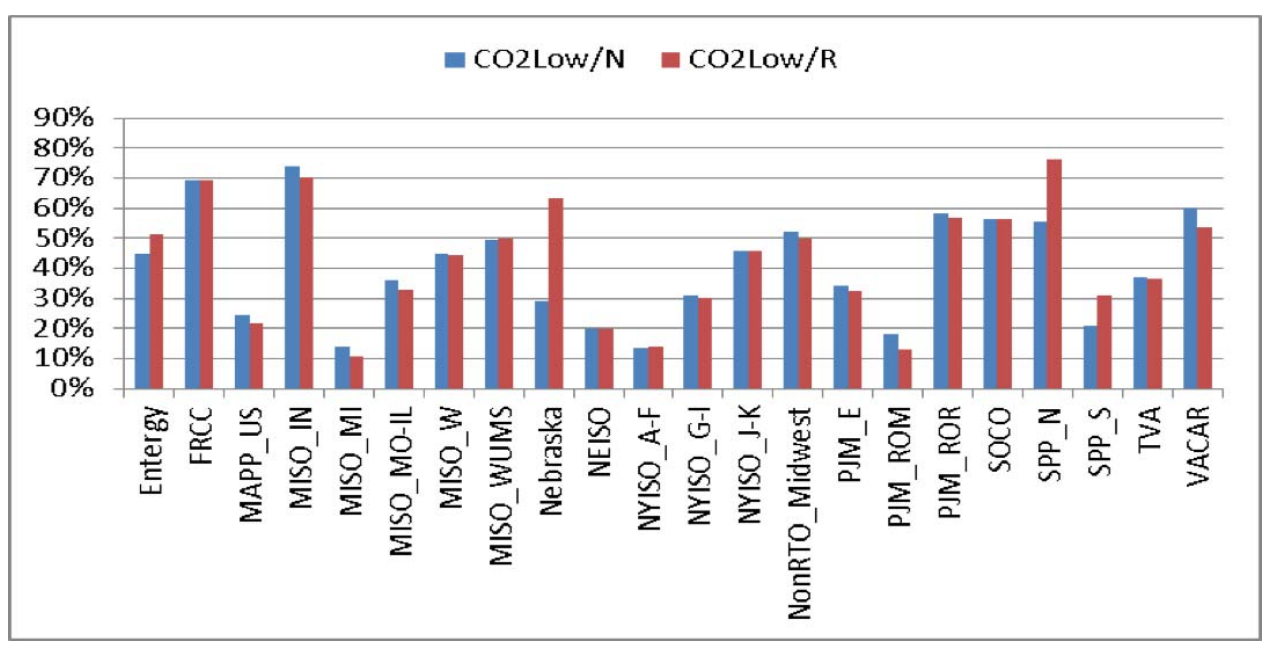

Fig. 123. $2020 \mathrm{CO}_{2}$ emissions levels relative to 2005 by NEEM region under low $\mathrm{CO}_{2}$ prices. 
As shown, for any particular region the $\mathrm{CO}_{2}$ emission reductions may increase or decrease under a regional or national implementation approach. This would be expected because, for example, the locations of the best national sources for reducing $\mathrm{CO}_{2}$ or meeting RPS requirements may not be able to be fully incorporated in a regional approach. Thus, for example, the $\mathrm{CO}_{2}$ emission levels in wind-rich regions will tend to increase under a regional implementation approach. This impact is not evident in the CES cases, where natural gas was grouped with wind as a clean energy source, mitigating the value of importing wind power in the national cases in favor of nearby natural gas.

\subsection{Conclusions}

The input assumptions used in the EIPC study were formulated by stakeholders largely in the late 2010 to early 2011 time frame. Because these input assumptions are now roughly 4 years old, this topic examined changes to four key input assumptions since the time of the EIPC study: (1) capital costs for new generation resources, (2) distributed solar projections, (3) electricity demand, and (4) environmental policies.

Capital Costs for New Generation Resources: Based on updated EIA sources similar to those used in the EIPC study, the projected capital costs of most fossil-fired resources are largely unchanged since the time of the EIPC study. The projected capital cost of onshore wind turbines is $7 \%$ to $11 \%$ lower today than in the EIPC study. All else being equal, this would result in the construction of more wind power facilities than projected in the EIPC study. Any increase would be tempered by other EIPC study input assumptions such as RPS requirements and penetration limits on intermittent resources. The projected capital cost of PV solar capacity has declined by $15 \%$ to $25 \%$ today from the time of the EIPC study. PV solar capacity was constructed in the three EIPC Phase 2 scenarios largely to meet solar RPS requirements. With these reduced capital costs, it is plausible that PV solar would substitute to a certain extent for biomass in the RPS/R scenario and possibly, depending on location, for onshore wind in all three Phase 2 scenarios.

Distributed Solar Projections: A comparison was made of current (EIA 2014) projections of PV solar capacity with those projected in the EIPC study for 2030, considering both utility and distributed solar installations. The EIA 2014 reference case has $12 \mathrm{GW}$ of total PV solar in service in 2030, of which 10 GW is distributed solar. In comparison, the BAU future in the EIPC study had $9 \mathrm{GW}$ of total PV solar in service in 2030, of which about $6 \mathrm{GW}$ was distributed solar. In the EIA 2014 sensitivity cases, the total PV solar capacity in the US EI reached as high as 25 to $30 \mathrm{GW}$ by 2030, with the share of distributed solar ranging from 50\% to 90\%. In comparison, the $\mathrm{CO}_{2}+$ scenario in the EIPC study had total PV solar capacity of $33 \mathrm{GW}$ in the US EI in 2030, of which about $90 \%$ was distributed solar. Overall then, while the total amount of solar capacity in service in the BAU scenario of the EIPC study in 2030 was somewhat lower than today's EIA 2014 projections, other EIPC study futures did capture the high range of solar capacity projected by EIA in some of its sensitivities.

Electricity Demand: The projected energy demand used in the EIPC study for the first 10 years was largely from the individual planning authorities for their regions, while later years used the growth rates from the 2011 AEO. Projected energy demands for 2011 were relatively the same in the BAU and 2011 AEO, differing just $0.7 \%$. But the utility estimates for growth between 2011 and 2015 were an annualized $1.2 \%$ growth rate while those in the 2011 AEO grew at only a $0.2 \%$ rate. From 2015 on, the growth rates were similar in both projections, around $0.8 \%$ per year. This led to differences in the amounts of around $4 \%$ for the study period. The projected demands from the 2014 AEO are even slightly lower than the 2011 AEO, so that the BAU was 4\% to 5\% higher than the current projection from EIA. Lowering demands by $5 \%$ could have a major impact on results. 
Environmental Policies: With the exception of EPA's proposed Clean Power Plan, the changes to proposed/finalized environmental regulations that have occurred after the Phase 1 modeling would be unlikely to have a significant impact on the modeling results. These changes include the reinstatement of the Cross-State Air Pollution Rule and the finalization of the Mercury and Air Toxics Standard, the New Source Performance Standard for $\mathrm{CO}_{2}$, and the Cooling Water Intake Structures rule. Similarly, changes in state RPS requirements would not have a major impact. No new state RPS has been added, and the modifications to existing ones have primarily been a redefinition of the resources that qualify or the creation of a carve-out for a specific technology. The most significant modification is in Ohio, which has established a 2-year hiatus for its RPS. The restrictions on $\mathrm{CO}_{2}$ emissions associated with the proposed Clean Power Plan would have a much greater effect. A number of Phase 1 sensitivities result in significant reductions in $\mathrm{CO}_{2}$ emissions, but they are not close matches to the proposed rule. The $\mathrm{CO}_{2}$ futures result in much greater reductions, while the RPS futures do not differentiate between higher and lower emission nonrenewable sources. Even though these sensitivities do not model the proposed rule specifically, they do indicate that a reduction in coal use, combined with an increase in renewables and natural gas, is a likely outcome. 


\section{REFERENCES}

Astrape Consulting, 2013, The Economic Ramifications of Resource Adequacy White Paper, National Association of Regulatory Commissioners, January. Available online at http://communities.nrri.org/documents/68668/68defc1f-5405-4fa9-8f91-8fa9ca59d116.

Baek, Young Sun, et al., 2012, Eastern Interconnection Demand Response Potential. ORNL/TM2012/303. Oak Ridge, TN: Oak Ridge National Laboratory, November. Available online at http://www.osti.gov/scitech/servlets/purl/1055536.

CRA, 2010, Working Draft of MRN-NEEM Modeling Assumptions and Data Sources for EIPC Capacity Expansion Modeling, prepared for the Eastern Interconnection Planning Collaborative by Charles River Associates, December. Available online at http://www.eipconline.com/uploads/MRN-

NEEM_Assumptions_Document_Draft_12-22-10.pdf.

EIA, 2010, Annual Energy Outlook 2010, DOE/EIA-0383(2010), Energy Information Administration, May. http://www.eia.gov/forecasts/archive/aeo10/

EIA, 2011a, Annual Energy Outlook 2011, with Projections to 2035: Early Release, DOE/EIA0383er(2011), US Energy Information Administration, April; available online at http://www.eia.gov/forecasts/archive/aeo11/.

EIA, 2011b, Annual Energy Outlook 2011, with Projections to 2035, DOE/EIA-0383(2011), US Energy Information Administration, April; available online at http://www.eia.gov/forecasts/archive/aeo11/.

EIA, 2014, Annual Energy Outlook 2014, DOE/EIA-0383(2014), Energy Information Administration, May. http://www.eia.gov/forecasts/aeo/

EIPC, 2011, Phase 1 Report: Formation of Stakeholder Process, Regional Plan Integration and Macroeconomic Analysis, EIPC, December. Available online at http://www.eipconline.com/uploads/Phase_1_Report_Final_12-23-2011.pdf

EIPC, 2012, Phase 2 Report: DOE Draft - Part 1 Interregional Transmission Development and Analysis for Three Stakeholder Selected Scenarios, EIPC, December. Available online at http://www.eipconline.com/uploads/20130103_Phase2Report_Part1_Final.pdf

EIPC, 2012, Phase 2 Report: DOE Draft - Part 2-7 Interregional Transmission Development and Analysis for Three Stakeholder Selected Scenarios, EIPC, December. Available online at http://www.eipconline.com/uploads/20130103_Phase2Report_Part2_Final.pdf

EIPC, 2012, Phase 2 Report: DOE Draft-Appendices Interregional Transmission Development and Analysis for Three Stakeholder Selected Scenarios, EIPC, December. Available online at http://www.eipconline.com/uploads/20130103_Phase2Report_Part3_Final.pdf EIPC data documents on their website:

- Phase 1 Modeling Results: http://www.eipconline.com/Modeling_Results.html.

- Phase II Modeling Inputs: http://www.eipconline.com/Modeling_Inputs.html.

- Phase II Modeling Results: http://www.eipconline.com/PhaseII_Modeling_Results.html. 
Fagan, Bob, Jeremy Fisher, and Bruce Biewald, 2013, An Expanded Analysis of the Costs and Benefits of Base Case and Carbon Reduction Scenarios in the EIPC Process: Preliminary Results, Synapse Energy Economics, Inc. July 19. Available online at http://www.synapseenergy.com/Downloads/SynapseReport.2013-07.Sust-FERC.EIPC-Expanded-Analysis.13-047Report.pdf.

FERC, 2009, A National Assessment of Demand Response Potential, Federal Energy Regulatory Commission Staff Report. Prepared by the Brattle Group; Freeman, Sullivan \& Co; and Global Energy Partners, LLC, June. Retrieved May 20, 2011, from http://www.ferc.gov/legal/staff-reports/06-09demand-response.pdf.

Hadley, Stanton, 2013, Additional EIPC Study Analysis: Interim Report on High Priority Topics, ORNL/TM-2013/447, Oak Ridge, Tennessee: Oak Ridge National Laboratory, November. Available online at http://www.osti.gov/scitech/biblio/1107841.

Hadley, Stanton, and Douglas Gotham, 2014a, Additional EIPC Study Analysis: Interim Report on Medium Priority Topics, ORNL/TM-2013/561, Oak Ridge, Tennessee: Oak Ridge National Laboratory, March. Available online at http://www.osti.gov/scitech/biblio/1126978.

Hadley, Stanton, and Douglas Gotham, 2014b, Additional EIPC Study Analysis: Report on Low Priority Topics, ORNL/TM-2014/134, Oak Ridge, Tennessee: Oak Ridge National Laboratory, August. Available online at http://www.osti.gov/scitech/biblio/1126978.

Hirst, Eric, 2004, U.S. Transmission Capacity: Present Status and Future Prospects, Edison Electric Institute and Office of Electric Transmission and Distribution, US Department of Energy, June. Available online at http://energy.gov/sites/prod/files/oeprod/DocumentsandMedia/transmission_capacity.pdf.

Navigant, 2013, Assessment of Demand-Side Resources within the Eastern Interconnection, prepared for Eastern Interconnection States' Planning Council, March 2013. Available online at http://communities.nrri.org/documents/68668/76ae1be0-2218-4255-8bd4-d7b0fc9ecf8c.

North American Electric Reliability Council 1997, NERC Planning Standards, Princeton, NJ, September.

NERC, 2013, Reliability Standards for the Bulk Electric Systems of North America, Updated December 5, 2013, North American Electric Reliability Corporation website, accessed 12/9/2013. Available online at http://www.nerc.com/pa/Stand/Reliability Standards Complete Set/RSCompleteSet.pdf.

Satchwell, Andrew, Galen L. Barbose, Charles A. Goldman, Ryan Hledik, and Ahmad Faruqui, 2013, Incorporating Demand Response into Western Interconnection Transmission Planning, LBNL-6381E, Lawrence Berkeley National Laboratory, July.

Sikes, Karen, Stanton W. Hadley, Ralph N. McGill, and Timothy Cleary, 2010, Plug-In Hybrid Electric Vehicle Value Proposition Study: Final Report, ORNL/TM-2010/46, Oak Ridge, Tennessee: Oak Ridge National Laboratory, July. Available online at http://info.ornl.gov/sites/publications/Files/Pub23365.pdf. 
APPENDIX A. COST, CAPACITY, AND GENERATION BY REGION 



\section{EASTERN INTERCONNECTION}

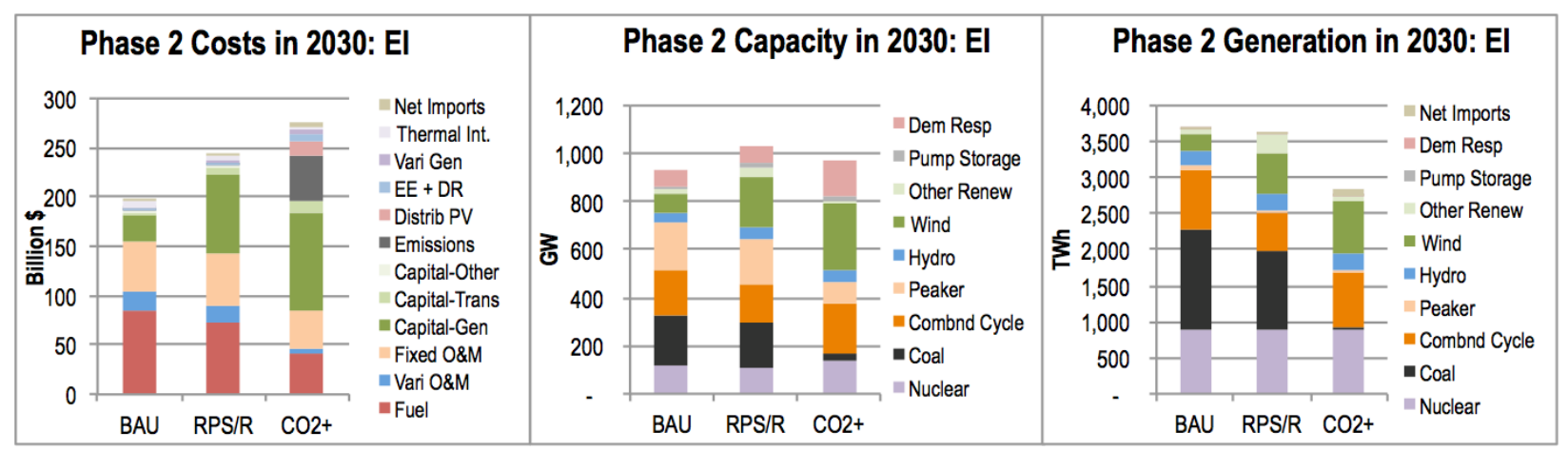

Fig. A-1. 2030 costs, capacities, and generation by type for the $\mathrm{BAU}, \mathrm{RPS} / \mathrm{R}$ and $\mathrm{CO}_{2}+$ scenarios in the Eastern Interconnection

\section{NORTHWEST TERRITORY}

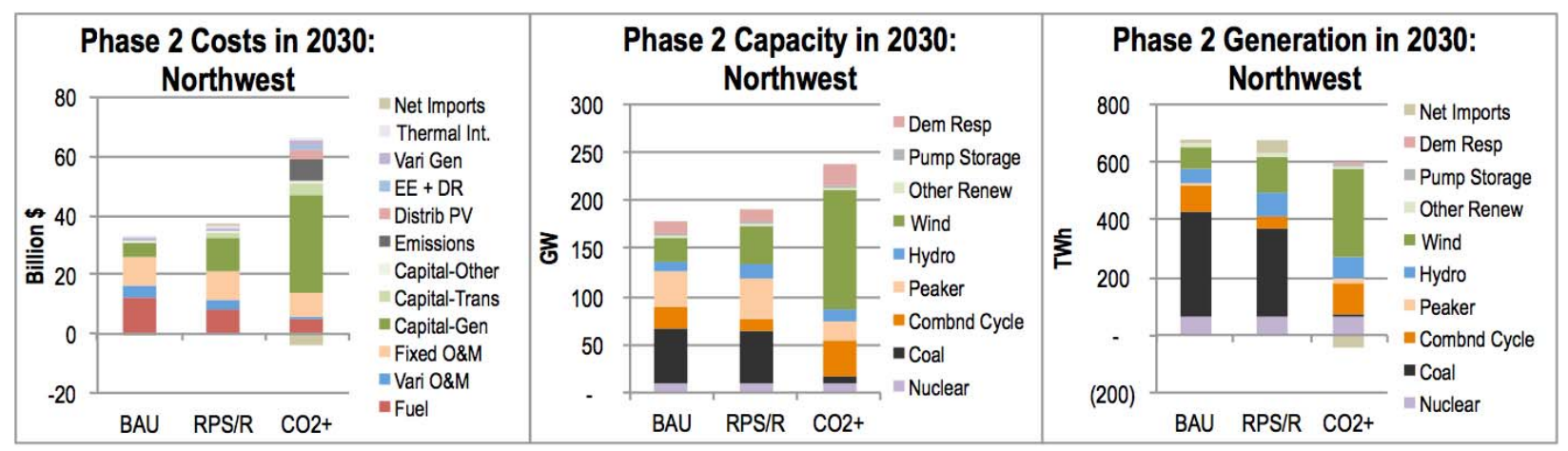

Fig. A-2. 2030 costs, capacities, and generation by type for the BAU, RPS/R and $\mathrm{CO}_{2}+$ scenarios in the Northwest territory

\section{Regions}

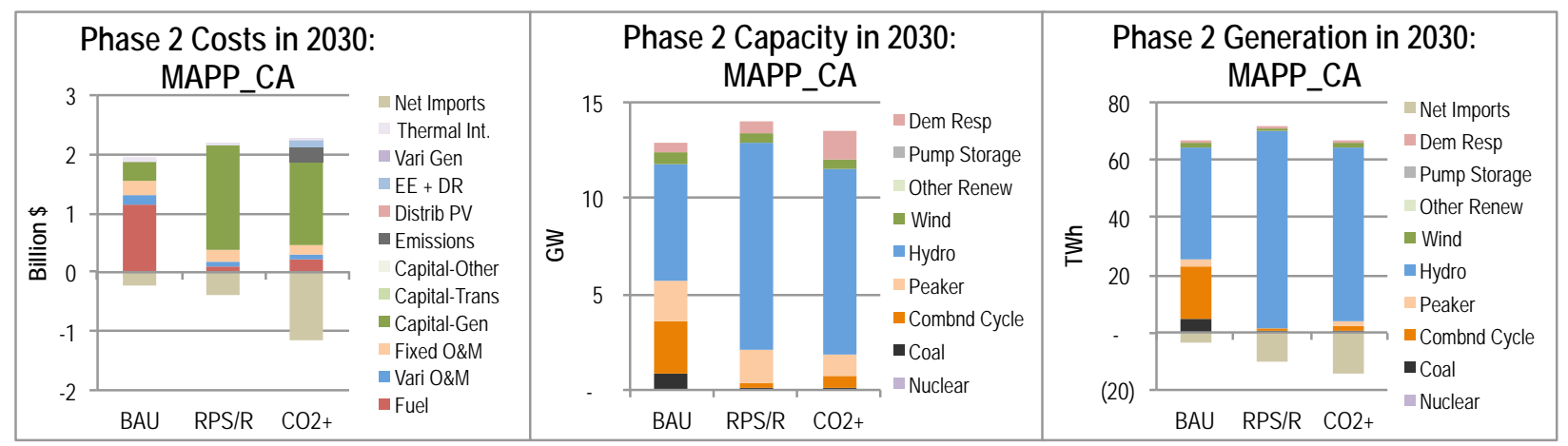

Fig. A-3. 2030 costs, capacities, and generation by type for the BAU, RPS/R and $\mathrm{CO}_{2}+$ scenarios in the MAPP CA region 


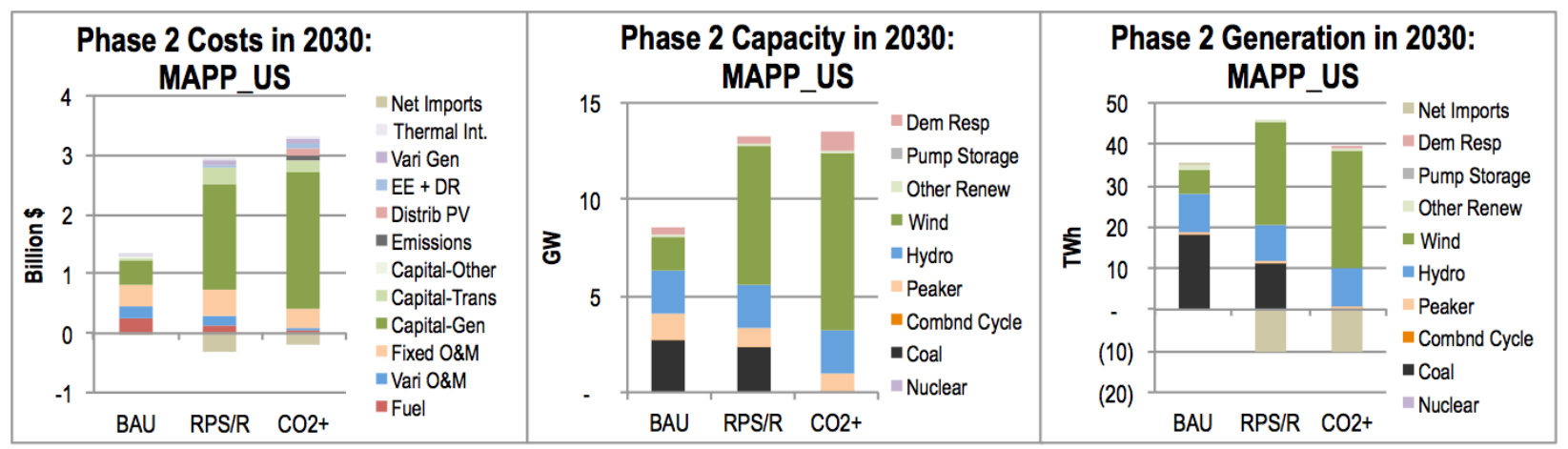

Fig. A-4. 2030 costs, capacities, and generation by type for the BAU, RPS/R and $\mathrm{CO}_{2}+$ scenarios in the MAPP US region

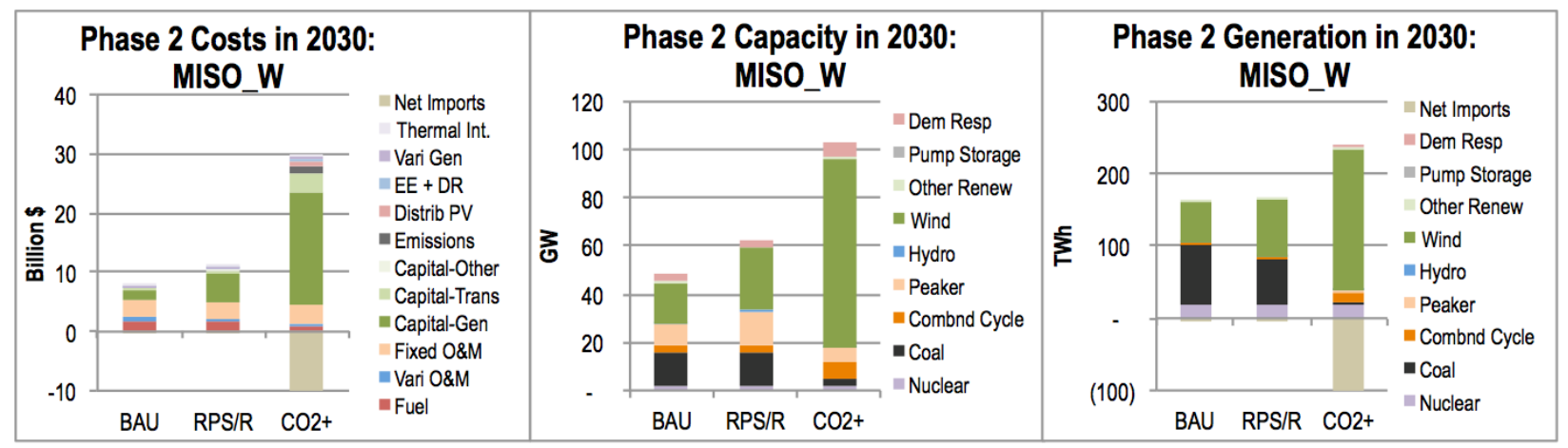

Fig. A-5. 2030 costs, capacities, and generation by type for the BAU, RPS/R and $\mathrm{CO}_{2}+$ scenarios in the MISO $W$ region

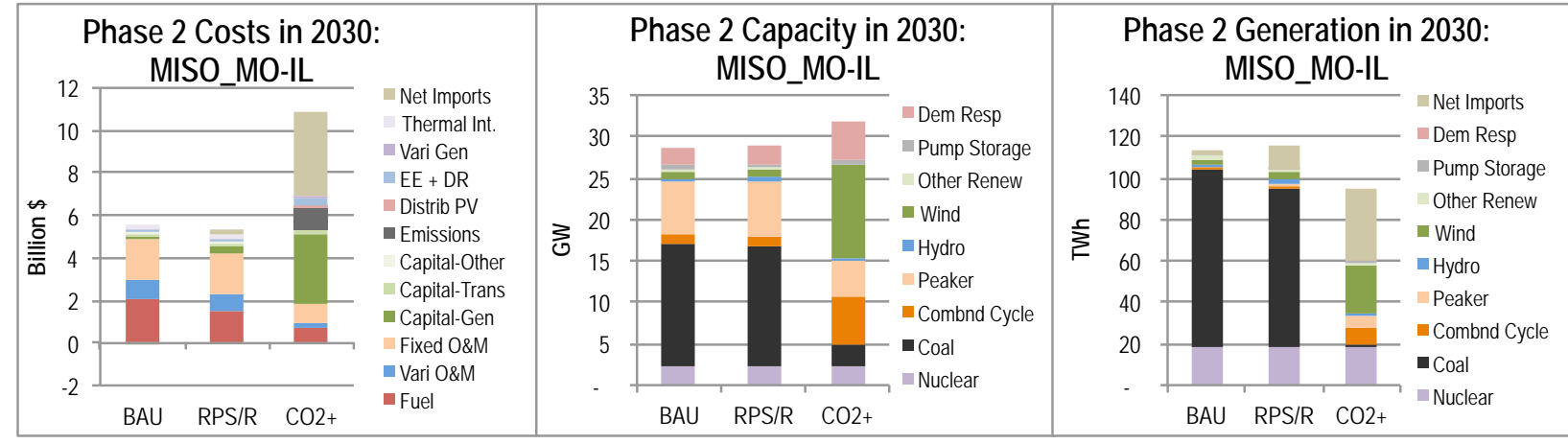

Fig. A-6. 2030 costs, capacities, and generation by type for the BAU, RPS/R and $\mathrm{CO}_{2}+$ scenarios in the MISO MO-IL region 


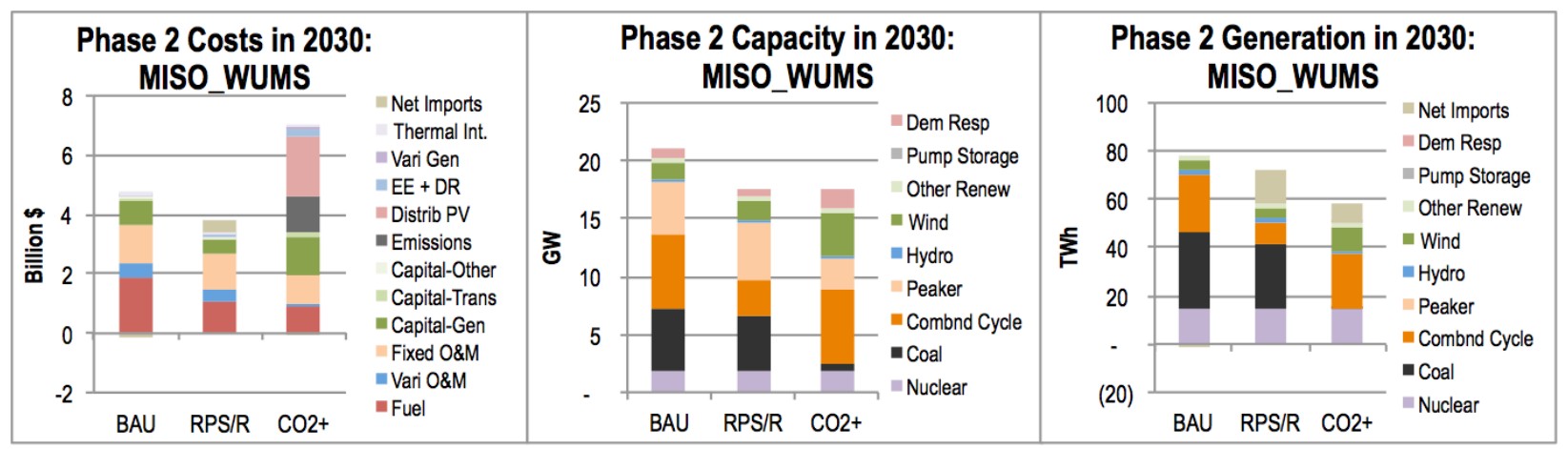

Fig. A-7. 2030 costs, capacities, and generation by type for the BAU, RPS/R and $\mathrm{CO}_{2}+$ scenarios in the MISO WUMS region

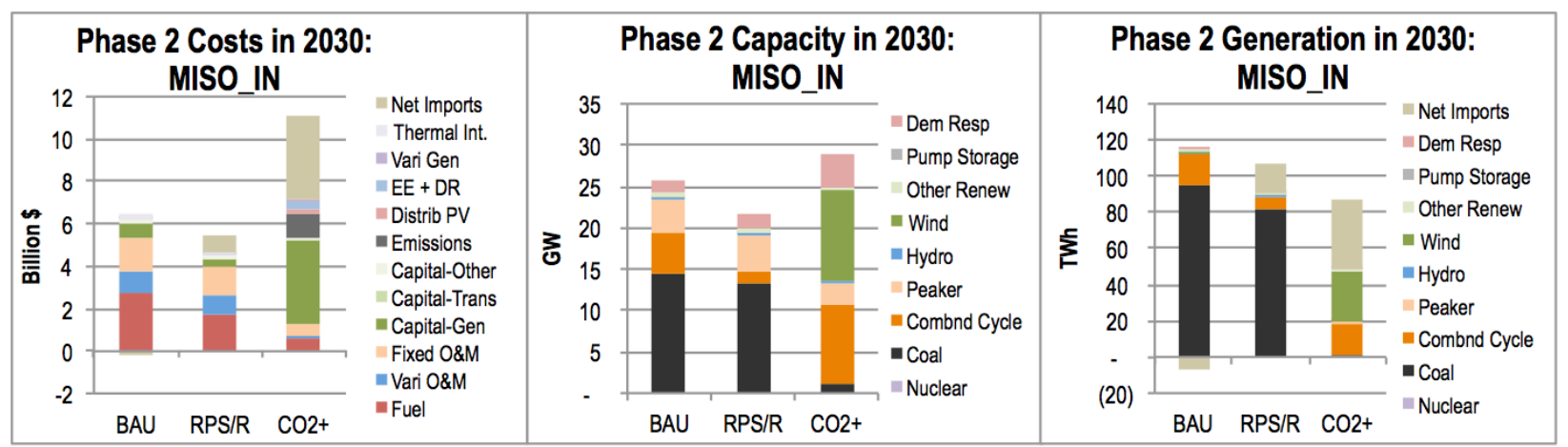

Fig. A-8. 2030 costs, capacities, and generation by type for the BAU, RPS/R and $\mathrm{CO}_{2}+$ scenarios in the MISO IN region

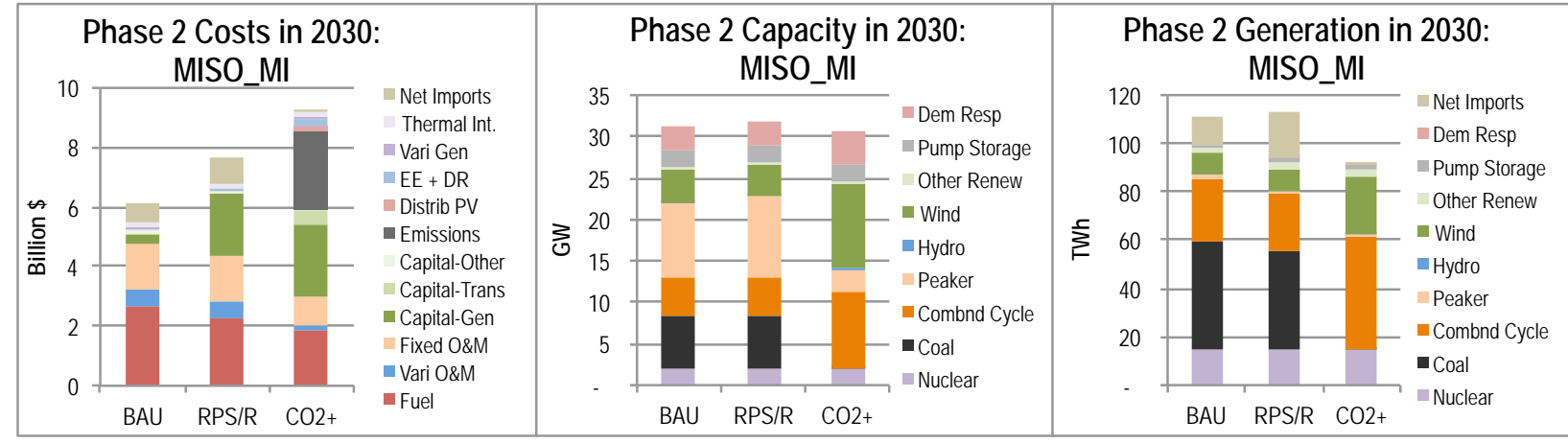

Fig. A-9. 2030 costs, capacities, and generation by type for the BAU, RPS/R and $\mathrm{CO}_{2}+$ scenarios in the MISO MI region 


\section{CENTRAL TERRITORY}

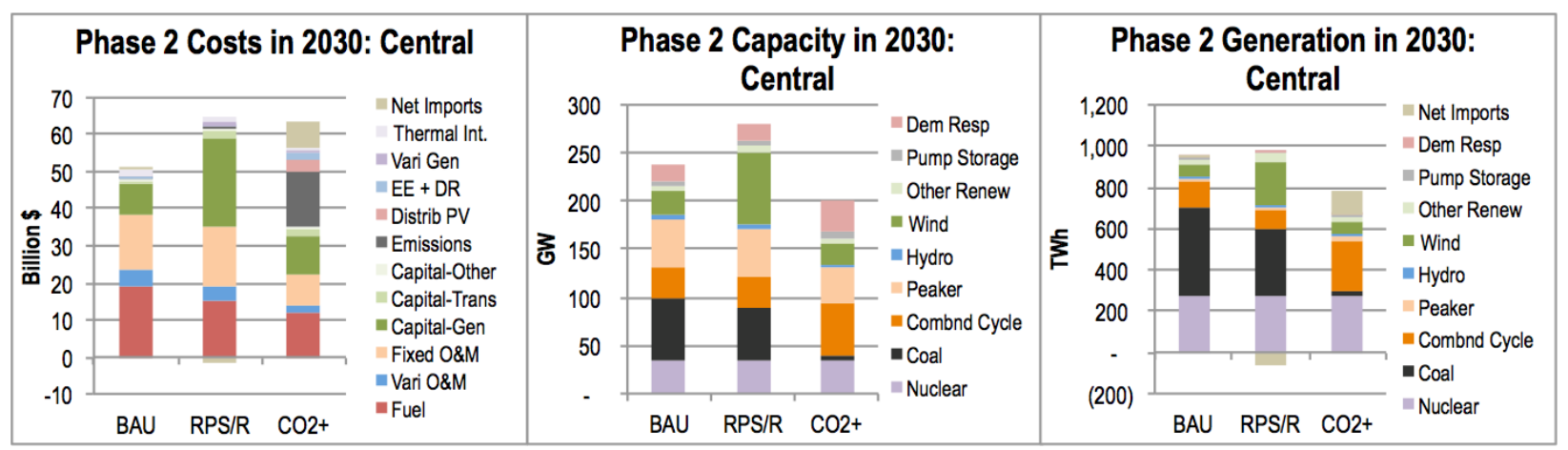

Fig. A-10. 2030 costs, capacities, and generation by type for the BAU, RPS/R and $\mathrm{CO}_{2}+$ scenarios in the Central territory

\section{Regions}

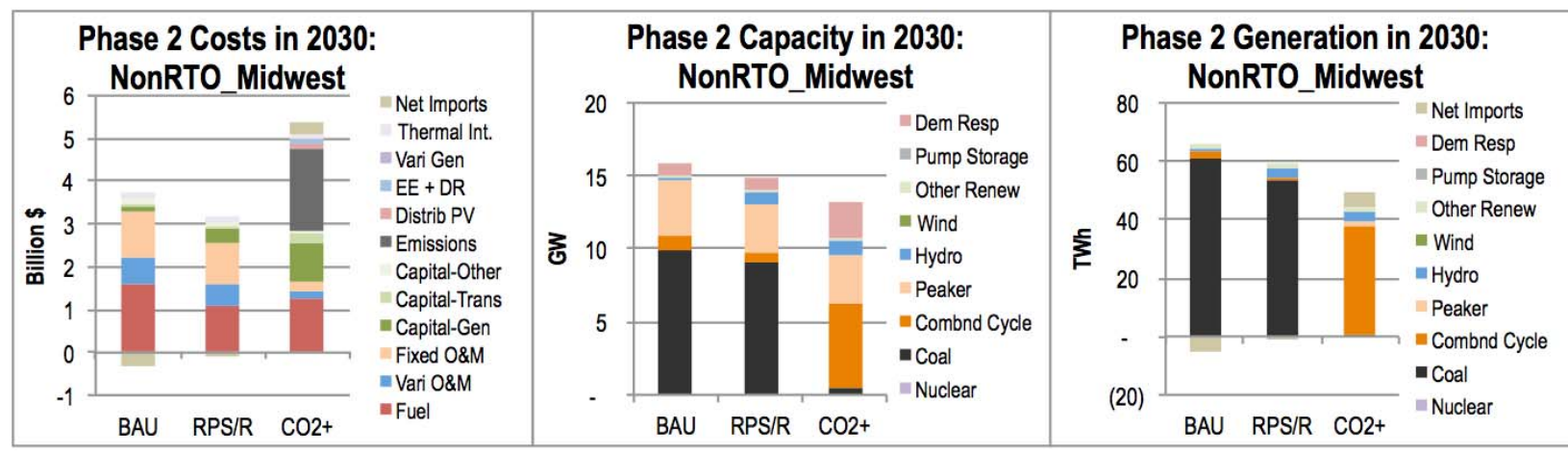

Fig. A-11. 2030 costs, capacities, and generation by type for the BAU, RPS/R and $\mathrm{CO}_{2}+$ scenarios in the NonRTO Midwest region

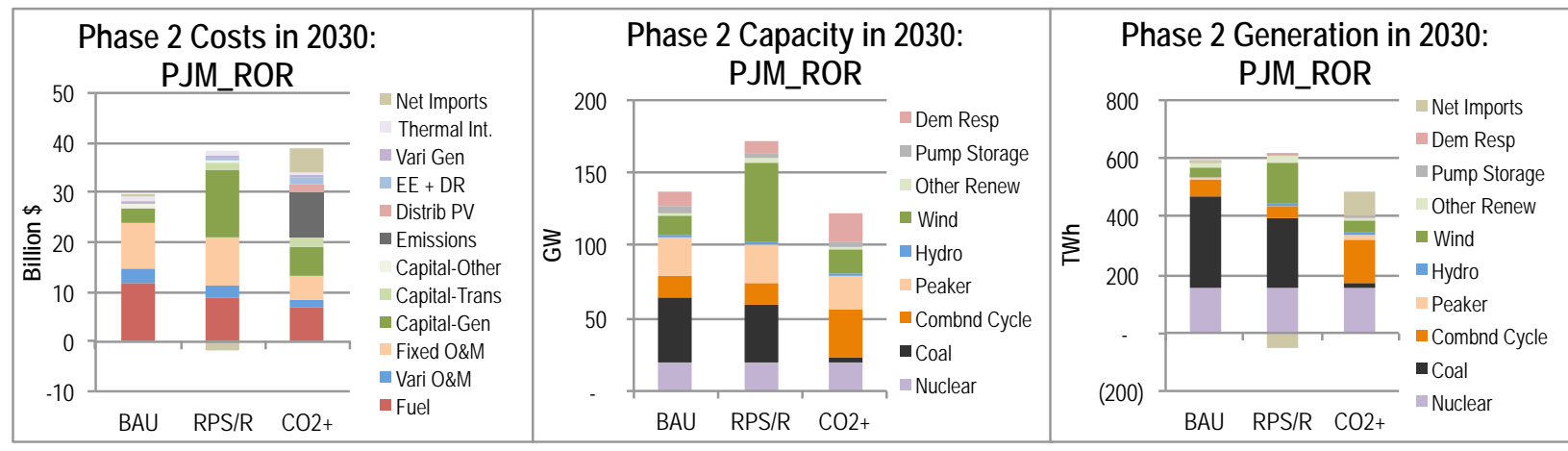

Fig. A-12. 2030 costs, capacities, and generation by type for the BAU, RPS/R and $\mathrm{CO}_{2}+$ scenarios in the PJM ROR region 


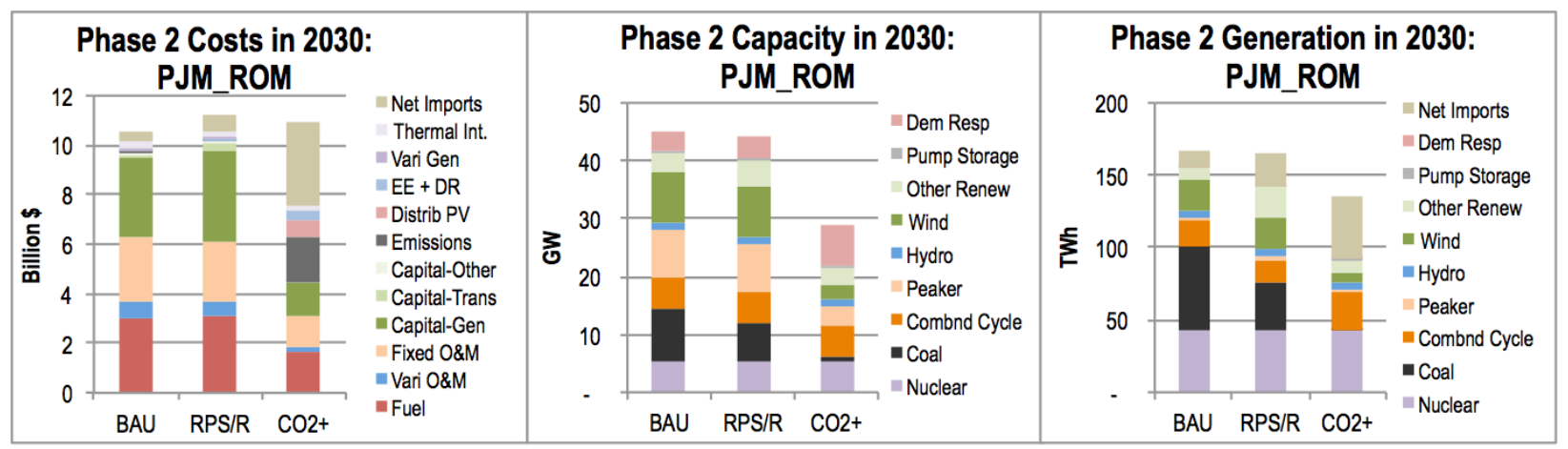

Fig. A-13. 2030 costs, capacities, and generation by type for the BAU, RPS/R and $\mathrm{CO}_{2}+$ scenarios in the PJM ROM region

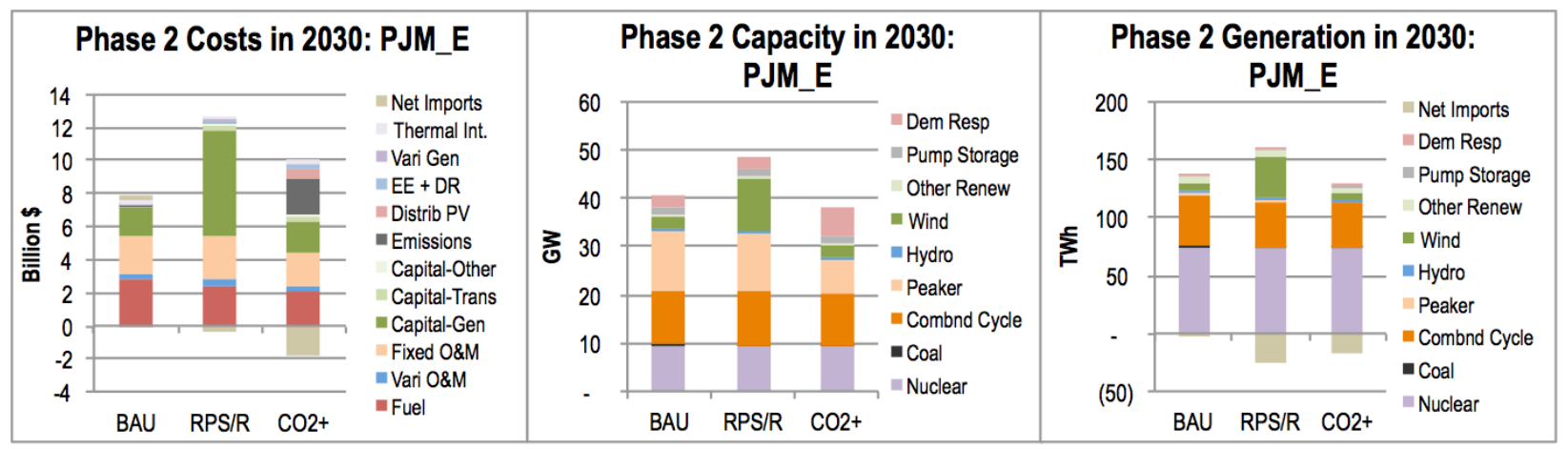

Fig. A-14. 2030 costs, capacities, and generation by type for the BAU, RPS/R and $\mathrm{CO}_{2}+$ scenarios in the PJM E region

\section{NORTHEAST TERRITORY}

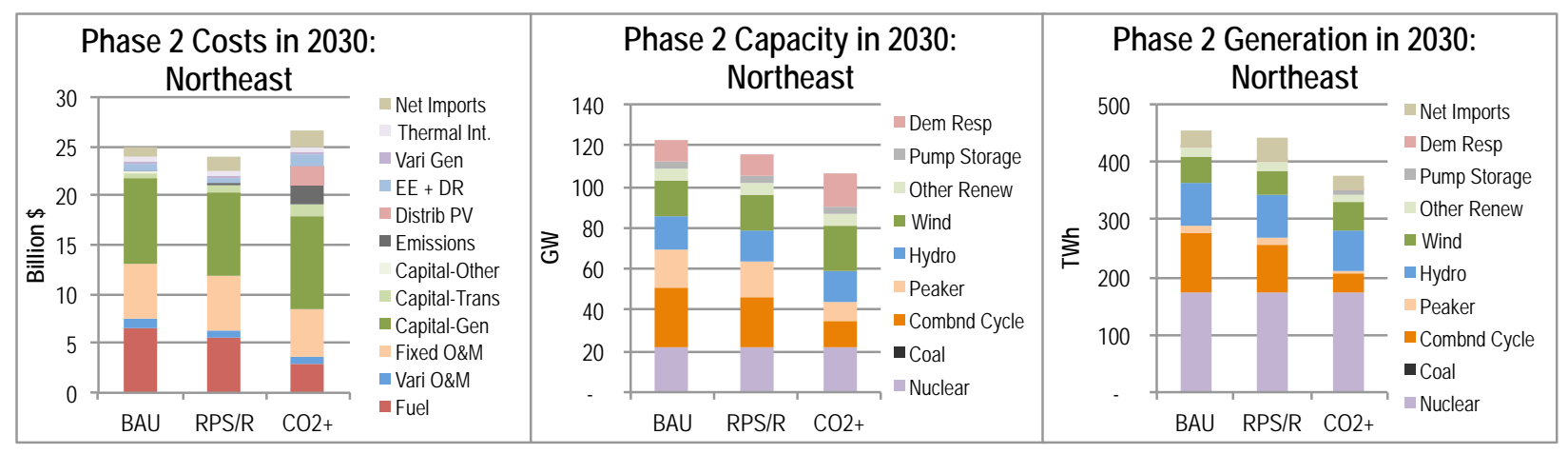

Fig. A-15. 2030 costs, capacities, and generation by type for the $\mathrm{BAU}, \mathrm{RPS} / \mathrm{R}$ and $\mathrm{CO}_{2}+$ scenarios in the Northeast territory 


\section{Regions}

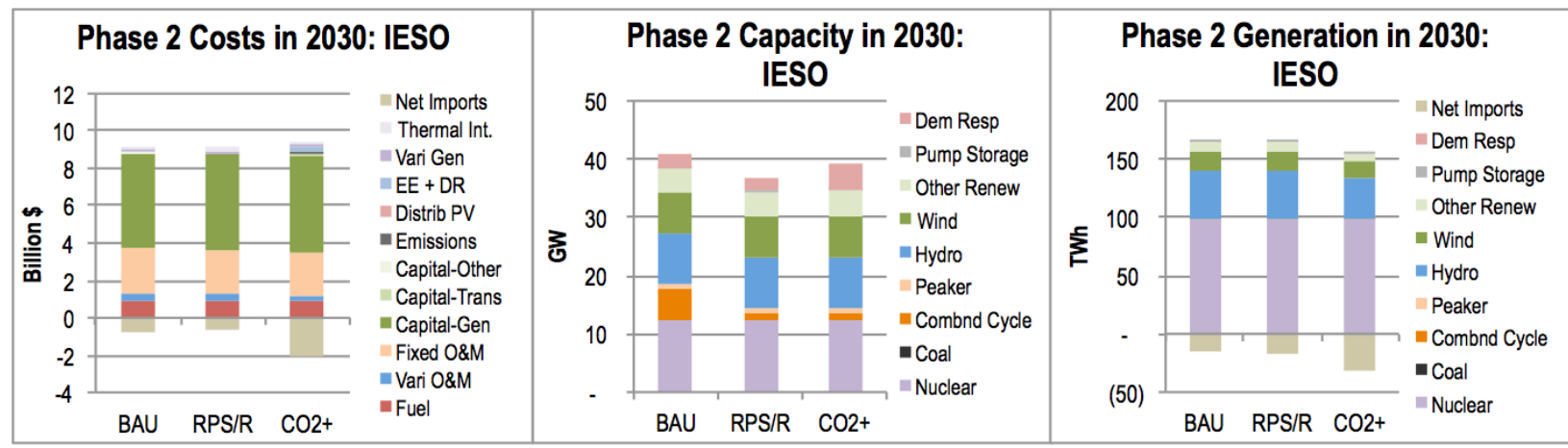

Fig. A-16. 2030 costs, capacities, and generation by type for the BAU, RPS/R and $\mathrm{CO}_{2}+$ scenarios in the IESO region

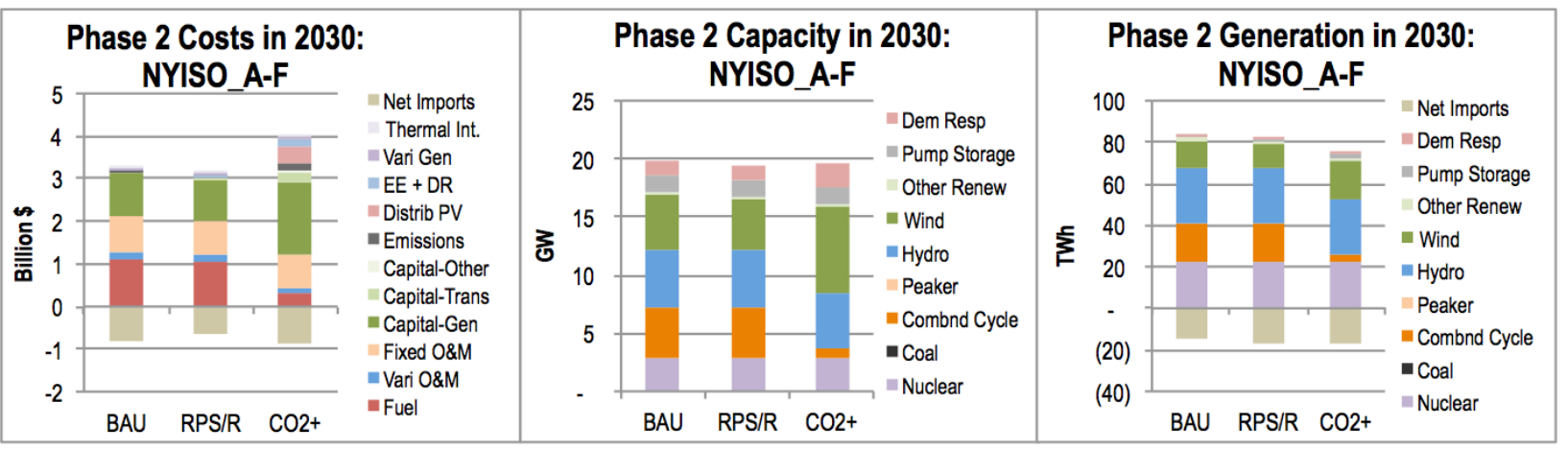

Fig. A-17. 2030 costs, capacities, and generation by type for the BAU, RPS/R and $\mathrm{CO}_{2}+$ scenarios in the NYISO A-F region

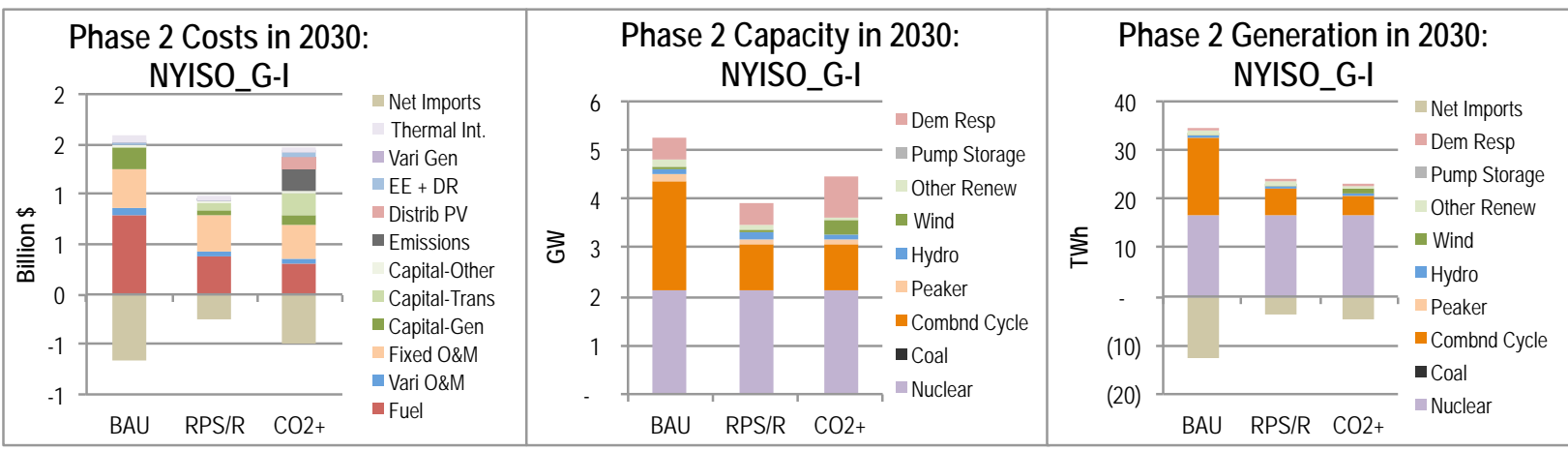

Fig. A-18. 2030 costs, capacities, and generation by type for the BAU, RPS/R and $\mathrm{CO}_{2}+$ scenarios in the NYISO G-I region 


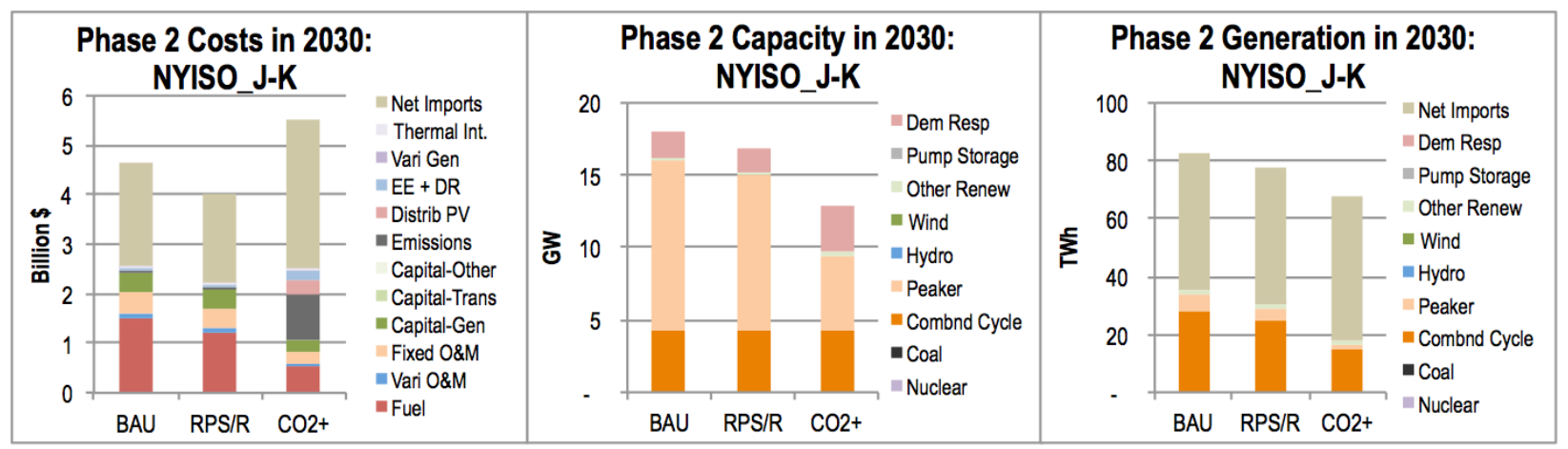

Fig. A-19. 2030 costs, capacities, and generation by type for the BAU, RPS/R and $\mathrm{CO}_{2}+$ scenarios in the NYISO J-K region

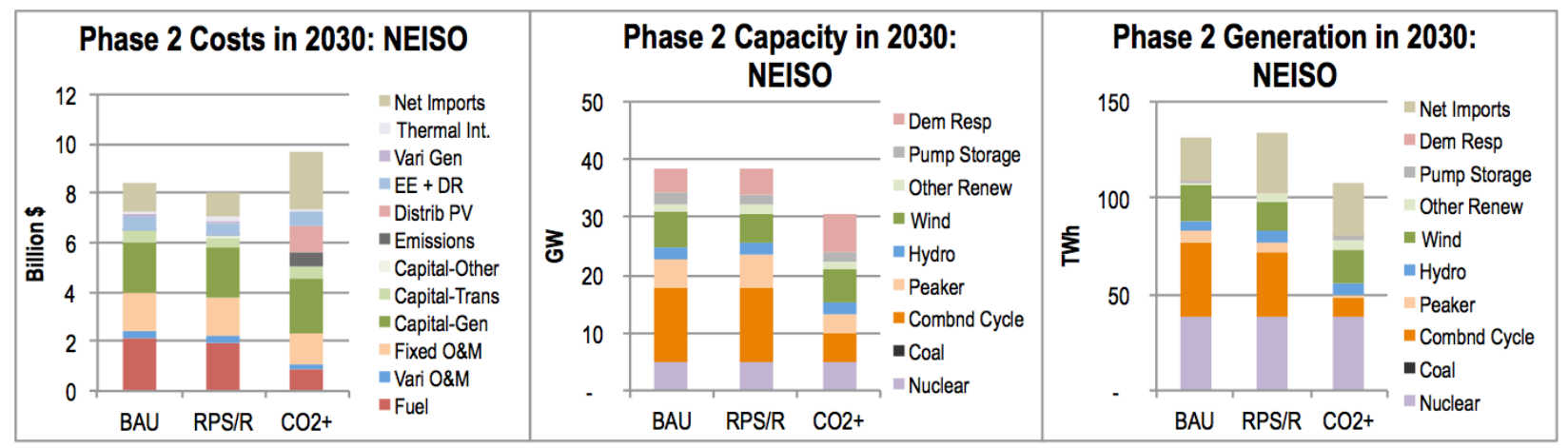

Fig. A-20. 2030 costs, capacities, and generation by type for the BAU, RPS/R and $\mathrm{CO}_{2}+$ scenarios in the NEISO region

\section{SOUTHWEST TERRITORY}

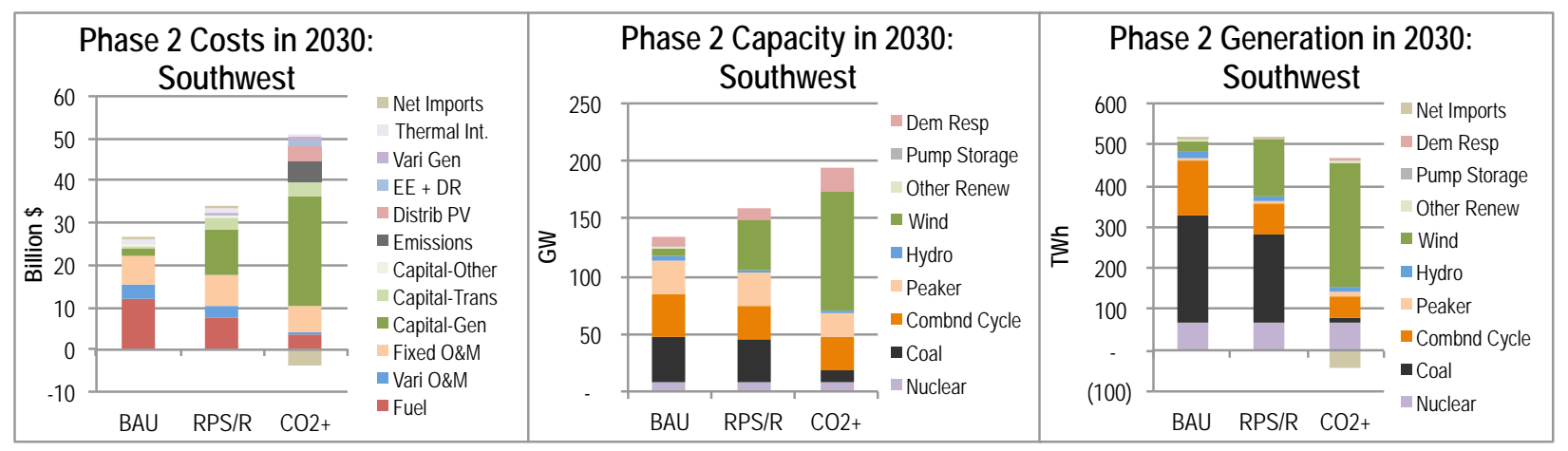

Fig. A-21. 2030 costs, capacities, and generation by type for the BAU, RPS/R and $\mathrm{CO}_{2}+$ scenarios in the Southwest territory 


\section{Regions}

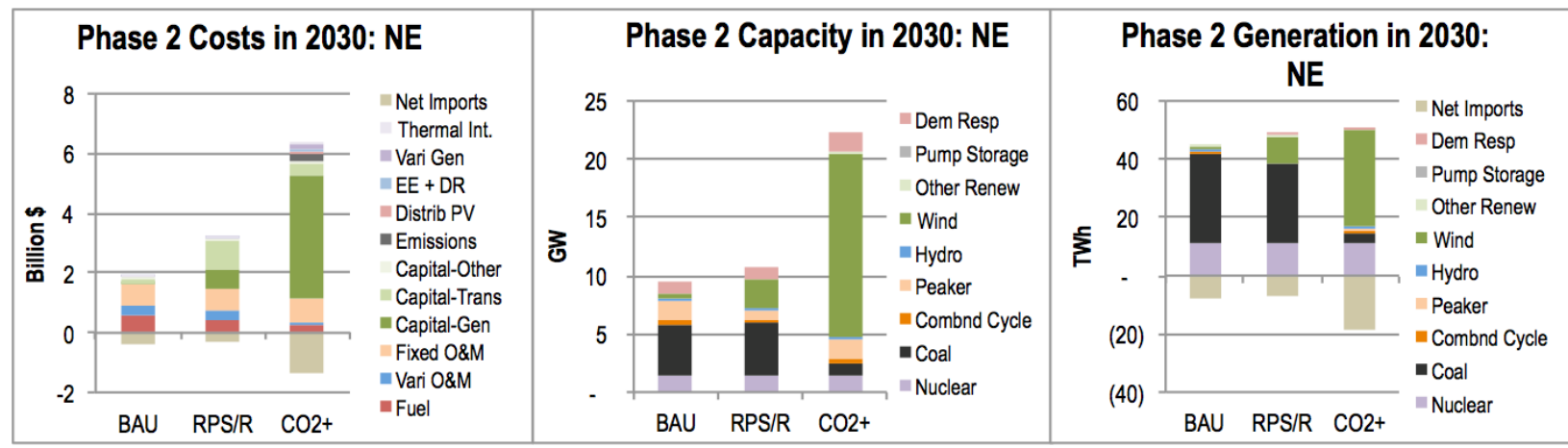

Fig. A-22. 2030 costs, capacities, and generation by type for the BAU, RPS/R and $\mathrm{CO}_{2}+$ scenarios in the Nebraska region

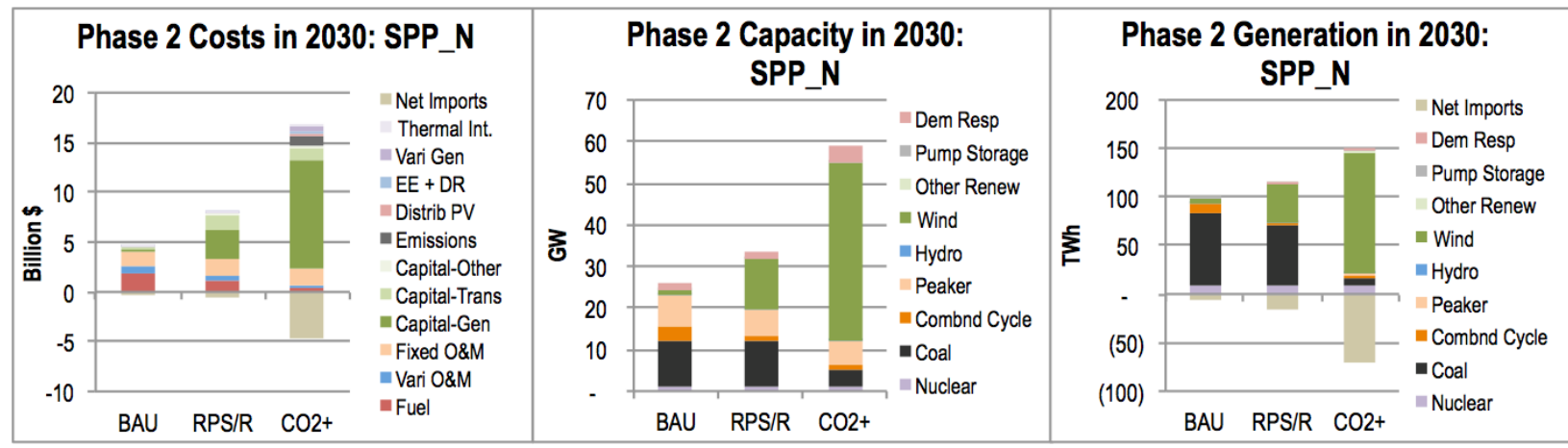

Fig. A-23. 2030 costs, capacities, and generation by type for the BAU, RPS/R and $\mathrm{CO}_{2}+$ scenarios in the SPP North region

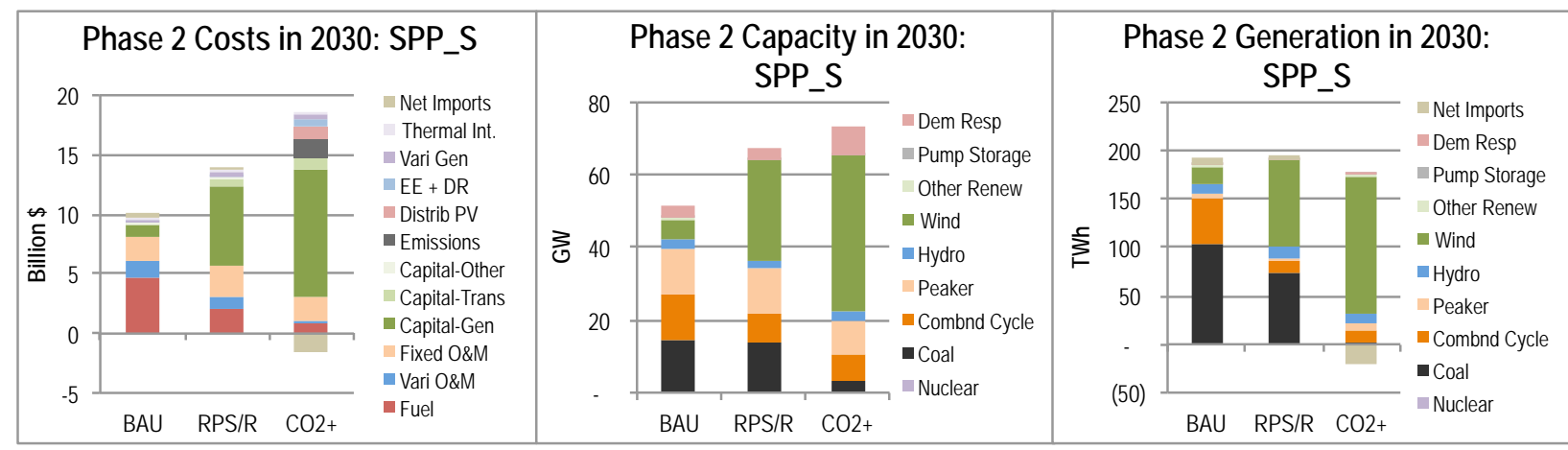

Fig. A-24. 2030 costs, capacities, and generation by type for the BAU, RPS/R and $\mathbf{C O}_{2}+$ scenarios in the SPP South region 


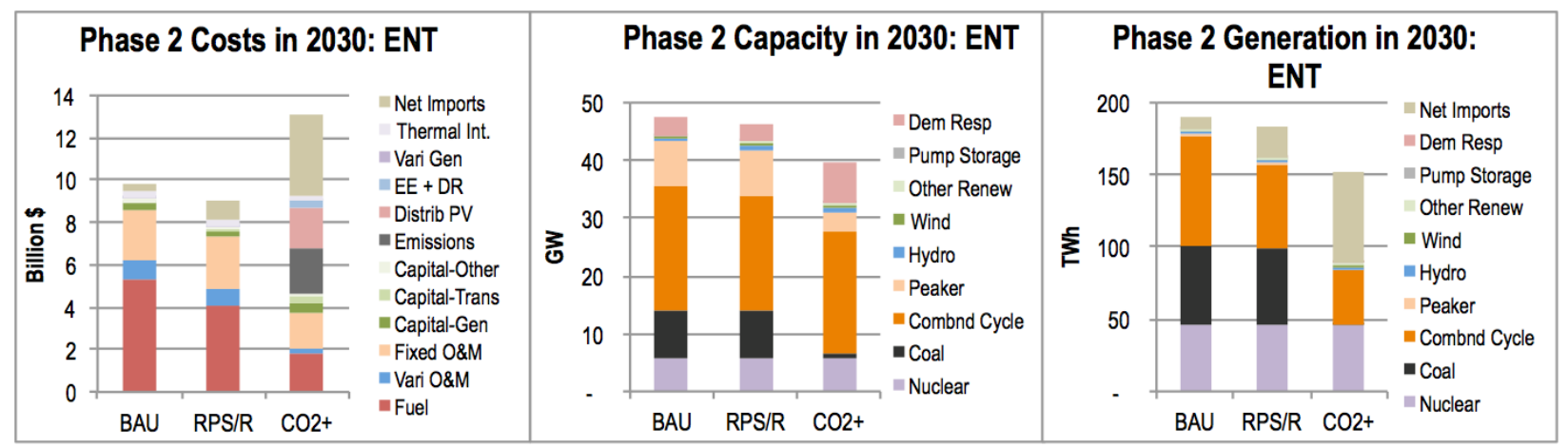

Fig. A-25. 2030 costs, capacities, and generation by type for the $\mathrm{BAU}, \mathrm{RPS} / \mathrm{R}$ and $\mathrm{CO}_{2}+$ scenarios in the Entergy region

\section{SOUTHEAST TERRITORY}

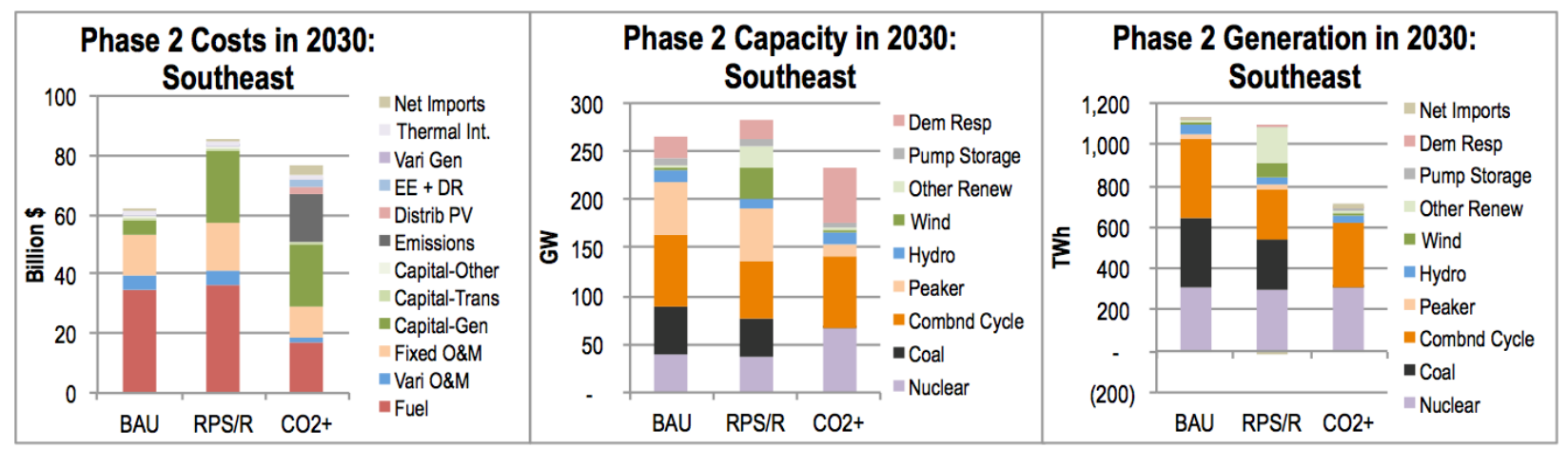

Fig. A-26. 2030 costs, capacities, and generation by type for the $\mathrm{BAU}, \mathrm{RPS} / \mathrm{R}$ and $\mathrm{CO}_{2}+$ scenarios in the Southeast territory

\section{Regions}

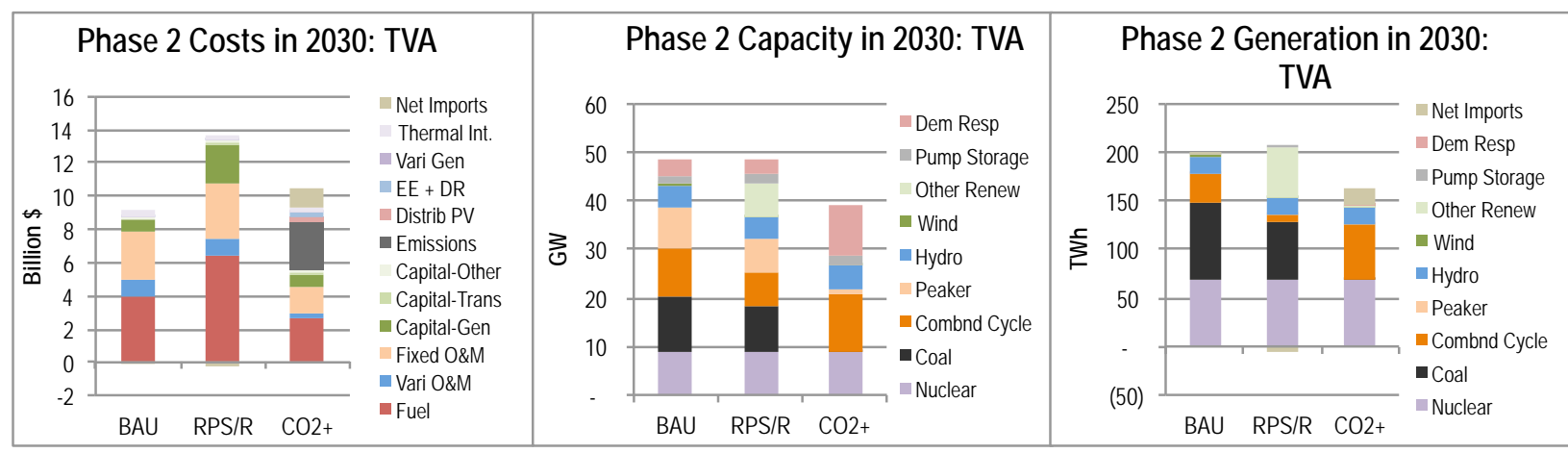

Fig. A-27. 2030 costs, capacities, and generation by type for the BAU, RPS/R and $\mathrm{CO}_{2}+$ scenarios in the TVA region 


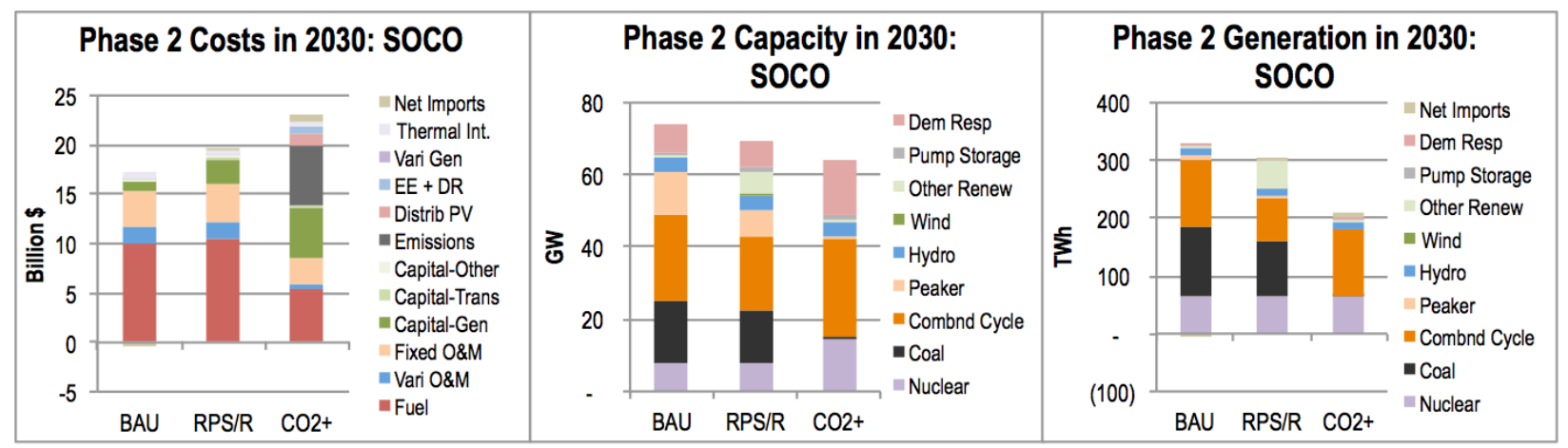

Fig. A-28. 2030 costs, capacities, and generation by type for the $\mathrm{BAU}, \mathrm{RPS} / \mathrm{R}$ and $\mathrm{CO}_{2}+$ scenarios in the SOCO region

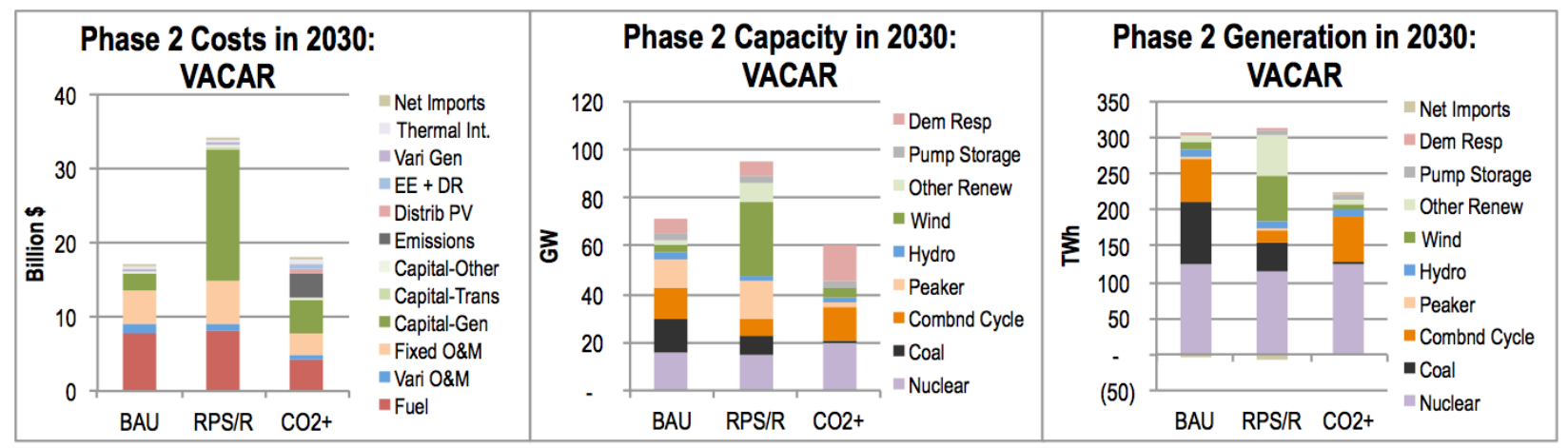

Fig. A-29. 2030 costs, capacities, and generation by type for the BAU, RPS/R and $\mathrm{CO}_{2}+$ scenarios in the VACAR region

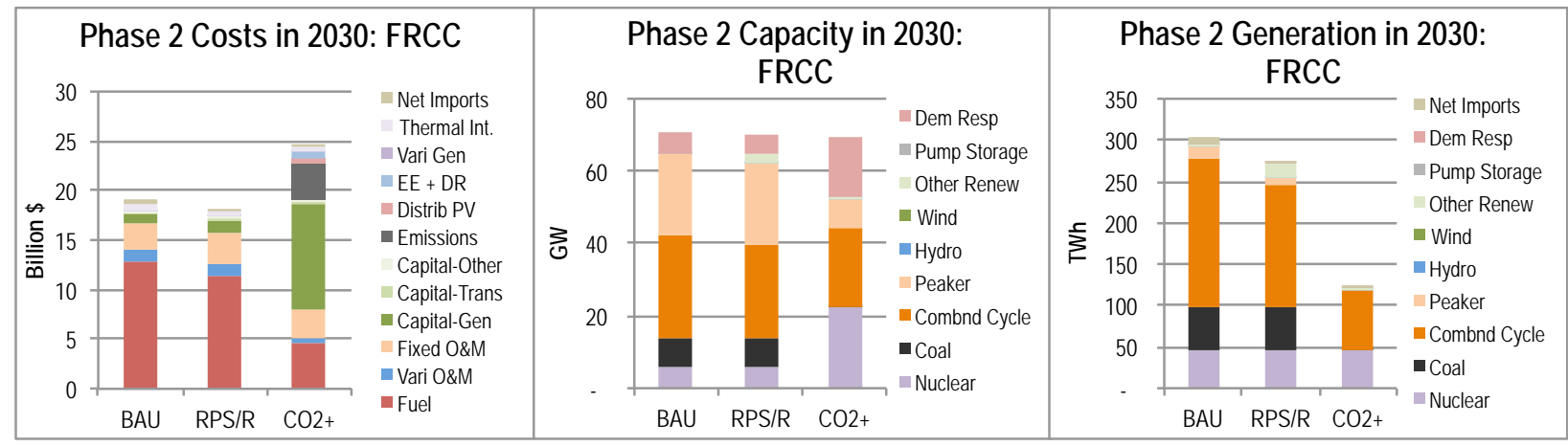

Fig. A-30. 2030 costs, capacities, and generation by type for the BAU, RPS/R and $\mathrm{CO}_{2}+$ scenarios in the FRCC region 
APPENDIX B: LINES AND TRANSFORMERS COMMON TO ALL SCENARIOS 

Table B-1. Lines and Transformers Common to All Scenarios

\begin{tabular}{|c|c|c|c|}
\hline Region & Name & Reason/Need & Description \\
\hline NEISO & $\begin{array}{l}\text { CT LAKES-SEA } \\
\text { STRATTON115 kV TL }\end{array}$ & $\begin{array}{l}\text { Interconnect New } \\
\text { Generation }\end{array}$ & $\begin{array}{l}\text { Include new transmission line and } 1 \\
\text { new } 115 \mathrm{kV} \text { substation }\end{array}$ \\
\hline NEISO & $\begin{array}{l}\text { PITTSTON ME-PITTSTN CLR1 } \\
115 \mathrm{kV} \text { TL }\end{array}$ & $\begin{array}{l}\text { Interconnect New } \\
\text { Generation }\end{array}$ & $\begin{array}{l}\text { Include new transmission line and } 2 \\
\text { new } 115 \mathrm{kV} \text { substation }\end{array}$ \\
\hline NEISO & Pittston ME 115/345 kV XFMR & $\begin{array}{l}\text { Interconnect New } \\
\text { Generation }\end{array}$ & 1 new 345/115 kV XFMR \\
\hline NEISO & $\begin{array}{l}\text { PITTSTON ME-HARRIS } \\
\text { HYDRO } 115 \mathrm{kV} \text { TL }\end{array}$ & $\begin{array}{l}\text { Interconnect New } \\
\text { Generation }\end{array}$ & Include new transmission line \\
\hline NEISO & $\begin{array}{l}\text { MARTHAS VYND-FALMOUTH } \\
\text { TAP } 115 \mathrm{kV} \text { TL }\end{array}$ & $\begin{array}{l}\text { Interconnect New } \\
\text { Generation }\end{array}$ & $\begin{array}{l}\text { Include new transmission line and } 1 \\
\text { new } 115 \mathrm{kV} \text { substation }\end{array}$ \\
\hline NEISO & Ashland ME 115/345 kV XFMR & $\begin{array}{l}\text { Interconnect New } \\
\text { Generation }\end{array}$ & 1 new 345/115 kV XFMR \\
\hline NEISO & Canal 115/345 kV XFMR & $\begin{array}{l}\text { Interconnect New } \\
\text { Generation }\end{array}$ & 1 new 345/115 kV XFMR \\
\hline NEISO & $\begin{array}{l}\text { CANAL-HATCHVILLE } 115 \mathrm{kV} \\
\text { TL }\end{array}$ & $\begin{array}{l}\text { Interconnect New } \\
\text { Generation }\end{array}$ & $\begin{array}{l}\text { Include new transmission line and } 1 \\
\text { new } 115 \mathrm{kV} \text { substation }\end{array}$ \\
\hline NEISO & $\begin{array}{l}\text { SEA STRATTON-PITTSTON } \\
\text { ME } 345 \mathrm{kV} \text { TL }\end{array}$ & $\begin{array}{l}\text { Interconnect New } \\
\text { Generation }\end{array}$ & $\begin{array}{l}\text { Includes new transmission line and } 2 \\
\text { new } 345 \mathrm{kV} \text { substations }\end{array}$ \\
\hline NEISO & $\begin{array}{l}\text { SEA STRATTON-ORRINGTON } \\
345 \mathrm{kV} \text { TL }\end{array}$ & $\begin{array}{l}\text { Interconnect New } \\
\text { Generation }\end{array}$ & Includes new transmission line \\
\hline NEISO & Sea Stratton 345/115 kV XFMR & $\begin{array}{l}\text { Interconnect New } \\
\text { Generation }\end{array}$ & 1 new 345/115 kV XFMR \\
\hline NEISO & $\begin{array}{l}\text { Sea Stratton } 345 \text { kV-50 Mvar } \\
\text { Reactor }\end{array}$ & $\begin{array}{l}\text { Interconnect New } \\
\text { Generation }\end{array}$ & Includes new reactor \\
\hline NEISO & $\begin{array}{l}\text { DRACTU MA-ORRINGTON } \\
345 \text { kV TL }\end{array}$ & $\begin{array}{l}\text { Interconnect New } \\
\text { Generation }\end{array}$ & Includes new transmission line \\
\hline NEISO & $\begin{array}{l}\text { DRACTU MA-MILLBURY } \\
345 \mathrm{kV} \text { TL }\end{array}$ & $\begin{array}{l}\text { Interconnect New } \\
\text { Generation }\end{array}$ & Includes new transmission line \\
\hline NEISO & $\begin{array}{l}\text { PITTSTON ME-ASHLAND ME } \\
345 \text { kV TL }\end{array}$ & $\begin{array}{l}\text { Interconnect New } \\
\text { Generation }\end{array}$ & $\begin{array}{l}\text { Includes new transmission line and } 1 \\
\text { new } 345 \mathrm{kV} \text { substation }\end{array}$ \\
\hline NEISO & $\begin{array}{l}\text { Pittston ME } 345 \text { kV-30 Mvar } \\
\text { Reactor }\end{array}$ & $\begin{array}{l}\text { Interconnect New } \\
\text { Generation }\end{array}$ & Includes new reactor \\
\hline NEISO & $\begin{array}{l}\text { WHITTING ME-HARRINGTON } \\
345 \text { kV TL }\end{array}$ & $\begin{array}{l}\text { Interconnect New } \\
\text { Generation }\end{array}$ & $\begin{array}{l}\text { Includes new transmission line, } 1 \text { new } \\
345 \mathrm{kV} \text { substation and } 1 \text { new } \\
345 / 115 \mathrm{kV} \text { XFMR }\end{array}$ \\
\hline NEISO & $\begin{array}{l}\text { WHITTING ME -ORRINGTON } \\
345 \mathrm{kV} \text { TL }\end{array}$ & $\begin{array}{l}\text { Interconnect New } \\
\text { Generation }\end{array}$ & $\begin{array}{l}\text { Includes new transmission line, } 1 \text { new } \\
345 \mathrm{kV} \text { substation and } 1 \text { new } \\
345 / 115 \mathrm{kV} \text { XFMR }\end{array}$ \\
\hline NEISO & $\begin{array}{l}\text { Whiting ME } 345 \text { kV-60 Mvar } \\
\text { Reactor }\end{array}$ & $\begin{array}{l}\text { Interconnect New } \\
\text { Generation }\end{array}$ & Includes new reactor \\
\hline NEISO & $\begin{array}{l}\text { HARRINGTON-TRENTON } \\
345 \text { kV TL }\end{array}$ & $\begin{array}{l}\text { Interconnect New } \\
\text { Generation }\end{array}$ & $\begin{array}{l}\text { Includes new transmission line, } 1 \text { new } \\
345 \mathrm{kV} \text { substation and } 1 \text { new } \\
345 / 115 \mathrm{kV} \text { XFMR }\end{array}$ \\
\hline NEISO & $\begin{array}{l}\text { Harrington } 345 \text { kV-40 Mvar } \\
\text { Reactor }\end{array}$ & $\begin{array}{l}\text { Interconnect New } \\
\text { Generation }\end{array}$ & Includes new reactor \\
\hline NEISO & $\begin{array}{l}\text { TRENTON-ORRINGTON } \\
345 \text { kV TL }\end{array}$ & $\begin{array}{l}\text { Interconnect New } \\
\text { Generation }\end{array}$ & Includes new transmission line \\
\hline NEISO & Trenton 345 kV-40 Mvar Reactor & $\begin{array}{l}\text { Interconnect New } \\
\text { Generation }\end{array}$ & Includes new reactor \\
\hline NEISO & $\begin{array}{l}\text { BARNSTABLE-LONG TRM LSM } \\
345 \mathrm{kV} \text { TL }\end{array}$ & $\begin{array}{l}\text { Interconnect New } \\
\text { Generation }\end{array}$ & $\begin{array}{l}\text { Includes new transmission line, } 1 \text { new } \\
345 \mathrm{kV} \text { substation and } 1 \text { new } \\
345 / 115 \mathrm{kV} \text { XFMR }\end{array}$ \\
\hline NEISO & $\begin{array}{l}\text { Barnstable } 345 \text { kV-150 Mvar } \\
\text { SVC }\end{array}$ & $\begin{array}{l}\text { Interconnect New } \\
\text { Generation }\end{array}$ & $\begin{array}{l}\text { Includes new static var controller } \\
\text { (SVC) }\end{array}$ \\
\hline NEISO & $\begin{array}{l}\text { ASHLAND ME-ORRINGTON } \\
345 \mathrm{kV} \text { TL }\end{array}$ & $\begin{array}{l}\text { Interconnect New } \\
\text { Generation }\end{array}$ & Includes new transmission line \\
\hline
\end{tabular}




\begin{tabular}{|c|c|c|c|}
\hline Region & Name & Reason/Need & Description \\
\hline NEISO & $\begin{array}{l}\text { Ashland ME } 345 \text { kV-20 Mvar } \\
\text { Cap Bank }\end{array}$ & $\begin{array}{l}\text { Interconnect New } \\
\text { Generation }\end{array}$ & Includes new capacitor bank \\
\hline NEISO & Whitefield-Littleton 230 kV TL & $\begin{array}{l}\text { Interconnect New } \\
\text { Generation }\end{array}$ & Includes new transmission line \\
\hline NEISO & $\begin{array}{l}\text { Lost Nation-Whitefield } 230 \mathrm{kV} \\
\text { TL }\end{array}$ & $\begin{array}{l}\text { Interconnect New } \\
\text { Generation }\end{array}$ & $\begin{array}{l}\text { Includes new transmission line and } 1 \\
\text { new } 230 \mathrm{kV} \text { substations }\end{array}$ \\
\hline NEISO & Paris-Lost Nation 230 kV TL & $\begin{array}{l}\text { Interconnect New } \\
\text { Generation }\end{array}$ & $\begin{array}{l}\text { Includes new transmission line and } 1 \\
\text { new } 230 \mathrm{kV} \text { substations }\end{array}$ \\
\hline NEISO & Pontook-Paris $230 \mathrm{kV}$ TL & $\begin{array}{l}\text { Interconnect New } \\
\text { Generation }\end{array}$ & $\begin{array}{l}\text { Includes new transmission line and } 2 \\
\text { new } 230 \mathrm{kV} \text { substations }\end{array}$ \\
\hline NEISO & $\begin{array}{l}\text { STURTEVANT-LIVERMORE FL } \\
115 \mathrm{kV} \text { TL }\end{array}$ & $\begin{array}{l}\text { Interconnect New } \\
\text { Generation }\end{array}$ & Includes new transmission line \\
\hline NEISO & $\begin{array}{l}\text { Merrimack } 230 \text { kV-150 Mvar } \\
\text { SVC }\end{array}$ & Low Voltage & Includes new SVC \\
\hline NEISO & Scobie-Tewksbury 345 kV TL & $\begin{array}{l}\text { Loading }>100 \% \text { of } \\
\text { System Emergency }\end{array}$ & Includes new transmission line \\
\hline NEISO & $\begin{array}{l}\text { BEEBE RIVER-WEBSTER } \\
115 \mathrm{kV} \text { TL }\end{array}$ & $\begin{array}{l}\text { Interconnect New } \\
\text { Generation }\end{array}$ & Includes new transmission line \\
\hline NEISO & $\begin{array}{l}\text { WEBSTER-DEERFIELD } 115 \mathrm{kV} \\
\text { TL }\end{array}$ & $\begin{array}{l}\text { Interconnect New } \\
\text { Generation }\end{array}$ & Includes new transmission line \\
\hline NEISO & $\begin{array}{l}\text { Woburn-N. Cambridge } 345 \mathrm{kV} \\
\text { TL }\end{array}$ & $\begin{array}{l}\text { Loading }>100 \% \text { of } \\
\text { System Emergency }\end{array}$ & Includes new transmission line \\
\hline NEISO & $\begin{array}{l}\text { BARNSTABLE-HATCHVILLE } \\
115 \mathrm{kV} \text { TL }\end{array}$ & $\begin{array}{l}\text { Interconnect New } \\
\text { Generation }\end{array}$ & Includes new transmission line \\
\hline NEISO & $\begin{array}{l}\text { BARNSTABLE-HARWICH } \\
\text { MCGR } 115 \mathrm{kV} \text { TL }\end{array}$ & $\begin{array}{l}\text { Interconnect New } \\
\text { Generation }\end{array}$ & Includes new transmission line \\
\hline NEISO & $\begin{array}{l}\text { FALMOUTH TAP-HATCHVILLE } \\
115 \mathrm{kV} \text { TL }\end{array}$ & $\begin{array}{l}\text { Interconnect New } \\
\text { Generation }\end{array}$ & Includes new transmission line \\
\hline NEISO & $\begin{array}{l}\text { WELLFLEET-ORLEANS } 115 \mathrm{kV} \\
\text { TL }\end{array}$ & $\begin{array}{l}\text { Interconnect New } \\
\text { Generation }\end{array}$ & Includes new transmission line \\
\hline NEISO & $\begin{array}{l}\text { HARWICH MCGR-ORLEANS } \\
115 \mathrm{Kv} \text { TL }\end{array}$ & $\begin{array}{l}\text { Interconnect New } \\
\text { Generation }\end{array}$ & Includes new transmission line \\
\hline NEISO & $\begin{array}{l}\text { MILLBURY-MANCHESTER } \\
345 \mathrm{kV} \text { TL }\end{array}$ & $\begin{array}{l}\text { Interconnect New } \\
\text { Generation }\end{array}$ & Includes new transmission line \\
\hline NEISO & Tewksbury-Woburn 345 kV TL & $\begin{array}{l}\text { Loading }>100 \% \text { of } \\
\text { System Emergency }\end{array}$ & Includes new transmission line \\
\hline NEISO & $\begin{array}{l}\text { Ward Hill-Wakefield JCT } 345 \text { kV } \\
\text { TL }\end{array}$ & $\begin{array}{l}\text { Loading }>100 \% \text { of } \\
\text { System Emergency }\end{array}$ & Includes new transmission line \\
\hline NEISO & $\begin{array}{l}\text { KENYON-KENT COUNTY } \\
115 \mathrm{kV} \text { TL }\end{array}$ & $\begin{array}{l}\text { Interconnect New } \\
\text { Generation }\end{array}$ & Includes new transmission line \\
\hline NYISO A-F & Leeds-Pleasant Valley 345 kV & $\begin{array}{l}\text { Loading }>100 \% \text { of } \\
\text { System Emergency }\end{array}$ & New 345 kV line \\
\hline PJM ROM & $\begin{array}{l}\text { Brighton-Kemptown } 500 \text { kV TL } \\
\text { (PATH) }\end{array}$ & $\begin{array}{l}\text { Loading }>100 \% \text { of } \\
\text { System Emergency }\end{array}$ & $\begin{array}{l}\text { Upgrade oper temp facil/reconductor } \\
500 \mathrm{KV} \text { line }\end{array}$ \\
\hline PJM ROM & $\begin{array}{l}\text { Conastone-Kemptown } 500 \text { kV } \\
\text { TL (PATH) }\end{array}$ & $\begin{array}{l}\text { Loading }>100 \% \text { of } \\
\text { System Emergency }\end{array}$ & $\begin{array}{l}\text { Upgrade operating temperature } \\
\text { facil/reconductor } 500 \mathrm{KV} \text { line }\end{array}$ \\
\hline PJM ROM & $\begin{array}{l}\text { North Temple-North Kill } 230 \mathrm{kV} \\
\text { TL (terminal equip. uprate) }\end{array}$ & $\begin{array}{l}\text { Interconnect New } \\
\text { Generation }\end{array}$ & $\begin{array}{l}\text { Upgrade } 230 \mathrm{KV} \text { sub/upgrade } 230 \mathrm{KV} \\
\text { sub }\end{array}$ \\
\hline PJM ROM & $\begin{array}{l}\text { North Temple-Hosensack } \\
230 \mathrm{kV} \text { TL (terminal equip. } \\
\text { uprate) }\end{array}$ & $\begin{array}{l}\text { Interconnect New } \\
\text { Generation }\end{array}$ & $\begin{array}{l}\text { Upgrade } 230 \mathrm{KV} \text { sub/upgrade } 230 \mathrm{KV} \\
\text { sub }\end{array}$ \\
\hline PJM ROR & $\begin{array}{l}\text { Doubs-Kemptown } 500 \text { kV TL } \\
\text { (PATH) }\end{array}$ & $\begin{array}{l}\text { Loading }>100 \% \text { of } \\
\text { System Emergency }\end{array}$ & $\begin{array}{l}\text { Upgrade operating temperature } \\
\text { facil/reconductor } 500 \mathrm{KV} \text { line }\end{array}$ \\
\hline PJM ROR & $\begin{array}{l}\text { Meadow Brook-Welton Springs } \\
500 \mathrm{kV} \text { TL (PATH) }\end{array}$ & $\begin{array}{l}\text { Loading }>100 \% \text { of } \\
\text { System Emergency }\end{array}$ & $\begin{array}{l}\text { Upgrade operating temperature } \\
\text { facil/reconductor } 500 \mathrm{KV} \text { line }\end{array}$ \\
\hline PJM ROR & $\begin{array}{l}\text { Welton Springs-Kemptown } \\
765 \text { kV TL (PATH) }\end{array}$ & $\begin{array}{l}\text { Loading }>100 \% \text { of } \\
\text { System Emergency }\end{array}$ & New $765 \mathrm{KV}$ line/new $765 \mathrm{KV}$ line \\
\hline
\end{tabular}




\begin{tabular}{|c|c|c|c|}
\hline Region & Name & Reason/Need & Description \\
\hline PJM ROR & $\begin{array}{l}\text { Welton Springs-John Amos } \\
765 \text { kV TL (PATH) }\end{array}$ & $\begin{array}{l}\text { Loading }>100 \% \text { of } \\
\text { System Emergency }\end{array}$ & New $765 \mathrm{KV}$ line/new $765 \mathrm{KV}$ line \\
\hline PJM ROR & $\begin{array}{l}\text { Welton Springs-Mt Storm } 500 \text { kV } \\
\text { TL (PATH) }\end{array}$ & $\begin{array}{l}\text { Loading }>100 \% \text { of } \\
\text { System Emergency }\end{array}$ & $\begin{array}{l}\text { Upgrade operating temperature } \\
\text { facil/reconductor } 500 \mathrm{KV} \text { line }\end{array}$ \\
\hline MISO MI & $\begin{array}{l}\text { MCV-Tittabawasee } 345 \text { Ckt } 1 \\
\text { Reconductor }\end{array}$ & $\begin{array}{l}\text { Loading }>100 \% \text { of } \\
\text { System Emergency }\end{array}$ & $\begin{array}{l}\text { Reconductored Transmission Line }+2 \\
\text { Upgraded Bays }\end{array}$ \\
\hline MISO MI & $\begin{array}{l}\text { MCV-Tittabawasee } 345 \text { Ckt } 2 \\
\text { Reconductor }\end{array}$ & $\begin{array}{l}\text { Loading }>100 \% \text { of } \\
\text { System Emergency }\end{array}$ & $\begin{array}{l}\text { Reconductored Transmission Line }+2 \\
\text { Upgraded Bays }\end{array}$ \\
\hline ENT & $\begin{array}{l}\text { New Sportman 345/161 kV third } \\
\text { auto }\end{array}$ & $\begin{array}{l}\text { Loading }>100 \% \text { of } \\
\text { System Emergency }\end{array}$ & Add 345 kV Auto \\
\hline VACAR & Wake-Wommack 500 kV TL & $\begin{array}{l}\text { Interconnect New } \\
\text { Generation }\end{array}$ & $\begin{array}{l}\text { Includes new transmission line, } 1 \text { new } \\
500 \mathrm{kV} \text { substation }\end{array}$ \\
\hline VACAR & $\begin{array}{l}\text { Cumberland-Wommack } 500 \mathrm{kV} \\
\text { TL }\end{array}$ & $\begin{array}{l}\text { Interconnect New } \\
\text { Generation }\end{array}$ & $\begin{array}{l}\text { Includes new transmission line, } 1 \text { new } \\
500 \mathrm{kV} \text { substation }\end{array}$ \\
\hline VACAR & New Bern 500/230 kV XFMR & $\begin{array}{l}\text { Interconnect New } \\
\text { Generation }\end{array}$ & New transformer \\
\hline VACAR & New Bern 500/230 kV XFMR & $\begin{array}{l}\text { Interconnect New } \\
\text { Generation }\end{array}$ & New transformer \\
\hline VACAR & New Bern-Wommack 500 kV TL & $\begin{array}{l}\text { Interconnect New } \\
\text { Generation }\end{array}$ & Includes New Transmission Line \\
\hline VACAR & Antioch 500/230 kV XFMR & $\begin{array}{l}\text { Loading }>100 \% \text { of } \\
\text { System Emergency }\end{array}$ & New transformer \\
\hline VACAR & Antioch 500/230 kV XFMR & $\begin{array}{l}\text { Loading }>100 \% \text { of } \\
\text { System Emergency }\end{array}$ & New transformer \\
\hline $\begin{array}{l}\text { Non-RTO } \\
\text { Midwest }\end{array}$ & $\begin{array}{l}\text { Upgrade Trimble Co to } \\
\text { Middletown } 345 \mathrm{kV}\end{array}$ & $\begin{array}{l}\text { Loading }>100 \% \text { of } \\
\text { System Emergency }\end{array}$ & Upgrade Operating Temperature \\
\hline ENT & $\begin{array}{l}\text { New Lewis Creek to West } \\
\text { Conroe SS } 230 \mathrm{kV}\end{array}$ & $\begin{array}{l}\text { Loading }>100 \% \text { of } \\
\text { System Emergency }\end{array}$ & $\begin{array}{l}\text { Construct new } 230 \mathrm{kV} \text { Line and } \\
230 \mathrm{kV} \text { substation at W. Conroe and } \\
\text { terminal at Lewis Creek }\end{array}$ \\
\hline ENT & $\begin{array}{l}\text { New } 230 / 138 / 13 / 8 \mathrm{kV} \text { three } \\
\text { winding transformer at Conroe } \\
\text { SS }\end{array}$ & $\begin{array}{l}\text { Loading }>100 \% \text { of } \\
\text { System Emergency }\end{array}$ & Add $230 \mathrm{kV}$ Auto \\
\hline ENT & $\begin{array}{l}\text { New West Conroe SS to Grimes } \\
230 \mathrm{kV}\end{array}$ & $\begin{array}{l}\text { Loading }>100 \% \text { of } \\
\text { System Emergency }\end{array}$ & $\begin{array}{l}\text { Construct new } 230 \mathrm{kV} \text { Line and } \\
230 \mathrm{kV} \text { substation at Grimes }\end{array}$ \\
\hline ENT & $\begin{array}{l}\text { Upgrade West Conroe SS to } \\
\text { Conroe } 138 \mathrm{kV}\end{array}$ & $\begin{array}{l}\text { Loading }>100 \% \text { of } \\
\text { System Emergency }\end{array}$ & Upgrade 138 kV line \\
\hline ENT & New $345 / 230 \mathrm{kV}$ auto at Grimes & $\begin{array}{l}\text { Loading }>100 \% \text { of } \\
\text { System Emergency }\end{array}$ & Add $345 \mathrm{kV}$ Auto \\
\hline ENT & New Addis to Tiger $230 \mathrm{kV}$ Ckt 2 & $\begin{array}{l}\text { Loading }>100 \% \text { of } \\
\text { System Emergency }\end{array}$ & $\begin{array}{l}\text { Construct new } 230 \mathrm{kV} \text { line and add } \\
\text { terminals at Addis and Tiger }\end{array}$ \\
\hline ENT & $\begin{array}{l}\text { Construct second Dowmeter to } \\
\text { Air Liquide Tap } 230 \mathrm{kV}\end{array}$ & $\begin{array}{l}\text { Loading }>100 \% \text { of } \\
\text { System Emergency }\end{array}$ & $\begin{array}{l}\text { Construct new } 230 \mathrm{kV} \text { line and add } \\
\text { terminals at Dowmeter }\end{array}$ \\
\hline ENT & $\begin{array}{l}\text { Upgrade Air Liquide Tap to } \\
\text { Chenango } 230 \mathrm{kV}\end{array}$ & $\begin{array}{l}\text { Loading }>100 \% \text { of } \\
\text { System Emergency }\end{array}$ & Upgrade 230 kV line \\
\hline ENT & $\begin{array}{l}\text { Upgrade Chenango to Iberville } \\
230 \mathrm{kV} \text { line }\end{array}$ & $\begin{array}{l}\text { Loading }>100 \% \text { of } \\
\text { System Emergency }\end{array}$ & Upgrade 230 kV line \\
\hline ENT & $\begin{array}{l}\text { Upgrade Iberville to Evergreen } \\
230 \mathrm{kV} \text { line }\end{array}$ & $\begin{array}{l}\text { Loading }>100 \% \text { of } \\
\text { System Emergency }\end{array}$ & Upgrade 230 kV line \\
\hline MISO IN & $\begin{array}{l}\text { 7WILSON 345-7REID } 345 \\
\text { Reconductor }\end{array}$ & $\begin{array}{l}\text { Loading }>100 \% \text { of } \\
\text { System Emergency }\end{array}$ & $\begin{array}{l}\text { Reconductored Transmission Line }+2 \\
\text { Upgraded Bays }\end{array}$ \\
\hline SOCO & $\begin{array}{l}\text { McGrau Ford-Hopewell } 230 \text { kV } \\
\text { TL }\end{array}$ & $\begin{array}{l}\text { Loading }>100 \% \text { of } \\
\text { System Emergency }\end{array}$ & $\begin{array}{l}\text { 230kV Transmission Line, 230kV Bay } \\
\text { @ McGrau Ford \& Hopewell }\end{array}$ \\
\hline SOCO & Hopewell 230 kV/115 kV TL & $\begin{array}{l}\text { Loading }>100 \% \text { of } \\
\text { System Emergency }\end{array}$ & $230 \mathrm{kV} / 115 \mathrm{kV}$ XFMR \\
\hline SOCO & Hopewell-Milton 230 kV TL & $\begin{array}{l}\text { Loading }>100 \% \text { of } \\
\text { System Emergency }\end{array}$ & 230 kV Transmission Line \\
\hline FRCC & Re-conductor CURRY FD 230.00 & Loading $>100 \%$ of & Replace conductors \\
\hline
\end{tabular}




\begin{tabular}{|c|c|c|c|}
\hline Region & Name & Reason/Need & Description \\
\hline & to STANTONW 230.00 & System Normal & \\
\hline FRCC & $\begin{array}{l}\text { Re-conductor SO WOOD } 230.00 \\
\text { to C CENTER } 230.00\end{array}$ & $\begin{array}{l}\text { Loading }>100 \% \text { of } \\
\text { System Normal }\end{array}$ & Replace conductors \\
\hline FRCC & $\begin{array}{l}\text { Re-conductor TAFT } 230.00 \text { to C } \\
\text { CENTER } 230.00\end{array}$ & $\begin{array}{l}\text { Loading }>100 \% \text { of } \\
\text { System Normal }\end{array}$ & Replace conductors \\
\hline MISO W & Brookings County-Big Stone 345 & $\begin{array}{l}\text { Interconnect New } \\
\text { Generation }\end{array}$ & New Transmission Line +2 Bays \\
\hline MAPP CA & MYSLKRD-DUNLOP 230 kV TL & $\begin{array}{l}\text { Loading }>100 \% \text { of } \\
\text { System Emergency }\end{array}$ & Line, two $230 \mathrm{kV}$ bays, \\
\hline MAPP CA & DUNLOP-PONTON 230 kV TL & $\begin{array}{l}\text { Loading }>100 \% \text { of } \\
\text { System Emergency }\end{array}$ & Line, two $230 \mathrm{kV}$ bays, \\
\hline MAPP CA & RIEL 500/230 kV XFMR & $\begin{array}{l}\text { Loading }>100 \% \text { of } \\
\text { System Emergency }\end{array}$ & $\begin{array}{l}\text { One } 500 \mathrm{kV} \text { transformer, one } 500 \mathrm{kV} \\
\text { bay }\end{array}$ \\
\hline MISO WUMS & $\begin{array}{l}\text { Oak Creek-Elm Rd 230-345 kV } \\
\text { T884 XFMR Replacement }\end{array}$ & $\begin{array}{l}\text { Loading }>100 \% \text { of } \\
\text { System Emergency }\end{array}$ & Includes 1 new 345kV/230kV XFMR \\
\hline
\end{tabular}


APPENDIX C. NATIONAL VERSUS REGIONAL FUTURE REGION-SPECIFIC RESULTS 



\section{CARBON DIOXIDE PRICE FUTURES}

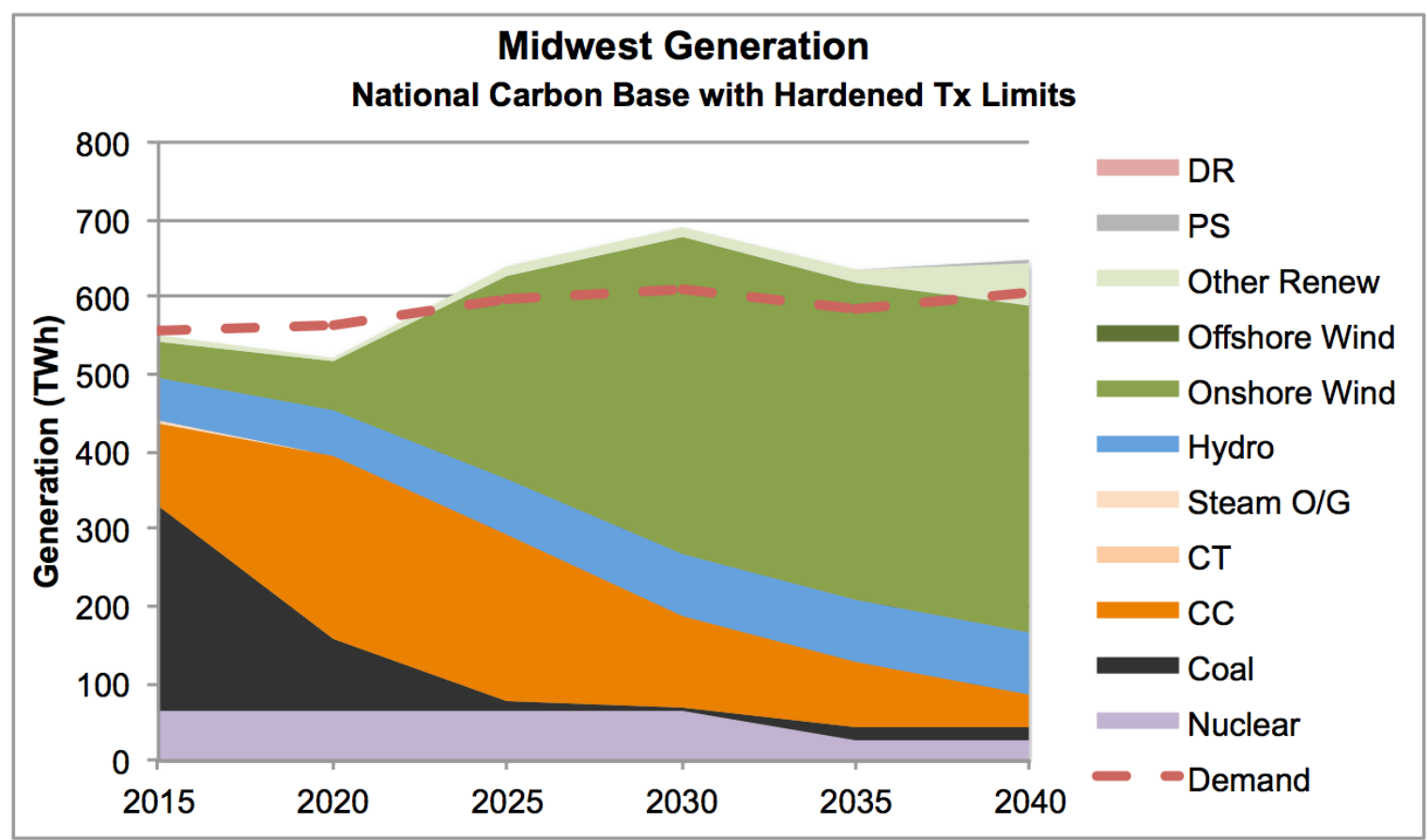

Fig. C-1. Midwest generation over study period in the $\mathrm{CO}_{2} / \mathrm{N}$ future

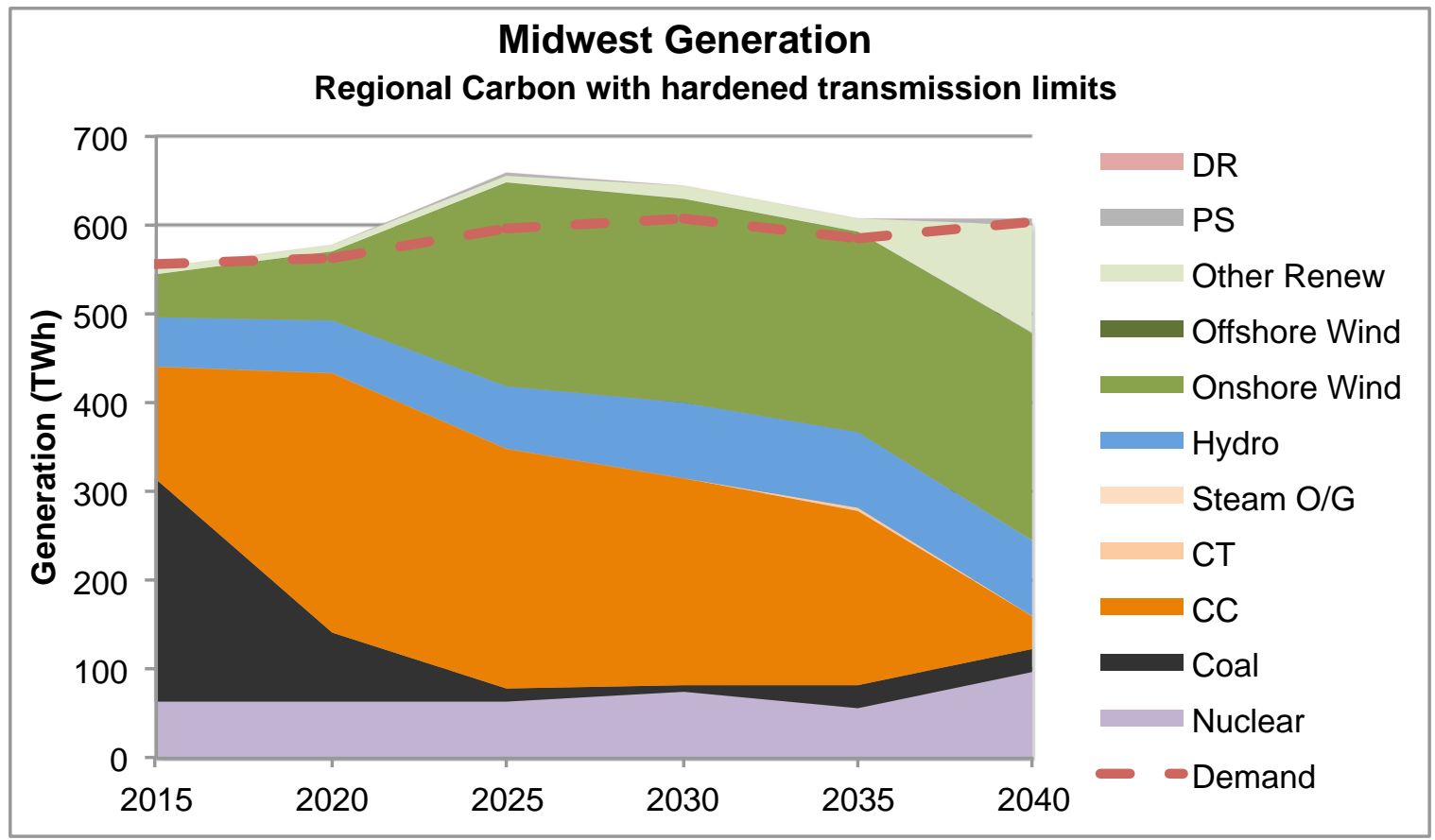

Fig. C-2. Midwest generation over study period in the $\mathrm{CO}_{2} / \mathrm{R}$ future 


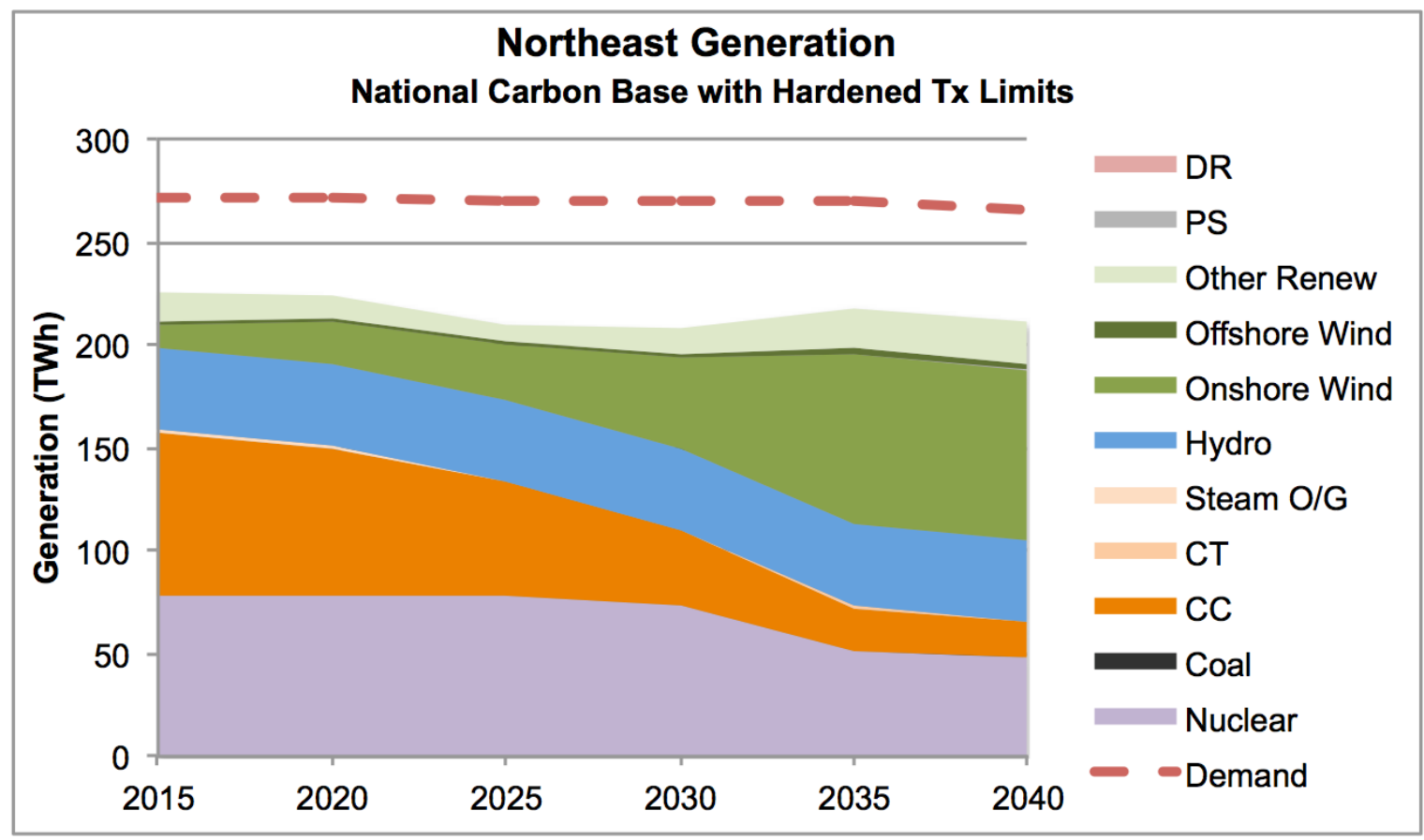

Fig. C-3. Northeast generation over study period in the $\mathrm{CO}_{2} / \mathrm{N}$ future

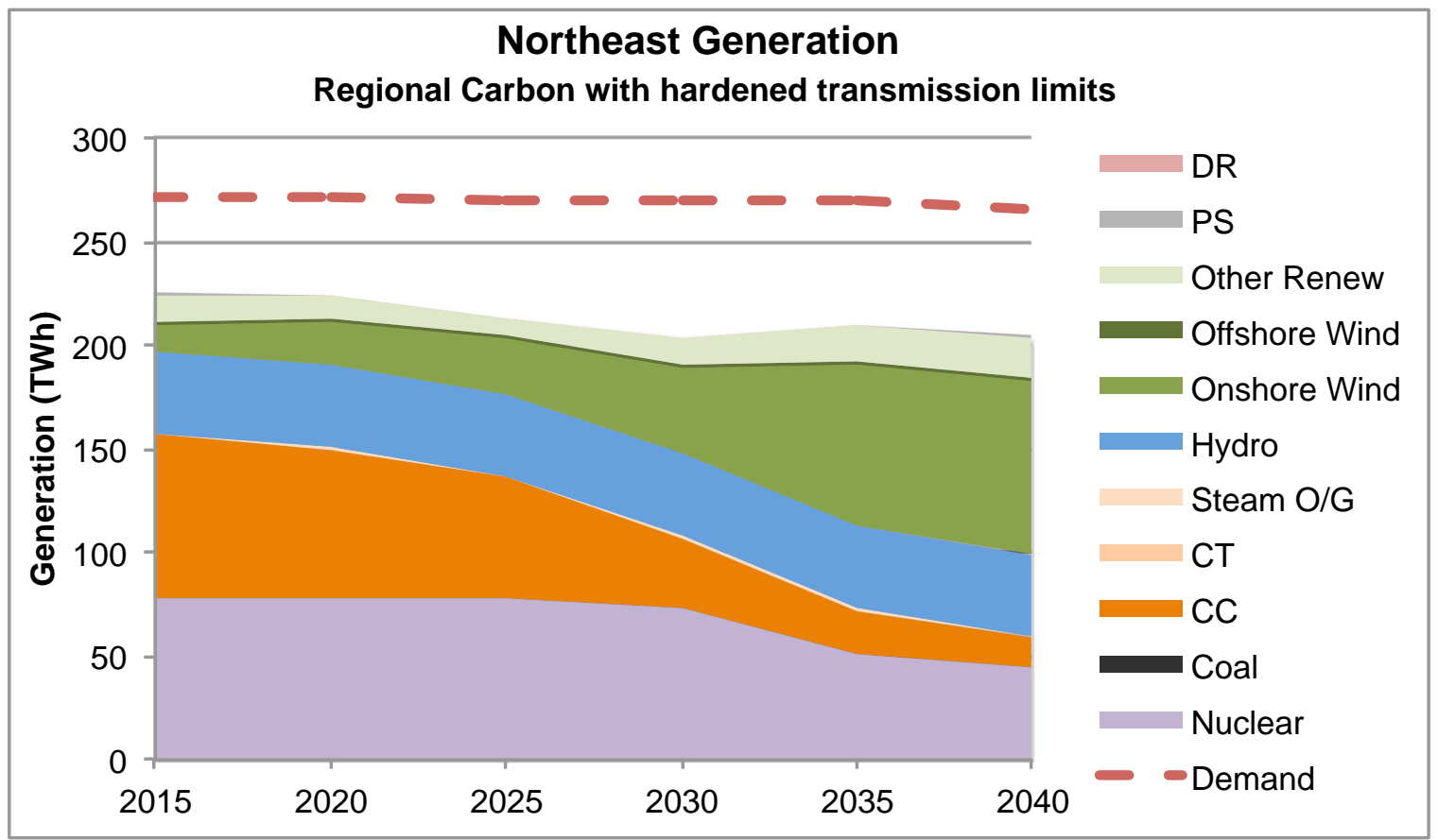

Fig. C-4. Northeast generation over study period in the $\mathrm{CO}_{2} / \mathrm{R}$ future 


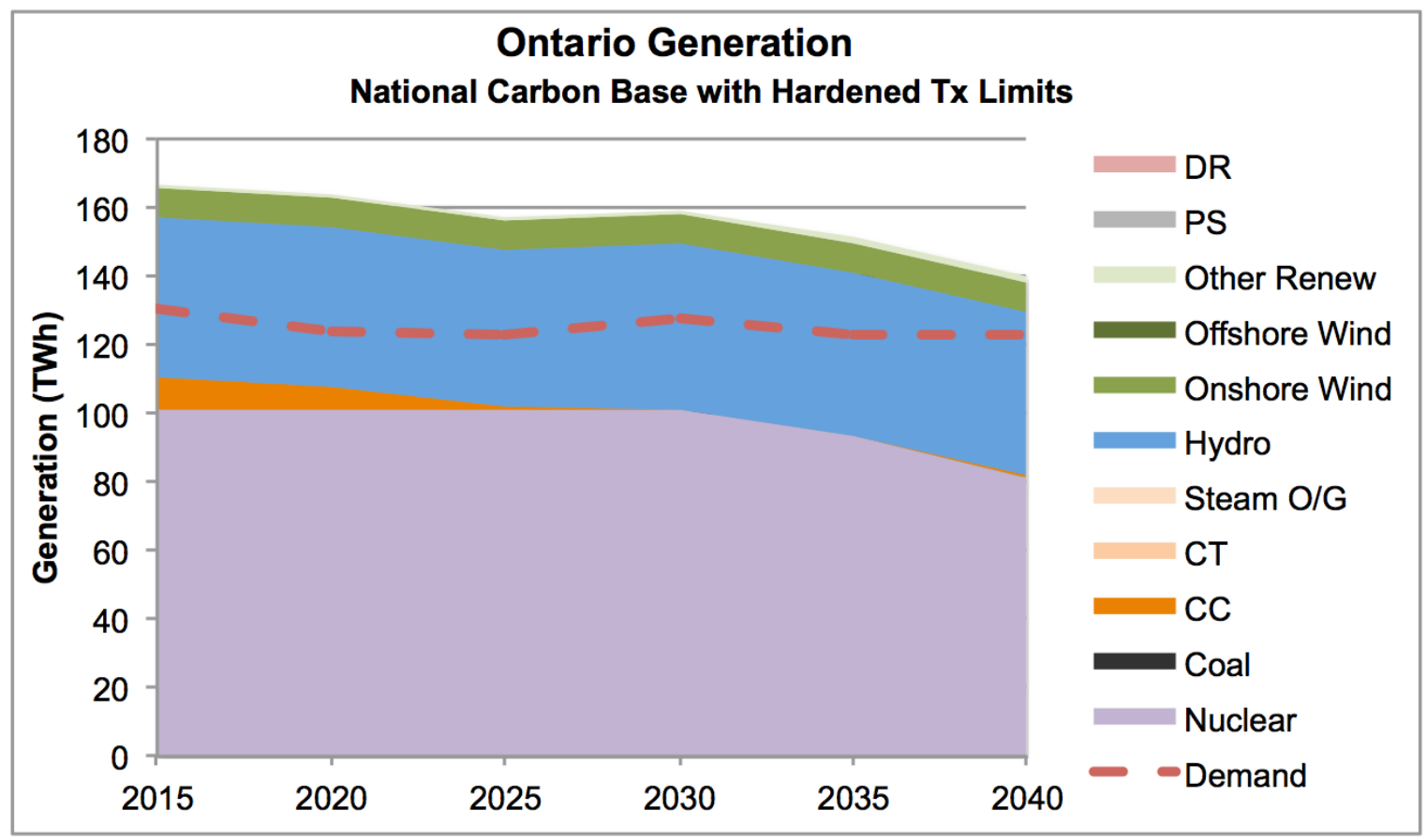

Fig. C-5. Ontario generation over study period in the $\mathrm{CO}_{2} / \mathrm{N}$ future

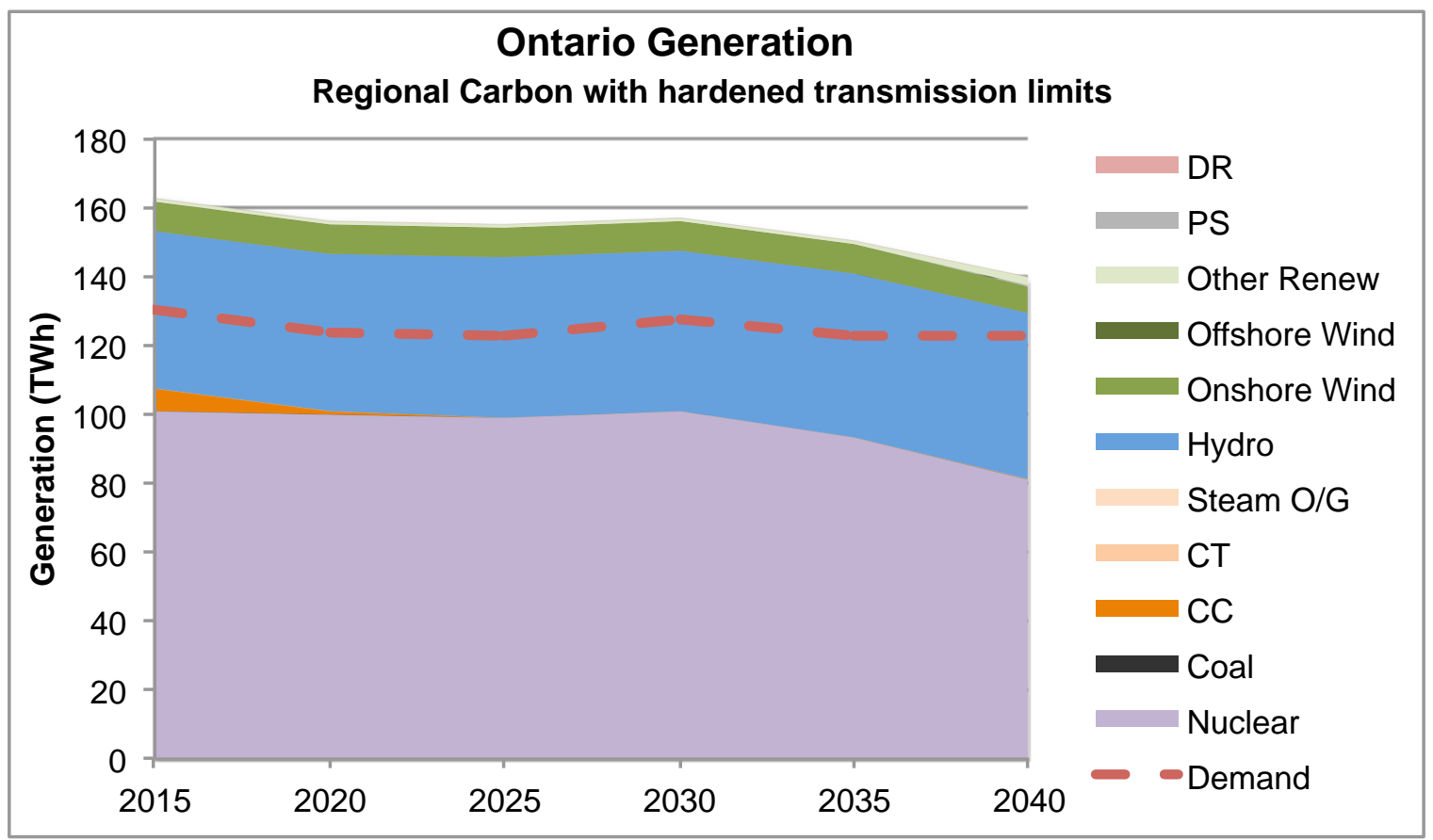

Fig. C-6. Ontario generation over study period in the $\mathrm{CO}_{2} / \mathrm{R}$ future 


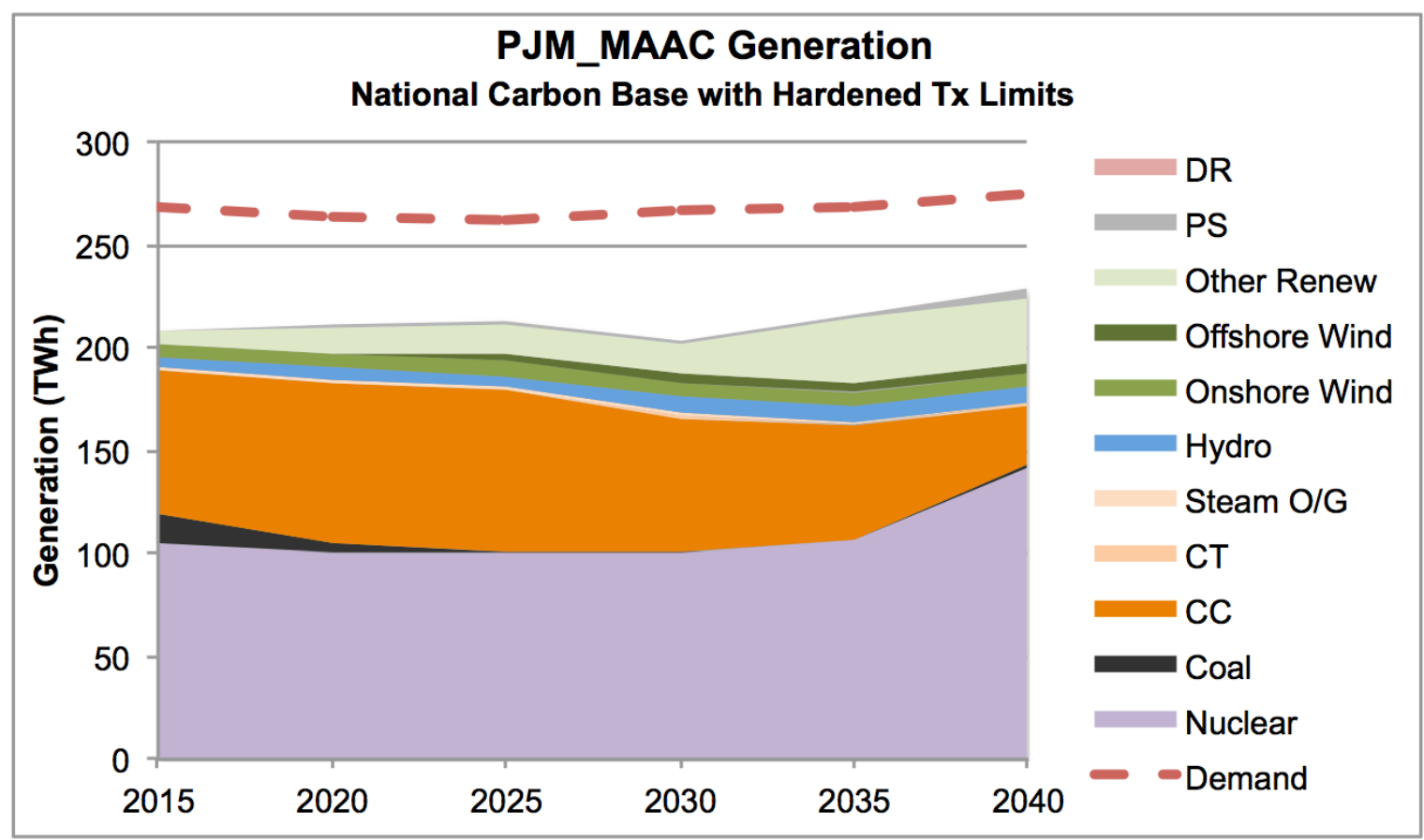

Fig. C-7. PJM MAAC generation over study period in the $\mathrm{CO}_{2} / \mathrm{N}$ future

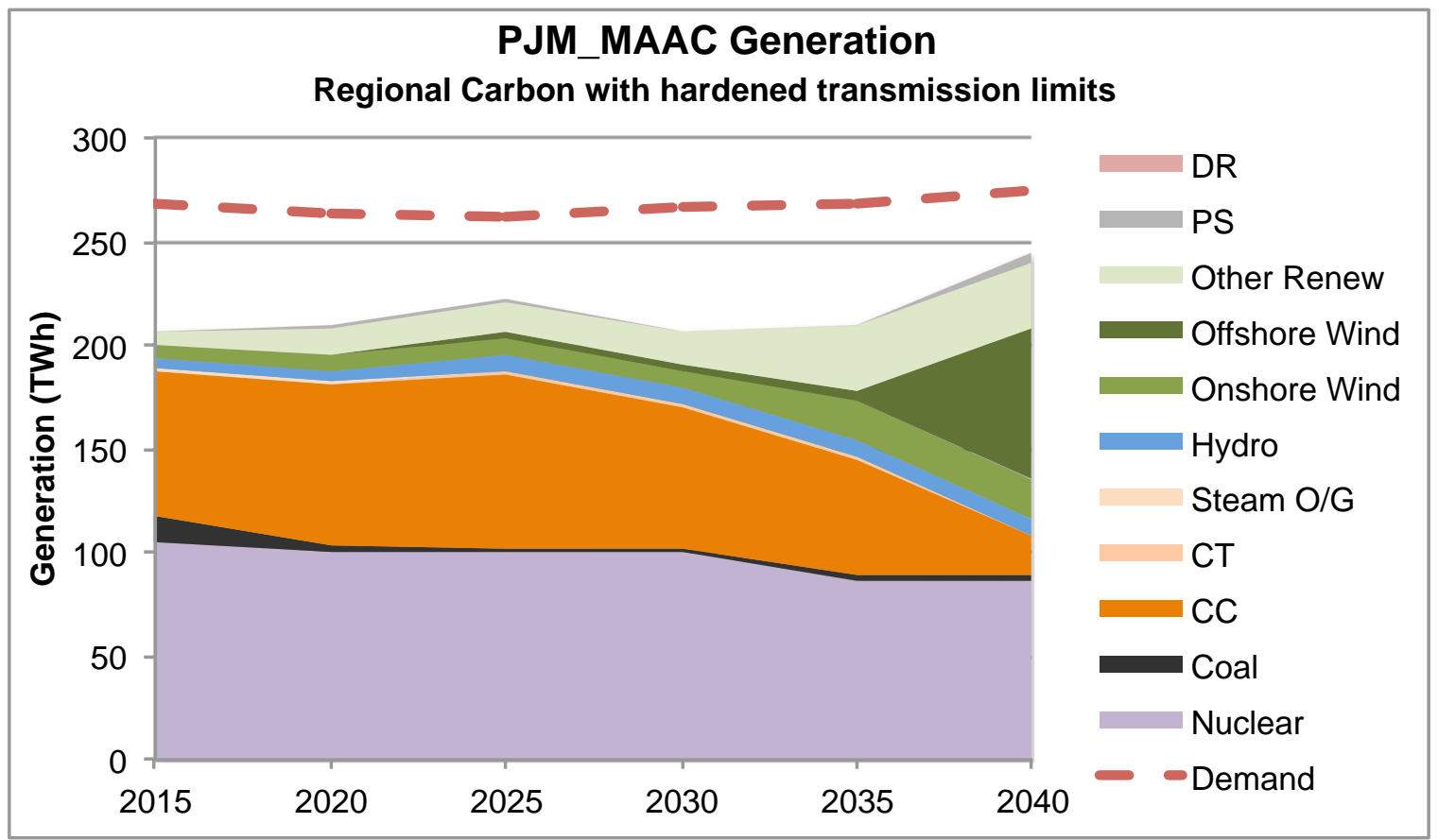

Fig. C-8. PJM MAAC generation over study period in the $\mathrm{CO}_{2} / \mathrm{R}$ future 


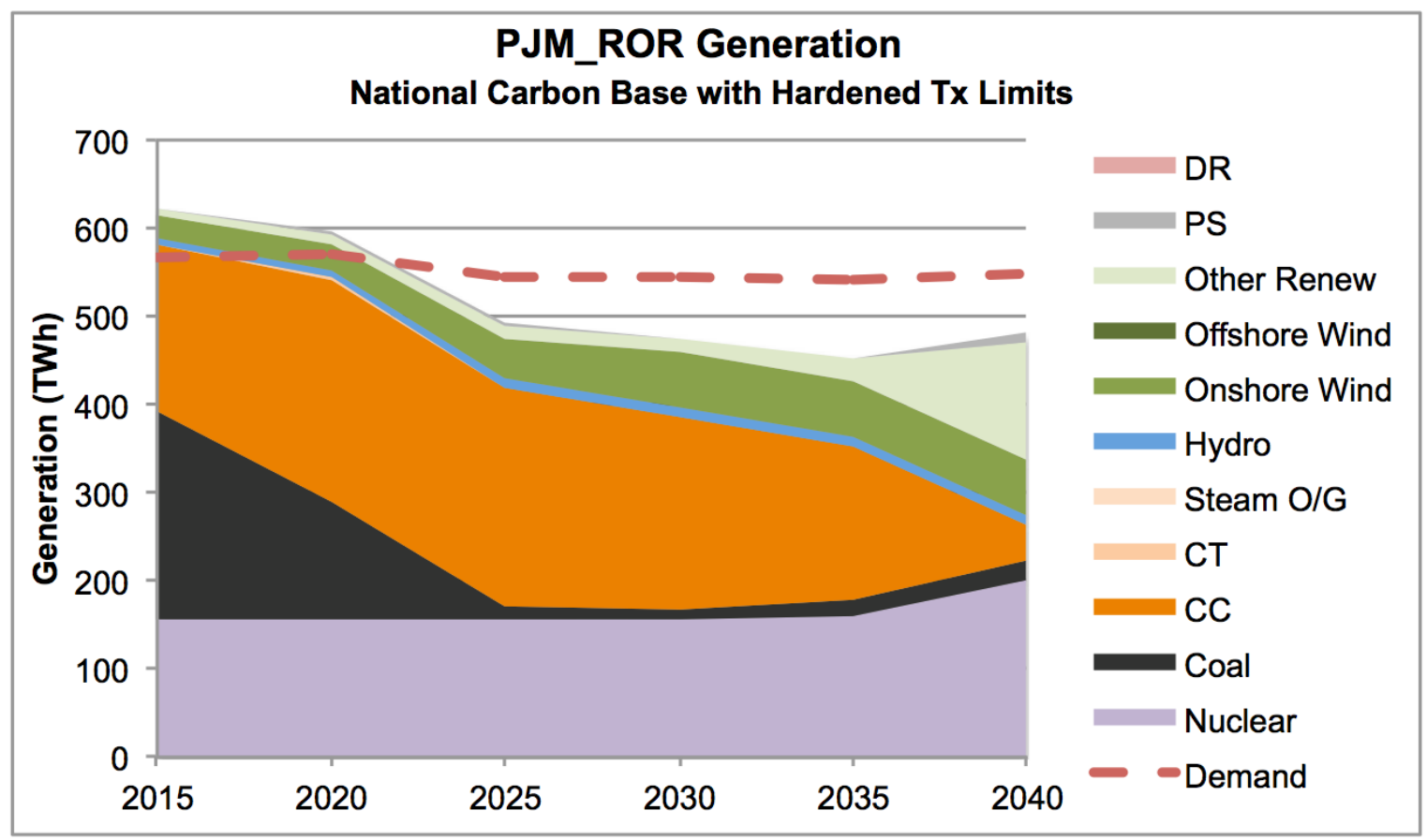

Fig. C-9. PJM ROR generation over study period in the $\mathrm{CO}_{2} / \mathrm{N}$ future

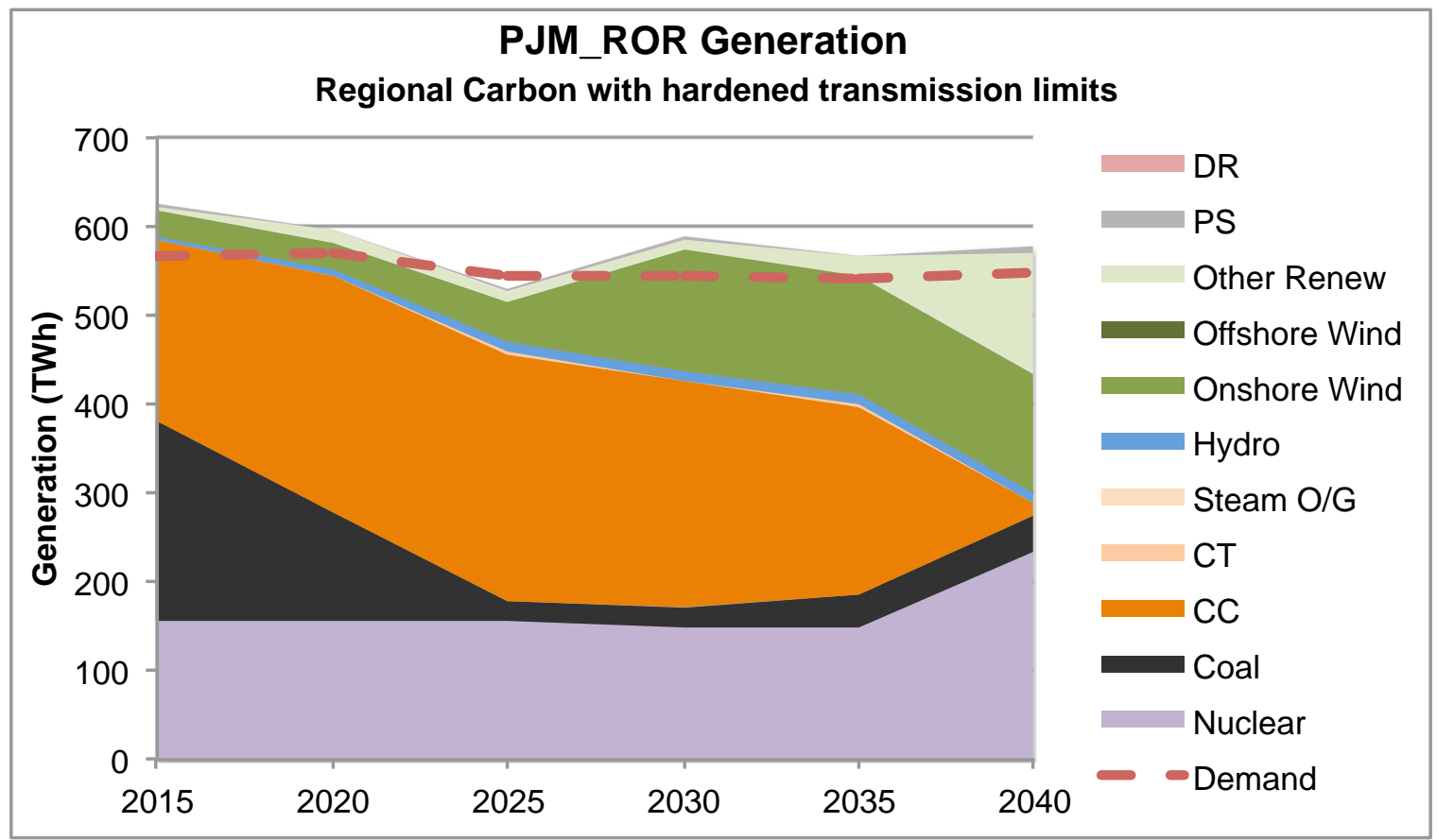

Fig. C-10. PJM ROR generation over study period in the $\mathrm{CO}_{2} / \mathrm{R}$ future 


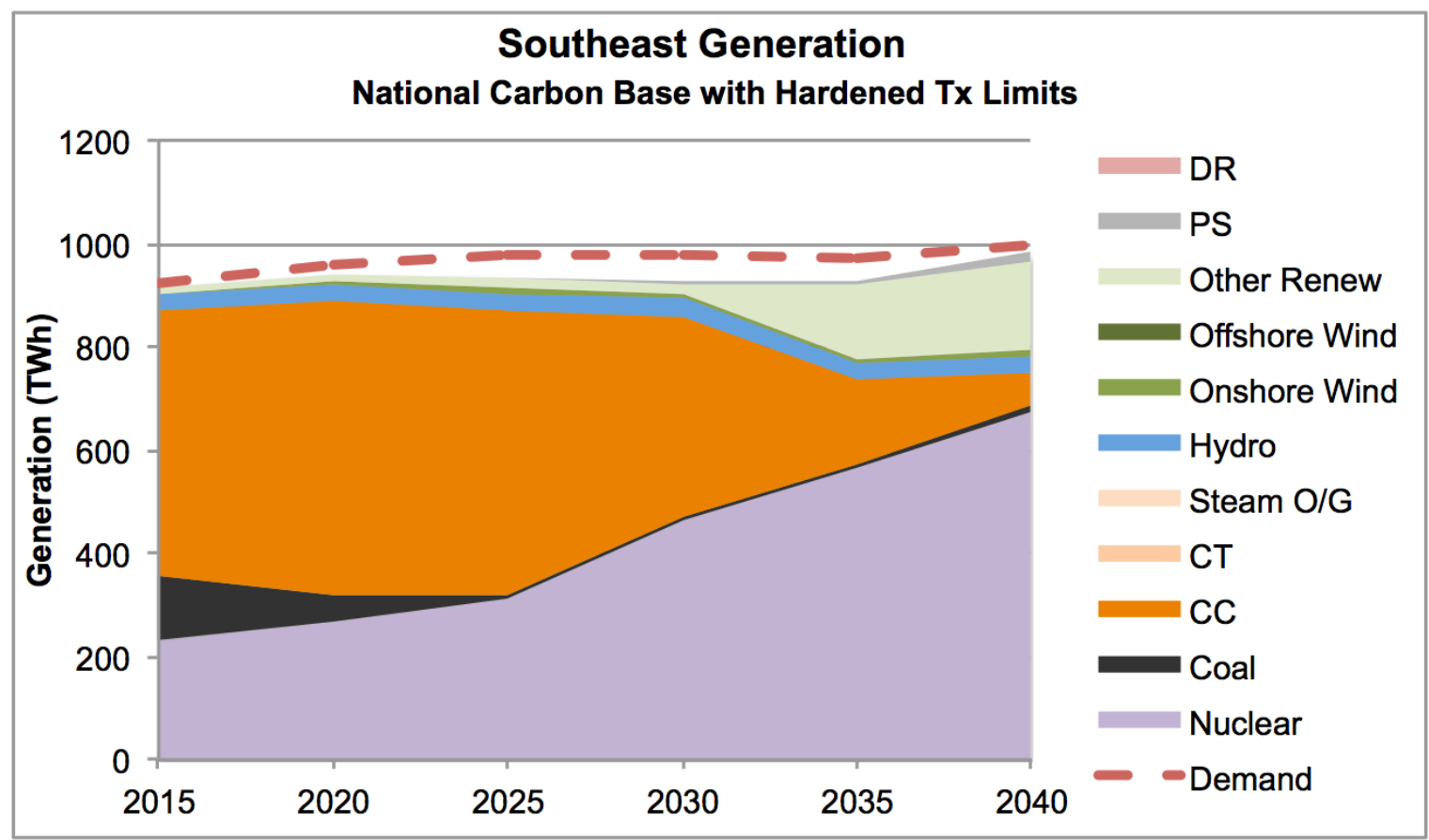

Fig. C-11. Southeast generation over study period in the $\mathrm{CO}_{2} / \mathrm{N}$ future

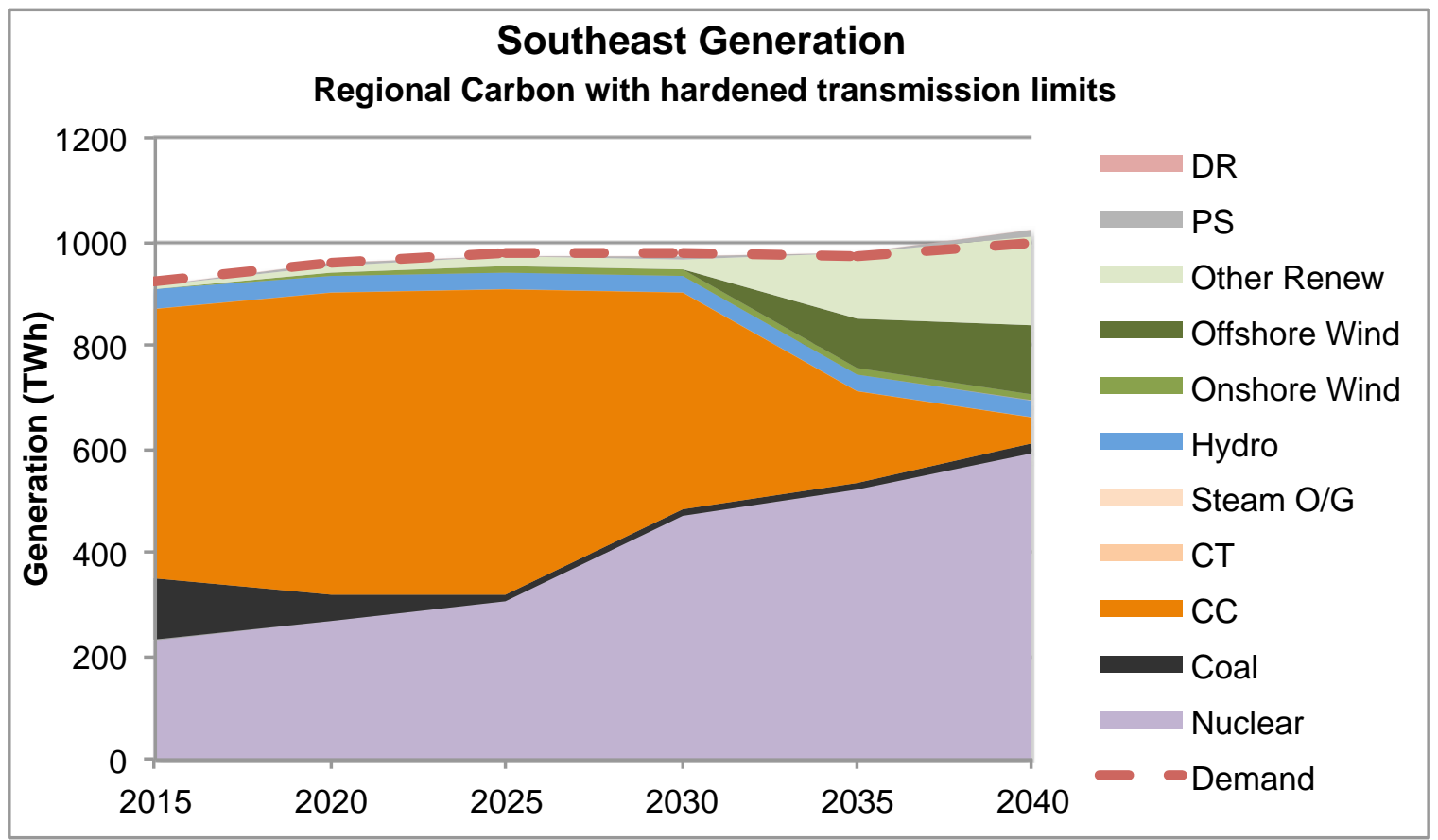

Fig. C-12. Southeast generation over study period in the $\mathrm{CO}_{2} / \mathrm{R}$ future 


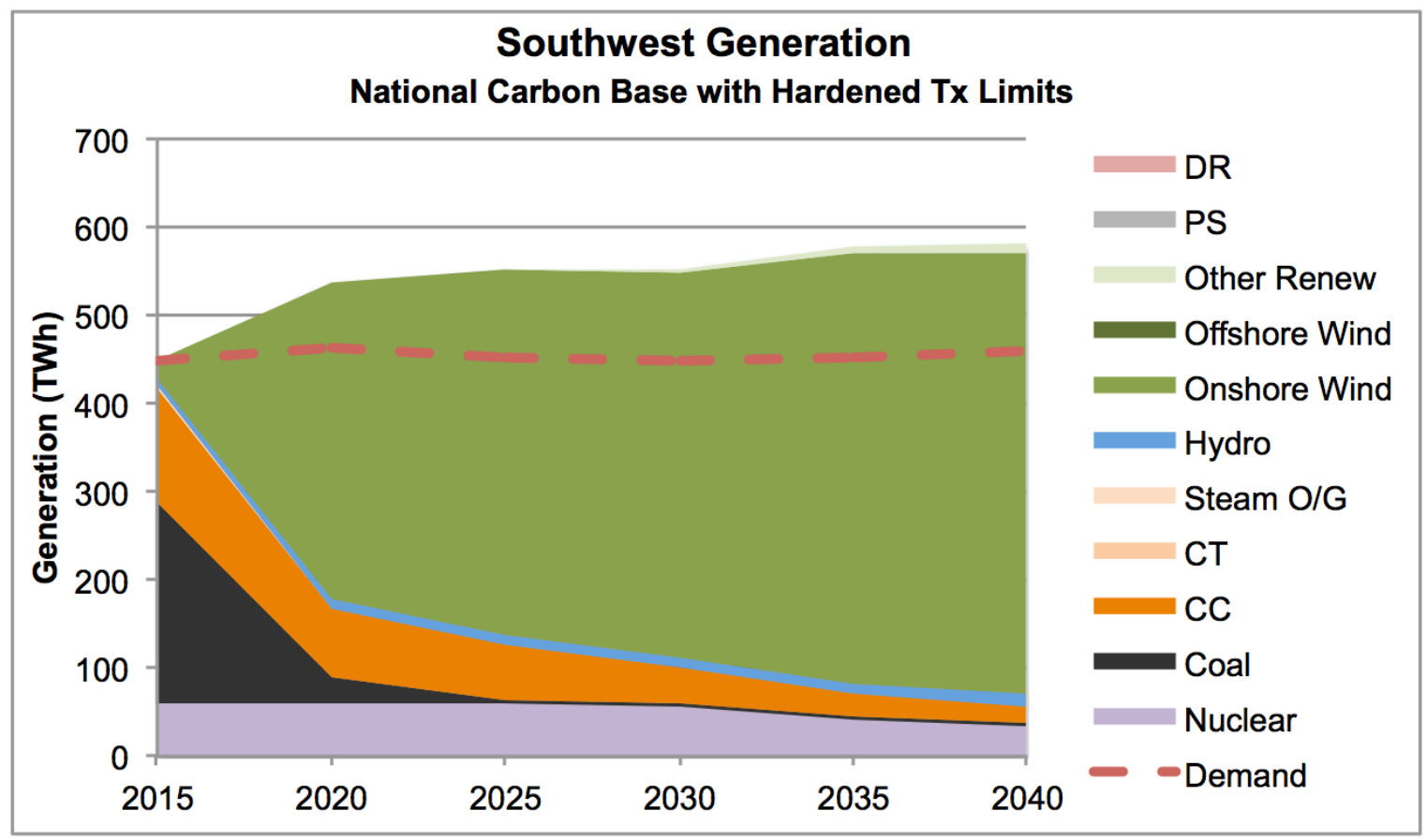

Fig. C-13. Southwest generation over study period in the $\mathrm{CO}_{2} / \mathrm{N}$ future

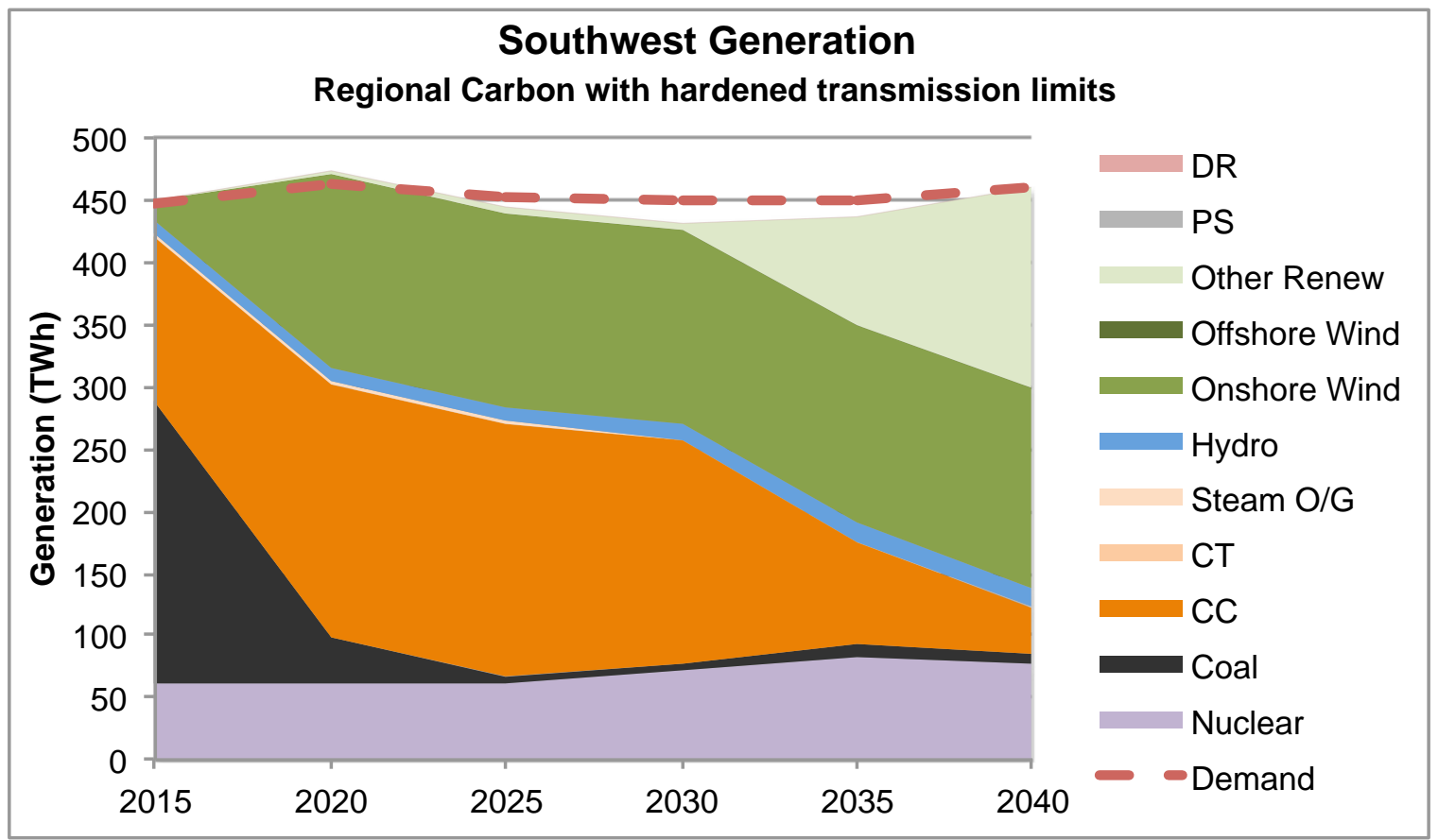

Fig. C-14. Southwest generation over study period in the $\mathrm{CO}_{2} / \mathrm{R}$ future 
RENEWABLE PORTFOLIO STANDARD (RPS) FUTURES

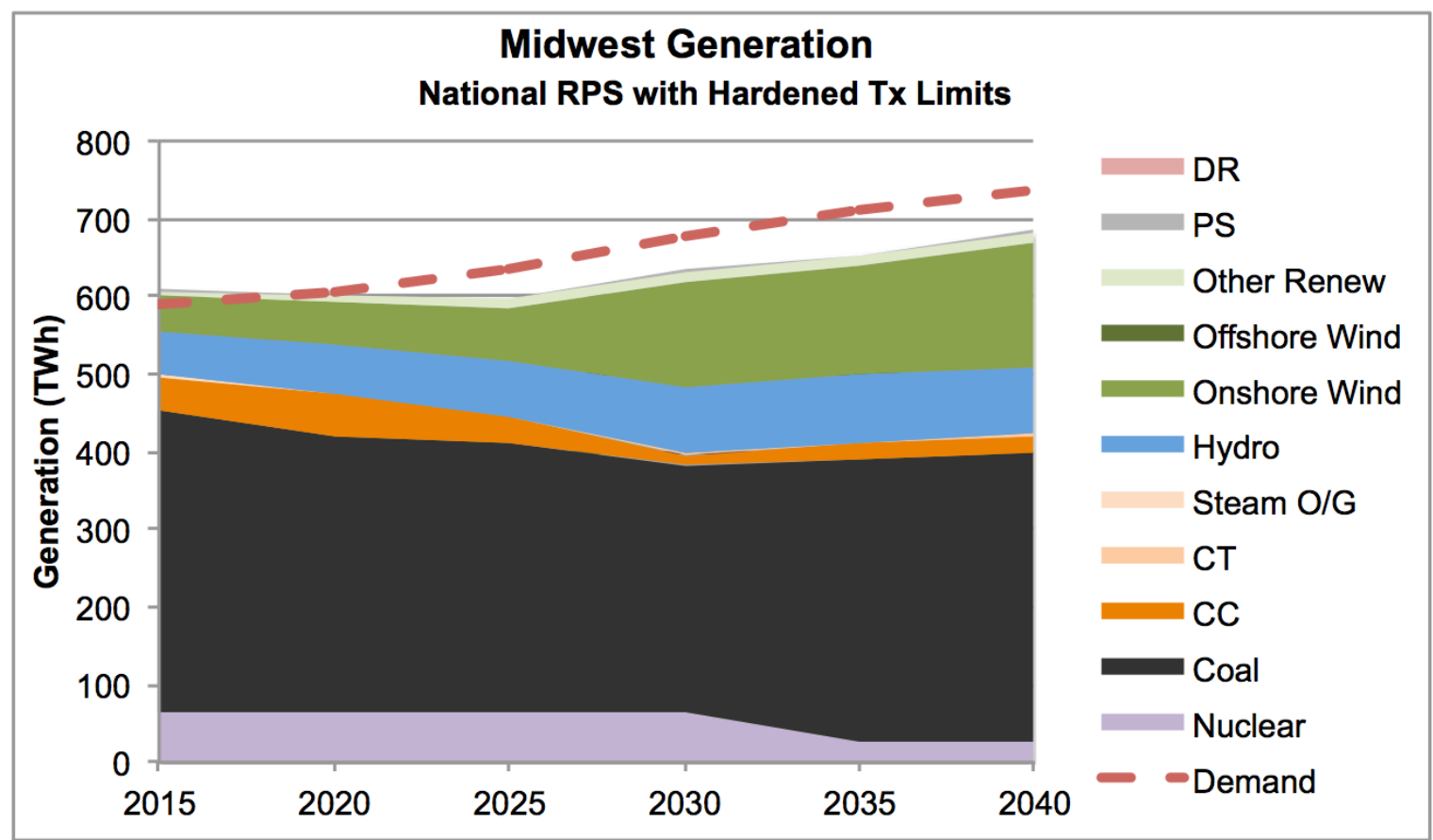

Fig. C-15. Midwest generation over study period in the RPS/N future

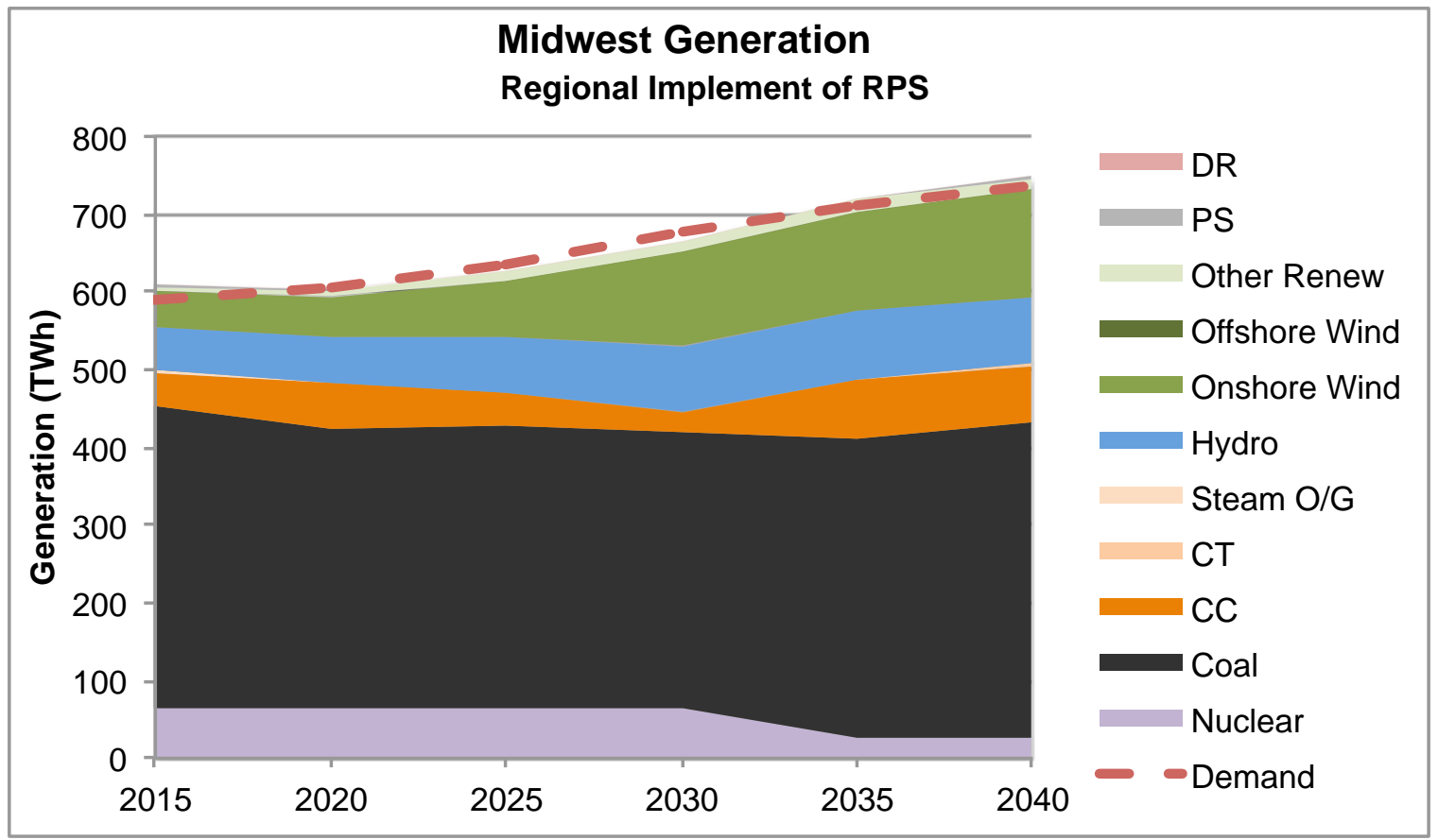

Fig. C-16. Midwest generation over study period in the RPS/R future 


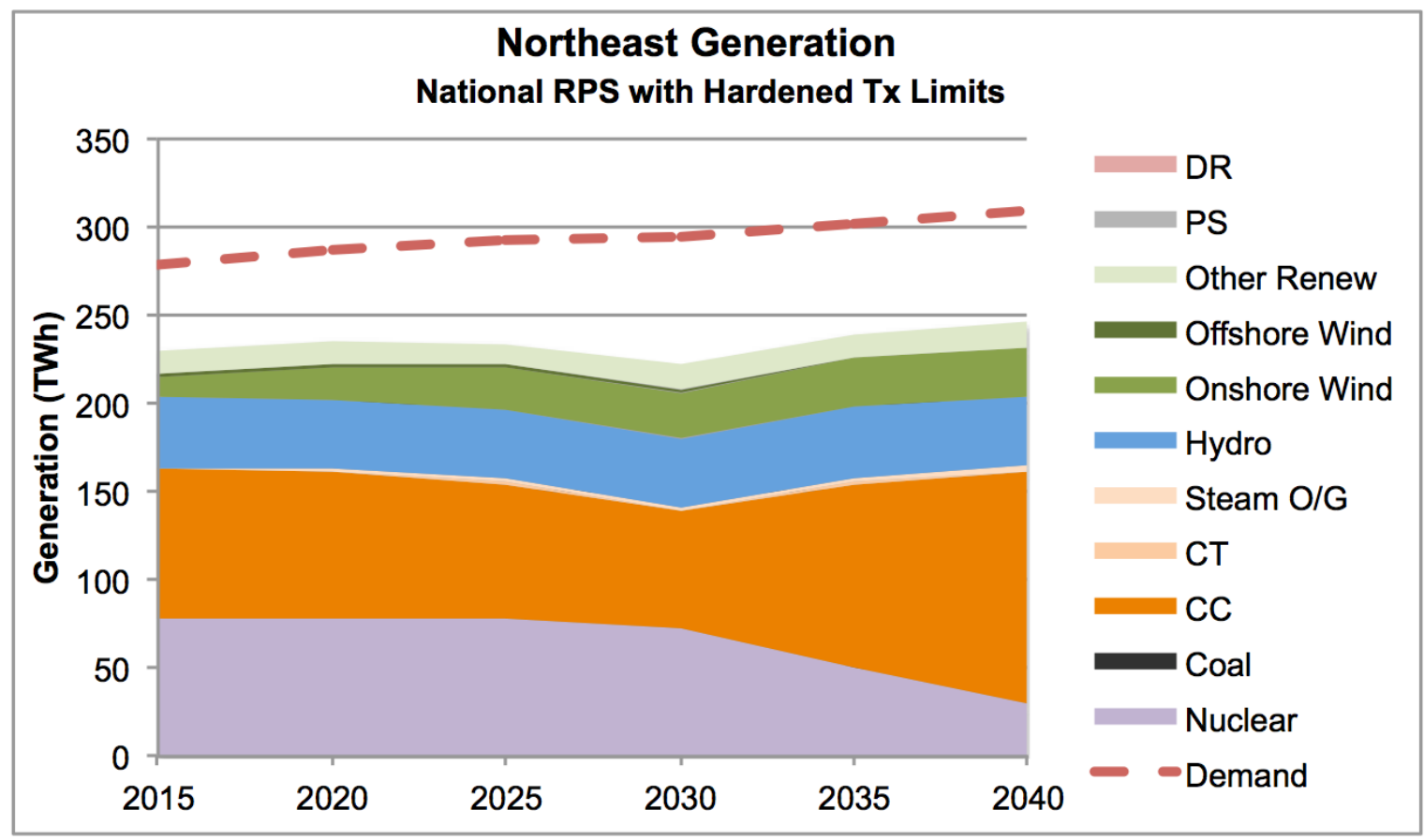

Fig. C-17. Northeast generation over study period in the RPS/N future

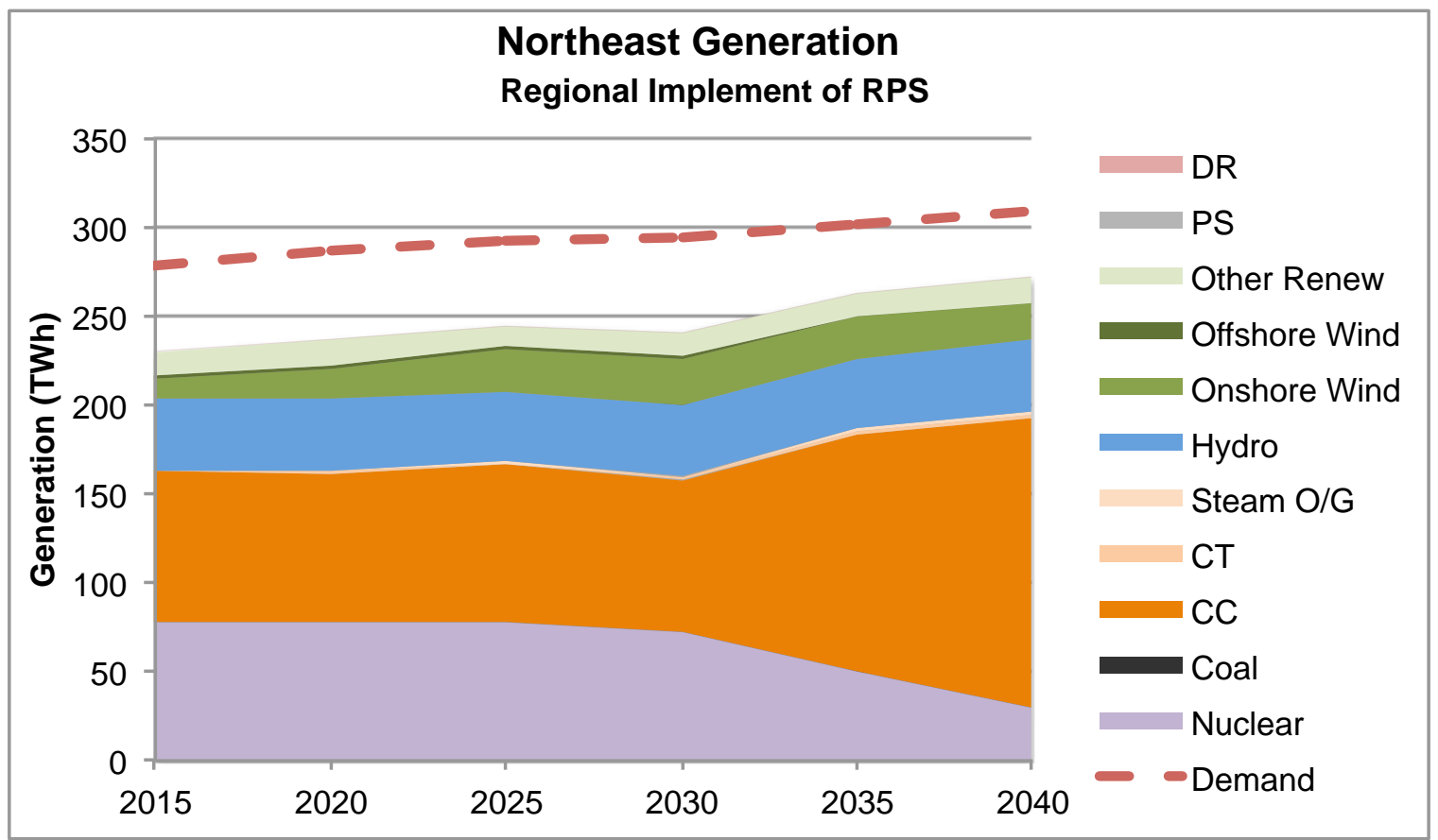

Fig. C-18. Northeast generation over study period in the RPS/R future 


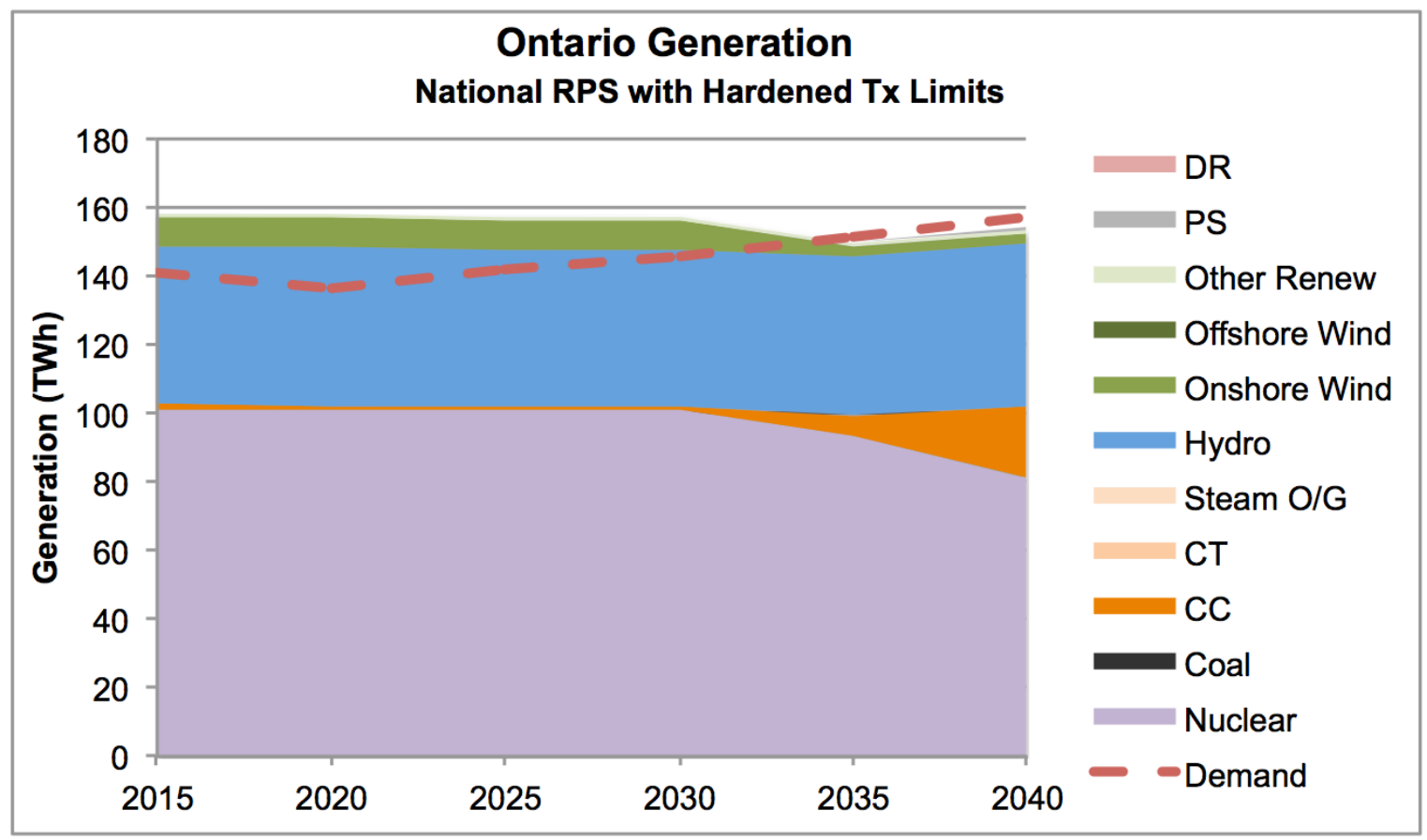

Fig. C-19. Ontario generation over study period in the RPS/N future

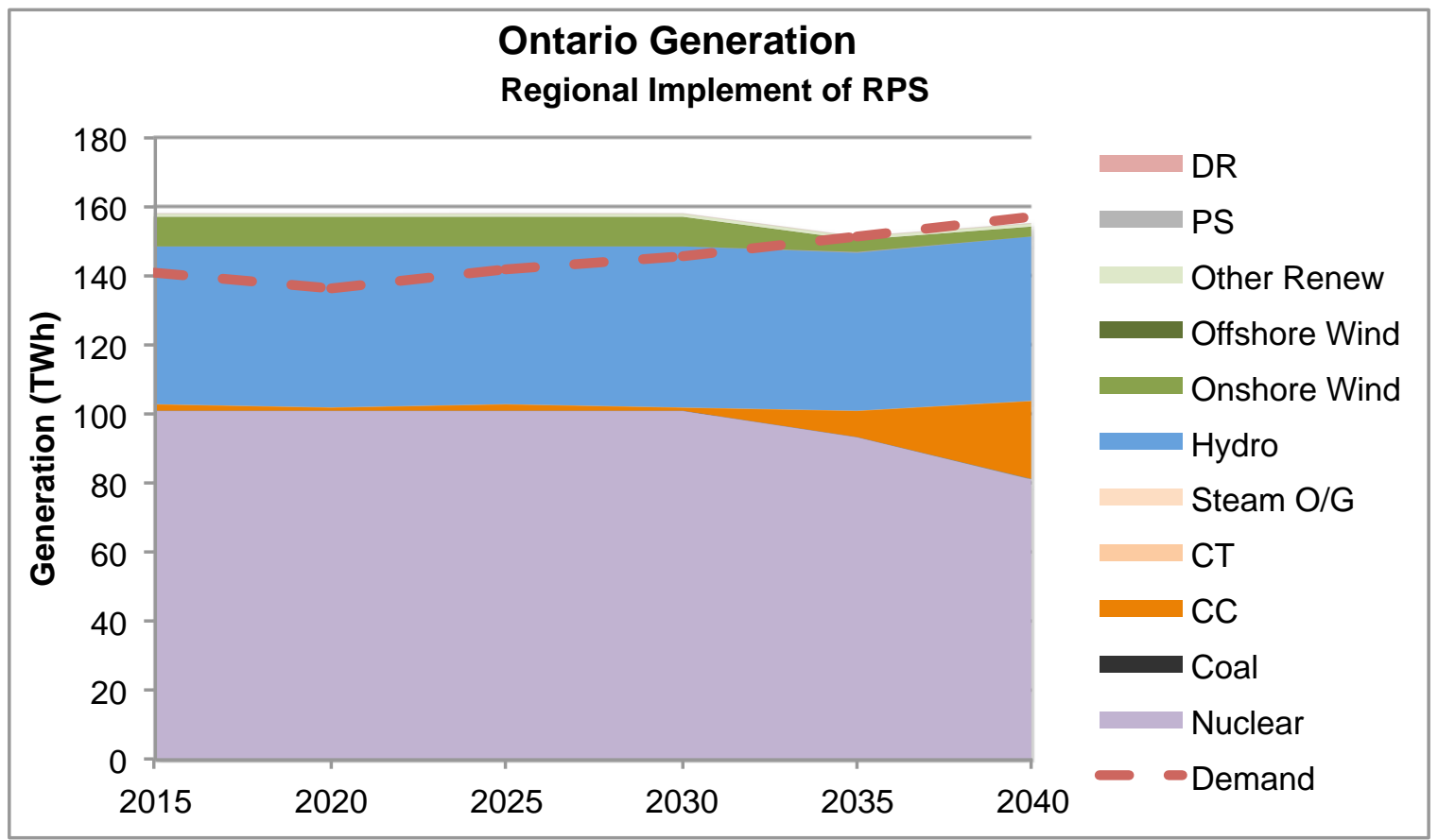

Fig. C-20. Ontario generation over study period in the RPS/R future 


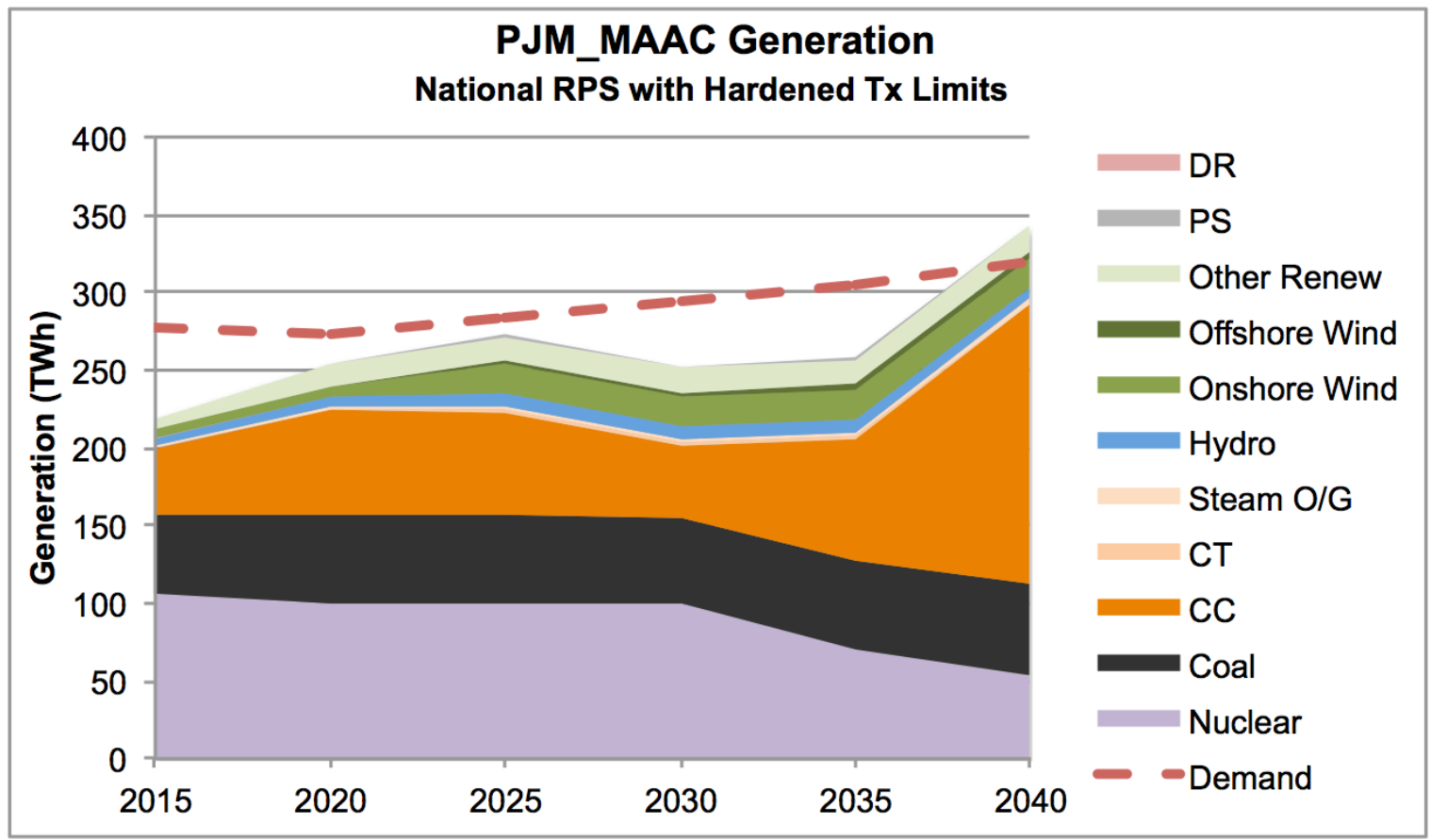

Fig. C-21. PJM MAAC generation over study period in the RPS/N future

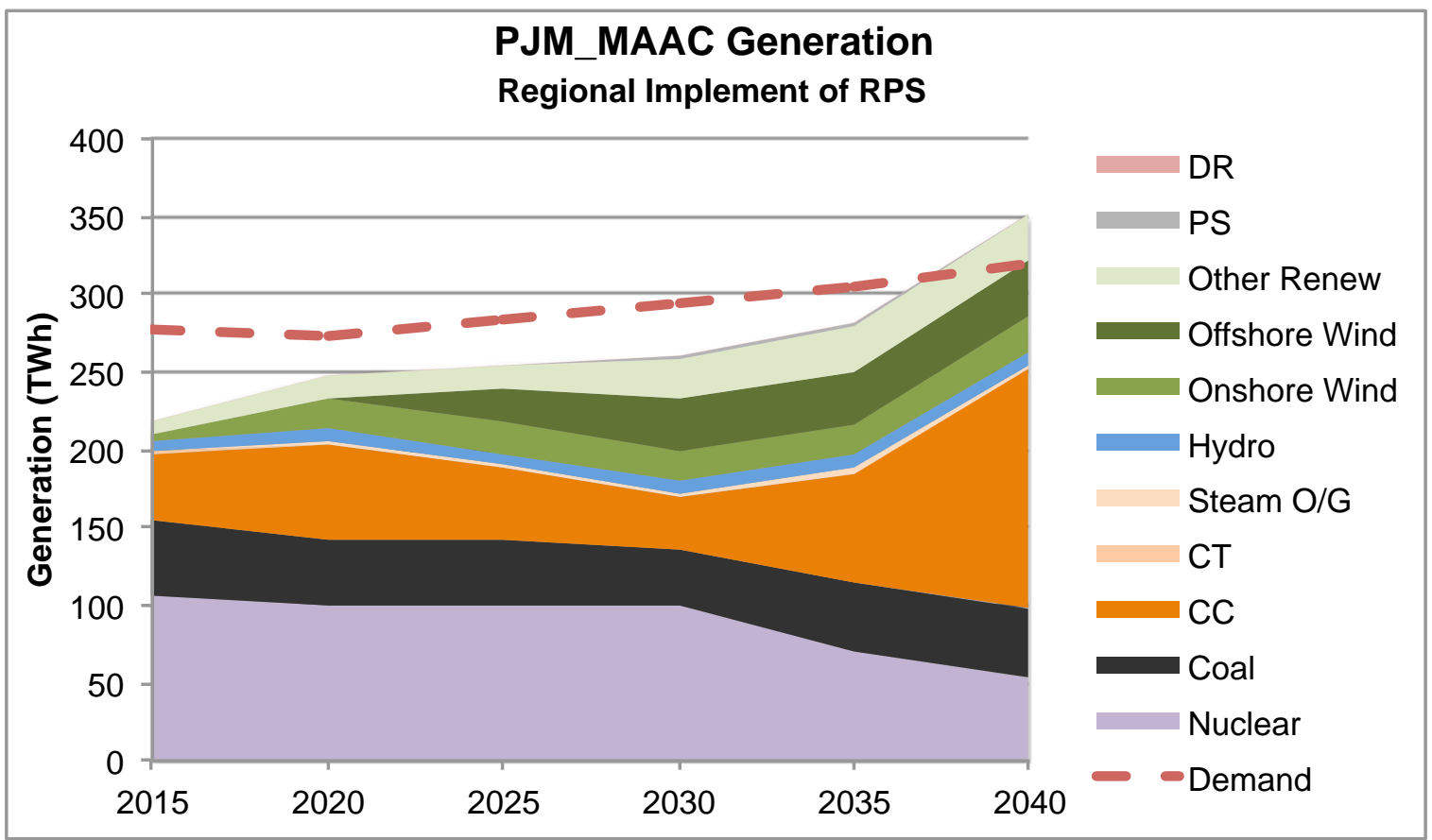

Fig. C-22. PJM MAAC generation over study period in the RPS/R future 


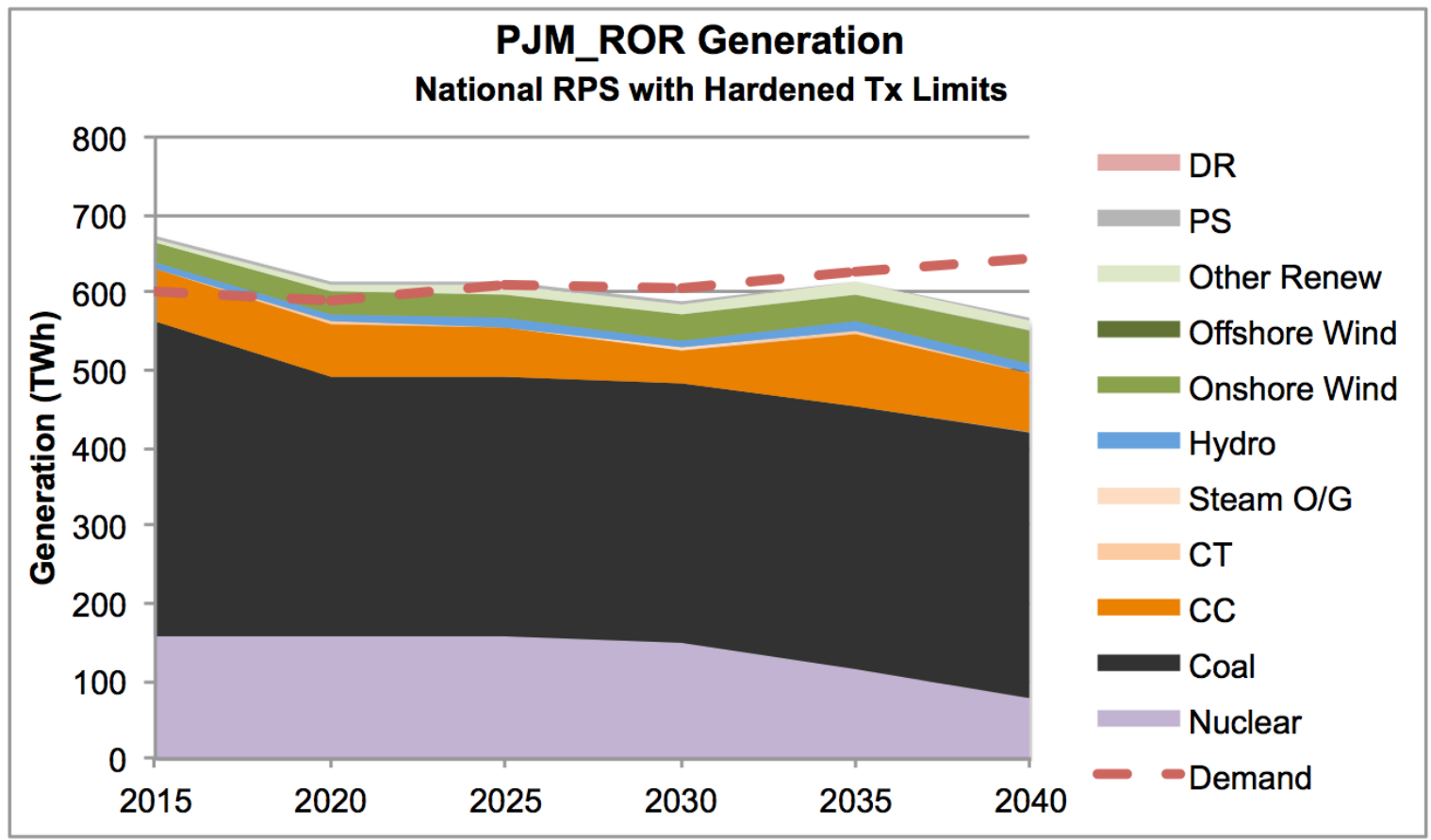

Fig. C-23. PJM ROR generation over study period in the RPS/N future

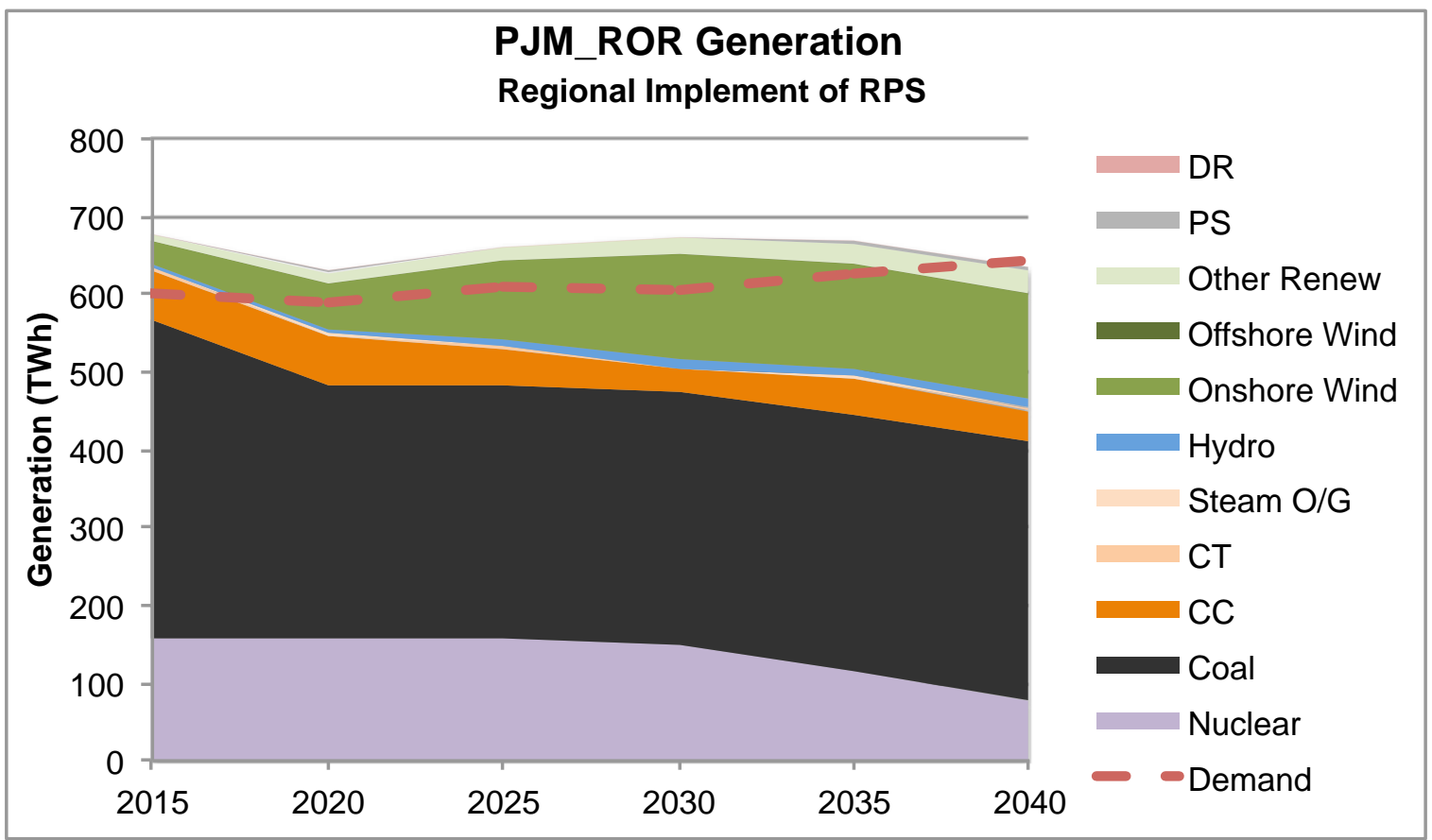

Fig. C-24. PJM ROR generation over study period in the RPS/R future 


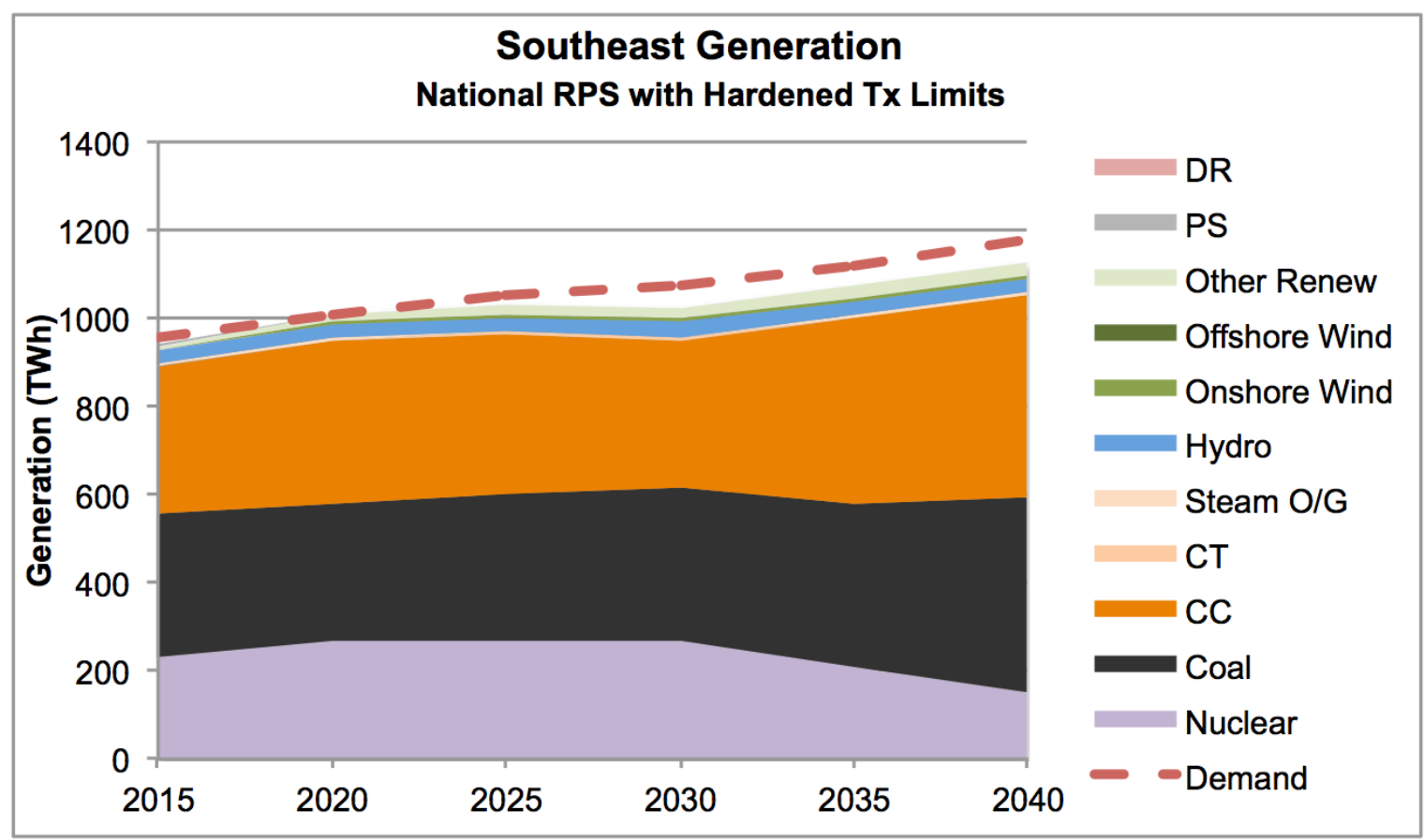

Fig. C-25. Southeast generation over study period in the RPS/N future

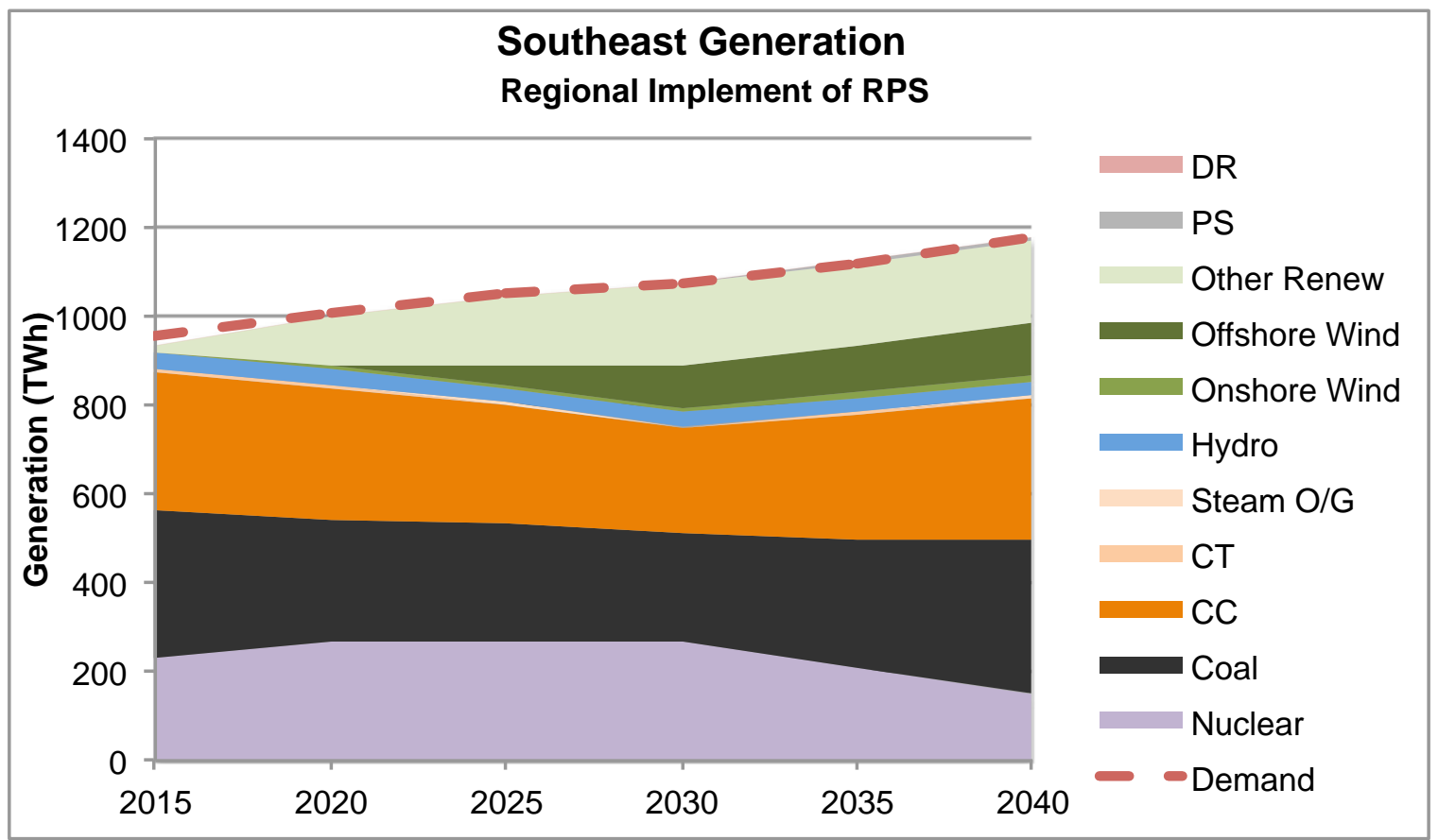

Fig. C-26. Southeast generation over study period in the RPS/R future 


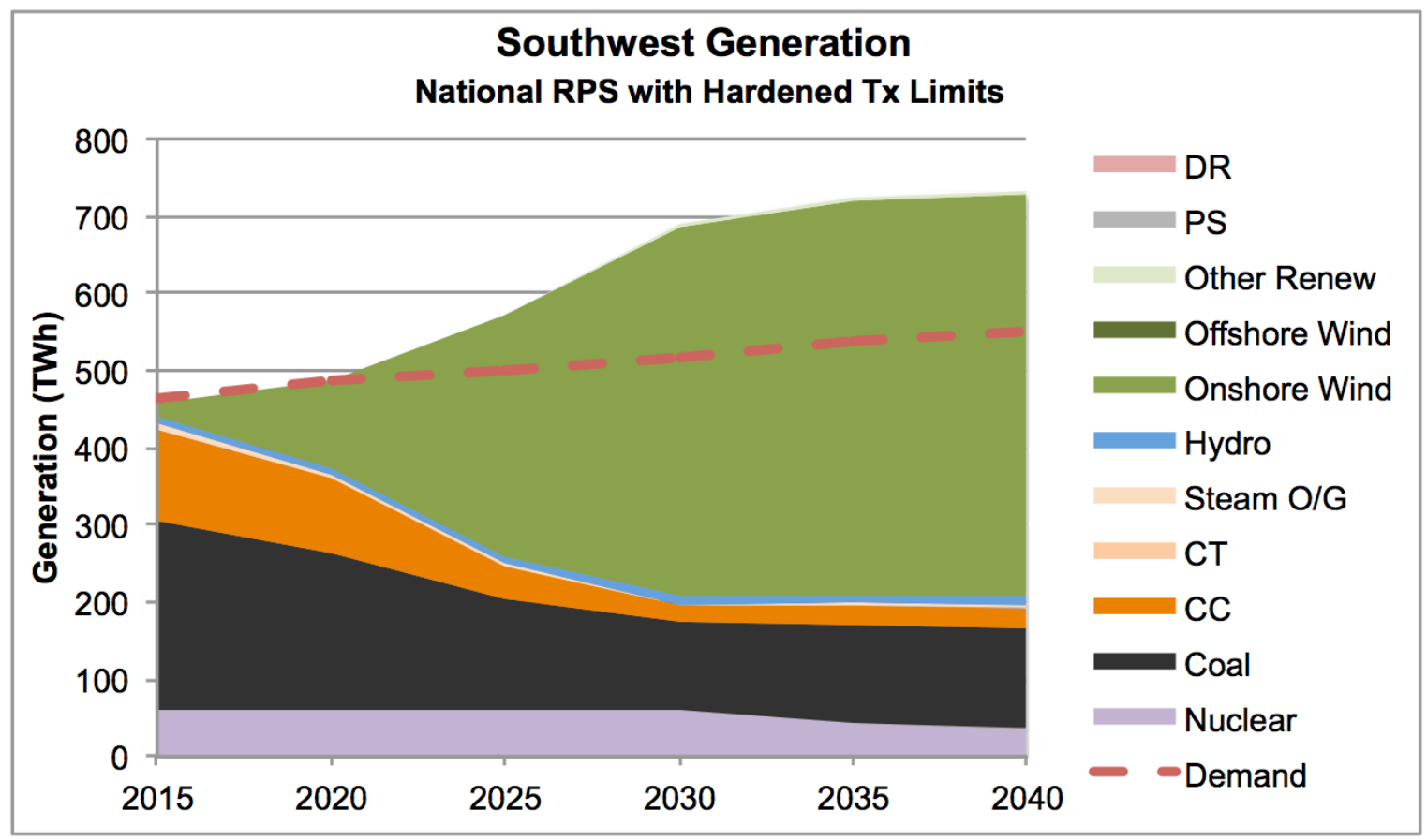

Fig. C-27. Southwest generation over study period in the RPS/N future

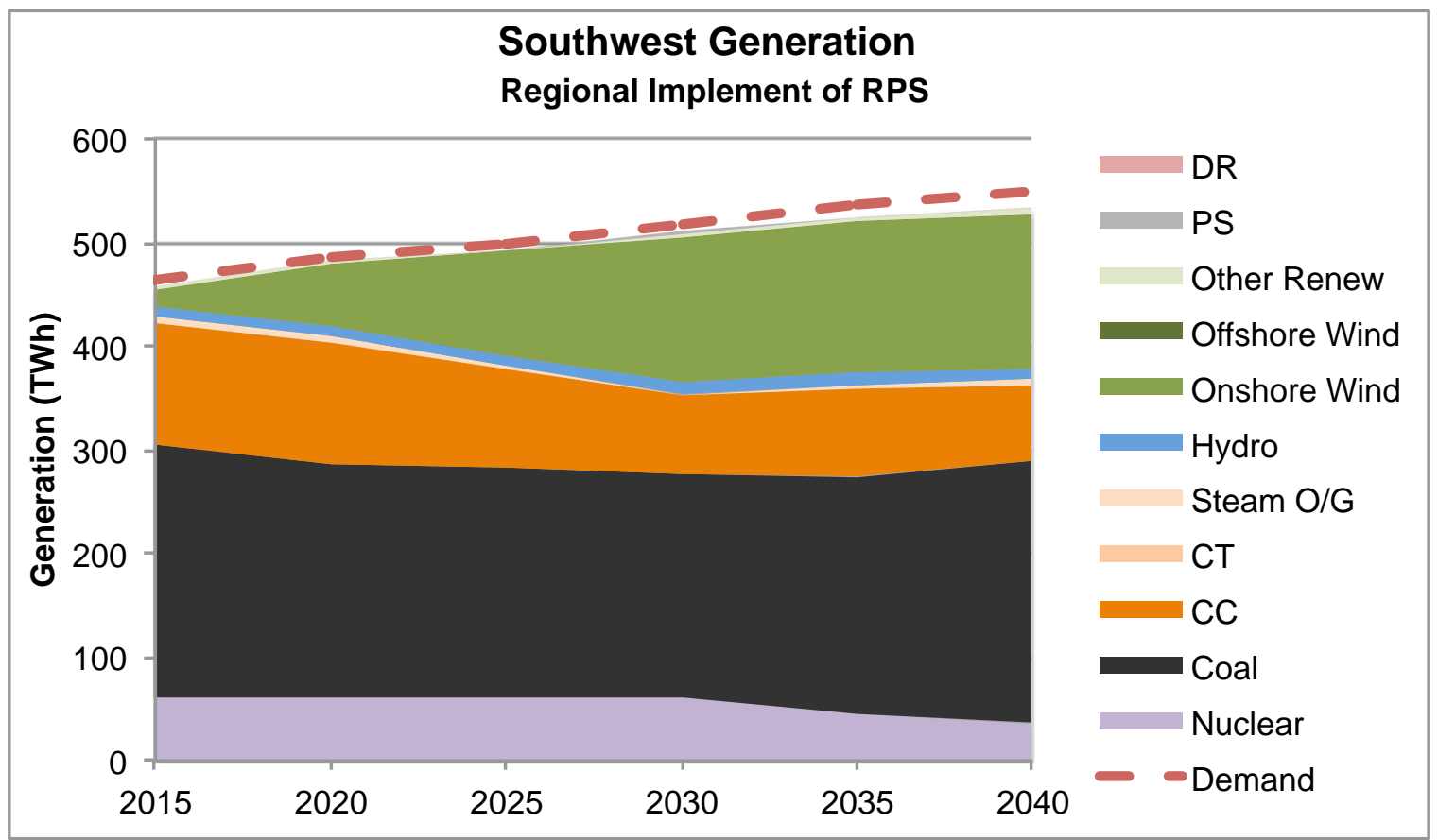

Fig. C-28. Southwest generation over study period in the RPS/R future 